\title{
Öffentliche Videoüberwachung in den USA, Großbritannien und Deutschland - Ein Drei-Länder-Vergleich
}

\author{
Dissertation \\ zur Erlangung des sozialwisssenschafltichen Doktorgrades der Sozial- \\ wissenschaftlichen Fakultät der \\ Georg-August-Universität Göttingen
}

vorgelegt von

Chen-Yu Lin

aus Yunlin, Taiwan

Göttingen 2006 
1. Gutachter: Prof. Dr. Wolf-Sighard Rosenbaum

2. Gutachter: Prof. Dr. Rainer-W. Hoffmann

Tag der mündlichen Prüfung: 19.07.2006 


\section{Inhaltsverzeichnis}

Inhaltsverzeichnis.

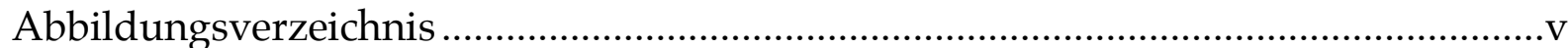

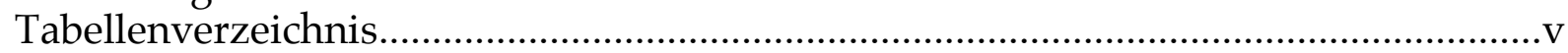

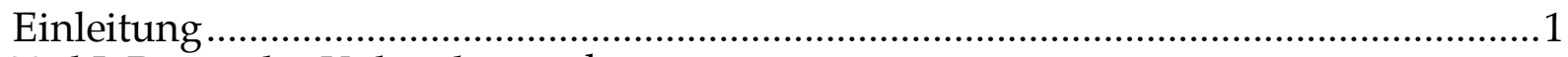

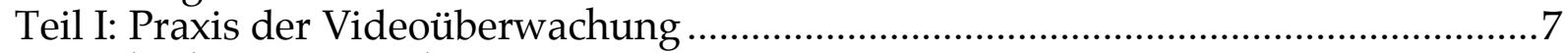

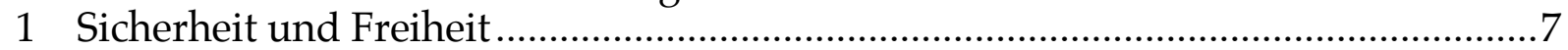

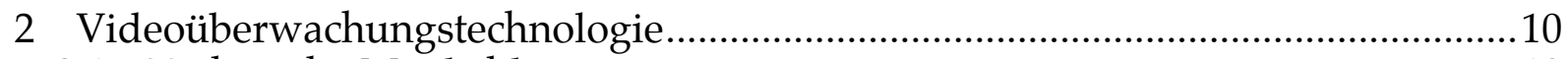

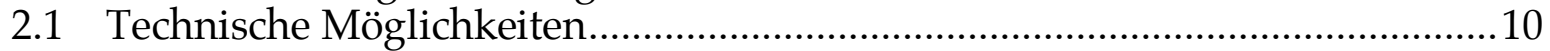

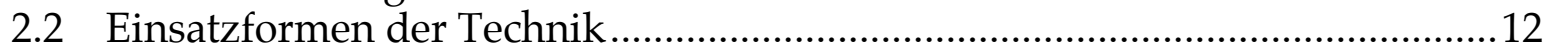

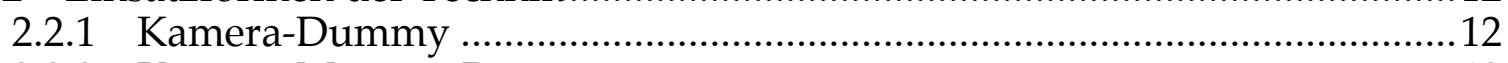

2.2.2 Kamera-Monitor-Prinzip .................................................................... 12

2.2.3 Videoüberwachung mit Aufzeichnung..................................................... 13

2.2.4 Offene und heimliche Videoüberwachung............................................. 13

2.3 Grenzen der Videoüberwachung ............................................................ 13

3 Videoüberwachung in drei Gesellschaften - eine deskriptive Darstellung ...........15

3.1 Videoüberwachung in Deutschland ..................................................... 15

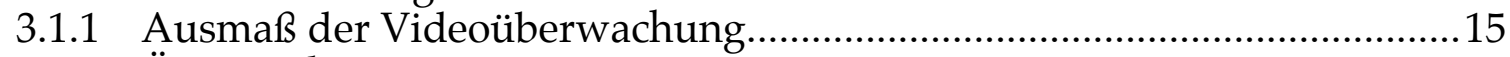

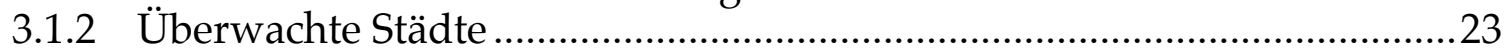

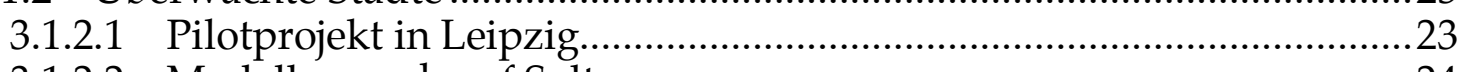

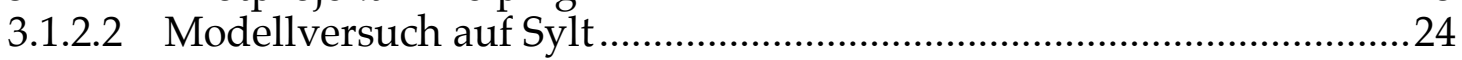

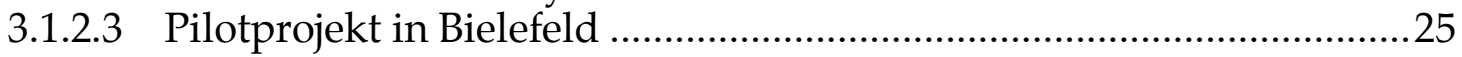

3.1.2.4 Pilotprojekt in Frankfurt am Main.......................................................2 25

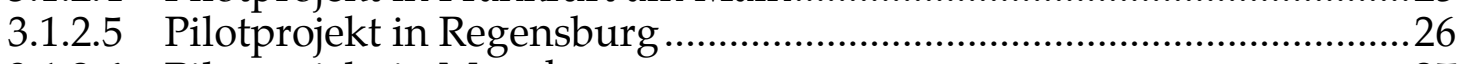

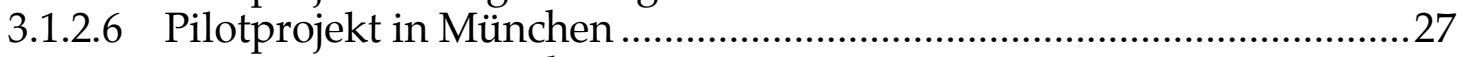

3.1.2.7 Pilotprojekt in Mannheim............................................................28

3.1.2.8 Pilotprojekt in Stuttgart .................................................................2 28

3.1.3 Andere überwachte Städte in Deutschland ........................................28

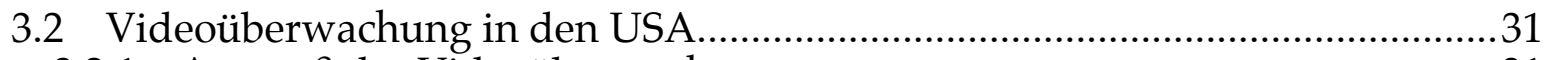

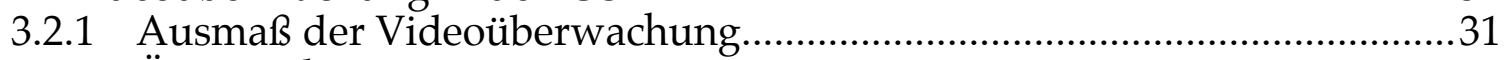

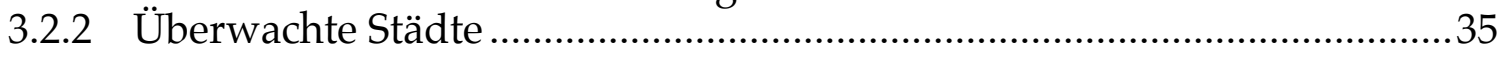

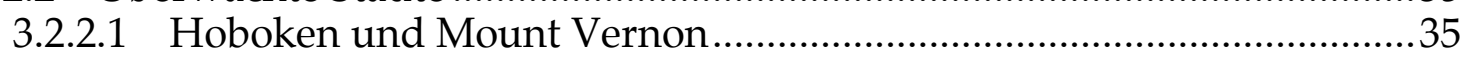

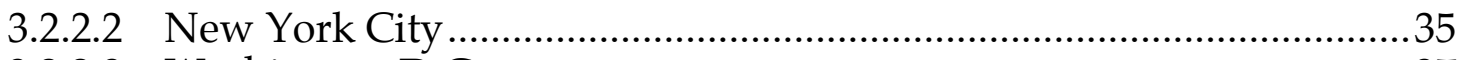

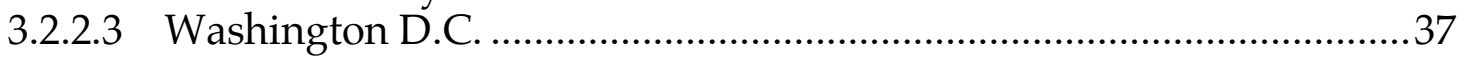

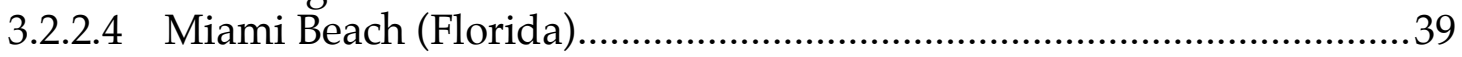

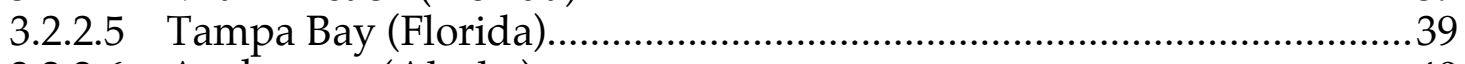

3.2.2.6 Anchorage (Alaska) ..................................................................... 40

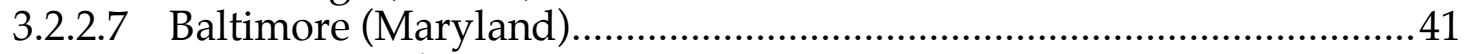

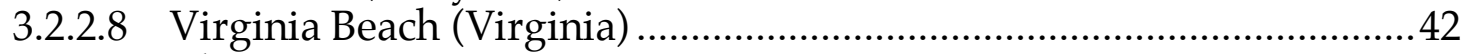

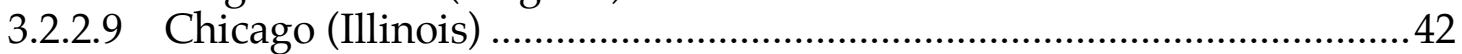

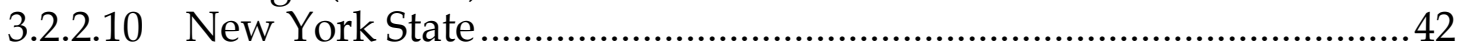

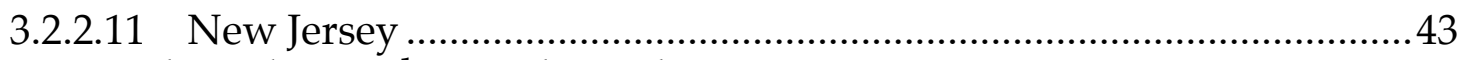

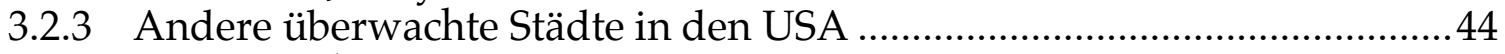

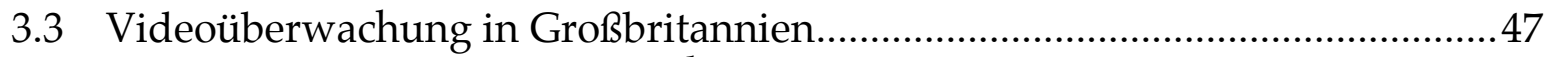

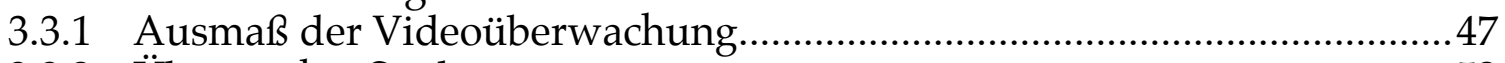

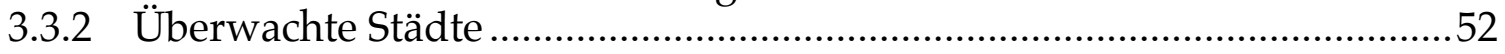

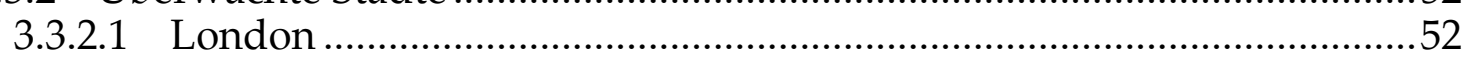

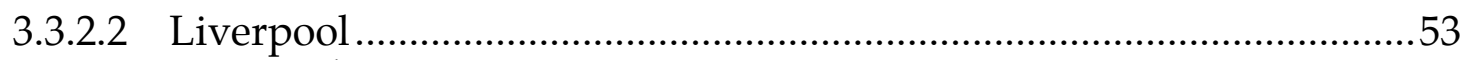

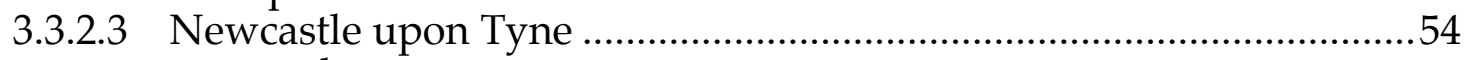

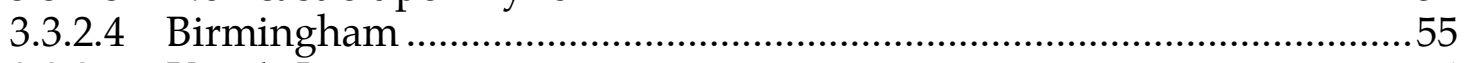

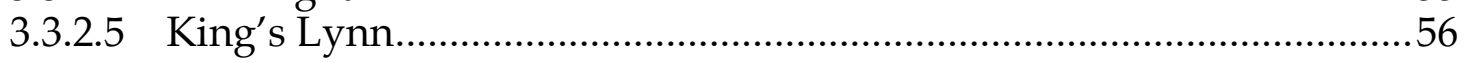




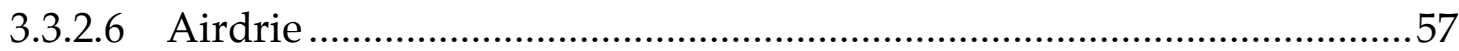

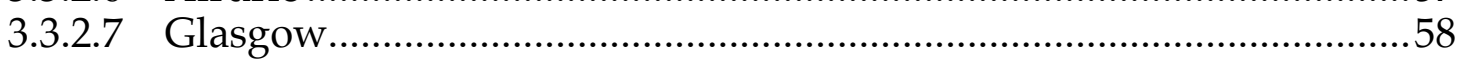

3.3.3 Andere überwachte Städte in Großbritannien ………………………….....58

3.4 Vergleich der Nutzungsintensität von CCTV-Systemen...................................59

Teil II: Kriminalistischer Nutzen und Folgen der Videoüberwachung ..........................63

4 Kriminalität, Kriminalitätsfurcht und Videoüberwachung.......................................63

4.1 Kameras als sicherheitspolitische Werkzeuge.....................................................63

4.2 CCTV-relevante Deliktformen.....................................................................65

4.3 Was ist Kriminalitätsfurcht? ........................................................................67

4.4 Kriminalität und Kriminalitätsfurcht - Ein Zusammenhang? …………….......70

4.5 Die Frage der Effektivität .................................................................................71

4.5.1 CCTV-Überwachung zur Reduzierung von Kriminalität ............................72

4.5.1.1 Kriminalprävention...........................................................................72

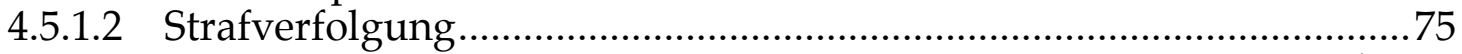

4.5.2 Einsatz von CCTV-Systemen zur Reduzierung von Kriminalitätsfurcht.76

4.5.3 Zusammenfassung .....................................................................................77

5 Nebenfolgen der Videoüberwachung ……………………………………….......79

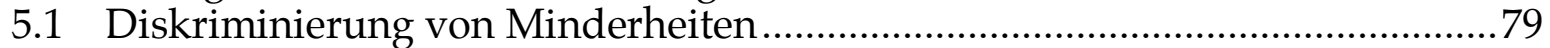

5.2 Eingriff in die Persönlichkeit und „Privatheit“ ................................................... 81

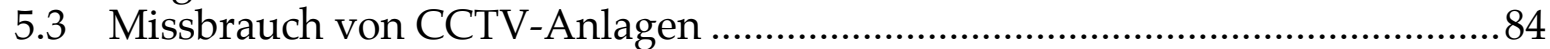

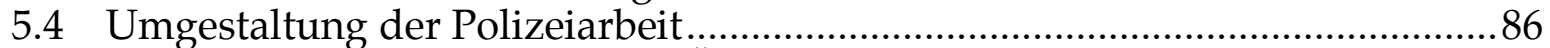

5.5 Vermehrte Angst durch CCTV-Überwachung ………….................................8

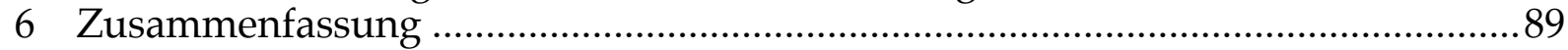

Teil III: Analyse der Ursachen unterschiedlicher Intensität von Videoüberwachung 91

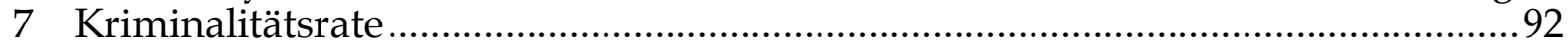

8 Einstellung der Bevölkerung ............................................................................99

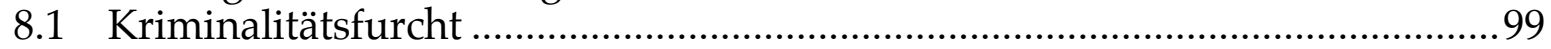

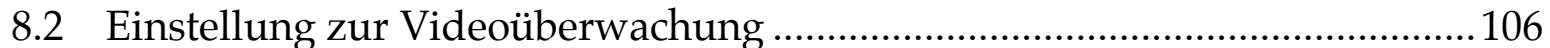

8.2.1 CCTV-Akzeptanz in Deutschland ...........................................................107

8.2.2 CCTV-Akzeptanz in den USA …………............................................. 108

8.2.3 CCTV-Akzeptanz in Großbritannien .......................................................109

9 Zusammenfassung ……………………………………………………….....111

10 Organisierte Akteure, ihre Funktionen und ihr Einfluss .....................................113

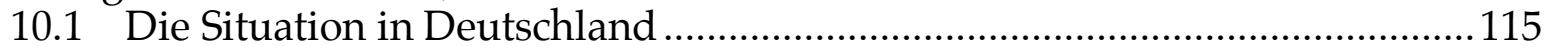

10.1.1 Proaktive Akteure ...........................................................................115

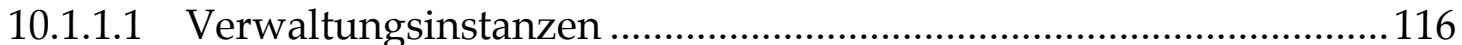

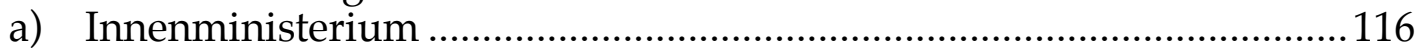

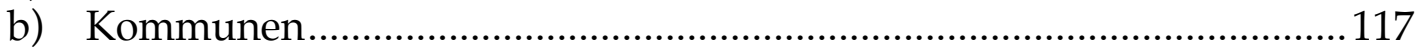

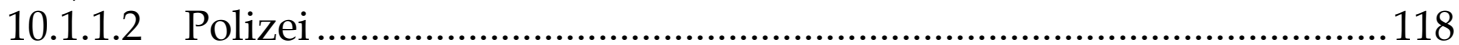

10.1.1.3 Öffentlich-private Kooperation .........................................................120

10.1.2 Staatsinterne Kontrollinstanzen..............................................................121

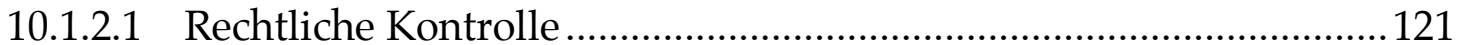

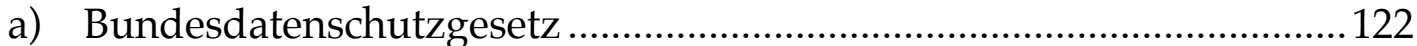

b) Polizeigesetze, Persönlichkeitsrecht und andere Rechtsgrundlagen ...123

c) Gerichtliche Entscheidungen .................................................................125

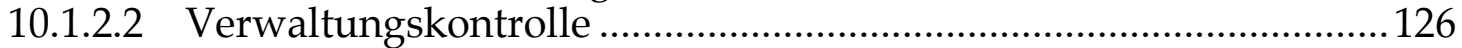

a) Datenschutzbeauftragte …………………………………………........126

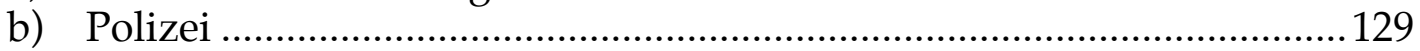

10.1.3 Nichtstaatliche Gegenkräfte ..................................................................130

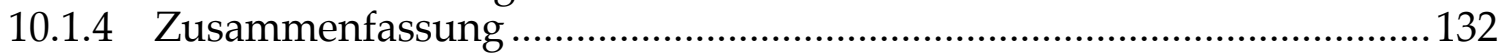

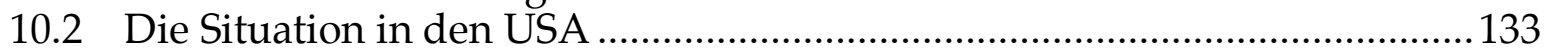

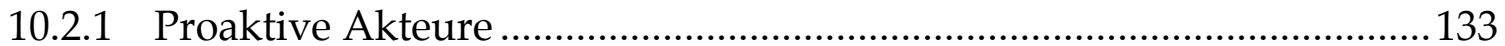

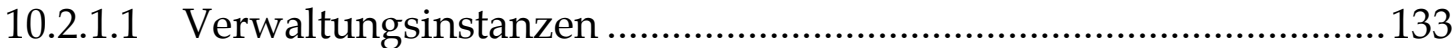

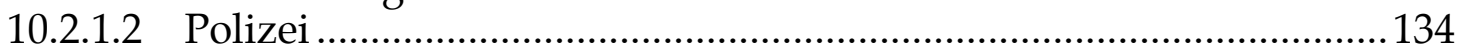




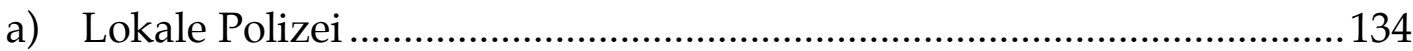

b) National Park Police und Park Service ...................................................135

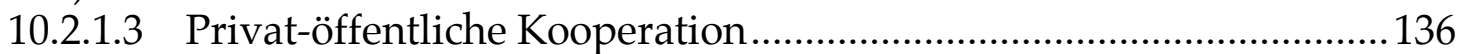

10.2.2 Staatsinterne Kontrollinstanzen...........................................................137

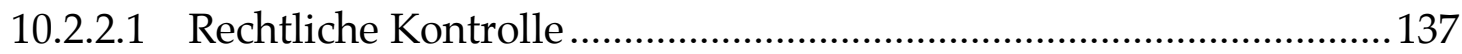

a) Gerichtliche Entscheidungen .................................................................137

b) Omnibus Crime Control and Safe Streets Act........................................139

10.2.2.2 Verwaltungskontrolle ................................................................... 140

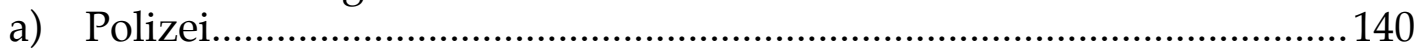

b) US-Kongress...................................................................................... 142

c) Kontrollinstanzen auf Länderebene .........................................................143

d) Andere staatliche Kontrollinstanzen .......................................................144

10.2.3 Nichtstaatliche Gegenkräfte ...................................................................146

10.2.3.1 American Civil Liberties Union (ACLU) ...........................................146

10.2.3.2 Institute for Applied Autonomy ……………....................................147

10.2.3.3 Surveillance Camera Players ...............................................................148

10.2.3.4 Electronic Privacy Information Center (EPIC) ...................................148

10.2.3.5 American Bar Association (ABA) ...................................................... 148

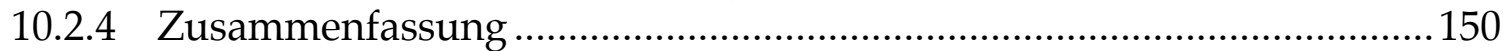

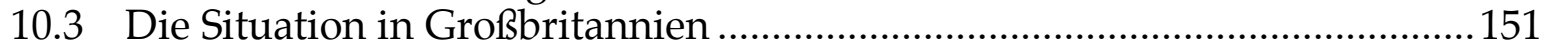

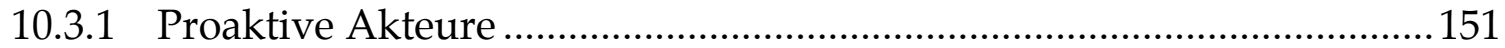

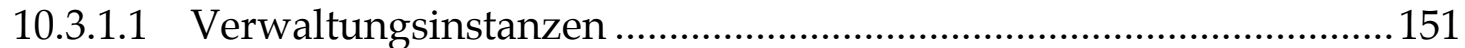

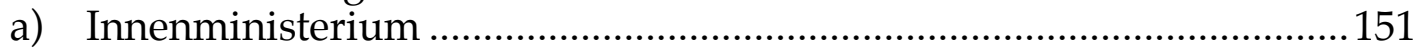

b) Kommunalbehörden ........................................................................ 153

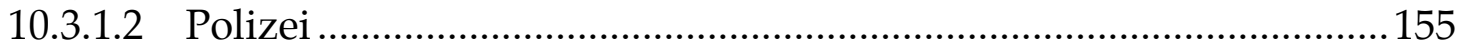

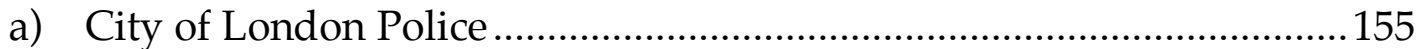

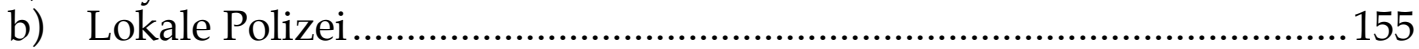

10.3.1.3 Privat-öffentliche Kooperation .........................................................157

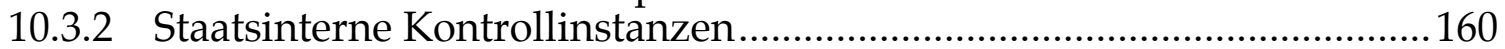

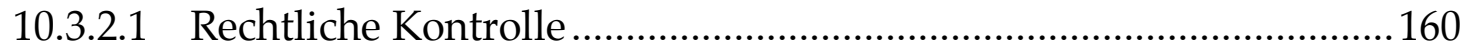

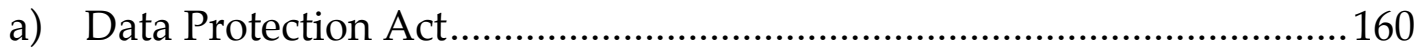

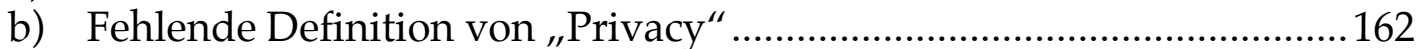

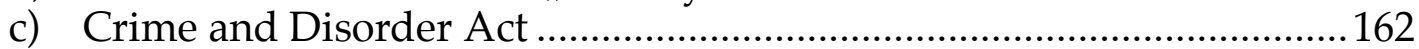

d) Regulation of Investigatory Power Acts und Privacy Security Act .....163

e) Human Rights Acts und Police and Criminal Evidence Act....................163

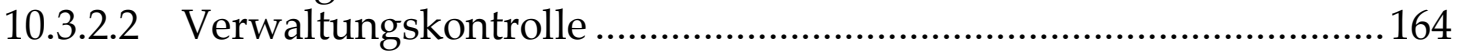

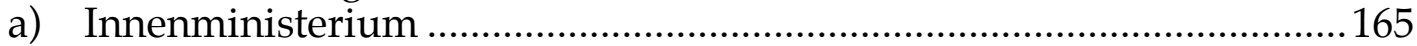

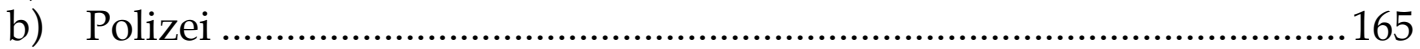

c) Kommunalbehörden...........................................................................167

d) Information Commissioner....................................................................169

e) House of Lord's Select Committee on Science and Technology ............169

f) Parliamentary Office of Science and Technology ………………….........170

10.3.3 Nichtstaatliche Gegenkräfte ....................................................................171

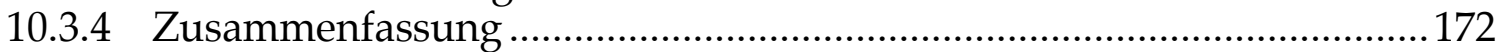

10.4 Einfluss der Akteure im Vergleich ...........................................................173

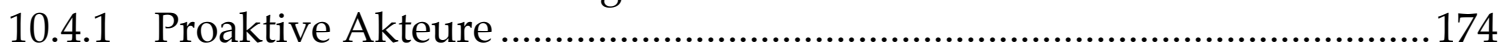

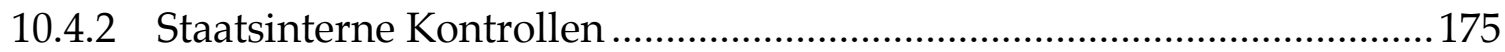

10.4.3 Nichtstaatliche Gegenkräfte ..............................................................176

10.4.4 Zusammenfassung …………………………………………………....176

Teil IV: Politisch-kulturelle Hintergründe …………………………………………....179

11 Deutschland - Rechtsstaatliche Repräsentativdemokratie ...................................180

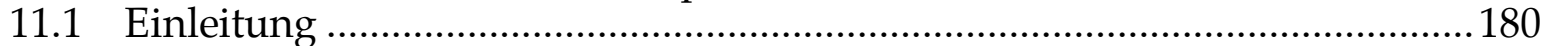

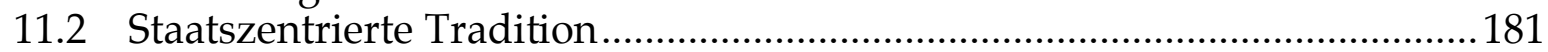

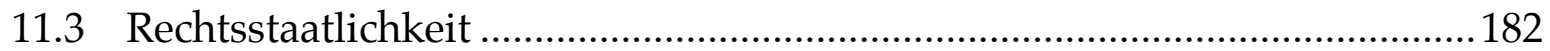




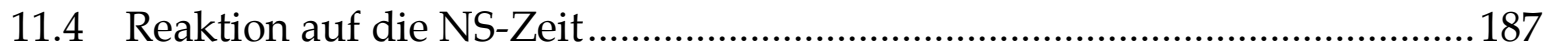

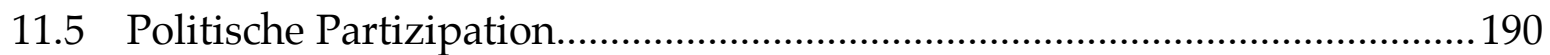

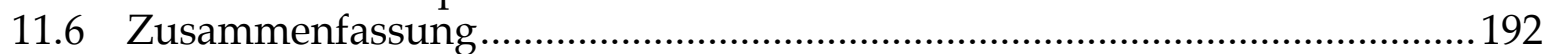

12 USA - Pluralistische Wettbewerbsdemokratie .................................................. 194

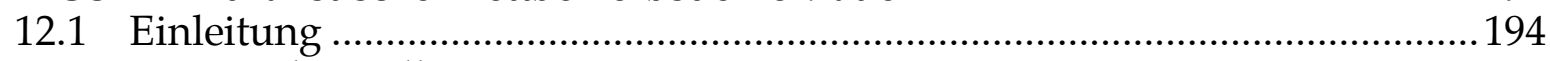

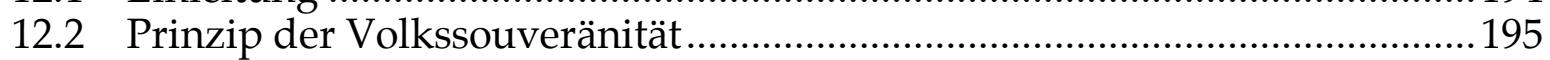

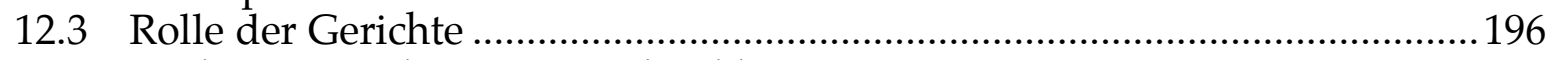

12.4 "Relative Statelessness" und Lobbyismus................................................ 199

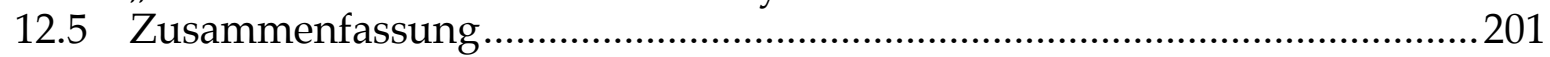

13 Großbritannien - Konsultative Westminster-Demokratie ................................203

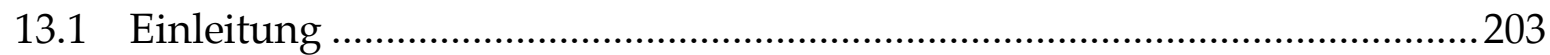

13.2 Dominanz der Exekutive und Suprematie des Parlaments ..........................204

13.3 Informelle Konsultationskultur und das „Old Boy's Network“ "....................206

13.4 Praxis der Praktikabilität...........................................................................2.

13.5 Politische Partizipation und Inaktivität .................................................... 211

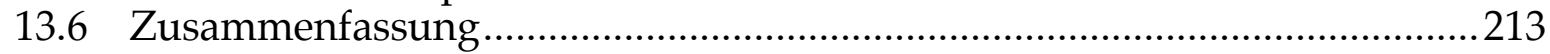

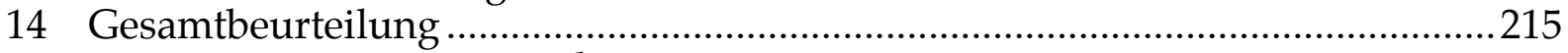

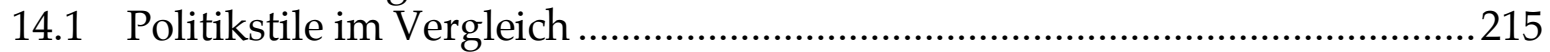

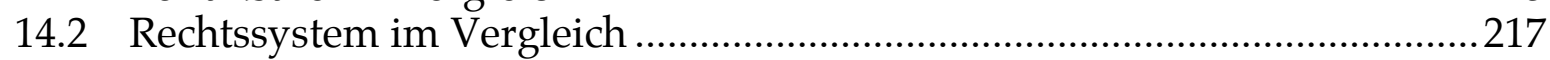

14.3 Bürgerengagement im Vergleich..........................................................219

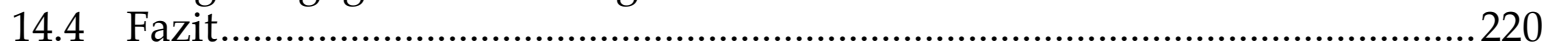

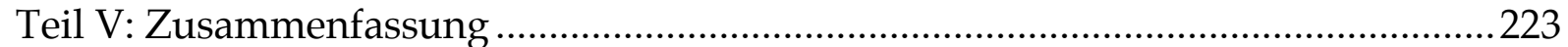

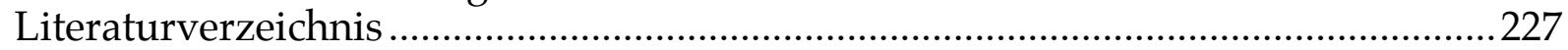

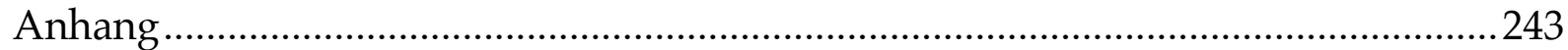

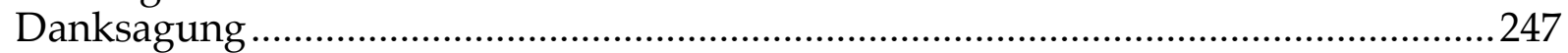




\section{Abbildungsverzeichnis}

Abbildung 1: Britische Städte mit Videoüberwachungsanlagen, in Betrieb oder staatlich geförderter Planung. Stand 1994.

Abbildung 2: Britische Städte mit Videoüberwachungsanlagen, in Betrieb oder staatlich geförderter Planung. Stand April 1999.

Abbildung 3: Polizeiliche Kriminalitätsentwicklung und ICVS Trends zwischen 19881999.

Abbildung 4: Entwicklung der Kriminalitätsfurcht in der EU zwischen 1996 und 2002.

\section{Tabellenverzeichnis}

Tabelle 1: Offene polizeiliche Videoüberwachung im öffentlichen Raum in Deutschland. Stand April 2002.

Tabelle 2: Deutsche Städte, in denen Videoüberwachung durchgeführt wurde oder wird. Stand 2003

Tabelle 3: Polizeiliche Videoüberwachung öffentlicher Straßen und Plätze. Stand 31. Mai 2005.

Tabelle 4: US-Städte mit öffentlicher Videoüberwachung (ohne Kalifornien). Stand 2002.

Tabelle 5: Kalifornische Städte mit öffentlicher Videoüberwachung. Stand 2002 _.....35

Tabelle 6: Polizeilich registrierte Gewaltverbrechen von 1997 bis 2001 in England \& Wales, Deutschland und den USA.

Tabelle 7: Polizeilich registrierte Raubüberfälle von 1997 bis 2001 in England \& Wales, Deutschland und den USA........................................................................96

Tabelle 8: Polizeilich registrierte Kfz-Diebstähle von 1997 bis 2001 in England \& Wales, Deutschland und den USA.

Tabelle 9: Anteil der Personen, die sich nach Einbruch der Dunkelheit unsicher fühlen. 



\section{Einleitung}

Großbritannien gilt weltweit im Bereich der Videoüberwachung als Vorreiter und weist mit Abstand die höchste Dichte an Überwachungskameras der Welt auf. ${ }^{1}$ Vor allem in der zweiten Hälfte der 1990er Jahre ist eine massive Zunahme der Überwachungskameras in Großbritannien zu beobachten. Wer von Geldautomaten Geld abhebt, in der Bibliothek liest, im Supermarkt einkauft oder einfach auf der Straße spazieren geht, kann, ohne es zu wissen, zum Objekt der Videoüberwachung werden und Spuren auf Datenträgern hinterlassen. Während die Observierung der Räume mittels Videotechnik früher vorwiegend im privaten Bereich stattgefunden hat, wird heute der öffentliche Raum in Großbritannien von einer Vielzahl unterschiedlicher Akteure systematisch videoüberwacht. Selbst in den USA, die als Pioniere in der biometrischen Videotechnik gelten, sind „britische Verhältnisse“ der intensiven Videoüberwachung noch nicht zu beobachten. Im Vergleich zu Großbritannien steckt die Verbreitung der Videoüberwachung in der Bundesrepublik Deutschland noch in den Kinderschuhen. Bisher werden hier nur die sog. „Kriminalitätsschwerpunkte“ im öffentlichen Bereich von polizeilichen Überwachungskameras beobachtet.

Mit der Erfindung der Videotechnik und Datenträger wurden Werkzeuge geschaffen, die eine einfache technische Lösung für die vielfältigen Kriminalitätsprobleme in öffentlichen Räumen suggerieren. Die Funktion der Bildaufnahme und -wiedergabe ermöglicht eine zeit- und raumunabhängige Observierung, die von vielen Ordnungshütern begrüßt wird. Als Mittel zur Kriminalprävention und Strafverfolgung sollen die Überwachungskameras nicht nur die polizeiliche Arbeit erleichtern, sondern auch das Sicherheitsempfinden der Bürger auf öffentlichen Straßen und Plätzen verbessern. Zudem kann die Videoüberwachung das Image der Stadtzentren als geschützte, saubere und somit attraktive Standorte für Investoren und Konsumenten herstellen, in denen die Menschen sich sicher fühlen und gerne aufhalten. Die Automatisierung räumlicher Überwachung als Maßnahme zur Stadtrevitalisierung gehört heute zum Alltag der Menschen, vor allem in Großbritannien.

Mit solchen offensichtlichen Vorteilen ist es selbstverständlich, dass die Automatisierung der Observierung als Erfolg versprechende Maßnahme gegen Kriminalität gefeiert und der großräumige Einsatz dieses Instruments akzeptiert wird. Trotz verstärkter Anwendung dieser Technik in vielen Ländern bleibt die Nutzungsintensität von Überwachungskameras in den öffentlichen Räumen Großbritanniens einzigartig.

\footnotetext{
${ }^{1}$ Buse; Schnibben (1999), S. 122 ff.; Büllesfeld (2002), S. 35 f.; Coleman (2004), S. 3.
} 
Es stellt sich die Frage, warum die flächendeckende Videoüberwachung ein typisch britisches Phänomen ist, während in den USA und vor allem in der Bundesrepublik die visuellen Überwachungseinrichtungen auf öffentlichen Straßen und Plätzen trotz zunehmender Tendenz noch in relativ geringem Umfang eingesetzt werden.

Die vorliegende Arbeit unternimmt den Versuch, die möglichen Ursachen für die unterschiedliche Nutzungsintensität dieser Technik in Großbritannien, den USA und Deutschland zu eruieren. Die Eindämmung der Kriminalität, die Stärkung des Sicherheitsgefühls der Bevölkerung sowie die Steigerung der Umsätze beim Einzelhandel werden regelmäßig als Gründe angeführt, wenn es um räumliche Observierung mittels Videotechnik in Großbritannien geht. Allerdings ist der Wunsch nach sozialer Ordnung und wirtschaftlichem Wachstum auch in den USA und Deutschland Grund für die Implementierung von Überwachungskameras. Diese Argumente können demnach nicht als alleinige Erklärung für die außergewöhnlichen Verhältnisse in Großbritannien dienen.

Es wird in dieser Arbeit angenommen, dass Vorbehalte auf Seiten der Überwachungskritiker sowie deren politische Einflussnahme in der Bundesrepublik und in den USA das Ausmaß öffentlicher Videografie einschränken und das Fehlen solcher Gegenkräfte für den „britischen Sonderweg“ verantwortlich ist. Um die Ursachen der unterschiedlichen Nutzungsintensität von Closed Circuit Television (CCTV) zu untersuchen, werden also die treibenden und hemmenden Kräfte für die Verbreitung der Überwachungskameras in den drei Vergleichsländern analysiert. Es gilt herauszufinden, welche Institutionen die Einführung von Videoüberwachungsmaßnahmen fördern und welche Akteure die Zunahme der Überwachung bremsen.

Während die Sicherheit aus Sicht der Befürworter von CCTV-Überwachung im Mittelpunkt der kriminalpräventiven Videoaufzeichnung steht, sehen die Überwachungsgegner in diesen Maßnahmen die Gefährdung bürgerrechtlicher Freiheiten. Es geht bei der Frage nach der Nutzungsintensität von Überwachungskameras in öffentlichen Räumen letztlich um das Spannungsfeld zwischen Sicherheit des Bürgers einerseits und seiner Freiheit andererseits. Zur Herstellung des Gleichgewichts zwischen Sicherheit und Freiheit gehört es zum staatlichen Aufgabenbereich, durch die Rechtsbindung staatlicher Instanzen nicht nur die Freiheitsrechte der mehrheitlichen Bevölkerungsgruppen zu garantieren, sondern auch gesellschaftliche Minderheiten vor willkürlichen Eingriffen zu schützen. Denn der Staat muss nicht nur die Freiheitsrechte derjenigen berücksichtigen, die sich mit der Einstellung „Ich-habenichts-zu-verbergen“ freiwillig dem Blick der Überwachungskameras aussetzen; er 
hat ebenso die Rechte derjenigen zu respektieren, die sich dem Blick der „elektronischen Augen“ entziehen wollen und ebenso das Grundrecht auf Persönlichkeitsentfaltung haben.

Die Mehrheit der Bürger begreift die Notwendigkeit des Sicherheitsschutzes, aber ist sich nicht immer über das damit verbundene Risiko der Freiheitseinschränkungen bewusst. Ausgehend vom Spannungsverhältnis zwischen Sicherheit und Freiheit stellt sich nun die Frage, wer in einer freiheitlich-demokratischen Gesellschaft die Sicherheitsbedürfnisse der Bürger gewährt und wer die bürgerlichen Freiheitsrechte verteidigt. Vor diesem Hintergrund wird das Hauptaugenmerk der Arbeit sowohl auf die staatlichen Institutionen gerichtet, die aus Sicht der Kriminalitätsproblematik den Kameraeinsatz unterstützen, als auch auf solche nichtstaatliche Organisationen bzw. Behördenstellen, die aus Rücksicht auf die bürgerlichen Freiheiten präventive Überwachungsmaßnahmen ablehnen. Der Einblick in das politische Institutionsgefüge sowie die Untersuchung der Verhandlungsdynamik des Policy-Prozesses zur Einführung von Videoüberwachung sollen die Gegenüberstellung von kompromisslosen Befürwortern und Gegnern verdeutlichen. Die Balance zwischen Sicherheit und Freiheit wird in dieser Hinsicht von den am horizontal und diagonal verflochtenen Policy-Prozess beteiligten Akteuren bestimmt.

Um mehr Einblick in die unterschiedlichen Machtstrukturen der Akteure in den drei Vergleichsländern zu gewinnen, werden ferner zum Abschluss dieser Arbeit politisch-kulturelle Rahmenbedingungen herangezogen. Es wird davon ausgegangen, dass beteiligte Akteure bestimmte institutionelle Strukturen verinnerlicht haben, welche ihre Macht-Ressourcen und ihr Handeln beeinflussen. Demnach wird die Überlegenheit bestimmter Akteure, die letztlich für die Intensität der Videoüberwachung verantwortlich sind, durch länderspezifische Staatsführungen, Rechtssysteme sowie politische Traditionen und historische Ereignisse bedingt. Es gilt dabei herauszufinden, welche traditionellen Rollen die Akteure in den verschiedenen Politikmodellen haben und wie sich diese auf ihre Machtpositionen in Auseinandersetzungen zum Thema Videoüberwachung auswirken. Somit dient die Untersuchung nationaler Politik- und Regulierungsstile hierbei als Erklärungsversuch für die Logik der Handlungszusammenhänge sowie die Dynamik länderspezifischer PolicyNetzwerke, die als Wurzel für die Rollenverteilung und Einflussnahme der Akteure gesehen werden können.

In vielen soziologischen und politikwissenschaftlichen Vergleichsstudien werden unter den europäischen Nationen gemeinsame Eigenschaften in Hinblick auf die po- 
litischen, sozio-kulturellen sowie wirtschaftlichen Entwicklungen festgestellt, die sich von denen der US-amerikanischen Gesellschaft deutlich unterscheiden. Unter der Bezeichnung des "American Exceptionalism“ werden diese Differenzen festgehalten. ${ }^{2}$ Zur Verdeutlichung verschiedener Dynamiken in der Politik öffentlicher Videoüberwachung innerhalb Europas ist das amerikanische Modell als Vergleichsland von großer Bedeutung. Aus dem Vergleich zweier europäischer Länder (Großbritannien und Deutschland) mit den Vereinigten Staaten lassen sich die für Europa charakteristischen Merkmale der CCTV-Politik herausfiltern. Ferner gehören die USA und Großbritannien zum angelsächsischen Kulturkreis, so dass in deren Gegenüberstellung zur Bundesrepublik die charakteristischen Merkmale angelsächsischer Kulturen hervorgehoben werden können. Im Gesamtvergleich werden somit die europäischen sowie angelsächsischen Wesensmerkmale verdeutlicht und von den spezifisch britischen Besonderheiten der Videoüberwachung separiert. Damit kann die Eigenart der „britischen Verhältnisse“ der intensiven Videoüberwachung aufgezeigt werden.

Die Arbeit beginnt mit der kurzen Darstellung der technischen Voraussetzungen und Einsatzmöglichkeiten von Überwachungskameras, um Auswirkungen und Grenzen von Überwachungskameras aufzuzeigen. Als Grundlage für weitere Analysen wird ferner im Teil I die gegenwärtige Praxis öffentlicher Videoüberwachung in den USA, Großbritannien und Deutschland vorgestellt. Anschließend wird im zweiten Teil dieser Arbeit die Videotechnik als sicherheitspolitisches Instrument näher beleuchtet, wobei die Effektivität sowie die Nebenwirkungen solcher kriminalpräventiven Maßnahmen der Videografie überprüft und bewertet werden. Die eigentliche Analyse der Ursachen von Intensität öffentlicher Videoüberwachung in den drei zu untersuchenden Nationen erfolgt anschließend im dritten Teil dieser Arbeit. Dabei stehen die Kategorisierung beteiligter Akteure in Entscheidungsprozessen zur Einführung öffentlicher Videografie sowie deren Einflüsse auf die Anwendungsintensität dieser Überwachungstechnik im Mittelpunkt. Zum Schluss dieser Arbeit werden die sozialkulturell verfestigen Rollen der Akteure am Policy-Prozess zur Einführung von Videobeobachtungsmaßnahmen im gesamtgesellschaftlichen Kontext betrachtet.

Um den Untersuchungsgegenstand klar festzulegen, konzentriert sich die Arbeit auf die Videoüberwachung öffentlicher Räume, wobei in allen drei Ländern die polizeilichen Videoüberwachungsmaßnahmen öffentlicher Straßen und Plätze im Mittelpunkt der Analyse stehen. Allerdings ist anzumerken, dass die Observierung öffentlicher Räume in vielen Fällen aufgrund der finanziellen bzw. betrieblichen Koopera-

${ }^{2}$ Vgl. Lipset (1996); vgl. auch Lockhart (2003). 
tionen zwischen der Polizei und privaten Akteuren nur schwer von der privaten Videoüberwachung öffentlich zugänglicher Räume abzugrenzen ist. Im Rahmen dieser Arbeit werden die Netzwerke der Videoüberwachung durch Differenzierung unterschiedlicher Akteure möglichst detailliert skizziert. 



\section{Teil I: Praxis der Videoüberwachung}

\section{Sicherheit und Freiheit}

Der Mensch hat das fundamentale Bedürfnis nach Sicherheit und Geborgenheit, wobei die Sicherung dieser Bedürfnisse nicht individuell hergestellt werden kann. Im Sinne des Gesellschaftsvertrages von Thomas Hobbes ${ }^{3}$ wird die Gewährleistung der Sicherheit und Ordnung als zentrale Aufgabe des Staates gesehen. Die Aufgabe legitimiert die Konzentration der Machtmittel in den Händen des Staates als übergeordneter Instanz.

Angesichts der zunehmenden Kriminalitätsprobleme und der steigenden Sicherheitsbedürfnisse der Bürger ist der Begriff Sicherheit zum zentralen politischen Thema avanciert. Der Staat steht damit vor der Herausforderung, wirksame Lösungsstrategien zu entwickeln und seine Sicherheit gewährleistende Funktion unter Beweis zu stellen, um die Legitimitätsgrundlage seines Regelungs- und Gewaltmonopols nicht zu verlieren. Die Sehnsucht nach sozialer Ordnung hat somit die Befugnisse staatlicher Sicherheitsinstanzen erweitert und polizeiliche Sicherheitsmaßnahmen beständig vorangetrieben. Dazu gehört auch die Verwendung von Überwachungskameras als kriminalpräventives Mittel.

Der moderne, demokratische Verfassungsstaat basiert weiterhin auf den Grundprinzipien, den Bürgern nicht nur ein sicheres, sondern auch ein freies Leben zu ermöglichen. Dies ist auch in der Charta der Grundrechte der Europäischen Union festgelegt: "Jede Person hat das Recht auf Freiheit und Sicherheit" (Art. 6 Grundrechtscharta). ${ }^{4}$ Dazu gehört neben Gefahrenabwehr und Verbrechensbekämpfung auch der Schutz der Bürger vor staatlichen Übergriffen. Der Staat ist also verpflichtet, einerseits die gesellschaftliche Ordnung aufrechtzuerhalten, andererseits die Freiheitsrechte der Bürger, vor allem die der sozial schwachen Individuen und Gruppen, wirksam zu schützen. Die Wahrung und Herstellung der Sicherheit in einem demokratischen Rechtsstaat versetzt den Staat somit in eine Zwangslage: Die Gewährleistung der staatlichen Sicherheitspflichten bringt zwangsläufig Freiheitseinschränkungen mit sich. Zudem kann kein Staatsorgan die absolute Sicherheit seiner Bürger garantieren, da die Kriminalitätsgefahr in einer freiheitlichen Gesellschaft nie voll-

\footnotetext{
${ }^{3}$ Vgl. Hobbes (1996), S. 144 f.; Glaeßner (2002), S. 7; vgl. auch Hüning (2005); Hüning (1998); Kersting (1996).

${ }^{4}$ Die Charta der Grundrechte der Europäischen Union wurde im Dezember 2000 in Nizza verabschiedet, vgl. Glaeßner (2002), S. 5.
} 
kommen beseitigt werden kann. ${ }^{5}$ Dieses staatliche Dilemma, das in den Grundprinzipien eines demokratischen Verfassungsstaates verankert ist, beschreibt Gössner wie folgt: „Ein Sicherheitsstaat ohne Freiheit für die Bürger wird ebenso zu einer Räuberbande wie ein Gemeinwesen mit Freiheit, das nicht in der Lage ist, seinen Bewohnern öffentliche Sicherheit zu gewährleisten. Sicherheit gehört zum Freisein des Menschen. Die Verfassungstexte des modernen Staates dokumentieren das Spannungsverhältnis zwischen Freiheit und Sicherheit. ${ }^{\prime \prime}$

Die moderne Kriminal- und Sicherheitspolitik demonstriert die Problematik, in Hinblick auf neue Gefahrenquellen die Sicherheitsgewährleistung und den Schutz der Freiheitsrechte in Einklang zu bringen. Die Balance zwischen Freiheit und Sicherheit ist somit ein viel diskutiertes, kontroverses Thema, das durch die Ausbreitung der Überwachungskameras immer mehr in den Vordergrund der politischen Debatten rückt. Während Befürworter von CCTV-Überwachung von der „Wunderwaffe gegen das örtliche Verbrechen ${ }^{\prime 7}$ sprechen und die innere Sicherheit in den Vordergrund stellen, warnen Kritiker vor der „Etablierung des Überwachungsstaates“ und Gefährdung der Freiheitsrechte, indem sie gerne die Worte von Benjamin Franklin zitieren: „Der Mensch, der bereit ist, seine Freiheit aufzugeben, um Sicherheit zu gewinnen, wird beides verlieren. ${ }^{48}$

Auch wenn die Erweiterung der staatlichen Instrumentarien zur Sicherheitsgewährleistung zwangsläufig zur Eingrenzung der Freiheitsrechte der Bürger führt, bedeutet es nicht, dass die Maßnahmen staatlicher Sicherheitsapparate in jedem Fall mehr Sicherheit garantieren können. Diese Freiheitseinschränkungen ohne Sicherheitsgarantie, die z.B. durch Videoüberwachung zustande kommen können, werden jedoch von Bürgern in Kauf genommen, wenn die Kriminalitätsgefahr die Lebensqualität mehr zu bedrohen scheint als der staatliche Eingriff in die eigene Privatsphäre. Mit anderen Worten: „Je stärker die Unsicherheitsgefühle sind, desto größer wird die Bereitschaft, neue Polizei- und Justizkompetenzen sowie verschärfte Gesetze hinzunehmen. ${ }^{\prime 9}$ Sicherheit ist also „zu einem Schlüsselkonzept und zu einem konstitutiven Symbol moderner Gesellschaften geworden“. ${ }^{10}$

\footnotetext{
${ }^{5}$ Büllesfeld (2002), S. 2 f.; Waechter (2001), S. 77 ff.

${ }^{6}$ Gössner (1995), S. 41; Frevel (1998), S. 131.

${ }^{7}$ Vgl. Weichert (1998b), S. 12 ff.; Kohl (1997a), S. 36 ff; Büllesfeld (2002), S. 1; Töpfer (2005), S. 5 ff.

${ }^{8}$ Das englische Original: "Those who would give up essential Liberty, to purchase a little temporary Safety, deserve neither Liberty nor Safety." Zitat. nach Sack (2005).

${ }^{9}$ Frevel (1998), S. 132 f.

${ }^{10}$ Dinges; Sack (2000), S. 11; vgl. auch Nogala (2002), S. 35.
} 
Die vorliegende Arbeit beschäftigt sich mit den Ursachen der unterschiedlichen Anwendungsintensität von Überwachungskameras in Großbritannien, Deutschland und den USA. Anhand der Analyse über die treibenden und hemmenden Faktoren in der jeweiligen Kriminal- und Sicherheitspolitik wird das Spannungsverhältnis zwischen Sicherheit und Freiheit illustrativ anhand von länderspezifischen Konstellationen der Videobeobachtungsmaßnahmen dargestellt. 


\section{Videoüberwachungstechnologie}

Closed Circuit Television (CCTV $)^{11}$ bezeichnet einen geschlossenen Kreislauf von Fernsehsende- und Empfangseinrichtungen. Heutzutage versteht man unter diesem Begriff die weit verbreiteten Videoüberwachungsanlagen. ${ }^{12}$ Bevor die Situationen der Videoüberwachung in Deutschland, den USA und Großbritannien detailliert geschildert werden, erscheint es zunächst erforderlich, die Eigenschaften, Möglichkeiten und Grenzen dieser Technik vorzustellen. Einerseits sollen Einblicke in die Funktionsweise dieser Technik und deren Vernetzung gewonnen werden, andererseits sollen die Konsequenzen für Überwacher und Überwachten in den zu untersuchenden Ländern aufgezeigt werden.

\subsection{Technische Möglichkeiten}

Die Sichtweite der Überwachungskameras hat sich dank der rasanten elektronischen Entwicklung beachtlich erweitert: Die heutigen Kameras sind überwiegend mit einem Zoomobjektiv ausgestattet und können in verschiedene Richtungen per Fernsteuerung gedreht und gekippt werden. Die Identifizierung eines Buchtitels oder gar die Aufschrift einer Zigarettenpackung in 100 Metern Entfernung ist für die modernen Überwachungskameras problemlos möglich. ${ }^{13}$

Mit Infrarottechnologie oder Restlichtverstärkern kann die Leistungsfähigkeit der Kameras zusätzlich erhöht werden, so dass diese rund um die Uhr, unabhängig von der Lichtstärke der Umgebung, eingesetzt werden können. Die USGrenzschutzpolizei Immigration and Naturalization Service (INS) Police setzen beispielsweise Infrarot-Sichtsysteme und Thermal-Überwachungskameras an der amerikanisch-mexikanischen Grenze ein, um illegale Immigranten ausfindig zu machen. Da die Technik auf Wärme reagiert und nicht auf Licht, können die Beamten sie auch bei schlechten Wetterbedingungen und in der Nacht anwenden. ${ }^{14}$ Eine Infrarotkamera (als ein Wärmestrahlen-Detektor), die elektromagnetische Signale von menschlichen Körpern empfängt, kann kältere Objekte wie Pistolen oder Messer aus einer Entfernung von vier bis zehn Metern sichtbar machen. Ein präzises Abbild derartiger

\footnotetext{
${ }^{11}$ In dieser Arbeit wird Closed Circuit Television als CCTV abgekürzt.

${ }^{12}$ Wehrheim (2002), S. 74.

${ }^{13}$ Schulzki-Haddouti (1998), S. 85. An der School of Engineering and Applied Science der Columbia University wurde 1997 eine sogenannte „Omnicam" entwickelt, die es dem Benutzer erlaubt, die komplette Räumlichkeit zu überwachen. Die Omnicam gewinnt ihre Flexibilität durch eine spezielle Spiegeltechnik sowie zwei interne Hochleistungskameras und erfasst jeden Winkel des Raumes. Mit einem Computer gekoppelt kann der Benutzer der Omnicam per Mausklick an jeden beliebigen Gegenstand in der überwachten Zone heranzoomen.Vgl. hierzu Deutsch (1997).

${ }^{14}$ Vgl. Nieto et al. (2002), S. 4.
} 
Gegenstände kann auf einem Monitor dargestellt werden und beim Einsatz polizeilicher Arbeit von großem Nutzen sein, da körperlicher Kontakt zwischen den Beamten und der zu untersuchenden Person dadurch nicht mehr erforderlich ist. ${ }^{15}$

Die Effektivität der Videoüberwachung kann außerdem durch Software zur biometrischen Gesichtserkennung verbessert werden. Mit dieser Technik werden die charakteristischen Merkmale eines menschlichen Gesichts auf einen digitalen Code reduziert und mit einer Datenbank, die eine Vielzahl von ebenfalls digitalisierten Gesichtseigenschaften speichert, verglichen. ${ }^{16}$ Dieses biometrische Verfahren soll trotz hoher Fehlerquote in der Lage sein, mit einer digitalen Analyse oberflächliche Veränderungen eines Gesichtes (z.B. Frisur, Kosmetik, Bärte) festzustellen und ein bestimmtes Gesicht anhand seiner biometrischen Merkmale aus einer Menschenmenge herauszufiltern. ${ }^{17}$ Mit der Technik zur Gesichtserkennung sind die optischelektronischen Überwachungseinrichtungen technisch so ergänzt, dass der Sprung von rein passiven und defensiven Sicherheitsmaßnahmen $\mathrm{zu}$ einer aktiven Identifizierung und Lokalisierung von Kriminellen möglich wird.

An der Universität Leeds in Großbritannien wird eine Software entwickelt, die körperliche Interaktion digitalisiert. In Verbindung mit einer Überwachungskamera kann das menschliche Verhalten zwischen „verdächtig“ und „normal“ unterschieden werden. Mit dieser Technik kann z.B. ein Dieb schon vor seiner Tat an seinem Gang von der Software als solcher entlarvt werden. ${ }^{18}$ Im Allgemeinen kennt man diese Technik unter der Bezeichnung "Thinking Camera“. Eine solche Kamera kann also feststellen, „wie Menschen sich in bestimmten Situationen (...) üblicherweise verhalten. Weicht das Benehmen davon über einen Toleranzwert hinaus ab, gibt das System Alarm. “19

Inzwischen ist es auch möglich, mit spezieller Software nicht nur Einzelpersonen, sondern auch kleinere Personengruppen in einer großen Menschenmenge ausfindig

\footnotetext{
${ }^{15}$ Whitaker (1999), S. 110; Wehrheim (2002), S. 74; Banisar (1998), S. 25.

${ }^{16}$ Ein Gesichtserkennungsprogramm namens „Person Spotter" wurde bereits an der Ruhr-Universität Bochum und der University of South California entwickelt. Vgl. Lischka (2000).

${ }^{17}$ Whitaker (1999), S. 108. Die Fehlerquote lag nach Angaben von Schulzki-Haddouti im Jahr 1998 bei 20\%, vgl. Schulzki-Haddouti (1998), S. 88. Im Jahr 2002 wurde die Quote der Fehl- bzw. Nichterkennung der Gesichtserkennungssysteme immer noch bis zu 50\% geschätzt. Vgl. Leopold (2002), S. 60 f.; Heise Online (2002). Trotz kritischer Stimmen aus der Wissenschaft behauptet die britische Polizei, dass diese Technik einzelne Personen in einer Gruppe zu identifizieren vermag, und zwar mit einer Erfolgsquote von 80\%. Vgl. Büllesfeld (2002), S. 15.

${ }^{18}$ Lischka (2000); Whitaker (1999), S. 108; Markoff (1997).

${ }^{19}$ Bäumler (1999), vgl. auch Wehrheim (2002), S. 76. Mehr zur Videoüberwachungstechnik vgl. Garfinkel (2000), S. $110 \mathrm{ff}$.
} 
zu machen. Dies ist z.B. bei einer Massenveranstaltung hilfreich, um eventuelle Unruhen oder Paniksituationen frühzeitig zu erkennen. ${ }^{20}$

\subsection{Einsatzformen der Technik}

\subsubsection{Kamera-Dummy}

Eine kostengünstige Variante der Videoüberwachung besteht darin, den Kameraeinsatz vorzutäuschen. Anstelle von funktionsfähigen Überwachungskameras werden nur Attrappen installiert oder Hinweisschilder auf die angebliche Praxis der Videoüberwachung angebracht, um preiswert den Abschreckungseffekt der technischoptischen Überwachung zu erzielen. ${ }^{21}$

\subsubsection{Kamera-Monitor-Prinzip}

Unter „Kamera-Monitor-Prinzip“ versteht man die Art von Videoüberwachung, bei der keine Speicherung der Bilddaten erfolgt und die technische Observierung nur „live“ am Monitor durchgeführt werden kann. Solche Anlagen erfordern dementsprechend die Anwesenheit und Konzentration des Überwachungspersonals, um optimale Überwachungserfolge zu erzielen. Im Gegensatz zu Kameraattrappen und Hinweisschildern auf Videoüberwachung ohne tatsächliche Existenz der Anlage stehen nicht nur der Abschreckungseffekt, sondern vor allem die Identifizierung und Verhaltensüberwachung von Personen im Mittelpunkt der technischen Observierung. Wenn der Einsatz von optisch-elektronischen Anlagen mit den modernen Zoomobjektiven kombiniert ist, die das Heranzoomen an die oberflächlichen Details der Überwachten erlauben, kann man nicht mehr bloß von einem „verlängerten menschlichen Auge“ ${ }^{22}$ sprechen. Die fernbedienbare Zoom-, Dreh-, Kipp- und Schwenkfunktion der Kameras vergrößert nämlich die Sichtweite und -schärfe der optischen Überwachung und intensiviert somit die Kontrolle, die das Auge eines Wächters oder eines Polizeibeamten auf der Straße nicht bewältigen kann. ${ }^{23}$

Solche Systeme finden häufig in Museen, Schulbussen und Kaufhäusern ihre Anwendung. Kombiniert mit Zoomobjektiven werden sie auch auf öffentlichen Straßen und Plätzen eingesetzt.

\footnotetext{
${ }^{20}$ Wehrheim (2002), S. 76. Norris et al. (1998), S. 264.

${ }^{21}$ Büllesfeld (2002), S. 19; vgl. auch Nürnberg (2000), S. 230 f.

${ }^{22}$ Büllesfeld (2002), S. 18 ff.; Brenneisen; Staack (1999a), S. 447.

${ }^{23}$ Nicht selten werden mehrere Kameras an wenigen Monitoren angeschlossen. Die Überwachungsarbeit am Bildschirm erfolgt durch das Umschalten von Kamera zu Kamera. Dadurch gehen auf jeden Fall Informationen (von den nicht gerade angezeigten Kameraaufnahmen) verloren.
} 


\subsubsection{Videoüberwachung mit Aufzeichnung}

Wenn die Bilddaten der Überwachungskameras nicht nur auf Monitore übertragen, sondern auch auf Datenträger gespeichert werden, spricht man von Videoüberwachung mit Aufzeichnung. Ein wesentlicher Vorteil solcher Videoüberwachung besteht darin, dass die Bildmaterialien bei Bedarf aufgerufen und nachträglich überprüft werden können. ${ }^{24}$

Durch die digitale Bearbeitungstechnik ist es mittlerweile möglich, unscharfe Aufnahmen aufzubereiten, so dass mehr Informationen (z.B. durch das Vergleichen mit einem Katalog von Straftätern) über die Überwachungssubjekte gewonnen werden können, die im Rahmen von strafrechtlichen Ermittlungsverfahren von großem Nutzen sind. ${ }^{25}$

\subsubsection{Offene und heimliche Videoüberwachung}

Je nach Überwachungszweck kann die Videoüberwachung offen oder verdeckt erfolgen. Eine Videoüberwachung ist dann heimlich, wenn diese von den Überwachten nicht wahrgenommen wird und von einem der zu observierenden Person unbekannten Ort aus durchgeführt wird. ${ }^{26}$ Die heimliche Videoüberwachung wird meistens im Rahmen der repressiven Tätigkeiten der Polizei durchgeführt, wenn Beweise gegen einen Verdächtigen nur heimlich gesammelt werden können. Da die Videoüberwachung öffentlicher Straßen und Plätze meistens offen durchgeführt wird, soll die Videoüberwachung heimlicher Natur in dieser Arbeit nicht weiter vertieft werden.

Eine offene Videoüberwachung ist gekennzeichnet durch die sichtbare Anbringung der Anlagen und/oder der Hinweisschilder, wobei die erkennbare Platzierung der Anlagen dem Abschreckungseffekt dienen soll. Die Existenz der Kameras signalisiert die Wachsamkeit der Polizei und deren Interventionsbereitschaft, damit potentielle Straftäter sich in dem überwachten Bereich normgerecht verhalten. ${ }^{27}$

\subsection{Grenzen der Videoüberwachung}

Trotz des Fortschritts in der Videoüberwachungstechnik stößt die Videoüberwachung in der Praxis dennoch an Grenzen. Abgesehen von der noch im Entwicklungsstadium befindlichen biometrischen Gesichtserkennungssoftware, die nach wie vor

\footnotetext{
${ }^{24}$ Büllesfeld (2002), S. 22.

${ }^{25}$ Ausführlich zur Problematik zum Beweiswert der Videoaufzeichnungen, vgl. ebenda, S. 64 ff.

${ }^{26}$ Wenn eine Person eine offensichtliche Überwachungskamera nicht wahrnimmt, obwohl diese für alle sichtbar angebracht ist, dann handelt es sich nicht um eine heimliche, sondern eine offene Videoüberwachung, Vgl. ebenda, S. 22 f.

${ }^{27}$ Ebenda.
} 
eine $\mathrm{zu}$ hohe Fehlerquote aufweist, spielt der menschliche Faktor hierbei eine wesentliche Rolle.

Die Effektivität der Videoüberwachung zu kriminalpräventiven Zwecken ist stark von der Ausbildung und der Professionalität des Überwachungspersonals abhängig, damit die Ereignisse in der überwachten Zone korrekt eingeschätzt, die richtige Entscheidung zur Intervention getroffen und die Kameras nicht $\mathrm{zu}$ voyeuristischen Zwecken missbraucht werden. Allerdings überfordert die Überwachungstätigkeit an Monitoren in vielen Fällen das Personal: Einige Studien zeigten, dass Wachpersonal nur 10 bis 20 Minuten intensiv die Kontrolltätigkeit an Monitoren durchführen kann und danach eine ähnlich lange Regenerationsphase benötigt. ${ }^{28}$ Dies ist allerdings nicht verwunderlich, wenn man in Erwägung zieht, welche Datenmenge in diesem Zeitraum bearbeitet werden muss. In Glasgow beobachten lediglich zwei Personen 12 Monitore, deren Bilder von insgesamt 32 Kameras stammen. Täglich müssen sie somit 768 Stunden Videobänder auswerten, die 69 Millionen Einzelbilder beinhalten. $^{29}$

Mit der heutigen Software zur Videoüberwachung werden allerdings aus datenschutzrechtlichen Gründen auch gewollte Grenzen gesetzt. Gewisse Einschränkungen können zugunsten der Überwachungssubjekte beim Überwachen einprogrammiert werden, so dass z.B. die Fenster von Wohnungen ausgeklammert werden, um die Privatsphäre der Bewohner zu schützen. Dies wird bereits in der BestwoodSiedlung in Nottingham, England praktiziert. Ähnliche Maßnahmen sollen auch an der Reeperbahn in Hamburg zur Fußballweltmeisterschaft 2006 praktiziert werden. ${ }^{30}$ Als in München im Jahr 2004 der Einsatz mobiler Videoüberwachung geplant wurde, setzte sich der bayerische Landesdatenschutzbeauftragte Reinhard Vetter für die Verwendung einer datenschutzfreundlichen Software ein, die alle überwachten Gesichter am Bildschirm unkenntlich machen sollte. Erst bei einem konkreten Tatverdacht sollte das Gesicht des Betroffenen für den Überwacher wieder sichtbar gemacht werden. ${ }^{31}$

\footnotetext{
${ }^{28}$ Gras (2003), S. 213 f.

${ }^{29}$ Norris et al. (1998), S. 257. Eine Möglichkeit zur Bewältigung des Problems ist die automatische Auswertung der Bilddaten, die allerdings aufgrund der datenschutzrechtlichen Bestimmungen nicht unbedenklich ist. Hierzu vgl. Norris; Armstrong (1999b), S. 19.

${ }^{30}$ Nach Aussagen von Innenbehörden soll die Bildübertragung in die Polizeizentrale umgehend unterbrochen werden, falls private Räume ins Visier der Kameras geraten sollten. Gärtner (2006); Wehrheim (2002), S. 76.

${ }^{31}$ Hutter (2004).
} 


\section{Videoüberwachung in drei Gesellschaften - eine de- skriptive Darstellung}

Im Folgenden wird der aktuelle Stand ${ }^{32}$ der Videoüberwachung öffentlicher Räume in der Bundesrepublik, in den Vereinigten Staaten und in Großbritannien dargestellt. Vorerst ist es wichtig anzumerken, dass hierbei alle Pilotprojekte und dauerhafte Maßnahmen polizeilicher Videoaufzeichnung in Deutschland vorgestellt und erläutert werden. Dagegen wird die britische Situation der Videoaufzeichnung aufgrund ihrer flächendeckenden Anwendung in fast allen Städten nur mittels der ersten und größten Projekte exemplarisch beschreiben. Eine Auflistung aller vorhandenen Videoüberwachungsprogramme in Großbritannien würde den Rahmen dieser Arbeit sprengen und trägt wenig zur Untersuchung ihrer Nutzungsintensität bei. Ferner kann in dieser Arbeit angesichts des Mangels an vollständigen Informationen über die gesamte öffentliche Videoüberwachung in den USA das Ausmaß des Videoeinsatzes nur anhand der öffentlich zugänglichen Daten skizziert werden. Dabei werden möglichst viele Städte mit Videobeobachtungsmaßnahmen vorgestellt, um die gegenwärtige Situation in den USA zu veranschaulichen. Es kann deswegen vor allem bezüglich der Situation in den USA keine Gewähr auf die Vollständigkeit und Aktualität des Einsatzes dieser optischen Überwachungstechnik in öffentlichen Räumen gegeben werden.

\subsection{Videoüberwachung in Deutschland}

\subsubsection{Ausmaß der Videoüberwachung}

Bisher hat sich die Videoüberwachung in Deutschland vorwiegend in privaten und halb-öffentlichen Bereichen etabliert, während die Nutzung dieser Technik in öffentlichen Räumen als polizeiliche Maßnahme noch relativ überschaubar ist. Im Jahr 2005 wurden „lediglich“ 94 polizeiliche Überwachungskameras auf öffentlichen Straßen und Plätzen gezählt. ${ }^{33}$ Die Voraussetzung hierfür ist das Vorliegen eines Kriminalitätsschwerpunktes. ${ }^{34}$

Der Kameraeinsatz im halb-öffentlichen und privaten Bereich zeigt jedoch ein anderes Bild: Im Jahr 1998 wurde die gesamte Anzahl der installierten Videokameras in der Bundesrepublik von der deutschen Industrie auf 500.000 Stück geschätzt, wäh-

\footnotetext{
${ }^{32}$ Die Literatur für diese Arbeit wurde bis Juli 2005 vollständig gesichtet und ausgewertet. Weitere Literatur nach diesem Zeitpunkt kann nur vereinzelt berücksichtigt werden.

${ }^{33}$ Töpfer (2005), S. 5 ff.

${ }^{34}$ Mehr zum Thema „Kriminalitätsschwerpunkt“ in Deutschland vgl. Teil III, Kap. 10.1 dieser Arbeit.
} 
rend nach Angaben der Datenschutzbeauftragten im Jahr 2000 insgesamt $30.000 \mathrm{Ka}-$ meras für Überwachungszwecke eingesetzt wurden. ${ }^{35}$ Die Anzahl privater Überwachungskameras, die in öffentlich zugänglichen Räumen aufgestellt wurden, wurde im selben Jahr auf 300.000 bis 400.000 Stück geschätzt. ${ }^{36}$ Die Bundesregierung gab im Jahr 2001 an, dass insgesamt 14.777 Kameras für 55 Liegenschaften des Bundes eingesetzt werden. ${ }^{37}$

Häufige Standorte dieser Kameras sind Tankstellen, Kaufhäuser, Banken und Bahnhöfe. So werden über 50\% aller deutschen Tankstellen in Deutschland bereits per Video überwacht und am Frankfurter Hauptbahnhof fertigen mehr als 120 Kameras täglich Aufnahmen von den Besuchern und Fahrgästen auf dem Gelände der Deutschen Bahn AG an. ${ }^{38}$ Auch in anderen öffentlich zugänglichen Bereichen wird die Videoüberwachung praktiziert bzw. deren Einführung diskutiert. Allerdings haben diese Art der Überwachungsmaßnahmen nicht nur den Schutz persönlicher Sicherheit, sondern vielmehr die Vorbeugung von Vandalismus öffentlicher Einrichtungen zum Ziel. Solche Kontrolltätigkeiten werden etwa in Schulbussen und sonstigen öffentlichen Verkehrsmitteln ${ }^{39}$, in Universitäten ${ }^{40}$, in Fußballstadien, auf Schulhöfen ${ }^{41}$, Spielplätzen, Friedhöfen oder an öffentlichen Müllcontainern und Recyclinganlagen ${ }^{42}$ durchgeführt.

Das erste Pilotprojekt öffentlicher Videoüberwachung von Kriminalitätsbrennpunkten wurde im Jahr 1996 in Leipzig gestartet. Im Jahr 1998 deklarierte sich die CDU

\footnotetext{
${ }^{35}$ Nürnberg (2000), S. 231. Im betrieblichen Bereich wird die Anzahl der Videoanlagen zu allgemeinen Überwachungszwecken auf ca. 400.000 Stück geschätzt. Vgl. Büllesfeld (2002), S. 44.

${ }^{36} \mathrm{Je}$ nach Angaben wird die Anzahl der Kameras insgesamt auf 300.000 bis zu einer halben Million Stück geschätzt, vgl. Gras (2003), S. 261; vgl auch Gössner (2000a), S. 26; Buse; Schnibben (1999), S. 113. Schneider; Daub (2000), S. 322.

${ }^{37}$ Schierbaum (2003), S. 439; vgl. auch Simitis (2003), §6bRn.2.

${ }^{38}$ Buse; Schnibben (1999), S. 113; Gras (2003), S. 261; Roos (2002), S. 466.

${ }^{39}$ Die Wagen der Berliner Verkehrs-Gesellschaft sowie die Züge der Deutschen Bahn AG sind bereits mit Überwachungskameras ausgestattet. Auch in Hamburg wurde unter Aufsicht von Datenschutzbeauftragten eine Probephase der Videoüberwachung in zwei Fahrzeugen der Hochbahn AG eingeleitet. Ebenso werden die Straßenbahnen in Halle und Cottbus per Video überwacht. In Dortmund, Fröndenberg, Nürnberg und Demnin werden die Bushaltestellen sowie die Busse selbst mit Kameras kontrolliert. Und die Straßenbahn-Gesellschaft in Hannover hat anlässlich der Weltausstellung 250 Überwachungskameras in Betrieb genommen. Vgl. Gras (2003), S. 262 f.; Nogala (2002), S. 45; Gössner (2000b), S. 26.

${ }^{40}$ Eine noch aus DDR-Zeiten stammende Überwachungskamera wurde zufällig in einem Hörsaal der Humboldt-Universität Berlin entdeckt und sorgte für Aufsehen unter den Berliner Datenschützern. An der Europa-Universität Viadrina in Frankfurt an der Oder wurden in einem Gebäude moderne, schwenkbare Kameras zur Regulierung der Kapazitätsprobleme installiert, vgl. Kulick (2002).

${ }^{41}$ Das erste Pilotprojekt zur Videoüberwachung in Schulen mit insgesamt 16 Kameras fand seit Februar 2002 in zwei Schulen in Schwerin und einer Schule in Greifswald statt. Die Kosten der Projekte werden von der Provinzial-Versicherung und einer Überwachungsfirma übernommen. Seit 2003 wird in einer Hamburger Handelsschule ebenfalls die Videoüberwachung praktiziert. Andere Überwachungspraktiken der Schulgebäude und -höfe mit Videotechnik kann man auch in Iserlohn, Bad Lippspringe und Schönberg finden. Vgl. Toepffer-Wenzel (2004), S. 60 ff.; Nogala (2002), S. 45.

${ }^{42}$ Solche Videoüberwachungsmaßnahmen sind z.B. in Eisenhüttenstadt, Zwickau und Berkersheim zu finden. Nogala (2002), S. 45; vgl. hierzu auch Büllesfeld (2002), S. 44; Post (2004), S. 31 f.
} 
mit dem Regierungswechsel auf Bundesebene als die Partei der inneren Sicherheit, um sich gegen die neu entstandene sozialdemokratische Konkurrenz zu behaupten, und forderte Videoüberwachung auch in den Städten der alten Bundesländer. ${ }^{43}$ Seitdem folgen andere deutsche Städte dem Leipziger Beispiel und praktizieren ähnliche

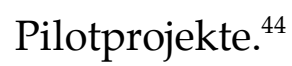

Im April 2002 wurden nach Angaben von Nogala die öffentlichen Räume in insgesamt 21 deutschen Städten in acht Bundesländern von der Polizei videoüberwacht, wobei die beendeten bzw. unterbrochenen Projekte in Flensburg und Bielefeld sowie die geplanten Maßnahmen in Gießen, Heilbronn und München mitgezählt wurden (Tabelle 1). ${ }^{45}$

\footnotetext{
${ }^{43}$ Nogala (2002), S. 10.

${ }^{44}$ Mehr zu den Pilotprojekten polizeilicher Videoüberwachung in Deutschland wird später in diesem Kapitel erläutert.

${ }^{45}$ Diese Daten wurden von Nogala im Jahr 2002 ohne Gewähr auf Vollständigkeit und Aktualität zusammengetragen und dienen hierbei lediglich als Veranschaulichung der damaligen Situation in Deutschland. Vgl. Nogala (2002), S. 43 f. Mehr zum Projekt auf Sylt, das vom Ordnungsamt durchgeführt wird, wird später in diesem Kapitel erläutert.
} 


\begin{tabular}{|c|c|c|c|}
\hline Ort/Bundesland & $\begin{array}{l}\text { Anzahl der } \\
\text { Kameras }\end{array}$ & $\begin{array}{l}\text { Zeitpunkt des } \\
\text { Betriebs }\end{array}$ & Anmerkungen zum Status \\
\hline \multicolumn{4}{|c|}{ Baden-Württemberg } \\
\hline Mannheim & 8 & Seit 07/01 & $\begin{array}{l}\text { Fußgängerzone, Marktplatz, Parade- } \\
\text { platz; Investition ca. 0,6 Mill. • }\end{array}$ \\
\hline Heilbronn & 3 & Geplant ab 07/02 & Plätze \\
\hline Stuttgart & 5 & Seit 01/02 & Rotebühlplatz, Innenstadt \\
\hline \multicolumn{4}{|l|}{ Bayern } \\
\hline Regensburg & 4 & Seit $06 / 00$ & $\begin{array}{l}\text { Bahnhofvorplatz, andere Plätze; Nut- } \\
\text { zung der Kameras der örtlichen Ver- } \\
\text { kehrsbetriebe; zwischenzeitliche Ver- } \\
\text { minderung der Kameraanzahl. }\end{array}$ \\
\hline München & & $\begin{array}{l}\text { Geplant im Verlauf } \\
2002\end{array}$ & $\begin{array}{l}\text { Ca. } 68 \text { Kameras der Verkehrsbetriebe } \\
\text { sollen wie beim Pilotprojekt in Regens- } \\
\text { burg von der Polizei genutzt werden. }\end{array}$ \\
\hline \multicolumn{4}{|l|}{ Sachsen } \\
\hline Leipzig & 6 & Seit 04/96 & $\begin{array}{l}\text { Bahnhofsvorplatz, Roßplatz (ab } \\
\text { 04/00), Kamera am Connewitzer Kreuz } \\
\text { zwischenzeitlich außer Betrieb ge- } \\
\text { nommen. }\end{array}$ \\
\hline Dresden & 2 & Seit $11 / 99$ & $\begin{array}{l}\text { Prager Straße (zentrale Einkaufsstra- } \\
\text { sse); von großem Kaufhaus ge- } \\
\text { sponsert. }\end{array}$ \\
\hline \multicolumn{4}{|l|}{ Sachsen-Anhalt } \\
\hline Halle & 3 & Seit 10/99 & Marktplatz, Südstadtring \\
\hline Dessau & 1 & Seit 11/99 & Stadtpark, wechselhafter Betrieb \\
\hline Magdeburg & 3 & Seit 12/97 & Zentrum, Parkplätze \\
\hline \multicolumn{4}{|l|}{ Brandenburg } \\
\hline Erkner & 2 & Seit 02/02 & Bahnhofsvorplatz, Parkplatz \\
\hline Bernau & 2 & Seit 02/02 & Bahnhofsvorplatz \\
\hline Potsdam & 6 & Seit 02/02 & Bahnhofsvorplatz \\
\hline Rathenow & 2 & Seit 02/02 & Straße vor Großdisko \\
\hline \multicolumn{4}{|l|}{ Schleswig-Holstein } \\
\hline Flensburg & 1 & Seit 1994 & $\begin{array}{l}\text { Hafenspitze } 23 \text { Einsätze, wieder ab- } \\
\text { gebaut }\end{array}$ \\
\hline Westerland/Sylt & 1 & Seit 1997 & Betrieben durch das Ordnungsamt \\
\hline \multicolumn{4}{|c|}{ Nordrhein-Westfalen } \\
\hline Bielefeld & 4 & 02/01-03/02 & $\begin{array}{l}\text { Betrieb unterbrochen, ggw. kein ,Kri- } \\
\text { minalitätsschwerpunkt }^{*}\end{array}$ \\
\hline \multicolumn{4}{|l|}{ Hessen } \\
\hline Fulda & 1 & Seit 6/01 & Bahnhofsvorplatz \\
\hline Frankfurt & 2 & Seit 2001 & Konstabler Wache \\
\hline Hofheim/Taunus & 3 & Seit $09 / 00$ & Bahnhofsvorplatz \\
\hline Gießen & & $\begin{array}{l}\text { Geplant ab Sommer } \\
2002\end{array}$ & Marktplatz, Bahnhofsvorplatz \\
\hline
\end{tabular}

Tabelle 1: Offene polizeiliche Videoüberwachung im öffentlichen Raum in Deutschland. Stand April 2002. ${ }^{46}$

${ }^{46}$ Quelle: Nogala, D. (2002), Jahrbuch StadtRegion 2002, S. 43 f. 
Im August 2003 wurden im Rahmen einer Evaluationsstudie zur Wirksamkeit von Videoüberwachung in Deutschland 27 Städte in neun Bundesländern mit dieser optischen Überwachungstechnik gezählt, wobei Städte wie Kassel, Limburg, Wiesbaden, Böblingen, Singen, Nürnberg sowie Bremen im Vergleich zu der Auflistung vom Jahr 2002 neu aufgenommen wurden und das geplante Projekt in München nicht in der Untersuchung berücksichtigt wurde.

\begin{tabular}{|c|c|c|c|c|c|c|c|}
\hline \multirow{2}{*}{$\begin{array}{l}\text { Bundesland } \\
\text { Baden- } \\
\text { Württemberg }\end{array}$} & \multicolumn{7}{|l|}{ Städte } \\
\hline & Böblingen" & Heilbronn & Singen & $\begin{array}{l}\text { Mann- } \\
\text { heim }\end{array}$ & $\begin{array}{l}\text { Stutt- } \\
\text { gart }\end{array}$ & & \\
\hline Bayern & Regensburg & Nürnberg & & & & & \\
\hline Brandenburg & Rathenow & Potsdam & Bernau & Erkner & & & \\
\hline Bremen & Bremen & & & & & & \\
\hline Hessen & Frankfurt & Fulda & Gießen & $\begin{array}{l}\text { Hofheim/ } \\
\text { Ts. }\end{array}$ & Kassel & $\begin{array}{l}\text { Limburg/ } \\
\text { Lahn }\end{array}$ & $\begin{array}{l}\text { Wies- } \\
\text { baden }\end{array}$ \\
\hline NRW & Bielefeld & & & & & & \\
\hline Sachsen & Dresden & Leipzig & & & & & \\
\hline $\begin{array}{l}\text { Sachsen- } \\
\text { Anhalt }\end{array}$ & Magdeburg & Halle/Saale & Dessau & & & & \\
\hline $\begin{array}{l}\text { Schleswig- } \\
\text { Holstein }\end{array}$ & Flensburg & $\begin{array}{l}\text { Westerland/ } \\
\text { Sylt" }\end{array}$ & & & & & \\
\hline
\end{tabular}

Tabelle 2: Deutsche Städte, in denen Videoüberwachung durchgeführt wurde oder wird. Stand 2003. ${ }^{47}$

Im Gegensatz zu den anderen Städten mit Videoüberwachungsprojekten sind im hessischen Hofheim und Fulda die Kommunen und nicht die Polizei die Hauptinitiatoren bei der Durchführung von Videobeobachtungsmaßnahmen. In den meisten Städten befinden sich die Standorte der polizeilichen Überwachungskameras in den Innenstädten, während in Böblingen, Bremen, Brandenburg, Fulda und Limburg die Bahnhofsvorplätze als Kriminalitätsschwerpunkte definiert und videoüberwacht werden. Überwachungskameras in Parkanlagen werden nur in Bielefeld und Dessau eingesetzt. In Magdeburg, Leipzig und Halle/Saale werden die Maßnahmen der Videoaufzeichnung auf Parkplätzen durchgeführt. Nur selten werden ganze Straßenzüge per Video observiert, wie in Leipzig und Rathenow. ${ }^{48}$

Im Mai 2005 wurden in der Bundesrepublik insgesamt 94 polizeiliche Kameras gezählt, die in 26 Städten bzw. acht Bundesländern eingesetzt werden. Tabelle 3 gibt einen Überblick polizeilicher Videoüberwachung öffentlicher Straßen und Plätze im Jahr 2005, wobei die bereits beendeten Videoüberwachungsmaßnahmen auf Sylt und

\footnotetext{
${ }^{47}$ Quelle: Eifler, S.; Brandt, D. (2005), in MschrKrim, 88. Jg. H. 3, S. 162.

${ }^{48}$ Eifler; Brandt (2005), S. 162.
} 
in Flensburg (Schlewig-Holstein) sowie in Böblingen (Baden-Württemberg) nicht in die Liste aufgenommen wurden. Städte wie Stuttgart, Singen und Dessau werden aufgrund der abgeschlossenen Projekte zur öffentlichen Videoüberwachung ebenfalls nicht berücksichtigt. Neu in der Aufzählung sind Projekte in Darmstadt, Mönchengladbach, Düsseldorf, München und Schweinfurt. Bevor diese einzelnen Projekte polizeilicher Videoüberwachung an Kriminalitätsschwerpunkten später in diesem Kapitel geschildert werden, werden zunächst die früheren Videoüberwachungsmaßnahmen öffentlicher Räume in der Bundesrepublik vorgestellt. 


\begin{tabular}{|c|c|c|c|c|}
\hline Stadt & Bundesland & Beginn & Kameras & Anmerkungen \\
\hline Bernau & Brandenburg & 2002 & 2 & \\
\hline Bielefeld & Nordrhein-Westfalen & 2001 & 4 & zwischenzeitlich Betrieb ausgesetzt \\
\hline Bremen & Bremen & 2002 & 1 & \\
\hline Darmstadt & Hessen & 2003 & 3 & \\
\hline Dresden & Sachsen & 1999 & 2 & \\
\hline Düsseldorf & Nordrhein-Westfalen & 2005 & 4 & \\
\hline Erkner & Brandenburg & 2001 & 2 & \\
\hline Frankfurt am Main & Hessen & 2000 & 6 & \\
\hline Fulda & Hessen & 2001 & 1 & Kooperation zw. Ordnungsamt, Polizei und BGS \\
\hline Gießen & Hessen & 2001 & 1 & \\
\hline Halle & Sachsen Anhalt & 1999 & 3 & \\
\hline Heilbronn & Baden-Württemberg & 2002 & 2 & \\
\hline Hofheim am Taunus & Hessen & 2000 & 3 & \\
\hline Kassel & Hessen & 2002 & 3 & \\
\hline Lcipzig & Sachsen & 1996 & 6 & \\
\hline Limburg an der Lahn & Hessen & 2002 & 14 & \\
\hline Magdeburg & Sachsen Anhalt & 1997 & 3 & \\
\hline Mannheim & Baden-Württemberg & 2001 & 8 & \\
\hline Mönchengladbach & Nordrhein-Westfalen & 2004 & 7 & \\
\hline München & Bayern & 2004 & 3 & als mobile Anlage deklariert \\
\hline Nürnberg & Bayern & 2002 & 2 & als mobile Anlage deklariert \\
\hline Potsdam & Brandenburg & 2001 & 6 & \\
\hline Rathenow & Brandenburg & 2001 & 2 & \\
\hline Regensburg & Bayern & 2000 & 4 & Polizei nutzt Kameras der Verkehrsbetriebe. \\
\hline Schweinfurt & Bayern & 2004 & 1 & als mobile Anlage deklariert \\
\hline Wiesbaden & Hessen & 2003 & 1 & \\
\hline Zusammen: 26 Städte & 8 Bundesländer & & 94 & \\
\hline
\end{tabular}

Tabelle 3: Polizeiliche Videoüberwachung öffentlicher Straßen und Plätze. Stand 31. Mai $2005{ }^{49}$

Die Videoüberwachung öffentlicher Orte ist kein neues Phänomen in Deutschland. Die ersten Kameras im öffentlichen Raum wurden schon im Jahr 1958 in München für die Verkehrsüberwachung installiert. Siebzehn Verkehrsschwerpunkte wurden videoüberwacht und von einer Verkehrszentrale aus geregelt. ${ }^{50}$ Ein Jahr später wurde in Hannover die Industriefernsehanlage auf dem Messegelände per Video über-

\footnotetext{
${ }^{49}$ Quelle: Töpfer, E. (2005), in DANA, 2/ 2005, S. 5 ff.

${ }^{50}$ Weichert (1998b), S. 12 ff.
} 
wacht. Diese Maßnahme wurde im darauf folgenden Jahr durch mobile Überwachungshubschrauber ergänzt. Die Münchener Polizei bekam im Jahr 1964 die erste mobile Fernsehaufnahme-Anlage, die die Beobachtung einer größeren Menschenansammlung ermöglichte. ${ }^{51}$ Schon in den 1960er Jahren setzte die Polizei bei Demonstrationen Kamerawagen und Handkameras ein, um die größeren Menschenansammlungen zu überwachen..$^{52}$

1976 war Hannover die erste Stadt in Deutschland, die permanent Videoüberwachung mit 25 Kameras durchführte, die mit schwenkbaren Zoomobjektiven ausgestattet waren. ${ }^{53}$ Ende der 1970er Jahre wurde am NATO-Hauptquartier im Raum Heidelberg versteckt Videoüberwachung durchgeführt. ${ }^{54}$

In den 1980er Jahren wurde die ehemalige Grenze zwischen BRD und DDR ebenfalls mittels Kameras überwacht, während die Kontrolle an den deutschen Grenzgebieten zu Polen und Tschechien zusätzlich mit Infrarotkameras sowie Lichtschranken und Bewegungsmeldern verstärkt wurde, um illegale Grenzübertritte aufzudecken. Als Vorbild dient hier die US-amerikanisch-mexikanische Grenze. ${ }^{55}$

Die schon seit den 1970er Jahren permanent montierten Videokameras in einigen deutschen Großstädten wie Hamburg, München und Hannover werden in den heutigen politischen Debatten vernachlässigt. ${ }^{56}$ Der Schwerpunkt der optischen Überwachung von Straßen und Plätzen lag in ihrer Anfangsphase eher im Bereich der reaktiven Strafverfolgung, während die Videoüberwachung zum Zweck der proaktiven Kriminalprävention erst seit den 1990er Jahren in politischen Diskussionen thematisiert wird. Wenn man heute in Deutschland von Videoüberwachung spricht, meint man die öffentliche Videoüberwachung, die in den neuen Bundesländern gestartet wurde, wie z.B. das erste Pilotprojekt zur Videoüberwachung von Kriminalitätsschwerpunkten in Leipzig. Im Folgenden werden diese Maßnahmen offener polizeilicher Videoüberwachung an Kriminalitätsbrennpunkten in Deutschland näher erläutert.

\footnotetext{
${ }^{51} \operatorname{Roos}(2002)$, S. 466.

${ }^{52}$ Mehr zur Geschichte der Videoüberwachung in Deutschland vgl. Weichert (1988).

${ }^{53}$ Seit 1977 werden Demonstranten von der Polizei mittels portabler Kameras gefilmt, vgl. Weichert (1998b), S. 12 f.

${ }^{54}$ Die verdeckte Ermittlung fand im Rahmen der RAF-,,Aktion Paddy“ statt. Roos (2002), S. 465; Weichert (1988), S. 14.

${ }^{55}$ Weichert (1998b), S. 12, 64; Roos (2002), S. 465; Weichert (1998a), S. 64.

${ }^{56}$ Nogala (2002), S. 9; vgl. auch Weichert (1988), S. 7 ff.; Weichert (1998b), S. 12 ff. 


\subsection{2 Überwachte Städte}

\subsubsection{Pilotprojekt in Leipzig}

Im Jahr 1996 begann die Polizeidirektion in Leipzig mit einem Pilotprojekt zur „Videoüberwachung von Kriminalitätsschwerpunkten“ gegen Autoeinbrüche, Taschendiebstähle und Drogenhandel am Bahnhofsvorplatz. In diesem, von offenen Rauschgiftgeschäften und damit zusammenhängenden sozialen Problemen belasteten Gebiet sollte die Kriminalitätsangst der Anwohner sowie der Geschäftsinhaber und der Besucher in der Stadt durch die Einführung von Überwachungskameras reduziert werden. ${ }^{57}$

Eingesetzt wurden hierbei Überwachungseinrichtungen, die über Schwenk-, Kippund Zoomobjektive verfügten, wobei an einzelne Personen aus datenschutzrechtlichen Gründen erst bei gegebenem Anlass herangezoomt werden durfte..$^{58}$

Bei der Einführung des Projektes wurde der sächsische Datenschutzbeauftragte konsultiert, um den Modellversuch mit einer polizei- und datenschutzrechtlichen Grundlage abzusichern. Gleichzeitig unterlag der Betrieb einer detaillierten polizeidienstlichen Anweisung der Leipziger Polizeidirektion, während veröffentlichte Dienstblätter, die Einrichtung eines Info-Telefons, Erklärungen bei Pressekonferenzen sowie die Anbringung mehrsprachiger Hinweisschilder im Rahmen der Informationskampagne den Bürger über das Ziel und die Reichweite der Videoüberwachung aufklären sollten. ${ }^{59}$

Nach mehrwöchigen Testphasen wurden die Kameras in Dauerbetrieb genommen. Die positiven Erfahrungen des ersten Pilotprojektes haben die Leipziger Polizei dazu bewogen, am Connewitzer Kreuz ebenfalls Videoüberwachungsmaßnahmen durchzuführen. ${ }^{60}$ Der Einsatz der Überwachungskamera am Connewitzer Kreuz hat die erste Leipziger Demonstrationswoche gegen Videoüberwachung ausgelöst und somit das Thema Videoüberwachung und die damit verbundenen Problematiken ins

\footnotetext{
${ }^{57}$ Müller (1998), S. 114 ff.; Müller (1997), S. 77 ff.; Müller (2000), S. 285 ff.

${ }^{58}$ Kohl (1997b), S. 24 ff.

${ }^{59}$ Ebenda.

${ }^{60}$ Während der ersten Phase des Pilotprojektes (10.04.-10.05.1996) wurden parallel Beamte in dem überwachten Gebiet eingesetzt. In dieser Testphase reduzierte sich die Anzahl der Kfz-Diebstähle um ca. $50 \%$, während die registrierten Delikte im Zusammenhang mit Betäubungsmitteln um ca. $25 \%$ zunahmen. Die vermehrten Drogendelikte wurden mit verstärkter Kontrolle der Streifenpolizisten in dem überwachten Gebiet erklärt. Nach der Beendigung der ersten Testphase stieg die Anzahl der Delikte des Kfz- und Taschendiebstahls kontinuierlich, so dass die Leipziger Polizei sich für eine zweite Testphase von 6 Monaten entschieden hat. Zu Details des Pilotprojektes: Müller (1997), S. 77 ff.; vgl. auch Müller (1998), S. 114 ff.
} 
öffentliche Bewusstsein gerückt. ${ }^{61}$ Die Überwachungskamera am Connewitzer Kreuz wurde am 19. April 2000 mit der Begründung der Polizei abmontiert, dass es sich hierbei nicht mehr um einen Kriminalitätsschwerpunkt handle. Allerdings wurden zeitgleich zwei weitere Kameras entlang des Leipziger Stadtringes installiert. ${ }^{62}$ Die Kosten für die Anschaffung und Inbetriebnahme betrugen ca. 163.000 DM, die jährlichen Miet- und Unterhaltungskosten wurden auf 84.000 DM geschätzt. ${ }^{63}$ Am Connewitzer Kreuz wurde im Juni 2003 erneut eine polizeiliche Überwachungskamera installiert. Der Anlass dafür war die Zunahme der Straftaten in diesem Bereich, insbesondere die Ausschreitungen in der Silvesternacht 2002/2003. ${ }^{64}$

\subsubsection{Modellversuch auf Sylt}

Im Jahr 1996 beiteiligte sich die Stadt Westerland auf Sylt an einem Modellversuch namens "community policing", in dem eine Überwachungskamera auf dem touristischen Platz „Wilhelmine“ zur Observierung von Trinkern, Drogenkonsumenten und zugereisten Punks in der Fußgängerzone installiert wurde. ${ }^{65}$

Im Gegensatz zu den Kameras, die im selben Jahr beim Leipziger Pilotprojekt eingesetzt waren, wurden hierbei keine Aufzeichnungen angefertigt. Die Ereignisse aus der von Urlaubern gefüllten Fußgängerzone wurden live auf den Monitor in die Polizeistation übertragen. Da die kommunale Polizei keinen Rund-um-die-Uhr-Dienst hatte, wurden die Aufnahmen an die Landespolizei Schleswig-Holstein weitergeleitet. ${ }^{66}$ Es handelte sich hierbei um ein einfaches Überwachungsgerät ohne Zoomobjektiv oder Schwenkfunktionalität.

Vor der Einführung wurde diesbezüglich umfangreiche Öffentlichkeitsarbeit geleistet, so dass das Projekt positiv von der Bevölkerung aufgenommen wurde. Nach der

\footnotetext{
${ }^{61}$ Vom 31. Januar 2000 bis 4. Februar 2000 fanden in Leipzig die "Anti-Kamera-Demonstrationen“ unter dem Motto „gegen die Repressions- und Überwachungsstaatlichkeit“ statt. Leipziger Volkszeitung (2000c); Leipziger Volkszeitung (2000a); Müller (2000), S. 288. Genauere Zahlen zu der Entwicklung der Straftaten während der Testphase des Modellversuchs vgl. Müller (2000), S. 286 ff.

${ }^{62}$ Leipziger Volkszeitung (2000b); Leipziger Volkszeitung (2000d); Leipziger Volkszeitung (2000a).

${ }^{63}$ Die Frage, warum die Überwachungskampagne in Deutschland zuerst im Osten des Landes gestartet wurde, begründete Reuband mit der Kriminalitätshysterie und der Suche nach nachgeholter Modernität in den neuen Bundesländern. Auch die sinkenden Preise der modernen Überwachungskameras und die Tendenz der Kriminalpolitik zur Vorbeugung von Straftaten trugen zur breiten Akzeptanz der Videoüberwachung bei. „Die neuen Formen der Kriminalprävention sind umfassender und breiter angelegt als früher, und die Kriminalitätsbedrohung und Kriminalitätsfurcht der Bürger nehmen hierbei in der Begründung für die Maßnahmen eine Schlüsselrolle ein." Auch die in den 1980er Jahren stattgefundene Debatte um den Datenschutz in den alten Bundesländern könnte, so Reuband, die Einstellung der Bürger gegenüber Missbrauchspotentialen der Videoüberwachung beeinflusst haben. Vgl. Reuband (2001), S. 6 ff; Büllesfeld (2002), S. 48.

${ }^{64}$ Müller (2003); vgl. auch Leipziger Kamera (2003a).

${ }^{65}$ Kohl (1997b), S. 24 ff.

${ }^{66}$ Ebenda.
} 
Testphase im Jahr 1996 wurde die Anlage ab Juli 1997 regelmäßig zur Urlaubssaison in Betrieb genommen. ${ }^{67}$

\subsubsection{Pilotprojekt in Bielefeld}

Am 23. Februar 2001 wurden im Ravensberger Park und im Rochdale Park in Bielefeld insgesamt vier Überwachungskameras installiert, um der „seit Jahren bestehende(n) Kriminalitätsbelastung“ entgegenzuwirken, die die Bürgerinnen und Bürger verunsicherte und dadurch „zum Verzicht auf die Nutzung der Grünanlage und Kultureinrichtungen“ hätte führen können. ${ }^{68}$ Durch die Nähe zum Zentrum und zur Drogenberatungsstelle hatte sich vor allem der Ravensberger Park zu einem beliebten Treffpunkt für Drogensüchtige entwickelt. Es handelte sich hierbei um einen Modellversuch im Rahmen der Kooperation zwischen dem Polizeipräsidium und der Stadt Bielefeld. ${ }^{69}$

Die Kosten für die Anschaffung und Installation der Kameras betrugen rund 60.000 DM. ${ }^{70}$ Das Aufzeichnungsgerät in der Polizeihauptwache wurde dann aktiviert, „wenn sich durch die Beobachtung der Verdacht einer begonnenen oder unmittelbar bevorstehenden Straftat“ ergab. Alle Bilddaten wurden für zwanzig Minuten von einem Computer gespeichert und bei polizeirelevanten Anlässen die entsprechenden Ereignissequenzen aufgerufen. ${ }^{71}$

Am 31.02.2002 wurde der Modellversuch in Bielefeld beendet, und nach Angaben des Landesministeriums des Inneren in Nordrhein-Westfalen ließ sich der „Erfolg (...) in Zahlen messen“. ${ }^{72}$

\subsubsection{Pilotprojekt in Frankfurt am Main}

Als Ergebnis der Novellierung des Hessischen Gesetzes für Sicherheit und Ordnung (HSOG) im Jahr 2000 wurde am 22. Dezember 2001 an der von hoher Drogenkriminalität und damit verbundener Beschaffungskriminalität belasteten Konstablerwache ein Projekt der polizeilichen Videoüberwachung mit insgesamt drei sichtbar angebrachten Überwachungskameras gestartet. Dieses Verfahren wurde in Übereinstimmung mit dem hessischen Datenschutzbeauftragten durchgeführt.

\footnotetext{
${ }^{67}$ Schumacher (1999); Klingelschmitt (1999); vgl. auch Keller (2000), S. 190; Gras (2003), S. 265; Weichert (1999), S. 7 f.; Reuband (2001), S. 5; Kohl (1997b), S. 24 ff.

${ }^{68}$ Boers (2004), S. 28.

${ }^{69}$ Bausch (2004), S. 139.

${ }^{70}$ Boers (2004), S. 29; Bausch (2004), S. 137 ff.

${ }^{71}$ Boers (2004), S. 28 ff.

${ }^{72}$ Nordrhein-Westfalen (2002); Bausch (2004), S. 144. Lietz (2004). Mehr zu den Daten der Kriminalitätsentwicklung während des Modellsversuchs vgl. Boers (2004), S. 56 ff.
} 
Über die Effektivität der Videoüberwachung an der Konstablerwache herrschte Uneinigkeit. Während das hessische Innenministerium das Projekt als Erfolg bezeichnet, das die Sicherheitslage und das Sicherheitsgefühl der Bevölkerung in dem überwachten Gebiet deutlich verbessert hat, beklagten die Einzelhändler in dem umliegenden Gebiet (Seitengassen und der unterirdischen Ebene im Umfeld des Überwachungsbereiches) über eine Verlagerung der Kriminalität. ${ }^{73}$ Die Frankfurter Polizei sowie der Sicherheitsdezernent führten die erhöhte Anzahl der registrierten Delikte auf die intensivere Kontrolltätigkeit der Streifenpolizisten nach der Einführung des Überwachungsprojektes zurück. ${ }^{74}$

Im Jahr 2003 erfolgte am Vorplatz des Frankfurter Hauptbahnhofs und dem angrenzenden Kaisersack ein Videoüberwachungsprogramm mit insgesamt vier Anlagen, obwohl Finanzierungsschwierigkeiten die Installation und Personalprobleme die Durchführung des Projektes gefährdeten. ${ }^{75}$ Die Aufnahmen wurden in die Einsatzzentrale des Polizeipräsidiums übertragen.

Neben den polizeilichen Überwachungseinrichtungen am Hauptbahnhof operieren seit 1992 ca. 120 Kameras der Deutschen Bahn AG, die im Rahmen des 3-SKonzeptes $^{76}$ Tag und Nacht die Ereignisse auf den Bahnsteigen in die 3-S-Zentrale übertragen. ${ }^{77}$

\subsubsection{Pilotprojekt in Regensburg}

Anfang Juni 2000 wurden Aufnahmen von 15 bereits sichtbar installierten Überwachungskameras der Verkehrsbetriebe in Regensburg an die örtliche Polizei weitergeleitet. Von einer Überwachungszentrale aus beobachtete die Regensburger Polizei "aggressive Ansammlungen von Jugendlichen und Personen sozialer Randgruppen“ an Kriminalitätsschwerpunkten. ${ }^{78}$ Das Ziel des Modellversuchs bestand darin, das Sicherheitsgefühl der Bevölkerung im überwachten Bereich zu steigern und potentielle Straftäter abzuschrecken.

Damit wurde das erste bayerische Pilotprojekt zur Videoüberwachung gestartet, wobei insgesamt sieben Plätze in der Innenstadt polizeilich überwacht wurden. Anlass

\footnotetext{
${ }^{73}$ Frankfurter Neue Presse (2002b); Frankfurter Allgemeine Zeitung (2002); Frankfurter Rundschau (2002c).

${ }^{74}$ Diese Information stammt aus einem Interview mit dem ersten Polizei-Hauptkommisar in Frankfurt a.M. Bernd Schuhmann am 08.04.2003 am Polizeipräsidium; vgl. auch Frankfurter Neue Presse (2002b); Frankfurter Rundschau (2001); Frankfurter Rundschau (2002b).

${ }^{75}$ Frankfurter Rundschau (2002a); Frankfurter Neue Presse (2003c); Frankfurter Neue Presse (2002a).

${ }^{76} 3 \mathrm{~S}$ steht für ",Service, Sicherheit, Sauberkeit".

${ }^{77}$ Wehrheim (2002), S. 137; Biedermann (2002).

${ }^{78}$ Gras (2003), S. 265.
} 
für diese Überwachung in Regensburg war die über dem Landesdurchschnitt liegende Kriminalitätsrate. ${ }^{79}$ Auf die Überwachungskameras wies die Polizei mit Schildern hin. Dabei erfolgten die Videoüberwachungsmaßnahmen nicht kontinuierlich, sondern überwiegend zu tatrelevanten Zeiten. Eine Videoaufzeichnung wurde erst bei Verdacht einer Straftat und nur zu deren Beweissicherung angefertigt. ${ }^{80}$ Die Einführung der polizeilichen Videoüberwachung in Regensburg wurde im Rahmen einer Pressekonferenz mit umfangreicher Information der Allgemeinheit bekannt gegeben. ${ }^{81}$

Am 10. Juli 2001 wurde das Polizeiaufgabengesetz vom bayerischen Landtag dahingehend geändert, dass polizeiliche Videoüberwachung mit Speicherung der Daten in öffentlichen Räumen in Bayern geregelt wurde. ${ }^{82}$

\subsubsection{Pilotprojekt in München}

In München wurden im Mai 2004 die ersten drei polizeilichen Überwachungskameras auf dem Pini-Haus am Stachus, dem Bahnhofsgebäude und dem Gebäude an der Ecke Schiller-/Bayerstraße montiert. ${ }^{83}$ Dabei handelte es sich nach Angaben des bayerischen Staatsministeriums um mobile Hochleistungskameras mit digitaler Bildübertragung per Funk, deren Überwachungsstandorte bei Bedarf gewechselt werden konnten.$^{84}$ Mit Hinweisschildern versehen, sollte die Entwicklung der Kriminalität in diesen Bereichen in der Testphase von zwölf Monaten beobachtet werden, um die Effektivität der Videoüberwachung zu prüfen.

Seit 2002 wurden an verschiedenen Stellen auf dem Wiesn-Gelände polizeiliche Kameras installiert, die während des Oktoberfestes Bildaufzeichnungen anfertigten. Dieses Projekt wurde mit Zustimmung der zuständigen Datenschutzbehörde durchgeführt, die angesichts der Vielzahl internationaler Besucher u.a. Hinweisschilder auch in englischer Sprache und einer Abbildung von einer Kamera forderte. ${ }^{85}$

Neben dem Einsatz dieser polizeilichen Kameras wurde im Jahr 2000 ein Plan entwickelt, die Videoaufnahmen von 1000 bereits fest montierten Überwachungsanlagen

\footnotetext{
${ }^{79}$ Die Kriminalitätsrate in Regensburg beträgt im Jahr 1999 25\% und in Bayern insgesamt 20,5\%. Vgl. Stolle; Hefendehl (2002), S. 267; Greiner (2000), S. 12; Gras (2003), S. 264.

${ }^{80}$ Bayerisches Staatsministerium des Innern (2000), S. 6; Stierand (2000), S. 93.

${ }^{81}$ Büllesfeld (2002), S. 43.

${ }^{82}$ Vgl. Klocke (2001), S. 88 ff.; Stolle; Hefendehl (2002), S. 267.

${ }^{83}$ Süddeutsche Zeitung (2004b).

${ }^{84}$ Bayerisches Staatsministerium des Innern (2004).

${ }^{85}$ Der Bayerische Landesbeauftragte für den Datenschutz (2004), S. 50 ff.
} 
an die Polizei weiterzuleiten, um die mit erhöhter Kriminalitätsrate belasteten Bereiche der Stadt besser kontrollieren zu können. ${ }^{86}$

\subsubsection{Pilotprojekt in Mannheim}

Nach Angaben des baden-württembergischen Landesbeauftragten für den Datenschutz findet seit 2001 stationäre Videoüberwachung statt. ${ }^{87} \mathrm{Im}$ Sommer 2000 hat der Gemeinderat der Stadt Mannheim dem geplanten Pilotprojekt zur Videoüberwachung zugestimmt, das von der Stadtverwaltung und dem Polizeipräsidium vorgeschlagen wurde. Im Juli 2001 hat Mannheim als erste baden-württembergische Stadt mit polizeilicher Videografie öffentlicher Räume begonnen. Mit sieben Kameras werden drei Kriminalitätsschwerpunkte in der Mannheimer Innenstadt (Paradeplatz, Marktplatz und um das Neckartor) rund um die Uhr von der Polizei überwacht. ${ }^{88}$

\subsubsection{Pilotprojekt in Stuttgart}

Unter den baden-württembergischen Städten spielt neben Mannheim auch Stuttgart die Vorreiterrolle in polizeilicher Videoüberwachung. In Stuttgart wurde der Rotebühlplatz in der Innenstadt vom 28.02.2002 bis zum 26.07.2003 von der Polizei mit fünf leistungsfähigen Kameras überwacht, wobei zwei Anlagen oberirdisch und drei in dem unterirdischen Fußgängerbereich installiert wurden. Das Projekt wurde unter Zustimmung des Stuttgarter Gemeinderats durchgeführt und vom Landesbeauftragten für den Datenschutz Baden-Württembergs beaufsichtigt. Der Einsatz war nach Angaben der Polizei so erfolgreich, dass die überwachte Zone nach 18 Monaten nicht mehr als Kriminalitätsbrennpunkt eingestuft wurde und die Anlagen abgeschaltet wurden. ${ }^{89}$

\subsubsection{Andere überwachte Städte in Deutschland}

In Dresden entschied sich die Polizeidirektion im September 1999 für eine Videoüberwachungsmaßnahme mit einer Anlage an dem Kriminalitätsschwerpunkt Prager Straße, welche von Geschäftsleuten finanziert wurde. Es handelt sich hierbei um eine „Live-Übertragung“ der Aufnahmen, d.h. dass eine generelle Speicherung der Bilddaten nicht gegeben ist. ${ }^{90}$

\footnotetext{
${ }^{86}$ Gras (2003), S. 264; Süddeutsche Zeitung (2000).

${ }^{87}$ Gras (2003), S. 264; Greiner (2000), S. 120; Der Landesbeauftragte für den Datenschutz BadenWürttemberg (2005b).

${ }^{88}$ Der Landesbeauftragte für den Datenschutz Baden-Württemberg (2001), S. 25 ff.

${ }^{89}$ Ebenda, S. 31 ff.; Das Innenministerium Baden-Württemberg (2002); Der Landesbeauftragte für den Datenschutz Baden-Württemberg (2005b).

${ }^{90}$ Schneider; Daub (2000), S. 322; Reuband (2001), S. 6.
} 
In Halle (Saale) benutzt heute die örtliche Polizei die moderne Bildübertragungstechnik, um gegen Rauschgifthändler, Kfz-Diebstähle sowie Raubdelikte am Marktplatz vorzugehen, ${ }^{91}$ während die Polizei in Bremen diese Technik am Sielwall-Eck einsetzt. ${ }^{92}$ In Magdeburg finden ähnliche polizeiliche Überwachungsmaßnahmen mittels Bildübertragungstechnik statt. ${ }^{93}$

Das Land Brandenburg startete im November 2001 das erste Pilotprojekt zur polizeilichen Videoüberwachung am Bahnhofsvorplatz in Erkner. ${ }^{94}$ Im Rahmen des polizeilichen Konzeptes zur Kriminalitätsbekämpfung waren nach der Presseerklärung des brandenburgischen Innenministeriums weitere Projekte in Bernau, Rathenow und Potsdam geplant. Die Effektivität der Videoüberwachung bei diesen Projekten soll nach Anordnung des Landtages durch ein unabhängiges Forschungsinstitut untersucht werden. Im Jahr 2006 wird der Landtag in Brandenburg über den permanenten Einsatz polizeilicher Videoüberwachung entscheiden. ${ }^{95}$

Nach den Erfahrungen in Stuttgart und Mannheim reihten sich auch Singen und Heilbronn in die baden-württembergischen Städte mit polizeilicher Videografie öffentlicher Räume ein. Im Juni 2003 nahm die Stadt Singen die Überwachungskameras in der Bahnhof- und August-Ruf-Straße in Betrieb, welche allerdings nach fünf Monaten zum 15.10.2003 wieder abgeschaltet wurden. Der finanzielle Aufwand sowie die mangelhafte Begründung für das Vorliegen eines Kriminalitätsbrennpunktes waren nach Angaben des Datenschutzbeauftragten die Gründe für die Stadt Singen und die zuständige Polizeidirektion Konstanz, diese Maßnahme einzustellen. ${ }^{96}$ Die polizeiliche Videoüberwachung in Heilbronn wurde zum 1. Juli 2002 in der Sülmer City gestartet, welche zum 1.10.2005 von der Polizei eingestellt wurde. Die Anzahl der Straftaten im überwachten Gebiet sank laut polizeilichen Aussagen nach der Einführung von Überwachungskameras kontinuierlich, so dass die Videoüberwachung nicht mehr erforderlich war. ${ }^{97}$ Temporäre Videobeobachtungsmaßnahmen setzte die baden-württembergische Polizei auch bei Volksfesten ein. In Ravensburg wurden auf dem traditionellen Rutenfest bestimmte Bereiche von der Polizei per Video überwacht, während die Polizeidirektion in Biberach das Schützenfest im Jahr 2004 eben-

\footnotetext{
${ }^{91} 10-15 \%$ der registrierten Verbrechen in Halle, in Form von Köperverletzungen, Taschendiebstählen usw., finden auf dem Marktplatz statt. Vgl. Gras (2003), S. 264.

${ }^{92}$ taz (2000).

${ }^{93}$ Reuband (2001), S. 5 f.; Gras (2003), S. 264.

${ }^{94}$ Brandenburg (2001).

${ }^{95}$ In Potsdam findet die Videoüberwachung nach Angaben des Polizeipräsidiums am Potsdam Center und am Hauptbahnhof statt. Vgl. ebenda.

${ }^{96}$ Der Landesbeauftragte für den Datenschutz Baden-Württemberg (2003), S. 10 ff.

${ }^{97}$ Der Landesbeauftragte für den Datenschutz Baden-Württemberg (2005a).
} 
falls mit Videokameras bewachen wollte. Allerdings musste die Polizei die letztere aufgrund eines verwaltungsgerichtlichen Beschlusses unterlassen. ${ }^{98}$

Nach dem Pilotprojekt in Regensburg und der Absicherung der gesetzlichen Grundlage von polizeilicher Videoüberwachung in Bayern werden seit Februar 2004 in Schweinfurt hochmoderne Überwachungseinrichtungen eingesetzt. ${ }^{99}$ In Hofheim im Main-Taunus-Kreis werden seit 1999 Bilder aus dem von Kriminalität schwer belasteten Busbahnhof mit drei optisch-elektronischen Überwachungseinrichtungen aufgezeichnet und bis zu vier Wochen gespeichert, um diese bei gegebenem Anlass auswerten zu können. ${ }^{100}$

Im Januar 2002 kündigte der Innenminister von Baden-Württemberg die Einführung mobiler Videoüberwachung an. Die mobile Anlage „sei im Prinzip von heute auf morgen einsetzbar, eigne sich besonders für den zeitlich begrenzten Einsatz an den Orten, an denen absehbar eine dauerhafte Videoüberwachung nicht erforderlich sei und stelle [...] für die jeweiligen Gemeinden eine kostengünstige Ergänzung des polizeilichen Sicherheitsangebots dar". ${ }^{101}$ Bis jetzt wurde diese Anlage am Bahnhofsplatz in Böblingen getestet, um der dortigen offenen Drogenszene Einhalt zu gebieten. Allerdings konnte die Verlagerung der Kriminalität in benachbarte Orte nur durch zusätzlichen Polizeieinsatz vermindert werden. ${ }^{102}$ Nach drei Monaten wurde die Anlage abgeschaltet, da kein Kriminalitätsbrennpunkt mehr vorlag. ${ }^{103}$

Ein ähnliches Projekt wurde auch in Bayern durchgeführt. Im Rahmen des „ZweiSäulen-Konzeptes “104 wurden in Nürnberg im Jahr 2002 zwei mobile Überwachungskameras abwechselnd am Bahnhofsvorplatz, an der Königstorpassage und der König- und Luitpoldstraße aufgestellt. ${ }^{105}$ Ein weiterer Einsatz solcher mobilen Überwachungsgeräte mit digitaler Bildübertragung per Funk war im Jahr 2004 für München vorgesehen. ${ }^{106}$

Allerdings gibt es Ausnahmen bei der Einführungswelle der Videoüberwachung: In Düsseldorf entschied sich der Polizeipräsident trotz des Vorschlages des Oberbür-

\footnotetext{
${ }^{98}$ Der Landesbeauftragte für den Datenschutz Baden-Württemberg (2005b); vgl. auch Der Landesbeauftragte für den Datenschutz Baden-Württemberg (2004), S. 13 ff.

${ }^{99}$ Bayerisches Staatsministerium des Innern (2004).

${ }^{100}$ Stierand (2000), S. 82.

${ }^{101}$ Hempel (2003).

102 Ebenda.

${ }^{103}$ Der Landesbeauftragte für den Datenschutz Baden-Württemberg (2003), S. 10.

${ }^{104}$ Das Konzept umfasst, nach Angaben des bayerischen Staatsministeriums des Innern, die stationäre Videoüberwachung von Kriminalitätsbrennpunkten (die erste Säule) und den Einsatz mobiler Videoüberwachungsanlagen (die zweite Säule). Vgl. Bayerisches Staatsministerium des Innern (2004).

${ }^{105}$ Hempel (2003).

${ }^{106}$ Hutter (2004).
} 
germeisters zunächst gegen den Einsatz der Überwachungskameras am Worringer Platz. Erst seit April 2005 werden vier Kameras zur Observierung in der Düsseldorfer Altstadt eingesetzt. ${ }^{107}$ Weitere Projekte zur Videoaufzeichnung öffentlicher Räume sind in Aachen, Bochum und Worms geplant. ${ }^{108}$

\subsection{Videoüberwachung in den USA}

\subsubsection{Ausmaß der Videoüberwachung}

Auch in den Vereinigten Staaten ist in den vergangenen Jahren nicht nur eine $\mathrm{Zu}$ nahme privater Anwendung optischer Überwachungstechnik wahrzunehmen, sondern auch die Polizei und andere staatliche Behörden greifen des Öfteren auf diese Technik zurück. ${ }^{109}$ Der Einsatz dieser Überwachungseinrichtungen scheint weit verbreitet zu sein: Sowohl im Norden (Massachusetts, Alaska) als auch im Süden (Tennessee, Alabama) und nicht nur an der Ostküste (und Virginia, South Carolina), sondern auch an der Westküste (Kalifornien, Washington-State) des Landes werden die Innenstädte bereits von wachsamen „elektronischen Augen“ überwacht. ${ }^{110}$ Nach Angaben der American Civil Liberties Union (ACLU) ist die Videoüberwachung in manchen größeren amerikanischen Städten inzwischen so flächendeckend im Einsatz, dass es unmöglich sei, dort spazieren zu gehen, ohne von Kameras überwacht zu werden. ${ }^{111}$

Der 1997 von der Security Industry Association veröffentlichte "CCTV for Public Safety Report" nannte CCTV-Systeme in 37 US-Städten, die bereits Gebrauch von Überwachungskameras machten, oder gerade dabei waren, den Kameraeinsatz zu planen. Nach Angaben dieses Reports schätzte die amerikanische Sicherheitsindustrie, dass insgesamt ca. zwei Millionen Überwachungskameras in den USA zum Zweck der Sicherheit in Banken, Garagen, Büros, Restaurants usw. eingesetzt wurden. Davon

\footnotetext{
${ }^{107}$ Das Innenministerium Nordrhein-Westfalen (2005a); Gras (2003), S. 264; Krischer; Holzer (2000), S. 53.

108 Töpfer (2005), S. 5, 9.

${ }^{109}$ Nachdem es in den 1990er Jahren mehrere Schießereien in amerikanischen Schulen gegeben hat, wie der Vorfall in Columbine, bekam die CCTV-Überwachung auch in den Schulen eine wichtige Rolle als kriminalpräventives Werkzeug. Nach der landesweiten American School E University (ASEU) Security Survey im Jahr 2000 stellte die CCTV-Anlage die zweitwichtigste Sicherheitseinrichtung in den amerikanischen Schulen dar. Die meisten befragten Schulen gaben an, dass Videoüberwachung im Jahr 2001 als meist gewünschte Einrichtung in ihrem Sicherheitssystem geplant sei. Die Schulbusse und Campus gehören zum Einsatzgebiet dieser Überwachungstechnik. Auch die teuren Laboreinrichtungen in den Schulen werden via Video geschützt. Solche CCTV-Überwachungssysteme findet man beispielsweise in Huntington Beach und Moreno Valley in Kalifornien. Nieto et al. (2002), S. 26 ff.; Büllesfeld (2002), S. 44 ff.

${ }^{110}$ Hierbei werden nur Videoüberwachungsmaßnahmen zur Kriminalprävention und -repression berücksichtigt. Mehr zu anderen Arten von Videoüberwachung, wie z.B. zur Verkehrskoordination und an Arbeitsplätzen vgl. Nieto et al. (2002), S. 19 ff.

${ }^{111}$ Stanley; Steinhardt (2002a), S. 2 f.
} 
wurden Tausende von staatlichen Institutionen betrieben, die nicht nur auf öffentlichen Straßen und Plätzen, sondern auch in Flughäfen, Verkehrskreuzungen, Gefängnissen und öffentlichen Gebäuden untergebracht waren. ${ }^{112}$ Auch in Sozialwohnungssiedlungen und für Transitunternehmen waren Maßnahmen zur Videografie keine Seltenheit. ${ }^{113}$

1997 konnten in einer Untersuchung vom California Research Bureau (CRB) insgesamt 13 US-Städte, die CCTV-Systeme in den öffentlichen Räumen anwendeten, gezählt werden. ${ }^{114}$ Als diese Untersuchung im Jahr 2002 wiederholt wurde, konnten die Forscher eine zunehmende Verwendung von Videoüberwachungstechnik in amerikanischen Städten feststellen. ${ }^{115}$

Anhand dieser Forschungsergebnisse sowie anderer relevanter Veröffentlichungen wird im Folgenden versucht, die aktuelle Verbreitung von Videoüberwachung in den Vereinigten Staaten möglichst umfangreich darzustellen. Es ist hierbei wichtig zu erwähnen, dass wegen der zahlreichen Kooperationen zwischen dem öffentlichen und dem privaten Sektor die Zuständigkeit für die öffentliche Videoüberwachung nicht immer eindeutig zu bestimmen ist. Außerdem ist es aufgrund der fehlenden gesetzlichen Grundlagen sowie vielfältiger Einsatzmöglichkeiten nicht immer klar definiert, was unter „öffentlicher Videoüberwachung“ zu verstehen ist. Deswegen handelt es sich hierbei um eine Darstellung, die die tatsächliche Situation der Videoüberwachung in den USA nicht in ihrem vollen Umfang wiedergibt. Dennoch genügt

\footnotetext{
${ }^{112}$ In Huntsville, Alabama sind Schulen durch CCTV-Überwachung geschützt, welche mit einem digitalen Übertragungssystem verbunden sind. Drei bis zwölf Kameras wurden jeweils in 41 Schulen installiert, um das Geschehen auf Schulhöfen, an den Eingängen und in Laboren, wo kostspielige Ausrüstungen aufbewahrt werden, zu kontrollieren. Ähnliche CCTV-Projekte werden beispielsweise auch in Indianapolis und Oregon durchgeführt. Mehr zur Videoüberwachung in Schulen vgl. Anderson (1997); Nieto et al. (2002), S. 33; Nieto (1997), S. 27 ff.; Evangelista (2001).

${ }^{113}$ Die Sozialwohnungsprojekte in Boston wie Roxie Homes, Camfield Gardens und Grant Manor setzen zur Sicherheit ihrer Wohneinheiten CCTV-Kameras ein, die im Rahmen des Safe Neighborhood Action Plan (SNAP) nach eigenen Angaben die Kriminalitätsrate um 30\% gesenkt haben. Ähnliche Einsätze von Überwachungskameras in Sozialwohnungsbauten sind auch in Porteville und Eureka in Kalifornien zu finden. In Heightstown, New Jersey wurden zehn Kameras ebenfalls in einem Housing Project eingesetzt, während man in Jersey City, New Jersey im Jahr 2000 mit Videoüberwachung öffentlicher Räume begann. New Jersey Transit startete im Januar 2004 mit heimlicher Videoüberwachung von Fahrgästen, nachdem mehrere Gegenstände gestohlen und beschädigt wurden. Nach Angaben des Security Industry Association Report 1996 wurden in Camden im Rahmen des Westfield Acres Housing Projects Kameras hinter kugelsicheren Scheiben installiert, nachdem Personen versucht hatten, diese durch Schüsse zu beschädigen. Die Aufnahmen von 33 Überwachungskameras in Wohngebieten in Garfield, New Jersey werden im Gegensatz zu den meisten Projekten gespeichert und nach verdächtigem Verhalten geprüft. Bei gegebenem Anlass werden die Bildmaterialien an die Polizei oder das FBI übermittelt. Verantwortlich für das Betreiben des Systems in Garfield ist die Garfield Housing Authority, wobei freiwillige Mitarbeit von Einwohnern geplant war. Vgl. CCTV for Public Safety (Security Industry Association Report 1996), S. 28 ff.; Burrows (1997), Rn. 1104, Rn. 1105; Nieto (1997), S. 25 ff.; Nieto et al. (2002), S. 15 ff.

${ }^{114}$ Nieto (1997).

${ }^{115}$ Es handelt sich hierbei um eine Telefonumfrage, die im Jahr 2002 vom California Research Bureau durchgeführt wurde, vgl. Nieto et al. (2002), S 13 ff.
} 
dies, um einen Einblick in die institutionellen Strukturen öffentlicher Videoüberwachung zu verschaffen.

Zunächst sollen die vom California Research Bureau im Jahr 2002 erstellten Tabellen einen Überblick schaffen, bevor die einzelnen Programme in den verschiedenen Städten, soweit die Informationen zugänglich sind, detailliert geschildert werden. ${ }^{116}$ Insgesamt wird eine intensivere Nutzung der Überwachungskameras in dem Ostteil der USA beobachtet, die vermutlich auf die Großstädte und die höhere Bevölkerungsdichte in dem östlichen Teil des Landes zurückzuführen sei (siehe Tabelle 4). ${ }^{117}$ In Kalifornien sind die Stadtzentren und Einkaufsgebiete bevorzugte Orte für öffentliche Videoüberwachung (siehe Tabelle 5). Die Finanzierungen solcher Anlagen erfolgen variierend zwischen rein privaten Investitionen und einer Kombination aus privaten und staatlichen Kassen. ${ }^{118}$

\footnotetext{
${ }^{116}$ Da das Forschungszentrum California Research Bureau neben der allgemeinen landesweiten Untersuchung sich speziell auf die kalifornischen Städte konzentriert hat, werden die videoüberwachten Städte in Kalifornien in einer anderen Tabelle separat aufgelistet.

${ }^{117}$ Nieto et al. (2002), S. $13 \mathrm{f}$.

${ }^{118}$ Diese Projekte werden im nächsten Abschnitt der Arbeit näher erläutert. Die Hervorhebung der kalifornischen Städte mit Videoüberwachungsmaßnahmen basiert auf der Trennung der Forschungsergebnisse vom California Research Bureau und hat in dieser Arbeit keine weitere Bedeutung.
} 


\begin{tabular}{|c|c|c|c|c|c|c|}
\hline \multicolumn{7}{|c|}{ U.S. Cities (not including California) Using CCTV Public Surveillance Cameras } \\
\hline City/Town & $\begin{array}{l}\text { Installation } \\
\text { Date }\end{array}$ & Site Location & $\begin{array}{l}\text { Funding } \\
\text { Source }\end{array}$ & $\begin{array}{l}\text { Reason For } \\
\text { Use }\end{array}$ & $\begin{array}{l}\text { Time of } \\
\text { Operation }\end{array}$ & $\begin{array}{l}\text { Type of } \\
\text { Surveillance }\end{array}$ \\
\hline Baltimore, MD & June 1996 & Downtown & Private/Public & $\begin{array}{l}\text { Drugs and } \\
\text { street crime }\end{array}$ & $\begin{array}{l}7 \text { a.m. to } 11 \\
\text { p.m. }\end{array}$ & $\begin{array}{l}\text { Active } \\
\text { monitoring }\end{array}$ \\
\hline Dover, NJ & $\begin{array}{l}\text { September } \\
1993\end{array}$ & Downtown & Federal funds & Loitering & $\begin{array}{l}\text { Around the } \\
\text { clock }\end{array}$ & $\begin{array}{l}\text { Active } \\
\text { monitoring }\end{array}$ \\
\hline Jersey City, NJ & 2000 & Citywide & $\begin{array}{l}\begin{array}{l}\text { Federal } \\
\text { grants }\end{array} \\
\end{array}$ & Street crime & $\begin{array}{l}7 \text { a.m. to } 11 \\
\text { p.m. }\end{array}$ & $\begin{array}{l}\text { Active } \\
\text { monitoring }\end{array}$ \\
\hline $\begin{array}{l}\text { South Orange, } \\
\text { NJ }\end{array}$ & 1994 & $\begin{array}{l}\text { City parking } \\
\text { lots and streets }\end{array}$ & $\begin{array}{l}\text { Federal and } \\
\text { city }\end{array}$ & $\begin{array}{l}\text { Crime } \\
\text { prevention }\end{array}$ & $\begin{array}{l}\text { Daytime } \\
\text { hours }\end{array}$ & $\begin{array}{l}\text { Active } \\
\text { monitoring }\end{array}$ \\
\hline Charleston, SC & 1997 & Citywide & Federal/state & Street crime & $\begin{array}{l}\text { Around the } \\
\text { clock }\end{array}$ & $\begin{array}{l}\text { Active } \\
\text { monitoring }\end{array}$ \\
\hline Tukwila, WA & August 1995 & $\begin{array}{l}\text { Business } \\
\text { district }\end{array}$ & City funds & $\begin{array}{l}\text { Drugs and } \\
\text { Prostitution }\end{array}$ & $\begin{array}{l}\text { Around the } \\
\text { clock }\end{array}$ & $\begin{array}{l}\text { Active } \\
\text { monitoring }\end{array}$ \\
\hline $\begin{array}{l}\text { Federal Way, } \\
\text { WA }\end{array}$ & 2001 & Downtown & Federal funds & $\begin{array}{l}\text { Drugs and } \\
\text { Prostitution }\end{array}$ & $\begin{array}{l}\text { Around he } \\
\text { clock }\end{array}$ & $\begin{array}{l}\text { Active } \\
\text { monitoring }\end{array}$ \\
\hline Tacoma, WA & August 1993 & Hilltop district & City funds & $\begin{array}{l}\text { Drugs and } \\
\text { Prostitution }\end{array}$ & $\begin{array}{l}\text { Around the } \\
\text { clock }\end{array}$ & $\begin{array}{l}\text { Active } \\
\text { monitoring }\end{array}$ \\
\hline $\begin{array}{l}\text { Tampa/St. } \\
\text { Pete, FL* }\end{array}$ & $\begin{array}{l}\text { September } \\
1996\end{array}$ & Ybor City & Public/private & $\begin{array}{l}\text { Crime } \\
\text { prevention }\end{array}$ & $\begin{array}{l}\text { Around the } \\
\text { clock }\end{array}$ & $\begin{array}{l}\text { Active } \\
\text { monitoring }\end{array}$ \\
\hline $\begin{array}{l}\text { Virginia } \\
\text { Beach, VA* }\end{array}$ & 2000 & $\begin{array}{l}\text { Waterfront } \\
\text { district }\end{array}$ & City/private & $\begin{array}{l}\text { Crime } \\
\text { prevention }\end{array}$ & $\begin{array}{l}6 \text { a.m. to } 7 \\
\text { p.m. }\end{array}$ & $\begin{array}{l}\text { Active } \\
\text { monitoring }\end{array}$ \\
\hline $\begin{array}{l}\text { Anchorage, } \\
\text { AK }\end{array}$ & 1992 & $\begin{array}{l}\text { Entertainment } \\
\text { district }\end{array}$ & State/private & $\begin{array}{l}\text { Drugs and } \\
\text { prostitution }\end{array}$ & $\begin{array}{l}7 \text { p.m. to } 4 \\
\text { a.m. }\end{array}$ & $\begin{array}{l}\text { Passive } \\
\text { monitoring }\end{array}$ \\
\hline Memphis, TN & 1996 & Downtown & State/private & $\begin{array}{l}\text { Crime } \\
\text { prevention }\end{array}$ & $\begin{array}{l}\text { Around the } \\
\text { clock }\end{array}$ & $\begin{array}{l}\text { Active } \\
\text { monitoring }\end{array}$ \\
\hline Gulfport, MS & 2000 & $\begin{array}{l}\text { Business } \\
\text { District }\end{array}$ & Private/public & $\begin{array}{l}\text { Crime } \\
\text { prevention }\end{array}$ & $\begin{array}{l}\text { Daytime } \\
\text { hours }\end{array}$ & $\begin{array}{l}\text { Active } \\
\text { monitoring }\end{array}$ \\
\hline Nevada, MO & 2001 & City Parklands & Private funds & $\begin{array}{l}\text { Petty crime } \\
\text { prevention }\end{array}$ & $\begin{array}{l}\text { Around the } \\
\text { clock }\end{array}$ & $\begin{array}{l}\text { Active } \\
\text { monitoring }\end{array}$ \\
\hline $\begin{array}{l}\text { New Orleans, } \\
\text { LA }\end{array}$ & 1998 & $\begin{array}{l}\text { Entertainment } \\
\text { district }\end{array}$ & Private/public & $\begin{array}{l}\text { Crime } \\
\text { prevention }\end{array}$ & $\begin{array}{l}\text { Around the } \\
\text { clock }\end{array}$ & $\begin{array}{l}\text { Active } \\
\text { monitoring }\end{array}$ \\
\hline Cleveland, $\mathrm{OH}$ & 1997 & $\begin{array}{l}\text { Entertainment } \\
\text { district }\end{array}$ & Private funds & $\begin{array}{l}\text { Crime } \\
\text { prevention }\end{array}$ & $\begin{array}{l}7 \text { p.m. to } 2 \\
\text { a.m. }\end{array}$ & $\begin{array}{l}\text { Passive } \\
\text { monitoring }\end{array}$ \\
\hline Honolulu, HI & 1998 & $\begin{array}{l}\text { Chinatown } \\
\text { area }\end{array}$ & City funds & $\begin{array}{l}\text { Crime and } \\
\text { Prostitution }\end{array}$ & $\begin{array}{l}\text { Around the } \\
\text { clock }\end{array}$ & $\begin{array}{l}\text { Active } \\
\text { monitoring }\end{array}$ \\
\hline
\end{tabular}

Source: California Research Bureau telephone survey and literature review, 2002

* Indicates use of biometric facial recognition technology in conjunction with CCTV

Tabelle 4: US-Städte mit öffentlicher Videoüberwachung (ohne Kalifornien). Stand 2002. ${ }^{119}$

${ }^{119}$ California Research Bureau, Telefonumfrage 2002. Nieto. et al. (2002): CRB 02-006, S. 14. 


\begin{tabular}{|l|l|l|l|}
\hline \multicolumn{4}{|c|}{ Cities in California And Use of CCTV Public Surveillance Programs } \\
\hline City & CCTV Surveillance System & $\begin{array}{l}\text { Location of } \\
\text { System }\end{array}$ & $\begin{array}{l}\text { Future } \\
\text { Consideration }\end{array}$ \\
\hline Sacramento & $\begin{array}{l}\text { Yes-privately operated and monitored by } \\
\text { the downtown merchants association. }\end{array}$ & $\begin{array}{l}\text { Downtown business } \\
\text { district }\end{array}$ & None \\
\hline San Francisco & Yes-to reduce criminal activity on buses. & $\begin{array}{l}\text { Various Muni buses } \\
\text { and rail system trains. }\end{array}$ & $\begin{array}{l}\text { Yes-as funds become } \\
\text { available }\end{array}$ \\
\hline Oakland & No-rejected in 1997 & $\begin{array}{l}\text { Was proposed for the } \\
\text { downtown area. }\end{array}$ & $\begin{array}{l}\text { Yes-the Oakland } \\
\text { International Airport }\end{array}$ \\
\hline $\begin{array}{l}\text { San Jose- } \\
\text { Silicon Valley }\end{array}$ & Yes & Commercial district & Yes \\
\hline Vallejo & Yes-to discourage crime & Downtown & Yes \\
\hline Los Angeles & $\begin{array}{l}\text { Discontinued in 1999 in the Hollywood } \\
\text { area of Los Angeles. }\end{array}$ & Yucca Street corridor & $\begin{array}{l}\text { Yes-a digital system is } \\
\text { in the planning stages }\end{array}$ \\
\hline Lakewood & $\begin{array}{l}\text { Discontinued in 2000 after two year } \\
\text { project to address graffiti and gang activity }\end{array}$ & $\begin{array}{l}\text { Residential } \\
\text { neighborhoods }\end{array}$ & $\begin{array}{l}\text { Yes-as the need for this } \\
\text { type of surveillance is } \\
\text { warranted }\end{array}$ \\
\hline Palm Springs & Yes & Business district & Yes \\
\hline San Diego & Yes & Balboa Park & Yes \\
\hline
\end{tabular}

Source: California Research Bureau Survey, 2002

Tabelle 5: Kalifornische Städte mit öffentlicher Videoüberwachung. Stand 2002. ${ }^{120}$

\subsection{2 Überwachte Städte}

\subsubsection{Hoboken und Mount Vernon}

Die ersten dokumentierten polizeilichen Videoüberwachungsprogramme öffentlicher Räume fanden 1966 in Hoboken, New Jersey und 1971 in Mount Vernon, New York statt. Das CCTV-Projekt in Hoboken wurde aufgrund von Unwirksamkeit nach fünf Jahren eingestellt, da die Kameras in diesem Zeitraum zu nur zwei Verhaftungen führten. In Mount Vernon wurde die Videobeobachtungsmaßnahme nach einer Laufzeit von drei Jahren ebenfalls abgebrochen, da sie keine einzige Straftat aufklären konnte. Trotz dieser schlechten Erfahrungen mit Überwachungskameras, deren technischen Fähigkeiten damals noch sehr begrenzt waren und öffentlich wenig Anerkennung fanden, folgten weitere Videoaufzeichnungsmaßnahmen. Allerdings wurden die staatlichen Zuschüsse wegen der fehlenden Erfolge eingestellt. ${ }^{121}$

\subsubsection{New York City}

Im Jahr 1973 wurde auf dem Times Square in Manhattan ein \$ 15.000 teures CCTVSystem von der New York Times und den örtlichen Geschäftsinhabern installiert. Allerdings erwies sich dieses Programm wie seine Vorgänger ebenfalls als eine Fehlinvestition, da das System in der zweijährigen Laufzeit zu weniger als zehn Verhaf-

\footnotetext{
${ }^{120}$ California Research Bureau Telefonumfrage 2002. Nieto et al. (2002): CRB 02-006, S. 19.

${ }^{121}$ Nieto (1997), S. 12; Burrows (1997), Rn. 1103.
} 
tungen führte. Das Programm wurde aufgrund der mangelhaften Effektivität abgebrochen. ${ }^{122}$

Trotzdem werden inzwischen alle wichtigen öffentlichen Straßen und Plätze in New York City mit Kameras überwacht. Die genaue Anzahl der Kameras lässt sich nur schwer ermitteln. Die New York Civil Liberties Union (NYCLU) zählte 1998 im Rahmen des NYCLU Surveillance Camera Project 2397 Kameras, die auf öffentliche Bereiche ausgerichtet waren. Davon wurden nach Schätzungen 2000 Kameras privaten Betreibern und die restlichen unterschiedlichen Behörden zugerechnet. ${ }^{123}$ Auf dem Times Square wurden im Jahr 1998 nach Angaben des Projektes 75 Überwachungskameras gesichtet, während im Mai 2005 in dem gleichen Bezirk die New York Surveillance Camera Players 604 Kameras zählten. ${ }^{124} 2004$ wurde die Gesamtzahl der Überwachungskameras auf Manhattan auf ca. 72000 geschätzt. ${ }^{125}$

Die Polizei in New York City war ebenfalls bemüht, ihre Videoüberwachungsgebiete auf Wohngebiete, Parkanlagen und U-Bahn-Stationen auszudehnen. Über manche Kamerastandorte wurde die Öffentlichkeit bewusst in Kenntnis gesetzt, z.B. Washington Square Park in Greenvillage: ${ }^{126}$

1997 wurden zwei polizeiliche Überwachungskameras auf der Südseite des Washington Square Park in New York City installiert. Sie waren deutlich sichtbar an den Straßenlaternen angebracht und sollten zur Überwachung und Bekämpfung von Drogenkriminalität im Park dienen. ${ }^{127}$ Durch diese Maßnahme, die vom ehemaligen Bürgermeister Rudolph W. Giuliani und dem damaligen Polizeipräsidenten Howard Safir angeordnet wurde, sollte der Park von offenem Drogenhandel befreit werden und für Familien und Bürger in New York zur Verfügung stehen. Der Erfolg stellte sich bereits ein paar Tage nach der Installation der Kameras ein. Die anfänglichen Reaktionen der Parkbenutzer waren angesichts der sinkenden Drogenkriminalität im Park meistens positiv. ${ }^{128}$

\footnotetext{
${ }^{122}$ Burrows (1997), Rn. 1103.

${ }^{123}$ New York Civil Liberties Union (1998). California Research Bureau berichtet im Jahr 2002, dass mehr als 2300 Überwachungskameras in Manhatten vorhanden sind, wobei 85\% im privaten Besitz waren. Vgl. Nieto et al. (2002), S. 13.

${ }^{124}$ Im Jahr 2000 zählten die New York Surveillance Camera Players 131 Kameras im Times Square und zwei Jahre später stieg diese Zahl auf 258. Vgl. New York Surveillance Camera Players (2005).

125 Tavernise (2004).

${ }^{126}$ Büllesfeld (2002), S. $41 \mathrm{f}$.

${ }^{127}$ Lee (1998).

${ }^{128}$ Ein Monat nach der Installation polizeilicher Kameras in Washington Square Park in New York City wurden die Proteststimmen gegen diese permanente Überwachung von vielen Parkbesuchern immer lauter. Vgl. Halbfinger (1998): "The protesters argued that surveillance cameras in the public spaces smacked of a police state. They said the cameras would destroy the kind of privacy in public spaces that New Yorkers have come to expect, eroding the quality of life for law-abiding city residents
} 
Die meisten Überwachungsmaßnahmen in Wohnhäusern wurden von privaten Hausverwaltungen durchgeführt. Im Juli 1997 startete jedoch das „Surveillance Program For Public Housing Projects" in einer Wohnsiedlung in New York City, wobei 39 polizeiliche Videokameras in privaten Aufzügen, Eingangshallen und Wohnungsfluren zur Observation eingesetzt wurden. Während die Bürgerrechtsgruppe New York Civil Liberties Union das Programm als Eingriff in die Privatphäre der Bewohner kritisierte, registrierte die New Yorker Polizei nach eigenen Angaben eine sinkende Kriminalitätsrate von 20,9\% im überwachten Gebiet. Weitere ähnliche Housing-Projekte wurden für das Jahr 1998 in 11 Wohnsiedlungen geplant, die aufgrund der hohen Kriminalität in dem jeweiligen Gebiet ausgewählt wurden. ${ }^{129}$

Im Mai 2005 kündigte der Polizeichef Raymond W. Kelly weitere 400 polizeiliche Überwachungskameras an, die zusätzlich zu den bereits vorhandenen 80 Überwachungsgeräten an einigen verkehrs- und kriminalitätsintensiven Gebieten in New York angebracht werden sollten. Heute hat die New Yorker Polizei überdies Zugang zu weiteren 3000 Kameras, die von New York Housing Authority an 15 Sozialwohnungsbauten installiert sind. ${ }^{130}$

\subsubsection{Washington D.C.}

Das intensivste Videoüberwachungsnetz in den USA wurde im Jahr 2002 in der Hauptstadt Washington D.C. errichtet. In diesem Netzwerk der Videoüberwachung gehören zwölf Kameras dem D.C. Metropolitan Police Department, die jederzeit von der Polizei genutzt werden können. ${ }^{131}$ Im Blickfeld dieser Kameras sind beispielswei-

\footnotetext{
far more than they would help catch and prosecute criminals." Nachdem die Drogenhändler den Park verlassen und in den angrenzenden Gebieten des Parks außerhalb der Sichtweite der Kameras ihren neuen Markt gegründet haben, sind es nun die gesitteten Bürger, die unter der ständigen Überwachung der Polizei stehen. Zwar werden die im Park aufgezeichneten Kassetten nach sieben Tagen gelöscht, doch ein Sprecher des New York City Gay and Lesbian Antiviolence Project weist darauf hin, dass eine Verbreitung solcher Überwachungskameras in bestimmten Stadtteilen, wo Homosexuelle sich oft aufhalten, z.B. Greenwich Village Piers in New York, dazu führen könnte, dass manche Homosexuelle aus Angst vor Missbrauch der Aufzeichnungen sich nicht natürlich verhalten könnten. NYCLU (New York Civil Liberties Union) befürchtet, dass das eigentliche Problem nicht wirklich gelöst wird, aber die freie und anonyme Natur in den öffentlichen Räumen der Stadt durch die unmerklich zunehmende Verbreitung von Überwachungskameras allmählich zerstört werden kann. "If cameras are the quick fix answer, then you'll soon have cameras on every block. If you don't deal with the root problems, then you're just pushing it elsewhere again." (Norman Siegel, der ehemalige Direktor von New York Civil Liberties Union, in: Lee (1999).

${ }^{129}$ Nach polizeilichen Angaben ist in den Projekten vor allem die Zahl der schweren Rechtsverletzungen, z.B. Mord, Vergewaltigung, Einbruchsdiebstahl, Raubüberfälle und Autodiebstahl gesunken. Kennedy (1997).

${ }^{130}$ Lee (2005).

${ }^{131}$ Nach den Berichten vom 22.03.2002 Hsu (2002d) und vom 23.03.2002 Hsu (2002c) der Washington Post besitzt die lokale Polizei in Washington D.C. 12 Überwachungskameras, während der Bericht vom 17.02.2002 Washington Post Hsu (2002a) von 13 Kameras berichtet. Die Bürgerrechtsinitiative "Surveillance Camera Players" aus New York berichtet von 14 polizeilichen Kameras, die im Raum Washington D.C. im Einsatz sind. Vgl. New York Surveillance Camera Players (2003).
} 
se das Capitol, das White House, das Washington Monument, die Union Station und die wichtigen Brücken der Stadt. ${ }^{132}$ Die Aktivierung des gesamten Überwachungsnetzwerks, also die Einschaltung der nichtpolizeilichen Kameras in dem Netzwerk, bedarf allerdings der Zustimmung der zuständigen Behörde, z.B. der öffentlichen Schulen, der U.S. Capitol Police oder der U-Bahn in Washington D.C. ${ }^{133}$ Anlässe zur Aktivierung des gesamten Netzwerks, in dem Hunderte von Kameras operieren, waren beispielsweise Demonstrationen vor der Weltbank und dem Internationalen Währungsfonds im April 2000 134 oder größere Menschenansammlungen und Feierlichkeiten wie der amerikanische nationale Feiertag am 4. Juli. ${ }^{135}$

Das im Herbst 2001 in Betrieb genommene Joint Operations Command Center vom D.C. Metropolitan Police Department dient heute der Koordination dieser Vielzahl von Videoüberwachungssystemen zwischen dem D.C. Metropolitan Police Department und den anderen lokalen und nationalen Law Enforcement Agencies. ${ }^{136}$ Die wichtigsten Verkehrsadern, die Transit-Stationen sowie Schulen und die Behördengebäude der amerikanischen Hauptstadt werden von diesem Netzwerk der Videoüberwachung erfasst. Mit der Übertragung der Videodaten kann sich die Polizei in Notfällen Einblicke in Schulgebäude und U-Bahn-Stationen verschaffen und diese an die Bildschirme in nahzu 1000 Polizeistreifenwagen weiterleiten. ${ }^{137}$ Unterstützung erhält das Projekt ebenfalls von anderen Law Enforcement Agencies wie dem Secret Service, FBI, der U.S. Capitol Police und der U.S. Park Police, indem diese der D.C. Metropolitan Police bei bestehender Gefahr Zugriff auf ihre Überwachungssysteme gewähren. Geplant sind ebenfalls Verbindungen zu regionalen Datenbanken. ${ }^{138}$

Neben der staatlichen Videoüberwachung werden bestimmte Straßen in der Innenstadt von Washington D.C. von uniformiertem Sicherheitspersonal patrouilliert, dem

\footnotetext{
${ }^{132} \mathrm{Hsu}(2002 \mathrm{a})$.

${ }^{133}$ Bartsch (2004), S. 32; Hsu (2002c).

${ }^{134} \mathrm{Hsu}(2002 \mathrm{a})$; New York Surveillance Camera Players (2003).

${ }^{135} \mathrm{Hsu}$ (2002a); vgl auch Bartsch (2004), S. 32.

${ }^{136}$ Stefan J. Gaffigan, der Leiter dieses polizeilichen Projektes (ein ehemaliger Justice Department Director of Community Policing), erklärte zu Beginn des Netzwerkaufbaus, dass die Polizei keine Integration privater Überwachungssysteme in das Netzwerk beabsichtigte. Ausnahme bildeten allerdings die Kameras im Stadtzentrum Georgetown Business District. Vgl. Hsu (2002a); Bartsch (2004), S. 31 f.

${ }^{137} \mathrm{Hsu}$ (2002a). Die mit hochmodernen Überwachungskameras oder Bildübertragungstechnik ausgerüsteten Polizeiwagen sind keine Seltenheit in den US-amerikanischen Städten. Vgl. Wehrheim (2002), S. 87.

${ }^{138}$ Mehr als 200 Kameras sind bereits zu Anfang des Projektes in dieses Netzwerk eingebunden. Immer mehr Kamerasysteme werden hinzugezogen. Die öffentlichen Schulen und das D.C. Department of Transportation haben sich beispielsweise im Februar 2002 bereit erklärt, diesem Netzwerk insgesamt 500 Kameras zur Verfügung zu stellen. Im März 2002 wurde Zeitungsberichten zufolge die Anzahl der bereitzustellenden Überwachungskameras auf 700 erhöht. Nicht nur die Hauptverkehrsadern und Bahnhöfe, sondern auch Schulen und öffentliche Gebäude gehören zu den Einsatzorten von Überwachungskameras. Vgl. Hsu (2002b); Hsu (2002c); Hsu (2002a); Hsu (2002d); vgl. auch Nieto et al. (2002), S. 14.
} 
CCTV-Kameras als zusätzliche Hilfsmittel zur Verfügung stehen. Dieser Einsatz wird von 792 örtlichen Grundstücksbesitzern finanziert, die sich bereit erklärt haben, monatlich einen Cent pro Quadratfuß zu zahlen, um Sicherheit, Sauberkeit und ungestörtes Geschäftsleben zu garantieren. ${ }^{139}$

\subsubsection{Miami Beach (Florida)}

Dade County in Miami Beach ist traditionell bekannt für seinen hohen Bevölkerungsanteil an Rentnern und seine relativ preisgünstigen Wohnanlagen. Angezogen von diesen Immobilienpreisen entschieden sich in den 1980er Jahren auch viele Menschen mit geringem Einkommen für dieses Gebiet als bevorzugten Wohnsitz. Mit dem Ansturm der schwarzen und lateinamerikanischen Zuwanderer nahm auch die Angst der ortsansässigen, älteren Bewohner vor Verbrechen zu. Infolgedessen forderten sie mehr Polizeipräsenz. ${ }^{140}$

Um die tägliche Polizeiarbeit ohne zusätzlichen Personalaufwand zu erleichtern, wurde 1982 in Dade County, Florida ein CCTV-Programm in innenstädtischen Einkaufszonen eingeführt. Es wurden insgesamt über 100 Überwachungskästen in der Haupteinkaufszone der Innenstadt installiert. Um Kosten zu reduzieren, waren tatsächlich nur 21 Kästen mit Überwachungskameras bestückt. Die Polizei wechselte alle 90 Tage die Standorte der Überwachungskameras in den Kästen, um einen optimalen Abschreckungseffekt zu erzielen. Ursprünglich waren Polizeibeamte als Dienstpersonal der Überwachungssysteme eingeplant, aber es waren die Angestellten des Gemeinderats, die die Kontrollarbeit an Monitoren durchführten. ${ }^{141}$

Allerdings wurde die Kriminalitätsangst dadurch nicht verringert und die Pflege der technischen Ausrüstungen sowie das ständige Wechseln der Standorte von Überwachungskameras erwiesen sich als schwierig für die Polizei. Nachdem kein einziger Krimineller durch die Überwachungsanlagen festgenommen werden konnte, wurde im Mai 1984 das Programm eingestellt. ${ }^{142}$

\subsubsection{Tampa Bay (Florida)}

Schon 1994 war das Gebiet zwischen Tampa Bay und St. Petersburg, bekannt als Gateway, von Kfz-Delikten so schwer belastet, dass die Stadt St. Petersburg staatliche Zuschüsse in Höhe von \$ 42.000 für mobile Videoüberwachung erhielt. Nach polizeilichen Angaben konnte dadurch die Sicherheitslage in diesem Bereich wesentlich

\footnotetext{
${ }^{139}$ Anderson (1997).

${ }^{140}$ Mehr zum Thema „Kriminalitätsangst“ vgl. Teil II, Kap. 4.3 dieser Arbeit.

${ }^{141}$ Burrows (1997), Rn. 1080.

${ }^{142}$ Ebenda, Rn. 1080, Rn. 1082 und Rn. 1103.
} 
verbessert werden. ${ }^{143} \mathrm{Im}$ Jahr 1995 installierte die Stadt Tampa Bay acht Überwachungskameras im Ybor City District, womit die Polizei Zehntausende Wochenendbesucher in diesem vorstädtischen Freizeit- und Geschäftsbezirk überwachte. ${ }^{144}$ Die Videoüberwachungsmaßnamen wurden von einem Sprecher des Tampa Bay Police Department als „,way of the future“ beschrieben. ${ }^{145}$

Im Januar 2001 filmte die Polizei bei einer Superbowl-Veranstaltung in Tampa die über 100.000 Besucher mit versteckten Kameras, die mit biometrischen Gesichtserkennungssystemen ausgestattet waren. Die Aufnahmen wurden mit den polizeilichen Datenbanken von registrierten Kriminellen abgeglichen. ${ }^{146}$ Kurz nach dieser Superbowl-Veranstaltung wurden Gesichtserkennungssysteme auf öffentlichen StraBen in Tampa Bay und Virginia Beach eingesetzt. ${ }^{147}$ Allerdings wurde das Gesichtserkennungsprogramm in Tampa Bay aufgrund der mangelhaften Trefferquote eingestellt. $^{148}$

\subsubsection{Anchorage (Alaska)}

In Anchorage, Alaska wurde 1990 ein Projekt zur Videoüberwachung eingeleitet, nachdem ein Pipeline-Projekt diverse soziale Probleme, z.B. Drogen, Prostitution und Körperverletzungen, nach sich zog. ${ }^{149}$ Die Überwachungsarbeit gehört in Anchorage nicht zu den alltäglichen Aufgaben der örtlichen Polizei; vielmehr werden die Polizeibeamte durch die privaten Überwacher über verdächtige Ereignisse informiert. Die Einwohner können selbstständig digitale Aufzeichnungen und Vergrößerungen von verdächtigen Personen vornehmen und diese an die Polizeidienststelle oder/und Ladenbesitzer weiterleiten. Privatpersonen geben sogar Mitteilungsblätter mit Fotos von den Delinquenten heraus, die mit Hilfe von Videoüberwachungsanlagen überführt werden konnten. Die Finanzierung des Projektes wird sowohl vom Staat Alaska als auch von der lokalen Geschäftsgemeinschaft in Anchorage getragen. ${ }^{150}$

\footnotetext{
${ }^{143}$ Nieto (1997), S. 15.

${ }^{144}$ Burrows (1997), Rn. 1106.

${ }^{145}$ Nieto et al. (2002), S. 15. Nach Angaben einer Untersuchung vom California Research Bureau im Jahr 1997 wurde das Projekt in Tampa im September 1996 gestartet, vgl. Nieto (1997), S. 15-16.

${ }^{146}$ Nieto et al. (2002), S. 6.

${ }^{147}$ Ebenda, S. 3.

${ }^{148}$ Ebenda, S. 15; vgl. auch Stanley; Steinhardt (2002b).

${ }^{149}$ Burrows (1997), Rn. 1083, Rn. 1103. Nach Angaben vom California Research Bureau begann das Programm im Jahr 1992. Vgl. Nieto et al. (2002), S. 16.

${ }^{150}$ Anderson (1997); Nieto et al. (2002), S. 16.
} 


\subsubsection{Baltimore (Maryland)}

Im September 1995 startete nach Angaben des California Research Bureau das Baltimore Police Department gemeinsam mit der örtlichen Verkehrsbehörde (Mass Transit Authority) und einer Gemeinschaft von innerstädtischen Geschäftsinhabern (Downtown Partnership of Baltimore) ein „Video Patrol Project", wodurch die Kriminalitätsrate und Kriminalitätsangst gesenkt und das Konsumklima verbessert werden sollte. ${ }^{151}$ Zur Finanzierung dieses Projekts wurde der Byrne Memorial Federal Grant in Höhe von $\$ 75.000$ beantragt und erteilt. ${ }^{152} 16$ Kameras wurden daraufhin an öffentlichen Plätzen, Straßen und Parks installiert, wozu auch das innerstädtische Gebiet Howard Street/Lexington Market gehörte.

Das System wurde im Rahmen des staatlich finanzierten Community Oriented Policing Service Program (COPS) von Polizeibeamten betrieben, die die Anfertigung von Bildaufzeichnungen vornahmen und diese bis zu 96 Stunden aufbewahrten. Ein Teil der finanziellen Mittel sollte für die Sammlung von Kriminalstatistiken verwendet werden, um die Effizienz des Kameraeinsatzes einschätzen zu können. Allerdings konnte bisher keine Bekanntmachung dieser Daten gefunden werden. ${ }^{153}$

Eine Gemeindegruppe in Baltimore beauftragte im Januar 1996 eine Non-ProfitOrganisation, ein Videoüberwachungsprojekt mit 16 Kameras im Zentrum von Baltimore zu starten, wobei Hinweisschilder die Passanten auf die Existenz der Kameras aufmerksam machen sollten. ${ }^{154}$ Das $\$ 58.000$ teure Projekt wurde von privaten Sponsoren und dem örtlichen Verkehrsamt finanziert. Heute wird die tägliche Überwachungsarbeit an den Monitoren von Polizeibeamten und Bürgern gemeinsam durchgeführt. $^{155}$

Das Projekt sollte nach Angaben des Security Industry Association Report 1996 auf mehr als 200 Überwachungskameras ausgedehnt werden. Inzwischen werden die zentral gesteuerten Kamerasysteme mit einem Gesichtserkennungssystem kombiniert, um Verdächtige schnell identifizieren zu können. ${ }^{156}$

\footnotetext{
${ }^{151}$ Nieto et al. (2002), S. 15.

152 Ebenda.

${ }^{153}$ Nieto (1997), S. 13 f.

154 Ebenda.

${ }^{155}$ Ein Polizeibeamter in Baltimore ist der Meinung, dass seine Arbeit an den Überwachungsmonitoren der Arbeit von acht Streifenpolizisten vor Ort gleichzusetzen sei. Vgl. Straub (1996).

${ }^{156}$ Banisar (1998), S. $19 \mathrm{ff}$.
} 


\subsubsection{Virginia Beach (Virginia)}

In Virginia Beach, Virginia begann im Jahr 1993 mit fünf CCTV-Kameras das Überwachungsprogramm, welches große Zustimmung bei den lokalen Einzelhändlern und Bürgern fand. Ein Jahr später wurde das Projekt um fünf Kameras ergänzt. ${ }^{157}$ Insgesamt waren zehn hoch auflösende Kameras mit um 360 Grad schwenkbaren Objektiven am Strand von Virginia Beach positioniert, deren Überwachungsbereich 27 Wohnblocks abdeckte. Selbst in der Dunkelheit konnten diese Geräte qualitativ hochwertige Bilder anfertigen. Das Programm kostete \$ 240.000 und wurde von lokalen Geschäften und öffentlichern Geldern der Stadt (Citys Reserve Fund, Drug Asset Forfeiture Fund) getragen. ${ }^{158}$ Die Überwachung erfolgte durchschnittlich 13 Stunden am Tag. ${ }^{159}$ Später wurde biometrische Technik zu dem System hinzugefügt, und im Jahr 2002 war Virginia Beach die einzige Stadt in den USA, die an Verkehrskreuzungen CCTV-Systeme mit Gesichtserkennungsprogramm installierte. ${ }^{160}$

\subsubsection{Chicago (Illinois)}

Im Jahr 1994 führte die Polizei in Chicago auf Anweisung des damaligen Bürgermeisters Richard Daley eine Anti-Graffiti-Kampagne mit Hilfe von versteckten Überwachungskameras durch. ${ }^{161}$ Aufgrund ihres Erfolgs gegen Vandalismus wurde diese Maßnahme in anderen Stadtteilen wiederholt. ${ }^{162}$ Im September 2004 kündigte die Polizei in Chicago die Vernetzung von 2000 Überwachungskameras an, wobei der Einsatz von 250 weiteren Kameras vom Bürgermeister angeordnet wurde, die bis zum Jahr 2006 in das System eingebunden werden sollen. ${ }^{163}$

\subsubsection{New York State}

Videoüberwachungsmaßnahmen sind nicht nur in Großstädten, sondern auch in kleineren Stadtbezirken zu finden, und zwar noch umfassender und effektiver, da die zu beobachtende Fläche viel kleiner ist. Das ländlich geprägte Städtchen Lyon in New York State hat 4.300 Einwohner und eine Polizeistation mit insgesamt zehn Po-

\footnotetext{
${ }^{157}$ Nieto (1997), S. 16.

${ }^{158}$ Burrows (1997), Rn. 1106; Nieto et al. (2002), S. 15.

${ }^{159}$ Nieto (1997), S. 16 f.

${ }^{160}$ Auch in Richmond, Virginia bekam ein Sozialwohnungskomplex einen Zuschuss von Housing and Urban Development (HUD) und Community Oriented Police (COP) für polizeiliche Patrouillen und digitale Überwachungskameras. Vgl. Nieto et al. (2002), S. $15 \mathrm{ff}$.

${ }^{161}$ Burrows (1997), Rn. 1107, Fn. 225.

${ }^{162}$ Beamte aus Illinois besuchten 1994 King's Lynn, um das britische Modell der Videoüberwachung zu begutachten. Vgl. Ebenda, Fn. 225.

163 "Cameras are the equivalent of hundreds of sets of eyes", sagt der Bürgermeister in Chicago Richard M. Daleys. „They're the next best thing to having police officers stationed at every potential trouble spot." In Kinbzer (2004); vgl. auch Lee (2005).
} 
lizeibeamten. Trotz nur geringen Ausmaßes von Kriminalität wurden Überwachungskameras im Stadtzentrum installiert. Der Polizeichef war davon überzeugt, dass die rund um die Uhr betriebenen Kameras die Polizeiarbeit erleichtern und die Drogendealer endgültig aus dem Städtchen vertreiben würden. ${ }^{164}$

Ein Warnschild an der Hauptstraße in Roslyn, einer kleinen Gemeinde mit 712 Häusern, macht die Besucher der Stadt darauf aufmerksam, dass sie in der Stadt nicht nur von Streifenwagen, sondern auch von 26 versteckten Kameras überwacht werden. $^{165}$

\subsubsection{New Jersey}

Im Jahr 1991 wurden die innerstädtischen Bereiche der Stadt Newark von sechs Überwachungskameras unter dem Namen „Video Patrol“ rund um die Uhr überwacht, welche mit staatlichen Geldern (Federal Economic Development Grants) in Höhe von \$ 101.791 finanziert wurden. ${ }^{166}$ Für die Instandhaltung des Systems war ein privates Unternehmen zuständig, wobei nur die Polizei die Kontrollaufgaben an Monitoren übernahm. Das Projekt wurde sowohl von der Polizei als auch von Einzelhändlern begrüßt, die von einer Reduzierung der Kfz-Delikte und kommerziellem Wachstum berichteten. ${ }^{167}$

In der kleinen Stadt East Newark mit ca. 2.377 Einwohnern wurden aufgrund einer einzigen Straftat im Jahr 199616 Überwachungskameras montiert. Mit Zoomobjektiven operierten die Kameras in der nur neun Häuserblocks umfassenden Gemeinde, um jede Straße Tag und Nacht zu beaufsichtigen. ${ }^{168}$

Auch in andern Städten in New Jersey, wie Dover und South Orange, sind Überwachungskameras im Einsatz. Das Videoüberwachungsprojekt in Dover startete 1993 im innerstädtischen Bereich und auf dem Flohmarkt mit vier Überwachungskameras, welche mit einem 180 Grad schwenkbaren Zoomobjektiv ausgestattet waren. Auch Schulhöfe und Verkehrskreuzungen gerieten später in das Blickfeld der Kameras, wobei von einer Zentrale aus drei verschiedene überwachte Gebiete gleichzeitig

\footnotetext{
${ }^{164}$ Büllesfeld (2002), S. 42.

${ }^{165}$ Die Installation der Kameras in Roslyn wurde nicht von der Polizei, sondern von den Bewohnern (voluntary neighborhood patrol) vorgenommen und auch finanziert. Das Projekt von Roslyn Country Club Civic Association hat bereits 1991 begonnen, als mehrere Bewohner auf dem Heimweg von videoüberwachten Einkaufszentren, in denen fast keine Straftaten begangen werden, beraubt wurden. Die Überwachungskameras werden an den Dächern von privaten Häusern versteckt, deren genauen Standorte nur den jeweiligen betroffenen Hausbewohnern bekannt sind. Vgl. Konig (1996).

${ }^{166}$ Anderson (1997).

${ }^{167}$ Nieto (1997), S. $14 \mathrm{f}$.

${ }^{168}$ Nieves (1997); Büllesfeld (2002), S. 42.
} 
kontrolliert wurden. ${ }^{169}$ Das $\$ 30.000$ teure Projekt fand anfänglich keine große $\mathrm{Zu}$ stimmung von Bürgern. Dies änderte sich jedoch, als die nicht erwünschten Obdachlosen und Jugendlichen verschwanden..$^{170}$ Seit 1994 operieren in South Orange sieben Kameras rund um die Uhr an Kreuzungen, Parkanlagen und Parkplätzen. Die staatlichen Zuschüsse in Höhe von \$ 10.000 waren eine Kombination von Bundes- (Federal Grant) und Gemeindegeldern (Municipal Funds). Die Polizei berichtete von einer Reduzierung der Kfz-Diebstähle um 40\%. Eine Beantragung für weitere Zuschüsse sollte eine 24-stündige Videoüberwachung ermöglichen. ${ }^{171}$

\subsubsection{Andere überwachte Städte in den USA}

Manche Innenstadtbereiche in Detroit (Michigan) wurden schon im Jahr 1980 von CCTV-Systemen überwacht, welche von der Republican National Convention finanziert wurden. Sechs Jahre später wurde das System mit Hilfe von privaten Sponsoren und Zuschüssen der Stadt Detroit für insgesamt \$ 640.000 erweitert. Das Projekt wurde allerdings 1994 aufgrund geringer Effektivität bei hohem Kostenaufwand beendet. ${ }^{172}$

Im Jahr 1997 operierten zehn Kameras im innerstädtischen Bezirk Pinch District Memphis (Tennessee), welche an Gebäuden montiert wurden und insgesamt einen Bereich von zwölf Wohnblöcken umfassten. Das \$ 450.000 teure Projekt war ein Ergebnis aus der Zusammenarbeit von privatem und öffentlichem Sektor. Es ist der Anfang eines geplanten Kriminalpräventionsnetzwerks, das die Bildübertragung von 72 bereits vorhandenen Überwachungskameras ermöglichte. ${ }^{173}$ Das Betreiben des Systems in Memphis sowie die tägliche Überwachungsarbeit an den Monitoren wurden gemeinsam von Freiwilligen und Polizeibeamten durchgeführt. Nach polizeilichen Angaben konnte durch die Installation der Kameras die Kriminalitätsrate in diesem Bereich um ca. $10 \%$ gesenkt werden. ${ }^{174}$

Aufgrund zunehmend offener Drogen- und Prostitutionsszene in Wohnbezirken wurde in Tacoma (Washington) 1993 nach zahlreichen Gemeindeversammlungen unter Beteiligung von Bürgern, Polizei und Kommunalbehörden die Entscheidung zur Einführung von Videoüberwachung getroffen. Mit staatlicher Finanzierung in Höhe von \$ 125.000 wurden drei polizeiliche Überwachungskameras in der Umgebung von Hilltop installiert. Das Besondere an diesem Projekt bestand darin, dass die

\footnotetext{
${ }^{169}$ Nieto et al. (2002), S. 15; Fn. 47.

${ }^{170}$ Ebenda, S. 18.

${ }^{171}$ Ebenda, S. 19.

172 Ebenda, S. 12.

${ }^{173}$ Burrows (1997), Rn. 1106; nach Angaben vom California Research Bureau begann das Programm in Memphis im Jahr 1996, vgl. Nieto et al. (2002), S. 16.

${ }^{174}$ Nieto (1997), S. 17 f.
} 
Standorte der Kameras nicht wie üblich in Stadtzentren, sondern in Wohnbezirken waren und die Initiative von den Einwohnern ausging. Bereits in den ersten vier Monaten nach der Installation wurden 55 Verhaftungen von Drogendealern veranlasst. ${ }^{175}$ Die registrierten Kriminalfälle sanken von $244 \mathrm{im}$ Jahr 1993 auf $87 \mathrm{im}$ Jahr 1994 und stiegen wieder leicht auf 125 im Jahr 1995. Das Projekt der sog. „Hilltop Action Coalition" wurde als Erfolg gefeiert. ${ }^{176}$ Diesem Beispiel folgten andere CCTVProgramme in Washington State: In Tukwila überwachten die Polizeibeamten gemeinsam mit ausgebildetem Zivilpersonal mit sechs Kameras ein Gebiet, das acht Wohnblöcke umfasste, um gegen Raubüberfälle und Prostitution vorzugehen. ${ }^{177}$ Die kleine Stadt Federal Way bei Seattle erhielt bundesstaatliche Unterstützung in Höhe von \$ 96.000 zur Installation von CCTV-Systemen und begann im August 2001 die Innenstadt zu überwachen, um Drogen- und Prostitutionsprobleme einzudämmen. ${ }^{178}$ Um die Sicherheit des Stadtzentrums in Nevada (Missouri) zu erhöhen, wurden dort zehn Überwachungskameras eingesetzt. Nach Angaben des Parks and Recreation Directors ${ }^{179}$ hat diese kleine Stadt ähnliche Sicherheitsprobleme wie eine Großstadt. ${ }^{180}$ 1997 wurden CCTV-Kameras in Charleston (South Carolina) eingeführt, wobei die überwachte Fläche im Laufe der Zeit auf das gesamte Einkaufsgebiet erweitert wurde. Das System wurde von der örtlichen Polizei betrieben, während die Geschäftsleute und Kriminalitätsopfer dieses finanziell unterstützen. Andere Kommunen nahe Charleston ziehen ebenfalls CCTV-Systeme als kriminalpräventives Werkzeuge in Erwägung. ${ }^{181}$

In Städten Kaliforniens ist die öffentliche Videoüberwachung ebenfalls keine Seltenheit. In Redwood City, Kalifornien kontrollieren die örtlichen Überwachungskameras 16 Wohnblöcke rund um die Uhr, wobei diese polizeiliche Überwachungsarbeit zusätzlich durch Abhöreinrichtungen unterstützt wird. ${ }^{182}$ Aufgrund des Personalund Geldmangels für vorbeugende Verbrechensbekämpfung durch die Polizei haben sich Grundstücksbesitzer und Immobilieninhaber in Hollywood im Jahr 1995 für ein gemeinsam finanziertes Videoüberwachungsprogramm (\$15.000) in Yucca Street, Hollywood entschieden. An den Gebäuden und Ladeneingängen wurden Kameras zur Kriminalprävention angebracht, die nach Aussagen von Polizeisprechern erfolg-

\footnotetext{
175 Anderson (1997); Hsu (2002a).

${ }^{176}$ Nieto (1997), S. 19 f.

177 Nieto et al. (2002), S. 16; Nieto (1997), S. 20.

${ }^{178}$ Auch in anderen kleineren Städten bei Seattle wird Videoüberwachung in Innenstädten und Einkaufsbezirken eingesetzt, vgl. Nieto et al. (2002), S. 16.

${ }^{179}$ Ebenda, S. 16.

${ }^{180}$ Ebenda.

${ }^{181}$ Ebenda.

${ }^{182}$ Burrows (1997), Fn. 210.
} 
reich waren. Allerdings wurden die Kameras wegen der veralteten Technik im Jahr 1999 abmontiert. Im Jahr 2002 plante die örtliche Polizei (Hollywood Division of the Los Angeles Police Department) und der Gemeindesprecher den Kauf von modernen digitalen Überwachungskameras, welche aus einer Kombination von privaten, bundesstaatlichen und kommunalen Geldern subventioniert werden sollten. ${ }^{183}$ Die Los Angeles Community Redevelopment Agency - eine von der Stadt Los Angeles ins Leben gerufene Non-Profit-Organisation - subventionierte das Projekt mit \$ 25.000 für den Kauf von drei weiteren Kameras. ${ }^{184}$

Im Jahr 1993 wurden im touristischen Balboa Park, San Diego fünf privat finanzierte Kameras in Betrieb genommen, welche die Fußgängerzone und die angrenzenden Museen kontrollierten. Die Besonderheit des Programms lag darin, dass die Implementierung der Kameras von den Parkaufsehern initiiert wurde und die lokalen Einzelhändler von diesen zur Finanzierung der Überwachungsanlagen überzeugt wurden. Auch wenn die Aufnahmen und Speicherung der Daten 24 Stunden am Tag erfolgen, wird heute die Überprüfungsarbeit an den Monitoren nur in den Geschäftszeiten durchgeführt. ${ }^{185}$

Die kalifornische Stadt Palm Springs erhielt im Juni 2001 einen „State Technology Grant“ und einen „Federal Justice Assistance Grant" zum Kauf von 14 Überwachungskameras, die am Palm Canyon Drive im Stadtzentrum von Palm Springs angebracht werden sollten. Das Kamerasystem wurde nur zeitlich begrenzt überwacht, aber alle Aufnahmen wurden, bevor diese endgültig gelöscht wurden, gesichtet. ${ }^{186}$ Auch die Stadtverwaltung in Vallejo (Kalifornien) bewilligte im November 2000 die innerstädtische Videoüberwachung, die nach Angaben von der Polizei ab Februar 2002 in Betrieb genommen werden sollte. ${ }^{187}$ Maßnahmen zur Videoaufzeichnung werden auch an regionalen Transitsystemen in Sacramento und an Kreuzungen und Verkehrsschwerpunkten zur Kontrolle von Verkehrssündern in San Francisco

\footnotetext{
${ }^{183}$ Die kalifornische Polizei benutzt beim Einsatz auch mobile Überwachungskameras, die sogenannten "CopCams", die die Beamten unauffällig an ihrer Uniform tragen und dabei Bilddaten direkt an die Streifenwagen übertragen.Vgl. Nieto et al. (2002), S. 17; Fn. 58; vgl. auch Garfinkel (2000), S. 112 ff.; Burrows (1997), Fn. 212.

${ }^{184}$ Nieto (1997), S. 20.

${ }^{185}$ Nieto et al. (2002), S. 17; Fn. 57; Nieto (1997), S. 22.

${ }^{186}$ Der City Manager David Ready sieht die CCTV-Überwachung als Ersatz für Polizeibeamte: „the idea is to give people a higher level of security so they can enjoy themselves. The reality is we can't afford to put an officer on every corner.", vgl. Nieto et al. (2002), S. 17, Fn. 59.

${ }^{187}$ Ebenda, S. 18, Fn. 60.
} 
durchgeführt. ${ }^{188}$ Weitere Projekte zur Observierung per Video werden in Phoenix und Cleveland geplant. ${ }^{189}$

\subsection{Videoüberwachung in Großbritannien}

\subsubsection{Ausmaß der Videoüberwachung}

Mit der Verwendung von Überwachungskameras in öffentlichen Räumen begann Großbritannien bereits 1985 in Bournemouth. 18 Kameras wurden in dieser touristischen Stadt installiert, um Vandalismus am Strand und auf der Seepromenade zu verhindern, wobei es sich um eine Kooperation zwischen Kommunalverwaltung und privaten Interessen handelte. ${ }^{190}$ Ende der 1980er Jahre gab es vereinzelte Systeme z.B. in King's Lynn, Coventry, Wolverhampton und Plymouth. ${ }^{191}$ Vor allem als im Jahr 1994 die konservative Regierung CCTV-Überwachung als einen Aspekt in die Sicherheitspolitik integrierte, wurde die rapide Ausbreitung dieser Technik zusätzlich beschleunigt. ${ }^{192}$

Schon im Jahr 1996 hatten alle Städte mit über 500.000 Einwohnern mit Ausnahme von Leeds Überwachungssysteme in ihren Zentren und Einkaufsstraßen im Einsatz. ${ }^{193}$ Zwischen 1994 und 1998 wurde der Umfang der Innenstadtprogramme um das Fünffache ausgeweitet. ${ }^{194}$ Bereits im Jahr 1998 wurden 450 britische Städte von Videotechnik überwacht. ${ }^{195} \mathrm{Im}$ Jahr 1999 wurde die Anzahl der Überwachungskameras in Großbritannien zwischen 200.000 und über einer Million Kameras geschätzt. ${ }^{196}$ Und jede Woche sollten 500 neue Überwachungseinrichtungen hinzukommen. ${ }^{197}$ Während es im Jahr 1994 noch vorwiegend größere Städte waren, die CCTV-Systeme

\footnotetext{
${ }^{188}$ Nach Angaben von National Transportation Research Board ist die Videoüberwachung in öffentlichen Verkehrsmitteln rechtlich erlaubt, solange die Passagiere durch Hinweisschilder auf diese aufmerksam gemacht werden. Diesbezügliche spezielle Regelungen sind je nach Bundesstaaten unterschiedlich. Vgl. ebenda, S. 21 f.; vgl. auch Nieto (1997), S. 23.

${ }^{189}$ Nieto (1997), S. 23.

${ }^{190}$ Bis zum Kameraeinsatz in Bournemouth im Jahr 1985 beschränkte sich die Praxis der Videoüberwachung in Großbritannien überwiegend auf private Einrichtungen (Supermärkte, Einzelhandel und Einkaufszentren) bzw. wurden die Kameras zur Verkehrsregulierung eingesetzt. Zwar griff die britische Polizei in manchen Fällen auf diese Bilddaten zurück, aber die öffentliche polizeiliche Videoüberwachung begann erst mit dem Projekt in Bournemouth. Heute überwachen mehr als 400 Kameras den öffentlichen Raum in Bournemouth. Vgl. McCahill; Norris (2002a), S. 8 f.; Gras (2003), S. 30 f.

${ }^{191}$ McCahill; Norris (2002a), S. 9; Norris; Armstrong (1999a), S. 80.

192 Williams; Johnstone (2000), S. 188.

${ }^{193}$ Inzwischen beobachten auch in Leeds mehr als 130 Überwachungskameras rund um die Uhr verschiedene Stadtteile. Vgl. Safer Leeds (2004).

${ }^{194}$ Büllesfeld (2002), S. 37; Norris (1998), S. 30 f.

195 Gras (2003), S. 30 f.

${ }^{196}$ Büllesfeld (2002), S. 35; Nürnberg (2000), S. 230 ff.

${ }^{197}$ Buse; Schnibben (1999), S. 122 ff.
} 
verwendeten, war im Jahr 1999 die CCTV-Überwachung selbst für kleinere Städte alltäglich geworden. ${ }^{198}$

Zwischen 1994 und 1998 zeigte in Großbritannien die Ausbreitung von CCTVSystemen eine stark steigende Tendenz. ${ }^{199}$ Neben den privaten Unternehmen haben sich vermehrt öffentliche Stellen für die Videoüberwachung entschieden. Allmählich ist ein Kooperationsnetz zwischen privaten und öffentlichen Stellen entstanden, das nur schwer zu durchschauen ist. ${ }^{200}$

Bis Mitte der 1990er Jahre wurden CCTV-Systeme von der britischen Regierung finanziell stark unterstützt, wobei das Ziel hauptsächlich darin bestand, terroristische Organisationen wie die IRA zu verfolgen und geplante Terroranschläge rechtzeitig zu erkennen und zu verhindern. Erst gegen Ende der 1990er Jahre gewann die allgemeine kriminalpräventive Wirkung von Videoüberwachung auf öffentlichen Straßen und Plätzen an Bedeutung. Heute scheint sie als polizeidienstliches Werkzeug in Großbritannien unverzichtbar zu sein. ${ }^{201}$

Im Jahr 2002 wies Großbritannien die höchste Kameradichte der Welt auf, wobei 95\% aller englischen Städte Videoüberwachungskameras einsetzten. Damit nahm Großbritannien in Bezug auf die Verwendung von CCTV-Anlagen weltweit eine Spitzenposition ein. ${ }^{202}$. Norris und Armstrong bezeichneten deswegen die britischen Bürger als die meistüberwachten der Welt. ${ }^{203}$

Im Herbst 2002 schätzte Privacy International die gesamte Anzahl der öffentlichen Überwachungskameras in Großbritannien auf 1,5 Millionen ${ }^{204}$, während das Urban Eye Project ${ }^{205}$ im selben Jahr schätzte, dass die gesamte Anzahl von CCTV-Kameras in Großbritannien 4.285 .000 betrug. ${ }^{206}$ Im öffentlichen Raum wird man in größeren briti-

\footnotetext{
${ }^{198}$ Im Jahr 1998 stellten auch Goodwin und Kollegen fest, dass „wenigstens 440 zuschussfinanzierte Innenstadtüberwachungsprogramme in Betrieb sind. (...) Während diese Programme noch 1994 im Wesentlichen auf die großstädtischen Bereiche beschränkt waren, haben sie sich bis 1998 auch auf die mittleren und kleineren Städte ausgedehnt." Vgl. Norris (1998), S. 30 ff.

${ }^{199}$ Ebenda, S. 30 f.; vgl. auch Büllesfeld (2002), S. 37 f.

${ }^{200}$ So können z.B. die Polizei und Feuerwehr Zugriff auf die Überwachungsanlagen von privaten Supermärkten haben. Oder der Polizei wird bei Vorfällen gezielt Zugang zu den Aufzeichnungen gewährt, die aus den kommunalen CCTV-Systemen stammen. Vgl. Büllesfeld (2002), S. 38 f.

${ }^{201}$ Norris (1998), S. 30 f.; Büllesfeld (2002), S. 36 f.

${ }^{202}$ Büllesfeld (2002), S. 36; Frerichs (2000), S. 78 ff.; Kohl (1997a), S. 36 ff.

${ }^{203}$ Norris; Armstrong (1999b), S. 39; Norris; Armstrong (1999a), S. 77 ff.

${ }^{204}$ von Grätz (2003).

${ }^{205}$ Urbaneye Project („,On the threshold to urban panopticon?”) ist ein von der TU Berlin koordiniertes und von der Europäischen Kommission finanziertes Projekt zur Analyse des Einsatzes von Videoüberwachung in europäischen Städten und zur Bewertung ihrer sozialen und politischen Wirkung. Die Laufzeit des Projektes begann im September 2001 und endete im September 2004. Mehr hierzu vgl. unter: www.urbaneye.net

${ }^{206}$ McCahill; Norris (2002b), S. 20.
} 
schen Städten durchschnittlich alle fünf Minuten von einer Kamera erfasst. ${ }^{207}$ Das Vereinigte Königreich ist mittlerweile der größte Markt für CCTV-Systeme in Europa. ${ }^{208} \mathrm{Im}$ Jahr 2004 befand sich ein Fünftel aller CCTV-Anlagen weltweit in Großbritannien. ${ }^{209}$ Wie viele Kameras heutzutage in Großbritannien existieren, ist selbst dem Innenminister, Charles Clarke, unbekannt. Im November 1999 erklärte er dem Parlament: „Information on the number of police, public sector and private operators of CCTV systems in operation and the number of cameras in use is not held centrally. ${ }^{\text {210 }}$

Roy Coleman beschreibt die aktuelle Situation der Videoüberwachung in Großbritannien wie folgt: „With the advent of mass camera surveillance it has become common to observe that the citizenry of the UK have become the most watched, catalogued and categorised people in the advanced world, and all with little public debate

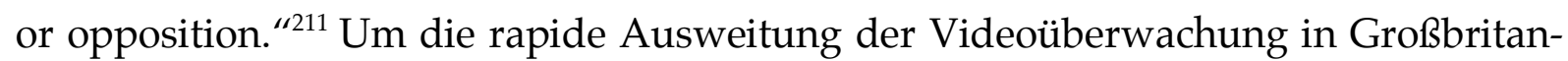
nien zu verdeutlichen, werden hierbei die Untersuchungsergebnisse bezüglich der Verbreitung der CCTV-Systeme von William \& Johnstone von den Jahren 1994 und 1999 herangezogen (siehe Abbildung 2). Während die Anzahl der überwachten Städte (insgesamt 78 Städte) im Jahr 1994 noch recht überschaubar war, haben sich innerhalb von fünf Jahren die Maßnahmen der Videoaufzeichnung in unzähligen Städten in Großbritannien etabliert. Schon im Mai 1999 wurden 530 Städte mit CCTVSystemen gezählt. ${ }^{212}$

\footnotetext{
${ }^{207}$ Stierand (2000), S. 50.

${ }^{208}$ Graham (1998), S. 45; Coleman (2004), S. 6.

${ }^{209}$ Coleman (2004), S. 6; Independent (2004).

${ }^{210}$ McCahill; Norris (2002a), S. 14.

${ }^{211}$ Coleman (2004), S. 3.

${ }^{212}$ Williams; Johnstone (2000), S. 184.
} 


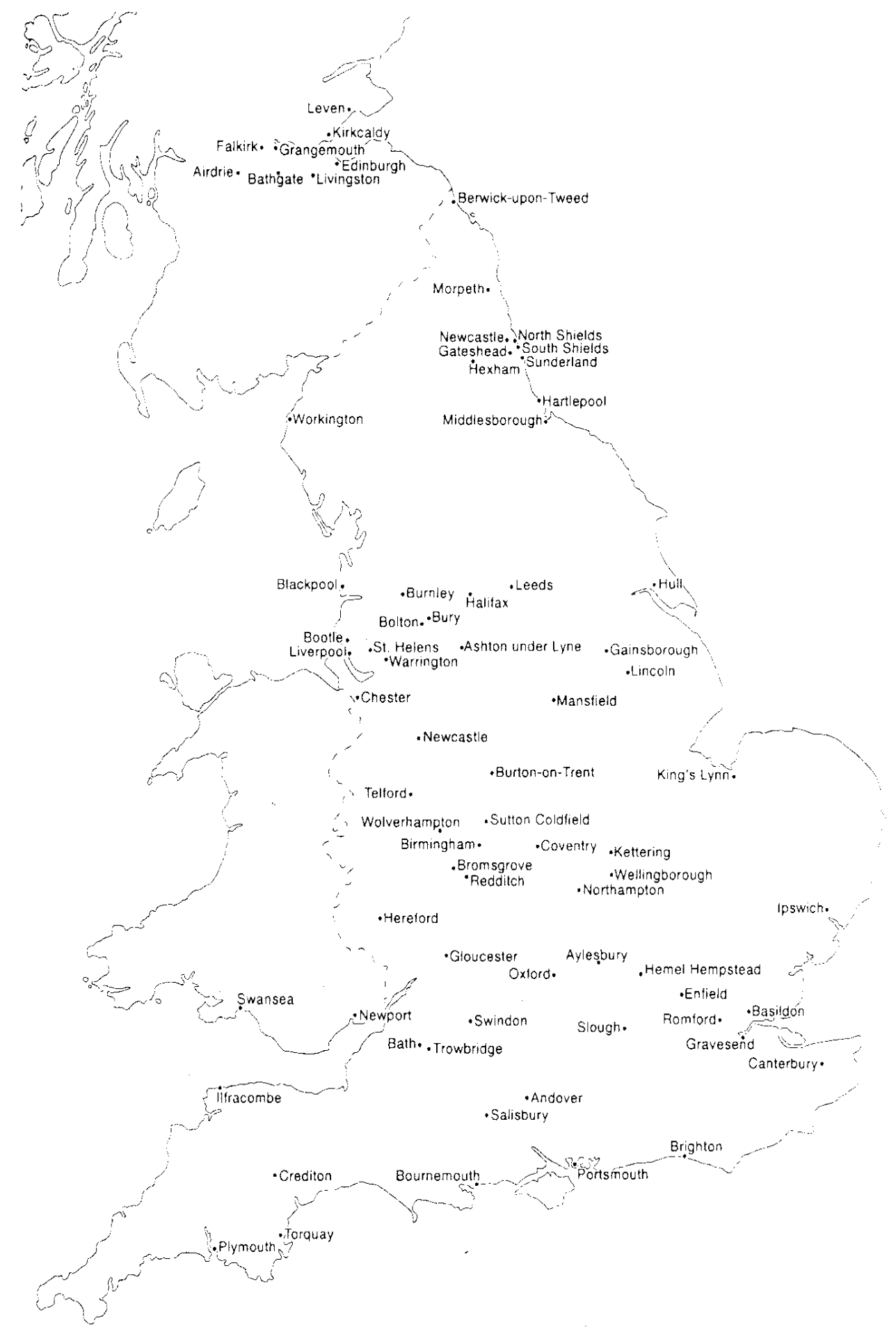

Abbildung 1: Britische Städte mit Videoüberwachungsanlagen, in Betrieb oder staatlich geförderter Planung. Stand 1994. ${ }^{213}$

${ }^{213}$ Quelle: Williams, K.; Johnstone, C. (2000): The politics of the selective gaze, in: Crime, law and social change, Jg. 34, H. 1/2, S. 185. 


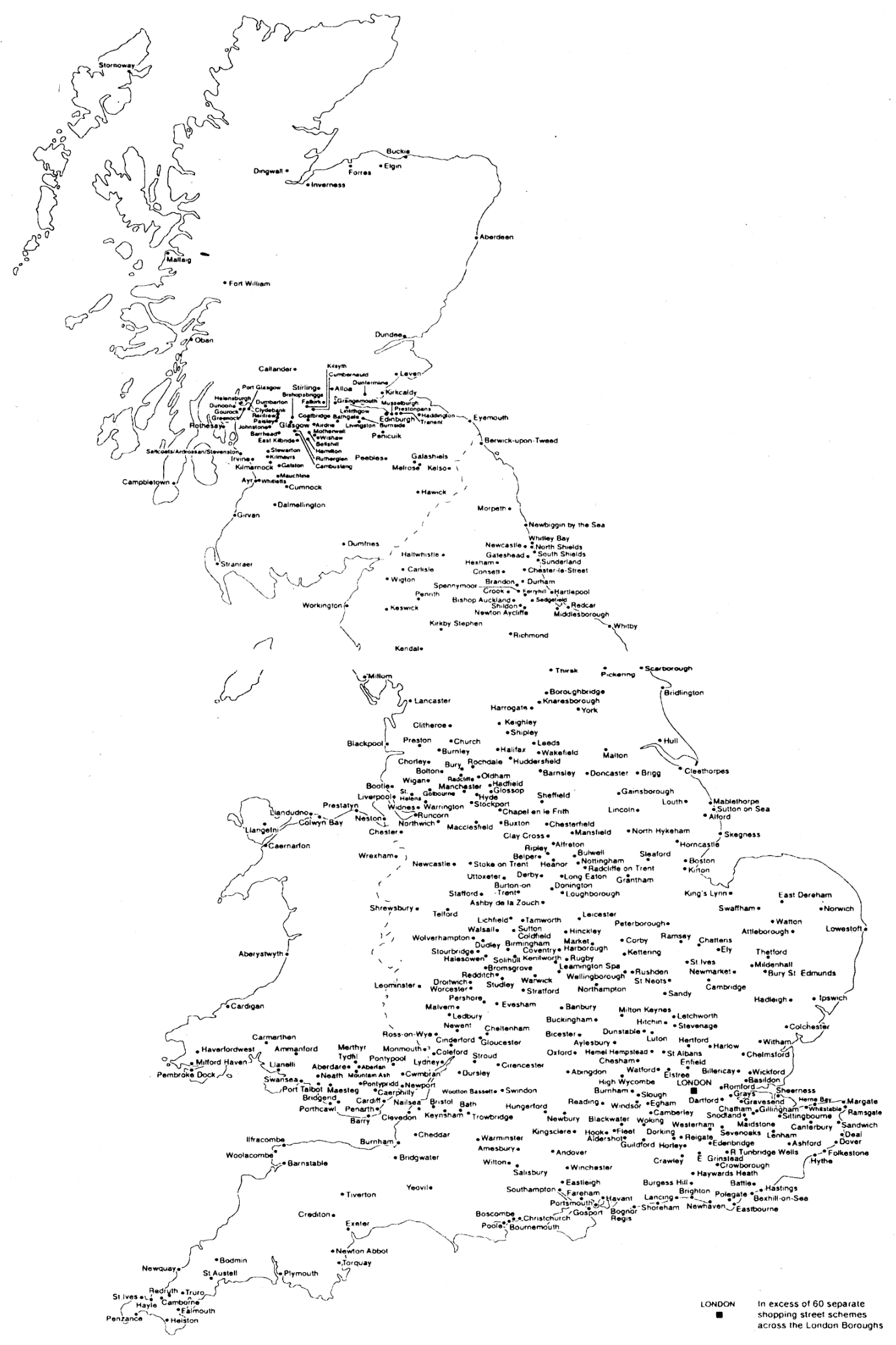

Abbildung 2: Britische Städte mit Videoüberwachungsanlagen, in Betrieb oder staatlich geförderter Planung. Stand April 1999. ${ }^{214}$

${ }^{214}$ Quelle: Williams, K.; Johnstone, C. (2000): The politics of the selective gaze, in: Crime, law and social change, Jg. 34, H. 1/2, S. 186 f. 


\subsection{2 Überwachte Städte}

\subsubsection{London}

In der britischen Hauptstadt London konnte in den vergangenen Jahren eine enorme Zunahme der Anzahl von Überwachungskameras beobachtet werden. Als Folge des IRA-Terroranschlags auf Bishopgate im Jahr 1993 wurde ein Netzwerk von Überwachungskameras zum sogenannten „Ring of Steel“ (ein Sperrring aus Überwachungskameras und Polizeikontrollen) um die Stadt London aufgebaut. In dieses System wurden bis heute viele private CCTV-Systeme von Banken und Büros integriert. Es ist unter der Bezeichnung "Camerawatch" bekannt geworden. Am „Camerawatch" waren nach Abgaben von Urbaneye Project im Jahr 2002 insgesamt 400 Organisationen, 373 Systeme mit mehr als 1200 Kameras beteiligt, die von der Polizeistation in Marylebon zentral kontrolliert wurden. ${ }^{215}$

Die bekannte Einkaufszone der Stadt Oxfordstreet wird von einem 500.000 Pfund teuren CCTV-System mit 35 Kameras überwacht, ${ }^{216}$ während der „Parliamentary Estate“, wo sich die wichtigsten Regierungsgebäude befinden, von einem Netzwerk mit 260 Überwachungskameras observiert wird. ${ }^{217}$

Insgesamt wurde im Jahr 2002 die Anzahl der Überwachungskameras in London auf 500.000 geschätzt. Das bedeutet bei 7,2 Millionen Einwohnern, dass jede Kamera durchschnittlich 14 Menschen beobachtet. ${ }^{218}$ Norris und Armstrong nehmen an, dass ein Londoner Bürger täglich von über 300 Kameras, die zu 30 unterschiedlichen Systemen gehören, gefilmt wird. ${ }^{219}$

Der Londoner Stadtteil Newham war für seine hohe Kriminalitätsrate bekannt. Im Oktober 1998 wurde in diesem kriminellen Krisengebiet ein digitales CCTV-System mit 140 fest stationierten und elf mobilen Kameras in Betrieb genommen. Neu bei diesem System war die Anwendung der elektronischen Gesichtserkennung. Dabei werden die Gesichter der Passanten automatisch mit einer Fahndungsdatenbank der

\footnotetext{
${ }^{215}$ Vgl. McCahill; Norris (2002b), S. 6. Im Auftrag einer Sicherheitsinitiative von 1996 bis 1997 wurden in Großbritannien insgesamt über 1.800 Überwachungskameras in 16 Bahnhöfen (Central London mainline stations) in Betrieb genommen. Im Januar 1998 wurde ein Bahnhof-Erneuerungsprogramm (station regeneration programm), das $£ 1$ Milliarde kostete, verkündet, wobei $£ 40$ Millionen davon für die Installation von CCTV-Systemen und besserer Beleuchtung an 800 Bahnhöfen geplant waren. Die U-BahnNetze in London arbeiten ebenfalls mit CCTV-Kameras. Die Hauptstrecke (Central Line), die über 55 $\mathrm{km}$ verläuft, 34 Stationen enthält und jährlich 166 Millionen Menschen transportiert, wird von 500 CCTV-Kameras überwacht. Ein sogenanntes "track to train CCTV system " verschafft dem Fahrer einen klaren Überblick vom Bahngleis bis zu den Türen der Bahn und dient somit der Sicherheit der Passagiere. Vgl. Norris; Armstrong (1999b), S. 47; vgl. auch McCahill; Norris (2002a), S. 8.

${ }_{216}$ McCahill; Norris (2002b), S. 6

${ }^{217}$ Ebenda.

${ }^{218}$ Ebenda, S. 20.

${ }^{219}$ Ebenda, S. 6; Norris; Armstrong (1999b), S. 42.
} 
Polizei verglichen ${ }^{220}$ Durch den Einsatz dieser biometrischen Technologie ist nicht mehr nur das reine Beobachten, sondern auch die automatische Identifizierung der Passanten möglich.

Wie umfangreich das Videoüberwachungsnetz in London ist, zeigt sich an dem Fall von Jill Dendo. Die prominente englische Fernsehmoderatorin wurde im April 1999 bei ihrem Einkaufsbummel in der Londoner Innenstadt von einem Unbekannten erschossen. Allein mit Hilfe der flächendeckenden CCTV-Systeme in der englischen Hauptstadt war ihr gesamter Tagesablauf fast lückenlos aufgezeichnet und konnte später bei der polizeilichen Ermittlung rekonstruiert werden. ${ }^{221}$

\subsubsection{Liverpool}

Schon seit Mitte der 1970er Jahre ist Liverpool durch eine hohe Kriminalitätsrate und kostenaufwändige Polizeigewalt gekennzeichnet. ${ }^{222} \mathrm{Im}$ Jahr 1993 wurde ein kleiner Junge namens Jamie Bulger in Liverpool aus einem Einkaufszentrum entführt und später brutal ermordet. Anhand der Videoüberwachungsaufnahmen des Einkaufzentrums konnten die Entführer als Jugendliche identifiziert werden und somit zur Aufklärung des Mordfalls beitragen. Dieser Fall wurde als Wendepunkt gesehen, der die Öffentlichkeit von der Wirksamkeit der Videoüberwachung überzeugte. Anlässlich dieses Gewaltverbrechens wurde der Kameraeinsatz in Liverpool von der Stadtverwaltung verstärkt. Das innerstädtische Netzwerk der Videoüberwachung wurde im Jahr 1994 mit 20 Überwachungseinrichtungen versehen. ${ }^{223}$ Ein häufig in den Medien zitierter Kommentar von einem örtlichen Verantwortlichen für das Liverpooler System lautete: „The system is like having 20 more officers on duty 24 hours a day who make a note of everything, never take a holiday and are very rarely off sick.“224

Als Reaktion auf die große Zustimmung der Bürger in Liverpool, die vor allem nach dem Fall Bulger CCTV-Systeme als geeignetes Mittel gegen Kriminalität anerkannten, wurde im Jahr 1998 das CCTV-System im Rahmen des Crime and Disorder Act erweitert. Seit 2003 überwachen 240 Kameras das Liverpooler Zentrum. Der Kameraeinsatz wurde durch $£ 1,7$ Millionen staatliche Zuschüsse vom Crime Reduction Programme ermöglicht. In dem Zeitraum zwischen 1994 und 2003 wurden insgesamt $E$ 5,2 Millionen vom Staat in das CCTV-System im Zentrum von Liverpool investiert

\footnotetext{
${ }^{220}$ König (2001); S. 35 f.; Buse; Schnibben (1999), S. 122 ff.

${ }^{221}$ Die CCTV-Aufzeichnungen haben allerdings nicht zur Identifizierung des Täters beigetragen. Krons (2000).

${ }^{222}$ Coleman; Sim (2000), S. 627 f.

${ }^{223}$ Davies (1996a), S. 173; Gras (2003), S. 33 f.

${ }^{224}$ Coleman (2004), S. 164; Times (1994).
} 
und die Anzahl der Kameras ist um das Zwölffache gestiegen. ${ }^{225}$ Heute werden die Aufnahmen von den Überwachungskameras in Liverpool durch eine privaten Sicherheitsfirma von einer geheim gelegenen Kontrollzentrale aus überprüft, wobei diese mit der Merseyside-Police-Zentrale und dem Police Shop an der Haupteinkaufsstraße (Church Street) vernetzt ist. ${ }^{226}$

Für die obige Darstellung werden die Videokameras in Taxis, Schulen und öffentlichen Fahrzeugen, die durch eine Mischung aus staatlichen Mitteln und privaten Geldern finanziert werden, nicht mit einbezogen. Langfristig ist eine Vernetzung dieser privaten CCTV-Systeme mit den staatlichen Kameras geplant, so dass nicht nur die öffentlichen Verkehrsmittel, sondern auch Nachtclubs, Einzelhandel und Wohnsiedlungen in Liverpool von einer Überwachungszentrale kontrolliert werden. Zusätzlich sollen Bildaufnahmen aus den Außenbezirken von Kensington, Old Swan und Dingle an die Liverpooler CCTV-Zentrale übertragen werden. Bei diesem großen Videoüberwachungsnetz verfügt die Polizei über „revolutionary talking cameras“ als begleitendes Hilfsmittel, die dem Überwachungspersonal ermöglichen, den potentiellen Übeltäter durch Lautsprecher vor der Existenz der Überwachungskameras zu warnen. 227

\subsubsection{Newcastle upon Tyne}

Newcastle upon Tyne ist eine Stadt im Nordosten von England, die am Fluss Tyne liegt. Im Dezember 1992 wurden in Newcastle 16 Überwachungskameras mit Zoomobjektiven sowie Kipp- und Schwenkfunktionen als zusätzliche Hilfsinstrumente zur Kriminalprävention für die örtliche Polizei (Northumbria Police Authority) installiert. Als offiziell angegebene Ziele dienen die Kameras an den öffentlichen Plätzen dazu, „to assist with the prevention and detection of crime. Closed circuit television will also assist greatly in the maintenance of public order, reducing nuisance and vandalism offenses and enhancing a sense of safety by members of the general public “. ${ }^{228}$

Der überwachte Raum beschränkt sich weitgehend auf die Fußgängerzone der Stadt. Die geradlinigen, weiten Straßenzüge in der Innenstadt von Newcastle begünstigen die räumliche Observierung. Brown stellte in seiner Untersuchung über Newcastle fest: „The area covered by each camera is considerable and overlaps with those areas

\footnotetext{
${ }^{225}$ Coleman (2004), S. 5; Davies (1996a), S. 175. Mehr zur Finanzierung der CCTV-Systeme vgl. Coleman (2004), S. 159.

${ }^{226}$ Coleman (2004), S. 159.

${ }^{227}$ Ebenda, S. 5.

${ }^{228}$ Aus dem "Codes of Practice for Newcastle City Center", § 2.1.; vgl. Brown (1997), S. 172.
} 
covered by neighboring cameras. Very few streets within the city center do not have some form of camera coverage. ${ }^{\prime 229}$

Die Finanzierung des Systems stammte aus der City Center Partnership Security Initiative, die neben den Geldmitteln von den lokalen Gewerbetreibenden auch staatliche Zuschüsse aus dem Umweltministerium (Department of Environment) erhält. Das CCTV-System befindet sich heute gänzlich im Besitz der Polizei, wobei die 24stündige Überwachungsarbeit an Monitoren sowohl von der Polizei als auch von zivilen Mitarbeitern übernommen wird. Die laufenden Kosten für das Betreiben und die Instandhaltung der Anlagen trägt allein die Polizei. ${ }^{230}$

Das CCTV-System findet insbesondere bei großen Menschenansammlungen und der damit verbundenen Unruhe seine Anwendung: z.B. anlässlich des königlichen Besuchs oder bei Fußballveranstaltungen im nahegelegenen Stadium von Newcastle $U$ nited. Der Kameraeinsatz in Newcastle wurde von Brown insgesamt als gelungen betrachtet, insbesondere in der Kategorie Einbruchsdiebstahl erzielen die Überwachungskameras den größten präventiven Effekt. ${ }^{231}$

\subsubsection{Birmingham}

Birmingham ist die zweitgrößte Stadt in England mit über einer Million Einwohnern. Seit den 1980er und 1990er Jahren finden regelmäßig im Zentrum von Birmingham Demonstrationen, Proteste sowie große Sportveranstaltungen wie "Kellogg's Cycle Race ${ }^{\prime \prime}$ statt. ${ }^{232}$ Die öffentliche Sicherheit gewinnt angesichts solcher großen Veranstaltungen mit vielen Besuchern zunehmend an Bedeutung.

Auch diese Millionenstadt hat Überwachungskameras in ihre kriminalpräventive Sicherheitspolitik integriert. Das CCTV-System operiert dort mit 14 Überwachungskameras, die das belebte Stadtzentrum mit Geschäften und Bürogebäuden kontrollieren. Die Installation der Anlagen wurde in vier Phasen eingeteilt. In den ersten zwei Phasen wurden Kameras jeweils im Kernbereich sowie auf dem Marktplatz der Stadt angebracht, während in den letzten Phasen die Videoüberwachungsprojekte u.a. am Kongresszentrum durchgeführt wurden. ${ }^{233}$

\footnotetext{
${ }^{229}$ Ebenda, S. 171.

${ }^{230}$ Brown (1995), S. 11; Brown (1997), S. 171.

${ }^{231}$ Ebenda; vgl. auch Teil II, Kap. 3.3.2.3 dieser Arbeit.

${ }^{232}$ Brown (1995), S. 27.

${ }^{233}$ Ebenda.
} 
Die finanziellen Fördermittel für das Projekt wurden im Rahmen des „Safer Cities“ Programms vom britischen Innenministerium bereitgestellt. ${ }^{234}$ Die Kamerabilder werden auf zehn Monitore in einen Kontrollraum der Polizeizentrale in Steelhouse Lane übertragen, für deren Überwachung sowohl Polizeibeamte als auch ziviles Personal zuständig sind. ${ }^{235}$

Neben den kriminalpräventiven Zielen des Projektes sollen die Kameras dazu dienen, das öffentliche Leben und den Verkehr in Birmingham besser zu kontrollieren, wobei die lokalen Geschäftsinhaber durch Funkverbindung in direktem Kontakt mit der Polizei und Sicherheitsbeamten im CCTV-Kontrollraum stehen. ${ }^{236}$

Trotz dieser Bemühungen wird der Kameraeinsatz in Birmingham aufgrund der Verlagerung der Kriminalität von überwachten Gebieten hin zu den benachbarten StraBen als wenig erfolgreich eingeschätzt. ${ }^{237}$

\subsubsection{King's Lynn}

In King's Lynn in Norfolk begann die innerstädtische Videoüberwachung bereits im Jahr 1987 mit sieben Kameras im Industriegebiet North Lynn. Das Projekt wurde eingeleitet, um den vermehrten Einbruchsdiebstahl in dem Bereich zu verhindern und resultierte aus einer Zusammenarbeit von lokaler Geschäftswelt, Polizei und dem Gemeinderat. Fünf Jahre später wurde das System auf 32 Kameras erweitert, obwohl die Kriminalitätsrate im Vergleich zu anderen britischen Städten nicht auffallend hoch war. Die Videoüberwachungsmaßnahmen werden seitdem ständig erweitert. Heute gehört das CCTV-System in King's Lynn mit über 60 Kameras zu den umfangreichsten innerstädtischen Kameraprojekten in Großbritannien. ${ }^{238}$

Zum Schwerpunkt der Videoüberwachung gehören die innerstädtischen Parkplätze und deren umliegende Zonen, die von 19 Kameras erfasst werden. Weitere öffentliche Kameraeinsätze finden in Wohnsiedlungen, am Sportzentrum der Stadt sowie der innerstädtischen Fußgängerzone statt. Damit sollen nicht nur die Kfz-Delikte, sondern auch Vandalismus und Diebstahl eingedämmt werden. Im Jahr 1994 wurden noch mehr Überwachungskameras im Auftrag des britischen Innenministeriums

\footnotetext{
${ }^{234}$ Vgl. hierzu Teil III, Kap. 10.3.1.1 dieser Arbeit.

${ }^{235}$ Brown (1995), S. 31 ff.

${ }^{236}$ Ebenda, S. 31; Veil (2001), S. 31.

${ }^{237}$ Vgl. Brown (1995), S. 33 ff. sowie Teil II, Kap. 4.5 dieser Arbeit.

${ }^{238}$ Davies (1996a), S. 175 ff.; nach Angaben von Müller wurde im Jahr 1992 die Innenstadt von King's Lynn von 25 Kameras überwacht, vgl. Müller (2002), S. 40. Nach Angaben von Brown wurden im selben Jahr 19 neue Kameras installiert. Vgl. Brown (1995), S. 47.
} 
an einem Krankenhaus in der Nähe des Stadtzentrums installiert, um Kfz-Delikte zu verhindern und die Sicherheit des Krankenhauspersonals zu verbessern. ${ }^{239}$

Die Überwachungsprojekte mit CCTV-Systemen in King's Lynn werden vom Kommunalrat verwaltet und die Überwachungsarbeit wird von einer privaten Sicherheitsfirma übernommen. ${ }^{240}$ Einige Infrarot-Kameras sind ebenfalls im Einsatz, die nächtliche Videografie ermöglichen. Die offiziellen Ziele der Videoüberwachung in King's Lynn bestehen darin, „to deter acts of vandalism and criminal damage, smash and grab raids etc. in the streets covered. The event that deterrence is ineffective the cameras are intended to detect an incident at the earliest possible moment" ${ }^{241}$

Die Geldmittel für diese umfangreichen Maßnahmen stammen zum großen Teil aus dem Erlös für Parkscheine für die innerstädtischen Parkplätze. Die Finanzierung der Anlagen in Wohnsiedlungen wird zum Teil von den Mietern getragen, während die lokalen Einzelhändler teilweise für die Kosten der CCTV-Systeme im Zentrum aufkommen. ${ }^{242}$ Der Präventionserfolg in King's Lynn ist trotz intensiver Observierung nicht eindeutig $\mathrm{zu}$ bestimmen. ${ }^{243}$

\subsubsection{Airdrie}

Airdrie ist eine schottische Stadt mit etwa 36.000 Einwohnern. Die Stadt verfügt seit 1992 über zwölf Überwachungskameras. ${ }^{244}$ Das CCTV-Programm in Airdrie wurde von privaten Einzelhändlern finanziert und von einem einzigen Polizeibeamten eingeführt: „[The system] was not part of any specific national or local government policy initiative. Indeed, it was principally and initially due to the single handed efforts of a single police officer working there. ${ }^{245}$ Aufgrund der Reduzierung registrierter Delikte in der überwachten Zone wird der Präventiveffekt der öffentlichen Videoüberwachung in Airdrie nach einer Studie des Scottish Office als erfolgreich angesehen, obwohl die Maßnahme aufgrund des Verlagerungseffektes umstritten ist. $^{246}$

\footnotetext{
${ }^{239}$ Brown (1995), S. $48 \mathrm{f}$.

${ }^{240}$ Davies (1996a), S. 177.

${ }^{241}$ Brown (1995), S. 49 f.

${ }^{242}$ Ebenda.

${ }^{243}$ Brown (1997), S. 179 ff.

${ }^{244}$ Ditton; Short (1998), S. 155.

${ }^{245}$ McCahill; Norris (2002a), S. 9; vgl. auch Ditton; Short (1998), S. 155 ff.

${ }^{246}$ Müller (2002); S. 40 f.; The Scottish Office (1999).
} 


\subsubsection{Glasgow}

Um der hohen Kriminalitätsrate entgegenzuwirken und die Stadt Glasgow als wirtschaftlichen Standort für potentielle Investoren attraktiv zu machen, begann im November 1994 das Videoüberwachungsprogramm mit 32 Kameras. Diese Initiative wurde gemeinsam von lokalen Behörden (u.a. Glasgow Development Agency) und Gewerbetreibenden eingeführt und kontrolliert. Sie ist unter dem Namen „Glasgow CityWatch" bekannt. ${ }^{247}$ "CityWatch was established as a crime prevention initiative which aimed to effect a reduction in the cost of crime to businesses, reduce the clean up costs of crime and vandalism, increase the opportunities for employment and improve the overall ,feel good' factor in the city centre. ${ }^{\prime 248}$ Diese angestrebten Ziele des Projektes wurden zwar nach einer Evaluationsstudie von Ditton \& Short nicht bestätigt, aber die CCTV-Anlagen waren trotzdem für die Mehrheit der Stadtbewohner in Glasgow ein willkommenes Instrument zur Kriminalitätsbekämpfung. ${ }^{249}$

\subsubsection{Andere überwachte Städte in Großbritannien}

Redton $^{250}$ ist eine Stadt im Norden Englands mit ca. 250.000 Einwohnern und hoher Arbeitslosenquote. Angesichts des sozialen Verfalls und der hohen Kriminalitätsrate im Stadtzentrum wurde im Oktober 1995 ein CCTV-System eingeführt, das vor allem die lokalen Einzelhändler und Bürger begrüßten. Das Projekt besteht aus 63 Überwachungsgeräten, deren Bildaufnahmen von zivilen Angestellten der Polizeibehörden rund um die Uhr kontrolliert werden. 47 „Help Points“ in der Innenstadt ermöglichen die direkte Kommunikation zwischen der Öffentlichkeit und dem Hauptkontrollraum von CCTV-Systemen in einer Polizeidienststelle. Die Präventionswirkung der Videoüberwachungsmaßnahmen in Redton wird insgesamt als positiv eingeschätzt. ${ }^{251}$

Im Jahr 1989 wurden fünf Kameras in Coventry zu kriminalpräventiven Zwecken installiert. Da die Initiative erfolgreich war, wurde das System wesentlich erweitert. Mittlerweile kontrollieren über 120 Kameras den Innenstadtbereich in Coventry. Die Fördermittel hierfür stammen vom britischen Innenministerium. Die tägliche Überwachungsarbeit wird inzischen von der privaten City Centre Company (CCC) übernommen. ${ }^{252}$ In den beiden Städten Aberystwyth und Cardigan in Wales wurden im

\footnotetext{
${ }^{247}$ Vgl. Teil III; Kap. 10.3.1.3 dieser Arbeit.

${ }^{248}$ The Scottish Office (1999).

${ }^{249}$ Ditton; Short (1999), S. 209, 693; vgl. auch Teil II, Kap. 8.2.3 dieser Arbeit.

${ }^{250}$ Redton ist ein Sammelname für die Stadt Doncaster und Green County. Vgl. Skinns (1998), S. 186.

${ }^{251}$ Ebenda, S. 175 ff.; vgl. auch Müller (2002), S. 41.

${ }^{252}$ Veil (2001), S. 77.
} 
Juli 1998 Maßnahmen zur Videoaufzeichnung trotz niedriger Kriminalitätsrate eingeführt. Zuschüsse vom Innenministerium, sowie der allgemeine Trend zur Videoüberwachung in benachbarten Städten wie Llanelli, Ammanford und Carmarthen waren die treibenden Faktoren für die Installation von CCTV-Anlagen. Im Mittelpunkt der Beobachtung mittels Videogeräte stehen vor allem Bagatelldelikte sowie alkoholbedingte Gewaltdelikte (,,rowdyism“). ${ }^{253}$

Die Zuständigkeit für die CCTV-Systeme und die Organisation der täglichen Praxis der Videoüberwachung ist in den unzähligen Videoüberwachungssystemen in Großbritannien sehr unterschiedlich: Während manche Kommunen allein die Verantwortung für die Überwachungsanlagen tragen, wie z.B. in East Grinstead, Windsor, Eaton und Maidenhead, sind andere Systeme, beispielsweise in Newcastle und Burgess Hill, im Besitz der Polizei. ${ }^{254}$ Auch die Überwachungsarbeit am Bildschirm wird je nach Projekt von unterschiedlichen Akteuren übernommen: In einigen Fällen ist privates Sicherheitspersonal (Stratford, Liverpool) oder sind Polizeibeamte (City of London) dafür zuständig. In anderen Fällen wird diese Aufgabe von den zivilen Mitarbeitern der Polizei (Tamworth) übernommen. ${ }^{255}$ In Ilkston sind spezielle Beamte (special constables) für diese Aufgabe autorisiert. ${ }^{256}$

Auffallend ist ferner, dass die Anzahl der Videokameras und die Größe der Städte nicht immer in Relation stehen: Die kleine Stadt Driffield in East Yorkshire mit 10.000 Einwohnern wird von 14 Kameras überwacht, während in Glasgow mit 750.000 Einwohnern 32 Kameras im Einsatz sind. ${ }^{257}$ Im Vergleich dazu verwendet Northhampton (180.000 Einwohner) zur Sicherung öffentlicher Räume insgesamt 112 Kameras und Sheffield mit ca. 500.000 Einwohnern benutzt ein System mit 200 Kameras. ${ }^{258}$ In der Industriestadt Stockton-on-Tees im Nordosten Englands mit einer Einwohnerzahl von knapp 178.000 befindet sich das verhältnismäßig teuerste System mit 46 Kameras, die insgesamt $£ 4,5$ Millionen kosten. ${ }^{259}$

\subsection{Vergleich der Nutzungsintensität von CCTV-Systemen}

Mit der Ausnahme von Leeds wurden, wie oben geschildert wurde, bereits im Jahr 1996 alle britischen Großstädte mit mehr als 500.000 Einwohnern per Video über-

\footnotetext{
${ }^{253}$ Williams; Johnstone (2000), S. 198 ff.

${ }^{254}$ Norris; Armstrong (1999b), S. 57. Gras (2003), S. 97; McCahill; Norris (2002a), S. 18.

${ }^{255}$ Gras (2003), S. 97 f.

${ }^{256}$ Norris; Armstrong (1999b), S. 57. Mehr hierzu vgl. Teil III, Kap. 10.3 dieser Arbeit.

${ }^{257}$ Ditton (2000), S. 693.

${ }^{258}$ Norris; Armstrong (1999b), S. 55; Stierand (2000), S. 52.

${ }^{259}$ Kohl (1997a), S. 36 ff.
} 
wacht, während in Deutschland im selben Jahr das erste Pilotprojekt polizeilicher Videoüberwachung in Leipzig eingeführt wurde.

Anhand der vorhandenen Informationsquellen können insgesamt in fünf von 31 USGroßstädten mit mehr als 500.000 Einwohnern Videoüberwachungsmaßnahmen im öffentlichen Raum festgestellt werden: Neben Baltimore und Memphis werden auch polizeiliche Kameras in Chicago gegen Vandalismus und Kriminalität eingesetzt. Im Vergleich dazu operieren privat finanzierte Überwachungsgeräte in San Diego und Los Angeles (Hollywood) ${ }^{260} \mathrm{Im}$ Gegensatz zu Deutschland wird zu diesem Zeitpunkt in den USA die Observierung der öffentlichen Räume via Videotechnik auch in kleineren Städten, wie z.B. in Dover, South Orange, Tukwila, Tacoma und Tampa durchgeführt.

Im Jahr 2000 setzten bereits 95\% aller britischen Städte optische Überwachungsanlagen ein, während im selben Jahr lediglich neun bundesdeutsche Städte Gebrauch von dieser Technik machten, wenn man den temporären Videoeinsatz auf Sylt einbezieht. Berücksichtigt man dabei die Einwohnerzahl in den Städten, partizipierten nur 10\% der 50 größten Städte Deutschlands zu diesem Zeitpunkt an solchen Maßnahmen. ${ }^{261}$ Anhand der zugänglichen Daten konnten im selben Jahr 22 US-Städte mit CCTV-Systemen identifiziert werden, womit $24 \%$ der 50 größten US-Städte zu diesem Zeitpunkt öffentliche Videoüberwachung durchführten. ${ }^{262}$

Während also im Jahr 2000 die Mehrheit der Großstädte in den USA und in der Bundesrepublik noch keine CCTV-Systeme anwendet, ist diese Technik bereits vier Jahre zuvor mit einer einzigen Ausnahme (Leeds) öffentlich in allen britischen Großstädten in Anwendung. Außerdem nimmt Großbritannien nicht nur in Anzahl der überwachten Städte, sondern auch in der Anzahl Überwachungskameras im Vergleich zu den anderen zwei Ländern eine Spitzenposition ein. ${ }^{263}$

Heute ist die Videoüberwachung in Großbritannien so flächendeckend, dass keine genauen Angaben über die Anzahl der Überwachungskameras gemacht werden können. Schätzungsweise überwachen insgesamt 4.285.000 Kameras mehr als 500

\footnotetext{
${ }^{260} \mathrm{Zu}$ den 50 größten Städten in den USA mit ihrer Einwohnerzahl vgl. Ullrich (2005), S. 145.

${ }^{261}$ Im Jahr 2000 wurden in Dresden, Frankfurt am Main, Halle, Leipzig, Magdeburg, Hofheim am Taunus, Regensburg, Dessau und auf Sylt die Videoüberwachungsmaßnahmen öffentlicher Räume durchgeführt, wobei die ersten fünf Städte unter die ersten 50 größten Städte in Deutschland fallen. Die Auflistung der 50 größten Städte in Deutschland wurde aus Dönicke (2005), S. 781 entnommen.

${ }^{262}$ Folgende 12 von den 50 größten US-Städten verwendeten im Jahr 2000 CCTV-Anlagen: Baltimore, Virginia Beach, Memphis, New Orleans, Cleveland, Honolulu, Chicago, New York City, San Diego, Los Angeles, Sacramento und San Francisco. Zu den 50 größten Städten in den USA mit ihrer Einwohnerzahl vgl. Ullrich (2005), S. 145.

${ }^{263}$ Vgl. hierzu Poole; Williams (1996), S. 34.
} 
britische Städte. ${ }^{264}$ In der Bundesrepublik ist bis heute der Einsatz von Überwachungskameras an öffentlichen Straßen und Plätzen relativ überschaubar. Die sogenannten „Kriminalitätsschwerpunkte" in 26 bundesdeutschen Städten werden mit insgesamt ca. 94 polizeilichen Kameras überwacht, und die Anzahl der Überwachungskameras in der gesamten Bundesrepublik ist mit der Anzahl dieser optischen Überwachungseinrichtungen allein in London vergleichbar. Es ist schwer, die Vielzahl der in der Öffentlichkeit vorhandenen optischen Überwachungsgeräte in den Vereinigten Staaten ihren zuständigen Stellen zuzuordnen. Es lässt sich außerdem anhand der zugänglichen Daten keine allgemeingültige Aussage über die Nutzungsintensität in den USA machen. Dennoch war es in der vorangegangenen Analyse möglich, die Situation der Überwachungstätigkeit öffentlicher Räume per Videotechnik von insgesamt 40 US-Städten zu skizzieren, um die Gegenüberstellung mit den zwei Vergleichsländern vornehmen zu können.

Nach den obigen Vergleichen ist es unschwer zu erkennen, dass Großbritannien als absoluter Vorreiter im Bereich der Videoüberwachung öffentlicher Räume gilt. Die diesbezügliche Entwicklung in Deutschland liegt im Vergleich dazu sowohl in Anzahl der Überwachungskameras als auch der überwachten Städte weit hinter dem „,britischen Verhältnis“. Auch in den USA kann eine dem britischen Beispiel ähnliche Nutzungsintensität von Videografie zum Zweck der Kontrolle nicht bestätigt werden. Als Ergebnis der vergleichenden Analyse kann demnach festgehalten werden, dass der öffentliche Einsatz von Überwachungskameras in den USA umfangreicher ist als in der Bundesrepublik, und Großbritannien in der Gegenüberstellung zu den Verhältnissen in den beiden Vergleichsländern mit einer enormen Nutzungsintensität von CCTV-Systemen unverkennbar hervorsticht.

${ }^{264}$ McCahill; Norris (2002b), S. 20; nach Angaben von Williams \& Johnstone wurde die gesamte Anzahl der Überwachungskameras im Jahr 2000 in Großbritannien auf 40.000 geschätzt. Vgl. Williams; Johnstone (2000), S. $183 \mathrm{ff}$. 



\section{Teil II: Kriminalistischer Nutzen und Folgen der Video- überwachung}

Im Teil I konnte verdeutlicht werden, dass der Kameraeinsatz in öffentlichen Räumen, vor allem in Großbritannien, in den vergangenen Jahren zunehmend an Popularität gewonnen hat. Es gilt in diesem Teil der Arbeit zu skizzieren, welchen gesellschaftlichen Nutzen die Videoüberwachungsmaßnahmen bieten und welche Nachteile sie mit sich bringen. Damit werden wichtige Hintergrundinformationen aufgedeckt, die es erlauben, die politische Motivation sowie Beweggründe in den Entscheidungsprozessen zur Einführung bzw. Ablehnung von räumlicher Observierung mittels Videotechnik sichtbar werden zu lassen.

\section{Kriminalität, Kriminalitätsfurcht und Videoüberwa- chung}

\subsection{Kameras als sicherheitspolitische Werkzeuge}

Wie bereits angedeutet wurde, ist der Staat als für die „innere Sicherheit“ verantwortliche Instanz verpflichtet, Antworten auf die steigende Kriminalitätsrate und wachsenden Sicherheitsbedürfnisse der Bevölkerung zu finden. Um den Zerfall der sozialen Ordnung und des politischen Gemeinwesens zu verhindern, muss er wirksame Strategien entwickeln, die seine Legitimitätsgrundlage als Garant für Ruhe und Ordnung sichern. Die britische konservative Regierung war Anfang der 1990er Jahre angesichts steigender Kriminalitätsrate gezwungen, über einen Imagewechsel ihrer Sicherheitspolitik nachzudenken. Nach dem erfolglosen Versuch, die Kriminalität durch Gehaltserhöhungen und vermehrte Einstellung von Polizeibeamten zu bekämpfen, entschied sich die Audit Commission ${ }^{265}$ für einen Kurswechsel der Sicherheits- und Kriminalpolitik: Anstelle der bisherigen reaktiven Kontrollstrategien treten nun die proaktiven Handlungsmethoden in den Vordergrund. Die Kommission erklärt dabei den Einsatz von CCTV-Systemen zum wirksamen Werkzeug der neuen Sicherheitspolitik. Diese Praktik wurde unter Blairs New Labour-Regierung mit dem Slogan "tough on crime, tough on the causes of crime" als die wahre "law and order"-Partei fortgesetzt. ${ }^{266}$

\footnotetext{
${ }^{265}$ The Audit Commission wurde von der ehemaligen konservativen Regierung gegründet und dient als Kontrollinstanz unter den Ministerien, die für die Prüfung der finanziellen Ausgaben zuständig ist. „[A] well-defined responsibility for making the best use of their resources, including a critical scrutiny of output and value for money", Norris; Armstrong (1999b), S. 36; vgl. auch Norris (1998), S. 30 ff.

${ }^{266}$ Ebenda.
} 
Im Gegensatz zur klassischen Vorgehensweise, bei der die zuständigen Behörden erst nach Straftaten aktiv werden, geht es in einer solchen Kriminalpolitik der „neuen Prävention“ ${ }^{\prime 267}$ vor allem darum, potentielle Ordnungsverstöße im Vorfeld zu erkennen und zu verhindern. Zur Verwirklichung dieses Ziels wird in Kauf genommen, dass eine Vielzahl von Menschen unter Generalverdacht (Depersonalisierung des Verdachts) gestellt wird, da „die Zahl potentieller Gefahrenquellen stets ungleich größer ist als die akuten Gefahren". ${ }^{268}$

Dieser Paradigmenwechsel ${ }^{269}$ der Sicherheits- und Kriminalpolitik ist keineswegs nur ein britisches Phänomen. Die USA gelten als kriminologisch-kriminalpolitischer Vorreiter. ${ }^{270}$ Die bekannte "Zero-Tolerance-Strategy" in New York, die sowohl in vielen anderen US-amerikanischen Städten als auch in einer Vielzahl internationaler Sicherheitsdebatten als Musterbeispiel für erfolgreiche Kriminalitätsbekämpfung dient, entspricht diesem vorbeugenden Handlungsmuster. ${ }^{271}$ Auch die Bundesrepublik hat sich in die Länder mit präventiver Sicherheitspolitik eingereiht. Die Strategie der „proaktiven Informationsbeschaffung und Auswertung“ vom Bundeskriminalamt (BKA), welche dazu dient, möglichst viele Informationen zu sammeln und systematisch auszuwerten, bevor Kriminalfälle sich ereignen, ist nur ein Beispiel hierfür. ${ }^{272}$ In Brandenburg wurden die Polizeigesetze im Jahr 1996 zugunsten der Erweiterung des polizeilichen Handelns novelliert, welche der brandenburgischen Polizei die bundesweit größten polizeilichen Befugnisse ermöglichten. Als die aus der ehemaligen DDR stammenden Abgeordneten gefragt wurden, warum ausgerechnet sie mit Erfahrungen aus der DDR wieder einen „Polizeistaat“ haben wollten, antworteten sie, dass man ihn früher gehabt habe und man ihn jetzt brauche. ${ }^{273}$ Der im Jahr 1991 nach dem skandinavischen Vorbild gegründete "Rat für Kriminalitätsverhütung“ in Schleswig-Holstein ist ein weiteres Beispiel für die Tendenz der Verbrechensvorbeugung. ${ }^{274}$

\footnotetext{
${ }^{267}$ Sack (1995), S. 454.

${ }^{268}$ Glaeßner (2002), S. 12; vgl. auch Legnaro (1997), S. 274; Feeley; Simon (1994), S. 173 ff.

${ }^{269}$ Das Wort „Paradigma“ ist ein erkenntnistheoretischer Ausdruck für wissenschaftliche Denkweise. Vgl. Kuhn (1991). „Paradigmenwechsel“ bezeichnet hier die radikale Änderung des Blickwinkels und der Einstellung von Politikern in der Sicherheitspolitik. Dies führt dazu, dass nicht mehr die übliche "reaktive“, sondern eine „proaktive“ Vorgehensweise in Bezug auf die Kriminalitätsproblematik bevorzugt wird.

${ }^{270}$ Sack (1995), S. $429 \mathrm{ff}$.

${ }^{271}$ Mehr zur Zero-Tolerance-Strategy vgl. Greene (2001); Wehrheim (2002), S. 66 ff.; Glaeßner (2002), S. 11; Sack (1995), S. 449 f.

${ }^{272}$ Glaeßner (2002), S. 11; Bundeskriminalamt (1997), S. 15, 23; vgl. auch Gössner (2000a), S. 11 ff.

${ }^{273}$ Legnaro (1997), S. 274.

${ }^{274}$ Sack (1995), S. 436. Nach Angaben des Autors gibt es ähnliche Institutionen auch in Hessen und Baden-Württemberg. Vgl. auch Finkel (1995), S. 415 ff.; Steinert (1995), S. 403.
} 
Der Trend zur Verlagerung des sicherheitspolitischen Schwerpunktes von reaktiven zu proaktiven Strategien erfordert andere Instrumente als die herkömmliche Strafverfolgung. Viele staatliche Sicherheitsbehörden, wie z.B. die britische Audit Commission, haben in diesem Fall die CCTV-Überwachung als das geeignete Instrument gesehen. Im Gegensatz zur traditionellen Vorgehensweise stehen nun nicht einzelne Personen im Mittelpunkt polizeilicher Kontrolltätigkeiten, sondern vielmehr die sozialen Räume. In diesem Sinne bedeutet verstärkter Kameraeinsatz in öffentlichen Räumen als entpersonalisierte Kontrolle nichts anderes als bessere Chancen zur Erkennung von Gefahren und Risiken des ordnungs- und gesetzwidrigen Verhaltens im Vorfeld. In den vergangenen Jahren hat sich also die Videoüberwachungstechnik, insbesondere in Großbritannien, als ein kriminalpräventives Mittel zur Unterstützung polizeilicher Arbeit durchgesetzt. Während sich noch Anfang der 1990er Jahre die meisten videoüberwachten Bereiche hauptsächlich auf private und semiöffentliche Räume beschränkten, erobert die staatliche Videoüberwachung mittlerweile nach und nach den öffentlichen Raum, auch wenn dies in den drei zu untersuchenden Nationen in verschiedener Geschwindigkeit geschieht.

Heute gehören Überwachungskameras auf internationaler Ebene bereits zu einem festen Bestandteil der Kriminal- und Sicherheitskonzepte, obwohl die versprochenen Ziele zur Reduzierung von (empfundener) Unsicherheit bisher nicht eindeutig bestätigt werden konnten. ${ }^{275}$ Die Hauptziele der Videoüberwachung, die in den politischen Debatten formuliert wurden, bestehen also darin, 1.) die Kriminalitätsrate in dem überwachten Gebiet zu reduzieren und/oder 2.) das Sicherheitsgefühl der Bürger zu steigern.

Bevor wir der Frage der Effektivität von Videoüberwachung nachgehen, ist zunächst erklärungsbedürftig, welche Deliktarten von den kameragestützten Verbrechensbekämpfungsmaßnahmen verhindert bzw. aufgeklärt werden können. Ebenfalls soll deutlich gemacht werden, woher Kriminalitätsfurcht kommt und inwiefern diese durch CCTV-Überwachung eingedämmt werden kann.

\subsection{CCTV-relevante Deliktformen}

Befürworter polizeilicher Videoüberwachungsmaßnahmen rechtfertigen den Kameraeinsatz mit der hohen bzw. steigenden Kriminalitätsrate. Der Begriff „Kriminalität“ bezeichnet Verbrechen als Sozialerscheinung. Darunter versteht man „die Summe

\footnotetext{
${ }^{275}$ Vgl. das Kapitel über „,die Frage der Effektivität“.
} 
der strafrechtlich missbilligten Handlungen. ${ }^{\prime 276}$ Es ist an dieser Stelle wichtig anzumerken, dass die Erscheinungsformen der Kriminalität vielfältig sind und Überwachungskameras keineswegs als erfolgreiche Instrumente in der Bekämpfung jeglicher Form von Delikten gesehen werden können. ${ }^{277}$ Vielmehr beschränkt sich der Zweck der Videoüberwachung öffentlicher Straßen und Plätze auf die Bekämpfung der sogenannten „Straßenkriminalität“. ${ }^{278}$ Dieser Begriff umfasst kriminalgeografisch „alle Straftaten, deren Tatausführung mehrheitlich auf der Straße i.w.S., d.h. im öffentlichen Raum geschieht oder die unmittelbar in die Öffentlichkeit hineinwirken und somit im unmittelbaren Zugriffsbereich der Polizei verübt werden“ ${ }^{279}$ Die Straßenkriminalität umfasst in diesem Sinne Delikte wie z.B. Diebstahl, Raub, Drogen- und damit verbundene Beschaffungskriminalität, sowie sonstige Gewaltdelikte, die sich in der Öffentlichkeit ereignen. Mittlerweile zählt zur Gewährleistung des öffentlichen Gemeinwohls auch die Bekämpfung sonstiger Bagatelldelinquenz (namentlich Vandalismus, Verschmutzung und aggressives Betteln) zum Aufgabenbereich der polizeilichen Überwachungspraxis.

Auch wenn man bei der Anwendung von CCTV-Systemen in den öffentlichen Räumen häufig allgemein von der Bekämpfung der Kriminalität spricht, betreffen also die Videoüberwachungsmaßnahmen öffentlicher Räume nur die Straßenkriminalität, die sich in dem überwachten Bereich ereignet. Dabei stellt die Straßenkriminalität nur einen Teil der Gesamtkriminalität eines Landes dar. In der Bundesrepublik macht beispielsweise die Straßenkriminalität nach Angaben vom Bundeskriminalamt etwa nur ein Viertel der Gesamtstraftaten aus. ${ }^{280}$ Unter Berücksichtigung der Differenzierung von CCTV-relevanten Deliktformen sowie der räumlichen und zeitlichen Begrenztheit der Überwachungsmaßnahmen per Videotechnik ist offensichtlich, dass die öffentliche Videoüberwachung nur gegen einen relativ kleinen Teil der Gesamtkriminalität wirkt. Die Maßnahmen der Videoaufzeichnung als „Wundermittel ge-

\footnotetext{
${ }^{276}$ Kaiser (1997), S. 176; Kaiser et al. (1993), S. 238.

${ }^{277}$ Nach der Struktur der Kriminalität (Art und Schwere der Delikte) kann man die Erscheinungsformen zwischen „Massenkriminalität“ (z.B. Diebstahl, Leistungserschleichung, Sachbeschädigung, einfache Körperverletzung sowie Drogen- und Verkehrsdelikte) und „Schwerkriminalität" (Mord, Totschlag, gefährliche Körperverletzung, Raub, Erpressung, Menschen-, Waffen- und Rauschgifthandel sowie Vergewaltigung und Geiselnahme) unterscheiden, wobei der größte Teil der polizeilich registrierten Delikte der ersten Kategorie zugeordnet werden kann. Mehr zu diesem Thema vgl. Kaiser (1997), S. 179; Kaiser et al. (1993), S. 242 ff.

${ }^{278}$ Büllesfeld (2002), S. 52.

${ }^{279}$ Ebenda, S. 52 f. Straßenverkehrsdelikte fallen dabei nicht unter diese Kategorie.

${ }^{280}$ Die Straßenkriminalität hat im gesamten Bundesgebiet einen Straftatanteil zwischen 26,5\% und 27,6\% in dem Zeitraum von 2000 bis 2003. Genauere Angaben zur Straßenkriminalität in Deutschland vgl. Bundeskriminalamt (2003).
} 
gen die Kriminalität ${ }^{\prime 281}$ müssen also in ihrer allgemeinen Wirksamkeit relativiert werden.

Ferner stellt sich die Frage, inwiefern die Straßenkriminalität als CCTV-relevante Deliktform das Sicherheitsempfinden der Bevölkerung beeinträchtigt, da Überwachungskameras nicht nur zur Bekämpfung von (Straßen-)Kriminalität, sondern auch zur Reduzierung von Kriminalitätsfurcht eingesetzt werden. Bei der näheren Betrachtung der Befragungsbögen zur Kriminalitätsfurcht kann festgehalten werden, dass diese sich häufig vorrangig auf die Straftaten auf öffentlichen Straßen und Plätzen konzentriert. ${ }^{282}$ Klassische Fragen zur Registrierung der Kriminalitätsfurcht wie z.B. „Wie sicher fühlen Sie sich, wenn Sie nach Einbruch der Dunkelheit allein zu Fuß in der Gegend unterwegs sind, in der Sie wohnen?“, erfassen also zum großen Teil die Straßenkriminalität, womit die Befürworter den Einsatz von öffentlichen Überwachungskameras rechtfertigen. Da es sich bei der Kriminalitätsfurcht um ein vielfältiges Phänomen mit zahlreichen Einflussfaktoren handelt, wird im folgenden Abschnitt der Begriff „Kriminalitätsfurcht“ näher erläutert.

\subsection{Was ist Kriminalitätsfurcht?}

Das Stadtzentrum ist ein öffentlicher Raum, der durch Anonymität, Unvorhersehbarkeit von Ereignissen und Kontakt zu sozialen Fremden gekennzeichnet ist. „Sie gilt damit als Sphäre der Unsicherheit, als Sphäre des individuellen Kontrollverlustes. (...) Kurz, die Stadt ist der Ort der Gefahr und der Freiheit, sie bedingen sich gegenseitig. ${ }^{\prime 283}$ Die Begegnungen mit Fremden und die Unvorhersehbarkeit von Geschehnissen führen bei vielen Bürgern offensichtlich zu einer Art "Stadtangst“, die wiederum als Auslöser einer allgemeineren, teilweise diffusen „Kriminalitätsangst” gesehen werden kann. ${ }^{284}$

\footnotetext{
${ }^{281}$ Vgl. Weichert (1998b), S. 12 ff; Kohl (1997a), S. 36 ff; Büllesfeld (2002), S. 1; Töpfer (2005), S. 5 ff.

${ }^{282}$ Mehr zur Kriminalitätsfurcht in den drei Vergleichsländern vgl. Teil III, Kap. 8.1 dieser Arbeit.

${ }^{283}$ Wehrheim (2002), S. 23; vgl. auch Bauman (1997), S. 207.

${ }^{284} \mathrm{Im}$ alltäglichen Sprachgebrauch wird oft nicht zwischen den zwei Begriffen „Angst“ und „Furcht" unterschieden. In der Psychologie dagegen werden diese unterschiedlich definiert: Während Angst einen unbestimmten Gefühlszustand bezogen auf physische oder psychische Integrität bedeutet und das Gefühl der Hilflosigkeit hervorrufen kann, ist Furcht auf konkrete und (bedingt) beherrschbare Gefährdung gerichtet. Nach dieser begrifflichen Trennung versteht man unter Kriminalitätsangst eine Gestimmtheit, die auf Kriminalität im Allgemeinen, aber nicht auf konkrete Delikte gerichtet ist. Kriminalitätsfurcht bezieht sich also auf die "Einschätzung bestimmter, konkret wahrgenommener Bedrohungen, denen das potentielle Opfer auch prinzipiell konkret begegnen kann (Flucht, Gegenwehr u.a.)“. In dieser Arbeit wird keine strenge Trennung der Begriffe vorgenommen. Vgl. Frevel (1998), S. 15; Nogala (2002), S. 34 f.
} 
Der Begriff Kriminalitätsfurcht bezeichnet eine „emotionale Reaktion gegenüber solchen Verhaltensweisen, die als persönliche Bedrohung empfunden werden“. ${ }^{285}$ Die Entstehung dieses Unsicherheitsempfindens basiert auf vielen Komponenten. Im Folgenden werden die klassischen theoretischen Erklärungsansätze zur Erfassung der Kriminalitätsfurcht kurz dargestellt:

Aus der Soziale-Kontroll-Perspektive lässt sich diese Angst vor Kriminalität auf den Verlust informeller Kontrolle durch Prozesse der Desorganisation in sozialen Nahräumen zurückführen. ${ }^{286}$ Gemeinden oder Wohnviertel, die freundlich und ordentlich sind, steigern die Kohäsion der Gemeinschaft und beeinflussen die Sicherheitsgefühle ihrer Bewohner positiv. Treten jedoch Unwirtlichkeit und soziale Desorganisation auf, wie z.B. hässliche Graffiti, vandalisierte Bushaltestellen oder Ähnliches, so erhöhen diese incivilities die Kriminalitätsfurcht der Bewohner. Gemeint ist Verhalten, welches von den "gesittete[n] Verhaltensweisen honoriger Bürger“ abweicht. ${ }^{287}$ Zusätzlich kann die diffuse Kriminalitätsangst durch nicht erwünschte Ansammlungen von sozialen Randgruppen noch verstärkt werden. ${ }^{288}$

\footnotetext{
${ }^{285}$ Boers (1996), S. 330; Frevel (1998), S. 15. Einige Kriminologen stützen sich zur Erfassung der persönlichen Kriminalitätseinstellung auf das sozialpsychologische Attitüdenkonzept und differenzieren zwischen affektiven, kognitiven und konativen Komponenten. Die affektive Haltung gegenüber Kriminalität, also die emotionale Komponente persönlicher Kriminalitätseinstellung (Kriminalitätsfurcht) ist nur einer der mehreren Faktoren zur Erfassung der persönlichen Bedrohungsgefühle. Häufig wird zur Messung der Kriminalitätsfurcht die sogenannte Standardfrage benutzt: „Wie sicher fühlen Sie sich, wenn Sie abends im Dunkeln allein durch die Straßen Ihres Stadtteils/Dorfes gehen?" Um der Kritik entgegenzuwirken, dass diese Art der Befragung nur diffuse Angst erfassen könnte, wird sie häufig durch konkrete Nennung bestimmter Deliktarten erweitert. Die kognitive Komponente bezieht sich auf die persönliche Risikoeinschätzung, d.h. die Wahrscheinlichkeit, tatsächlich Opfer einer bestimmten Straftat zu werden. Auch hier liegt der Schwerpunkt der Befragung auf der Straßenkriminalität. Unter konativer Komponente versteht man das Vermeideverhalten. Die wichtige Frage hierbei ist herauszufinden, welche Möglichkeit eine Person hat und benutzt, um einer Gefahrensituation auszuweichen. Eine weitere Komponente, die häufig in der Fachliteratur nicht explizit erwähnt wird, ist die Bewertung der persönlichen Copingfähigkeit. Es wird die Frage gestellt, wie die persönliche Fähigkeit, mit der Gefahrensituation umgehen zu können (Copingfähigkeit), eingeschätzt wird. Wie schätzt z.B. eine Person ihre Fähigkeit ein, zu flüchten, Gegenwehr zu leisten oder andere Schutzmaßnahmen einzusetzen, wenn sie angegriffen wird? Hiermit spielt die Einschätzung der eigenen psychischen und physischen Verletzbarkeit (Vulnerabilität) eine entscheidende Rolle. So können körperlich schwächere Menschen ihr Verletzungsrisiko und Folgeschäden in einer Gefahrensituation höher einschätzen als jemand mit physischer Stärke, was wiederum ihre Kriminalitätsfurcht beeinflusst. Vgl. Frevel (1998), S. 15 f.; Boers (1993), S. 67; mehr zum Thema Kriminalitätsfurcht vgl. auch Boers (1991); Kreuter (2002).

${ }^{286}$ Frevel (1998), S. $49 \mathrm{ff}$.

${ }^{287}$ Hölscher (2003), S. 51; Ronneberger (2000), S. 129; Frevel (1998), S. 45 ff.

${ }^{288}$ Aus der Soziale-Kontroll-Perspektive lässt sich die vergleichsweise hohe Kriminalitätsfurcht in den neuen Bundesländern nach der Vereinigung u.a. plausibel erklären: Aus der Studie von Boers; Kurz (1997) hat sich gezeigt, dass die "Verwahrlosung“" und der Verlust formeller und informeller sozialer Kontrolle sich auf die Kriminalitätseinstellung der Bevölkerung in den neuen Bundesländern auswirkt. Die Gemeinden in Ostdeutschland werden mit steigender Arbeitslosigkeit und dem Abbau der orientierungsvermittelnden Strukturen (Schließung von Jugendheimen) konfrontiert, der insgesamt als sozialer Desorganisationsprozess erlebt wird. Der schnelle Veränderungsprozess, ungewohnte Lebensformen und steigende Kriminalität lösen im Osten des Landes größere Sorge und Furcht aus als in Westdeutschland, obwohl die objektive Kriminalitätsrate im Vergleich dazu relativ gering ausfällt. Vgl. auch Kury; Obergfell-Fuchs (1998b); Kury; Obergfell-Fuchs (1998a).
} 
Nach der Soziale-Problem-Perspektive ist die Kriminalitätsfurcht im Wesentlichen das Ergebnis verzerrter, übertriebener Darstellungen von Gewaltverbrechen in den Massenmedien. ${ }^{289}$ Die Berichterstattung spielt insofern eine Rolle bei der Wahrnehmung der Kriminalität als sie der Bevölkerung das Bild der Kriminalität außerhalb des sozialen Nahraums vermittelt. Das vermittelte Bild ist jedoch oft verzerrt und übertrieben, da schlechte Nachrichten sich besser vermarkten lassen als gute und dem Ungewöhnlichen mehr Aufmerksamkeit geschenkt wird als dem Alltäglichen. ${ }^{290}$ Auch wenn schwere Delikte nur einen kleinen Anteil an der Gesamtkriminalität ausmachen, werden sie öfter in den Massenmedien erwähnt. Die Medien vermitteln somit nicht die Realität der Kriminalitätsentwicklung, sondern ein verzerrtes Bild, was die Kriminalitätsfurcht der Menschen verstärkt.

Die Theorie der Viktimisierungsperspektive besagt, dass Personen, die schon einmal Opfer einer kriminellen Handlung wurden, aufgrund dieser Erfahrung eine höhere Kriminalitätsfurcht entwickeln. ${ }^{291}$ Im Gegensatz zu dieser Theorie belegen empirische Studien, dass entweder nur eine schwache oder gar keine Korrelation zwischen Kriminalitätsfurcht und Opfererfahrung besteht. ${ }^{292}$ Boers hat im Vergleich mehrerer Forschungsergebnisse festgestellt, dass Opfer gewaltsamer Kriminalität nicht im erwarteten Maße mehr Kriminalitätsfurcht zeigen als Nicht-Opfer. Er ist sogar zu dem überraschenden Ergebnis gekommen, dass Opfer von Eigentumsdelikten zu weniger Kriminalitätsfurcht neigen. ${ }^{293}$

Vor dem Hintergrund dieser Erklärungsansätze lässt sich die Kriminalitätsangst, die auf die Medien (Sozial-Problem-Perspektive) oder die Opfererfahrung (Viktimisierungsperspektive) zurückzuführen ist, nur schwer durch den Einsatz von Überwachungskameras auf öffentlichen Straßen und Plätzen unmittelbar vermindern. Dage-

\footnotetext{
${ }^{289}$ Frevel (1998), S. 45.

290 „Den Weg in die überregionalen Medien finden i.d.R. nur die „großen“ Delikte, wie Mord, Geiselnahme, Banküberfälle mit hohem Raubertrag oder mit besonderer Gewalteinwirkung sowie Delikte, die in mittelfristigen Epochen besondere Aufmerksamkeit finden und außerhalb dieser Epoche weniger Beachtung finden (z.B. fremdenfeindliche Angriffe auf Ausländer [insbesondere 1990-1993], sexueller Missbrauch von Kindern, Kinderpornographie [insbesondere 1995 ff.]." Ebenda, S. 52.

${ }^{291}$ Ebenda, S. 45 f.

${ }^{292}$ Vgl. Boers (1991), S. 45 ff; vgl. auch Wetzels et al. (1995) und Sessar et al. (1991).

${ }^{293}$ Boers (1991), S. 48; Frevel (1998), S. 45. Zu Untersuchungen, bei denen sich Opfer und Nicht-Opfer im Hinblick auf die Kriminalitätsfurcht deutlich unterscheiden vgl. Wetzels et al. (1995), S. 235 ff. Zur Klärung dieser unterschiedlichen empirischen Befunde werden verschiedene Gründe vermutet. So kann das Erleben einer Straftat zu einem kurzfristigen Ansteigen der Kriminalitätsfurcht führen, die dann vom Opfer kognitiv vorbearbeitet wird und sich mit Schutz- und Vermeideverhalten für die Zukunft vorbereitet. Da das Opfer bewusst Gefahrensituationen ausweicht oder die eigene Copingfähigkeit steigert, sinkt die Kriminalitätsfurcht. Auch das Vergessen von Viktimisierung wird als möglicher Grund für das Nichtkorrelieren zwischen Kriminalitätsfurcht und Opfererfahrung genannt. In Untersuchungen zum Sicherheitsgefühl der Deutschen wurde festgestellt, dass Opfer schwerwiegender Straftaten, wozu Kontaktdelikte (z.B. Raub und Vergewaltigung) sowie Wohnungseinbruch zählen, sowohl höhere Kriminalitätsfurcht als auch höhere Risikoeinschätzung zeigen als Nicht-Opfer. Vgl. Wetzels et al. (1995), S. 235; vgl. auch Frevel (1998), S. 46.
} 
gen könnte das Unsicherheitsgefühl, das von empfundener sozialer Unordnung oder Störung (Sozial-Kontroll-Perspektive) herrührt, durch Maßnahmen der Videoaufzeichnung bekämpft werden. So wird z.B. ein Videoüberwachungsprogramm in Chicago eingesetzt, um dem Graffiti-Problem der Stadt entgegenzuwirken. Auch Ansammlungen von Teenagern oder Ausländern oder die Anwesenheit von anderen sozialen Minderheiten, die Unsicherheitsgefühl bei der Mehrheit der Bevölkerung auslösen können, gelten als Grund zur Installation von Überwachungskameras. Dies zeigt sich beispielsweise am Pilotprojekt auf Sylt, das zum Ziel hat, die vermehrte Anwesenheit von Punks auf der Insel einzudämmen. ${ }^{294}$ Auch wenn diese „potentiellen Kriminellen" in Wirklichkeit keine Straftat ausüben, werden sie trotzdem als Bedrohung empfunden und aus bestimmten Räumen vertrieben, um das allgemeine Sicherheitsempfinden in der überwachten Zone zu pflegen. Die damit verbundenen Rechtseinschränkungen sozialer Randgruppen sowie die Notwendigkeit des Minderheitenschutzes zum Wohl der Menschen, die mit anderem Habitus den öffentlichen Raum nutzen, werden später in diesem Teil der Arbeit diskutiert. Zunächst soll im nächsten Abschnitt der Zusammenhang zwischen Kriminalität und Kriminalitätsangst untersucht werden, um anschließend die Effektivität öffentlicher Videografie auf diese zwei Motive der Videoüberwachung zu prüfen.

\subsection{Kriminalität und Kriminalitätsfurcht - Ein Zusammenhang?}

Die Entstehung der Kriminalitätsfurcht basiert, wie oben gezeigt werden konnte, auf mannigfaltigen Komponenten. Man kann demnach nicht davon ausgehen, dass das Sicherheitsempfinden allein auf die Kriminalitätsentwicklung zurückgeführt werden kann. Karl-Heinz Reuband konnte anhand eines Vergleichs der Kriminalitätsfurcht in der Bundesrepublik Deutschland und den USA zwischen 1965 und 1990 zeigen, dass subjektive Kriminalitätsfurcht nur teilweise durch die tatsächliche Entwicklung der Kriminalität geprägt wird. ${ }^{295}$

In der Bundesrepublik hat sich die Zahl der Gewaltdelikte zwischen 1965 und 1990 fast verdoppelt, während sie in den USA beinahe auf das Dreifache gestiegen ist. Aus den Viktimisierungsumfragen in dem Zeitraum hat sich ergeben, dass die Wahrscheinlichkeit, einem Gewaltdelikt zum Opfer zu fallen, in den USA mehr als doppelt so hoch war wie in der Bundesrepublik. ${ }^{296}$ Allerdings waren es die Bundesbürger, die in den 1960er Jahren stärkere Kriminalitätsfurcht zeigten.

\footnotetext{
${ }^{294} \mathrm{Vgl}$. Teil I, Kap. 3.1.2.2 dieser Arbeit.

${ }^{295}$ Reuband (1992), S. 344.

${ }^{296}$ Ebenda, S. 347. 
Die Gründe für diese paradoxe Entwicklung der objektiven und subjektiven Bedrohung in den 1960er Jahren sind unklar. Reuband sieht eine mögliche Ursache in der Berichterstattung der Medien. ${ }^{297}$ Eine andere mögliche Ursache für die Diskrepanz zwischen der Kriminalitätsangst und der tatsächlichen Kriminalitätsentwicklung könnte, so Reuband, in den Gewöhnungsprozessen liegen. Menschen arrangieren sich mit Gefahren und entwickeln ein Routineverhalten gegenüber Gefahrensituationen, so dass sie selbst bei steigender Kriminalitätsrate nicht unbedingt eine höhere Kriminalitätsfurcht zeigen, sofern der Anstieg der Kriminalität nicht zu drastisch ist. Zwischen Kriminalitätsfurcht und objektiver Kriminalitätsrate sind also eine „Reihe verschiedener intervenierender Einflussfaktoren geschaltet“. ${ }^{298}$

Die schwache Korrelation zwischen Kriminalitätsgefahr und -angst wird ebenfalls von der International Crime Victims Survey (ICVS) bestätigt, die in siebzehn Industrienationen in dem Zeitraum zwischen 1989 und 2000 viermal durchgeführt wurde. ${ }^{299}$ Die Ergebnisse zeigen, dass die Angst, nach Einbruch der Dunkelheit alleine unterwegs zu sein, nur selten mit dem tatsächlichen Risiko übereinstimmt, Opfer eines Verbrechens (Raub, Körperverletzung, sexuelle Übergriffe usw.) zu werden. Die Forscher vermuten die mediale Präsentation von Gewaltdelikten als möglichen Einflussfaktor für diese Diskrepanz. ${ }^{300}$

Zusammenfassend kann man sagen, dass es sich bei der Kriminalitätsfurcht um ein vielschichtiges Phänomen mit vielen Auslösern handelt, die in einem komplexen Zusammenhang zueinander stehen. Die empfundene Angst vor Verbrechen steht also nicht in unmittelbarem Zusammenhang zu der tatsächlichen Kriminalitätsentwicklung und wird durch persönliche Erfahrungen und damit verbundenen Verarbeitungsprozessen beeinflusst. Auch die persönliche Copingfähigkeit, Berichterstattung sowie andere sozialen Bedingungen spielen beim subjektiven Empfinden zur Kriminalität eine wichtige Rolle.

\subsection{Die Frage der Effektivität}

Aufgrund der komplexen Zusammenhänge der Ursachen für das Sicherheitsempfinden und der tatsächlichen Sicherheitslage kann man davon ausgehen, dass eine ein-

\footnotetext{
${ }^{297}$ Es ist möglich, dass „die Medienberichterstattung in den beiden Ländern im Zeitverlauf unterschiedliche Inhalte vermittelt hat und sich deshalb die wahrgenommenen Kriminalitätstrends nicht mit den objektiven Realitäten decken“. Reuband (1992), S. 346.

${ }^{298}$ Unabhängige Untersuchungen haben gezeigt, dass ältere Menschen und Frauen im Allgemeinen ein hohes Unsicherheitsgefühl haben, auch wenn sie seltener Opfer von Kriminalität werden. Junge Männer dagegen, die am häufigsten in Gewaltdelikten verwickelt sind, äußern am seltensten Angstgefühle. Vgl. Reuband (1999), S. 16; Stierand (2000), S. 22; Hölscher (2003), S. 42 ff.

${ }_{299}^{29}$ Vgl. Teil III, Kap. 7 dieser Arbeit.

${ }^{300}$ Van Kesteren et al. (2000), S. 80 f.
} 
zige Maßnahme der Sicherheitspolitik, wie der Einsatz von Überwachungskameras, nicht automatisch die Kriminalitätsfurcht der Bürger abbauen kann. Ganz zu schweigen von der Frage, ob die Anwendung dieser Technik überhaupt effektiv genug ist, um einen tatsächlichen Rückgang der Verbrechensrate zu erreichen.

Es ist deswegen notwendig, zur Überprüfung der Effektivität von Videoüberwachung die kriminalpräventiven Zwecke (Kriminalitätsrate) von den Zielen zur Steigerung des Sicherheitsgefühls der Bürger (Kriminalitätsangst) zu unterscheiden. Im Folgenden wird vor diesem Hintergrund die Effektivität des Einsatzes von optischen Überwachungseinrichtungen einerseits hinsichtlich der objektiven Sicherheitslage und andererseits hinsichtlich des subjektiven Sicherheitsempfindens in öffentlichen Räumen beleuchtet.

\subsubsection{CCTV-Überwachung zur Reduzierung von Kriminalität}

In der Praxis der Verbrechensbekämpfung kann CCTV-Technik als kriminalpräventives Mittel gesehen werden, das im Vorfeld mögliche Gefahrenquellen erkennen und verhindern lässt. Ferner dient sie auch als Instrument zur Strafverfolgung, das nach Straftaten zur Identifizierung von Straftätern eingesetzt wird. In diesem Abschnitt wird die Nutzbarkeit von CCTV-Technik unter diesen beiden Gesichtspunkten untersucht.

\subsubsection{Kriminalprävention}

Die Diskussionen über die Effektivität der Videoüberwachung zur vorbeugenden Verbrechensbekämpfung führen oft zu Uneinigkeiten, da es bislang keine haltbaren, unabhängigen Langzeituntersuchungen gibt, sondern nur Kurzzeitstudien, die sich auf lokale Ereignisse konzentrieren und nicht selten widersprüchliche Resultate erzielen. ${ }^{301}$ Während Befürworter der weiträumigen Videoüberwachung die rückläufige Verbrechensrate präsentieren, weisen die Kritiker auf die steigende Kriminalitätsrate in den angrenzenden Zonen durch den Verdrängungseffekt hin und zweifeln an dem tatsächlichen Erfolg beim Dauereinsatz dieser optisch-elektronischen Einrichtungen unter Berücksichtigung der gesamten Kriminalitätsentwicklung. ${ }^{302}$

Bisher stammen die meisten Evaluationsstudien zur Effektivität der Videoüberwachung zur Gefahrenabwehr aus Großbritannien, da sich die Praxis der elektronischen

\footnotetext{
${ }^{301}$ Gemeint ist hierbei die „Straßenkriminalität“, deren Bekämpfung das Ziel der präventivpolizeilichen Videoüberwachungsmaßnahmen gilt. Sie umfasst u.a. Deliktarten wie Raub, Körperverletzungen und sonstige Gewalt- und Drogendelikte. Mehr hierzu vgl. Büllesfeld (2002), S. 52 f.; Norris (1998), S. 30 ff.; Weichert (1999), S. 4; Weichert (1998b), S. 12 ff.

${ }^{302} \mathrm{Mehr}$ zur Auswirkung der Videoüberwachung auf die Kriminalität, vgl. Studien von Skinns (1998) und von Ditton; Short (1999). Vgl. auch Nogala (2002), S. 47 ff.
} 
Observation dort schon länger und in großem Ausmaß im Alltag etabliert hat. Aus diesem Grund stützt sich die folgende Darstellung über die Effektivität solcher Überwachungsmaßnahmen hauptsächlich auf die vorhandenen Materialien aus Großbritannien. Einzelne Studien aus Deutschland sollen ebenfalls berücksichtigt werden.

Die bisherigen Untersuchungen zur Frage der Effektivität von CCTV-Anlagen liefern keine eindeutigen Erkenntnisse:

Der kriminalistische Nutzen der CCTV-Systeme in Newcastle zeigt sich in einer Reduzierung der erfassten Straftaten um 19\%. ${ }^{303}$ Während einige Evaluationsergebnisse auf die Reduzierung des Einbruchdiebstahls in dem Einsatzgebiet von Überwachungskameras um 60\% hinweisen, zeigen andere Studien eine Verlagerung der Einbruchsdelikte in die nahe liegenden Gebiete sowie die wieder zunehmende Kriminalitätsrate nach anfänglichem Erfolg. ${ }^{304}$ Dennoch wird der Einsatz von CCTVSystemen in Newcastle als erfolgreich gesehen.

Auch in Birmingham, der zweitgrößten Stadt Großbritanniens, werden CCTVSysteme zur Kriminalitätsverhütung eingesetzt. Nach Angaben einer vom britischen Innenministerium finanzierten Studie ist der Kameraeinsatz dort wenig erfolgreich. Bei Delikten wie Sachbeschädigungen und Körperverletzungen liegen die Raten im Überwachungsbereich auf ähnlichem Niveau wie im benachbarten Stadtteil. Der Rückgang der Anzahl von Kfz-Diebstählen lässt sich vermutlich auf die gleichzeitige Eröffnung der Fußgängerzone zurückführen. ${ }^{305}$ Bei manchen Deliktarten, wie z.B. Raubüberfällen und Diebstählen sind sogar Zunahmen der registrierten Straftaten zu verzeichnen. ${ }^{306}$

Bei der Evaluation der CCTV-Anlage in King's Lynn ist die Effektivität der Kameras umstritten, da einige Deliktarten schon vor der Einführung der CCTV-Kameras sinkende Tendenzen aufwiesen. Eine Verlagerung der Kfz-Kriminalität ist angesichts der präventiven Erfolge möglich. ${ }^{307}$ Dagegen wird die Videoüberwachung in Airdrie als Erfolg gefeiert, auch wenn der von der Polizei angegebene Rückgang der Kriminalitätsrate um $74 \%$ von einigen kriminologischen Forschern unter Berücksichtigung allgemeiner Kriminalitätsentwicklung auf eine „echte“ Reduzierung um 21\% relativiert wurde.$^{308}$ Die angegebene Verdreifachung der Aufklärungsquote von Verbre-

\footnotetext{
${ }^{303}$ Büllesfeld (2002), S. 60; Brown (1995), S. 26.

${ }^{304}$ Müller (2002), S. 39.

${ }^{305}$ Ebenda, S. 40; Brown (1995), S. $34 \mathrm{ff}$.

${ }^{306}$ Büllesfeld (2002), S. 60; Brown (1995), S. 34 ff.

${ }^{307}$ Müller (2002), S. 40; Brown (1995), S. 34 ff.

${ }^{308}$ Büllesfeld (2002), S. 59. Nach einer anderen Angabe war auch von einem Kriminalitätsrückgang von 35\% in Airdrie die Rede, vgl. Müller (2002), S. 40; vgl. auch Ditton; Short (1998), S. 162.
} 
chen wurde durch die Evaluationsstudie auf eine Steigerung um ein Sechstel korrigiert. $^{309}$

Das erste Pilotprojekt zur polizeilichen Videoüberwachung öffentlicher Straßen und Plätze in Leipzig führte nach Angaben von Polizei zu einem Rückgang der Diebstähle und Kfz-Delikte um 50\%, wobei ein Verlagerungseffekt nicht festgestellt werden konnte. ${ }^{310}$ Nach der Beendigung des Pilotprojekts stieg die Zahl der erwähnten Straftaten wieder an, die nach der Wiedereinführung der Videoüberwachung erneut um 20\% sank. ${ }^{311}$ Aufgrund des Erfolgs in der Testphase wurden die Kameras zum Dauereinsatz eingeschaltet, wobei die Zahl der registrierten Delikte auf ein niedrigeres Niveau sank als vor der Einführung.

Auch die zusammenfassende NACRO-Studie ${ }^{312}$ vom Jahr 2002 über die Effektivität der CCTV-Systeme in Großbritannien zeigt ein ambivalentes Bild: Einerseits erwies sich die Videoüberwachung als effektives Werkzeug gegen Kfz-Delikte, vor allem auf Parkplätzen, andererseits übt die elektronische Observierung kaum Einfluss auf Raub- oder andere Gewaltdelikte aus. Einige Studien stellen den Verdrängungseffekt des Kameraeinsatzes fest und andere zeigen, dass die Videoüberwachung keinerlei Abschreckungseffekt auf manche kriminelle Handlungen hat. ${ }^{313}$

Es ist insgesamt eine offene Frage, ob nicht andere Maßnahmen zur allgemeinen Kriminalitätsvorsorge letztlich mehr Erfolg erzielen können; in manchen Fällen wird sogar ein Anstieg der Kriminalität durch die Anwendung von Videogeräten festgestellt. Nach polizeilichen Angaben wurde beispielsweise am Kölner Bahnhof nach der Einführung der Überwachungskameras eine Zunahme des Diebstahls festgestellt, während in dem bekannten englischen Badeort Brighton zwar insgesamt ein Rückgang der Kriminalität um 10\% in dem überwachten Gebiet zu verzeichnen ist, aber gleichzeitig auch ein leichter Anstieg der Gewaltdelikte um 1\% ${ }^{314}$ In Glasgow ist sogar eine erhöhte Strafanfälligkeit von $9 \%$ nach der Einführung von CCTVSystemen zu verzeichnen. Bei der Aufklärungsquote gibt es ebenfalls keine signifikante Steigerung festzustellen. ${ }^{315}$ Graham et al. argumentieren in diesem Zusam-

\footnotetext{
${ }^{309}$ Büllesfeld (2002), S. 59.

${ }^{310}$ Ein leichter Verdrängungseffekt wurde bei Drogendelikten festgestellt, der allerdings auf die verstärkte Polizeikontrolle zurückzuführen ist. Vgl. ebenda, S. 61; Nürnberg (2000), S. 230.

${ }^{311}$ Büllesfeld (2002), S. 63; Details zu Ergebnissen einzelner Deliktformen vgl. Müller (2000), S. 285 ff.; Müller (1997), S. 77 ff.

${ }^{312}$ Armitage (2002).

${ }^{313}$ Ebenda.

${ }^{314}$ Ebenda.

${ }^{315}$ McCahill; Norris (2002a), S. 4; Ditton; Short (1999), S. 201 ff. Mehr zur Evaluation in Glasgow vgl. auch The Scottish Office (1999); vgl. auch Müller (2002), S. 41; Ditton (2000), S. 692 ff.; Büllesfeld (2002), S. 61.
} 
menhang, "by encouraging people to have faith in some disembodied electronic eye, CCTV may actually undermine the natural surveillance in towns and communities. (...) The result may be a further spiral of social fragmentation and atomization, which leads to more alienation and even more crime. ${ }^{.316}$

Die Effektivität der Videoüberwachung als ein kriminalpräventives Werkzeug kann bislang also nicht mit Bestimmtheit bestätigt werden. Zwar gibt es Fälle, in denen die CCTV-Anlagen ihren kriminalistischen Nutzen unter Beweis stellen können, allerdings gibt es auch reichliche Beispiele, die das Gegenteil zeigen. Letztendlich kann keine allgemeingültige Aussage über die tatsächliche Wirkung der Videoüberwachungsgeräte auf das Kriminalitätsaufkommen getroffen werden, denn ein Rückgang der Verbrechensrate in dem überwachten Bereich muss stets unter Berücksichtung des gesamten Kontextes der Kriminalitätsentwicklung sowie der demographischen und anderen sozialen Faktoren betrachtet werden, die in den bisherigen Evaluationsstudien nur schwer realisierbar war. Denn eine deutlich niedrigere Kriminalitätsrate in der Überwachungszone als die in den benachbarten Gebieten kann zwar als positives Ergebnis der Videoüberwachung verstanden werden, aber ebenso auf einen möglichen Verdrängungseffekt hindeuten, der die Effektivität der technischen Observation wiederum relativiert. ${ }^{317}$

\subsubsection{Strafverfolgung}

Auch wenn die Effektivität der CCTV-Überwachung als kriminalpräventives Mittel nicht eindeutig bestimmt werden kann, so konnten anhand der Aufzeichnungen von den Überwachungskameras in einigen Fällen die Täter identifiziert werden.

Das Federal Building in Oklahoma City, USA wurde am 19. April 1995 zum Ziel eines Bombenanschlags. Der Lastwagen, der die explosiven Stoffe zum Tatort transportiert hatte, konnte für eine lange Zeit nicht identifiziert werden. Dank einer privaten Überwachungskamera eines dem Gebäude nahe liegenden Wohnhauses (Regency Towers Apartment Building) konnte der Lastwagen kurz vor der Explosion auf Band festgehalten werden, was für die weitere Verfolgung des Attentäters von großer Bedeutung war. ${ }^{318}$ Sechs Jahre später wurden die bisher größten Terroranschläge auf die USA in New York City und Washington D.C. ausgeübt, wobei die CCTVSysteme zwar die Angriffe nicht verhindern konnten, aber dennoch zur Identifizierung der Terroristen beigetragen haben.

\footnotetext{
${ }^{316}$ Graham et al. (1995), S. 22 f.; vgl. auch Ditton (2000), S. 707.

${ }^{317}$ Vgl. Frerichs (2000), S. 78, 85; Büllesfeld (2002), S. 62 f.

318 Thomas (1997); Burrows (1997), Rn. 1123.
} 
Auch bei dem bekannten Mordfall Jamie Bulger ${ }^{319}$ in England sowie bei den Terroranschlägen auf die Londoner U-Bahn im Sommer 2005 dienten CCTV-Anlagen als nutzbare Werkzeuge zur Strafverfolgung. In Norwegen konnten dank CCTVAufzeichnungen die Diebe des Meisterwerks „Der Schrei“ von Edvard Munch gefasst werden. ${ }^{320}$

\subsubsection{Einsatz von CCTV-Systemen zur Reduzierung von Kriminalitäts- furcht}

Nicht nur die Verbrechensbekämpfung steht im Mittelpunkt bei der Praxis der Videoüberwachung, auch die Angst in der Bevölkerung, der Kriminalität zum Opfer zu fallen, genügt häufig als Rechtfertigung für die Installation dieser technischen Überwachungseinrichtungen. ${ }^{321}$ Das Sicherheitsbedürfnis zählt wie erwähnt zu den grundlegenden Bedürfnissen der Menschen und die (empfundene) Sicherheit kann die gesamte Lebensqualität stark beeinflussen. Die Gewährleistung des Sicherheitsgefühls der Bürger gehört wie die Bekämpfung von Kriminalität zu dem Zuständigkeitsbereich der Polizei.

Zur Überprüfung der Effektivität der Videoüberwachung auf das Sicherheitsgefühl der Bürger stammen die meisten Erkenntnisse ebenfalls aus britischen Studien. Allerdings handelt es sich auch hierbei nur um eine geringe Anzahl von Untersuchungen, woraus sich keine eindeutige Aussage über die Wechselbeziehung zwischen der subjektiven Kriminalitätsangst und dem Einsatz weiträumiger Observationseinrichtungen treffen lässt. Dieses insgesamt ambivalente Bild soll anhand der folgenden Fälle skizziert werden.

Während in Birmingham die Einwohner sich durch CCTV-Überwachung sicherer fühlen und die videoüberwachten Stadtteile bei ihrem Aufenthalt in der Innenstadt bevorzugen, stieg in Glasgow zwei Jahre nach der Einführung von Überwachungskameras die Anzahl der Menschen, die zu bestimmten Zeiten ausgerechnet solche Bereiche mit Überwachungskameras meiden. ${ }^{322}$

Ein positiver Effekt der Videoüberwachung auf das Sicherheitsempfinden der Überwachten konnte in Sutton gefunden werden, wobei 73,6\% der Befragten dies bejah-

\footnotetext{
${ }^{319}$ Vgl. Teil I, Kap. 3.3.2.2 dieser Arbeit.

${ }^{320}$ Burrows (1997), Rn. 1123.

${ }^{321}$ Graham (1998), S. 91; Gras (2003), S. 211.

${ }^{322}$ Mehr zur Evaluation in Birmingham vgl. Brown (1995), S. 35 ff. Zu den Ergebnissen in Glasgow vgl. Ditton (2000), S. 689 ff. Allerdings muss hierbei vermerkt werden, dass das CCTV-System in Glasgow zwei Jahre nach der Einführung lediglich einem Drittel der dortigen Einwohner bekannt war, so dass die Mehrheit der Stadtbewohner in Glasgow nicht für die Wirkung der CCTV-Überwachung auf deren Sicherheitsempfinden untersucht werden konnte. Vgl. hierzu The Scottish Office (1999).
} 
ten. ${ }^{323}$ Ein ähnliches Ergebnis wurde in Cambridge erzielt. ${ }^{324}$ Nachdem eine Londoner U-Bahn-Linie mit CCTV-Systemen ausgestattet war, stieg die Zahl der Fahrgäste, die sich dadurch sicherer fühlten. ${ }^{325}$

Weitere Umfragen können die Tendenz bestätigen, dass CCTV-Überwachung scheinbar das subjektive Sicherheitsgefühl der Menschen erhöht. ${ }^{326}$ Allerdings gibt es auch Gegenbeispiele, wie in Brighton, wo sich 48\% der Bewohner nach einem Jahr technischer Observation immer noch nicht sicherer fühlten, obwohl 85\% der Befragten durchaus die Existenz der Kameras wahrgenommen hatten. ${ }^{327}$ Trotz der großen Akzeptanz der lokalen CCTV-Anlagen in Glasgow zeigte sich auch bei den Bürgern dort, nach einer Studie von Ditton, langfristig keine Verbesserung des Sicherheitsempfindens. ${ }^{328}$

Insgesamt konnten Forscher feststellen, dass mehr ältere Menschen sich durch die Kameras in den öffentlichen Räumen sicherer fühlen. ${ }^{329} \mathrm{Im}$ Gegensatz dazu führt der Einsatz von Überwachungskameras bei den Frauen nicht unbedingt zur Steigerung ihres Sicherheitsempfindens. Brown fand in ihrer Studie heraus, dass Frauen sich trotz Videoüberwachungsmaßnahmen vor Stadtzentren und öffentlichen Verkehrsmitteln fürchten. ${ }^{330}$

\subsubsection{Zusammenfassung}

Nach der vorigen Analyse kann die CCTV-Überwachung weder in Hinsicht auf die Reduzierung der Kriminalitätsrate noch bezüglich der Verbesserung des Sicherheitsgefühls der Bürger eindeutig als ein erfolgreiches Instrument bestätigt werden. Vielmehr zeigt eine Vielzahl von Untersuchungen und Befragungen ein sehr ambivalentes Bild im Hinblick auf die Wirksamkeit dieses kriminalpräventiven Instruments in der Sicherheitspolitik. Dennoch ist in allen drei zu untersuchenden Nationen - USA, Großbritannien und Deutschland - eine steigende Tendenz der Nutzungsintensität von Überwachungskameras zu verzeichnen, so dass die Vermutung nahe liegt, dass letztlich im sicherheitspolitischen Trend der Kriminalprävention der Frage der Effektivität wenig Bedeutung beigemessen wird. Vor allem für die britischen Behörden, die das Instrument zum festen Bestandteil ihrer Sicherheitspolitik erklärt haben,

\footnotetext{
${ }^{323}$ Gras (2003), S. 190.

${ }^{324} 67 \%$ der Befragten in Cambridge fühlen sich sicherer durch CCTV-Überwachung, vgl. Ebenda, S. 191.

${ }^{325}$ Ebenda, S. 190.

${ }^{326}$ Ebenda, S. 190 f.

${ }^{327}$ Ebenda.

${ }^{328}$ Ditton (2000), S. $692 \mathrm{ff}$.

${ }^{329}$ Honess; Charman (1992), S. 19 ff.

${ }^{330}$ Brown (1998), S. 207 ff.
} 
scheint der tatsächliche, kriminalistische Nutzen nicht das ausschlaggebende Argument für ihre Entscheidung zur weiträumigen Videoüberwachung zu sein.

Angesichts der polizeieigenen Begleitstudie zum ersten Pilotprojekt in Leipzig, das erst nach einer Testphase mit positiven Ergebnissen als Dauermaßnahme eingeführt wurde, sowie die Beendigung der Videoüberwachungsmaßnahmen (z.B. in Stuttgart und Singen) nach erfolgreicher Reduzierung der Kriminalität, ist ein vorsichtigerer Umgang mit dieser Technik seitens der deutschen Polizei zu vermuten. Manche USamerikanische Polizeidienststelle zeigt ebenfalls in der Gegenüberstellung zu Großbritannien mehr Skepsis gegenüber der Wirksamkeit der Videoüberwachung. In Detroit und Miami Beach wurde beispielsweise der öffentliche Einsatz von Überwachungskameras aufgrund der Ineffektivität bzw. des unklaren kriminalistischen Nutzens abgebrochen. ${ }^{331}$

Zusammenfassend stellt der Kameraeinsatz in öffentlichen Räumen einen strukturellen Wandel der Sicherheits- und Kriminalpolitik in allen drei Ländern dar. Die Effektivitätsfrage von Videobeobachtungsmaßnahmen kann allerdings bisher weder in Hinsicht auf die Kriminalitätsentwicklung noch bezüglich der Besserung des Sicherheitsgefühls von Bürgern eindeutig geklärt werden. In der Gegenüberstellung zu der extremen Nutzungsintensität von CCTV-Systemen scheinen manche deutschen und US-amerikanischen Sicherheitsbeamte insgesamt mehr Vorbehalte gegenüber der Wirksamkeit dieser Technik zu zeigen als ihre britischen Kollegen. Es ist fraglich, ob letztlich andere kriminalpräventive Maßnahmen mit geringeren sozialen und finanziellen Kosten die gleichen oder gar besseren Ergebnisse zur Steigerung des Sicherheitsempfindens der Menschen erzielen könnten.

${ }^{331}$ Vgl. Teil I, Kap. 3.2.2.4 dieser Arbeit. 


\section{$5 \quad$ Nebenfolgen der Videoüberwachung}

Der erwähnte Paradigmenwechsel der Sicherheits- und Kriminalpolitik von reaktiven zu präventiven, proaktiven Strategien beeinflusst nicht nur die Politik der „inneren Sicherheit", sondern auch andere Bereiche des gesellschaftlichen Zusammenlebens. Die Erweiterung polizeilichen Handlungspielraums sowie die Einführung von neuen Überwachungsinstrumenten haben neben dem offensichtlichen Nutzen, der allerdings nicht eindeutig bestimmt werden kann, auch Schattenseiten. In diesem Teil wird die Frage untersucht, welche Nebenfolgen die kriminalpräventiven Videoüberwachungsmaßnahmen mit sich bringen. Dabei ist es wichtig anzumerken, dass die folgende Darstellung im Gegensatz zum letzten Kapitel nicht durch empirisch nachweisbare Untersuchungen belegt werden kann, sondern lediglich auf einzelnen Beispielen beruht.

\subsection{Diskriminierung von Minderheiten}

Die Überwachungsarbeit in Kontrollräumen erfolgt nach den Ergebnissen der Studie "The Unforgiving Eye" von Norris \& Armstrong oft selektiv. ${ }^{332}$ "[J]unge Leute, Schwarze, Schwule und andere Minderheiten ${ }^{\iota 333}$ geraten nicht selten aufgrund ihrer Bekleidung ins Visier der Überwacher, während „Leute mit Hemd und Schlips“ als unauffällig durchgehen. ${ }^{334}$ Dabei dienen oftmals die persönlichen Vorurteile als Richtlinien für die Interpretation bestimmter Verhaltensweisen und zur Typisierung gewisser Personen. Entscheidend für die Selektion ist häufig nicht das Verhalten an sich, sondern das Erscheinungsbild der Überwachten, das sich mit einem bestimmten (unerwünschten) Verhaltensmuster assoziieren lässt.

Während die Polizei die Notwendigkeit des breiten Einsatzes von Videokameras in der Kriminalität und den Sicherheitsbedürfnissen der Bürger begründet sieht, rechtfertigen Einzelhändler den Kameraeinsatz mit der Tatsache, dass im innerstädtischen Einkaufsgebiet im Vergleich zu anderen attraktiveren und sichereren Standorten, wie die von Sicherheitspersonal bewachten Einkaufszentren in den suburbanen Bezirken, immer weniger Umsätze erzielt werden konnten. ${ }^{335}$ Tatsächlich zeigt Reeve in seiner Untersuchung über den ökonomischen Nutzen von CCTV-Überwachung, dass Konsum der Hauptzweck für Besuche in der Innenstadt darstellt. ${ }^{336}$ Es ist deswegen nicht verwunderlich, dass besonderer Wert auf den „Wohlfühl-Faktor“ der Konsumenten

\footnotetext{
${ }^{332}$ Norris; Armstrong (1999b), S. 95 ff. ; Wehrheim (2002), S. $91 \mathrm{ff}$.

${ }^{333}$ Schulzki-Haddouti (1998), S. 85 ; vgl. auch Wehrheim (2002), S. 91; Graham (1998), S. 101.

${ }^{334}$ Ebenda.

${ }^{335}$ Poole; Williams (1996), S. 29 ff.

${ }^{336}$ Reeve (1998b), S. $69 \mathrm{ff}$.
} 
im Rahmen des britischen Town Centre Management gelegt wird und z.B. die Werbung für die technische Observierung in Glasgow „CCTV doesn't just make sense it makes business sense" lautet. $^{337}$

Viele öffentliche und halb-öffentliche Räume werden also zunehmend mit Videokameras ausgerüstet, um eine angenehme und sicher empfundene Einkaufsatmosphäre für die potentiellen Kunden zu schaffen, während andere sozial „unerwünschte Randgruppen“, z.B. Obdachlose, Betrunkene und Punks, oft zum Erhalt des Images einer "sauberen und sicheren Stadt" aus dem Blickfeld der Kunden und Besucher verbannt werden sollen. Die Selektion zum Wohl der gesitteten und konsumfähigen Bürger wirft die Frage auf, wem der öffentliche Raum gehört. ${ }^{338}$

Es droht bei einer weiträumigen Überwachung durch Videotechnik zur Gefahrenabwehr die Entstehung unterschiedlich sicherer bzw. sicher empfundener Räume. Die Abwesenheit von sozial auffälligen Gruppen wird meistens mit Sicherheit gleichgesetzt, und die Videoüberwachung dient hierbei nicht nur als ein Verhütungsmittel gegen sicherheitsgefährdende Vorkommnisse, sondern führt in den meisten Fällen zwangsläufig zur Ausgrenzung von Individuen und Diskriminierung bestimmter sozialer Minderheiten, die keine direkte Gefahr für die Gesellschaft darstellen, aber von der Mehrheit der Bevölkerung als solche wahrgenommen werden. Die Observierung der Räume via Videotechnik setzt in den Augen der Kritiker deshalb eine allgegenwärtige Kontrolle des sozialen Verhaltens der Bürger in Gang. Jeder, der im öffentlichen Raum sich anders benimmt als die Mehrheit, sieht sich gezwungen, seine auffallende Verhaltensweise zu rechtfertigen. ${ }^{39}$ Die Rechte der Bürger, die ungewöhnliches Benehmen zeigen bzw. durch ihr äußeres Erscheinungsbild aus der Menge hervorragen, werden den allgemeinen Sicherheitsbedürfnissen oder gar den eigenen Regeln des Überwachers untergeordnet. Davies spricht in diesem Zusammenhang von einer „Politik sozialer Ausgrenzung“ und „Militarisierung des öffentlichen Lebens". ${ }^{340}$

\footnotetext{
${ }^{337}$ Bannister et al. ebenda, S. 30; vgl auch Wehrheim (2002), S. 89.

${ }_{338}$ "Die Feststellung, dass öffentlicher Raum zu bestimmten Zeiten für einige Gruppen mit Angst verbunden wird - was nicht nur Frauen betrifft - darf nicht dazu führen, dass dieser Raum dann nur aus dieser Perspektive geplant werden soll. Schließlich dient der gleiche Ort Obdachlosen oder Drogensüchtigen, die gar keinen privaten oder halb-öffentlichen Raum zur Verfügung haben, als letzter und teilweise lebenswichtiger Rückzugsraum." Diese Meinung von Eickhoff wird allerdings angesichts zunehmender Installation visueller Überwachungstechnologien nicht von der Mehrheit der Gesellschaft geteilt. Eickhoff (1998), S. 21; vgl. auch Wehrheim (2002), S. 208.

${ }^{339}$ Vgl. Bäumler (1999), Norris; Armstrong (1999b), S. 205 ff.

${ }^{340}$ Englische Originale: "policing of social boundaries" und "the militarization of street life", Davis (1990), S. 223; vgl. auch Coleman; Sim (2000), S. 634.
} 
Im Zuge der erwähnten Betonung der kriminalpräventiven Elemente in der Sicherheitspolitik entwickeln sich Kooperationsformen zwischen den Kommunalbehörden und Polizeidienststellen, die in Großbritannien beispielsweise unter dem Begriff „Safer Cities Programme“ bekannt sind. In manchen Fällen werden auch die lokalen Einzelhändler eingebunden, die in vielen Projekten der Videoüberwachung eine wichtige Finanzierungsquelle darstellen. ${ }^{341}$ Im Auftrag der „inneren Sicherheit“ und unter Berufung auf Sicherheitsbedürfnisse der Bürger fokussiert der Blick solcher Kontrollgemeinschaften auf einzelne, auffällige Individuen. Ausgehend von der subjektiven Wahrnehmung und Kriminalitätsfurcht wird unter polizeilicher Leitung der Begriff der „sozialen Ordnung“ neu definiert und im Vorfeld potentielle Risikogruppen im Sinne der neuen Sicherheitspolitik kontrolliert und ggf. verdrängt.

Die exklusive Nutzung "sauberer“ und „sicherer“ Räume scheint im Sinne der Videoüberwachung nur für die normkonformen Bürger vorgesehen. Nachdem die auffälligen Randgruppen vertrieben wurden, geht es anschließend um die Einhaltung der vorgegebenen Regeln in dem überwachten Bereich. Wer nicht die von Überwachern bestimmten Regeln beachtet, dem droht ebenfalls das Schicksal der Vertriebenen. „Im Nottinghamer Stadtteil Broxtone ist die Abgleichung des Kamerabildes mit der gesetzten Norm bereits Realität: Eltern, deren Kindern sich häufiger zusammenrotten, eher in Raufereien verstrickt sind oder wiederholt bei Diebstählen beobachtet werden, wird mit Kündigung gedroht. Ändert sich nichts oder werden einzelne Kinder straffällig, fliegt auch der Rest der Familie auf die Straße. Sippenhaftung als Möglichkeit der ,Wohnfeldverbessserung'. Und als Alternative zu vorsorgender Verbrechensbekämpfung: Verlagerung. ${ }^{\prime 342}$ Demnach handelt es sich bei Videoüberwachung lediglich um eine technische Notlösung der sozialen Probleme, die meistens nicht nur die Kriminalität, sondern auch damit verbundene gesellschaftliche Probleme verdrängt, wobei notwendige soziale Prozesse zur tatsächlichen Konfliktbeseitigung ausbleiben. ${ }^{343}$

\subsection{Eingriff in die Persönlichkeit und „Privatheit“}

Mit der "Theorie der objektiven Selbstaufmerksamkeit" beschreiben Psychologen ein Phänomen, das von vielen Kritikern der Videoüberwachungsmaßnahmen als negative Folge einer weiträumigen technischen Observierung befürchtet wird, und zwar dass langfristig die Psyche der Überwachten verändert werden könnte. Diese Theorie besagt, dass, wenn sich ein Mensch seiner ständigen Überwachung bewusst wird, er

\footnotetext{
${ }^{341}$ Vgl. Teil III, Kap. 10.3.1.3 dieser Arbeit.

${ }^{342}$ Sack et al. (1997), S. 318.

${ }^{343}$ Mehr zum Thema sozialer Segregation vgl. Wehrheim (2002), S. 27 ff.
} 
sich dann als Objekt wahrnimmt und sich dementsprechend normgerecht verhält. Eine unter Beobachtung stehende Person, so vermuten Psychologen, wird insgesamt umsichtiger, furchtsamer und argwöhnischer. ${ }^{344}$ Die Videoüberwachung (im Dauerbetrieb), die im Gegensatz zu gewöhnlichen polizeidienstlichen Tätigkeiten permanent und anonym durchgeführt werden kann, ist somit ein typisches Beispiel für die Gefährdung individueller Handlungsfreiheit.

Diese Verhaltensänderungen werden häufig auch mit Hilfe des panoptischen Prinzips erklärt. Im Sinne von Foucault gilt für viele Forscher Videoüberwachung als Musterbeispiel für die Disziplinierung eines überwachten Menschen. ${ }^{345}$ Selbst wenn die Überwachungsarbeit an Monitoren nicht kontinuierlich durchgeführt wird, kann die Wahrnehmung visueller Überwachungseinrichtungen oder das Gefühl, permanent unter Beobachtung zu stehen, panoptische Disziplinierungseffekte auslösen. ${ }^{346}$ Auch Erving Goffmann, der das menschliche Verhalten in der Öffentlichkeit und im Privatleben analysierte, vertritt die Ansicht, dass Menschen unter einer kontinuierlichen Observierung auffallend ihre Verhaltensweise modifizieren. ${ }^{347}$

In diesem Sinne sehen Datenschützer und Bürgerrechtler die durch die Videoüberwachung entstandene Verhaltensänderung der Bürger als Eingriff in das Recht der Persönlichkeitsentfaltung. Manche sprechen sogar in diesem Zusammenhang von der Einschränkung der Demonstrations- und Versammlungsrechte der Bürger. Da das Gefühl, bei der Teilnahme an politischen Veranstaltungen und Massenkundgebungen gefilmt zu werden, „die Hemmschwelle der demokratischen Partizipation“ beeinflussen und somit die demokratischen Grundzüge gefährden könnte. ${ }^{348}$

Privatheit gilt als ein fester Bestandteil des schutzbedürftigen Persönlichkeitsrechts. Nach Westins Definition beinhaltet der Begriff Privatheit u.a. das Recht eines Indivi-

\footnotetext{
${ }^{344}$ Büllesfeld (2002), S. 75; Höfling (2000), S. 36.

${ }^{345}$ Für Foucault stellt die architektonische Idee des „Panopticons“ von Jeremy Bentham, das ursprünglich im Jahr 1789 als Konstruktion von Gefängnisbauten konzipiert worden war, ein idealtypisches Modell jener Architektur dar, die die Machttechniken der Disziplinargesellschaft zum Ausdruck bringt. Durch die spezielle architektonische Gestalt des Panopticons kann jede kleine Bewegung in den Zellen von einem Turm aus überwacht werden. Diese Art der Raumorganisation erlaubt dem Aufseher, seine wirkungsvolle Kontrolle über die Körper in den Zellen auszuüben, da der Sträfling damit rechnen muss, dass er bei jedem Regelverstoß sofort bestraft werden kann. Die Hauptwirkung des Panopticons ist nach Foucault „die Schaffung eines bewussten und permanenten Sichtbarkeitszustandes beim Gefangenen, der das automatische Funktionieren der Macht sicherstellt". Foucault (1994), S. 258. Das Individuum in der Zelle weiß nicht, wann es beobachtet wird und wann nicht, da das Panopticon so gebaut ist, dass die An- oder Abwesenheit eines Aufsehers nicht von den Insassen in den Zellen wahrgenommen werden kann. Der Gefangene muss sich also so verhalten, als sei die Kontrolle permanent, endlos und vollkommen. Der Machtapparat funktioniert auch in Abwesenheit des Aufsehers. Allein die antizipierte Möglichkeit einer Beobachtung und des sofortigen Eingreifens funktioniert als Kontrollmechanismus: Der Gefangene kontrolliert sich selbst.

${ }^{346}$ Vgl. Wehrheim (2002), S. 209.

${ }^{347}$ Goffman (1971); vgl. auch Wehrheim (2002), S. 94.

${ }^{348}$ Lietz (2004).
} 
duums, frei von jeglichen Beobachtungen zu sein (Alleinsein) und in einer großen Menschenmenge die eigene Identität nicht verraten zu müssen (Anonymität). ${ }^{349}$ Bisher gehört es zu den Eigenschaften von Großstädten, dass die Menschen dort durch eine gewisse Anonymität ihre Privatheit genießen können. Durch die geringere soziale Kontrolle (im Sinne von "Neighbourhood-Watch", die in einem Dorf stärker ausgeprägt ist,) haben Menschen in Großstädten mehr „Freiheit für Abweichung und Veränderung“ und die "Möglichkeit, durch den Wechsel des Wohnortes ihre Vergangenheit hinter sich zu lassen“. ${ }^{350}$ Die Ausweitung von CCTV-Überwachung in städtischen Räumen sowie die damit verbundene präventive Ausrichtung der bereits erwähnten lokalen Sicherheitskooperationen, so die Befürchtung der Datenschutzund Bürgerrechtsorganisationen, könnten diese Möglichkeiten einschränken und die Bedeutung dieser öffentlichen Anonymität verändern.

Wie komplex der Begriff „Privatheit“ ist und wie problematisch die rechtliche Definition und der Schutz dieses Persönlichkeitsrechts in Hinblick auf die aufdringliche Wirkung moderner Überwachungstechnologie sein kann, zeigen US-amerikanische Gerichtsentscheidungen zum „Right of Privacy“:

Im Jahr 1890 wurde in „Harvard Law Review“ ein Aufsatz mit dem Titel „The Right to Privacy“ von Samuel Warren und Richter Louis Brandeis veröffentlicht, der einen enormen Einfluss auf die Rechtsentwicklung des Datenschutzes in den USA ausübte. ${ }^{351}$ In diesem Aufsatz betonten die Verfasser das Recht des Einzelnen auf seine Privatsphäre und plädierten dafür, dass die Verletzung der Privatsphäre (z.B. durch die Regenbogenpresse) als kompensierbare, unerlaubte Handlung gesehen werden sollte. Um eine Prozessflut und mögliche Einschränkung der Pressefreiheit zu vermeiden, blieb das Recht auf Privatsphäre allerdings lange ein außergerichtliches Thema. $^{352}$

Im Jahr 1928 erkannte man im Olmstead-Urteil die Gefahren, die moderne Überwachungstechniken mit sich bringen könnten: „Subtilere und weitreichendere Mittel

\footnotetext{
${ }^{349}$ Nach Westin kann die Privatheit einer Person erreicht werden, wenn 1) eine Person frei von jeglichen Beobachtungen und Anwesenheit anderer sein kann (Alleinsein), 2) ein Individuum in einer kleinen Gruppe, z.B. Familie oder Freundeskreis, Geborgenheit findet (Intimität), 3) ein Mensch in einer großen Menschenmenge die eigene Identität nicht verraten muss (Anonymität), oder 4) der Wunsch nach Kommunikationslosigkeit in einer Gruppe respektiert und akzeptiert werden kann (Reserviertheit oder Zurückhaltung). Westin (1967), S. 7; vgl. auch Gräf (1993), S. 11 ff.

${ }^{350}$ Wehrheim (2002), S. 91.

${ }^{351}$ Burrows (1997), Rn. 1084; Nieto et al. (2002), S. 40; Original vgl. Brandeis, Louis; Warren, Samuel (1890): „The Right to Privacy“, 4 Harvard Law Review, 193 (1890).

${ }^{352} \mathrm{Im}$ Jahr 1903 wurde vom Staat New York erstmals ein Gesetz erlassen, das die Anwendung von Namen und Bildern von Personen für Geschäfts- und Werbezwecke ohne deren Zustimmung für schadensersatzpflichtig erklärt. Drei Jahre später wurde in einem Gerichtsurteil in Georgia, dem die Thesen des Aufsatzes „,The Right to Privacy“ zu Grunde lagen, zum ersten Mal in den USA das Recht auf Privatsphäre anerkannt. Vgl. Nieto et al. (2002), S. 40 ff.; Rossnagel (2003), S. 34.
} 
zur Beeinträchtigung der Privatsphäre sind für die Regierung verfügbar geworden. Entdeckung und Erfindung haben es den Regierenden durch Mittel, die viel effektiver als die Streckbank sind, ermöglicht, vor Gericht herauszufinden, was im Hinterzimmer geflüstert worden ist. ${ }^{4353}$ Der Begriff "Privacy" wurde von ihm als "the most comprehensive of rights and the right most valued by man" bezeichnet. ${ }^{354} \mathrm{Im}$ Jahr 2001 betonte der Richter Antonin Scalia im Jahr erneut die Balance zwischen Technik und Privatsphäre: „The question we confront today is what limits there are upon this power of [surveillance] technology to shrink the realm of guaranteed privacy. ${ }^{\prime 355}$

Angesichts der Leichtigkeit und Schnelligkeit, mit denen Informationen im Zuge der Videoüberwachung gesammelt, gespeichert und verbreitet werden, ist es also fraglich, ob Privatheit bzw. Anonymität in diesem Sinne überhaupt noch existieren. Heute lässt die moderne Überwachungstechnologie die Grenze zwischen Öffentlichkeit und Privatheit nicht mehr klar definieren und das Individuum hat keine Kontrolle mehr über die Anfertigung, Speicherung und Verbreitung seiner persönlichen Informationen, die seine Persönlichkeitsrechte gefährden könnten. Kritiker sehen deswegen in den Videobeobachtungsmaßnahmen eine Bedrohung freiheitlichdemokratischer Grundprinzipien, die aus einer informationellen Asymmetrie zwischen Staat und Bürgern herrührt. Durch die Implementierung der Überwachungskameras wird der polizeiliche Handlungsspielraum ausgeweitet, der dem Staat erlaubt, mehr Informationen von Bürgern zu sammeln, um potentielle Gefahren und Risiken zu erkennen. Zudem sind die Zuständigkeiten sowie der Datenverkehr der Videoüberwachungsnetzwerke für die Bürger undurchschaubar, so dass sie mögliche Missbräuche dieser Technik seitens des Staates nicht prüfen können und die damit verbundenen Risiken stillschweigend hinnehmen müssen. Durch den Vorrang der kriminalpräventiven Ziele der räumlichen Observierung werden Grundrechte der Bürger, wie z.B. die Freiheit vor staatlichen Übergriffen, in den Hintergrund gedrängt.

\subsection{Missbrauch von CCTV-Anlagen}

Zusätzlich zu Eingriffen in die Privatsphäre sowie Diskriminierung von sozialen Randgruppen kann zweckentfremdete Nutzung von Überwachungskameras zu Problemen führen. Der häufigste Missbrauch der visuellen Überwachungstechnik dient dem voyeuristischen Zweck und dieser wird nicht nur vom privaten Sicher-

\footnotetext{
${ }^{353}$ Vgl. Banisar (1998), S. 19 ff.

${ }^{354}$ Olmstead v. United States, 277 U.S. 438, 478 (1928), vgl. Nieto et al. (2002), S. 40.

${ }^{355}$ Ebenda, S. 37.
} 
heitspersonal, sondern auch von Polizeibeamten praktiziert. ${ }^{356}$ Brown argumentierte sogar in ihrer Untersuchung über das Sicherheitsempfinden der Geschlechter in Städten, dass die von männlichen Kontrolleuren dominierte Überwachungsarbeit an Monitoren wenig zum verbesserten Sicherheitsgefühl der weiblichen Überwachten beiträgt. ${ }^{357}$ Ganz im Gegenteil könnte sogar der männliche Blick ein negativer Faktor für die empfundene Sicherheit der Frauen sein. Brown begründet, „indeed, in one sense it [CCTV] is a part of the male gaze, and therefore part of the problem rather than the solution“. 358

In vielen Fällen werden Aufnahmen von CCTV-Systemen nicht vernichtet, sondern an Fernsehsender zur Veröffentlichung weitergegeben. ${ }^{359}$ Es ist in Großbritannien alltäglich geworden, in den Fernsehnachrichten CCTV-Aufzeichnungen von Mordopfern oder Verdächtigen zu zeigen. ${ }^{360}$ Die Aufzeichnungen der ermordeten Moderatorin Jill Dendo ${ }^{361}$ und des kleinen Jungen Jamie Bulger ${ }^{362}$ lieferten medienwirksame Bilder, die die britische Öffentlichkeit davon überzeugten, dass es sich hierbei um ein unverzichtbares Mittel in der Kriminalitätsbekämpfung handelt. Britische Fernsehsendungen wie "Crime Watch“ oder "Crimestopper", bei denen die Zuschauer anhand von Videoaufzeichnungen tatrelevante Hinweise an die Polizei geben können, machen Videoüberwachungsanlagen in den Augen der Bürger zu einem Helfer der Polizei und somit auch zu einem notwendigen Instrument der öffentlichen Sicherheit und Ordnung. ${ }^{363}$ Allerdings gibt es auch andere Fernsehsendungen wie "Crime Beat" oder „Eye Spy“, bei denen die Zuschauer durch die aufgezeichnete Vorgehensweise und Verhaftung von Kriminellen auf CCTV-Videobändern unterhalten werden. Die-

\footnotetext{
${ }^{356}$ Beispiele zu Missbrauch von CCTV-Überwachung in den USA vgl. Burrows (1997), Rn. 1119, Rn. 1110, Fn. 244.

${ }^{357}$ Brown (1998), S. 218.

${ }^{358}$ Ebenda.

${ }^{359}$ Mehr zu Einschränkungen der Weitergabe bzw. der Aufbewahrungszeit von Aufzeichnungen vgl. Teil III, Kap. 10.1.2.1, Kap. 10.2.2.1, Kap. 10.3.2.1 dieser Arbeit.

${ }^{360}$ Die Rolle der journalistischen Medien darf bei der Verbreitung der Videoüberwachung nicht unterschätzt werden und bedarf einer differenzierten Analyse. Die britischen Medien dienen nicht nur als Plattform für CCTV-Befürworter, diese Technik in der Öffentlichkeit als geeignetes Präventionsmittel darzustellen; durch die häufige Verwendung der aus den CCTV-Anlagen stammenden Aufzeichnungen als Unterhaltungsmaterial im Fernsehen steigt der Bekanntheitsgrad der Technologie. Es ist deswegen nicht verwunderlich, dass CCTV-Überwachung die wohl populärste und am meisten Vertrauen erweckende kriminalpräventive Technik für die britische Öffentlichkeit geworden ist. Die Kriminalität auf regionaler Ebene wird nicht selten vor der Einführung der CCTV-Systeme von den am Einsatz dieser Technik interessierten Akteuren in der Lokalpresse akzentuiert, wobei die Videoüberwachung gleichzeitig als praktische Lösung propagiert wird. Die Videoüberwachung hat ihren Bekanntheits- und Beliebtheitsgrad sowie ihre starke öffentliche Unterstützung der Berichterstattung auf nationaler Ebene zu verdanken. Vgl. hierzu Graham (1998), S. 90; Coleman (2004), S. 129 ff.; 163.

${ }^{361}$ Vgl. Teil I, Kap.3..3.2.1 dieser Arbeit; vgl. auch Krons (2000); Gras (2003), S. 115.

${ }^{362}$ Vgl. hierzu Teil I, Kap. 3.3.2.2 dieser Arbeit; vgl. auch Coleman (2004), S. 106, 153; vgl. auch Levin (2002); Gras (2003), S. 33.

${ }^{363}$ Norris; Armstrong (1999b), S. 67 ff.
} 
se dienen in erster Linie nicht der Aufklärung von Straftaten, was das eigentliche Ziel der Videoüberwachung sein sollte, sondern dem Entertainment des Publikums. ${ }^{364}$

\section{$5.4 \quad$ Umgestaltung der Polizeiarbeit}

Die britischen Polizisten, die von den Bürgern liebevoll als „Bobby“ bezeichnet werden, genießen bisher ein positives Ansehen bei der Bevölkerung. ${ }^{365}$ Dieses Vertrauen verdanken sie ihrer bürgernahen Gegenwart sowie ihrer traditionell großen Zurückhaltung bei privaten und politischen Angelegenheiten. ${ }^{366}$ Die umfassenden Videoüberwachungsnetze in Großbritannien gefährden jedoch solche bürgernahe Polizeiarbeit. Das Vertrauen der Bürger in die Polizei kann unter der "Automatisierung“ polizeilicher Kontrolle durch CCTV-Überwachung leiden, falls nicht zusätzliches Personal eingesetzt wird. Die Akzeptanz von Videoüberwachungsmaßnahmen ist zwar allgemein hoch, aber die Polizeipräsenz wird meistens bevorzugt. ${ }^{367}$ Der direkte, freundliche Kontakt zu Bürgern verschafft der Polizei letztlich mehr Vertrauen von Bürgern als die technische Lösung gegen die Kriminalität.

Die räumliche Observierung via Videotechnik verändert außer der beeinträchtigten Interaktion mit den Bürgern auch die sonstigen polizeidienstlichen Tätigkeiten: Während für manche polizeilichen Dienststellen in Großbritannien die Einführung der optisch-elektronischen Einrichtungen eine Entlastung bedeutete wie im Fall West Yorkshire Police in Bingley ${ }^{368}$, beklagten andere die zusätzliche Arbeit durch Überwachung der Monitore, Auswertung des Datenmaterials sowie vermehrte Einsätze durch CCTV-bedingte Entdeckungen von Straftaten. ${ }^{369}$ Es ist zweifelhaft, wie effektiv die Polizei neben der zusätzlichen Arbeit an Monitoren noch ihre sonstigen Tätigkeiten zur Bekämpfung von Kriminalität bewältigen kann. In vielen CCTV-

\footnotetext{
${ }^{364}$ Hierdurch wird eine Atmosphäre geschaffen, in der CCTV-Überwachung in den Augen der Zuschauer freundlich, amüsant und vertraut wirkt. Nur selten werden in den Medien Videoüberwachungsanlagen in Zusammenhang mit polizeilicher Überwachung von Demonstrationen oder dem Vertreiben von Jugendlichen in Gruppen oder Obdachlosen aus bestimmten Einkaufszonen gebracht. Norris \& Armstrong haben in ihrer Untersuchung belegt, dass in den meisten britischen Medien Videoüberwachung positiv dargestellt wird. Ein Sprecher eines CCTV-Unternehmens freute sich über eine Fernsehsendung, die "die öffentliche Überwachung als einen ,Ritter in glänzender Panzerung' darstellt, sowohl, was den Kampf gegen Kriminalität, als auch den Kampf gegen Kriminalitätsfurcht betrifft“. Die Sendung sieht er als „,repräsentativ für eine Welle von positiven Reportagen über unsere [CCTV-]Industrie in allen Bereichen der Medien“. Einige der wenigen kritischen Reportagen und Kommentare bezeichnete er als unbedeutend. Vgl. ebenda, S. 70 ff.; Gras (2003), S. 53, 115.

${ }^{365}$ Birch (1990), S. 245, Tabelle 17.1.

${ }^{366}$ Döring (1993), S. 177 ff.

${ }^{367}$ Brown (1998), S. 213; vgl. auch Coleman (2004), S. 203 ff. Mehr zur Rolle der britischen Polizei vgl. Teil III, Kap. 10.3.2.2. b) dieser Arbeit.

${ }^{368}$ Die Anzahl der Polizeibeamten in Bingley sank nach der Einführung von CCTV-Systemen von 24 auf drei; vgl. Gras (2003), S. 219.

${ }^{369}$ Fay (1998), S. 239 ff. Nicht selten wird die Kontrollarbeit der Streifenpolizisten beim Kameraeinsatz intensiviert, um eventuelle Verdrängung der Kriminalität aufzudecken und zu verhindern, wie in Frankfurt a.M. und Leipzig.
} 
Gemeinschaftsprojekten der Polizei und des privaten Sektors wird aus diesem Grund vermehrt privates Sicherheitspersonal für die tägliche Überwachungsarbeit eingesetzt. Die Privatisierung der Überwachungsarbeit ist jedoch nicht unproblematisch: Die uneinheitliche Qualifikation des privaten Dienstpersonals ist schwer zu überprüfen. Außerdem gelten die polizeieigenen Regeln nicht unbedingt für die privat angestellten Sicherheitskräfte, so dass die täglichen Kontrolltätigkeiten an Monitoren nicht immer geregelt sind. ${ }^{370}$

Die Zusammenarbeit zwischen dem öffentlichen und dem privaten Sektor bei der räumlichen Observierung beeinflusst zudem die Einsatzgebiete der Polizei. Durch die Kooperationen mit der privaten Geschäftswelt und deren finanzielle Unterstützung wird häufig die polizeiliche Kontrollarbeit in bereits videoüberwachten Einkaufszonen intensiviert. Dabei können andere Gebiete vernachlässigt werden, die eventuell durch die Verlagerungseffekte mehr von Kriminalität belastet sind. ${ }^{371}$

\subsection{Vermehrte Angst durch CCTV-Überwachung}

Die zum Zweck der Kriminalitätsverhütung und der Erhöhung des Sicherheitsempfindens eingeführten Videoüberwachungsmaßnahmen können zwar die Kriminalitätsfurcht an überwachten Orten mindern, sie können allerdings genausogut die Kriminalitätsfurcht an nicht überwachten Orten verstärken.

Der Verdrängungs- bzw. Verlagerungseffekt der Videoüberwachung ist ein bekannter, möglicher Nebeneffekt, der nur schwer zu erfassen ist. Um der permanenten technischen Observierung zu entgehen, ziehen sich viele Kriminelle in angrenzende Gebiete zurück, wo die (empfundene) Sicherheit der Menschen dementsprechend sinkt. Aufgrund der dort verschlechterten Sicherheitslage sieht man wiederum die Notwendigkeit, durch den Kameraeinsatz die Überwachungsgebiete auszuweiten, um die öffentliche Ordnung herzustellen. „Wenn man die Orte der Sicherheit verlässt, muss die Angst zwangsläufig größer werden und wenn man in ihnen verbleibt, wird man zumindest permanent an die ,Gefahr' vor der Tür erinnert. Je mehr Orte demonstrativ als sicher dargestellt werden, desto mehr Orte wecken Assoziationen von Gefahr, es entsteht ein neuer Circulus-Vitiosus: Immer mehr Räume müssen ü-

\footnotetext{
${ }^{370}$ Vgl. Teil III, Kap. 10.3.1.3 dieser Arbeit.

${ }^{371}$ Viele Videoüberwachungsmaßnahmen werden heute vom privaten Sektor finanziert und durchgeführt. Oft werden hauseigene Regeln und Sanktionen bei Entdeckung von Straftaten, z.B. Ladendiebstählen, durch das private Sicherheitspersonal angewandt, wobei die Polizei nicht einmal alarmiert wird. Diese Privatisierung öffentlicher Disziplinierungsarbeit beeinflusst ebenfalls die Rolle staatlicher Ordnungshüter. So werden $32 \%$ der Ladendiebstähle in Liverpool ausschließlich vom privaten Sicherheitspersonal sanktioniert, wobei die Polizei nicht einmal in Kenntnis gesetzt wird. Mehr zur Rolle der Polizei und privaten Sicherheitsdiensten vgl. Wehrheim (2002), S. 64 ff; Gras (2003), S. 218ff. Vgl. auch Goold (2005), S. 221.
} 
berwacht werden! ${ }^{\prime \prime 372}$ Diesen Teufelskreis kann man an der flächendeckenden Videoüberwachung öffentlicher Straßen und Plätze in Großbritannien erkennen: Es wurde beispielsweise festgestellt, dass sich der Einsatz von Videoüberwachung, ausgehend von London, von einer Stadt zur nächsten ausbreitet, und zwar bis hin zur kleinen walisischen Stadt Newcastle Emlyn mit 1.500 Einwohnern und einer sehr niedrigen Kriminalitätsrate. ${ }^{373}$

Der Einsatz der Überwachungskameras zur Reduzierung von Kriminalitätsfurcht kann also nicht in seiner Wirksamkeit eindeutig bestimmt werden. Einerseits kann die Videografie nicht immer als ein hilfreiches Werkzeug zur Steigerung des Sicherheitsempfindens genutzt werden, andererseits ruft sie in manchen Fällen sogar neue Ängste hervor, und zwar sowohl bei den Menschen, die sich vor Verlagerung der Kriminalität fürchten, als auch bei den Überwachten, die den kontrollierten Raum als gefährlichen Ort wahrnehmen. ${ }^{374}$

\footnotetext{
${ }^{372}$ Wehrheim (2002), S. $218 \mathrm{f}$.

${ }^{373}$ Gras (2003), S. 34.

${ }^{374}$ Mehr zur vermehrten Angst der Überwachten vgl. Teil III, Kap. 8.1.
} 


\section{Zusammenfassung}

Zusammenfassend kann in allen drei untersuchten Ländern ein struktureller Wandel der sicherheitspolitischen Konzepte von reaktiven hin zur präventiven Handlungsweise festgestellt werden. Der polizeiliche Handlungsspielraum wird vor diesem Hintergrund, vor allem durch den Einsatz von Überwachungskameras in öffentlichen Räumen, wesentlich erweitert. Trotz der diffusen Begrifflichkeit rückt das Thema "Sicherheit“ immer mehr ins Zentrum der Politik. Die Gewährleistung sozialer Ordnung wird als dringende Aufgabe des Staates gesehen. Um möglichst viele Risiken und Gefahren im Vorfeld zu identifizieren, nehmen die kriminalpräventiven Strategien mit Kameraeinsatz in Kauf, generell alle in dem überwachten Gebiet befindlichen Bürger unter Verdacht zu stellen. Dabei werden sozial abweichende Personengruppen häufiger als gefährlich angesehen. ${ }^{375}$ Dieser sicherheitspolitische Trend ist nach Auffassung von Fritz Sack „anti-sozialstaatlich, resozialisierungsfeindlich, angebotsorientiert, abschreckungsgerichtet im Sinne der negativen Generalprävention und anti-rechtsstaatlich in Bezug auf die tendenzielle Autonomisierung der Polizei im System der strafrechtlichen Sozialkontrolle“ ${ }^{376}$

Obwohl die Effektivität der Videoüberwachung nicht eindeutig bestimmt werden kann, findet diese Technik zunehmend in öffentlichen Räumen Einsatz, vor allem in Großbritannien. Dies lässt die Vermutung zu, dass letztlich die Frage der Wirksamkeit einen niedrigen Stellenwert hat für die proaktiven Akteure in der Kriminalpolitik. Um die diffusen Sicherheitsgefühle der Bürger steigern zu können, wird der Sicherheitsbegriff anhand von konkreten gesellschaftlichen Gegebenheiten definiert: Einerseits werden "gefährlich" wirkende Randgruppen oder Minderheiten für vermeintlich „unsichere“ Innenstädte verantwortlich gemacht, während andererseits ein mit Kameras observierter Raum mit Sicherheit und Konsumentenfreundlichkeit assoziiert wird. Letztendlich führt diese Politik, wie Feeley \& Simon erkannt haben, dazu, dass komplexe soziale und ökonomische Konflikte auf das Problem der Sicherheit reduziert werden. ${ }^{377}$

In einem demokratischen Rechtsstaat bedeutet der Einsatz optisch-elektronischer Überwachungseinrichtungen und anderer polizeilicher Kontrollmaßnahmen zur Aufrechterhaltung öffentlicher Sicherheit hinsichtlich der verfassungsrechtlichen

\footnotetext{
${ }^{375}$ Vgl. hierzu Wehrheim (2002). S. 27 ff.

${ }^{376}$ Sack (1995), S. 433; Legnaro (1997), S. 277.

${ }^{377}$ Englischer Originaltext: „complex social problems about migration, economic dispossession and political oppression are reduced to problems of security." Vgl. Johnston (1995), S. 434; vgl. auch Legnaro (1997), S. 275.
} 
Prinzipien eine Gefahr für die Freiheitsrechte. Mit der Erkenntnis, dass die Mehrheit der Bürger die Notwendigkeit des Sicherheitsschutzes begreift, aber sich nicht immer über das damit verbundene Risiko der Freiheitseinschränkungen bewusst ist, werden die Fragen aufgeworfen, wer die Schutzpflichten der Freiheitsrechte bei Videoüberwachung öffentlicher Straßen und Plätze übernimmt und wer in verfassungsrechtlicher Hinsicht die erforderlichen Voraussetzungen für den Kameraeinsatz bestimmt.

Die Fragen sind insofern für die Intensität der Kameraanwendung interessant als sie deutlich machen können, welche Antriebe bzw. welche Gegenkräfte hinter der Verbreitung dieser Technik verborgen sind, die das Gleichgewicht zwischen Sicherheit und Freiheit beeinflussen.

Im Streben nach mehr „innerer Sicherheit“ erklären die proaktiven Akteure der kriminalpräventiven Sicherheitspolitik unter Berufung auf Sicherheitsbedürfnisse der Bevölkerung den Einsatz von CCTV-Systemen zum geeigneten Mittel zur Früherkennung von möglichen Gefahren und Risiken. Demgegenüber sehen die Kritiker solcher kriminalpräventiven Vorgehensweise in dem breiten Einsatz von Videoüberwachungsmaßnahmen eine Gefahr für elementare Grundrechte der Bürger und demokratisch-freiheitliche Prinzipien. Vor diesem Hintergrund wird in dieser Arbeit die These entwickelt, dass weder die Diskrepanz der Kriminalitätsentwicklung noch die Sicherheitsbedürfnisse, sondern das Kräfteverhältnis zwischen den vorantreibenden und den kritischen Akteuren, d.h. zwischen den Protagonisten von Ordnung und Sicherheit und denen von Freiheit und Minderheitenschutz, ausschlaggebend sind bei der Beantwortung der Frage nach Ursachen unterschiedlicher Nutzungsintensität von Überwachungskameras in Großbritannien, Deutschland und den USA. 


\section{Teil III: Analyse der Ursachen unterschiedlicher Intensität von Videoüberwachung}

Dieser Abschnitt der Arbeit befasst sich mit den möglichen Ursachen für unterschiedliche Nutzungsintensitäten von CCTV-Systemen in Großbritannien, Deutschland und den USA. Da CCTV-Systeme in erster Linie als Instrumente zur Gefahrenabwehr eingesetzt werden, soll zunächst überprüft werden, inwiefern die unterschiedlichen Kriminalitätsraten im Zusammenhang mit der unterschiedlichen Anwendung von Überwachungskameras in öffentlichen Räumen steht.

Es konnte im letzten Abschnitt verdeutlicht werden, dass die reale Kriminalitätsbelastung nicht unbedingt mit der Kriminalitätsfurcht der Bevölkerung korreliert. Da die Steigerung des Sicherheitsgefühls der Bürger sowie deren vermeintliche Forderung nach mehr Kameras als Argumente zur Einführung von Überwachungskameras genannt werden, sollen Unterschiede im subjektiven Sicherheitsempfinden der Bevölkerung sowie deren Einstellung zur Videoüberwachung als gesellschaftliche Reaktion auf die gesamte Sicherheitslage analysiert werden, um zu ermitteln, ob diese für die Unterschiede in der Anwendungsintensität von CCTV-Systemen verantwortlich sind.

Um weitere mögliche Faktoren für die länderspezifischen Diskrepanzen in Bezug auf die öffentliche Videoüberwachung zu durchleuchten, wird ferner im nächsten $\mathrm{Ab}$ schnitt eine detaillierte Kategorisierung der Akteure in der CCTV-Politik der drei Länder vorgenommen. Es wird in dieser Arbeit die These aufgestellt, dass nicht die meistgenannten Argumente, wie z.B. die unterschiedlichen Kriminalitätsraten oder furcht, für das unterschiedliche Ausmaß der Videoüberwachungstätigkeiten ausschlaggebend sind, sondern vielmehr die länderspezifischen Konstellationen der Akteure in der CCTV-Politik. An den jeweiligen Prozessen der Willensbildung und Entscheidungsfindung sind sowohl staatliche Akteure als auch Nichtregierungsorganisationen beteiligt, die letztlich für die Entscheidung für bzw. gegen Maßnahmen der Videoaufzeichnung zuständig sind. Während die Befürworter öffentlicher Videoüberwachungsmaßnahmen zu kriminalpräventiven Zwecken den Kriminalitätsproblemen absolute Priorität einräumen, sehen die Kritiker in der Automatisierung räumlicher Überwachung eine Gefahr für die Freiheitsrechte der Bürger und Einschränkung der allgemeinen, demokratischen Prinzipien, die verteidigt werden müssen.

Die systematische Vorstellung der Akteure soll einen Einblick in die institutionellen Entscheidungsstrukturen der drei Länder verschaffen und somit die Enthüllung wei- 
terer Hintergründe zur Frage der CCTV-Nutzungsintensität ermöglichen. Zunächst sollen die Kriminalitätsrate sowie die gesellschaftlichen Reaktionen darauf näher untersucht werden.

\section{Kriminalitätsrate}

Da die Bekämpfung der steigenden Kriminalitätsraten immer wieder als Hauptgrund für die Videoüberwachungsmaßnahmen angegeben wird, ist zunächst zu prüfen, ob die objektive Sicherheitslage in Großbritannien im Vergleich zu anderen Ländern tatsächlich den breiten Einsatz dieser Technik rechtfertigt.

Eine komparative Analyse der Kriminalstatistiken auf internationaler Ebene erweist sich aufgrund der unterschiedlichen Kriminalitätsstrukturen, des Kriminaljustiz- und Verfolgungssystems sowie Meldeverfahrens und Anzeigeverhaltens der Bürger als äußerst schwierig. Die uneinheitlichen statistischen Messmethoden und Definitionen von Straftaten in unterschiedlichen Forschungsarbeiten beeinflussen selbst die Vergleichbarkeit der Kriminalitätsdaten innerhalb eines Landes, von Schwierigkeiten bei internationalen Studien ganz zu schweigen. Landesspezifische Polizeistatistiken sind deswegen für Aussagen über inländische Entwicklungen zwar geeignet, aber weniger sachdienlich für länderübergreifende Vergleiche. ${ }^{378} \mathrm{Um}$ dennoch die Kriminalitätsentwicklung in Großbritannien, Deutschland und den USA trotz dieser empirischen Schwäche gegenüberstellen zu können, werden in dieser Arbeit zunächst Daten aus International Crime Victimization Survey (ICVS) herangezogen. ${ }^{379}$ Diese im Auftrag der Vereinten Nation durchgeführte internationale Opferbefragung in insgesamt über vierzig Ländern, darunter siebzehn Industrieländern, basiert weitgehend auf standardisierten Untersuchungskriterien, welche die komparative Analyse der Kriminalitätsentwicklungen wesentlich erleichtern. Es wurden vier Untersuchungen von 1989 bis 2000 durchgeführt, wodurch eine Längsschnittsstudie über die öffentliche Sicherheit in den untersuchten Ländern ermöglicht wurde. ${ }^{380}$

Bei der ICVS-Untersuchung im Jahr 1989 wurde zwar Westdeutschland berücksichtigt, aber die Bundesrepublik hat sich an den folgenden drei Untersuchungen nicht beteiligt. Um die Daten aus allen drei Vergleichsländern untersuchen zu können,

\footnotetext{
${ }^{378}$ Mehr zu unterschiedlichen statistischen Messmethoden von komparativen Analysen internationaler Kriminalitätsentwicklungen vgl. Kangaspunta (1995); Aebi (2004), S. 163 ff.; Killias et al. (2003); Bennett; Lynch (1990), S. 153 ff.; Aebi et al. (2002), S. 22 ff.

${ }^{379} \mathrm{Zu}$ Datenqualität der ICVS sowie anderer Untersuchungen vgl. Aebi et al. (2002), S. $22 \mathrm{ff}$.

${ }^{380}$ Die Untersuchungsergebnisse wurden jeweils im Jahr 1989, 1992, 1996 und 2000 veröffentlicht, wobei sich die Daten jeweils auf das Jahr zuvor beziehen. Im Folgenden wird das Datum der Veröffentlichungen angegeben. Mehr zu Erhebungsverfahren der ICVS vgl. Van Kesteren et al. (2000), S. 11 ff.; Van Dijk; Mayhew (1992).
} 
werden ferner Ergebnisse aus "International Comparison of Criminal Justice Statistics 2001" einbezogen, wobei alle europäischen Länder sowie die USA bewertet wurden. Die folgende Untersuchung stützt sich hauptsächlich auf Daten aus den oben genannten Befragungen, wobei die für die Videoüberwachungsmaßnahmen relevante „Straßenkriminalität“381 differenziert untersucht werden wird.

Es konnte nach den Untersuchungen von ICVS insgesamt eine steigende Tendenz der Kriminalitätsrate ${ }^{382}$ in allen europäischen Untersuchungsländern zwischen 1988 und 1991 festgestellt werden. Zwischen 1991 und 1995 stagnierte bzw. sank diese Rate in fast allen befragten Ländern, welche nach 1999 wieder anstieg. ${ }^{383}$ In England und Wales wurde im Jahr 2000 eine höhere Kriminalitätsrate als im Jahr 1988 festgestellt. Die Kriminalitätsentwicklung in den USA unterschied sich jedoch von der allgemeinen Tendenz in Europa und präsentierte im gleichen Zeitraum eine abnehmende Kriminalitätsrate, welche im Jahr 2000 niedriger war als im Jahr $1988 .{ }^{384}$ In Abbildung 3 wird dieser Trend anhand der ICVS- Ergebnisse und der Daten von den jeweiligen Polizeibehörden verdeutlicht.

\footnotetext{
${ }^{381}$ Vgl. hierzu Teil II, Kap. 4.2 dieser Arbeit.

${ }^{382}$ Der Begriff Kriminalität wird bei den ICVS-Untersuchungen wie folgt definiert: „The ICVS is similar to most crime surveys of householders with respect to the crime it covers. It is confined to counting crimes against clearly identifiable individuals, excluding children. (Crime surveys cannot easily cover organisational victims, or victimless crime such as drug abuse.) For the crimes it covers, the ICVS asks about incidents that by and large accord with legal definitions of offences. In essence, it accepts respondents' accounts of what happend - or at least the accounts they are prepared to give to interviewers. In this respect, it applies a broader definition of crime than the police - who, if incidents are reported to them, are likely to filter out those which may not be felt to merit the attention of criminal justice system, or meet legal or organisational demands for reasonable evidence." Van Kesteren et al. (2000), S. $14 \mathrm{f}$.

${ }^{383}$ Deutschland befand sich nicht unter den befragten Ländern.

${ }^{384}$ Van Kesteren et al. (2000), S. 93.
} 


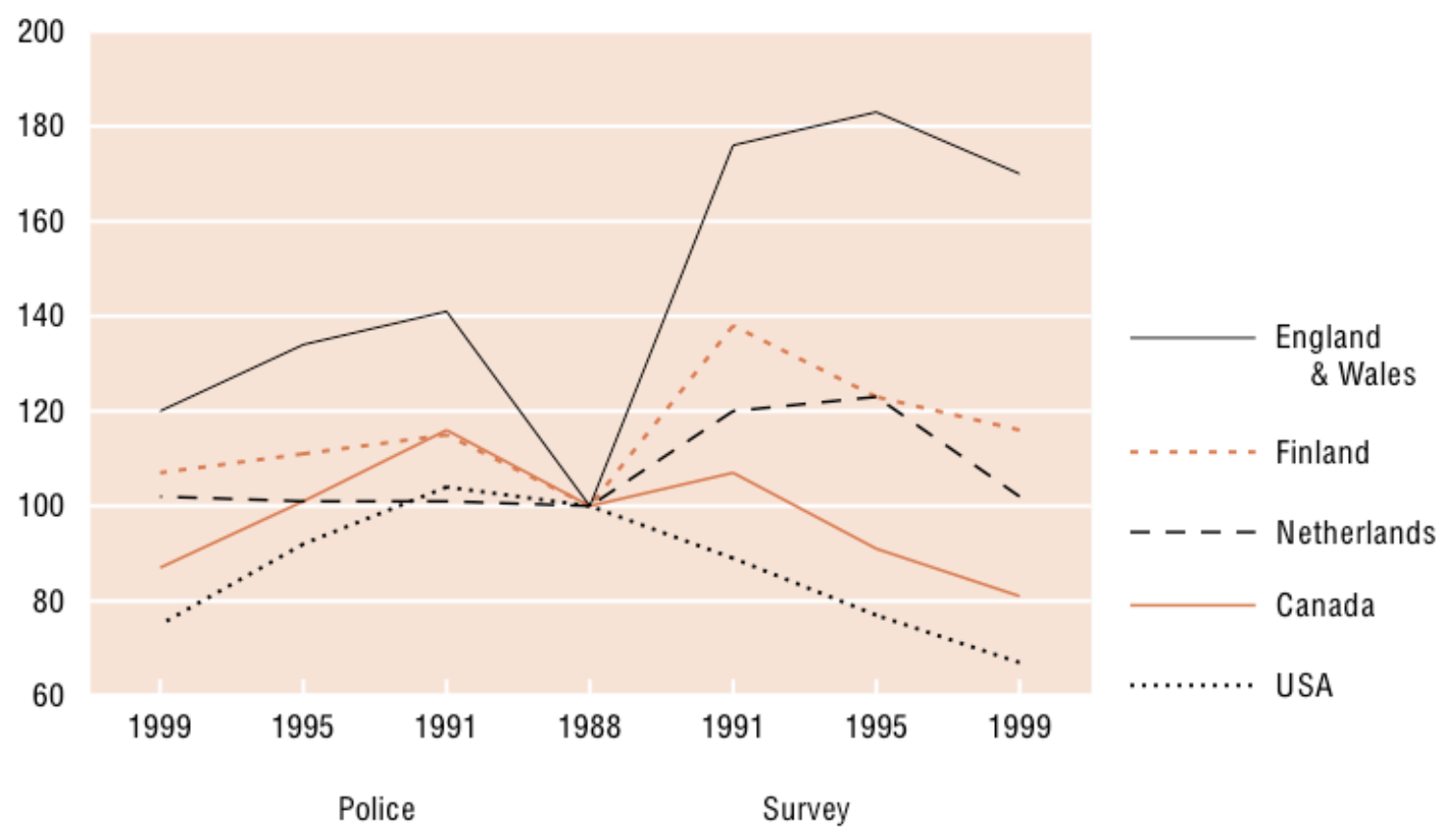

Abbildung 3: Polizeiliche Kriminalitätsentwicklung und ICVS Trends zwischen 1988-1999. ${ }^{385}$

Zwischen 1988 und 1991 registrierten sowohl die Polizei als auch ICVS einen ähnlichen zunehmenden Trend der Kriminalität, wobei die USA im Vergleich zu den anderen vier untersuchten Ländern eine abnehmende Entwicklung aufwiesen. Dagegen zeigten England und Wales bei beiden Messverfahren im gleichen Zeitraum den steilsten Anstieg. Dies entsprach also den Aussagen der britischen Befürworter von CCTV-Überwachung, die die Einführung der Überwachungsmaßnahmen mit dem hohen Anstieg der Kriminalitätsrate begründeten. Zwischen 1991 und 1995 stellte in allen untersuchten Ländern die Polizei eine allgemeine sinkende Tendenz der Kriminalität fest, während nach Angaben von ICVS der Anstieg der Kriminalität in England und Wales sich stabilisierte. Vom Jahr 1995 bis 1999 sank nach Angaben der Polizei die Kriminalitätsrate in allen Untersuchungsländern mit Ausnahme der Niederlande. Nach dem Verfahren von ICVS wurde für diesen Zeitraum eine allgemeine Abnahme der Kriminalität festgestellt. ${ }^{386}$

\footnotetext{
${ }^{385}$ Zur Vereinfachung des Vergleichs werden die Werte vom Jahr 1988 auf 100 festgelegt (Index $1988=100)$. Es handelt sich bei den Werten auf der Y-Achse um prozentuale und nicht um absolute Zahlen. Die linke Hälfte der Zeitachse (X-Achse) stellt die polizeiliche Kriminalitätsentwicklung der angegebenen Länder von 1988 bis 1999 dar. Die vergleichbaren ICVS-Daten sind auf der rechten Hälfte der Zeitachse eingetragen. Quelle: Criminal victimisation in seventeen industrialised countries: Key findings from the 2000 International Crime and Victims Survey, S. 93.

${ }^{386} \mathrm{Im}$ Jahr 2000 zeigten England und Wales in der International Crime and Victims Survey (ICVS) die höchste und die zweithöchste Rate in Deliktarten Kfz-Diebstahl und Raub. Vgl. Mayhew; White (1997); vgl. auch Van Kesteren et al. (2000). Deutschland nahm an diesen Befragungen nicht teil und kann deswegen hierbei nicht berücksichtigt werden. Die deutsche polizeiliche Kriminalstatistik (PKS) zeigt jedoch vom Jahr 1993 bis 2000 sowohl bei Diebstahl von Kfz (insgesamt 56,4\%) und aus Kfz (insgesamt 41,4\%) eine stark sinkende Tendenz. Vgl. Büllesfeld (2002), S. 53.
} 
Wenn man diese Gesamtentwicklung der Kriminalität betrachtet, scheinen der bemerkenswerte Anstieg der Kriminalitätsrate in Großbritannien in der ersten Hälfte der 1990er Jahre und die abnehmende Tendenz kurz vor der Jahrhundertwende keineswegs einzigartig zu sein, da diese Entwicklung dem europäischen Trend entspricht. Es kann festgestellt werden, dass der CCTV-Boom in Großbritannien (19941998 ${ }^{387}$ gerade in dem Zeitrahmen stattfand, in dem nach Angaben der ICVS die europaweite Stagnation bzw. Abnahme der Verbrechensrate eintrat. Es kann allerdings anhand der vorliegenden Ergebnisse die unverkennbar hohe Kriminalität in England und Wales gegenüber 1988 bestätigt werden, welche vom britischen Innenministerium immer wieder als Begründung für den Einsatz von CCTV-Programmen angegeben wurde. Es ist aber zu hinterfragen, ob die insgesamt hohe Kriminalität in England und Wales die Einführung einer flächendeckenden Videoüberwachung ausreichend rechtfertigt. Schließlich können Überwachungskameras in öffentlichen Räumen nur gegen Straßenkriminalität eingesetzt werden, die nur einen Teil der Gesamtkriminalität ausmacht.

Um die Entwicklung der CCTV-relevanten Deliktart - die Straßenkriminalität - zu untersuchen und die Daten aus der Bundesrepublik zu berücksichtigen, werden Ergebnisse aus "International Comparisons of Criminal Justice Statistics 2001“ herangezogen. ${ }^{388}$ Die Entwicklung der Gewaltverbrechen, Raubüberfälle und Kfz-Diebstähle werden im Folgenden als Indikatoren für die Straßenkriminalität analysiert.

\footnotetext{
${ }^{387}$ Vgl. Teil I, Kap. 3.3.1 dieser Arbeit.

${ }^{388}$ Hierbei werden zur Veranschaulichung nur die für diese Arbeit relevanten Daten aus England und Wales, Deutschland und den USA dargestellt. Die detaillierten Auflistungen aller Untersuchungsdaten befinden sich im Anhang dieser Arbeit. Es handelt sich um absolute Zahlen der registrierten Fälle bei der Polizei. Ferner ist zu beachten, dass die Definitionen von untersuchten Straftaten aufgrund länderspezifischer Untersuchungsmethoden unterschiedlich sein können. Vgl. Barclay; Tavares (2003).
} 


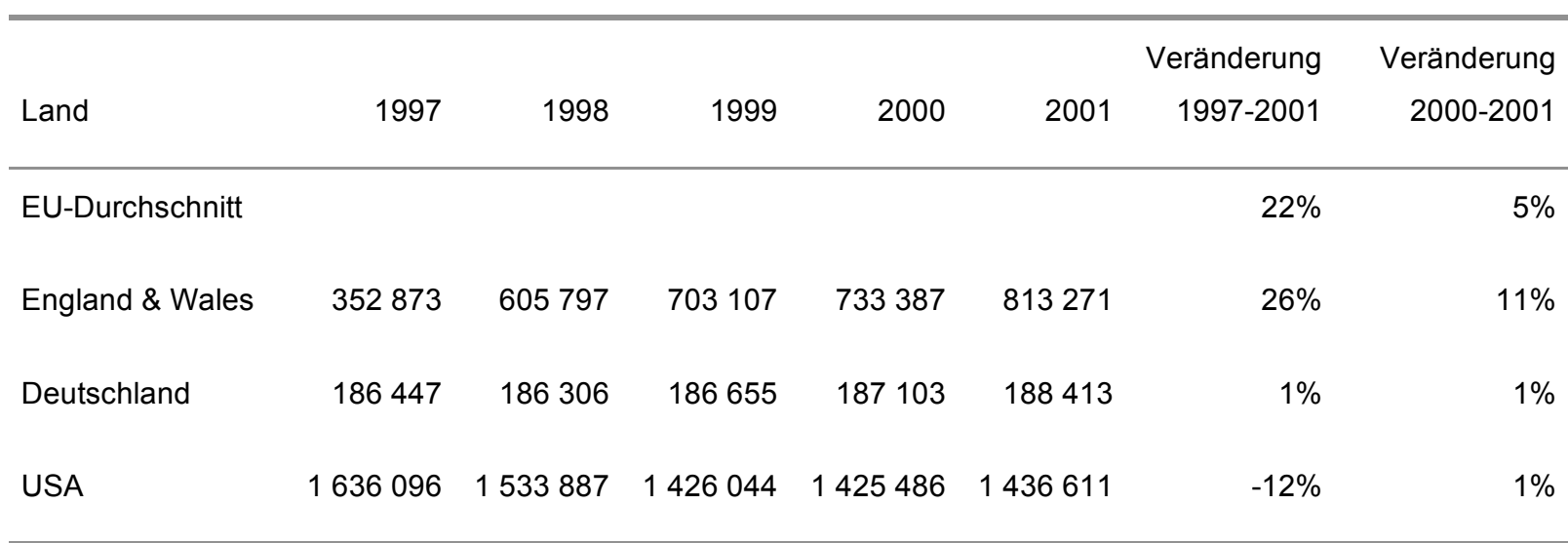

Tabelle 6: Polizeilich registrierte Gewaltverbrechen von 1997 bis 2001 in England \& Wales, Deutschland und den USA. ${ }^{389}$

In Tabelle 6 werden die bei der Polizei registrierten Gewaltverbrechen ${ }^{390}$, die prozentualen Veränderungen zwischen 1997 und 2001 in England und Wales, in Deutschland sowie in den USA aufgelistet. Zum Vergleich werden die EUDurchschnittswerte der Veränderungen zwischen 1997 und 2001 sowie zwischen 2000 und 2001 angeführt. ${ }^{391} \mathrm{Zu}$ beachten ist hierbei, dass diese Werte nicht auf die Verbrechen im öffentlichen Raum beschränkt sind. Insofern soll diese Liste nur zur Veranschaulichung der Gesamtsituation der Gewaltverbrechen dienen. Es kann festgestellt werden, dass zwischen 1997 und 2001 in England und Wales ein überdurchschnittlicher Anstieg von Gewaltverbrechen (26\%) zu verzeichnen war, während diese in Deutschland nur um 1\% stieg und in den USA sogar um 12\% sank.

\begin{tabular}{|c|c|c|c|c|c|c|c|}
\hline Land & 1997 & 1998 & 1999 & 2000 & 2001 & $\begin{array}{r}\text { Veränderung } \\
1997-2001\end{array}$ & $\begin{array}{r}\text { Veränderung } \\
2000-2001\end{array}$ \\
\hline EU Durchschnitt & & & & & & $24 \%$ & $5 \%$ \\
\hline England \& Wales & 62652 & 66835 & 84277 & 95154 & 121370 & $92 \%$ & $28 \%$ \\
\hline Deutschland & 69569 & 64405 & 61420 & 59414 & 57108 & $-18 \%$ & $-4 \%$ \\
\hline USA & 498534 & 447186 & 409371 & 408016 & 422921 & $-15 \%$ & $4 \%$ \\
\hline
\end{tabular}

Tabelle 7: Polizeilich registrierte Raubüberfälle von 1997 bis 2001 in England \& Wales, Deutschland und den USA. ${ }^{392}$

\footnotetext{
${ }^{389}$ Quelle: International comparisons of criminal justice statistics 2001. Barkley, G. \& Tavares, C.; Ausgabe $12 / 03,24$. Oktober 2003.

${ }^{390}$ Der Begriff „Gewaltverbrechen“ (violent crime) wird hierbei als „violent against the person, robbery and sexual offences" definiert. Vgl. Barclay; Tavares (2003).

${ }^{391}$ Die genaueren Zahlen der registrierten Verbrechen zwischen 1991 und 2001 befinden sich im Anhang.

${ }^{392}$ Quelle: International comparisons of criminal justice statistics 2001. Barkley, G. \& Tavares, C.; Ausgabe $12 / 03,24$. Oktober 2003.
} 
Ferner konnte in der Untersuchung (siehe Tabelle 7) gezeigt werden, dass zwischen 1997 und 2001 die Raubüberfälle ${ }^{393}$ in Deutschland um 18\% und in den USA um 15\% sanken, während diese gleichzeitig in England und Wales um 92\% anstiegen. Während in den Jahren 1997 und 1998 die Anzahl der Raubüberfälle in England und Wales auf gleichem Niveau mit der Bundesrepublik lagen, stiegen sie jedoch ab 1999 so rapide an, dass sie doppelt so hoch waren wie in Deutschland. Diese hohen Werte aus England und Wales lagen weit über dem EU-Durchschnitt von $24 \%$.

\begin{tabular}{lrrrrrrr}
\hline Land & 1997 & 1998 & 1999 & 2000 & 2001 & $\begin{array}{r}\text { Veränderung } \\
1997-2001\end{array}$ & Veränderung \\
\hline & & & & & & & \\
EU Durchschnitt & & & & & & $-7 \%$ & $-7 \%$ \\
England \& Wales & 40024 & 391807 & 374686 & 338796 & 328147 & $-30 \%$ & $-3 \%$ \\
Deutschland & 190585 & 162518 & 140636 & 127750 & 121533 & $-36 \%$ & $-5 \%$ \\
USA & 1354189 & 1242781 & 1152075 & 1160002 & 1226457 & $-9 \%$ & $6 \%$ \\
\hline
\end{tabular}

Tabelle 8: Polizeilich registrierte Kfz-Diebstähle von 1997 bis 2001 in England \& Wales, Deutschland und den USA. ${ }^{394}$

Der Kfz-Diebstahl ${ }^{395}$ zeigte zwischen 1997 und 2001 sowohl in England und Wales ($30 \%)$ als auch in der Bundesrepublik (-36\%) eine starke Abnahme der registrierten Fälle, die weit unter dem Durchschnittswert der EU von $-7 \%$ lag. Wenn man die absoluten Zahlen betrachtet, war in England und Wales in diesem Zeitraum eine zweibis dreifach höhere Zahl der Kfz-Diebstähle zu verzeichnen als in der Bundesrepublik. In den USA war ein vergleichsweise leichter Abstieg der Werte von -9\% zu verzeichnen (siehe Tabelle 8).

Es ist äußerst schwierig, angesichts der mannigfaltigen Einflussfaktoren, den Anstieg bzw. den Rückgang der Kriminalitätsrate auf wenige Ursachen zurückzuführen. Neben demografischen und wirtschaftlichen Faktoren werden u.a. auch neue Konzepte der Kriminal- und Sicherheitspolitik als mögliche Ursachen genannt. ${ }^{396}$ Für diese Ar-

\footnotetext{
${ }^{393}$ Der Begriff „,Raubüberfall“ (robbery) wird hierbei wie folgt definiert: „Stealing from a person with force or threat of force. Includes mugging (bag-snatching) and theft with violence; excludes pickpocking, extortion and blackmailing." Vgl. Barclay; Tavares (2003).

${ }^{394}$ Quelle: International comparisons of criminal justice statistics 2001. Barkley, G. \& Tavares, C.; Ausgabe 12/03, 24. Oktober 2003.

${ }^{395}$ Der Begriff „Kfz-Diebstahl“ (theft of a motor vehicle) wird hierbei wie folgt definiert: "All land vehicles with an engine that run on road which are used to carry people (including cars, motor cycle, buses, lorries, contruction and agricultural vehicles, ect.). Vgl. Barclay; Tavares (2003).

${ }^{396}$ Neue sicherheitspolitische Maßnahmen wie "New Policing“ in den USA, vor allem die New Yorker „Null-Toleranz-Strategie“ sorgte wegen ihrer rasch sichtbaren Erfolge weltweit für Aufsehen. Mehr
} 
beit genügt die Erkenntnis, dass die absoluten Kriminalitätszahlen ${ }^{397}$ in England und Wales in verschiedenen Untersuchungen und Deliktformen ein höheres Niveau im Vergleich zu den USA und Deutschland aufweisen. Diese relativ hohen (Straßen)Kriminalitätszahlen sowie die steigende Tendenz der Kriminalitätsentwicklung machen die Motivation zur Einführung von CCTV-Überwachung in den von Delinquenz belasteten urbanen Räumen plausibel und werden von den britischen Befürwortern der Videoüberwachung immer wieder als Argumente angeführt. Allerdings erklären diese Faktoren nicht die flächendeckende Videoüberwachung in Großbritannien, die sich nicht nur auf Großstädte beschränkt, sondern auch rasch in kleineren Städten und Gemeinden mit wenig Kriminalität weiträumigen Einsatz findet. Beispielsweise haben kleinere Städte wie Emlyn, Cardigan oder Aberystwyth mit wenigen tausend Einwohnern sich trotz niedriger Kriminalitätsrate für Videoüberwachung entschieden. ${ }^{398}$

Wenn man ferner die Entwicklung der (Straßen-)Kriminalität verfolgt, kann man die hohe Kriminalitätsrate in England und Wales nicht nur zu Anfang der 1990er Jahre, also zum Zeitpunkt der Einführung von CCTV-Projekten, sondern auch bis 2001, als die Videoüberwachung in Großbritannien bereits omnipräsent war, beobachten. Dies wirft die Frage auf, inwiefern die Videoüberwachung als effektives Werkzeug der Kriminalprävention gesehen werden kann. Angesichts der explosionsartigen Ausbreitung dieser optischen Überwachungseinrichtungen und zugleich ansteigender bzw. konstant hoher Straßenkriminalität sowie ambivalenter Forschungsergebnisse über Wirkung von CCTV-Überwachung ${ }^{399}$ liegt die Vermutung nahe, dass die Effektivitätsfrage der Videoaufzeichnung und die hohe Kriminalitätsrate letztlich nicht ausschlagend sind für den weltgrößten Einsatz dieser Überwachungstechnik in Großbritannien. Es ist deswegen sinnvoll, neben den statistischen Kriminalitätsdaten nach anderen Erklärungen für die überproportionale Nutzung von CCTV-Systemen als neues Konzept der Kriminal- und Sicherheitspolitik zu suchen.

\footnotetext{
hierzu vgl. Teil I, Kap. 1 dieser Arbeit und Wehrheim (2002), S. 68; Bartsch (2004), S. 36 ff.; Greene (2001), S. $43 \mathrm{ff}$.

${ }^{397}$ Es ist an dieser Stelle zu erwähnen, dass die angegebenen Zahlen das kriminalstatistische „Dunkelfeld“, das die der Polizei nicht bekannt gewordene Kriminalität umfasst, nicht berücksichtigen und daher nicht die tatsächliche Kriminalitätsentwicklung in diesen drei Ländern vollständig widerspiegeln.

${ }_{398}^{39}$ Vgl. hierzu Teil I, Kap. 3.3.3 dieser Arbeit.

${ }^{399}$ Vgl. hierzu Teil II, Kap. 4.5 dieser Arbeit. 


\section{Einstellung der Bevölkerung}

Die statistischen Angaben zur Kriminalität stehen nicht immer in Korrelation zum Sicherheitsempfinden der Bevölkerung und sind demnach nicht als Indikatoren für die subjektive Sicherheit geeignet. Vielmehr dienen diese als Grundlage für die politischen Entscheidungsträger, um Argumente für den Einsatz von Überwachungskameras in öffentlichen Räumen darzulegen. Für das gemeinschaftliche Wohlergehen ist demnach nicht nur die objektive Sicherheitslage entscheidend, sondern vor allem die Einstellung der Bevölkerung zur öffentlichen Sicherheit. In diesem Kapitel werden zwei Faktoren - Kriminalitätsfurcht und die Einstellung zur Videoüberwachung - als gesellschaftliche Reaktionen auf die gesamtgesellschaftliche Sicherheitslage analysiert.

\subsection{Kriminalitätsfurcht}

Es konnte bereits deutlich gemacht werden, dass viele Menschen aus Angst vor Kriminalität bereit sind, die Videoüberwachung als Sicherheit versprechendes Werkzeug trotz möglicher Freiheitseinschränkungen zu akzeptieren. Demnach befürworten Menschen eher die (polizeiliche) Videoüberwachung zu kriminalpräventiven Zwecken, je mehr Angst sie vor Straftaten empfinden. Da die Kriminalitätsfurcht der Menschen in der Regel in städtischen Räumen stärker ausgeprägt ist als in ländlicher Gegend, ist es nicht verwunderlich, dass in Ballungszentren die Videoüberwachung bevorzugt zur Anwendung gebracht wird.

Vor diesem Hintergrund kann angenommen werden, dass die intensive Nutzung von Überwachungskameras in Großbritannien letztlich auch als politische Reaktion auf die empfundene Angst vor Straßenkriminalität und die langjährige Bedrohung durch IRA-Terrorismus gesehen werden kann. Es muss allerdings an dieser Stelle erneut darauf hingewiesen werden, dass es sich bei „Kriminalitätsfurcht” um ein schwer zu erfassendes Konstrukt handelt, so dass Vergleiche der entsprechenden Daten trotz standardisierter Messungen problematisch sind. Auch wenn die Indikatoren des Sicherheitsgefühls zunehmend wissenschaftliche Anerkennung finden, sind international vergleichende Studien für das Sicherheitsempfinden dennoch selten und die Messgenauigkeit oft zweifelhaft. Mit der bekannten Standardfrage „Wie sicher fühlen Sie sich oder würden Sie sich fühlen, wenn Sie hier in dieser Gegend nachts draußen allein sind?" kann beispielsweise nicht unbedingt die Furcht vor Verbrechen, sondern die allgemeine Angst vor der Dunkelheit erfasst werden. Ferner haben die Gestaltung der Fragebögen sowie der Gesamtkontext, in dem die Fragen 
gestellt werden, Einfluss auf die Antworten der Befragten. ${ }^{400}$ Vor diesem Hintergrund erscheint es sinnvoll, in der vorliegenden Untersuchung die Daten aus der bereits erwähnten internationalen ICVS-Opferbefragung sowie dem Zentrum für Umfragen, Methoden und Analysen (ZUMA) ( $^{401} \mathrm{zu}$ entnehmen, in der Erwartung, dass deren internationale, erfolgreiche Durchführung über einen längeren Zeitraum zumindest die strukturellen Schwächen solcher Untersuchungen minimieren konnte.

Aufgrund des Fehlens einer standardisierten Studie, die das Sicherheitsempfinden der Bevölkerung in allen drei zu untersuchenden Ländern berücksichtigt, konzentriert sich die folgende Analyse zunächst auf die Gegenüberstellung von Großbritannien und Deutschland, welche sich auf die vom ZUMA veröffentlichten Angaben zur Wahrnehmung und Bewertung von Kriminalität in den EU-Ländern zwischen 1996 und 2002 stützt. ${ }^{402}$ Anschließend wird das Sicherheitsempfinden der amerikanischen Bevölkerung von der International Crime and Victimization Survey (ICVS) mit den entsprechenden britischen Daten aus den Jahren 1992, 1996 und 2000 verglichen. Trotz des Fehlens einer einheitlichen Untersuchung genügen hierbei die Ergebnisse aus diesen zwei Studien, um das subjektive Gefühl des Bedrohtseins als mögliche Ursache für die besondere Nutzungsintensität von CCTV-Systemen in Großbritannien zu überprüfen.

Im Jahr 1996 zeigte sich nach Angaben des ZUMA im Vereinigten Königreich eine Kriminalitätsfurcht, die leicht unter dem EU-Durchschnitt lag (vgl. Abbildung 4). Damit hatten die Bürger in Großbritannien und Nord-Irland ein höheres Sicherheitsgefühl als die Deutschen im Jahr 1996, die mit einer Kriminalitätsfurchtrate von 39\% unter den damaligen EU-Ländern den höchsten Prozentanteil aufwiesen.

Während das Sicherheitsempfinden der Deutschen in den darauf folgenden Jahren entgegen dem allgemeinen EU-Trend sich verbesserte, gehörte Großbritannien zusammen mit Nord-Irland (Vereinigtes Königreich) zu den EU-Ländern, die den stärksten Anstieg der Kriminalitätsfurcht von 1996 bis 2002 zeigten. Im Jahr 2002 lag

\footnotetext{
${ }^{400}$ Zur Kritik an der Messgenauigkeit vgl. Smith; Torstensson (1997), S. 609; vgl. auch Hale (1996), S. 79 ff. und die Arbeiten von Hough (1995) und Kreuter (2002).

401 "Das Zentrum für Umfragen, Methoden und Analysen (ZUMA) in Mannheim berät die Sozialforschung bei der Anlage, Durchführung und Auswertung sozialwissenschaftlicher Untersuchungen, führt eigene Untersuchungen durch, erleichtert den Zugang zu amtlichen Daten und beobachtet und analysiert die gesellschaftliche Entwicklung mit sozialen Indikatoren. ZUMA führt auch eigene Forschungen durch mit dem Ziel, die methodischen und technischen Grundlagen der sozialwissenschaftlichen Forschung zu verbessern." Siehe hierzu http:/ / www.gesis.org/zuma/.

${ }^{402}$ Vgl. Dittmann (2005). Als Datenbasis dienen hierbei verschiedene repräsentative Umfragen aus Deutschland sowie Daten des Eurobarometers. Die Eurobarometer-Umfrage wurde in den 15 EULändern von 1996 bis 2002 dreimal durchgeführt. Die Probanden wurde gefragt, wie sicher sie sich fühlen, wenn sie nach Einbruch der Dunkelheit allein zu Fuß in der Gegend unterwegs sind, in der sie wohnen. In dieser Untersuchung wurden die USA nicht berücksichtigt.
} 
Deutschland im Vergleich zu den anderen europäischen Ländern im mittleren Feld der Kriminalitätsfurcht, wobei das Unsicherheitsgefühl in den neuen Bundesländern leicht über dem EU-Durchschnittswert (in Abbildung 4 mit EU-15 gekennzeichnet) von 35\% lag. Dagegen zeigte die Kriminalitätsfurcht im Vereinigten Königreich einen überdurchschnittlichen Anstieg auf 43\%. 


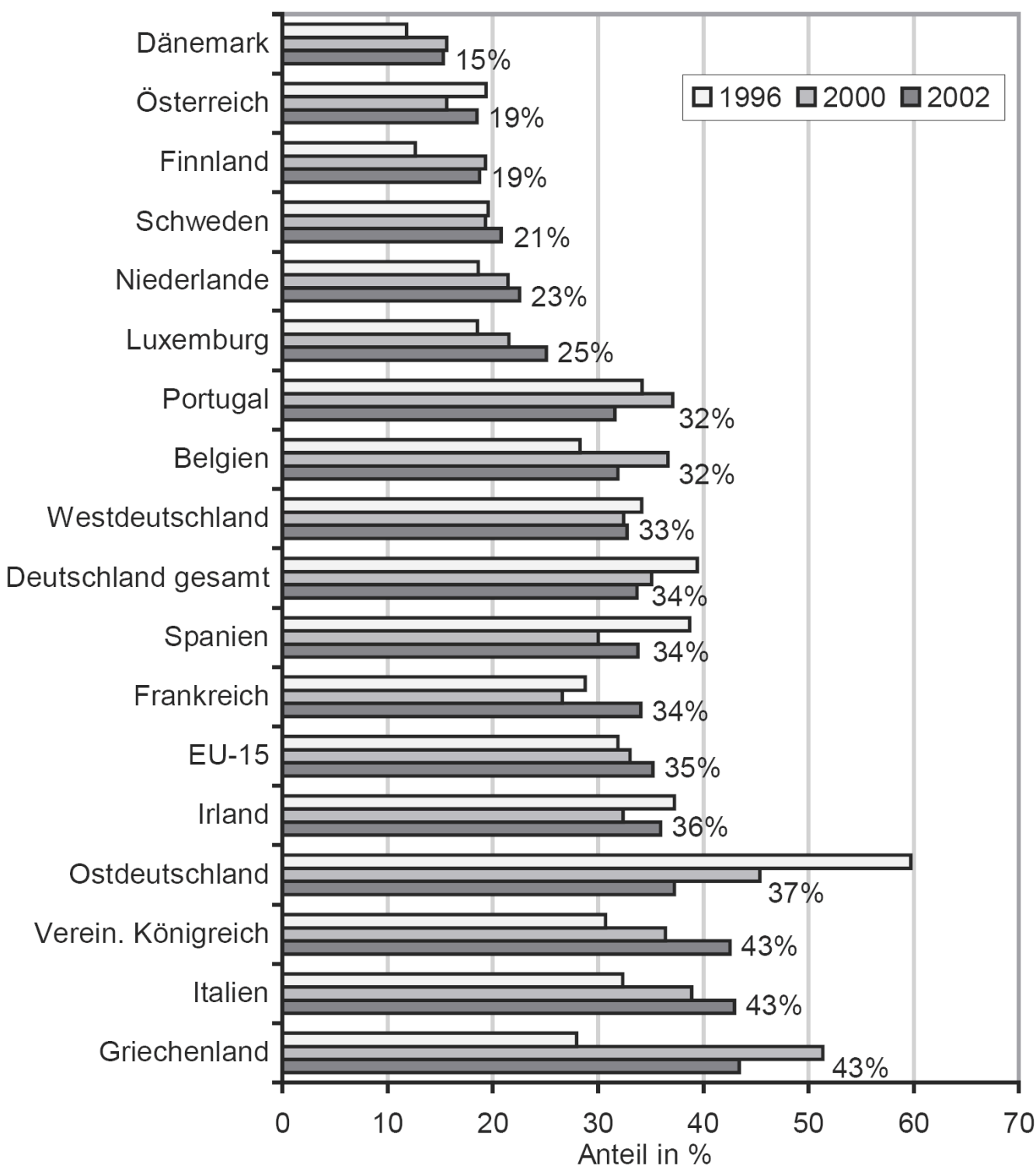

Datenbasis: Eurobarometer 44.3 (1996), 54.1 (2000) und 58.0 (2002) - eigene Berechnungen. Verwendeter Indikator: „Wie sicher fühlen Sie sich, wenn Sie nach Einbruch der Dunkelheit allein zu Fuß in der Gegend unterwegs sind, in der Sie wohnen?" Dargestellt: Prozentanteil "etwas unsicher" oder "sehr unsicher“. Die Länder sind aufsteigend nach dem Anteil im Jahr 2002 sortiert.

Abbildung 4: Entwicklung der Kriminalitätsfurcht in der EU zwischen 1996 und 2002. ${ }^{403}$

Auch das persönliche Viktimisierungsrisiko für Diebstahl, Raubdelikte, Körperverletzungen und Raubüberfälle wurde im Jahr 2002 von den britischen Bürgern überdurchschnittlich hoch geschätzt, wenn sie nach Einbruch der Dunkelheit zu Fuß in ihrer Wohngegend unterwegs waren. Die Erwartung, selbst Opfer eines Verbrechens zu werden, zeigte dagegen in Deutschland in allen genannten Kategorien im EUVergleich die niedrigsten Werte auf (vgl. Abbildung 5). So sahen im Jahr 2002 ledig-

${ }^{403}$ Quelle: Informationsdienst Soziale Indikatoren (ISI), Ausg. 34, Juli 2005, S. 8. 
lich 10\% der befragten Deutschen das Risiko, in den nächsten zwölf Monaten Opfer eines Raubes zu werden, während der EU-Durchschnitt bei $29 \%$ lag. ${ }^{404}$ An dieser Stelle ist allerdings darauf hinzuweisen, dass die angegebenen Delikte nicht immer eindeutig der CCTV-relevanten Straßenkriminalität zugeordnet werden können. Da die Viktimisierungserwartung hierbei lediglich als Indikator für das subjektive Wohlbefinden dient, das auch unabhängig von den tatsächlichen persönlichen Kriminalitätsrisiken sein kann, dürfte in diesem Fall die scharfe räumliche Trennung von geringerer Bedeutung sein. Trotz aller Probleme solcher internationaler Vergleiche können diese Ergebnisse darauf hindeuten, dass die britische Bevölkerung hinsichtlich der Einschätzung des Opferwerdens ängstlicher ist als andere EU-Bürger.

${ }^{404}$ Vgl. Dittmann (2005), S. 7. 


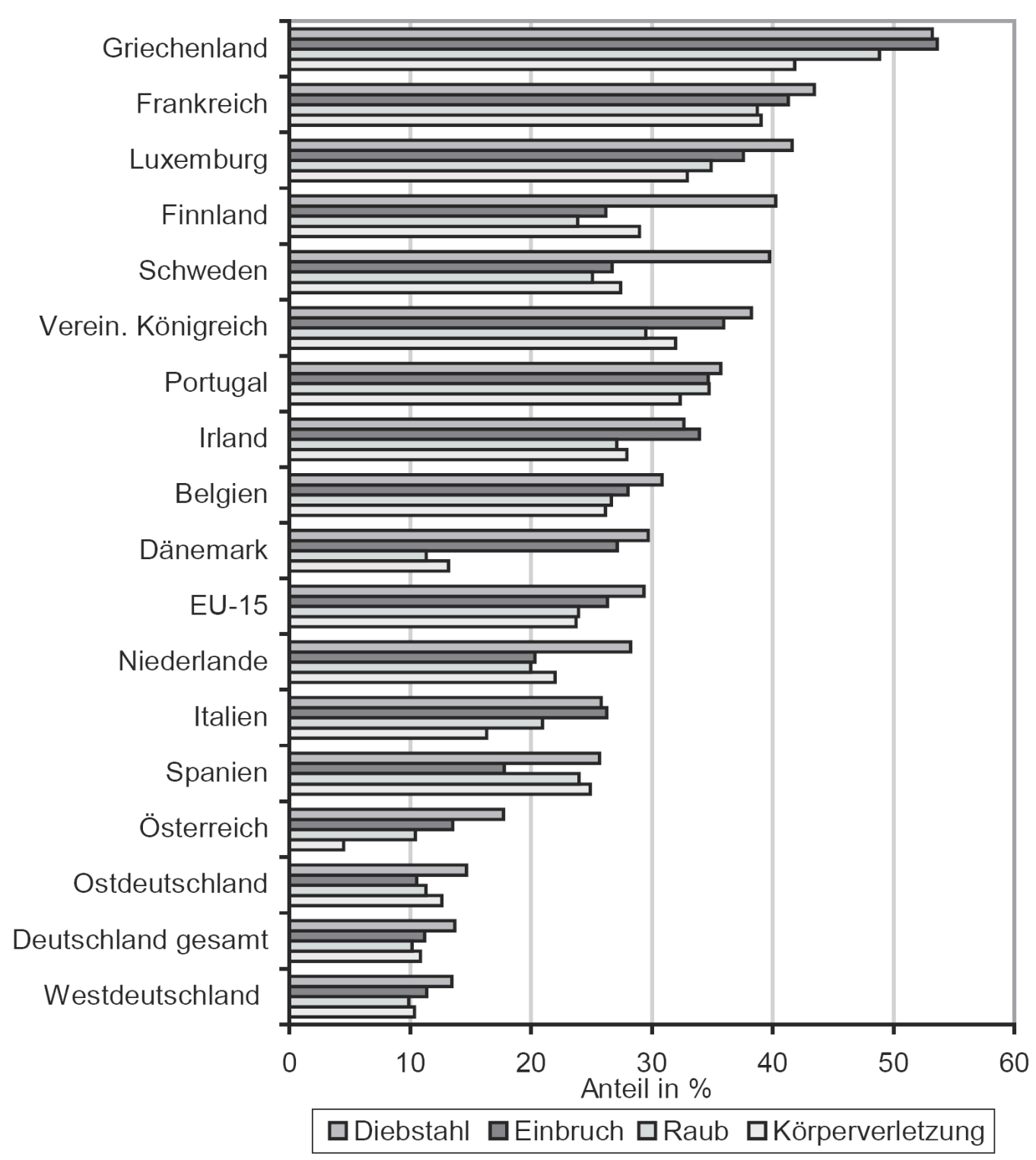

Datenbasis: Eurobarometer 58.0 (2002) - eigene Berechnungen.

Verwendeter Indikator: „Glauben Sie, dass Sie in den nächsten 12 Monaten selbst das Opfer einer der folgenden Straftaten werden?“ Antwort: ja/nein. Dargestellt: Prozentanteil „ja”. Die Länder sind absteigend nach dem Anteil der Viktimisierungserwartungen bezüglich Diebstahlsdelikten sortiert.

Abbildung 5: Viktimisierungserwartungen der EU-Bürger 2002. ${ }^{405}$

${ }^{405}$ Quelle: Informationsdienst Soziale Indikatoren (ISI), Ausg. 34, Juli 2005, S. 9. 


\begin{tabular}{|c|c|c|c|}
\hline & 1992 & 1996 & 2000 \\
\hline Australia & 31 & & $\uparrow 34$ \\
\hline Belgium & 20 & & 21 \\
\hline Canada & 20 & $\uparrow 26$ & $\downarrow 16 \downarrow$ * \\
\hline England \& Wales & 33 & 32 & $\downarrow 27$ \\
\hline Finland & 17 & 17 & 18 \\
\hline France & & 20 & 22 \\
\hline Netherlands & 22 & 20 & $\downarrow 18$ \\
\hline Northern Ireland & & 22 & 23 \\
\hline Poland & 43 & $\downarrow 34$ & $34 \downarrow$ * \\
\hline Scotland & & 26 & $\downarrow 20$ \\
\hline Sweden & 14 & $\downarrow 11$ & $\uparrow 15$ \\
\hline Switzerland & & 17 & $\uparrow 22$ \\
\hline USA & & 25 & $\downarrow 15$ \\
\hline
\end{tabular}

Tabelle 9: Anteil der Personen, die sich nach Einbruch der Dunkelheit unsicher fühlen. ${ }^{406}$

Vergleichende Daten zur Kriminalitätsfurcht aus den USA und Großbritannien liegen mit der International Crime and Victimization Survey (ICVS) ${ }^{407}$ vor, die aus den Jahren 1992, 1996 und 2000 stammen. Anhand Tabelle 9 ist zu erkennen, dass nach den Ergebnissen von ICVS im Jahr 1992 die Kriminalitätsangst in Großbritannien nach Polen die zweithöchsten Werte unter den Vergleichsländern aufwies, welche in den folgenden zwei Untersuchungen eine leicht sinkende Tendenz zeigte. Während im Jahr 1996 32\% der britischen Befragten sich nach Einbruch der Dunkelheit unsicher fühlten, lag der Anteil bei den amerikanischen Bürgern bei 25\%. Den stärksten Zuwachs an Sicherheitsempfinden von 1996 bis 2000 verzeichneten die nordamerikanischen Länder USA und Kanada. Trotz sinkender Tendenz blieb im Jahr 2000 die Angst vor Verbrechen in der eigenen Wohngegend in Großbritannien 12\% höher als in den USA.

Die obigen Vergleiche zeigen die Schwierigkeiten, einen eindeutigen Zusammenhang zwischen der Intensität der CCTV-Anwendung und der Entwicklung der Kriminalitätsfurcht in Großbritannien herzustellen. Angesichts der im EU-Vergleich (Abbildung 4) niedrigen Rate der Kriminalitätsfurcht im Jahr 1996 im Vereinigten Königreich liegt die Vermutung nahe, dass die unterdurchschnittliche Kriminalitäts-

\footnotetext{
${ }^{406}$ Quelle: ICVS Untersuchungen aus den Jahren 1992, 1996 und 2000. Crimial Victimisation in Seventeen Industrialised Countries: Key findings from the 2000 International Crime Victims Survey, S. 79. ${ }^{407}$ Van Kesteren et al. (2000), S. 77 ff.
} 
furcht nicht der ausschlaggebende Faktor für den britischen CCTV-Boom in der zweiten Hälfte der 1990er Jahren sein kann. Die ICVS-Ergebnisse vom Jahr 1996 zeigen jedoch ein anderes Bild: Die britischen Bürger empfinden mehr Angst vor Kriminalität als die Bürger anderer Länder, auch der USA. Diese Furcht in Großbritannien blieb trotz leicht sinkender Tendenz bis zum Jahr 2000 relativ hoch.

Im Hinblick auf die steigende Kriminalitätsfurcht zwischen 1996 und 2002 nach den ZUMA-Ergebnissen bzw. die vergleichsweise hohen Werte nach ICVS ist es ferner zweifelhaft, inwieweit der intensive Einsatz von Überwachungskameras zur Steigerung des Sicherheitsempfindens der britischen Bevölkerung beigetragen hat. ${ }^{408} \mathrm{Nach}$ den ZUMA-Daten erscheint es sogar möglich, dass der intensive Einsatz von Überwachungskameras auf öffentlichen Straßen und Plätzen in Großbritannien die Bevölkerung verunsichert, da die britischen Bürger trotz der hohen Kriminalitätsrate Mitte der 1990er Jahre weniger Angst vor Verbrechen empfanden, aber im Jahr 2002 signifikant mehr Kriminalitätsfurcht zeigten als der Durchschnitt der EU-Bürger. ${ }^{409}$ Das Vorhandensein von Überwachungseinrichtungen, so die Behauptung hier, könnte die Gefährlichkeit eines Raumes signalisieren. ${ }^{410}$ Mit anderen Worten: Menschen können einen per Video überwachten Raum als gefährlich wahrnehmen und sich darin mehr fürchten, da Überwachungskameras normalerweise an von Kriminalität belastenden Orten installiert werden. Solche Aussagen sind jedoch aufgrund der genannten strukturellen Schwächen der Umfragemethode, die besonders bei internationalen Vergleichen problematisch sind, mit großer Vorsicht zu treffen.

\subsection{Einstellung zur Videoüberwachung}

Häufig wird der erwähnte Fall James Bulger, der im Jahr 1993 in Liverpool ermordet wurde, als Auslöser für die Hochkonjunktur der Kameraüberwachung bezeichnet. ${ }^{411}$ Die von einer Überwachungskamera aufgezeichneten, medienwirksamen Bilder, die die letzten Stunden des kleinen Jungen mit seinen Mördern zeigten, riefen in der britischen Bevölkerung große Zustimmung gegenüber CCTV-Systemen hervor. Anlässlich dieses Falls wurde das Videoüberwachungssystem im Liverpooler Stadtzentrum eingeführt, wobei der damalige Innenminister David Maclean zur Eröffnung des Systems das Erfordernis und den Nutzen dieser Technik betonte. ${ }^{412}$ Im Folgenden wird die öffentliche Unterstützung der Bevölkerung zu CCTV-Maßnahmen als möglicher

\footnotetext{
${ }^{408}$ Mehr zu den Ergebnissen über die Entwicklung der Kriminalitätsfurcht in den EU-Ländern vgl. Dittmann (2005), S. $6 \mathrm{ff}$.

${ }^{409}$ Vgl. hierzu die Daten aus dem vorherigen Kapitel.

${ }^{410}$ Vgl. hierzu Teil II, Kap. 5.5 dieser Arbeit.

411 Zurawski (2004); Gras (2003), S. 33 f.

${ }^{412}$ Gras (2003), S. 33 f.; vgl. hierzu Teil I, Kap. 3.3.2.2 dieser Arbeit. 
Einflussfaktor für die weiträumige Nutzung von CCTV-Systemen in Großbritannien geprüft.

\subsubsection{CCTV-Akzeptanz in Deutschland}

Die Videoüberwachung ist in der Bundesrepublik von den Bürgern weitgehend akzeptiert. Eine Umfrage von FORSA im Juli 1999 zeigte, dass 59\% der Berliner Befragten nichts gegen Überwachungskameras hatten, während eine Anfang 2000 stattgefundene Befragung in Deutschland feststellte, dass 77,5\% der Probanden das technische Mittel zur Observierung begrüßten. ${ }^{413}$ Im März desselben Jahres zeigte eine EMNID-Umfrage ein geteiltes Bild: 48\% waren für die Videoüberwachung, aber genauso viele waren gegen diese Maßnahmen, wobei die Zustimmung der Ostdeutschen bei $60 \%$ lag. ${ }^{414}$

Ferner zeigte eine am 15. und 16. Mai 2001 von EMNID in Deutschland durchgeführte Umfrage, dass vier von fünf Bundesbürgern die polizeiliche Videoüberwachung von Kriminalitätsschwerpunkten auf öffentlichen Plätzen und Straßen positiv fanden. ${ }^{415}$ Nach Angaben der deutschen Datenschutzbeauftragten begrüßten $80 \%$ aller Deutschen die Überwachung öffentlicher Plätze per Videotechnik. ${ }^{416}$

In Reubands Untersuchung zum Thema Akzeptanz von Videoüberwachung in Dresden und Düsseldorf im Jahr 2000 wurden ähnliche Tendenzen festgestellt. In diesen beiden Städten wurden jeweils 800 Probanden befragt und die Mehrheit der Befragten stimmten der Videoüberwachung im öffentlichen Raum zu: 77\% der befragten Dresdener und 66\% der Befragten in Düsseldorf fanden Videoüberwachung ,sehr gut" oder "gut". ${ }^{417}$

\footnotetext{
${ }^{413}$ Die Welt (1999); Gras (2003), S. 268.

${ }^{414}$ Der Berliner Beauftragte für Datenschutz und Akteneinsicht (1999), S. 36.

${ }^{415}$ Laut dieser Umfrage sind 79\% für die Videoüberwachung, während 19\% dagegen stimmen und 2\% keine Angabe äußerten. Zentralverband der Elektrotechnik- und Elektroindustrie e.V. (ZVEI) (2001a); vgl. auch Kraudzun (2002).

${ }^{416}$ Nürnberg (2000), S. 231.

${ }^{417}$ Reuband erklärt dieses Phänomen u.a. durch die in den 1980er Jahren stattgefundene Debatte um den Datenschutz in den alten Bundesländern, die die Einstellung der Bürger gegenüber Missbrauchspotentialen der Videoüberwachung beeinflusst haben. Interessant ist auch die Feststellung, dass 43\% der Befragten in Düsseldorf meinten, in ihrer Stadt öffentliche Videoüberwachung wahrgenommen zu haben, obwohl solche Projekte dort zu dem Zeitpunkt gar nicht existierten. Dieses Missverständnis ist, so Reuband, damit zu begründen, dass „,... man in Düsseldorf bereits schon so sehr an die Videoüberwachung an halb-öffentlichen Orten gewöhnt ist, dass man es für mehr oder minder plausibel hält, dass es auch eine Videoüberwachung von Straßen und Plätzen gibt. (...) [Die Gesamtzahl der Überwachungskameras in Düsseldorf] dürfte insgesamt höher liegen als in Dresden und damit eher zur vertrauten Umgebung gehören. “ Tendenziell zeigen in dieser Untersuchung Männer sowie jüngere Menschen mit höherer Bildung eine kritischere Haltung gegenüber Videoüberwachung. Besonders kritisch sind die Befragten unter 30 Jahren in Düsseldorf. Rund 47\% von ihnen glauben Missbrauchgefahren zu erkennen, während die Quote in Dresden 26\% beträgt. Vgl. Reuband (2001), S. 5 ff.
} 
Das Institut für Soziologie der Universität Leipzig hat im Juni $2000 \mathrm{zu}$ der Einstellung der Bürger in Leipzig eine Befragung durchgeführt, wobei 770 Personen befragt wurden. In dieser Untersuchung sollte ermittelt werden, wie sicher sich die Befragten in der Öffentlichkeit fühlten und was sie von der Videoüberwachung in Leipzig erwarteten. Die Forschungsergebnisse zeigten, dass rund $79 \%$ der Befragten sich für die öffentliche Videoüberwachung aussprachen. ${ }^{418}$

\subsubsection{CCTV-Akzeptanz in den USA}

Es kann aufgrund fehlender repräsentativer Untersuchungen keine umfassende Aussage über die gesellschaftliche Reaktion auf die Videoüberwachung in den Vereinigten Staaten gemacht werden. Die ersten Maßnahmen polizeilicher Videografie in den 1960er und 1970er Jahren wurden von den Bürgern wenig unterstützt. ${ }^{419}$ Nach Angaben des California Research Bureau ist mittlerweile die Meinung zu der raschen Verbreitung der Überwachungskameras auf öffentlichen Straßen und Plätzen gespalten. Einerseits gibt es Menschen, die bereit sind, für mehr Sicherheit ein Stück Privatsphäre aufzugeben, andererseits ist man besorgt über den Missbrauch der gesammelten Daten und über heimliche Überwachung wie beim Finale der US-amerikanischen American-Football-Profiliga Super Bowl 2001 in Tampa, Florida. ${ }^{420}$ Im Juni 2005 ergab eine Umfrage der Washington Post, dass die Mehrheit der Befragten sich allgemein für eine Ausweitung der Überwachungstätigkeit des FBI aussprach. ${ }^{421}$

Es kann allerdings vermutet werden, dass Vorkommnisse wie die Terroranschläge vom 11.09.2001 und der Bombenanschlag in Oklahoma City die allgemeinen Sicherheitsbedenken verstärkt, welche die Popularität von Überwachungskameras steigern. Ein Sprecher der Sicherheitsindustrie berichtet von zunehmender Akzeptanz dieses Überwachungsinstruments in der amerikanischen Öffentlichkeit: „[Y]ears ago shoppers objected to electronic eyes recording their moves; today it's not only accepted, it's preferred. ${ }^{\prime 422}$ Die Beliebtheit der Überwachungskameras wird von den rasch zunehmenden Erträgen der CCTV-Herstellern bestätigt. Ein Hauptunternehmer in

\footnotetext{
${ }^{418}$ Die Ergebnisse zeigen, dass ein großer Teil der Befragten sich nicht so sehr durch konkrete Straftaten bedroht fühlt, sondern vielmehr durch das in ihren Augen ",abweichende Verhalten“ von Randgruppen und sozialen Minderheiten. Allerdings erwarten die Befragten, dass durch die Videoüberwachung an den Kriminalitätsschwerpunkten Delikte wie Diebstahl/Handtaschenraub, Raub/Überfall und Drogendelikte vermindert werden könnten. „Es scheint also ein Missverständnis zwischen der Art der Bedrohung und dem erwarteten Sicherheitsgewinn in Bezug auf die Videoüberwachung zu geben", vgl. Hölscher (2003), S. 42 ff.

${ }_{419}$ Nieto (1997), S. 12.

${ }^{420}$ Nieto et al. (2002), S. 6.

${ }^{421}$ Langer (2005).

${ }^{422}$ Nieto (1997), S. 11.
} 
diesem Gebiet berichtete im Jahr 1994 einen Gewinn von \$ 16 Millionen und erhöhte diesen in dem darauf folgenden Jahr auf \$ 120 Millionen. ${ }^{423}$

\subsubsection{CCTV-Akzeptanz in Großbritannien}

In Großbritannien, das oft als „Mutterland der Videoüberwachung “424 beschrieben wird, sind Videokameras nicht nur nach Meinung der Betreiber, sondern auch nach Meinung der Bevölkerung, willkommene Überwachungsinstrumente in öffentlichen Räumen.

Die erste Umfrage zur Einstellung zu CCTV-Systemen wurde im Jahr 1992 von Honess \& Charman ${ }^{425}$ veröffentlicht. Diese vom britischen Innenministerium finanzierte Untersuchung fand heraus, dass $85 \%$ bis $92 \%$ der Befragten die Installation dieser optisch-elektronischen Einrichtungen begrüßten. ${ }^{426}$ Auch Williams und Johnstone haben in ihrer Studie in zwei kleinen Städten in Wales - Aberystwyth und Cardigan - die hohe Akzeptanz der Videoüberwachung bestätigt. In beiden Städten wurden die Systeme im Jahr 1998 installiert, obwohl die Mehrheit der Bewohner sich bereits vor der Installation der CCTV-Systeme in ihren Städten sicher fühlte. Die Ergebnisse zeigten, dass 85\% der Erwachsenen in Aberystwyth und 87\% in Cardigan den öffentlichen Kameraeinsatz gut fanden. ${ }^{427}$

Auch in anderen britischen Städten kann man eine hohe Akzeptanz der Videoüberwachung feststellen. In King's Lynn waren nach Zeitungsberichten 96\% der Bevölkerung mit der Installation der Videokameras in der Innenstadt zufrieden, während 90\% der Einwohner in Harlow sich ebenfalls positiv über die CCTV-Systeme äußerten. Ähnlich hohe Akzeptanz ließ sich in Brighton (86\%) und Sutton (85\%) feststellen. $^{428}$

Allerdings weisen professionelle Umfragen auf einen wesentlich niedrigeren Anteil von CCTV-Befürworten:

Eine im Jahr 1993 in Glasgow von einem Marktforschungsinstitut durchgeführte Befragung zeigte, dass über $90 \%$ der Befragten die flächendeckende Videoüberwachung im Zentrum von Glasgow unterstützten, wobei $66 \%$ davon der Meinung waren, dass die Innenstadt dadurch attraktiver geworden sei. ${ }^{429}$ Dieser hohe Zustim-

\footnotetext{
${ }^{423}$ Ebenda, S. 10.

${ }^{424}$ Vgl. Post (2004), S. 62; Nürnberg (2000), S. 230.

${ }^{425}$ Honess; Charman (1992).

${ }^{426}$ Vgl. McCahill; Norris (2002a), S. 19.

${ }^{427}$ Vgl. Williams; Johnstone (2000), S. 203.

${ }^{428}$ McCahill; Norris (2002a), S. 19; Ditton (2000), S. 693 f.

${ }^{429}$ König (2001), S. 197 f.; vgl. auch Graham (1998), S. 92. Ditton (2000), S. 693.
} 
mungsanteil der Bevölkerung wurde im Jahr 1994 von Forschern der Scottish Centre for Criminology auf "nur“ 69\% reduziert. ${ }^{430}$ Ditton führte den Unterschied von ca. $20 \%$ auf die Art der Befragung zurück. ${ }^{431}$ Der Interviewer kann nach Dittons Auffassung systematisch die Interviewten zu einer bestimmten Aussage verleiten: Die Probanden, die in der Befragung von der Marktforschungsorganisation mit Kriminalitätsproblemen in Glasgow konfrontiert wurden, neigten tendenziell dazu, die öffentliche Videoüberwachung zu befürworten. Dagegen zeigten die Befragten bei den Fragen von Scottish Centre for Criminology, die auf datenschutzrechtliche Fragen der CCTVSysteme hinwiesen, eine eher ablehnende Haltung gegenüber dieser Technik. ${ }^{432}$

Trotz unterschiedlicher Untersuchungsbedingungen kann festgehalten werden, dass die Mehrheit der britischen Bevölkerung positiv gegenüber Maßnahmen der Videoüberwachung eingestellt ist.

\footnotetext{
${ }^{430}$ Ditton (1998), S. 223.

431 "I am beginning to have a nasty suspicion that CCTV's acceptability has been inflated by the way that questionaires (rather than samples) are designed, and that professionals may be making the same mistakes as amateurs (albeit to a lesser degree)." Ebenda, S. 223.

${ }^{432}$ Um dieses Phänomen der Manipulierung während des Interviews zu demonstrieren, machte Ditton ein Experiment mit drei Versuchsgruppen jeweils mit Pro-CCTV-Fragen, Kontra-CCTV-Fragen und neutraler Frageweise. Das Ergebnis legt die Vermutung nah, dass allein 20\% der Befürworter durch die Interviewfragen manipuliert sein könnten: In der neutralen Gruppe waren $71 \%$ für die Videoüberwachung, während die Pro-CCTV-Gruppe eine Prozentzahl von 91\% aufweist. Und wenn man nur die Akzeptanz bei den Umfragen mit Passanten (also Interviews mit denjenigen, die auch tatsächlich die öffentlichen Räume und Straßen benutzen und nicht bei denjenigen zu Hause, die wahrscheinlich nicht oft auf den Straßen sind) berücksichtigt, sinkt die Rate der Akzeptanz um weitere 20\%. Das bedeutet, dass die hohe Akzeptanzquote der Videoüberwachung durch die zusätzlichen Nebenbedingungen insgesamt um 40\% reduziert werden kann. Vgl. ebenda, S. 224 ff.
} 


\section{Zusammenfassung}

Die hohe Kriminalitätsrate in Großbritannien stellt häufig für die Befürworter der Videoüberwachung eine Rechtfertigung zur Einführung dieser Technik dar. Die Analyse der Entwicklung von Straßenkriminalität in allen drei Ländern bestätigt die beträchtliche Kriminalitätsrate in Großbritannien. Allerdings scheint dieser Faktor zwar die Motivation zur Einführung von Videobeobachtungsmaßnahmen zu begründen, aber nicht die weltweit höchste Kameradichte der britischen Insel ausreichend zu erklären, da Kameras auch in kleineren Orten mit geringerer Verbrechensrate eingesetzt werden. Die konstant hohe Straßenkriminalitätsrate trotz der weiträumigen Observierung in Großbritannien stellt überdies die Effektivität der öffentlichen Videografie als kriminalpräventives Werkzeug in Frage.

Ferner wurde in diesem Kapitel die Kriminalitätsfurcht als mögliche Ursache analysiert. Die ICVS- und ZUMA-Untersuchungen zeigten uneinheitliche Ergebnisse: Nach ZUMA wies Großbritannien im Jahr 1996 eine im EU-Vergleich niedrige Kriminalitätsfurcht auf, während in Deutschland die Bürger mehr Angst vor Verbrechen zeigten als der Durchschnitt der EU-Bürger. Eine zunehmende Tendenz der Kriminalitätsfurcht wurde in den darauf folgenden Jahren in Großbritannien beobachtet. Zeitgleich nahm die Angst der deutschen Bevölkerung vor Verbrechen so stark ab, dass dies im Jahr 2002 unter dem EU-Durchschnittsniveau lag. Somit trägt der Faktor Kriminalitätsfurcht wenig zur Erklärung des intensiven Kameraeinsatzes auf den britischen Inseln bei, da die Kriminalitätsfurcht in Großbritannien nach der Einführung der Videoüberwachung stieg. Es kann sogar die Vermutung aufgestellt werden, dass die Zunahme der optischen Überwachungseinrichtungen die Bevölkerung verunsichert, da sie überwachte Räume als gefährliche Orte wahrnehmen. Die ICVS- Untersuchung zeigte dagegen, dass britische Bürger im Jahr 1996 mehr Angst vor Kriminalität hatten als die Befragten anderer Nationen. Dieser hohe Anteil der Kriminalitätsfurcht blieb in den folgenden Jahren trotz leicht sinkender Tendenz signifikant hoch. Aufgrund dieser widersprüchlichen Untersuchungsresultate kann die Kriminalitätsfurcht als Auslöser für den britischen CCTV-Boom in den 1990er Jahren nicht eindeutig bestimmt werden.

Gemäß der obigen Analyse kann auch die Einstellung der Bevölkerung zum Einsatz von CCTV-Systemen als entscheidender Faktor für die intensive Nutzung von Überwachungskameras ausgeschlossen werden. Trotz des Mangels an repräsentativen, international vergleichbaren Studien kann bezüglich der gesellschaftlichen Resonanz 
auf das Thema Videoüberwachung festgehalten werden, dass sowohl in Großbritannien als auch in Deutschland die Einstellung gegenüber CCTV-Überwachung eher positiv ausfällt, während sich in den USA ein ambivalentes Bild ergibt. Die hohe Akzeptanz der Bevölkerung kann die unterschiedliche Verbreitung dieser Technik in den zu untersuchenden Ländern nicht erklären, da die mehrheitliche Zustimmung der Bevölkerung nicht nur in Großbritannien, sondern ebenfalls in Deutschland zu finden ist. Vor diesem Hintergrund kann die gesellschaftliche Reaktion zwar als möglicher treibender Faktor gesehen werden, sie erklärt aber nicht die rasche Ausbreitung von CCTV-Systemen in Großbritannien.

Die hohe Kriminalitätsrate, die Kriminalitätsfurcht sowie die öffentliche Unterstützung für Videoüberwachungsmaßnahmen können also als Impulse für den allgemeinen Kameraeinsatz gesehen werden. Sie können allerdings die unterschiedliche Nutzungsintensität von Überwachungskameras nicht ausreichend erklären. Die genannten Faktoren tragen weder zur Klärung der außergewöhnlichen, explosionsartigen Verbreitung von CCTV-Anlagen in Großbritannien bei, noch können diese die Ursachen für das relativ geringe Ausmaß von Überwachungskameras in Deutschland aufzeigen. Um den Ursachen weiter nachzugehen, erscheint es sinnvoll, sich im nächsten Kapitel einen Einblick in die internen Strukturen und Akteurskonstellationen der CCTV-Politik in Großbritannien, Deutschland und den USA zu verschaffen. 


\section{Organisierte Akteure, ihre Funktionen und ihr Einfluss}

Carl Joachim Friedrich schrieb im Jahr 1970, dass „es ein Irrtum ist, zu glauben, dass die Mehrzahl der Bürger einer politischen Ordnung ein Maximum an Freiheit für erstrebenswert hält" ${ }^{433}$ Er zweifelt an den Idealen des klassischen Liberalismus und behauptet, dass der Mensch nur ein Minimum an Freiheit wünscht. Eine Vielzahl der Menschen, so Friedrich, scheint es zu bevorzugen, dass andere die meisten Entscheidungen für sie treffen und ihre Handlungen und Einstellungen durch andere bestimmt werden. Er erklärt dieses Verhalten durch den Wunsch des Menschen, „möglichst bequem zu leben und seine lebenswichtigen Aufgaben auf dem Weg des geringsten Widerstandes zu verwirklichen“. Der Mensch entwickelt somit daraus die Neigung, ",das mögliche Maximum an Freiheit zu vermeiden“ ${ }^{434}$

Diese Vermutung von Friedrich scheint in Hinsicht auf die Frage der öffentlichen Sicherheit und des Schutzes von Bürgerrechten bis heute noch zu gelten. Einerseits steht die Sicherung öffentlicher Ruhe und Ordnung und somit auch die Lebensqualität der Bürger in staatlicher Obhut, andererseits überlassen sie die Wahrung ihrer Freiheitsrechte den Bürgerrechtlern bzw. den zuständigen staatlichen Kontrollbehörden. In treuhändischer Verantwortung entscheiden also staatliche Instanzen bzw. zivilgesellschaftliche Akteure, ob Maßnahmen zur Videoüberwachung eingeführt werden sollen.

In der vorliegenden Arbeit wird die These aufgestellt, dass die unterschiedliche Nutzungsintensität von Überwachungskameras in Großbritannien, Deutschland und den USA auf die strukturellen Besonderheiten der Akteurs- und Organisationsnetzwerke in der Politik innerer Sicherheit zurückzuführen ist. Die Dynamik eines Politikfeldes wird in modernen Demokratien nicht nur vom Staat, sondern ebenfalls von einer Vielzahl unterschiedlich organisierter, zivilgesellschaftlicher Akteure gesteuert. Je nach ihren Macht-Ressourcen versuchen sie, am Prozess der politischen Willensbildung und Entscheidungsfindung mitzuwirken. Ihre Machtpositionen, Handlungskonzepte sowie ihre Partizipationsbereitschaft im jeweiligen Politikfeld sind richtungweisend für die Politikgestaltung. Nach dieser These genießen die britischen Hauptbefürworter von CCTV-Überwachung in den jeweiligen politischen Entscheidungsprozessen eine den CCTV-Gegnern überlegene Führungsrolle. Dagegen beteiligen sich an den deutschen und US-amerikanischen Politikprozessen auch einfluss-

\footnotetext{
${ }^{433}$ Friedrich (1970), S. 228 ff.

${ }^{434}$ Ebenda.
} 
reiche Akteure und Organisationen, die die Ausweitung des öffentlichen Videoeinsatzes blockieren.

Es geht hierbei also um eine Reihe von Akteuren und Organisationen mit unterschiedlichen politischen Herkünften und Prioritäten. Manche von ihnen stellen die Sicherheitspolitik in den Vordergrund und sehen in CCTV-Überwachung eine Lösung für die Kriminalitätsproblematik, während andere den Schutz bürgerlicher Freiheitsrechte als ihre Aufgabe betrachten und Videoüberwachung als Gefahr für gesellschaftliche Minderheiten sehen. ${ }^{435}$ Als Vertreter der sich widersprechenden Interessen geraten diese Akteure des Öfteren in Konflikt um die Durchsetzung ihrer eigenen Vorteile. Dabei sind die Machtpositionen der einzelnen Akteure sowie ihre Handlungsmöglichkeiten in den politischen Verhandlungsprozessen von entscheidender Bedeutung. Um die verschiedenen Akteure und Organisationen sowie deren politischen Einflussgröße auf die Einführung bzw. Ablehnung von Videoüberwachung zu bestimmen, erscheint eine detaillierte Analyse über die inneren Strukturen der zuständigen Institutionen, die als treibende oder hemmende Kräfte in den politischen Entscheidungsprozessen zur Videoüberwachung agieren, unverzichtbar. Dieser Teil der Arbeit unternimmt deswegen den Versuch, eine funktionsspezifische Einteilung von Akteuren in der Politikgestaltung von Sicherheits- und Bürgerrechtsdebatten in allen drei Nationen vorzunehmen. Damit sollen Machtverhältnisse der Akteure anhand ihrer Tätigkeiten im Bereich öffentlicher Videoüberwachung skizziert werden, um deren Auswirkungen auf die Ausweitung der Überwachungsanlagen zu verdeutlichen.

Insgesamt werden zwischen drei Analyseebenen bzw. Akteursgruppen unterschieden:

1) Die erste Ebene betrifft die Befürworter der Videoüberwachung, die als „proaktive Akteure" bezeichnet werden. Dazu zählen neben den staatlichen Verwaltungsinstanzen und Polizeibehörden auch unterschiedliche Kooperationsformen zwischen Staat und privaten Gruppen. Eine Vielzahl von Initiativen und Projekten zur Videoüberwachung werden hier vorgestellt, die als ",treibende Kräfte“ für die Expansion der Überwachungstechnik gesehen werden können.

2) Die zweite Ebene beschreibt solche staatlichen Instanzen, die strukturell in den Policy-Prozessen der CCTV-Implementation eingebunden sind und durch 
ihre Kontrollbefugnisse und Aufsichtsfunktionen die Entwicklung von Videoüberwachung hemmen, z.B. in Form von Datenschutzbeauftragten. Es erscheint sinnvoll, die gesetzlichen Rahmenbedingungen zur Einschränkung von CCTV-Überwachung in den jeweiligen Ländern darzustellen, da diese als Instrument und Rechtsgrundlage der zuständigen Aufsichtsbehörden dienen.

3) Die dritte Ebene der Analyse beschreibt Nichtregierungsorganisationen, die unabhängig von den staatlichen Einrichtungen als „Gegenkräfte“ fungieren. Damit sind solche nichtstaatliche Gruppen gemeint, die durch soziale Mobilisierung, z.B. in Form von Protesten oder Öffentlichkeitsarbeit Einfluss auf die politische Entscheidung zur Anwendung von CCTV-Systemen ausüben.

Die Differenzierung in drei Ebenen soll dazu beitragen, die länderspezifischen Ursprünge der treibenden und hemmenden Kräfte in der CCTV-Politik hervorzuheben, um die komplexen Netzwerke der Entscheidungsprozesse zu entflechten. Dabei ist es nicht nur wichtig, den Einfluss der Akteure anhand ihrer Tätigkeiten, politischer Instrumente und Interaktionen mit anderen Akteuren aufzuzeigen, sondern auch deren Erfolge und Misserfolge zu dokumentieren. Dies dient dem Zweck, mehr Einblick in die Machtstruktur der jeweiligen Akteursnetzwerke in den drei Nationen zu gewinnen.

An dieser Stelle ist es wichtig zu erwähnen, dass Rechtsanwälte als mögliche Akteure in diesem Zusammenhang nicht berücksichtigt werden, da nur selten einzelne Privatpersonen in der Videoüberwachung öffentlicher Räume eine mögliche Missachtung ihrer Grundrechte sehen. Die Mehrheit der Bevölkerung ist nicht über den konkreten Ablauf der Videoüberwachung bzw. Datenspeicherung und -weitergabe informiert. Infolgedessen sind Rechtsanwälte nur selten als Rechtsvertreter gegen staatliche Videoüberwachung tätig, da die Bürger sich der möglichen Grundrechtsverletzungen nicht bewusst sind und Anwälte nur auf Anfrage und gegen Honorar ihren Mandanten Rechtsberatung geben. Zudem sind die Erfolgschancen meistens gering und somit auch die Vergütung der juristischen Leistung in diesem Bereich wenig gewinnbringend, so dass solche Rechtsstreitfälle für Rechtsanwälte wenig reizvoll sein dürften.

\subsection{Die Situation in Deutschland}

\subsubsection{Proaktive Akteure}

In diesem Abschnitt werden die deutschen Akteure zusammengeführt, die an Pilotprojekten polizeilicher Videoüberwachung auf öffentlichen Straßen und Plätzen be- 
teiligt sind. Zunächst werden die staatlichen Instanzen beschrieben, die für die jeweiligen administrativen Genehmigungsverfahren zuständig sind, um anschließend das ausführende Staatsorgan dieser Maßnahmen - die Polizei - vorzustellen. Die Zusammenarbeit zwischen den deutschen Behörden und dem privaten Sektor wird zum Schluss des Kapitels dargestellt.

\subsubsection{Verwaltungsinstanzen}

\section{a) Innenministerium}

Im Mai 2000 wurde auf der Sitzung der Innenminister der deutschen Bundesländer beschlossen, sich prinzipiell für die Möglichkeit des Einsatzes von Videoüberwachung in Deutschland auszusprechen. Die Innenministerkonferenz sieht „in dem offenen Einsatz von Videoüberwachungsmaßnahmen an Kriminalitätsbrennpunkten im öffentlichen Raum ein geeignetes Mittel, um die Wahrnehmung der polizeilichen Aufgaben im Rahmen der Gefahrabwehr und der Strafverfolgung wirksam zu unterstützen. Durch den offenen Einsatz von Videotechnik an Kriminalitätsbrennpunkten im Rahmen eines den jeweils spezifischen Gegebenheiten Rechnung tragenden Konzeptes können die Prävention verstärkt, die Kriminalitätshäufigkeit reduziert, die Aufklärung von Straftaten gesteigert und das Sicherheitsgefühl verbessert werden. ${ }^{4436}$

Mit diesem einstimmig verabschiedeten Beschluss rücken das Thema öffentlicher Videoüberwachung und die damit verbundenen rechtlichen Rahmenbedingungen in den Vordergrund politischer Debatten. In Brandenburg beispielsweise forderte der Innenminister Schönbohm im Jahr 2001 einen "starken, handlungsfähigen Staat“, wobei er in Überwachungskameras nützliche Werkzeuge für vorbeugende Verbrechensbekämpfung sah. Dagegen warnten der zuständige Landesbeauftragte für Datenschutz sowie die Politiker der SPD vor einem leichtsinnigen Umgang mit dieser optisch-elektronischer Technik. ${ }^{437}$ Der Innenminister von Nordrhein-Westfalen betonte zur Einführung polizeilicher Videoüberwachung in Düsseldorf im Jahr 2005 einerseits die kriminalpräventiven Effekte der Maßnahme, andererseits teilte er mit, dass es keine flächendeckende Videoüberwachung in Nordrhein-Westfalen geben würde: „Videoüberwachung ist (...) kein Allheilmittel. Sie muss, wie hier in Düsseldorf, in ein Sicherheitskonzept eingebunden werden. ${ }^{\prime 438}$

\footnotetext{
${ }^{436}$ Ständige Konferenz der Innenminister und -senatoren der Länder (2000), S. 27. Vgl. auch Stierand (2000), S. 71; Töpfer (2005), S. 5 ff.

${ }^{437}$ Gras (2003), S. 266.

${ }^{438}$ Das Innenministerium Nordrhein-Westfalen (2005b).
} 


\section{b) Kommunen}

Die Videoüberwachung stellt durch den Beschluss des deutschen Innenministeriums auf der Kommunalebene zunehmend ein populäres Instrument zur Gefahrenabwehr dar. Neben der behördeninternen Überwachung per Videokamera (vor allem im Kassenbereich) gewinnen Projekte zur Videoüberwachung auf Wertstoffsammelplätzen, Schulhöfen, Schulbussen und Friedhöfen immer mehr an Bedeutung. Auch Museen, Bibliotheken und Schwimmbäder der Gemeinde gehören zum Überwachungsbereich der Videotechnik. ${ }^{439}$ Als Eigentümer kommunaler Einrichtungen haben die Kommunen das Recht, sämtliche angemessenen Maßnahmen zu ergreifen, um den Betrieb ihrer öffentlichen Einrichtungen vor Destruktion und sonstigen Störungen zu bewahren. Dazu zählt auch der Einsatz von Videotechnik zu Überwachungszwecken. Aufgrund der mangelhaften Regelungen im Gemeinderecht bezüglich Videoüberwachungsmaßnahmen sind bei der kommunalen Anwendung von visuellen Überwachungsanlagen ${ }^{440}$ die Vorschriften im Landesdatenschutzgesetz (LDSG) zu beachten. $^{441}$

In Programmen zur Videoüberwachung an öffentlichen Straßen und Plätzen übernehmen die deutschen Kommunen überwiegend die Rolle des Geldgebers, seltener fungieren sie als selbstständige Initiatoren der Projekte. ${ }^{442} \mathrm{Im}$ Fall Bielefeld handelt es sich um eine Kooperation zwischen dem Polizeipräsidium und der Stadt, wobei die Stadt Bielefeld sowohl die Anschaffungskosten von vier Überwachungskameras als auch die Kosten zur Übertragung, Speicherung von Bildmaterial und sonstige laufenden Kosten übernimmt. ${ }^{443}$ Durch diese Vereinbarung wird der Polizei ermöglicht, sich bei der Entscheidung über die Laufzeiten der Überwachungskameras nach gegebener Notwendigkeit bei der Verfolgung polizeilicher Ziele und nicht nach den laufenden Kosten zu orientieren. ${ }^{44}$

Für das Jahr 2003 waren 256.000 Euro in der Haushaltskasse in Frankfurt a.M. für den möglichen Ausbau der Videoüberwachung im Stadtzentrum vorgesehen, ob-

\footnotetext{
${ }^{439}$ Weichert (1998a), S. 64; Weichert (1998b), S. 12 ff.; Büllesfeld (2002), S. 29.

${ }^{440}$ Während bloße Bildübertragungen in der Regel zulässig sind, können Bildaufzeichnungen nur bei irregulären Ereignissen, etwa vermehrter Sachbeschädigung durch Farbsprühereien oder Diebstahlversuche, als statthaft angesehen werden. Büllesfeld (2002), S. 29.

${ }^{441}$ Zur rechtlichen Bewertung einer Videoüberwachung im privatrechtlichen Tätigkeitsbereich der Gemeinde vgl. ebenda, S. 29.

${ }^{442}$ Leopold (2005), S. 273.

${ }^{443}$ Die Kooperationsvereinbarung zwischen dem Polizeipräsidium Bielefeld und der Stadt Bielefeld wurde am 21.12.2000 getroffen und trat am 01.01.2001 in Kraft. Die Vereinbarung galt zunächst für zwei Jahre und wurde dann automatisch um weitere zwei Jahre verlängert, falls eine Kündigung sechs Monate vor dem Ablauf der Frist nicht eingereicht wurde. Vgl. Post (2004), S. 139.

${ }^{444}$ Ferner wurde in der Vereinbarung schriftlich festgehalten, dass die aktiven Überwachungszeiten nicht die kommunalen Interessen berücksichtigen. Vgl. ebenda, S. 139.
} 
wohl gegen Ende des Jahres 2002 den zuständigen Behörden die nötigen Mittel für weitere Videoprojekte nach dem Modellversuch an der Konstablerwache fehlten. ${ }^{445}$ Nach wiederholten Debatten wurde dennoch das Videoüberwachungsprojekt in der Frankfurter Innenstadt erweitert. ${ }^{446}$ Die Kosten für die Anschaffung der CCTVAnlagen am Frankfurter Hauptbahnhof wurden von der Stadt getragen, während die Finanzierung des zusätzlichen Überwachungspersonals vom Land Hessen gestellt werden sollte. ${ }^{447}$

Ein weiteres Beispiel für die kommunale Finanzierungsrolle ist Westerland auf Sylt. Die Finanzierung der dortigen Überwachungsanlage, die mittlerweile nur temporär eingesetzt wird, trägt die Gemeinde Westerland, wobei für eine eventuelle Erweiterung der Anlage auch die örtlichen Geschäftsinhaber mit einbezogen werden. ${ }^{448}$

\subsubsection{Polizei}

Als staatliches Vollzugsorgan hat auch die deutsche Polizei in den vergangenen Jahren vermehrt Videotechnik bei kriminalpräventiven Maßnahmen eingesetzt. ${ }^{499}$ Wie bereits im Teil I geschildert wurde, hat die Leipziger Polizei im Jahr 1996 das erste Pilotprojekt zur „Videoüberwachung von Kriminalitätsschwerpunkten“ in der Leipziger Innenstadt angefangen. Diesem Beispiel folgend starteten andere Polizeibehörden ähnliche Pilotprojekte, z.B. in Dresden, Stuttgart, Bremen und Bielefeld.

Im $\S 481$ der Strafprozessordnung (StPO) wird festgelegt, dass die Videoüberwachung zum „unbestimmten Zweck der Vorbeugung“ durch Landespolizeirecht geregelt werden soll. ${ }^{450} \mathrm{Um}$ die Rechtmäßigkeit dieser polizeilichen Observierungsmaßnahmen in der Öffentlichkeit zu untermauern, wurden inzwischen in den meisten Bundesländern die Polizeigesetze zugunsten öffentlicher Videoüberwachung zum

\footnotetext{
${ }^{445}$ Frankfurter Rundschau (2002c); Frankfurter Allgemeine Zeitung (2002); Frankfurter Rundschau (2002a); Frankfurter Neue Presse (2003a).

${ }^{446}$ Frankfurter Neue Presse (2003b); Frankfurter Rundschau (2003); Frankfurter Allgemeine Zeitung (2003b).

${ }_{447}^{40}$ Frankfurter Allgemeine Zeitung (2003a); Frankfurter Neue Presse (2003d).

${ }^{448} \mathrm{Kohl}$ (1997b), S. 24 ff. Die Finanzierung der Modellversuche zu polizeilicher Videoüberwachung ist unterschiedlich. In Dresden wurde die Finanzierung der mehr als 100.000 DM teuren CCTV-Anlage in der Innenstadt vom Kaufhaus Karstadt und anderen privaten Geschäftsinhabern im Überwachungsbereich übernommen, die an einem kundenfreundlichen Einkaufsklima interessiert waren. Vgl. Reuband (2001), S. 6. In Baden-Württemberg wurde, wie bereits im Teil I, Kap. 3.1.3 erwähnt wurde, das mobile Videoüberwachungssystem eingeführt. Mit einer Leihgebühr von 350 Euro pro Woche kann diese Anlage im Wert von 230.000 Euro an Städte und Gemeinden des Landes verliehen werden. Durch diesen flexiblen Einsatz sollen Kosten, die sonst bei einer stationären Anlage anfallen, gespart werden. Allerdings haben sich bisher keine Interessenten für dieses System gemeldet. Vgl. Hempel (2003).

${ }^{449}$ Mehr zu Videoüberwachung im repressiven und präventiven polizeilichen Aufgabenbereich, vgl. Büllesfeld (2002), S. $32 \mathrm{ff}$.

${ }^{450}$ Gras (2003), S. 257.
} 
Zweck der vorbeugenden Kriminalitätsbekämpfung geändert. Dabei fallen die speziellen Bestimmungen in den Bundesländern unterschiedlich aus. ${ }^{451}$

Beispielsweise ist in Nordrhein-Westfalen nach der Gesetzesänderung des Polizeirechts im Jahr 2001 (§ 15a Abs. PolG NW) die Polizei zur Nutzung von optischen Überwachungseinrichtungen ermächtigt worden. Mit der Gewährung des Polizeigesetzes erhält der Polizei in Nordrhein-Westfallen die rechtliche Grundlage, öffentliches Gebiet offen mit Kameras zu observieren. Die Bedingung für die Videoüberwachung ist nach $\S 15 \mathrm{a}$ nicht mehr der Vorfall von "Straftaten von erheblicher Bedeutung“ am zu überwachenden Gebiet, sondern das Vorhandensein eines „Kriminalitätsschwerpunktes“, an dem „wiederholt Straftaten begangen wurden“ und „solange Tatsachen die Annahme rechtfertigen, dass an diesem Ort weitere Straftaten begangen werden“ ${ }^{452}$ In Bayern wird die polizeiliche Videoüberwachung durch das erneuerte Polizeiaufgabengesetz ( $\$ 32$ Abs. 2 PAG) vom Jahr 2001 geregelt, wobei eine maximale Datenspeicherungsdauer von zwei Monaten vorgeschrieben ist, falls diese den Zweck der Strafverfolgung nicht erfüllt. In Hessen wird nicht nur die Polizei unter Berücksichtigung des Hessischen Gesetzes über die öffentliche Sicherheit und Ordnung (HSOG) zu öffentlicher Videoüberwachung ermächtigt; auch den Kommunen sind unter $\S 14$ Abs. 4 Nr. 1 HSOG solche Maßnahmen gestattet. ${ }^{453}$ In weiteren Bundesländern wie dem Saarland, Thüringen und Sachsen sind ähnliche Regelungen zur öffentlichen Videoüberwachung in den Polizeigesetzen zu finden. In SachsenAnhalt ist die Polizei durch das Gesetz der Sicherheit und Ordnung des Landes Sachsen-Anhalt (SOG LSA) ermächtigt, Orte offen mittels Videografie zu beobachten, an denen „Personen Straftaten verabreden, vorbereiten oder verüben ${ }^{\prime 454}$, wobei nach dem allgemeinen Polizeigesetz nur die Bildübertragung, aber nicht die Bildaufzeichnung zulässig ist. In Schleswig-Holstein dient das Allgemeine Verwaltungsgesetz für das Land Schleswig-Holstein als rechtliche Grundlage für polizeiliche und ordnungsbehördliche Bildaufzeichnung in öffentlichen Räumen. Die meisten Befugnisse zur polizeilichen Videoüberwachung zum Zweck der allgemeinen Gefahrenabwehr erhalten die Polizeibehörden in Hessen, Sachsen und

\footnotetext{
${ }^{451}$ Die Lockerung der Polizeigesetze zugunsten der Videoüberwachung erfolgte in den Bundesländern zu unterschiedlichen Zeitpunkten: Mecklenburg-Vorpommern (1998), Sachsen (1999), BadenWürttemberg (2000), Brandenburg (2000), Bayern (2001) und Hessen (2000). Vgl. Nogala (2002), S. 43. Hierbei handelt es sich um gefahrenunabhängige Videoüberwachung in den einzelnen Bundesländern. Zu Regelungen des Videoeinsatzes bei konkreter Gefahr vgl. Gras (2003), S. 245 ff.

${ }^{452}$ Allgemein gilt die Bundesländer übergreifende Voraussetzung beim Einsatz von polizeilichen CCTV-Systemen, dass es sich bei den Einsatzräumen um Kriminalitätsbrennpunkte handeln muss. Mit anderen Worten müssen im Prinzip die Überwachungskameras wieder abgebaut werden, wenn die Gefahr wiederholter Straftaten im Überwachungsbereich nicht mehr vorhanden ist, wie es in Connewitz in Leipzig der Fall war. Vgl. Gras (2003), S. 251 f.; Müller (2003), S. 7 f.

${ }^{453}$ Ausführlich zu den einzelnen Regelungen vgl. Gras (2003), S. 246 ff.; von Zezschwitz (2000), S. 670.

${ }^{454}$ Vgl. Gras (2003), S. 246 ff. und Büllesfeld (2002), S. 151 ff.
} 
ten die Polizeibehörden in Hessen, Sachsen und Bayern, da in diesen Bundesländern rechtlich nicht zwischen der reinen Bildübertragung und Aufnahmenanfertigung differenziert wird, womit eine fortwährende Bildaufnahme rechtlich zulässig ist. In Bayern rechtfertigen selbst Ordnungswidrigkeiten eine permanente Bildaufzeichnung. ${ }^{455}$

\subsubsection{3 Öffentlich-private Kooperation}

Videoüberwachungsmaßnahmen in semi-öffentlichen Räumen, z.B. in Warenhäusern, Banken und Supermärkten sind in Deutschland kein neues Phänomen. Der Kameraeinsatz zum Schutz vor Ladendiebstählen wird vom Rat für Kriminalitätsverhütung in Schleswig-Holstein als effektiv eingeschätzt: „[E]ine Abschreckung vor dem heimlichen Zugriff auf Waren wird am besten erreicht, wenn das Risiko der Entdeckung möglichst groß gestaltet und dem Kunden dies deutlich vor Augen geführt wird. Kamera-Anlagen, die für die Kunden sichtbar in den Verkaufsräumen angebracht sind und auf Monitoren den überwachten Bereich deutlich wiedergeben, erfüllen beide Kriterien in hohem Maße. ${ }^{.456}$ Die Videoüberwachung an Arbeitsplätzen zeigt ebenfalls eine steigende Tendenz. ${ }^{457}$

Aufgrund der langjährigen Erfahrungen der privaten Betreiber mit Überwachungskameras sowie der offensichtlichen Kostenvorteile entstehen in Deutschland zwischen dem Staat und dem privaten Sektor häufig profitable Kooperationen in Bezug auf Nutzung von Überwachungskameras. Die privaten Betreiber unterstützen die Polizei, indem sie ihren Kooperationspartnern den Zugang zu den eigenen Überwachungsanlagen gewähren oder die Überwachungsergebnisse an sie weiterleiten. Für die privaten Betreiber ist die Gemeinschaftsarbeit ebenfalls vorteilhaft, da die vermehrte Polizeipräsenz und -kontrolle für mehr Sicherheit und Ordnung in der überwachten Zone sorgt.

Das Paradebeispiel für solche Zusammenarbeit ist in Bahnhöfen zu finden. Die Sicherheitsdienste der Deutschen Bahn verfügen im Rahmen der 3-S-Programme ${ }^{458}$ über Überwachungsanlagen, die das Geschehen in Bahnhöfen Tag und Nacht beobachten, wobei sowohl der Bundesgrenzschutz als auch die Polizei bei gegebenem Anlass auf das Datenmaterial dieser Videoanlagen zugreifen können. Beispielsweise wurden am Düsseldorfer Hauptbahnhof im Jahr 1998 insgesamt 72 Überwachungskameras angebracht, die rund um die Uhr Bilder aus der Bahnhofshalle, dem Vor-

\footnotetext{
${ }^{455}$ Ebenda.

${ }^{456}$ Brenneisen; Staack (1999b), S. 5.

${ }^{457}$ von Zezschwitz (2002), S. 11; Büllesfeld (2002), S. 24 ff.; Edenfeld (2000), S. 323 ff.

${ }^{458} 3$-S steht für "Service, Sicherheit und Sauberkeit“.
} 
platz und von Bahnsteigen in eine Zentrale mit 16 Monitoren übertragen, zu der der Polizei und dem Bundesgrenzschutz durch einen eigenen Arbeitsplatz Zugang gewährt wird. ${ }^{459}$ Auch in Berlin kooperieren am Bahnhof Zoologischer Garten die Deutsche Bahn AG und die Beamten des Bundesgrenzschutzes als Einheit gegen die lokale Kriminalität. ${ }^{460}$

Die Zusammenarbeit zwischen den privaten Gruppen und staatlichen Behörden kann man ebenfalls am Videoüberwachungsprojekt in Sylt beobachten. Wie schon in Teil I dargestellt, handelt es sich hierbei um eine Sicherheitspartnerschaft zwischen den Vertretern der Gemeinde, Grundstücksbesitzern, Ladeninhabern sowie Polizeibeamten. ${ }^{461}$

Ferner ist der Zentralverband Elektrotechnik- und Elektroindustrie e.V. (ZVEI) als Vertreter der deutschen Elektroindustrie zu nennen, der nicht nur Konzepte von Videoüberwachungsmaßnahmen für Unternehmen und Behörden, sondern auch für öffentliche Räume entwirft. Der Verband erteilt den potentiellen Betreibern von Überwachungskameras Hinweise zu Voraussetzungen, Rahmenbedingungen und Vorgehensweise bei der Implementierung von Videoüberwachungssystemen. Die Anwendung von Überwachungskameras auf dem Hardenberg-/Breitscheidplatz in Berlin wurde beispielsweise von ZVEI neben alternativen Sicherheitsmaßnahmen gegen die Kriminalitätsprobleme, wie z.B. Erhöhung der Polizeipräsenz, Umgestaltung und Beleuchtung des Platzes, als geeigneter Problemlösungsansatz vorgestellt. $^{462}$

\subsubsection{Staatsinterne Kontrollinstanzen}

Im Folgenden werden die Vorbehalte gegen die Ausweitung polizeilicher Videoüberwachung auf Seiten des Staates erläutert. Zunächst sollen die gesetzlichen Rahmenbedingungen als rechtliches Instrument zur Einschränkung der Ausweitung von Überwachungskameras geschildert werden. Anschließend werden die Akteure, die die Einhaltung dieser rechtlichen Grundlagen beaufsichtigen, als kontrollierende Verwaltungsinstanzen dargestellt.

\subsubsection{Rechtliche Kontrolle}

Eine widerrechtliche Videoaufzeichnung sowie deren Weitergabe können rechtliche Konsequenzen nach sich ziehen. Gesetzwidrige Aufnahmen dürfen beispielsweise

\footnotetext{
${ }^{459}$ Weichert (1998a), S. 65 ff.

${ }^{460}$ Gras (2003), S. 262; Wehrheim (2002), S. 134.

${ }^{461} \mathrm{Vgl}$. Teil I, Kap. 3.1.2.2 dieser Arbeit.

${ }^{462}$ Zentralverband der Elektrotechnik- und Elektroindustrie e.V. (ZVEI) (2001b); vgl. auch Zentralverband der Elektrotechnik- und Elektroindustrie e.V. (ZVEI) (2003).
} 
nicht vor Gerichten zugelassen werden und können unter Umständen zu Schadensersatz-, Unterlassungs- und sogar Schmerzensgeldansprüchen führen. Im Folgenden werden die relevanten rechtlichen Regelungen zur Videoüberwachung in der Bundesrepublik vorgestellt.

\section{a) Bundesdatenschutzgesetz}

Seit der Novellierung des Bundesdatenschutzgesetzes (BDSG) im Jahr 2001, die auf der Basis der EU-Datenschutzrichtlinie erfolgte, sind datenschutzrechtliche Vorschriften beim Videoeinsatz in öffentlich zugänglichen Räumen in Deutschland zu beachten. ${ }^{463}$

Sowohl die Erhebung, Verarbeitung und Nutzung personenbezogener Daten $(\S 1$ Abs. 2 BDSG) als auch die Sachdienlichkeit bei der Anwendung von Videogeräten (Zulässigkeitsprüfung gemäß § 4 BDSG) werden im BDSG geregelt. Auch das Prinzip der Datenvermeidung und Datensparsamkeit (§ 3a BDSG) sowie die Videoüberwachung zu Geschäftszwecken (§ 28 BDSG) werden im Gesetzestext näher erläutert. $^{464}$

Neu aufgenommen in das novellierte Datenschutzgesetz ist der $\S 6 \mathrm{~b}$ BDSG, womit der Einsatz optisch-elektronischer Einrichtungen im öffentlichen Raum in der Bundesrepublik geregelt wird. Nach $\S 6 \mathrm{~b}$ des Gesetzes ist die Durchführung der Videoüberwachungsmaßnahme zulässig, „,soweit sie zur Aufgabenerfüllung öffentlicher Stellen, zur Wahrnehmung des Hausrechts oder zur Wahrnehmung berechtigter Interessen für konkret festgelegte Zwecke erforderlich ist und keine Anhaltspunkte bestehen, dass schutzwürdige Interessen der betroffenen Personen überwiegen“. 465 Die Speicherung der Bildmaterialien ist dann zu bejahen, wenn diese zum Zweck der Videoüberwachung unbedingt erforderlich ist. ${ }^{466}$

Diese Bestimmungen gelten auch für private Betreiber, die ihre Videoanlagen auf öffentlich zugängliche Räume richten. ${ }^{467}$ Ferner ist nach dem Gesetz die Videoüberwachung offen zu führen, wobei die Anbringung eines sichtbaren Hinweisschildes

\footnotetext{
${ }^{463}$ Die Gesetze erfassen nur die öffentlich zugänglichen Räume wie Bahnhöfe oder Museen. Für die nicht öffentlich zugänglichen Räume gilt z.B. das Arbeitnehmer-Datenschutzgesetz. Vgl. Schierbaum (2003), S. $439 \mathrm{ff}$.

${ }^{464}$ Mehr zu den gesetzlichen Bestimmungen vgl. ebenda, S. 439 ff.

${ }^{465}$ Vgl. Gras (2003), S. 258 und Bausch (2004), S. 138 ff.

${ }^{466}$ Ebenda.

${ }^{467}$ Am 18. Dezember 2003 entschied das Berliner Amtsgericht Mitte in einem Präzedenzfall, dass private Videoüberwachung am Gebäude den Bereich eines einen Meter breiten Streifens um das Bauwerk herum nicht überschreiten darf. Private Personen und Unternehmen sind für ihre Überwachungseinrichtungen eigenverantwortlich und müssen dabei die bundesdatenschutzrechtlichen Bestimmungen berücksichtigen. Vgl. Lietz (2004). Vgl. auch Gras (2003), S. 258; Gerhold; Heil (2001), S. 379.
} 
im Sinne dieser Vorschrift ausreichend ist. Die Nutzung der gesammelten Daten, die nicht im Rahmen der Verwendungszwecke (mit Ausnahme von behördlicher Gefahrenabwehr und Strafverfolgung) vorgesehen ist, wird hierbei nicht zugelassen. ${ }^{468}$ Für die Transparenz des Überwachungsvorganges ist ebenfalls vorgeschrieben, dass die Verantwortlichen für die Videoüberwachung an den Hinweisschildern kenntlich gemacht werden sollen, damit die Betroffenen sich gegebenenfalls an die zuständigen Stellen wenden können. ${ }^{469}$

Durch diese Vorschriften im BDSG wird in Deutschland eine gesetzliche Grundlage für den Einsatz optischer Überwachungstechnik in öffentlich zugänglichen Räumen geschaffen, die weiter reicht als die allgemeinen EU-Datenschutzrichtlinien. ${ }^{470}$ Dies macht deutlich, welche Bedeutung der deutsche Gesetzgeber der Wahrung des Rechts auf informationelle Selbstbestimmung beimisst.

\section{b) Polizeigesetze, Persönlichkeitsrecht und andere Rechtsgrundlagen}

Die speziellen Regelungen zur Videoüberwachung öffentlicher Straßen und Plätze in Polizeigesetzen ermächtigen einerseits die deutschen Polizeibehörden in den jeweiligen Bundesländern, Überwachungskameras in Maßnahmen zur vorbeugenden Kriminalitätsbekämpfung einzusetzen, andererseits bringen sie auch gewisse rechtliche Einschränkungen mit sich. Die maximale Frist zur Speicherung der Daten ist beispielsweise vorgeschrieben. Die Dauer kann je nach Bundesland von zwei Wochen (z.B. dem Saarland) bis zu zwei Monaten (z.B. in Bayern) variieren. In NordrheinWestfalen ist das gespeicherte Bildmaterial sogar „unverzüglich“ zu löschen, sofern es nicht den Zweck der Strafverfolgung erfüllt. Brandenburg schreibt überdies als einziges Bundesland explizit eine Probephase für die Maßnahme vor. Die Landesregierung Brandenburg ist damit verpflichtet, nach fünf Jahren dem Landtag einen umfassenden Lagebericht als Entscheidungsgrundlage für die Fortsetzung der Regelungen vorzulegen. ${ }^{471}$ Ferner darf nach den allgemeinen Polizeigesetzen in SachsenAnhalt und Niedersachsen die Polizei lediglich nach dem Kamera-Monitor-Prinzip arbeiten, d.h. nur die reine Bildübertragung ist rechtlich gestattet und die Polizeidienststelle ist nicht befugt, Aufnahmen von überwachten Orten anzufertigen. ${ }^{472}$

Das allgemeine Persönlichkeitsrecht im Grundgesetz (Art 2 Abs. 1 GG in Verbindung mit Art. 1 Abs. 1 GG) umfasst u.a. sowohl das Recht an Intim- und Privatsphäre als

\footnotetext{
${ }^{468}$ Vgl. Gras (2003), S. 258 und Gerhold; Heil (2001), S. 379 ff.

${ }^{469}$ Roos (2002), S. 467.

${ }^{470}$ Mehr zu § 6b BDSG vgl. Schierbaum (2003), S. 439 ff.

${ }^{471}$ Büllesfeld (2002), S. $157 \mathrm{ff}$.

${ }^{472}$ Ebenda, S. 152 ff.
} 
auch das vom Bundesverfassungsgericht (BVerfG) entwickelte Recht auf informationelle Selbstbestimmung und das Recht am eigenen Bild. „Das Recht am eigenen Bild schützt nicht nur vor jeder Art unbefugter Verbreitung und Veröffentlichung, sondern auch vor jeder Art der unbefugten Anfertigung eines Bildes einer Person. ${ }^{4473}$ Die Überwachung via Videotechnik zählt aufgrund der informationsreichen Bildmaterialien zu den eindringlichsten Formen der Sammlung, Speicherung und Verwendung von personenbezogenen Daten. Vor diesem Hintergrund ist bei Videoüberwachung auf jeden Fall das allgemeine Persönlichkeitsrecht zu beachten. Der Eingriff in das Recht am eigenen Bild, der durch Videoüberwachung zustande kommen könnte, ist ebenfalls in der Strafprozessordnung ( $\$ 100 \mathrm{c} \mathrm{I} \mathrm{Nr.} \mathrm{1a} \mathrm{StPO)} \mathrm{geregelt.} \mathrm{Hier} \mathrm{wird} \mathrm{die}$ Überwachungskamera als Mittel zur Observierung bestimmter verdächtiger Personen verstanden und nicht als Werkzeug der allgemeinen Kriminalprävention. Polizeiliche Videoüberwachung mit kriminalpräventivem Charakter wird von diesem Gesetz nicht erfasst. ${ }^{474}$

Auch das Kunsturhebergesetz (KUG) enthält Regelungen zur Anwendung von Videogeräten. $\S 22$ und $\S 23$ KUG regeln das Recht am eigenen Bild und verleihen dem Betroffenen das Recht, über die Weitergabe seines eigenen Bildnisses zu bestimmen. ${ }^{475}$ Nach § 24 KUG dürfen personenbezogene Daten zum "Zweck der Rechtspflege und der öffentlichen Sicherheit" veröffentlicht werden, wenn diese Maßnahme von den zuständigen Behörden bestätigt wird. ${ }^{476}$

$\S 12 \mathrm{a}$ und $\S 19 \mathrm{a}$ des Versammlungsgesetzes versetzen die Polizei in die Lage, Videoaufnahmen von Teilnehmern einer Versammlung anzufertigen, falls „tatsächliche Anhaltspunkte die Annahme rechtfertigen, dass von ihnen erhebliche Gefahren für die öffentliche Sicherheit oder Ordnung ausgehen“ (§ 12a Abs. 1 VersammlG). ${ }^{47}$ Es handelt sich hierbei jedoch um eine spezielle Form von polizeilicher Videoüberwachung, die zeitlich und örtlich beschränkt ist. ${ }^{478}$

\footnotetext{
${ }^{473}$ Schierbaum (2003), S. 440.

${ }^{474} \S 481$ StPO gibt an, dass die gesetzliche Grundlage zur Verwendung von optisch-elektronischen Einrichtungen zum „unbestimmten Zwecke der Vorbeugung“ in dem jeweiligen Landespolizeirecht $\mathrm{zu}$ finden ist. Vgl. Gras (2003), S. $252 \mathrm{ff}$.

${ }^{475}$ Schierbaum (2003), S. $439 \mathrm{ff}$.

${ }^{476} \operatorname{Roos}(2002)$, S. 466.

${ }^{477}$ Gras (2003), S. 251; vgl. auch Frerichs (2000), S. 78 ff.; Weichert (1998a); S. 68 f.

${ }^{478}$ Inwiefern diese mit dem Grundrecht zur Versammlungsfreiheit zu vereinbaren ist, vgl. Gras (2003), S. 251.
} 


\section{c) Gerichtliche Entscheidungen}

Das Bundesverfassungsgericht betrachtet die technische Überwachung mit Wissen der Überwachten als Eingriff in die bürgerrechtlichen Persönlichkeitsrechte der Betroffenen:

„Wer unsicher ist, ob abweichende Verhaltensweisen jederzeit notiert und als Informationen dauerhaft gespeichert, verwendet und weitergegeben werden, wird versuchen, nicht durch solche Verhaltensweisen aufzufallen. Wer damit rechnet, dass etwa die Teilnahme an einer Versammlung oder Bürgerinitiative behördlich registriert wird und dass ihm dadurch Risiken entstehen können, wird möglicherweise auf eine Ausübung seiner entsprechenden Grundrechte (Art. 8, 9 GG) verzichten. Dies würde nicht nur die individuellen Entfaltungschancen des Einzelnen beeinträchtigen, sondern auch das Gemeinwohl. ${ }^{4479}$

Auch das Recht auf informationelle Selbstbestimmung, das vom Bundesverfassungsgericht im Volkszählungsurteil vom 15. Dezember 1983 besiegelt wurde, findet heute bei allen Überwachungsmaßnahmen mit Videokameras Anwendung:

„Wer nicht mit hinreichender Sicherheit überschauen kann, welche ihn betreffenden Informationen in bestimmten Bereichen seiner sozialen Umwelt bekannt sind, und wer das Wissen möglicher Kommunikationspartner nicht einigermaßen abzuschätzen vermag, kann in seiner Freiheit wesentlich gehemmt werden, aus eigener Selbstbestimmung zu planen oder zu entscheiden. Mit dem Recht auf informationelle Selbstbestimmung wären eine Gesellschaftsordnung und eine Rechtsordnung nicht vereinbar, in der Bürger nicht mehr wissen können, wer was wann und bei welcher Gelegenheit über sie weiß. ${ }^{4480}$

Der Verwaltungsgerichtshof Baden-Württemberg hat in seinem Urteil vom 21.07.2003 erklärt, dass ein „Kriminalitätsschwerpunkt“, der die öffentliche Videoüberwachung rechtfertigt, sich in Hinsicht auf die Kriminalitätsbelastung deutlich von anderen vergleichbaren Standorten in derselben Stadt abheben muss. ${ }^{481}$ Dabei ist eine Lagebeurteilung des Kamerastandortes unter Berücksichtigung der Straftaten, insbesondere der Straßenkriminalität, die das Sicherheitsgefühl der Bevölkerung beeinträchtigen, erforderlich. Dazu gehören genauere Angaben über die bisherigen Ereignisse an der zu überwachenden Örtlichkeit, wobei allgemeine statistische Daten nicht ausreichen. Obligatorisch sind die Angaben über die Kriminalitätsbelastung im

\footnotetext{
${ }^{479}$ Weichert (1998a), S .66 und Schierbaum (2003), S. 439 ff.

${ }^{480}$ Lietz (2004); Büllesfeld (2002), S. 235; Schierbaum (2003), S. 439 ff.

${ }^{481}$ Der Bayerische Landesbeauftragte für den Datenschutz (2004), S. 49 ff.
} 
zu observierenden Gebiet im Vergleich zur Straßenkriminalität im gesamten Stadtbezirk und anderen Stadtvierteln. Solche Verwaltungsvorschriften, die z.B. in BadenWürttemberg unter der Bezeichnung „Führungs- und Einsatzanordnung Videoüberwachung im öffentlichen Raum “482 bekannt sind, dienen als Erläuterung der Gesetze in der alltäglichen Praxis der Videoüberwachung. Eine geplante polizeiliche Videoüberwachungsmaßnahme auf dem Schützenfest in Biberach im Jahr 2004 wurde beispielsweise vom Verwaltungsgericht Sigmaringen untersagt, da es sich dabei nicht um einen Kriminalitätsschwerpunkt handelte. ${ }^{483}$ Neben der Festlegung des Einsatzziels und der Begründung der Videoaufzeichnung ist die Anbringung von Hinweisschildern eine notwendige Voraussetzung zur Durchführung offener, polizeilicher Videoüberwachung. ${ }^{484}$

\subsubsection{Verwaltungskontrolle}

Verwaltungsrechtliche Bestimmungen zur polizeilichen Videoüberwachung sind nicht ohne Weiteres praktikabel. Zur wirksamen Einhaltung der Gesetze und Verwaltungsvorschriften sind Kontrollinstanzen notwendig, um die praktische Umsetzung solcher Anordnungen zu beaufsichtigen. Als verwaltungsrechtliche Aufsichtsbehörde fungieren hierbei die Landesbeauftragten für den Datenschutz. Außerdem üben manche deutsche Polizeidienststellen "Selbstkontrolle“ aus. Im Folgenden werden diese zwei Akteure in der Durchführung ihrer Kontrollaufgaben näher erläutert.

\section{a) Datenschutzbeauftragte}

In den 1970er Jahren fand in Deutschland ein grundlegender Konzeptwandel in der Kontrollfrage im Hinblick auf Datenerhebung statt. Während man früher keine Notwendigkeit darin gesehen hatte, die Einhaltung der betreffenden Gesetze durch eine umfassende externe Kontrolle abzusichern, beschlossen Vertreter aller Fraktionen nach intensiven Debatten und öffentlichen Anhörungen die Einführung einer externen Kontrollinstanz. ${ }^{485}$

\footnotetext{
${ }^{482}$ Der Landesbeauftragte für den Datenschutz Baden-Württemberg (2001), S. 24.

${ }^{483}$ Pressemitteilung vom Verwaltungsgericht Sigmaringen (2004b).

${ }^{484}$ Der Landesbeauftragte für den Datenschutz Baden-Württemberg (2001), S. 23 ff.

485 „Während die Bundesregierung für die Schaffung einer externen Kontrollinstanz keine Notwendigkeit gesehen hat, da die Einhaltung der Gesetze durch Parlament, Rechnungshöfe und Gerichte sowie durch verwaltungsinterne Aufsicht bereits hinreichend kontrolliert werde, bekannten sich im Verlauf der intensiven parlamentarischen Beratungen die Vertreter aller Fraktionen zur Einführung einer umfassenderen externen Kontrolle. Sie entsprachen damit einer praktisch einhelligen Forderung der Wissenschaft und der Öffentlichkeit, der lediglich Stimmen der von der Kontrolle betroffenen Personen und Stellen gegenüberstanden." Rossnagel (2003), S. 751 ff.
} 
Das hessische Datenschutzgesetz vom Jahr 1970 wurde als weltweit erste gesetzliche Regelung zur Gewährleistung der Grund- und Freiheitsrechte der Staatsbürger und zur Kontrolle öffentlicher Befugnisse verabschiedet. ${ }^{486}$ Am 1. Februar 1977 folgte die Verkündung des ersten Bundesdatenschutzgesetzes. ${ }^{487}$

Zuständig für die Einhaltung der Regelungen des Datenschutzgesetzes sind die Datenschutzbeauftragten. Sie haben ferner die Aufgabe, Transparenz im Umgang mit den Daten der Bürger zu gewährleisten und die Sicherung des Grundrechts auf informationelle Selbstbestimmung zu garantieren. Sie sind mit eigener Zuständigkeit versehen und nur dem Innenminister unmittelbar untergeordnet, auch wenn sie organisatorisch gesehen zum Innenministerium gehören. Demnach kann man die Datenschutzbeauftragten als ranghöchste Bundesbehörde betrachten. Jeder Bürger kann ohne zusätzliche behördliche oder gerichtliche Dienstwege den direkten Kontakt zu ihm als „Anwalt des Bürgers“ aufnehmen. ${ }^{488}$ In regelmäßigen Zeitabständen informieren sie durch Tätigkeitsberichte das Innenministerium und die Öffentlichkeit über Ergebnisse ihrer Arbeit. Im Gegensatz zu der britischen Kontrollinstanz „Information Commissioner ${ }^{\prime 489}$ handelt es sich bei den deutschen Datenschutzbehörden um einen ausgebauten Verwaltungsapparat, der in vielen datenschutzrelevanten Bereichen aktiv seine Kontrollfunktion ausübt.

In den Entscheidungsprozessen zur polizeilichen Videoüberwachung öffentlicher Straßen und Plätze fungieren die Landesbeauftragten für Datenschutz in vielen Fällen als wichtige Berater und Inspekteure. In der Vorbereitungsphase des ersten Pilotprojektes zur Videoüberwachung in Leipzig wurden beispielsweise die sächsischen Datenschutzbeauftragten in die Rechtsberatung einbezogen. Damit wollten die Verantwortlichen des Projektes die Rechtsgrundlage ihres Vorhabens absichern. Wei-

${ }^{486}$ Nungesser (1988), S. XIII.

${ }^{487}$ Simitis (1977), S. 729 ff.; Simitis (1990), S. 138 ff; Panagiotides (1998), S. 20.

${ }^{488}$ Der Bundesbeauftragte für den Datenschutz (BfD) ist für die Kontrolle der Bundesbehörden sowie anderer öffentlichen Stellen wie die Telekommunikations- und Postdienstunternehmen zuständig, während die Prüfung von Behörden der Landes- und Kommunalverwaltung und sonstigen öffentlichen Stellen ihres jeweiligen Bundeslandes zu dem Aufgabenbereich des Landesbeauftragten für den Datenschutz (LfD) gehört. Für den privaten Bereich und die interne betriebliche Kontrolle sind zusätzlich die Aufsichtsbehörden für den nichtöffentlichen Bereich und betriebliche Datenschutzbeauftragte zuständig. Der Landesbeauftragte für den Datenschutz (LfD) verfügt auf der Landesebene über ähnliche Aufgaben und Ermächtigungen wie der BfD. Die Wahl sowie die Abwahl des LfD werden von den jeweiligen Landtagen bestimmt. Der LfD ist allerdings nur in einigen Bundesländern die oberste Landesbehörde, wobei ihre Arbeitsstellen entweder bei der Landesregierung oder beim Landtag zu finden sind. $\mathrm{Zu}$ den Kontrollinstanzen des Datenschutzes gehören auch die Aufsichtsbehörden für den nichtöffentlichen Bereich, die durch die Landesregierung ermächtigt sind und "staatliche“ Kontrolle ausüben. Dagegen üben die betrieblichen und behördlichen Datenschutzbeauftragten interne (Selbst-) Kontrolle aus. In der Konferenz der Datenschutzbeauftragten des Bundes und der Länder, die zum ersten Mal im Dezember 1978 in Hessen stattfand und seitdem regelmäßig erfolgt, wird die Möglichkeit einer Zusammenarbeit mit den Kontrollbehörden anderer Länder und des Bundes wahrgenommen. Vgl. Rossnagel (2003), S. 749 ff.

${ }^{489} \mathrm{Vgl}$. später in diesem Kapitel. 
tere Pilotprojekte zur Videoüberwachung in Deutschland, z.B. in Stuttgart und Frankfurt a.M. wurden ebenfalls von den zuständigen Datenschutzbehörden begleitet. $^{490}$

Die Kommunikation zwischen den ausführenden und kontrollierenden Behörden ist uneinheitlich. Während in manchen Fällen die Polizeidirektionen die Datenschutzbehörden selbstständig auffordern, die geplanten Projekte auf Rechtmäßigkeit zu überprüfen und sie über den Vorgang der Maßnahmen informieren, erfahren Datenschutzbeauftragte in anderen Fällen die Planung eines Videoeinsatzes durch die Medien. Erst durch die aktive Einforderung der notwendigen Unterlagen durch die Datenschutzbeauftragten wird eine genauere Überprüfung der Rechtslage vorgenommen: Die Münchener Polizei hat frühzeitig vor dem Beginn des Oktoberfestes im Jahr 2002 die Datenschutzbehörde vom Einsatz von neun Kameras auf der Wiesn unterrichtet und ist dem Vorschlag des Datenschützers nachgekommen, Hinweisschilder in deutscher und englischer Sprache sowie mit der grafischen Darstellung einer Kamera anzubringen. ${ }^{491}$ Eine gute Zusammenarbeit zwischen Polizei und Datenschutzbehörde war auch bei den Videoüberwachungsmaßnahmen in Stuttgart zu beobachten. Anhand eines detaillierten Kriminalitätslagebildes der zuständigen Polizeidirektion Stuttgart II bestätigte der baden-württembergische Datenschutzbeauftragte die videoüberwachte Zone des Rotebühlplatzes als Kriminalitätsschwerpunkt, welcher den Einsatz von Überwachungskameras rechtfertigte. ${ }^{492}$ Als die Kriminalitätslage sich durch den Videoeinsatz verbesserte, wurde die Datenschutzbehörde von der Polizei über das Abschalten der Anlagen informiert. Dagegen blieb das Bedenken der baden-württembergischen Datenschutzbehörde bezüglich des Projektes in Mannheim unberücksichtigt. Nachdem das Verwaltungsgericht Karlsruhe die Klage eines Mannheimer Bürgers gegen die Videoüberwachung in der Mannheimer Innenstadt abgewiesen hat, betreibt die Polizei die Maßnahme der Videografie heute weiterhin mit dem Einverständnis des Innenministeriums. ${ }^{493}$

Nicht nur die Videoüberwachung öffentlicher Straßen und Plätze gehört zum Aufgabenbereich der Datenschutzbeauftragten. Auch die Observierung öffentlich zugänglicher Räume wird aktiv von ihnen inspiziert. Durch die Kontrolle der Datenschützer hat die Stadt Freiburg die Videoüberwachungsmaßnahmen in den Umkleidekabinen eines Hallenbades eingestellt, bevor datenschutzkompatible Lösungen

\footnotetext{
${ }^{490}$ Müller (1997), S. 78.

${ }^{491}$ Der Bayerische Landesbeauftragte für den Datenschutz (2002), S. 111 ff.

${ }^{492}$ Der Landesbeauftragte für den Datenschutz Baden-Württemberg (2001), S. 23 ff.

${ }^{493}$ Ebenda, S. 25 ff.
} 
erarbeitet werden konnten. ${ }^{494}$ Auch das städtische Krankenhaus in Sindelfingen hat Überwachungskameras im Eingangsbereich abgeschaltet, nachdem die Datenschutzbeauftragten die zuständigen Stellen auf das Fehlen zwingender datenschutzrechtlicher Voraussetzung dieser Maßnahmen hinwiesen. ${ }^{495}$ Durch die Intervention der Datenschutzbehörden wurden die Verantwortlichen der Universität Konstanz ebenfalls auf die Unrechtmäßigkeit der Bildaufzeichnungsmaßnahmen in ihrer Universitätsbibliothek aufmerksam gemacht. ${ }^{496}$

\section{b) Polizei}

Trotz zunehmender polizeilicher Videoüberwachung wird die Ausweitung dieser Technik auch durch Vorbehalte auf Seiten der Polizei eingeschränkt. Die Bundesarbeitsgemeinschaft kritischer Polizisten in Köln sowie die Polizeidirektion in Heidelberg lehnen beispielsweise die öffentliche Videoüberwachung ab. ${ }^{497}$ In Brandenburg und in Düsseldorf wurden die Maßnahmen zur öffentlichen Videografie erst widerwillig von der Polizei umgesetzt. ${ }^{498}$ Der Bundesvorsitzende der Gewerkschaft der Polizei (GdP) äußerte sein „Unbehagen über die zunehmende Videoüberwachung“ beim Innenausschuss des Bundestages. ${ }^{49}$ Neben Vorbehalten gegenüber der langweiligen Beobachtungsarbeit an Monitoren dürfte die Befürchtung von Stellenabbau im Zusammenhang mit Videoüberwachung für die ablehnende Haltung der Polizei entscheidend sein. Deswegen hieß es in einem Positionspapier der Gewerkschaft der Polizei: „Die notwendige polizeiliche Präsenz ist durch die technische Überwachung nicht zu ersetzen bzw. einzuschränken. ${ }^{4500}$

Das Bedenken der Polizei gegenüber der Videoüberwachung resultiert jedoch nicht nur aus Ängsten vor Personaleinsparungen. Häufig weisen die deutschen Polizeibehörden darauf hin, dass in Deutschland keine „englischen Verhältnisse“ der Videoüberwachung erwünscht seien. ${ }^{501}$ In Wiesbaden stimmte der Polizeipräsident zwar dem temporären Einsatz von Überwachungskameras an Kriminalitätsschwerpunkten im Zeitraum von wenigen Monaten zu, lehnte aber eine permanente Videoüberwachung ab..$^{502}$ In Leipzig lehnte man ebenfalls aus datenschutzrechtlichen Gründen eine Vernetzung der polizeilichen Kameras mit den Anlagen der Bahn und der Ver-

\footnotetext{
${ }^{494}$ Der Landesbeauftragte für den Datenschutz Baden-Württemberg (2003), S. 103 ff.

${ }^{495}$ Ebenda.

${ }^{496}$ Ebenda.

${ }^{497}$ Gras (2003), S. 268.

${ }^{498}$ Töpfer (2005), S. 7 ff.; vgl. auch Teil I, Kap. 3.1.3 dieser Arbeit.

${ }^{499}$ Die Welt (1999); Spinrath (1999), S. 87.

500 Töpfer (2005), S. 5 ff.

${ }^{501}$ Frerichs (2000), S. 83f; Bäumler (1999).

${ }^{502}$ Töpfer (2005), S. 5 ff.
} 
kehrsüberwachung ab, obwohl diese technisch realisierbar war. ${ }^{503}$ Der Bund Deutscher Kriminalbeamter (BDK) zeigt zwar kein Verständnis für die Ablehnung dieser Maßnahmen, forderte aber die Regierung auf, rechtsstaatliche Fragen der Videoüberwachung im Polizeigesetz zu regeln. Der Landesvorsitzende vom BDK erklärte: „Der BDK will nicht Big Brother. ${ }^{\prime 504}$

Das im Januar 2001 gestartete Videoüberwachungsprojekt in Stuttgart wurde nach 18 Monaten im Juli 2003 von der Polizeidirektion Stuttgart II beendet. Die Ergebnisse der Überwachungsmaßnahmen waren nach Angaben der Polizei so erfolgreich, dass der videoüberwachte Rotebühlplatz nicht mehr als Kriminalitätsbrennpunkt eingestuft werden konnte. Der Polizeipräsident begründete diese Entscheidung als „rechtlich geboten und auch konsequent, (...), um nicht ohne Not in die Grundrechte der Bürgerinnen und Bürger einzugreifen“ ${ }^{405}$ Die Polizeidirektion in Heilbronn hat ebenfalls zum 1. Oktober 2005 das seit dem 1. Juli 2002 laufende Videoüberwachungsmaßnahme abgebrochen, da der Überwachungsbereich aufgrund des Erfolges nicht mehr als Kriminalitätsschwerpunkt galt und somit die zwingende Voraussetzung für die Fortsetzung dieses Beobachtungsmittels entfallen war. ${ }^{506}$

\subsubsection{Nichtstaatliche Gegenkräfte}

Das erste Pilotprojekt polizeilicher Videoüberwachung in Leipzig hat die ersten Protestbewegungen gegen Videoüberwachung ausgelöst. Gegen die polizeiliche Videoüberwachung wurde mehrmals im Zeitraum zwischen Januar und Oktober 2000 mit dem Motto "Abschotten, Überwachen, Ausgrenzen - null Toleranz" demonstriert. Veranstaltet wurden diese Gegenbewegungen von den lokalen Bürgerinitiativen wie z.B. Das Bündnis gegen Rechts Leipzig als „Kampagne zur Rückgewinnung öffentlicher Räume“. Eine der Demonstrationen wurde von einem PDS-Landtagsabgeordneten gemeinsam mit einem Mitglied des sächsischen Landesvorstands von Bündnis 90/Die Grünen angemeldet. Während die Demonstranten die Demontage der Kamera am Connewitzer Kreuz im Jahr 2000 als Erfolg der Proteste sahen, begründete die Polizei den Entschluss mit dem Rückgang der Straftaten im überwachten Gebiet. ${ }^{507}$ Mit einer Eingabe an den sächsischen Datenschutzbeauftragten konnte die Initiative gegen Überwachung „Leipziger Kamera“ veranlassen, dass die polizeiliche Video-

\footnotetext{
${ }^{503}$ Ebenda; vgl. auch Krischer; Holzer (2000), S. 52.

${ }^{504}$ Pressemitteilung vom BDK am 06.04.2000. Bund Deutscher Kriminalbeamten (2000).

${ }^{505}$ Polizei Stuttgart (2003).

${ }^{506}$ Der Landesbeauftragte für den Datenschutz Baden-Württemberg (2005a).

${ }^{507}$ Leipziger Volkszeitung (2000a).
} 
überwachung an der Ritterstraße in Leipzig beendet wurde, die gesetzwidrig den ganzen Straßenzug erfasste. ${ }^{508}$

Neben Erfahrungen in Leipzig wurde auch das Pilotprojekt in Weimar zum Schutz der Pressefreiheit abmontiert: Im Oktober 2003 begann in Weimar am Goethe- und Theaterplatz das Projekt zur Videoüberwachung, wobei drei Überwachungskameras verwendet wurden, um die zwei Kriminalitätsbrennpunkte unter Überwachung zu stellen. Dies fand im Rahmen des Sicherheitspakets statt, das der Thüringer Landtag als Reaktion auf die Terroranschläge vom 11. September 2001 in den USA verabschiedet hat. ${ }^{509}$ Allerdings gerieten dabei die Redaktionsräume zweier Lokalzeitungen (Thüringer Allgemeine und Thüringische Landeszeitung) sowie das Büro der Vizepräsidentin des Thüringer Landtages in das Blickfeld der Überwachungskameras, so dass das Projekt bundesweit Empörung hervorrief. Parlamentarier der SPD, der PDS und der Grünen sowie der Journalistenverband DJV und die betroffenen lokalen Zeitungen protestierten mit offenen Briefen, Pressemitteilungen und Beschwerden an die Landesregierung. Nur wenige Tage nach dem Beginn des Projektes wurden alle Kameras abgebaut und alle gespeicherten Bilddaten gelöscht, um den "sehr sensibl[en] Bereich des Pressehauses" wieder vor Eingriffen in die Pressefreiheit zu schützen. ${ }^{510}$

Angesichts des Zuwachses von Überwachungskameras in öffentlichen Räumen haben sich in verschiedenen deutschen Städten lokale Initiativen gegen Videoüberwachung gebildet. In Bremen hat die lokale Gruppe Aktuelle Kamera ${ }^{511}$ die Standorte der Überwachungskameras in der Bremer Innenstadt im Internet veröffentlicht, während ähnliche Informationen über die Überwachung öffentlicher Räume in Köln von der Initiative Chaos Circuit Television ${ }^{512}$ zur Verfügung gestellt werden. Der Anlass für diese Aktion war die intensive Nutzung der Videotechnik zum Weltwirtschaftsgipfel in Köln im Jahr 1999. Ähnliche Bürgerinitiativen sind ebenfalls in Hamburg (Offenes Auge) $)^{513}$, München (Der Große Bruder $)^{514}$, Mannheim (Kamera weg) $)^{515}$ und in Leipzig (Neues Forum Leipzig; Leipziger Kamera) zu finden. ${ }^{516}$

\footnotetext{
${ }^{508}$ Leipziger Kamera (2003b).

${ }^{509}$ Musharbash (2003).

${ }^{510}$ Barclay; Tavares (2003); Musharbash (2003).

${ }^{511}$ Vgl. unter: http:/ / www.aktuelle-kamera.org/.

512 http: / / koeln.cc. de/prozesse / zombies / cctv/.

${ }^{513}$ http: / / www.offenes-auge.de/.

${ }^{514}$ http: / / dergrossebruder.org/ times / 20040520000000.html?comment.

${ }^{515}$ http: / / www.rheinneckarinfo.net/ kameras-weg/navi/uepresse.html.

${ }^{516}$ http: / / www.nadir.org/nadir/initiativ/infoladen_leipzig/camera/ .
} 
Eine bundesweite Initiative mit Diskussionsforum bietet das Projekt STOP $1984^{517}$. Die im Jahr 1977 gegründete Deutsche Vereinigung für Datenschutz e.V. (DVD) hat sich zur Aufgabe gemacht, Bürger über die mögliche Einschränkung ihres Rechts auf informationelle Selbstbestimmung durch den Einsatz von elektronischer Datenverarbeitungstechnologie aufzuklären. ${ }^{518}$

Unter den verschiedenen Initiativen gegen Videoüberwachungsmaßnahmen findet häufig Gemeinschaftsarbeit statt. Das Forum InformatikerInnen für Frieden und gesellschaftliche Verantwortung e.V. (FIfF) hat beispielsweise im Jahr 2002 mit Mitgliedern der ältesten Bürgerrechtsorganisation in Deutschland, der Humanistischen Union ${ }^{519}$ sowie Wissenschaftlern aus verschiedenen Fachbereichen, darunter Sozialwissenschaftlern, Kriminologen und Informatikern der TU Berlin, HU Berlin und TU Darmstadt den Arbeitskreis Videoüberwachung und Bürgerrechte gegründet, der sich mit dem Thema auseinandersetzt und diesbezüglich Seminare und Infoveranstaltungen anbietet. $^{520}$

\subsubsection{Zusammenfassung}

In der Bundesrepublik beschränken sich öffentliche Videoüberwachungsmaßnahmen bisher auf gesetzlich definierte Kriminalitätsschwerpunkte. Das deutsche Innenministerium sieht den offenen Kameraeinsatz auf öffentlichen Straßen und Plätzen als hilfreiches Instrument für die Polizei, wobei die meisten Projekte von Kommunen oder Arbeitsgemeinschaften zwischen staatlichen und privaten Akteuren finanziert werden.

In Deutschland bieten die novellierten Bundesdatenschutzgesetze (BDSG) eine einheitliche gesetzliche Grundlage für die polizeiliche Observierung in öffentlichen Räumen, auch wenn die Polizeigesetze auf Landesebene in Details unterschiedlich ausfallen. Außerdem bieten u.a. das allgemeine Persönlichkeitsrecht und die Polizeigesetze den Überwachten in Deutschland die Möglichkeit, sich rechtlich vor der unerwünschten Videoaufnahme zu schützen. Vorbehalte gegenüber öffentlichen Videoaufzeichnungen sind in der Bundesrepublik bei der Polizei zu beobachten. Während manche Polizeibehörden die räumliche Observierung mittels Videotechnik begrüßen, pflegen andere Dienststellen einen eher skeptischen Umgang mit diesem

\footnotetext{
${ }^{517} \mathrm{http}: / /$ www.stop1984.org/.

${ }^{518} \mathrm{http}: / /$ www.datenschutzverein.de/.

${ }^{519}$ Die Humanistische Union, als älteste deutsche Bürgerrechtsorganisation, wurde im Jahr 1961 gegründet und hat sich zum Ziel gemacht, gegen die Einschränkung des Rechts auf freie Entfaltung der Persönlichkeit durch Staat, Wirtschaft und Kirchen vorzugehen. Vgl. http://www.humanistischeunion.de/info.php.

${ }^{520} \mathrm{http}$ / / waste.informatik.hu-berlin.de/peter/cctv/cctv_und_buergerrechte.html.
} 
technischen Instrument. Beispielsweise verzichten manche Polizeidienststellen freiwillig auf die Vernetzung der CCTV-Systeme, während andere die Überwachungsprojekte beim Fehlen eines vorhandenen „Kriminalitätsschwerpunktes“, der als notwendige Voraussetzung für die Maßnahmen gilt, selbstständig beenden.

Als Aufsichtsbehörde für die Einhaltung rechtlicher Rahmenbedingungen sind die jeweiligen Landesbeauftragten für den Datenschutz zuständig. Die Tätigkeiten der Datenschützer variieren zwischen aktiver Kontrolle der polizeilichen Überwachungspraxis und Kooperation mit der Polizei als Ratgeber für anstehende Maßnahmen. Zusätzlich zu den staatsinternen Kontrollinstanzen gibt es auch nichtstaatliche Protestbewegungen, z.B. in Weimar und Leipzig, die meistens spontan entstehen und sich auf bestimmte lokale Ereignisse richten.

\subsection{Die Situation in den USA}

\subsubsection{Proaktive Akteure}

Zunächst werden die Befürworter von CCTV-Überwachung als treibender Faktor für die Ausweitung der Videoüberwachung in den Vereinigten Staaten vorgestellt. Dazu zählen nicht nur staatliche Institutionen (Verwaltungsinstanzen und Polizei), sondern auch die Gemeinschaftsarbeit zwischen dem Staat und privaten Organisationen.

\subsubsection{Verwaltungsinstanzen}

Auf nationaler Ebene stellen das U.S. Office of Justice Assistance und das National Institute of Justice wichtige Finanzgeber für die CCTV-Programme in den USA dar. Im Rahmen von Bryne Memorial Formula Grant Program, Local Crime Prevention Block Grant Program und Office of Science and Technology Program wurden lokale Überwachungssysteme mit staatlichen Geldern unterstützt. ${ }^{521}$

Auf Ebene der Bundesstaaten werden ebenfalls staatliche Gelder für Videoüberwachungsprojekte bereitgestellt, wobei in den meisten Fällen Anträge für die Subventionen der Anlagen gemeinsam von der Stadtverwaltung, der örtlichen Polizei und lokalen Initiativen gestellt werden ${ }^{522}$ Für die Beantragung öffentlicher Gelder sind allerdings kriminalstatistische Nachweise zur Auswahl des CCTV-Standortes nicht notwendig. Staatlich finanzierte Projekte zur Videoüberwachung sind z.B. in Newark, Dover und South Orange zu finden. ${ }^{523}$

\footnotetext{
${ }^{521}$ Nieto et al. (2002), S. 13.

${ }^{522}$ Ebenda; vgl. auch Nieto (1997), S. 13 ff.

${ }^{523}$ Ebenda.
} 
Laut Aussage der League of California Cities gehört in Kalifornien die Videoüberwachung öffentlicher Räume zum Zweck der Kriminalprävention nicht zum gewöhnlichen polizeilichen Tätigkeitsbereich. Vielmehr wird diese Technik von lokalen Institutionen eingesetzt, wie z.B. in Bibliotheken, Parkanlagen und Sozialsiedlungen, um öffentliche Gebäude und Eigentum zu schützen. ${ }^{524}$

\subsubsection{Polizei}

Die verschiedenen US-amerikanischen Vollzugsbehörden bzw. Exekutivorgane, die entweder auf nationaler oder lokaler Ebene agieren, werden als Law Enforcement Agencies bezeichnet. Dazu gehören u.a. die lokalen Polizeibehörden, die bei der Einführung der Videoüberwachung in den USA mitwirken. Nach Angaben der International Association of Chiefs of Police steigt die Verwendung von Videokameras durch die US-amerikanische Polizei stetig. Bereits im Jahr 2001 benutzten nach Angaben einer Umfrage 80\% der insgesamt 19.000 US-amerikanischen Polizeibehörden Überwachungskameras. ${ }^{525}$ Und mehr als 200 amerikanische Vollzugsorgane auf Kommunal- und Länderebene (Local and State Law Enforcement Agencies) arbeiteten in polizeilichen Operationen mit der CCTV-Technik. ${ }^{526}$ Einer Umfrage der International Association of Chiefs of Police zufolge verwendeten 2002 die meisten Behörden Überwachungskameras in Polizeiwagen, innerhalb und außerhalb von Regierungsgebäuden oder bei besonderen Veranstaltungen. ${ }^{527}$ Im Folgenden werden einige dieser polizeilichen Dienststellen vorgestellt.

\section{a) Lokale Polizei}

Wie bereits in Teil I dieser Arbeit geschildert wurde, wird in der amerikanischen Hauptstadt Washington D.C. seit dem Jahr 2002 das größte Videoüberwachungsnetzwerk der USA aufgebaut, das vor allem vom D.C. Metropolitan Police Department kontrolliert wird. Auch in anderen US-Staaten haben sich die Polizeibehörden für Videoüberwachungsmaßnahmen entschieden. Seit 1986 wendet die Polizei in Georgia die Videoüberwachungstechnik an und wertet das Bildmaterial nicht nur in Polizeirevieren aus, sondern überträgt es direkt an jeden zehnten Streifenwagen. ${ }^{528}$ Die Polizei in Dade County, Florida beispielsweise entschied sich schon im Jahr 1982 für ein Videoüberwachungsprogramm, um dem Sicherheitsbedürfnis der Bewohner von

\footnotetext{
${ }^{524}$ Für das Betreiben der Videoüberwachung an Verkehrsampeln sind die Bundes- und Lokalbehörden (state and local law enforcement) sowie auserwählte Beamte zuständig. Seit 1992 investiert die Federal Highway Administration Millionen Dollar in Förderung von Überwachungskameras an Ampeln (red light surveillance cameras). Nieto et al. (2002), S. 17 ff.

${ }_{525} \mathrm{Hsu}(2002 \mathrm{~d}) ; \mathrm{Hsu}(2002 \mathrm{a})$; vgl. auch Bartsch (2004), S. 31.

${ }^{526}$ Nieto et al. (2002), S. 13.

${ }^{527}$ Ebenda.

${ }^{528}$ Wehrheim (2002), S. 87.
} 
Miami Beach nachzukommen und die Effizienz der kleinen polizeilichen Einheit zu steigern. Die lokale Polizei agiert in den meisten Videoüberwachungsprojekten als Hauptinitiator, wie z.B. in Baltimore, Tampa, Virginia und Dover. Selbst wenn die Vorschläge zur Implementierung der Überwachungskameras nicht von der Polizei stammen, wird diese jedoch immer in die entsprechenden Programme mit einbezogen, wie z.B. in Tacoma und Anchorage. Häufig übernehmen Polizeibeamte die Kontrollaufgaben an den Monitoren. ${ }^{529}$

Die Videoüberwachung erfolgt im Normalfall stationär oder wie erwähnt auch in Verbindung mit Streifenwagen. Inzwischen werden US-Städte auch aus der Luft überwacht. In Los Angeles wird beispielsweise die polizeiliche Videoüberwachung auch von Helikoptern aus durchgeführt. Zur besseren Orientierung und Beobachtung werden die Wohneinheiten mit Straßennummern gekennzeichnet. ${ }^{530}$

\section{b) National Park Police und Park Service}

Für die Unversehrtheit der National Mall mit ihren zahlreichen nationalen Wahrzeichen und Kriegsdenkmälern in der US-amerikanischen Hauptstadt Washington D.C. ist die National Park Police zuständig. Diese Aufgabe bewältigt sie seit Herbst 2002 ebenfalls mit einem Videoüberwachungssystem, in dem hunderte Kameras rund um die Uhr die nationalen Wahrzeichen überwachen. ${ }^{531}$ Anlass für diesen besonderen Schutz ist die Angst vor terroristischen Anschlägen, die seit dem 11. September 2001 in den USA extrem zugenommen hat. ${ }^{532}$ Schon im Jahr 1998 zeigte eine Studie des Park Service, unter deren Aufsicht die National Park Police steht, dass diese nationalen Denkmäler beliebte Ziele terroristischer Anschläge waren und deswegen besonderer Schutzmaßnahmen bedürften: ${ }^{533}$ "The icons of democracy are high targets of terrorist activity. That is [the cameras'] sole purpose. “534

Auch wenn die Überwachungskameras an den nationalen Einrichtungen nicht in erster Linie zu Zwecken der Strafverfolgung eingesetzt werden, so werden bei gege-

\footnotetext{
${ }^{529} \mathrm{Vgl}$. Teil I, Kap. 3.2.2.6 dieser Arbeit.

${ }^{530}$ Wehrheim (2002), S. 87.

${ }^{531} \mathrm{Hsu}(2002 \mathrm{~d})$.

${ }^{532}$ Bartsch (2004), S. 32.

${ }^{533} \mathrm{Hsu}(2002 \mathrm{~d})$.

${ }^{534}$ Neben den nationalen Wahrzeichen in Washington D.C. wie Washington Monument, Jefferson und Lincoln Memorials sowie Vietnam Veterans und Korean War Gedenkstätten stehen auch die Freiheitsstatue und Liberty Island in New York unter der Videoüberwachung von Park Police. Insgesamt agieren 800 Park-Polizeibeamte für die Sicherheit der amerikanischen nationalen Denkmäler. Vgl. Hsu (2002c) und Hsu (2002d).
} 
benem Anlass die daraus entstehenden Bilddaten, wie bereits in Teil I erwähnt, dem D.C. Metropolitan Police Department zugänglich gemacht. ${ }^{535}$

\subsubsection{Privat-öffentliche Kooperation}

Im privaten Bereich ist die Implementierung von Überwachungskameras schon länger Bestandteil der Sicherheitsvorkehrungen in den USA. ${ }^{536}$ Auch in vielen öffentlich zugänglichen Räumen wie Flughäfen und Bahnhöfen werden Überwachungskameras eingesetzt. Mit biometrischen Systemen kombinierte Videoüberwachung wurde bereits im Logan International Airport in Boston und T.F. Green Airport in Providence getestet, während Oakland International Airport und Fresco International Airport in Kalifornien diese bereits im produktiven Einsatz haben. ${ }^{537}$ Mittlerweile wird in einigen Städten der USA sogar die Videoüberwachung öffentlicher Räume hauptsächlich vom privaten Sektor betrieben. Beispielsweise werden in Hollywood die Initiative zur räumlichen Observierung mit Kameras von Grundbesitzern und Hauseigentümern eingeleitetet und finanziert. Auch der Balboa Park in San Diego wird mit Anlagen überwacht, die von privaten Gruppen finanziert werden. In Anchorage werden die öffentlichen Videobeobachtungsanlagen hauptsächlich von den Bürgern betrieben.

In der Praxis handelt es sich bei öffentlicher Videoüberwachung meistens um Zusammenarbeit zwischen dem privaten und öffentlichen Sektor. Private Akteure tragen hierbei nicht nur die (Teil-) Kosten der Anlagen, sondern übernehmen in vielen Fällen auch Überwachungsaufgaben an Monitoren. Bei den bereits erwähnten Videoüberwachungsprojekten in Miami Beach und einigen Städten in New Jersey werden beispielsweise Privatpersonen als Überwacher eingesetzt, um der Polizei ihren Dienstalltag zu erleichtern. ${ }^{538}$ Ähnliche Kooperationen lassen sich auch in Baltimore, Tampa Bay, Memphis, Los Angeles und Portland finden. ${ }^{539}$

Zugriffe auf private Überwachungskameradaten durch US-Behörden stellen ebenfalls eine Form der Kooperation zwischen privaten Gruppen und staatlichen Behörden dar. In New York arbeiten beispielsweise die U-Bahn-Mitarbeiter mit der Polizei

\footnotetext{
${ }^{535} \mathrm{Hsu}(2002 \mathrm{~d})$.

${ }^{536}$ Überwachungskameras mit Gesichtserkennungsprogrammen werden seit Jahren in amerikanischen Kasinos in Las Vegas und Atlantic City eingesetzt. Eine Sicherheitsfirma schätzt, dass mehr als 100 Kasinos in den USA bereits die biometrische Gesichtserkennung verwenden. Vgl. Nieto et al. (2002), S. 7.

${ }^{539}$ Das Videoüberwachungsprogramm in Los Angeles wurde von Landbesitzern gestartet, wobei relevante Videodaten an das Los Angeles Police Department weitergeleitet werden. In Portland, Oregon werden polizeiliche Überwachungskameras von privaten Sicherheitsfirmen betrieben. Ebenda, Rn. 1105 , Rn. 1106.
} 
zusammen, indem sie für die Polizei ihre Kameras auf Kriminalitätsschwerpunkte richten. ${ }^{540}$ Der öffentliche Kameraeinsatz zur vorbeugenden Verbrechensbekämpfung ist für die lokalen Akteure wie Kommunalbehörden, Großunternehmer und eine Vielzahl von Einzelhändlern vorteilhaft, so dass sie sich gegenseitig in den Überwachungstätigkeiten unterstützen.

\subsubsection{Staatsinterne Kontrollinstanzen}

In der "Common Law" Tradition des anglo-amerikanischen Rechtssystems sind gerichtliche Entscheidungen von zentraler Bedeutung. Es existiert in den USA keine einheitliche Rechtsprechung. Vielmehr ist das föderalistische Rechtssystem durch Rechtsvielfalt und Einzelfallentscheidungen geprägt. Über 50 Gerichte in den USBundesstaaten sind für Streitfragen in der Praxis der Videoüberwachung zuständig und klären diese anhand unterschiedlicher Rechtsgrundlagen. Aufgrund der föderalistischen Systeme und der Mannigfaltigkeit der Rechtsprechungen ist es nicht möglich, die komplexe Rechtslage in Bezug auf die räumliche Observierung mittels Kameras ausreichend darzustellen. Infolgedessen handelt es sich hierbei lediglich um eine fragmentarische Skizze der rechtlichen Lage zur öffentlichen Videoüberwachung in den Vereinigten Staaten.

\subsubsection{Rechtliche Kontrolle}

\section{a) Gerichtliche Entscheidungen}

Es gibt in den USA bis heute keine einheitlichen Regelungen für die Praxis öffentlicher Videoüberwachung. Die Entscheidung, inwiefern Maßnahmen der Videoaufzeichnung zulässig sind, ist den Gerichten in den einzelnen US-Bundesstaaten vorbehalten. Dabei sind die Definitionen des Rechts auf Privatsphäre (right of privacy) in den einzelnen Bundesstaaten entscheidend. ${ }^{541}$

Der United States Supreme Court als höchste juristische Instanz in den Vereinigten Staaten, hat sich wiederholt geweigert, das Recht auf Privatsphäre auf den öffentlichen Raum zu erweitern. Unverbindliche Richtlinien vom U.S. Supreme Court führen dazu, dass in Rechtsstreitfällen über Kameraanwendung die Entscheidungen der Federal Courts stark voneinander abweichen. Während z.B. der Federal District Court in Hawaii die Verwendung von Teleskopen durch FBI-Agenten beim Spionieren als Eingriff in die Privatsphäre der Betroffenen sieht, gewährt der United States District Court for the Northern District of Illinois dem FBI den heimlichen Zugang zu privaten

\footnotetext{
${ }^{540}$ Halbfinger (1998): „At Metro Networks, camera operators have done favors for the police serveral times by training their lenses on areas of frequent criminal activity."

${ }^{541} \mathrm{Vgl}$. hierzu die Erläuterung zu „right of privacy“ im Teil II, Kap. 5.2 dieser Arbeit.
} 
Wohnungen, um Abhörgeräte und Überwachungskameras zu installieren. ${ }^{542} \mathrm{Im}$ Fall United States vs. Torres betonte der Seventh Circuit Court of Appeals, dass die Videoüberwachungstechnik ein äußerst aufdringliches und leicht $\mathrm{zu}$ missbrauchendes Werkzeug sein kann. ${ }^{543}$ Dagegen genehmigte der Tenth Circuit Court of Appeals bei einer polizeilichen Untersuchung einer Geldfälschung die heimliche Überwachung eines Gebäudes in Kansas mit Videokameras. ${ }^{544}$

Solche Gerichtsentscheidungen machen deutlich, dass zwischen den speziellen Überwachungsaktivitäten zum Zweck der Strafverfolgung (narrow surveillance activities with specific targets) und der allgemeinen Überwachung der gesamten Bevölkerung (general public surveillance) ${ }^{545}$ unterschieden wird. In der Regel sind Polizeibeamte und andere Bundesagenten bei Genehmigungsverfahren zur staatlichen Videoüberwachung verpflichtet, ihre speziellen Überwachungsziele und -gründe vor Gericht vorzulegen.

Da kein Gesetz die Anwendung von Videoüberwachungstechnik eindeutig regelt, sind die Gerichtsentscheidungen und die Rechtsprechung ausschlaggebend. Gerichtsentscheidungen wie z.B. das Olmstead-Urteil aus dem Jahr $1928^{546}$, Katz vs. United States aus dem Jahr $1967^{547}$ sowie der Fall Kyllo vs. United States im Jahr $2001^{548}$

\footnotetext{
${ }^{542}$ Burrows (1997), Rn. 1094.

${ }^{543}$ Richter Posner vom Seventh Circuit forderte den US-Kongress auf, der Videoüberwachung mehr Aufmerksamkeit zu widmen und beschreibt die visuelle Überwachung als „,inherently indisciminate“ (von Natur aus wahllos). Allerdings vertritt die Federal Appellate Court die Einsicht, dass die Videoüberwachung von Verdächtigen nicht per se verfassungswidrig ist. Vgl. ebenda, Rn.1095.

${ }^{544}$ Ebenda.

${ }^{545}$ Burrows (1997), Rn. 1096.

${ }^{546}$ Nach dem Olmstead-Urteil aus dem Jahr 1928 ist Telefonüberwachung, trotz des Minderheitsvotums von Richter Brandeis, nicht mit Hausdurchsuchungen vergleichbar und der vierte Verfassungszusatz greift somit bei dieser Art von Überwachung nicht. Dieses Urteil bewirkte, dass gerichtliche Ansichten in Bezug auf verschiedenartige Überwachungstechnologien und die dadurch gesammelten Daten unbestimmt blieben. Banisar (1998), S. 19 ff.; vgl. auch hierzu Teil II, Kap. 5.2 dieser Arbeit.

${ }^{547}$ Der Fall Katz vs. United States aus dem Jahr 1967 wurde dadurch bekannt, dass die Modernisierung der Technologien bei Gerichtsentscheidungen berücksichtigt und somit die Begriffe von Privatsphäre neu definiert wurden. Der U.S. Supreme Court erklärte: „What a person knownly exposes to the public, even in his own home or office, is not a subject of Fourth Amendment protection (...) [but] what he seeks to preserve as private, even in an area accessible to the public may be constitutionally protected.“ Richter Harlan entwickelte zu diesem Anlass den bekannten Test unter der Bezeichnung „reasonable expectation of privacy test", wobei die Überwachungstechnologien bei einer angemessenen Erwartung auf Schutz der Privatsphäre doch dem vierten Verfassungszusatz unterworfen seien. Eine richterliche Anordnung und Prüfung der gegebenen Bedingungen sowie ein genügender Tatverdacht sind hiernach notwendig, um den Einsatz einer Überwachungstechnik zu genehmigen. Allerdings fällt nach vorherrschender Meinung die Videoüberwachung nicht unter den Schutz des vierten Verfassungszusatzes. Vgl. ebenda; Nieto et al. (2002), S. 38 f.

${ }^{548}$ Der Fall Kyllo vs. United States im Jahr 2001 rückt das Thema über den Schutz des vierten Verfassungszusatzes sowie staatlichen Einsatz von fortgeschrittener Überwachungstechnologie erneut in den Vordergrund in den juristischen Diskussionen. Auch wenn es in diesem Fall nicht um Überwachungskameras geht, beeinflusst jedoch diese Gerichtsentscheidung auch deren Anwendung zu kriminalpräventiven Zwecken. Der U.S. Supreme Court setzt sich hierbei mit der Frage auseinander, ob der Einsatz von Thermal-Überwachungsgeräten durch staatliche Vollzugsbehörden bei privaten Haushalten ohne Wissen der Betroffenen im Sinne des vierten Verfassungszusatzes zulässig ist. Es handelt sich dabei um die Untersuchung der intensiven Wärme spezieller Lampen, die beim Anbau
} 
sind richtungsweisend für die heutige Praxis der (Video-)Überwachung in den USA. Es bleibt noch abzuwarten, ob die in der amerikanischen Rechtsprechung vorherrschende Meinung zum Schutz der Privatsphäre, die bisher durch die Entscheidung im Fall Katz gekennzeichnet ist, durch den Fall Kyllo langfristig zugunsten der Privatsphäre der Betroffenen verschoben werden kann, indem man unter Berücksichtigung der modernen Technologien, u.a. auch Überwachungskameras, den Begriff der Privatsphäre neu definiert.

\section{b) Omnibus Crime Control and Safe Streets Act}

Eine eindeutige Rechtsgrundlage für den Einsatz der Videoüberwachung in den Vereinigten Staaten ist also nicht vorhanden. Bis Ende der 1990er Jahre sah man keine Notwendigkeit, da die Videoüberwachung bis dahin lediglich als eine Art „passiver Ersatz" für einen Polizeibeamten angesehen wurde. ${ }^{549}$ Allerdings hat sich die Situation geändert, nachdem die Technik drastisch modernisiert wurde und optischelektronische Einrichtungen vermehrt zum Einsatz kommen. Diese Entwicklung sowie einige bekannte Missbrauchsfälle drängen zu weiteren rechtlichen Einschränkungen der weiträumigen Observierung mittels Videotechnik. ${ }^{550}$

Im Jahr 1968 wurde vom US-Kongress der Title III des Omnibus Crime Control and Safe Streets Act verabschiedet, in dem staatliche Überwachung von Kommunikation durch elektronische Geräte geregelt wurde. Da Videoüberwachungsmaßnahmen nicht in diese Kategorie fielen, gab das amerikanische Justizministerium zusätzliche Richtlinien für die staatliche Videoobservierung vor, durch die die verfassungsrechtlich geschützte Privatsphäre der Individuen berücksichtigt wurde. Im US Department of Justice Criminal Resource Manual steht heute ausdrücklich, „six circuits, while recognizing that Titel III does not govern video surveillance, require that search warrants for video surveillance meet certain higher, constitutional standards than required under Titel III“. ${ }^{51}$ Ein Durchführungsbefehl ist somit bei staatlicher Videoüberwachung notwendig, ähnlich wie bei der sonstigen elektronischen Kommunika-

von Marihuana eingesetzt werden. Nach vielen Anhörungen und Beschlüssen von Berufungsgerichten wird diese Art der Überwachung als nicht „aufdringlich“ erklärt, da der Kläger Kyllo in diesem Fall keine subjektive Erwartung von Privatsphäre haben kann. Er hat sich keine Mühe gemacht, die Wärmestrahlungen der Lampen einzudämmen, um diese zu verheimlichen: „Kyllo made no attempt to conceal [these] heat emissions, demonstrating a lack of concern with the heat emitted and a lack of subjective privacy expectation in the heat." Der Durchsuchungsbefehl wurde genehmigt und die Marihuana-Pflanzen als Beweismittel in der Anklage zugelassen. Der Richter Scalia, der schon einmal den Katz-Test als „notoriously unhelpful“ beschrieb, erklärte zu diesem Fall: „where ... the government uses a device that is unknowable without physical intrusion, the surveillance is a 'search' and is presumptively unreasonable without a warrant." Vgl. Nieto et al. (2002), S. $38 \mathrm{f}$.

${ }^{549}$ Ebenda, S. 37.

${ }^{550}$ Beispiele zum Missbrauch von Überwachungskameras vgl. Burrows (1997), Rn. 1109.

${ }^{551}$ Nieto et al. (2002), S. 37 ff., 43 ff. 
tionsüberwachung, wobei diese zusätzlich mit weiteren Vorschriften eingeschränkt wird. $^{552}$

Allerdings bleiben aufgrund des Fehlens einer präziseren Auslegung des USKongresses zu diesem Sachverhalt die Diskrepanzen zwischen den gerichtlichen Entscheidungen bestehen. Während einige von ihnen bei der Anwendung von Videoüberwachungstechnik die Bedingungen des Gesetzes aus dem Jahr 1968 berücksichtigen, vertreten andere Gerichte die Ansicht, dass die Regelungen des Title III bei dieser Art der Überwachung nicht greifen. Dies geschieht, obwohl einige Gerichte die Videoüberwachung als eine aggressivere Art von Überwachung als die Audioüberwachung erklären (video surveillance is more invasive of privacy than aural (audio) surveillance). ${ }^{553}$

\subsubsection{Verwaltungskontrolle}

Aufgrund des Fehlens standardisierter Richtlinien in den USA erscheint es erforderlich, die staatliche Kontrolle über den öffentlichen Kameraeinsatz im Hinblick auf die zuständigen Verwaltungsstellen sowie deren Tätigkeiten zu untersuchen, welche als hemmende Faktoren die Entwicklung von Videoüberwachung in den einzelnen USBundesstaaten einschränken.

\section{a) Polizei}

Das gesamte Überwachungsnetzwerk in Washington D.C., an dem mehrere verschiedene Kamerasysteme beteiligt sind, wird erst bei Zwischenfällen und besonderen Anlässen eingeschaltet. In alltäglichen Situationen operiert die Washingtoner Polizei lediglich mit den zwölf polizeieigenen Überwachungskameras. ${ }^{554}$ Als kritische Stimmen bezüglich des polizeilichen Videoüberwachungsnetzwerks im District of Columbia laut wurden, konsultierte der Executive Assistant Police Chief Gainer die Bürgerrechtsgruppe American Civil Liberties Union (ACLU) und die Vorsitzende des Judiciary Committee im Stadtrat von Washington D.C., Kathy Patterson, und verkündete, dass öffentliche Debatten über die Regeln für die Videoüberwachung gewünscht wären. ${ }^{555}$

Der Chief of Metropolitan Police Department hat im Juli 2002 die District of Columbia Municipal Regulations (DCMR) ${ }^{556}$ nach einer Anhörung im Kongress im März ange-

\footnotetext{
552 "A Title III search warrant must contain four requirements to be valid: (1) probable cause, (2) particularity, (3) necessity, and (4) minimization." Burrows (1997), Rn. 1097, 1098; Nieto et al. (2002), S. 50.

${ }^{553}$ Burrows (1997), Rn. 1097.

${ }^{554} \mathrm{Hsu}(2002 \mathrm{a})$.

${ }^{555} \mathrm{Hsu}$ (2002b); Hsu (2002a).

${ }^{556}$ Kommunale Rechtsverordnungen des District of Columbia. Übersetzt von Bartsch (2004), S. 130.
} 
ordnet. Die DCMR sind die ersten Normierungen der polizeilichen Videoüberwachung öffentlicher Orte und basieren auf den Standards on Technologically Assisted Physical Surveillance (TAPS) der American Bar Association. ${ }^{557}$ Dabei werden nicht nur die Standorte der Überwachungskameras sowie die Ziele der Videoaufzeichnungen, sondern auch die Aufbewahrung der Bilddaten geregelt. ${ }^{558}$

Nach diesen Regeln dient die Videoüberwachung zum Schutz der Stadt Washington D.C. und der öffentlichen Sicherheit sowie der Reduzierung von Kriminalitätsangst. In Überwachungsgebieten der Kameras soll die Privatsphäre der Bürger nicht verletzt werden. ${ }^{59}$ Ferner bedarf die Speicherung der Videodaten einer schriftlichen Genehmigung des Chief of Police. ${ }^{560}$ Vor der Anbringung der Überwachungsgeräte ist ferner die Öffentlichkeit durch den Polizeichef in Kenntnis zu setzen. Während der Videoüberwachung soll die lokale Polizeibehörde die Öffentlichkeit über die technischen Möglichkeiten der verwendeten CCTV-Anlagen informieren ${ }^{561}$ In einem Abstand von sechs Monaten soll im Rahmen der Gemeindeversammlung die Öffentlichkeit über den aktuellen Stand der Videoüberwachung informiert werden. Weiterhin sind Hinweisschilder an den Standorten der Überwachungsgeräte anzubringen und die Kooperation mit anderen öffentlichen und privaten Stellen hat nur im Rahmen der Bestimmungen von DCMR zu erfolgen. ${ }^{562}$

Die für die Videoüberwachung an den Washingtoner Denkmälern verantwortliche Park Police stimmte einer Aufstellung interner Richtlinien nach einer Anhörung im Kongress zu. ${ }^{563}$ Dabei sollten nicht nur die Frage der Anwendung geklärt werden, auch die Zugangsrechte zu den Bildmaterialien sollten explizit festgelegt werden. ${ }^{564}$

Laut einer Umfrage des California Research Bureau im Jahr 1997 verwendete die Mehrheit der Polizeibehörden in Kalifornien keine CCTV-Systeme. Aufgrund des

\footnotetext{
${ }^{557}$ Vgl. „American Bar Association“ später in diesem Kapitel.

${ }^{558}$ Diese Regelungen sind unter Chapter 25 of Title 24 of the District of Columbia Municipal Regulations (Public Space and Safety) zu finden. Vgl. Bartsch (2004), S. 130.

${ }^{559}$ Ebenda, S. $131 \mathrm{ff}$.

${ }^{560}$ Ebenda.

${ }^{561}$ Ebenda.

562 Ebenda.

563 "This hearing has brought us to an awareness that we need standards and policies", erklärte John G. Parsons, associate regional director für the national Park Service's national Capital region, in der Anhörung im Kongress am 22.03.2002 zu the House Government reform subcommittee on the District. Der D.C. Police Chief Charles H. Ramsey sagte: "Policies and procedures governing our use of video were not as specific and formalized as they should be. (...) There are legitimate issues that need to be clarified." Vgl. Hsu (2002c).

${ }^{564}$ Ebenda.
} 
ungeklärten kriminalistischen Nutzens dieser Technik, so die kalifornische Polizei, werden andere kriminalpräventive Strategien bevorzugt. ${ }^{565}$

\section{b) US-Kongress}

Der Einsatz von Videoüberwachungskameras auf öffentlichen Straßen und Plätzen wurde nie explizit im US-Kongress angesprochen. Bis heute weigert sich der Kongress, Maßnahmen zum Schutz der amerikanischen Bürger vor permanenter Videoüberwachung zu verabschieden. ${ }^{566}$ Dies hat zur Folge, dass polizeiliche Videoüberwachung amerikanischer Bürger zum Zweck der Strafverfolgung (also mit einem speziellen Überwachungsobjekt) oder zum Zweck der Kriminalitätsprävention (d.h. die Allgemeinheit wird unter Überwachung gestellt) grundsätzlich ungeregelt bleibt. Ironischerweise wurde aber vom US-Kongress der Federal Intelligence Surveillance Act (FISA) im Jahr 1978 verabschiedet, der die Videoüberwachung ausländischer Agenten (nicht aber der eigenen Bürger) standardisiert. Schon im Jahr 1968 wurde, wie bereits erwähnt, Title III of the Omnibus Crime Control and Safe Streets Act of 1968 vom Kongress verabschiedet, der die Überwachung von elektronischer und verbaler Kommunikation regelt. Allerdings fallen die heutigen Videoüberwachungsmaßnahmen nicht in den Bereich dieser Regelung. ${ }^{567}$

Dadurch, dass der Kongress sich nie konkret zur Regulierung der öffentlichen Videoüberwachung geäußert hat und auch der Title III of the Omnibus Crime Control and Safe Streets Act of 1968 die Videoüberwachung nicht umfasst, weichen die Entscheidungen vom U.S. Federal Courts stark voneinander ab. Quentin Burrows beschreibt diesen Mangel an Bestimmung bezüglich Videoüberwachung in den USA wie folgt: "Thus, legislation at the state and federal level is needed because the current law is inconsistent, ineffective, and it creates divergent court opinions in the absence of congressional clarification. As more video surveillance problems surface, the need for comprehensive policies becomes clear, but the Supreme Court and Congress have simply sidestepped the problem. ${ }^{“ 568}$

Im Jahr 1984 hat der Kongressabgeordnete Kastenmier einen Versuch unternommen, die Regelungen des Title III of the Omnibus Crime Control and Safe Streets Act of 1968

\footnotetext{
${ }^{565}$ Nieto (1997), S. 24.

${ }^{566}$ Burrows (1997), Rn. 1083, Rn. 1096, Rn. 1097, Rn. 1098.

${ }^{567}$ Nach diesem Title III müssen Law Enforcement Agencies eine gerichtliche Genehmigung beantragen, wenn sie bei ihrer Strafverfolgung bestimmte Kommunikation der Verdächtigen mithören wollen. Ebenda, Rn. 1097.

${ }^{568}$ Ebenda, Rn. 1098.
} 
auf die Videoüberwachung zu erweitern. Allerdings wurde dieser Gesetzentwurf nicht vom Kongress verabschiedet und auch nie wieder vorgelegt. ${ }^{569}$

Als für Oktober 2002 die Videoüberwachung an den nationalen Denkmälern in Washington D.C. geplant war, wurde in einem Ausschuss des US-Kongresses (congressional panel) eine Anhörung durchgeführt. ${ }^{50}$ Dabei sollten Fragen nach den Verantwortlichen für diese Systeme sowie die genaueren Absichten bei der Überwachung geklärt werden. Angesichts des expansiven Zuwachses der Überwachungsanlagen forderten die Rechts- und Sicherheitsberater (legal and security analysts) den USKongress auf, das Betreiben von solchen staatlichen Einrichtungen zu standardisieren, während die Beamten des Park Service an die Öffentlichkeit appellierten, ebenfalls an dem Entscheidungsprozess teilzunehmen. Die D.C. Federation of Citizens Associations plante zu diesem Anlass eine öffentliche Versammlung mit den zuständigen Beamten des polizeilichen Videoüberwachungsprogramms, damit die Bürger über die Videoüberwachung informiert werden und debattieren konnten. ${ }^{57}$ Die Mitglieder des Kongresses betonten zudem die Notwendigkeit von Grundrichtlinien für die (staatliche) Videoüberwachung. Die Standards on Technologically Assisted Physical Surveillance (TAPS) der American Bar Association ${ }^{572}$ wurden ausdrücklich als Grundlage für Regelungen der Videoüberwachung in Washington D.C. genannt. ${ }^{573}$

\section{c) Kontrollinstanzen auf Länderebene}

Im US-amerikanischen Föderalismus erlaubt die verfassungsgemäße Souveränität der einzelnen Bundesstaaten die Rechte auf Privatsphäre auch auf die Anwendung von Videoüberwachung auszuweiten oder neue Rechte für die Angehörigen eines Bundesstaates zu entwerfen. In der Tat fordert der Supreme Court die State Courts auf, mit ihrer eigenen Landesverfassung den Begriff der Privatsphäre eigenständig weiter zu definieren. ${ }^{574}$ Die einzelnen Länder sind somit zum Verteidiger der individuellen Rechte auf Privatsphäre geworden und bieten in vielen Fällen den amerikanischen Bürgern Schutz vor Videoüberwachung.

Allerdings hat nicht jeder Bundesstaat in den USA einen klar definierten verfassungsrechtlichen Schutz vor Eingriffen in die Privatsphäre seiner Bürger. Während einige US-Bundesstaaten sich bemühen, die Rechte ihrer Bürger auf Privatsphäre vor

\footnotetext{
${ }^{569}$ Ebenda, Fn. 153.

${ }^{570} \mathrm{Hsu}(2002 \mathrm{~d})$.

${ }^{571} \mathrm{Hsu}(2002 \mathrm{c})$.

${ }^{572}$ Vgl. „American Bar Assocation“ später in diesem Kapitel.

${ }^{573}$ Bartsch (2004), S. 131; Hsu, Rules Urged for Surveillance, in: The Washington Post vom 23.03.2002.

${ }^{574}$ Diese Bewegung des Verfassungsrechts auf der Länderebene (the state constitutional law movement) wurde als „New Federalism“ bezeichnet ; vgl. Burrows (1997), Rn. 1112.
} 
unerwünschter Observierung zu schützen, begünstigen wiederum andere Bundesstaaten, die dem Recht auf Privatsphäre keinen besonderen Wert beimessen, polizeiliche Videoüberwachungsmaßnahmen auf öffentlichen Straßen und Plätzen. Insgesamt kann man also anhand des Anerkennungsgrads des Rechtes auf Privatsphäre in den einzelnen Staaten feststellen, wie gut der Bürger in dem entsprechenden Staat vor (polizeilichen) Videokameras geschützt ist.

Die höchste gerichtliche Instanz in Hawaii - der Hawaii Supreme Court - hat beispielsweise spezielle verfassungsrechtliche Bestimmungen geschaffen, um übermäBige staatliche Ermittlungen zu untersagen. Damit soll die individuelle Freiheit und menschliche Würde der Bürger garantiert werden. Diese Bestimmungen betreffen auch die elektronische Überwachungstechnik. ${ }^{575}$ Dementsprechend wird in Hawaii die Anwendung gesetzwidrig aufgenommener Videodaten als Beweismittel in Frage gestellt. ${ }^{576}$ Auch in anderen Bundesstaaten in den USA wird der Schutz vor Videoüberwachung großgeschrieben. Gerichte in Montana agieren beispielsweise als Gegengewicht zu polizeilichen Überwachungsmaßnahmen. Auch der Washington Supreme Court beharrt auf dem Verfassungsschutz vor visueller Überwachung. ${ }^{577}$

In solchen US-Bundesstaaten, die die Rechte auf Privatsphäre und den Schutz vor Videoüberwachung garantieren, können Pläne zur Videoüberwachung tendenziell eher verhindert werden als in solchen Bundesstaaten, die staatliche Eingriffe in die bürgerliche Privatsphäre erlauben bzw. tolerieren. Der Supreme Court of California hat beispielsweise die Veröffentlichung eines Fotos erlaubt, das ohne das Wissen der Betroffenen aufgenommen und veröffentlicht wurde. Ähnliche Fälle, in denen die individuellen Rechte auf Privatsphäre und Schutz vor elektronischer Überwachung eingeschränkt werden, ereigneten sich beispielsweise ebenfalls in Georgia, New York und Florida. ${ }^{578}$

\section{d) Andere staatliche Kontrollinstanzen}

Im Jahr 1996 entschied sich die Stadt Orlando in Florida gegen Überwachungsmaßnahmen mit moderner Videotechnik. Als Begründung für diesen Entschluss kommentierte der Commissioner Randy Morris: „It looks like we're getting out of the surveillance business. (...) The risk in term of privacy is too high. ${ }^{4579} \mathrm{Er}$ wies die Öffentlichkeit darauf hin, dass ohne rechtliche Grundlagen und Einschränkungen die

\footnotetext{
${ }^{575}$ Ebenda, 1119.

${ }^{576}$ ACLU (1999).

${ }^{577}$ Mehr zu den Staaten, die ihren Bürgern den Schutz vor Videoüberwachungstechnik bieten, vgl. Burrows (1997), Rn. 1120, Rn. 1121.

${ }^{578}$ Ebenda, Rn. 1115, Rn. 1116, Rn. 1121.

${ }^{579}$ Ebenda, Rn. 1079.
} 
moderne Videotechnik Eingriffe in die persönliche Privatsphäre verursachen konnte. Laut Burrows begann damit der Widerstand gegen die Videoüberwachung in öffentlichen Räumen der USA. Während die Stadt Orlando die Videoüberwachung auf öffentlichen Straßen zum Schutz der Privatsphäre der Bürger ablehnte, entschieden sich allerdings im selben Jahr 15 andere US-Städte für den Einsatz von Videoüberwachung. ${ }^{580}$

Nachdem im Jahr 2002 in Washington D.C. das größte Videoüberwachungsnetzwerk der USA aufgebaut wurde, wurden Bedenken bezüglich der Balance von Sicherheit und Freiheit vom House Government Reform Subcommittee on the District geäußert. ${ }^{581}$ Zusammen mit dem Stadtrat von Washington D.C. verlangte der Unterausschuss eine öffentliche Anhörung, wobei die notwendigen Konsequenzen des polizeilichen Videoüberwachungsprojektes diskutiert wurden. ${ }^{582}$

Die Vorsitzende des House Government Reform Subcommittee on the District äußerte nach der Anhörung im Kongress: „As I learn more about this issue, it is becoming more evident that Congress may have to step in and ensure that this technology does not take away our right to be left alone. (...) Once this system is in place, it will be too tempting for the police not to use its full force. ${ }^{\text {“583 }}$ Nach der Anhörung wurde eine Studie vom Kongress geplant, die die Effektivität von Videoüberwachung als präventives Werkzeug untersuchen sollte. ${ }^{584}$

Im Mai 2005 legte Gouverneur Robert L. Ehrlich jr. ein Veto gegen den Gesetzesentwurf zur Installation von Geschwindigkeitskameras in Montgomery County ein, während er zwei Jahre zuvor ebenfalls einen Einspruch gegen einen Gesetzesentwurf eingelegt hatte, der den Einsatz von Überwachungskameras in Maryland erlauben sollte. ${ }^{585}$ Nach Meinung des Gouverneurs stellen die Kameras einen unnötigen Eingriff in die Privatsphäre der Bürger dar: "[Speed cameras would be] another step towards the pervasive use of cameras by the government to monitor and regulate the conduct of its people." ${ }^{1586} \mathrm{Um}$ unkontrollierte Expansion von Überwachungskameras zu verhindern, entschied sich der Gouverneur trotz Kritik gegen den Einsatz von Überwachungskameras.

\footnotetext{
${ }^{580}$ Ebenda.

${ }^{581}$ Diese Bedenken wurden vor allem von der Vorsitzenden des House Government Reform Subcommittee on the District, Constance A. Morella, geäußert. Verschiedene Anhörungen zum Thema Videoüberwachung in Washington D.C. beruhten auf ihrer Initiative. Vgl. Hsu (2002b); Hsu (2002a); Hsu (2002c).

${ }^{582} \mathrm{Hsu}(2002 b) ; \mathrm{Hsu}(2002 \mathrm{a})$.

${ }^{583} \mathrm{Hsu}(2002 \mathrm{c})$.

${ }^{584}$ Ebenda.

${ }^{585}$ Synder (2005).

${ }^{586}$ Ebenda.
} 
Das Oakland City Council's Public Safety Committee entschied im Jahr 1999, das Videoüberwachungsprojekt in Oakland nicht mehr fortzusetzen, da keine Senkung der Kriminalitätsrate durch das Projekt erzielt wurde. Innerhalb von zwei Jahren hat sich Oakland damit schon zweimal gegen Videoüberwachungsmaßnahmen ausgesprochen. Der Bürgermeister von Oakland, Jerry Brown, betonte, dass Kameras allein nicht die Sicherheit erhöhten und die staatlichen Eingriffe mit jeder Dekade immer aufdringlicher wurden. ${ }^{587}$

\subsubsection{Nichtstaatliche Gegenkräfte}

Im Folgenden werden exemplarisch US-amerikanische Bürgerrechtsgruppen und Interessenvertretungen vorgestellt, die in der Politik der öffentlichen Videoüberwachung als staatsunabhängige Gegenkräfte wirken.

\subsubsection{American Civil Liberties Union (ACLU)}

American Civil Liberties Union (ACLU) ist die größte Bürgerrechtsgruppe in den USA und wurde im Jahr 1920 gegründet. Die ACLU hat sich zur Aufgabe gemacht, neben in der amerikanischen Verfassung verankerten Bürgerrechten auch das Recht auf Privatsphäre gegen übermäßige staatliche Eingriffe zu verteidigen. ${ }^{588}$ Mit 46 Vertretungsbüros in fast jedem US-Bundesstaat und über 400.000 Mitgliedern versteht sich die ACLU als the nation's largest law firm. ${ }^{589}$ Mit über 6.000 Gerichtsfällen jährlich ist die ACLU die nichtstaatliche Organisation, die am häufigsten vor dem Supreme Court erscheint. ${ }^{590}$

Auch die öffentliche Videoüberwachung gehört zu den Angelegenheiten, mit denen sich die ACLU beschäftigt. Die ACLU ist besorgt über die Verbreitungsgeschwindigkeit der Videoüberwachungstechnik in öffentlichen Räumen, die die Anonymität der amerikanischen Bürger gefährden könnte. ${ }^{591}$ Barry Steinhardt, National ACLU Associate Director, warnt: „Today's video technology turns police officers into supermen and -women with powers of observation that extends well beyond what can be seen by the naked eye. ${ }^{\prime 592}$

Nicht selten sind die Mitglieder der ACLU Ansprechpartner in Fragen zum Thema über Regulierung öffentlicher Videoüberwachung. Beispielsweise fand, wie erwähnt,

\footnotetext{
${ }^{587}$ ACLU (1999).

588 ,Your right to privacy - freedom from unwarranted government intrusion into your personal and private affairs"; vgl. http:/ / www.aclu.org/about/aboutmain.cfm.

${ }^{589}$ Walker (1999), S. 4.

${ }^{590}$ Ebenda.

${ }^{591}$ Hsu (2002a).

${ }^{592}$ ACLU (1999).
} 
ein Informationsaustausch zwischen ACLU und dem National Park Service statt, als Hunderte von Überwachungsanlagen an den nationalen Einrichtungen installiert werden sollten. ${ }^{593}$

Die New York Civil Liberties Union (NYCLU), das Vertretungsbüro des ACLU in New York City, startete im Jahr 1998 das NYC Surveillance Camera Project, bei dem freiwillige Mitarbeiter Überwachungskameras, die ihren Blick auf öffentliche Räume in Manhattan richten, ausfindig machten und die Standorte der Kameras veröffentlichten. Dieses Projekt wurde nicht wie geplant auf weitere Stadtbezirke New Yorks erweitert, da nach Aussage der Leiterin von NYCLU, Donna Liebermann, die Botschaft ihres Projektes bereits der Öffentlichkeit bekannt gemacht werden konnte. ${ }^{594}$

\subsubsection{Institute for Applied Autonomy}

Das Institute for Applied Autonomy (IAA) wurde im Jahr 1998 als eine Forschungsund Entwicklungsorganisation mit dem Ziel gegründet, die eingeschränkte Autonomie des menschlichen Handelns durch Technologie zu erweitern und zu schützen. Am 11. Oktober 2001 hat IAA das ISEE-Projekt gestartet. ${ }^{595}$ Dabei handelt es sich um einen Online-Service, der „den Weg der geringsten Überwachung“ (paths of least surveillance) anzeigt. Dabei muss der Benutzer seinen Standort und sein Ziel angeben und das ISEE-Programm liefert ihm die Route mit der geringsten Anzahl von Überwachungskameras. Das ISEE-Projekt versteht sich als Gegenwehr zu dem zunehmenden Verlust der Anonymität, die durch die breitflächige Videoüberwachung in Großstädten verursacht wird.

Für New York City hat das Programm bereits eine detaillierte CCTV-Karte in Kooperation mit anderen Bürgerrechtsorganisationen wie New York Surveillance Camera Players und Eyebeam Atelier Workshop ${ }^{596}$ erstellt. Auch die Informationen über die über 2400 Überwachungskameras in Manhattan, die aus dem Surveillance Camera Project von New York Civil Liberties Union (NYCLU) im Jahr 1998 gewonnen wurden, werden in diesem „ISEE-System“ berücksichtigt. Weitere ISEE-Projekte wurden ebenfalls in

\footnotetext{
${ }^{593}$ Als im Jahr 2002 die Netzwerke der Videoüberwachungsanlagen in Washington D.C. aufgebaut wurden und im selben Jahr Hunderte von Kameras an den nationalen Denkmälern geplant waren, befürchteten die Bürgerrechtsgruppen, u.a. auch die ACLU, dass die Demonstrationsfreiheit und Versammlungsrechte der amerikanischen Bürger durch diese Art visueller Überwachung beeinträchtigt werden könnten. Die Mitarbeiter und ACLU in Washington D.C. setzten sich für den Abbau der Uberwachungsanlagen ein und verlangten, dass entsprechende Regulierungen für diese Anlagen notwendige Voraussetzungen sind. Vgl. Hsu (2002d); Hsu (2002c).

${ }^{594}$ Aus dem Interview mit Donna Liebermann am 18. März 2003 in NYCLU. Vgl. auch New York Civil Liberties Union (1998).

${ }^{595}$ Vgl. http:/ / www.appliedautonomy.com/isee.html.

${ }^{596}$ Eyebeam Atelier ist eine Non-Profit-Organisation, die Studenten, Künstlern und Bürgern den Zugang zum Bereich der Kunst und der Technologie ermöglicht. Mehr Information unter: http:// www.eyebeam.org/.
} 
Chicago, Seattle und London geplant. ${ }^{597}$ Im November 2002 wurde das ISEE-Projekt in Amsterdam mit einer lokalen Bürgerinitiative gestartet, während im Juni 2003 in Ljubljana ebenfalls auf ähnliche Weise den Bürgern der slowenischen Hauptstadt der Weg der geringsten Videoüberwachung aufgezeigt werden konnte. Im Winter 2005 wurde ein weiteres Projekt in Boston geplant. Dabei wurden die Kriminalitätsentwicklungen an den Standorten der Überwachungskameras dargestellt, um die Notwendigkeit und Effektivität der Kameras zu hinterfragen. ${ }^{598}$

\subsubsection{Surveillance Camera Players}

Seit 1996 demonstrieren die Surveillance Camera Players ihre Unzufriedenheit über den Zuwachs der Überwachungsanlagen in New York City, indem sie Theaterstücke direkt vor den Überwachungskameras aufführen. Die Standorte der Überwachungsgeräte in vierzehn Stadtteilen New Yorks, sowie in anderen Städten wie Boston, Chicago, New Haven, Portland und Providence werden von den Mitgliedern der Surveillance Camera Players im Internet veröffentlicht. ${ }^{599}$ Bill Brown, einer der Gründer dieser Organisation, leitet regelmäßig Surveillance Camera Outdoor Walking Tours, an denen alle Interessierten sich über die aktuelle Überwachungsintensität in zehn Stadtgebieten, z.B. Fifth Avenue, Harlem und Washington Square Park, informieren können. ${ }^{600}$

\subsubsection{Electronic Privacy Information Center (EPIC)}

Das Electronic Privacy Information Center (EPIC) ist ein Forschungszentrum für öffentliche Interessen (public interest research center), das im Jahr 1994 in Washington D.C. gegründet wurde. Mit dem Projekt „Observing Surveillance“ macht EPIC die Öffentlichkeit auf die Videoüberwachung in Washington D.C. aufmerksam, um öffentliche Debatten über die Anwendung von Überwachungskameras anzuregen. ${ }^{601}$

\subsubsection{American Bar Association (ABA)}

American Bar Association versteht sich als repräsentativer Berufsverband mit über 400.000 Mitgliedern in Anwaltsberufen, der die Weiterbildung in Rechtswissenschaft fördert, die Öffentlichkeit über das Rechtswesen in den USA informiert und Pro-

\footnotetext{
${ }^{597}$ Roos (2002), S. 465 ff.

${ }^{598} \mathrm{http}$ / / www.appliedautonomy.com/isee.html.

${ }^{599}$ Vgl. http:/ / www.notbored.org/ the-scp.html.

${ }^{600}$ Tavernise (2004).

${ }^{601}$ http: / / www.observingsurveillance.org/. 
gramme anbietet, die den Rechtsanwälten und Richtern in ihren Berufen assistieren. $^{602}$

Schon im Jahr 1995 erkannte die ABA die Gefahr des polizeilichen Einsatzes mit technischen Hilfsmitteln für die Gesellschaft und beauftragte die Projektgruppe Task Force on Technology and Law Enforcement Standards zur Regulierung der Videoüberwachung zu entwerfen. ${ }^{603}$ Diese Projektgruppe vertritt im Gegensatz zur Rechtsprechung des U.S. Supreme Court, dass Privacy „in ihren Ausprägungen Anonymität, Einsamkeit und Gewährung eines Ruhebereichs “604 auch in der Öffentlichkeit bestehen und durch die Videoüberwachung beeinträchtigt werden kann.

Als Ergebnis dieser Projektgruppe der ABA wurden die "Standards on Technologically Assisted Physical Surveillance" (TAPS ${ }^{605}$ verfasst, die als Muster für weitere Regelungen zur Videoüberwachung anderer Law Enforcement Agencies auf Bundes- und Landesebene dienen sollen. ${ }^{606}$ Die bereits erwähnte Neuregelung der District of Columbia Municipal Regulations basieren beispielsweise auf diesen Standards. ${ }^{607}$

In TAPS werden die polizeilichen Interessen zur Verbesserung der Straftatverhinderung und die Gefahr der Beeinträchtigung der Privacy in der Öffentlichkeit gewichtet, um allgemeine Regeln zur Durchführung visueller Überwachung sowie zur Weitergabe von Überwachungsergebnissen zu entwickeln. Weiterhin wird die langfristige, offene Videoüberwachung im öffentlichen Raum analysiert und vorgeschlagen, dass die verantwortlichen Beamten (politically accountable law enforcement official) ${ }^{608}$ die Vorabprüfung der Voraussetzungen für Videoüberwachungsmaßnahmen übernehmen sollen. Ferner gilt der Vorschlag in TAPS, dass nicht nur die Polizei, sondern auch die Gerichte, der Gesetzgeber, die Verwaltung sowie die Bevölkerung an den Regelungen der Anwendung von Videoüberwachung mitwirken sollen. ${ }^{609}$

\footnotetext{
${ }^{602}$ http: / / www.abanet.org/about/home.html.

${ }^{603}$ Bartsch (2004), S. 126.

${ }^{604}$ Ebenda.

${ }^{605}$ Verfügbar unter: https: / / www.ananet.org/crimejust/standards/taps_blk.html.

${ }^{606}$ Bartsch (2004), S. 125ff, vgl auch Hsu (2002c).

${ }^{607} \mathrm{Hsu}$ (2002a); Bartsch (2004), S. 130.

${ }^{608}$ Es sind z.B. der Polizeibehördenleiter (department head) oder ein Staatsanwalt (prosecutor) oder eine staatlich verantwortliche Regierungsbehörde (politically accountable governmental authority). Übersetzung vgl. Bartsch (2004), S. 129.

${ }^{609}$ Bei den Regelungen von TAPS handelt es sich sowohl um private als auch öffentliche Videoüberwachung. Bei der Regelung 2-9.3 sind z.B. folgende drei Abschnitte enthalten: 1) For video surveillance of private locations, the ABA standards require a warrant based upon probable cause to be in issued prior to surveillance; 2) Overt video surveillance and other video surveillance is permissible when ,a politically accountable law enforcement official“ or governmental authority concludes that the surveillance will: (1) not view a private activity or condition; and (2) be reasonably likely to achieve a legitimate law enforcement objective; 3) When public video surveillance is used to deter rather than investigate crime, the ABA Standards suggest that the public be: (1) notified of the location
} 


\subsubsection{Zusammenfassung}

In den USA wird der Einsatz von Überwachungskameras an öffentlichen Orten sowohl staatlich als auch privat unterstützt. Häufig entstehen dabei Zweckgemeinschaften zwischen den Behörden und Privatpersonen, um gemeinsam die Einrichtungen zu finanzieren und die Überwachungsarbeiten an Monitoren aufzuteilen.

Aufgrund des föderativen Staatssystems sowie des Vorherrschens des Common Laws ist die rechtliche Regulierung für den öffentlichen Einsatz von Überwachungskameras offener, flexibler, aber auch unübersichtlicher als die Situation in der Bundesrepublik. Es gibt diesbezüglich keine einheitliche Regelung oder Rechtsprechung. Die CCTV-relevanten Gerichtsurteile fallen je nach Bundesstaat sehr unterschiedlich aus. Während beispielsweise die Polizei in Tampa diese Überwachungstechnik mit Gesichtserkennungsprogramm ohne Wissen der Betroffenen bei einem Super-BowlSpiel erprobte und später im Innenstadtbereich einsetzte, veranlassten andere Städte eine Selbstkontrolle über den Einsatz von Überwachungsanlagen, z.B. die District of Columbia Municipal Regulations (DCMR) in Washington D.C. Wie gut der Schutz der amerikanischen Bürger vor öffentlicher Videoüberwachung ist, hängt davon ab, wie umfangreich die jeweiligen landesverfassungsrechtlichen Vorgaben definiert und interpretiert werden und wie das juristische Verständnis des Rechts auf Privatsphäre (Right to Privacy) ist.

Auffallend sind die ausgeprägten, vielfältigen Protestaktionen der USamerikanischen Interessenvertretungen und Bürgerinitiativen. Die American Civil Liberties Union als die größte Bürgerrechtsorganisation in den USA fungiert in manchen Fällen als Berater in den Entscheidungsprozessen zur staatlichen Einführung von Videoüberwachungsmaßnahmen. Und die "Standards on Technologically Assisted Physical Surveillance" (TAPS), die u.a. als Grundlage für die oben genannten District of Columbia Municipal Regulations (DCMR) gelten, stammen vom Berufsverbund American Bar Association. Dies zeigt die gewichtige Rolle der nichtstaatlichen Organisationen in den USA als hemmende Faktoren in der Praxis öffentlicher Videoüberwachung. Angesichts der regionalen Vielfältigkeit des US-amerikanischen PolicyProzesses, ist es wichtig anzumerken, dass die obig erwähnten Beispiele keinesfalls als allgemeingültige, sondern lediglich als exemplarische Darstellung der USamerikanischen Akteurskonstellation in der CCTV-relevanten Sicherheitspolitik verstanden werden können.

and capability of the CCTV; and (2) given the opportunity to publicly comment through a hearing. Vgl. Nieto et al. (2002), S. 51; vgl. auch Bartsch (2004), S. 125 ff. 


\subsection{Die Situation in Großbritannien}

\subsubsection{Proaktive Akteure}

In diesem Abschnitt der Arbeit werden die Akteure und Institutionen vorgestellt, die für die rasche Entwicklung von CCTV-Überwachung in Großbritannien verantwortlich sind. Zuerst werden die Tätigkeiten des Innenministeriums sowie der kommunalen Behörden beschrieben, um die starke politische und finanzielle Unterstützung vom Staat für den öffentlichen Kameraeinsatz aufzuzeigen. Anschließend sollen die verflochtenen Netzwerke der Videoüberwachung zwischen dem öffentlichen und dem privaten Sektor skizziert werden.

\subsubsection{Verwaltungsinstanzen}

\section{a) Innenministerium}

Angesichts der extrem hohen Kriminalitätsrate in den 1980er Jahren und Anfang der 1990er Jahre sah die Audit Commission nach vergeblichen Versuchen, die Polizei zu reformieren, die Nutzung von Überwachungskameras als Lösung für die britische Verbrechensproblematik. Schon Anfang der 1990er Jahre finanzierte das britische Innenministerium den Einsatz von Videoüberwachung im Rahmen der "Safer Cities Initiative“. Nachdem CCTV-Programme im Jahr 1994 zum ersten Mal ihr eigenes Budget vom Home Office bekamen, gewann der Einsatz von Videoüberwachung immer mehr an Bedeutung in Großbritannien. ${ }^{610}$

Anfang des Jahres 1995 veranstaltete das britische Innenministerium einen CCTVWettbewerb (City Challenge Competition of CCTV), wobei die Sieger die Unterstützung von $£ 5$ Millionen für die Erweiterung ihrer Videoüberwachungsanlagen erhielten. ${ }^{611}$ Die Teilnahme an diesem Wettbewerb war nicht in erster Linie für Großstädte, sondern für kleine Städte und Kommunen vorgesehen. ${ }^{612}$ Über 480 Bewerbungen wurden eingereicht, wovon letztlich 106 Programme finanzielle Zuschüsse erlangten. Allerdings galt dabei die Voraussetzung, dass 50\% der Gesamtfinanzierung sowie die laufenden Kosten zur Instandhaltung des Systems durch private Unterstützung aus der Geschäftswelt gedeckt werden sollten. ${ }^{613}$ Dieser Wettbewerb wurde in den folgenden Jahren drei Mal wiederholt, wobei bei der zweiten Wettbewerbsrunde die größeren Städte die Hauptteilnehmer ausmachten. Zusätzlich wurden für weitere Wettbewerbsrunden die Teilnahmekategorie auf Schulen, Wohnanlagen und Kran-

\footnotetext{
${ }^{610}$ Norris; Armstrong (1999b), S. 35 f.; Norris (1998), S. 30 ff.; McCahill; Norris (2002b); Gras (2003), S. $36 \mathrm{f}$.

${ }^{611}$ Büllesfeld (2002), S. 37; vgl. Walker (1996), S. 345.

${ }^{612}$ McCahill; Norris (2002a), S. 12.

${ }^{613}$ Ebenda, S. 12 f.
} 
kenhäuser erweitert. Insgesamt wurden durch diese vier Wettbewerbsrunden mehr als 580 CCTV-Systeme mit einem Investitionsvolumen von $£ 85$ Millionen finanziert, wobei $£ 31$ Millionen aus dem Innenministerium und $£ 54$ Millionen aus CCTVPartnerschaften stammten. ${ }^{614}$

Die staatliche Finanzierung des Kameraeinsatzes endete jedoch nicht mit der letzten Runde des CCTV-Wettbewerbs. Die britische Regierung erklärte CCTV-Systeme zum Hauptwerkzeug der britischen Kriminalitätsbekämpfung und unterstützte diese weiter großzügig. Beispielsweise war für die Jahre zwischen 1999 und 2001 ein Budget von ca. $£ 170$ Millionen im Rahmen des "Crime Reduction Programmes" für CCTVSysteme vorgesehen. ${ }^{615}$ Zwischen 1992 und 2002 wurde die Summe von über $£ 250$ Millionen aus staatlichen Kassen für Videoüberwachungsmaßnahmen ausgegeben. ${ }^{616}$ Diese CCTV-freundliche Kriminalpolitik wurde sowohl von der konservativen Regierung von John Major als auch unter Tony Blairs New Labour betrieben. Ein Berater der lokalen Regierungsstelle in Liverpool beobachtete eine verstärkte Finanzierungswelle für kurzfristige CCTV-Projekte seitens der Zentralregierung in Wahlperioden: „[E]very government I've seen has beaten the law and order drum and there doesn't seem to be any substantial change in that respect. ${ }^{\text {a617 }}$

Auch in Schottland wurde die öffentliche Videoüberwachung ebenso enthusiastisch eingeführt wie in den restlichen Gebieten Großbritanniens. Das Scottish Office veranstaltete zwei schottische CCTV-Wettbewerbe (CCTV Challenge Competitions) in den Jahren 1996-1997 und 1997-1998. In der ersten Runde wurden 32 Systeme mit $£ 1.851$ Millionen finanziert und im Rahmen des zweiten Wettbewerbs wurden weitere 30 Projekte durch insgesamt $£ 1.861$ Millionen staatliche Zuschüsse ermöglicht. ${ }^{618}$

Die britische Regierung und ihre Minister sind nicht nur großzügig in der finanziellen Unterstützung für CCTV-Projekte. Sie zeigen - unabhängig von ihrer Parteizugehörigkeit - eine unterstützende Haltung gegenüber CCTV-Programmen und stellen diese Technologie als ein willkommenes Instrument zur Stabilisierung der öffentli-

\footnotetext{
${ }^{614}$ Ebenda, S. 13 f.; Kohl (1997a), S. 36 ff. Die Zuschüsse der britischen Regierung für CCTV-Systeme betrugen von 1994 bis 1995 ca. $£ 5$ Millionen, während in den Jahren von 1996 bis 1997 diese auf $£ 17$ Millionen zunahmen. Zwischen 1997 und 1998 investierte die Regierung weiterhin $£ 15$ Millionen in den Bereich. Vgl. Nürnberg (2000), S. 230. Zu den Voraussetzungen für die Beantragung der Gelder vgl. Bässmann; Posiege (1998), S. 40; Büllesfeld (2002), S. 37; Möller et al. (2000), S. 11.

${ }^{615}$ Nach Angaben von Urban Eye Projekt beträgt die Summe $£ 153$ Millionen, vgl. McCahill; Norris (2002a), S. 14; Nürnberg (2000), S. 230 ff.

${ }^{616}$ McCahill; Norris (2002a), S. 3. Nach Angaben von Roy Coleman wurden zwischen 1994 und 1999 insgesamt $£ 38$,5 Millionen vom brititischen Innenministerium und $£ 51$ Millionen vom privaten Sektor für die Installationen von CCTV-Systemen ausgegeben. Vgl. Coleman (2004), S. 5.

${ }^{617}$ Coleman (2004), S. $197 \mathrm{f}$.

${ }^{618}$ Ditton (2000), S. $692 \mathrm{f}$
} 
chen Sicherheit dar. Kritische Töne sind dabei in den öffentlichen Diskussionen selten zu hören.

Im Oktober 1995 verkündete der regierende Premierminister John Major auf dem Parteitag der Konservativen neben der Gründung von Bundespolizei, Unterstützung für Zusammenarbeit zwischen der Polizei und Geheimdienst auch die Beschaffung von 10.000 neuen Überwachungskameras ${ }^{619}$ Er zeigte außerdem kein Verständnis für die Bürgerrechtsgruppen, die gegen den Einsatz von CCTV-Systemen protestierten, und vertrat die Meinung: „Anything that helps people and hinders the criminals is fine by me. ${ }^{\text {“20 }}$ Weiter erklärte er: „I have no doubt we will hear some protest about a threat to civil liberties. Well, I have no sympathy what so ever for so-called liberties of that kind. “621 Auch Sir Paul Beresford, der ehemalige Umweltminister, forderte die Kommunalbehörden auf, kriminalpräventive Maßnahmen bei der Raum- und Entwicklungsplanung in den Kommunen zu berücksichtigen, und argumentierte, dass CCTV-Systeme dafür ein geeignetes Mittel seien: „CCTV can bring enormous benefits to towns and cities. ${ }^{1622}$ Ferner bezeichnete der ehemalige britische Innenminister CCTV-Anlagen als "friendly eye in the sky" und behauptete, "there is nothing sinister about it and the innocent have nothing to fear. It will put criminals on the run and evidence will be clear to see. ${ }^{\star 623}$

\section{b) Kommunalbehörden}

Die Kommunalbehörden (local authority) werden nach $\S 163$ des Criminal Justice and Public Order Act 1994 dazu ermächtigt, in Rücksprache mit dem Leiter der lokalen Polizei (Chief Officer of Police) öffentliche Mittel für Videoüberwachungssysteme in öffentlichen Räumen einzusetzen. ${ }^{62}$ Diese Befugnis ist nach der Auslegung des Gesetzes dazu da, um „Kriminalität und asoziales Verhalten zu verhindern und (...) die Kriminalitätsfurcht zu verringern“ ${ }^{625}$

Wie erwähnt wurde durch die CCTV-Wettbewerbe des britischen Innenministeriums nur die Hälfte der zur CCTV-Installation benötigten Geldmittel bereitgestellt und die kommunalen Behörden mussten zuvor andere Geldgeber für die restlichen Installationskosten gefunden haben, um sich für die Wettbewerbe zu qualifizieren. ${ }^{626}$ Meist

\footnotetext{
${ }^{619}$ Wasser; Dingeldey (1996), S. 76.

${ }^{620}$ Graham (1998), S. 91.

${ }^{621}$ Gras (2003), S. 38.

${ }^{622}$ Graham (1998), S. 91.

${ }^{623}$ Ebenda.

${ }^{624}$ Der CCTV-Einsatz in London wurde bereits zuvor durch den London Local Authorities Act (No.2) 1990 geregelt. Vgl. Gras (2003), S. 55.

${ }^{625}$ Ebenda, S. 55.

${ }^{626}$ Norris; Armstrong (1999b), S. 36; Gras (2003), S. 36.
} 
waren die nichtstaatlichen Geldgeber in der privaten Wirtschaft zu finden, deren Geschäfte und Betriebe sich in dem geplanten Bereich der Videoüberwachung befanden. ${ }^{627}$ Dies hatte zur Folge, dass die kommunalen Behörden bereits vor der Teilnahme an den CCTV-Wettbewerben viel Öffentlichkeitsarbeit für ihre Interessen geleistet hatten, so dass im Fall einer Ablehnung seitens der Zentralregierung die Suche nach anderen Finanzierungsmöglichkeiten fortgesetzt wurde. Nur selten wurde das Vorhaben zum CCTV-Einsatz aufgegeben. Die Kommunalbehörde in Cottingham, East Yorkshire, hat beispielsweise zum Zweck der CCTV-Installation eine Sondersteuer eingeführt, um die neuen Anlagen finanzieren zu können. ${ }^{628}$ Nach Schätzung von Norris \& Armstrong stellte die britische Regierung in den unterschiedlichen CCTV-Wettbewerben „nur“ einen Betrag in Höhe von $£ 37$ Millionen bereit, während durch die Wettbewerbe zwischen den Städten und deren eifrige Suche nach privaten Geldgebern letztlich eine Gesamtsumme von $£ 100$ Millionen in CCTV-Anlagen investiert wurde. $^{629}$

Während manche Kommunalbehörden die Initiative ergriffen und sich an CCTVWettbewerbsprogrammen beteiligten, zeigten sich andere Kommunen anfänglich gegenüber dem Einsatz dieser Technologie als Präventionsmittel noch skeptisch, wie z.B. Exeter und Birmingham. ${ }^{630}$ Allerdings wurde das Verweigerungsrecht der Kommunalbehörden zur Installation von CCTV-Anlagen schnell durch die Zentralregierung aberkannt, indem sie die Notwendigkeit solcher Genehmigungen im Jahr 1993 abschaffte. Den Kommunen wurde dieses Recht entzogen, nachdem die Stadtverwaltung von Birmingham sechs Monate zuvor eine Maßnahme zur öffentlichen Videoüberwachung abgelehnt hatte. ${ }^{631}$ Mittlerweile hat sich die optisch-elektronische Überwachungsmethode längst als fester Bestandteil der kommunalen Sicherheitspolitik etabliert.

Der Einfluss der nationalen CCTV-Politik auf die lokale Sicherheitspolitik wird von einem Home Office Advisor in Liverpool treffend beschrieben: "Around CCTV, as with other central government initiatives, if you have a Minister who is enthusiastic about

\footnotetext{
${ }^{627}$ Die Zusammenarbeit zwischen dem privaten und dem öffentlichen Sektor erweist sich für alle Beteiligten als profitabel: Aufgrund der Übernahme der entstandenen Kosten durch die privaten Sponsoren müssen die kommunalen Behörden bzw. die Polizei diese Überwachungsmaßnahmen nicht aus ihrer vorwiegend unterversorgten Kasse subventionieren und die privaten Geschäftsleute gewinnen durch die Kooperation ein größeres Mitspracherecht in der gesamten Planung. Vgl. Reeve (1998b), S. 75; Norris; Armstrong (1999b), S. 37; Gras (2003), S. 36.

${ }^{628}$ Norris; Armstrong (1999b), S. 37.

${ }^{629}$ Norris (1998), S. 31; Norris; Armstrong (1999b), S. 37; vgl auch Gras (2003), S. 36.

${ }^{630}$ Davies (1996a), S. 187.

${ }^{631}$ Vgl. Gras (2003), S. 35.
} 
a particular course of action then that particular course of action will find funding. If a minister says it is a good idea, then it is a good idea. ${ }^{~} 632$

\subsubsection{Polizei}

\section{a) City of London Police}

Die Londoner Polizei (City of London Police) kontrolliert seit Februar 1997 sämtliche Fahrzeuge, die täglich an acht Zufahrtspunkten in die Innenstadt von London City vorbeifahren, mit Kameras, die an einem "Automatic Licence Plate Recognition System" angeschlossen sind. Die Integration von digitalen Kameras und Computertechnologien ermöglicht einen sofortigen Vergleich der erfassten Kennzeichen mit den Polizeidatenbanken von verdächtigen oder gesuchten Fahrzeugen. Das Nummernschilderkennungssystem ist fähig, 300.000 Fahrzeugkennzeichen in einer Stunde zu verarbeiten. Im Juli desselben Jahres wurde das System auf das gesamte Gebiet von London erweitert. ${ }^{633}$ Ebenso werden alle Fahrzeuge, die den Euro-Tunnel passieren, mit einem ähnlichen elektronischen Kontrollsystem überwacht. Die erfassten Daten werden an die zentrale Polizeidatenbank in London weitergeleitet und innerhalb von vier Sekunden überprüft. ${ }^{634}$

\section{b) Lokale Polizei}

Durch die hohe Kriminalitätsrate in den 1990er Jahren wandelte sich das britische kriminalpolitische Klima grundlegend. „[The] Labour Party had undergone a conversion from Left Idealism to New Left Realism, with its stress on the victim, the impact of crime on the working classes, and lived realities of crime. ${ }^{\prime \prime 35}$ Der damalige Innenminister (Home Secretary) Jack Straw erklärte dabei Überwachungskameras zu geeigneten Instrumenten der Unterstützung polizeilicher Dienste. ${ }^{636}$ Der polizeiliche Handlungsspielraum wird in der bereits erwähnten "Safer Cities Initiative“ ersichtlich. In solchen Gemeinschaftsarbeiten zwischen der Polizei und den Kommunalbehörden genießt die britische Polizei umfassende Entscheidungsfreiheit, die praktisch und rechtlich kaum Einschränkungen unterliegt. ${ }^{637}$

\footnotetext{
${ }^{632}$ Coleman (2004), S. 197.

${ }^{633}$ Norris; Armstrong (1999b), S. 45.

${ }^{634}$ Weichert (1998a), S. 65.

${ }^{635}$ Norris; Armstrong (1999b), S. 36; Gras (2003), S. 37.

${ }^{636}$ Die Politiker zeigten ihre Unterstützung, indem sie beispielsweise an der Inbetriebnahme der neuen CCTV-Systeme teilnahmen und die „enorme Auswirkung“ (tremendous impact) der Technologie propagierten. John Smith, ein ehemaliger Labour Leader, war bei der Inbetriebnahme des Airdrie Systems anwesend und Tony Blair setzte sich für das Chester-le-Street System ein, vgl. Norris; Armstrong (1999b), S. 36; Gras (2003), S. 37 f. Vgl. auch Teil II, Kap. 4.1 dieser Arbeit.

${ }^{637}$ Legnaro (1997), S. $271 \mathrm{ff}$.
} 
$\mathrm{Zu}$ den wenigen von Bürgerrechtsgruppen geäußerten Bedenken bezüglich der raschen Verbreitung der Anlagen in den öffentlichen Räumen rechtfertigte sich die britische Polizei mit dem Argument: „CCTV surveillance increases public freedom, enhancing opportunities for people to enjoy public places. ${ }^{438}$ Ein NorthumbriaPolizeibeamter meinte, „it is a much greater infringement on civil liberties getting beaten up or mugged, than being filmed walking down the streets“. ${ }^{639}$

Die Labour-Regierung unterstützte zudem tatkräftig die informationsgeleitete Polizei (,information-driven policing“), indem sie sowohl hohe finanzielle Zuschüsse für Kommunikations- und Informationstechnologien für die Polizei genehmigte als auch Gesetze verabschiedete, die die polizeilichen Befugnisse wesentlich erweiterten. ${ }^{640}$ Durch das Zusammenführen der Datenbanken, die Ermächtigung der polizeilichen Gewalt und die Unterstützung der Geheimdienste (zumindest in der Bekämpfung gegen den Drogenhandel und die organisierte Kriminalität) wurde eine Polizei in Großbritannien geschaffen, „die zentralisiert und informationsgeleitet, sehr mächtig und trotzdem zum großen Teil unsichtbar" ist. ${ }^{641}$ Die lokalen CCTV-Systeme, die allmählich die Lücken zwischen den kleineren privaten Videoüberwachungssystemen überbrückten, verliehen der lokalen Polizei die Möglichkeit, Informationen in ihren Kontrollbereichen nicht nur zu erwerben, sondern diese auch zu dokumentieren. „Wenn Information Macht bedeutet, so stattet die Labour-Regierung die Polizei mit erheblichen potentiellen Machmitteln aus, und CCTV-Überwachung spielt, zumindest auf lokaler Ebene, eine entscheidende Rolle, parallel zu den Entwicklungen auf nationalem Niveau. ${ }^{4642}$

\footnotetext{
${ }^{638}$ Graham (1998), S. 92.

${ }^{639}$ Ebenda.

${ }^{640}$ Die britische Zentralregierung stellt beispielsweise für eine DNA-Datenbank von 300.000 Kriminellen vorerst $£ 34$ Millionen zur Verfügung und genehmigt weitere Unterstützungen in Höhe von $£ 50$ Millionen für das Fingerabdruckerkennungssystem National Automated Fingerprint Identification System (NAFIS) und das Public Safety Communications Radio Project (PSRCP). All diese Maßnahmen begünstigten den Informationszugang der Polizei zu ermittlungsrelevanten Daten. Zugleich wurden durch den Police Act 1997 geheimdienstähnliche Befugnisse der Polizei erweitert, wie beispielsweise Kameras und Mikrofone versteckt anzubringen. Vgl. Gras (2003), S. 50.

${ }^{641}$ Ebenda, S. 50.

${ }^{642}$ Ebenda, S. 51. Wenn man bedenkt, dass die Polizei durch die Installationen der Überwachungskameras meist keine zusätzlichen Kosten tragen muss, da diese durch die staatlichen Gelder und privaten Unternehmen finanziert werden, ist es nicht verwunderlich, dass die polizeilichen Behörden diese Technologie als kriminalpräventives Mittel sehr willkommen heißen. Videoüberwachung stellt somit ein Werkzeug für die Polizei dar, ohne zusätzliche Kosten an mehr Informationen in ihren Einsatzgebieten zu kommen. Angesichts der Tatsache, dass die Polizei in Großbritannien oft überlastet ist, mag dies eine plausible Erklärung für die Verbreitung dieser Technologie sein. Vgl. Williams; Johnstone (2000), S. 195; Gras (2003), S. 220.
} 


\subsubsection{Privat-öffentliche Kooperation}

Die Vorteile der Videoüberwachung sind für die Einzelhändler, Kaufhäuser und Konsumenten offensichtlich: Durch den Einsatz von CCTV-Systemen wird in den urbanen Räumen ein Klima geschaffen, das dem Gewinn-Maximierungsprinzip der Wirtschaft entgegenkommt. ${ }^{643}$ Es ist deswegen nicht verwunderlich, dass die Geschäfte und vor allem die Großkonzerne, die Interesse an Investitionen in den Innenstädten haben, bereit sind, für die Kosten der CCTV-Installationen aufzukommen.

Programme zur Revitalisierung öffentlicher Räume sind in Großbritannien unter der Bezeichnung "Town Centre Management" (TCM) bekannt. Im Jahr 1998 dokumentierte Alan Reeve 180 britische Innenstädte mit einem Town Centre Manager oder einer Mitgliedschaft in einem solchen Programm. Acht Jahre zuvor wurden lediglich sechs derartige Manager registriert. ${ }^{644}$

Auch wenn es sich bei solchen Programmen um eine Kooperation zwischen privaten und öffentlichen Stellen handelt, kann man unschwer erkennen, dass das Funktionieren der Programme stark von den privaten Geldern und somit auch den privatwirtschaftlichen Akteuren abhängt. Ein Sprecher von einem der größten Konzerne in Großbritannien äußerte sich zum Town Centre Management wie folgt: „[In] essence we can almost compel local authorities to do what we want. ${ }^{\prime \prime 45}$ Es ist anzunehmen, dass die privaten Sponsoren einen großen Einfluss auf die kommunalen Entscheidungen zur CCTV-Planung ausüben. Neben den üblichen kriminalpräventiven Zielen dienen die öffentlichen Überwachungskameras in Newcastle beispielsweise dazu, „dem Handel zu assistieren". ${ }^{646}$

Die größten Konzerne in Großbritannien wie die Drogeriekette "Boots the Chemist" oder die Kaufhäuser von „Marks E Spencers" sind die wichtigsten Sponsoren beim Town Centre Management. Sie finanzieren die Programme, indem sie die Gehälter der Manager oder die Zahlung der Installation von Videoüberwachungsanlagen übernehmen. ${ }^{647}$ „Marks \& Spencers“ pflegt zudem nicht nur ein gutes Arbeitsverhältnis mit der Regierungsstelle (Government Office), sondern hat auch regelmäßige Treffen mit den Staatsministern (Home Office Minister of State) ${ }^{648}$

Die Versicherungs- und die Überwachungsindustrien leisten ferner weit reichende Arbeit zur Verbreitung der CCTV-Systeme. In einigen Städten Großbritanniens er-

\footnotetext{
${ }^{643}$ Vgl. hierzu Teil II, Kap. 5.1 dieser Arbeit.

${ }^{644}$ Reeve (1998b), S. 75 f.

${ }^{645}$ Ebenda.

${ }^{646}$ Gras (2003), S. 109; Graham et al. (1995), S. 9.

${ }^{647}$ Reeve (1998b), S. 76.

${ }^{648}$ Coleman; Sim (2000), S. 631.
} 
halten die Einzelhändler bis zu 30\%ige Nachlässe auf ihre Versicherungsbeiträge, wenn sie sich an den Kosten der weiträumigen CCTV-Systeme beteiligen. ${ }^{649}$ Die Kosteneinsparungen bei den Versicherungsprämien sowie mögliche Verbesserung der Umsätze durch die Rückgewinnung der Kunden sind für den Einzelhandel attraktive Bedingungen zur Unterstützung von weiträumiger Observierung mittels Videotechnik.

Es handelt sich bei Videoüberwachungsmaßnahmen häufig um eine Gemeinschaftsarbeit zwischen öffentlichem und privatem Sektor, die unter Bezeichnungen wie "Crime and Disorder Partnerships" oder "multi-agency-partnerships" bekannt sind. ${ }^{650}$ Häufig werden die Interessen zur Installation von Überwachungskameras von der örtlichen Polizei oder von einigen Bürgern, die auch als "moralische Unternehmer" bezeichnet werden, geäußert. ${ }^{651}$ Das gemeinsame Anliegen wird dann in der Lokalpresse artikuliert, bevor die eigentlichen CCTV-Kampagnen gestartet werden. Das britische Innenministerium fordert ausdrücklich die Betreiber der CCTV-Systeme auf, die lokale Presse als wichtigen Partner in der Sicherheitspolitik zu berücksichtigen: „Home Office guidelines urge scheme manager to get the local press on your side from the start and ensure they realise what your objectives are in focusing them on the safer shopping/walking element. ${ }^{\text {“652 }}$

Die an solchen Partnerschaften Beteiligten sind also die örtliche Polizei, die kommunalen Behörden und Privatpersonen. Nicht nur die Finanzierungsfrage und die Betriebsführung werden in solchen Gremien geklärt, sondern auch die Positionen und Einsatzgebiete der anzubringenden Überwachungskameras werden hier entschieden. ${ }^{63}$ In Liverpool finden sogar monatlich überregionale Treffen von verdeckt ermittelnden Polizeibeamten, den örtlichen Ladenbesitzern und privaten Sicherheitsbeamten statt, um die Verlagerung von bestimmten „unerwünschten“ Personengruppen in die angrenzenden Städte zu verhindern. ${ }^{64}$

In Liverpool findet beispielsweise die CCTV-Gemeinschaftsarbeit im Rahmen der Liverpool City Centre Partnership (LCCP) statt, welche im Jahr 1992 gegründet wurde. Ziele des Kameraeinsatzes waren die Förderung der Sicherheit sowie Revitalisierung der Innenstadt in Liverpool. Die Kommunal- und Polizeibehörden entscheiden heute gemeinsam mit kommerziellen Organisationen wie „Liverpool Stores Committee“, „Lo-

\footnotetext{
${ }^{649}$ Reeve (1998b), S. 90.

${ }^{650}$ Coleman; Sim (1998), S. 28; Gras (2003), S. 51.

${ }^{651}$ McCahill (1998), S. 42; Gras (2003), S. 35.

${ }^{652}$ Coleman (2004), S. 163. Mehr zu CCTV-Überwachung in lokalen Medien vgl. ebenda, S. 129 ff.

${ }^{653}$ Gras (2003), S. 51.

${ }^{654}$ Coleman; Sim (2000), S. 628, Coleman (2004), S. 211.
} 
cal Chamber of Commerce", "Merseytravel" sowie den zwei Universitäten Liverpools über die lokalen Sicherheitsmaßnahmen mit Überwachungskameras. ${ }^{655}$ Diese lokale Initiative wird von einem nicht gewählten City Centre Manager geleitet, der die öffentliche Sicherheit in Liverpool und die Rolle der Überwachungskameras in der lokalen Sicherheitspolitik stark aus Sicht des privaten Wirtschaftssektors definiert: "The location of the cameras in Liverpool is decided on the basis of police crime patterns and knowledge of incidents along with the hands-on experience of store security so that escape routes and access points would be covered. ${ }^{\prime 456}$ Derartige Kooperationen sind beispielsweise auch in Städten wie Ilford, Brighton und King's Lynn zu finden. Birmingham und Glasgow haben Partnerschaftsorganisationen, die beide "City Watch" genannt werden. Während in Glasgow die partnerschaftliche Körperschaft aus kommunalen Behörden (Glasgow Development Agency) und örtlichen privaten Ladenbesitzern besteht, handelt es sich in Birmingham um eine Kooperation zwischen der örtlichen Polizei und der Birmingham City Centre Association. Dagegen sind es die industriellen Konzerne, die Stadtverwaltung und die Polizei, die in King's Lynn die CCTV-Programme vorantreiben, wobei die privaten Sicherheitsdienste die tägliche Überwachungsarbeit übernehmen. ${ }^{67}$

Es ist in solchen kooperativen Körperschaften nicht immer klar, wer für die tägliche Überwachungsarbeit an Monitoren zuständig ist. In manchen Fällen sind es die Polizeibeamten, die diese Aufgabe übernehmen. In den meisten Fällen wird diese allerdings aus Kostengründen den zivilen Mitarbeitern oder den privaten Sicherheitsdiensten überlassen. Gemäß einer Studie von Alan Reeve werden 50\% der untersuchten CCTV-Systeme von privaten Sicherheitsdiensten kontrolliert, wobei die Kommunen oft die Auftraggeber dieser privaten Sicherheitsfirmen sind. ${ }^{658}$ Allerdings lässt sich eine eindeutige Zuständigkeit für die Überwachungsanlagen in solchen unübersichtlichen CCTV-Netzwerken, die durch die vielschichtigen Gemeinschaftsarbeiten zwischen den privaten und dem staatlichen Akteuren entstanden sind, nur schwer bestimmen. Ein Economic Development Officer in Liverpool beschreibt das lokale Videoüberwachungssystem wie folgt: „At the moment responsibility for the system lies between the City Centre Manager and the private sector; the police and the City Council. Nobody owns it and everyone owns it. Everyone wants to promote it and

\footnotetext{
${ }^{655}$ Coleman; Sim (1998), S. 30; Coleman; Sim (2000), S. 625.

${ }^{656}$ Kommentar vom City Centre Manager in Liverpool, vgl. Coleman (2004), S. 163.

${ }^{657}$ Brown (1995), S. 27, 47; Gras (2003), S. 98.

${ }^{658}$ Reeve (1998a), S. 51.
} 
nobody is actually promoting it. Nobody really seems to be championing the cause of CCTV in a clear and consistent way. “659

Durch die Vernetzung der Überwachungs-Systeme sind vielfältige Kooperationsformen der beteiligten Akteure entstanden. „Somit ist neben einem Kameranetzwerk ein Netzwerk von nicht demokratisch (oder verwaltungsrechtlich) kontrollierten Organisationen in Großbritannien entstanden, die entscheiden, wie dieses Instrument betrieben werden soll. ${ }^{\text {“660 }}$ Dabei ist oft nicht klar, wer rechtlich für das gesamte CCTV-Netzwerk Verantwortung trägt.

\subsubsection{Staatsinterne Kontrollinstanzen}

Dieses Kapitel beschäftigt sich zunächst mit den gesetzlichen Rahmenbedingungen für Videoaufnahmen im öffentlichen Raum. Angesichts der raschen Verbreitung dieser Überwachungstechnik liegt die Vermutung nahe, dass die Sicherheitsbehörden über weitreichende Entscheidungsbefugnisse verfügen, die durch diese Richtlinien nicht einzuschränken sind. Ferner sollen die staatlichen Akteure, die gewisse Aufsichtsfunktion über die Entwicklung dieser Technik ausüben können, näher untersucht werden.

\subsubsection{Rechtliche Kontrolle}

\section{a) Data Protection Act}

Während die Gesetzgeber verschiedener Nationen Anfang der siebziger Jahre die Wichtigkeit des Datenschutzes erkannt haben und bemüht waren, die entsprechenden Regelungen zu entwickeln, zeigte Großbritannien dazu wenig Bereitschaft.

Als im Jahr 1984 das britische Datenschutzgesetz endlich in Kraft trat, war Datenschutz für viele Länder bereits eine Selbstverständlichkeit. Um sich am internationalen Datenaustausch beteiligen zu können, entschied sich Großbritannien im Jahr 1984 für den „Data Protection Act", der eine Zusammenfassung der anfänglichen Grundsätze von der Datenschutzkonvention des Europarates war. Angesichts der Weiterentwicklung des Datenschutzes in anderen Nationen in den 1970er Jahren, hatten die britischen Gesetzgeber die besten Voraussetzungen moderne Datenschutzregelungen aus diesen Modellen zu entwickeln. Trotzdem war der „Data Protection Act“ schon bei seiner Verabschiedung überholt und lückenhaft. ${ }^{661}$

\footnotetext{
${ }^{659}$ Coleman (2004), S. 201.

${ }^{660}$ Coleman; Sim (1998), S. 28.

${ }^{661}$ Durch die sehr allgemein gehaltenen Vorschriften ist ein großer Spielraum für britische Sicherheitsbehörden und Datenverarbeitungsstellen entstanden. Datenschutzregelungen, so einige Forscher, scheinen für die britische Regierung ineffektiv zu sein, da man die möglichen Vorteile der gesammel-
} 
Im DPA 1984 war die automatische Verarbeitung personenbezogener Daten geregelt. Allerdings fiel das manuell gesteuerte Betreiben an CCTV-Monitoren (Heranzoomen, Vor- und Rückspulen der Aufzeichnungen) nicht unter diese Kategorie. Auch das Filmen und Aufzeichnen von Personen mit CCTV-Anlagen wurde nicht von den Normen des DPA 1984 berücksichtigt. ${ }^{662}$ Zur Standardisierung des weit verbreiteten Gebrauchs von CCTV-Systemen in der britischen Öffentlichkeit war lediglich die unverbindliche Registrierung der Anlagen vorgesehen. ${ }^{663}$

Der novellierte Data Protection Act 1998, der erst am 1. März 2000 in Kraft getreten ist, soll den veralteten Data Protection Act von 1984 ersetzen und die ersten Grundlagen für die Kontrolle von CCTV-Überwachung in Großbritannien schaffen. Nach den neuen Regelungen ist es vorgeschrieben, dass die CCTV-Anlagen beim Information Commissioner ${ }^{664}$ registriert werden sollen. Die Registrierungsfrist ist je nach Installationsdatum der Systeme unterschiedlich. ${ }^{665}$

Im Rahmen des Data Protection Act 1998 werden sowohl die privaten als auch die öffentlichen Überwachungssysteme reguliert. ${ }^{666}$ Zwar werden bestimmte Systeme von dem Registrierungszwang befreit, aber die Einhaltung der gesetzlichen Regelungen ist für alle Systembetreiber unabdingbar. Eine Missachtung dieser Datenschutzgesetze kann als Straftat angesehen werden, bei der dem Verantwortlichen eine Geldstrafe bis zu $£ 5.000$ droht. $^{667}$

ten Informationen ausnutzen und die Potentiale der heimischen Datenbearbeitungsindustrie ausschöpfen möchte. Aus diesen Gründen ist es zweifelhaft, ob das Hauptinteresse des britischen Gesetzgebers in der Erstellung effektiver Datenschutzregelungen liegt, oder vielmehr in der wirtschaftlichen Nutzbarmachung der gesammelten Daten. Vgl. Panagiotides (1998), S. 17 ff.

${ }^{662}$ McCahill; Norris (2002a), S. 50.

${ }^{663}$ Gras (2003), S. 66.

${ }^{664}$ Mehr zu „Information Commissioner“ vgl. später in diesem Kapitel.

${ }^{665}$ CCTV-Systeme, die vor dem 24. Oktober 1998 in Betrieb aufgenommen wurden, mussten bis zum 23. Oktober 2001 registriert sein, während Anlagen, die in dem Zeitraum vom 24. Oktober 1998 bis zum 1. März 2000 installiert wurden, die Registrierung erst im Jahr 2003 vorgenommen haben mussten. Eine sofortige Registrierung gilt allerdings bei allen neuen CCTV-Systemen, die nach dem 1. März 2000 angebracht werden. Vgl. Gras (2003), S. 63; Data Protection Office UK (2000).

${ }^{666}$ In Großbritannien hat ein Privateigentümer das Recht, innerhalb seines Besitzes Kameras aufzustellen und dies zu überwachen, auch wenn es sich dabei um semi-öffentliche Räume (z.B. Banken) handelt. Die englischen Gesetzgeber sehen in diesem Fall keine Beeinträchtigung der Betroffenen und deswegen auch keine Notwendigkeit, die Rechte der Eigentümer einzuschränken. Es ist allerdings mittlerweile trotz der Rechte des Eigentümers, die Videoüberwachung heimlich durchzuführen, üblich geworden, die Betroffenen mit Hinweisschildern auf die technischen Aufzeichnungen aufmerksam zu machen. Allerdings beruht diese Handhabung weniger auf der Rücksichtnahme auf die Betroffenen, sondern vielmehr auf Abschreckungseffekte, die dadurch erzielt werden können. Der Data Protection Act 1998, der der Videoüberwachung in Großbritannien ab Oktober 2003 eine gesetzliche Grundlage bietet, macht inzwischen eine Ausschilderung obligatorisch. Allerdings ist nicht bekannt, ob das Fehlen eines Hinweisschilds rechtliche Konsequenzen nach sich zieht. Vgl. Data Protection Office UK (2000); Brown (1995), S. 7; Gras (2003), S. 54, 66.

${ }^{667}$ Gras (2003), S. 66; Mehr zu den CCTV-Regelungen in DPA 1998 vgl. McCahill; Norris (2002a), S. 52 ff. 


\section{b) Fehlende Definition von "Privacy“}

Das Fehlen von spezifischen Regelungen bezüglich der Anwendung von CCTVSystemen liegt vor allem daran, dass das Recht auf Privacy bis heute in Großbritannien juristisch nicht hinreichend definiert ist. ${ }^{668} \mathrm{Im}$ Common Law wird das Recht auf die Privatsphäre nicht berücksichtigt. ${ }^{699}$ In diesem Sinne ist eine Person frei, das zu tun, was nicht verboten ist: „,[W]here the law is silent on a matter it will be assumed that the conduct is not forbidden that is to say, a person is free to do that which is not forbidden. “670

Um die eigene Privatsphäre zu schützen, muss man auf andere Rechte des Common Laws zurückgreifen, wie z.B. Hausfriedensbruch (trespass) oder Vertrauensbruch (breach of trust). „Keines von ihnen könnte man in der Öffentlichkeit, d.h. von seinem Privatgrundstück entfernt, durchsetzen, weder gegen eine andere Privatperson, noch den Staat. ${ }^{4671}$ Daraus resultierend kann man annehmen, dass das Common Law keinen Schutz gegen die durch CCTV-Systeme beeinträchtigte persönliche Privatsphäre bietet, weil man im Sinne der Gesetze keine Privatsphäre in der britischen Öffentlichkeit erwarten kann. Sharpe sieht in dieser gesetzlichen Lücke die Gefährdung der bürgerlichen Freiheiten ${ }^{672}$ : „The right to privacy is therefore unlikely to exist in relation to those ransom public surveillance activities which cause the greatest outcry on the basis that personal libierties are being infringed. ${ }^{4673}$

Trotz der Novellierung des Datenschutzgesetzes fehlen bis heute spezielle, bindende Regelungen zum öffentlichen Einsatz von Überwachungskameras. Einige gesetzliche Bestimmungen, die die Anwendung dieser optisch-elektronischen Einrichtungen betreffen, werden im Folgenden kurz dargestellt. ${ }^{674}$

\section{c) Crime and Disorder Act}

Im Jahr 1994 wurden durch den Crime Justice and Public Order Act für die Kommunen zum ersten Mal die rechtlichen Möglichkeiten geschaffen, Videoüberwachungssysteme auf öffentlichen Straßen und Plätzen einzurichten. § 163 dieses Gesetzes ver-

\footnotetext{
${ }^{668}$ McCahill; Norris (2002a), S. 49 f.

${ }^{669}$ Panagiotides (1998), S. 40; Gras (2003), S. 59.

${ }^{670}$ Norris; Armstrong (1999b), S. 98. Mehr zu Kooperation vgl. Gras (2003), S. 97, 107.

${ }^{671}$ Gras (2003), S. 59.

${ }^{672}$ Selbst als eine öffentliche Stelle Videomaterial von einem Mann, dessen Selbstmord von einem CCTV-System aufgezeichnet wurde, an TV-Sender weitergab, war es den Gerichten mangels gesetzlicher Regulierung nicht möglich, dies zu untersagen. Vgl. McCahill; Norris (2002a), S. 50.

${ }^{673}$ Ebenda, S. 50.

${ }^{674}$ Büllesfeld (2002), S. $39 \mathrm{ff}$.
} 
ordnet eine Absprache zwischen der Polizei und den Kommunen bezüglich der Installation von Überwachungskameras in öffentlichen Räumen. ${ }^{675}$

Der „Crime and Disorder Act“ im Jahr 1998 erweiterte diese Rechtsgrundlage, wobei eine Zusammenarbeit zwischen privaten bzw. öffentlich-privaten Akteuren ermöglicht wurde. Die sogenannten Crime and Disorder Reduction Partnerships wurden zur Kriminalitätsbekämpfung und zur Herstellung öffentlicher Ordnung gegründet. In einer solchen Gemeinschaftsarbeit kooperieren Private, Kommunen und die Polizei miteinander, wobei in den meisten Fällen die Polizei die leitende Position einnimmt. Die Instandhaltung lokaler CCTV-Anlagen ist in vielen Fällen ebenfalls Aufgabe solcher Zusammenschlüsse. ${ }^{676}$

\section{d) Regulation of Investigatory Power Acts und Privacy Security Act}

Durch die Verabschiedung des Regulation of Investigatory Power Acts (RIPA) im Jahr 2000 wird die Anwendung von Überwachungstechnik bei Ermittlungen durch die Polizei sowie durch den Staatssicherheitsdienst reguliert. Damit betrifft der RIPA unter anderem auch den Gebrauch von CCTV-Systemen. Allerdings handelt es sich dabei vor allem um versteckte Videoüberwachung, wobei vorab die Verhältnismäßigkeit, die Rechtsmäßigkeit sowie Notwendigkeit und Verantwortlichkeit des Verfahrens geprüft und bestätigt werden muss. Die umfangreiche Videoüberwachung auf öffentlichen Straßen und Plätzen in Großbritannien wird nicht von RIPA reguliert. $^{677}$

Der Privacy Security Act 2001 schreibt den Mitgliedern der privaten Sicherheitsindustrie in England und Wales eine Registrierung ihrer CCTV-Anlagen bei Security Industry Authority (SIA) vor. Ausgenommen von dieser Lizensierung sind bisher solche Betreiber, die unmittelbar von Kommunen beauftragt werden. Dies betrifft jedoch nicht solche CCTV-Benutzer, die zwar für die Kommunalbehörden arbeiten, aber nicht direkt von diesen beauftragt werden. Ab 20. März 2006 sind allerdings alle Betreiber, die öffentliche CCTV-Maßnahmen durchführen, gesetzlich verpflichtet, sich bei SIA registrieren zu lassen. ${ }^{678}$

\section{e) Human Rights Acts und Police and Criminal Evidence Act}

Der Human Rights Act 1998, der seit Oktober 2000 die europäische Menschenrechtsrichtlinie (European Convention on Human Rights) berücksichtigt, betrifft unter $\S 6$

\footnotetext{
${ }^{675}$ Nürnberg (2000), S. 231; Gras (2003), S. 55; Büllesfeld (2002), S 39 ff.; Kohl (1997a), S. 36 f.

${ }^{676}$ Vgl. "Privat-öffentliche Kooperationen“ in diesem Kapitel.

${ }^{677}$ McCahill; Norris (2002a), S. 5.

${ }^{678}$ Vgl. Parliamentary Office of Science and Technology (2002); http://www.thesia.org.uk/home/licensing/cctv/cctv.htm.
} 
(the right to a fair trial) und $\S 8$ (the right to respect for familiy and private life) die Anwendung von Überwachungskameras. ${ }^{679}$ Allerdings werden diese Regelungen eingeschränkt und Videoüberwachungsprojekte trotzdem durchgeführt, wenn es um nationale Sicherheit und kriminalpräventive Maßnahmen geht. ${ }^{600}$

Nach dem britischen Beweisverwertungsrecht führt eine Missachtung der CCTVrelevanten Gesetze nicht automatisch zur Aberkennung der Beweismittel, die durch Videoüberwachungsanlagen entstanden sind. Der Police and Criminal Evidence Act 1984 erlaubt den Gerichten, selbstständig zu entscheiden, welche Beweismaterialien für die Verhandlungen zugelassen werden und welche als illegitim zu betrachten sind. In England und Wales werden die von CCTV-Überwachung erzeugten Daten meistens von Richtern gebilligt. Demnach spielen für die Gerichtsverhandlungen die Regeln zur Anwendung von CCTV-Systemen eine nachrangige Rolle, da die Aufzeichnungen auch bei Verstößen gegen entsprechende Gesetze zugelassen werden können. ${ }^{61}$

Eine gesetzlich verbindliche Kontrolle über die Benutzung von CCTV-Systemen existiert also bis zum heutigen Tage nicht. Nach Aussagen von Williams \& Johnstone kann die Videoüberwachung von jedem durchgeführt werden: „A CCTV system can be set up by anyone, there is no need for a license and the central government does not control the use to which it is put.."182 Die gesetzliche Grauzone begünstigt die stete Ausweitung der Überwachungssysteme erheblich. Es ist zweifelhaft, ob der bestehende CCTV-Einsatz in Großbritannien mit den novellierten Datenschutzrichtlinien und der Einführung der europäischen Menschenrechtskonvention in Einklang zu bringen ist.

\subsubsection{Verwaltungskontrolle}

Nach der vorherigen Analyse fehlen in Großbritannien wirksame, verbindliche Bestimmungen sowohl für die privaten als auch für die staatlichen CCTV-Betreiber. Im kommenden Abschnitt soll untersucht werden, inwiefern zuständige, staatliche Instanzen trotz dieses gesetzlichen Mangels fähig bzw. geneigt sind, die Entwicklung von CCTV-Projekten zu kontrollieren und ggf. zu unterbinden.

\footnotetext{
${ }^{679}$ Mehr zu den Regulierungen sowie Rechtsstreitfälle, vgl. McCahill; Norris (2002a), S. 50 f.

${ }^{680}$ Parliamentary Office of Science and Technology (2002).

${ }^{681}$ Gras (2003), S. 68.

${ }^{682}$ Williams; Johnstone (2000), S. $194 \mathrm{f.}$
} 


\section{a) Innenministerium}

Seit 1984 existiert eine Verordnung des britischen Innenministeriums, die nicht nur die akustische, sondern auch die visuelle Überwachung regelt. Diese Verordnung dient bis heute als generelle Bestimmung für die Videoüberwachung auf den britischen Inseln. ${ }^{683} \S 1$ und $\S 4$ der Verordnung regeln die geheime Überwachung, während $\S 15$ und $\S 16$ für die offene visuelle Überwachung ausschlaggebend sind. ${ }^{684} \mathrm{Al}-$ lerdings fällt bei einer genaueren Betrachtung der Richtlinien auf, dass es von dem subjektiven Ermessen eines hochrangigen Polizeibeamten abhängt, was bei der Videoüberwachung unter „einem unzumutbaren Eingriff in die Privatsphäre“ der Betroffenen verstanden wird. Diese subjektive Definition durch einen Polizeibeamten bestimmt über die Zulässigkeit der Videoüberwachungstechnik in einer Ermittlung, womit diese Regelung keine tatsächliche Einschränkung für den Videoeinsatz darstellt.

Als Ratgeber in Bezug auf die Aufstellung und das Betreiben von Kameras zu Überwachungszwecken empfiehlt das britische Innenministerium den (potentiellen) Betreibern einen Code of Practice ${ }^{685} \mathrm{zu}$ formulieren, der u.a. die Überwachungszwecke erläutern soll. Als Geldgeber für eine Vielzahl von CCTV-Programmen verlangt das britische Innenministerium obligatorisch einen solchen Code für den Erhalt öffentlicher Gelder. Diese Bedingung stellt jedoch keine erhebliche Beschränkung für die Installation und Inbetriebnahme von CCTV-Anlagen dar, vor allem nicht für solche Systeme, die durch private Gelder subventioniert werden. ${ }^{686}$ Das Innenministerium weist bezüglich der Videoüberwachung in Wohngebieten lediglich darauf hin, dass die Observierung von feinfühligen, gut ausgebildeten Kontrolleuren durchgeführt werden soll. ${ }^{687}$

\section{b) Polizei}

Die britische Polizei sieht, wie bereits erläutert, keine Notwendigkeit darin, die Installation oder das Betreiben von Überwachungskameras auf öffentlichen Straßen und Plätzen einzuschränken bzw. zu regeln. Zum Schutz der Privatsphäre von Ü-

\footnotetext{
${ }^{683}$ Gras (2003), S. 55, $66 \mathrm{f}$.

${ }^{684} \S 1$ der Verordnung schreibt vor, dass die Konstellationen vor dem Einsatz der Videoüberwachung sorgfältig von einem hochrangigen Polizeibeamten überprüft werden sollen. Ein Eingriff in die Privatsphäre der Betroffenen, so § 4 der Verordnung, darf erst bei schweren Straftaten vorgenommen werden. $\S 16$ gibt dem hochrangigen Polizeibeamten - dem Chief Superintendent - das Recht, eine Überwachung des öffentlichen Verhaltens mittels Überwachungskameras zu genehmigen, während § 15 fordert, dass „,kein unzumutbarer Eingriff in die Privatsphäre erfolgt, und dass der Eingriff vollkommen gerechtfertigt ist - unter allen Aspekten der konkreten polizeilichen Ermittlungen." Honess; Charman (1992), S. 1; Gras (2003), S. 56.

${ }^{685}$ Code of Practice steht für Regeln zur guten Praxis. Vgl. hierzu Teil I, Kap. 3.3.2 dieser Arbeit.

${ }^{686}$ Gras (2003), S. 58.

${ }^{687}$ Ebenda, S. 59.
} 
berwachten dienen lediglich die polizeieigenen Richtlinien bei der Anwendung von CCTV-Anlagen, deren Missachtung letztlich keine rechtlichen Konsequenzen nach sich zieht.

Der Code of Conduct, der von dem höchsten polizeilichen Beirat - Association of Chief Police Officers of England, Wales and Northern Ireland - (A.C.P.O.) nach den allgemeinen Datenschutzregelungen des Data Protection Act 1998 und des Human Rights Act 1998 erarbeitet wurde, dient als Hauptrichtlinie für den polizeilichen Umgang mit CCTV-Systemen, die von der Polizei selbst betrieben werden. Diese Vorschriften regeln die Verwendung und Weitergabe von den aufgenommenen Bilddaten, wobei die öffentliche Sicherheit die höchste Priorität hat und den individuellen Rechten vorgezogen werden soll. Entscheidungen über die gesammelten Daten sollen im Sinne des Code of Conduct von einem hochrangigen Polizeibeamten getroffen werden. ${ }^{68}$

Als die höchste Kommission der britischen Polizei vertritt A.C.P.O. außerdem die Ansicht, dass eine CCTV-Anlage praktisch wie ein Polizeibeamter in Zivil sei. Einer Kommentierung dieser Aussage zufolge dürften also Videoüberwachungsgeräte in Großbritannien „,zu jeder Zeit und in jeder Situation an einem öffentlichen Ort aufgestellt werden“ ${ }^{689}$ Nach Angaben einer amtlichen Publikation der Polizei kann die Polizei auf öffentlichen Plätzen unbegrenzt filmen. ${ }^{690}$

Vereinzelt wurde aber auch eine skeptische Einstellung zur CCTV-Überwachung von lokalen Polizeibehörden gezeigt. Der Polizeipräsident in Liverpool äußert sich zur raschen Verbreitung von CCTV-Systemen beispielsweise wie folgt: „In my experience of 22 years in the police you can do a far better job by being in a place than by looking at it through a camera. The deterrent effect by a physical presence is greater than that of CCTV. I'm not overtly enthusiastic about CCTV. I see it as a tool in the armoury but not the be all and end all. This is not a view shared by some ministers, unfortunately. ${ }^{\text {“691 }}$ Angesichts der allgemeinen Begeisterung für die Videoüberwachungsmaßnahmen in Großbritannien dürfte es sich dabei um eine unverbreitete Meinung handeln. Durch die Aussage wird zudem die bedeutende Rolle der Zentralregierung in der lokalen Sicherheitspolitik ersichtlich.

\footnotetext{
${ }^{688}$ Gras (2003), S. 62; Data Protection Office UK (2000).

${ }^{689}$ Gras (2003), S. 56.

${ }^{690}$ Ebenda.

${ }^{691}$ Coleman (2004), S. 204.
} 


\section{c) Kommunalbehörden}

Ähnlich wie bei der Polizei gelten für die Kommunalbehörden bei der Regulierung von CCTV-Systemen interne Richtlinien, die im Code of Practice zusammengefasst sind. Dieser Code betrifft vor allem solche Kamerasysteme, die nicht von der Polizei kontrolliert werden. Wenn man bedenkt, dass im Jahr 1997 60\% der öffentlichen CCTV-Anlagen von den Kommunalbehörden und 29,5\% von der Polizei kontrolliert wurden und 98,6\% der Kommunalbehörden einen solchen Code besitzen, kann man davon ausgehen, dass die Mehrheit der Videoüberwachungssysteme in Großbritannien einem solchen Code of Practice unterliegt. ${ }^{692}$

Die Local Gorvernment Information Unit verfasste im Jahr 1996 den Model Code of Practice zur Kontrolle des Kameraeinsatzes. Dieser basiert auf den Regelungen des Data Protection Act 1984 und sollte für die britischen Kommunalbehörden als Leitbild und Wegweiser für die Praxis mit CCTV-Anlagen dienen. Er wurde auch von der Regierung als Musterbeispiel für die (freiwillige) Aufstellung derartiger Richtlinien empfohlen. ${ }^{693}$

Nach dem Model Code of Practice sollen neben der Frage der Verantwortlichkeit (Wem gehören die CCTV-Anlagen? Wer betreibt und kontrolliert sie?) auch die Überwachungszwecke geklärt werden. Wichtig ist dabei auch die öffentliche Bekanntgabe dieser Ziele und des Überwachungsschwerpunktes. Sowohl die Pflichten der Betreiber als auch die Aufbewahrung und Weitergabe der gesammelten Daten sollen in diesen Leitlinien festgehalten werden. Dabei ist die Vorgehensweise des Überwachungspersonals bei der Entdeckung von Straftaten ebenfalls vorgeschrieben.

Besonders viel Wert legt der Model Code of Practice auf die Achtung des Privateigentums. Dementsprechend wird in vielen CCTV-Programmen in Stadtzentren darauf geachtet, dass die Überwachungskameras auf die Geschäfte und nicht auf die darüber liegenden Privatwohnungen gerichtet sind. Bei vorhandener technischer Ausrüstung ist es inzwischen sogar möglich, den Überwachungswinkel der Kameras zu kontrollieren, so dass bei einer Missachtung der erlaubten Bedingungen das zuständige Überwachungspersonal von der Betriebsleitung zur Rede gestellt werden kann. $^{694}$

Allerdings besteht bei solchen internen Richtlinien ebenfalls kein Zwang für die Behörden, diese auch tatsächlich zu übernehmen. Insofern handelt es sich hierbei ledig-

\footnotetext{
${ }^{692}$ Gras (2003), S. 58 f.

${ }^{693}$ Ebenda, S. 60.

${ }^{694}$ Gras (2003), S. 60 f.
} 
lich um eine Konkretisierung von Regelungen, deren praktische Zweckdienlichkeit zweifelhaft ist. Mit anderen Worten: Diese Codes of Practices haben keine effektive kontrollierende Funktion im Hinblick auf die Anwendung von Videoüberwachung. Beispielsweise kann man eine fehlende Zugangskontrolle zu den aufgenommen Daten feststellen: Trotz der vorgeschriebenen Regelung stehen die Aufnahmen - laut einer Untersuchung von Reeve - oft nicht nur der Polizei, sondern auch den Mitgliedern der Town Centre Management Committees zur Verfügung. ${ }^{695}$ Eine andere Untersuchung zeigte, dass die Aufnahmen in manchen Fällen sogar den Führungskräften der Betreiberfirma oder den privaten Geldgebern zugänglich gemacht werden ${ }^{696}$ Norris \& Armstrong stellen in ihrer Untersuchung der CCTV-Zentralen ebenfalls eine schwache Kontrolle über die Einhaltung der Code of Practices fest. Viele Mitarbeiter des Überwachungsdienstes führen oft polizeiliche Anweisungen aus, obwohl dies gegen die Regeln verstößt, da die Polizeibeamten im Vergleich zu ihnen einen höheren autoritären Status genießen. ${ }^{697}$

In Liverpool werden nicht nur Reduzierung von Verbrechen und Kriminalitätsfurcht, sondern auch die Steigerung der Attraktivität für Investoren, Konsumenten und Touristen als offizielle Ziele im Code of Practice festgelegt. Dabei wird das private Überwachungspersonal aufgefordert, Missetäter von den Straßen fernzuhalten. ${ }^{698}$ Die informellen Kontrollinstanzen für die Einhaltung dieser Regelungen werden neben der Polizei (City Centre Commander for Merseyside Police) von City Centre Manager und Crime Alert gebildet, die in erster Linie die wirtschaftlichen Interessen der Stadt vertreten. Der Vorsitzende vom privaten "Stores' Committee“ in Liverpool, zu dem der Crime Alert gehört, bezeichnet die Kontrolle der täglichen Überwachungsarbeit ohne polizeiliche Beteiligung als ausreichend: „Although everything we do has to be closely worked out with the police - they don't control it, only over evidence. This is all part of maintaining the system's integrity and confidence with the public. So there is not a lot of need for detailed control. (...) I'm not saying it's not there because there is a management chain. ${ }^{\prime 699}$

Der Standort der von einer privaten Sicherheitsfirma betriebenen Überwachungszentrale in Liverpool wird vor der Öffentlichkeit geheim gehalten. Ein Beamter der Stadtverwaltung in Liverpool zeigt zwar diesbezüglich Bedenken, allerdings bleiben

\footnotetext{
${ }^{695}$ Reeve (1998b), S. 81.

${ }^{696}$ Honess; Charman (1992), S. 16.

${ }^{697}$ Norris; Armstrong (1999b), S. 154 f.

${ }^{698}$ Coleman (2004), S. 162.

${ }^{699}$ Kommentar des Vorsitzenden von Stores' Committee in Liverpool, vgl. ebenda, S. 162. Zur Spannung bei der Zusammenarbeit zwischen Polizei und Crime Alert in Liverpool vgl. ebenda, S. 206 ff.
} 
Forderungen nach mehr betrieblicher Transparenz für die Bürger erfolglos: “When the system was launched nobody was supposed to know where it was. (...) It's not big brother and we don't want people to think we are in a war zone here. We need a certain level of transparency about it and proper regulation, control and monitoring, none of which we really have. It's a situation where no one really knows what's going on. “700

\section{d) Information Commissioner}

Der Information Commissioner, auch unter der früheren Bezeichnung Data Protection Registrar oder Data Protection Commissioner bekannt, fungiert als Kontrollinstanz bei der Einhaltung des Data Protection Act 1998 und des Freedom of Information Act 2000, wobei er dem Parlament jährlich Berichte erstatten muss. ${ }^{701}$ Der Commissioner ist befugt, auf Grundlage des Data Protection Act 1998 bei Beschwerden von Bürgern die Umstände der öffentlichen Videoüberwachung zu prüfen. Er nimmt außerdem die Registrierung neuer CCTV-Systeme vor.

Von ihm kann eine Information Notice herbeigeführt werden, wenn er einen Verstoß gegen die datenschutzrechtlichen Vorschriften bei den CCTV-Betreibern vermutet. Er ist ermächtigt, die notwendigen Informationen anzufordern oder gar eigenständig einen Durchsuchungsbefehl zu beantragen, um die Einhaltung der Datenschutzbestimmungen zu garantieren.

Allerdings bleibt formelles Verfahren gegen die CCTV-Betreiber eine Seltenheit. In den meisten Fällen werden die Verantwortlichen durch Gespräche zur Erfüllung ihrer Pflichten gemahnt. Im Vergleich zu den deutschen Datenschutzbehörden handelt es sich hierbei vielmehr um einen symbolischen Posten als um eine effektive Kontrollinstanz. Es ist insgesamt fraglich, ob eine so kleine Dienststelle wie die des Data Protection Commissioners in der Lage ist, mit dieser Arbeitsweise die tatsächliche Umsetzung des neuen britischen Datenschutzgesetzes in vollem Umfang zu kontrollieren. ${ }^{702}$

\section{e) House of Lord's Select Committee on Science and Technology}

Das House of Lord's Select Committee on Science and Technology wurde 1979 gegründet und besteht aus 15 Mitgliedern. Dieses Untersuchungskomitee hat es sich zur Auf-

\footnotetext{
${ }^{700}$ Ebenda, S. 203.

${ }^{701}$ Vgl. : http: / / www.informationcommissioner.gov.uk.

${ }^{702}$ Maguire (1998), S. 232. Das Information Commissioner's Office wird von einem Information Commissioner geleitet, der von ca. 13 Mitarbeitern unterstützt wird. Seit Dezember 2002 ist Richard Thomas der amtierende Information Commissioner für Großbritannien. Vgl. http:/ / www.ico.gov.uk/eventual.aspx?id=252.
} 
gabe gemacht, relevante Themen aus Wissenschaft und Technologie aus Expertensicht zu untersuchen und der britischen Regierung Berichte mit Vorschlägen im Umgang mit dem untersuchten Gegenstand zu erstatten. ${ }^{703}$

Der achte Bericht, der im Jahr 1998 veröffentlicht wurde, beschäftigt sich mit dem Thema CCTV-Überwachung. Das Komitee spricht sich für eine stärkere Kontrolle des Einsatzes von CCTV-Systemen aus und setzt dabei die Unterstützung der betreffenden Gemeinden voraus. Auch die Bürgerrechte und die persönliche Privatsphäre, so die Experten des Komitees, sollen berücksichtigt werden: „CCTV system must be deployed and operated with integrity and with respect for personal privacy and civil liberties. ${ }^{4704}$

\section{f) Parliamentary Office of Science and Technology}

Das Parliamentary Office of Science and Technology (POST) ist eine parlamentsinterne Dienststelle, die zur Aufgabe hat, sowohl dem britischen Unterhaus (House of Commons) als auch dem Oberhaus (House of Lords) Informationen über wissenschaftlich und technisch relevante Themen bereitzustellen. In Form von Informationsgesprächen, Veröffentlichung von Berichten, z.B. POSTnotes, sowie unabhängigen Datenanalysen untersützt diese Dienststelle die Select Committees, sich auf die parlamentarische Fragestunden vorzubereiten. ${ }^{705}$

Im April 2002 wurde vom Parliamentary Office of Science and Technology ein kurzer Bericht (POSTnote) über CCTV-Überwachung publiziert, in dem nicht nur die Effektivität der Videoüberwachung, sondern auch gesetzliche und gerichtliche Rahmenbedingungen für die Anwendung dieser Technik und den Schutz des Bürgers vor CCTV-Missbrauch, diskutiert werden. ${ }^{706} \mathrm{Im}$ Bericht spricht sich das POST für eine Balance zwischen öffentlichen Interessen und Bürgerrechten aus und bemängelt dabei, dass das notwendige Wissen über einen tatsächlich effektiven Einsatz von CCTV-Systemen trotz reichlicher staatlicher Förderungen fehlt. Auch wenn CCTVÜberwachung wertvolle Informationen für die Polizei und Gerichte liefern kann, so der Bericht des POST, können manche CCTV-Aufnahmen als Beweismittel qualitativ unzureichend sein. Das Parliamentary Office of Science and Technology ordnet der Berücksichtigung von datenschutzrechtlichen Bestimmungen und der Achtung von

\footnotetext{
${ }^{703}$ Vgl. hierzu: http: / / www.parliament.uk/parliamentary_committees/lords_s_t_select.cfm.

${ }^{704}$ Vgl. http: / / www.publications.parliament.uk/pa/ld199798/ldselect/ldsctech/121/12105.htm.

${ }^{705}$ http: / / www.parliament.uk/parliamentary_offices/post.cfm

${ }^{706}$ Parliamentary Office of Science and Technology (2002).
} 
Privatsphäre eine überragende Rolle zu, um Missbrauch dieser Technik zu vermeiden. $^{707}$

\subsubsection{Nichtstaatliche Gegenkräfte}

Nach der obigen Analyse staatlicher Konstellationen, Akteure und Netzwerke ist ersichtlich, dass seitens des britischen Staates kein wirksamer Widerstand gegen die Ausweitung von CCTV-Systemen geleistet wird. Im Folgenden gilt es deswegen herauszufinden, inwiefern die zivilgesellschaftlichen Gruppen in Großbritannien dieser Entwicklung entgegenwirken können.

Im Jahr 1934 wurde die britische Bürgerrechtsgruppe Liberty unter der Bezeichnung The National Council for Civil Liberties mit dem Ziel gegründet, sich für die Rechte der Menschen einzusetzen und diese vor staatlichen Eingriffen zu schützen. ${ }^{708}$ Gegenüber der raschen Ausbreitung von Videoüberwachung zeigt Liberty insgesamt eine positive Haltung und fordert lediglich diesbezüglich mehr rechtliche Kontrolle. John Wadham, Direktor von Liberty, plädiert für eine Balance zwischen der Sicherheit und dem Schutz der Bürgerrechte: „CCTV systems can be a valuable weapon in tackling crime in certain situations; but we need clearer controls in law so that the data they gather isn't misused to intrude on people's privacy or infringe their rights. ${ }^{\prime 709}$ Der Direktor bezeichnet CCTV-Systeme als „an extra set of eyes watching over us” und spricht sich für mehr Transparenz in den Überwachungsprozessen aus. ${ }^{710}$ Insgesamt fällt der Widerstand in Großbritannien gegen die Videoüberwachung in öffentlichen Räumen eher dürftig aus. ${ }^{711}$

Neben der Unüberschaubarkeit des Überwachungsapparates und der diesbezüglichen Inaktivität der Bürgerrechtsgruppen begünstigt die Popularität dieser kriminalpräventiven Instrumente in der britischen Öffentlichkeit zusätzlich deren Ausbreitung. Die wenigen Skeptiker werden zum „Freunde von Kriminellen “712 erklärt. In einer Gesellschaft, in der der Leitsatz des CCTV-Einsatzes „Wer nichts zu verbergen hat, hat auch nichts zu befürchten“ in den Vordergrund gestellt wird, scheinen die Kontrollmechanismen, die auf bewusster Wahrnehmung der Bürgerrechte seitens der Bevölkerung beruhen, auszubleiben. ${ }^{713}$

\footnotetext{
${ }^{707}$ Ebenda.

${ }^{708}$ http: / / www.liberty-human-rights.org.uk/ about/ index.shtml.

${ }^{709}$ Liberty (2001).

${ }^{710}$ Ebenda.

${ }^{711}$ Norris; Armstrong (1999b), S. 38; Norris; Armstrong (1998), S. 9; vgl. auch Norris; Armstrong (1999a), S. 85.

${ }^{712}$ Norris; Armstrong (1999b), S. 60; Davies (1996b), S. 328.

${ }^{713}$ Gras (2003), S. 69.
} 
Seitens der Betreiber sollen hauseigene Regeln die Praxis der Videoüberwachung regulieren. CCTV User Group ist beispielsweise eine private Organisation für Betreiber privater Videoüberwachungssysteme. Sie umfasst ca. 200 Organisationen und hat inzwischen ebenfalls einen Model Code of Practice erstellt. Da es diese Gruppe sich zur Aufgabe gemacht hat, in erster Linie die Interessen der CCTV-Benutzer zu vertreten, handelt es sich hierbei um keine Kontrollinstanz. ${ }^{714}$

Die in Privatbesitz befindlichen Überwachungssysteme werden meist von privaten Geschäftsleuten aufgestellt und finanziert, während die privaten Sicherheitsfirmen die tägliche Überwachungsarbeit übernehmen. Neben CCTV User Group zählt auch die Britisch Security Industry Association zu den Betreibern mit eigenen Richtlinien. Diese Organisation fungiert als Berufsverband für die Sicherheitsfirmen und hat für die tägliche Überwachungsarbeit an Monitoren ebenfalls einen Code of Practice herausgegeben, der vom Sicherheitspersonal in der Praxis befolgt werden soll. Allerdings enthält er nur vage formulierte Richtlinien, deren Nichteinhaltung keine Konsequenzen nach sich zieht. Dabei wird die Beachtung der Privatsphäre von Betroffenen nur mit einer einzigen unpräzisen Angabe definiert: „Kein unangemessener Eingriff (undue intervention) in das allgemeine Recht auf Privatsphäre (general right to privacy) der Mitglieder der Öffentlichkeit sollte erfolgen. ${ }^{4715}$

\subsubsection{Zusammenfassung}

Das britische Innenministerium unterstützt die flächendeckende Videoüberwachung sowohl finanziell als auch politisch. Der Mangel an verbindlichen, rechtlichen Regelungen vereinfacht die verwaltungsrechtlichen Verfahren zur Genehmigung von öffentlichen Videobeobachtungsmaßnahmen. Trotz des Data Protection Act (DPA) 1998 und Criminal Justice and Public Order Act ist der CCTV-Einsatz in Großbritannien häufig der Willkür der Betreiber unterworfen.

Lediglich die „Regeln zur guten Praxis“ (Code of Practice) dienen als Richtlinien, wobei die Missachtung dieser Regeln keine rechtlichen Konsequenzen nach sich zieht. Die unpräzisen Formulierungen solcher Regeln überlassen außerdem den Betreibern einen großen (gesetzesfreien) Spielraum, die Einsatzorte und -ziele sowie die Datenverarbeitung und -speicherung ihrer CCTV-Anlagen eigenständig zu bestimmen. Aufzeichnungen von Videoüberwachungsgeräten, selbst wenn sie aus gesetzwidrigen Handlungen resultieren, werden meistens als Beweismittel vor Gericht zugelas-

\footnotetext{
${ }^{714}$ http: / / www.cctvusergroup.com/Public\%20Support $\% 20$ for $\% 20$ CCTV.htm.

${ }^{715}$ Honess; Charman (1992), S. 1; Gras (2003), S. 54.
} 
sen. ${ }^{716}$ Damit eignet sich der Code of Practice ebenfalls nicht als effektives Kontrollinstrument. Es ist insgesamt fraglich, wie effektiv eine solche selbst auferlegte Kontrolle ist, wenn die Betreiber (staatliche Polizeibeamte oder auch private Ladenbesitzer) ohne rechtliche Folgen selbst über die Vorgehensweise der Überwachung, sowie die Verwendung des gesammelten Bildmaterials entscheiden dürfen. Es ist nicht verwunderlich, wenn sie diese Entscheidungen zu ihren Gunsten treffen und einen eher unvorsichtigen Umgang mit den Daten an den Tag legen.

Zudem werden die Kontrollfunktionen des Information Commissioners als staatsinterne Aufsichtsstelle nur unzureichend ausgeübt, so dass dieser kaum die Praxis der Videoüberwachung beeinflussen kann. Im Gegensatz zu den deutschen Datenschutzbehörden handelt es sich hierbei um eine kleine Dienststelle, die primär mit informellen Ermahnungen ohne rechtliche Konsequenzen die Betreiber des öffentlichen Kameraeinsatzes beaufsichtigt. Es ist zweifelhaft, ob der Information Commissioner tatsächlich die Einhaltung datenschutzrechtlicher Rahmenbedingungen des Data Protection Act 1998 kontrollieren kann. Auch seitens der gesellschaftlichen Interessenvertretungen sind keine wirksamen Gegenaktionen festzustellen, die das Ausweiten der Überwachungskameras in der britischen Öffentlichkeit hindern.

Auffällig ist insgesamt die dominante Rolle der Zentralregierung in der CCTVPolitik, die die wenigen kritischen Stimmen seitens der Polizei und Kommunen in den politischen Hintergrund drängt. Durch die enge Zusammenarbeit zwischen privaten Gruppen und staatlichen Behörden bei der Instandhaltung und Finanzierung der CCTV-Anlagen kann außerdem in den meisten Fällen keine eindeutige Zuständigkeit für die jeweiligen Systeme ausgemacht werden.

\subsection{Einfluss der Akteure im Vergleich}

Die Verbreitung der CCTV-Systeme ist abhängig von einem komplexen Netzwerk verschiedener Akteure, wobei einige unter ihnen die rasche Expansion dieser Technik vorantreiben wollen, während andere diese zu drosseln versuchen. Die Nutzungsintensität von Überwachungskameras in öffentlichen Räumen ist, so die These dieser Arbeit, abhängig von dem Grad der Einflussnahme sowohl der Befürworter als auch der Skeptiker auf die Automatisierung räumlicher Überwachung. Im kommenden Abschnitt werden die Ergebnisse aus den länderspezifischen Analysen zusammengetragen. Zur Verdeutlichung der unterschiedlichen Rolle der proaktiven Akteure in diesen drei Nationen werden diese miteinander verglichen. Auch die un-

\footnotetext{
${ }^{716}$ Anhand von Kommentaren von Polizeisprechern wird eine steigende Tendenz der Nutzung solcher CCTV-Aufnahmen in Gerichten festgestellt. Vgl. Gras (2003), S. 87.
} 
terschiedliche Stärke der Gegenkräfte im Staat sowie der zivilgesellschaftlichen Initiativen wird in unmittelbarer Gegenüberstellung aufgezeigt.

\subsubsection{Proaktive Akteure}

Diejenigen, die sich für die öffentliche Anwendung von Closed Circuit Television einsetzen, kooperieren in allen drei Ländern häufig, da die Vorteile einer Zusammenarbeit für alle Beteiligten offenkundig sind. Somit ist die CCTV-Infrastruktur in der Praxis häufig das Ergebnis einer Vernetzung verschiedener privater und öffentlicher Überwachungssysteme. Auffallend sind dabei die ineinander verflochtenen Beziehungen der proaktiven Akteure in Großbritannien, die die unüberschaubare Ausweitung von CCTV-Anlagen begünstigen. Die Grundzüge solcher Gemeinschaften werden von Stefan Graham in Bezug auf die Situation in Großbritannien treffend als Supply-Push meets Demand-Pull ${ }^{717}$ bezeichnet:

„In effect, these coalitions provide a potent supply push mixing together many factors into an almost irresistible recipe for generating large scale public investment in ever-more elaborate and extensive CCTV infrastructures. Here we fuse the competitive instincts of local authorities and development agencies, with the instincts of the police to install the technical infrastructures that ease their job and maximise convictions. We add high-profile national TV simulations and semi-voyeuristic shows like CrimeWatchUK, which directly transmit footage from CCTV on the streets into domestic space for entertainment (so, indirectly, legitimising and supporting its further spread). We blend in the tendency of local media to sensationalise local crime in the language of moral panic. And, finally, we add the strong vested interests of the burgeoning security and correction 'industrial complex' (including CCTV manufactures, video, IT and telecoms firms, private security firms, consultants and service providers), to portray their technologies as simple, transformative, even utopian solutions to complex social problems surrounding crime, disorder and public space. ${ }^{\prime 718}$

Insgesamt scheint die Kooperation zwischen dem privaten und dem öffentlichen Sektor in Großbritannien und in den USA üblicher zu sein als in Deutschland. Während in den zwei zuerst genannten Ländern viele Privatdienste die Überwachungsarbeit an öffentlichen Überwachungssystemen übernehmen und manches Überwachungsmaterial an private Fernsehsender weitergeleitet wird, findet die entsprechende Zusammenarbeit in Deutschland eher in Form von polizeilichem Zugriff auf die privaten Überwachungsdaten statt und seltener umgekehrt. Auch die Überwa-

\footnotetext{
${ }^{717}$ Graham (1998), S. 90.

${ }^{718}$ Ebenda.
} 
chungsarbeit an Monitoren wird in der Bundesrepublik, im Gegensatz zu den anderen zwei Ländern, meistens nur von Polizeibeamten übernommen. Manche Polizeibehörden in Deutschland verzichten sogar freiwillig auf die Vernetzung der Systeme, obwohl dies technisch möglich ist.

Wenn man also das komplexe Zusammenspiel der proaktiven Gruppen betrachtet, wird deutlich, dass in der britischen Gesellschaft der Einsatz der Videoüberwachungstechnologie sowohl von den staatlichen Instanzen (Verwaltungsbehörden, Polizei) als auch vom privaten Sektor im Vergleich zu Deutschland und den USA als unproblematisch eingeschätzt wird. Auch wenn in allen drei Nationen die Entwicklung des CCTV-Einsatzes eine steigende Tendenz zeigt, wird in Großbritannien die Gesamtsituation der CCTV-Anwendung durch Reduzierung von bürokratischen Hürden und die tatkräftige finanzielle Unterstützung der britischen Zentralregierung begünstigt.

\subsubsection{Staatsinterne Kontrollen}

Sowohl in den USA als auch in Großbritannien bieten die aktuellen gesetzlichen Rahmenbedingungen keine effektive Kontrolle für die Praxis der Videoüberwachung öffentlicher Räume, während diese in Deutschland vor allem nach der Novellierung des Datenschutzgesetzes verankert ist. Im Gegensatz zu den USA existieren in Deutschland und Großbritannien staatsinterne Verwaltungsinstanzen zur Kontrolle von Rechtsgrundlagen der Videoüberwachungsmaßnahmen. Im direkten Vergleich wird deutlich, dass die Aufsichtsfunktion der deutschen Datenschutzbehörden besser zu bewerten ist als die des zuständigen Verwaltungsapparates in Großbritannien:

Die Kontrolltätigkeiten des britischen Information Commissioners, der für die Einhaltung der datenschutzrechtlichen Bedingungen des Data Protection Act 1998 zuständig ist, sind angesichts der expansiven Verbreitung der CCTV-Systeme und der gesetzlichen Grauzone in Großbritannien als unzureichend zu bewerten. Diese Kontrollinstanz wird nämlich in der Praxis erst bei Beschwerden aktiv, auch wenn ihm Rechte zugesprochen werden, diese Überprüfung auf selbständige Weise durchzuführen. Diese Arbeitsweise ist ineffektiv, da die Mehrheit der Bevölkerung weder die Videoüberwachung in der Öffentlichkeit bewusst wahrnimmt noch über die Rechtmäßigkeit der Aufzeichnungen sowie deren Weitergabe aufgeklärt zu sein scheint.

Demgegenüber üben die deutschen Datenschutzbeauftragten mehr Einfluss auf die Praxis polizeilicher Videoüberwachung aus. Die Datenschutzbeauftragten werden einerseits in manchen Fällen bei den Entscheidungsprozessen zur Einführung öffent- 
licher Videoüberwachung mit einbezogen, andererseits üben sie aktiv ihre Aufsichtsfunktion aus. Sie sind mit eigener Zuständigkeit versehen, welche ihnen erlaubt, eine unabhängige Datenkontrolle bei staatlichen Institutionen durchzuführen. Es konnte anhand einiger Beispiele bestätigt werden, dass die Kontrolltätigkeiten der Datenschutzbehörden zur Besserung der Überwachungsbedingungen geführt haben.

In den USA wird die Praxis öffentlicher Videoüberwachung aufgrund des föderalistischen Staatsaufbaus sehr unterschiedlich geregelt. Es gibt keine speziellen Verwaltungsstellen zur Kontrolle von öffentlichem Kameraeinsatz. Für den Schutz der Bürger vor ungewollten Videoaufzeichnungen sind die unterschiedlichen Gerichte in den einzelnen US-Bundesstaaten zuständig, deren diesbezügliche Urteile je nach dem juristischen Verständnis und der Interpretation vom Begriff des Rechts auf Privatsphäre (Right to Privacy) sehr unterschiedlich sein können.

\subsubsection{Nichtstaatliche Gegenkräfte}

Die Bürgerrechtsorganisationen, vor allem solche mit einer Anti-CCTV-Kampagne, sind in den USA am häufigsten vertreten. Sie scheinen die Bürgerinitiativen in Großbritannien und Deutschland nicht nur in ihrer Anzahl zu übertreffen, sondern auch in ihrer organisatorischen Größe und Struktur überlegen zu sein. Nicht selten werden in den USA Experten aus größeren Bürgerrechtsorganisationen, wie der American Civil Liberties Union (ACLU), in der Praxis öffentlicher Videoüberwachung zur Beratung herangezogen. Dies demonstriert den Einfluss dieser zivilgesellschaftlichen Akteure in der US-amerikanischen Gesellschaft, welche als kompetente, nichtstaatliche Gegenkräfte das Voranschreiten der CCTV-Verbreitung bremsen.

In der Bundesrepublik sind einzelne, spontan entstandene soziale Proteste gegen öffentliche Videoüberwachungsmaßnahmen zu verzeichnen, die sogar zum Abbau polizeilicher Kameras geführt haben. Allerdings sind langfristige, aktive AntiCCTV-Kampagnen in Deutschland eher selten. Im Vergleich zu den USamerikanischen Bürgerrechtsgruppen verfügen die zivilgesellschaftlichen Gruppen in Deutschland nicht über so viel Einfluss und genießen dementsprechend weniger Medienaufmerksamkeit.

\subsubsection{Zusammenfassung}

Zusammenfassend kann man festhalten, dass in Großbritannien, im Gegensatz zu den zwei Vergleichsländern, bei der Anbringung von Videoüberwachungsanlagen in öffentlichen und öffentlich zugänglichen Räumen praktisch keine Beschränkung besteht. Während die Datenschützer und die gesetzlichen Vorgaben den Schutz der 
Bürgerrechte in Deutschland gewähren, übernehmen in den USA die Bürgerrechtsorganisationen ähnliche Funktionen.

Die Videoüberwachung in Großbritannien wurde relativ früh und unkritisch als nützliches Werkzeug in die kriminalpräventiven Programme aufgenommen. ${ }^{719}$ Einige spektakuläre Kriminalfälle, ${ }^{720}$ bei denen CCTV-Überwachung eine große Rolle bei der Aufklärung gespielt hat, tragen dazu bei, dass diese Art der Überwachung in der Bevölkerung viel Anklang findet. Dies wird durch die britische Politik unterstützt, die alles rechtlich legitimiert, solange es kriminalpräventiven Zielen dient. ${ }^{721}$ Angesichts der Tatsache, dass die Zentralregierung verstärkt mit finanziellen Mitteln die Videoüberwachung in Großbritannien unterstützt und den Kommunalverwaltungen die Verweigerungsrechte zur Installation von CCTV-Systemen entzogen hat, ${ }^{722}$ liegt die Vermutung nahe, dass diesbezügliche kommunale Kontrolle in Großbritannien unerwünscht ist. Aufgrund der Haltung zur CCTV-Überwachung ist weiterhin mit keiner Verschärfung der Kontrollmaßnahmen in Großbritannien zu rechnen.

Im Vergleich zu ihren Pendants in Großbritannien und Deutschland üben die USamerikanischen Bürgerrechtsgruppen mehr Einfluss auf die politischen Entscheidungen zur Einführung von Videoüberwachung öffentlicher Räume aus. Neben dem Organisieren von Demonstrationen und Kampagnen fungiert die Bürgerrechtsorganisation American Civil Liberties Union (ACLU) als Berater in Bürgerrechtsfragen bei manchen Entscheidungsprozessen zur weiträumigen Observierung per Videotechnik, was im Gesamtvergleich der Länder einzigartig ist. Allerdings muss hierbei erwähnt werden, dass in der vorliegenden Arbeit lediglich exemplarische Fälle untersucht wurden. Angesichts der regionalen Heterogenität und uneinheitlicher Rechtsprechung, die auch für die unübersichtliche Ausbreitung von Überwachungskameras in den verschiedenen US-Bundesstaaten verantwortlich sind, ist es schwer eine allgemeingültige Aussage über die Führungsrolle verschiedener Akteure zu machen. Das Kräfteverhältnis zwischen den Protagonisten der Sicherheitspolitik und den kritischen Akteuren der Bürgerrechtsgruppen kann je nach den gegebenen Rahmenbedingungen sehr unterschiedlich sein. Im Ganzen kann jedoch festgestellt werden,

\footnotetext{
${ }^{719}$ Gras (2003), S. 57.

${ }^{720}$ Die öffentliche Aufmerksamkeit auf und Akzeptanz von CCTV-Überwachung in Großbritannien wurde erheblich gesteigert durch dramatische Fälle wie beispielsweise der bereits erwähnte „BurglerFall" in Liverpool. "An argument against CCTV was interpreted as an argument in favour of baby killers." Vgl. Krons (2000); Davis (1999), S. 244; Wehrheim (2002), S. 88.

${ }^{721}$ Davies (1996a), S. 191.

${ }^{722}$ Es handelt es sich um das bereits erwähnte Beispiel in Birmingham: Nachdem der Stadtrat von Birmingham die Baugenehmigung eines CCTV-Systems abgelehnt hatte, wurde das Recht der Kommunalbehörde sechs Monate später von der Regierung aberkannt. Gras (2003), S. 58; Davies (1996a), S. 187.
} 
dass in den USA überwiegend die lokalen Gruppen bei der Entscheidung über die Implementierung von Überwachungskameras zum Zweck der Strafverfolgung dominieren.

Die Videoüberwachung in Deutschland ist derzeitig auf „Kriminalitätsbrennpunkte“ beschränkt und wird es in naher Zukunft vermutlich auch bleiben. Eine flächendeckende Videoüberwachung nach britischem Vorbild wird selbst von überzeugten Befürwortern abgelehnt. Gedrosselt wird die Entwicklung der Videoüberwachung nicht nur durch die Datenschützer als Kontrollinstanzen, sondern auch durch Vorbehalte seitens der Polizei, die insgesamt im Vergleich zu den britischen Polizeibehörden einen behutsameren Umgang mit den Überwachungsmaßnahmen pflegen.

Anhand dieser Darstellung der Machtpositionen der beteiligten Gruppen in der CCTV-Debatte wird deutlich, warum die weltweit intensivste Anwendung dieser Überwachungssysteme auf den britischen Inseln stattfindet: Einerseits die Dominanz der proaktiven Akteure, die sich für die Einführung der CCTV-Maßnahmen einsetzen und andererseits der Mangel an einflussreichen Akteuren, die die Zunahme der Überwachung verhindern. 


\section{Teil IV: Politisch-kulturelle Hintergründe}

Großbritannien ist weltweit das Paradebeispiel für die Observierung öffentlicher Räume mittels Videotechnik. Trotz zunehmender Verbreitung und Beliebtheit dieser Technik in allen drei Nationen sind die britischen Verhältnisse der Videoüberwachung einzigartig. Die Einführung der Maßnahmen wird dort ohne zusätzliche rechtliche Einschränkungen und kritische Stimmen durchgesetzt. Die finanziellen Förderungen und politische Unterstützung durch die Regierung sowie das Fehlen einflussreicher Kontrollinstanzen sorgen gemäß der vorangegangenen Analyse für die uneingeschränkte Verbreitung dieses Überwachungswerkzeugs. Im Gegensatz zu Großbritannien verhindern in der Bundesrepublik die rechtlichen Vorschriften, Vorbehalte seitens der Polizei sowie Datenschutzbehörden als kontrollierende Institution die weiträumige Überwachung ganzer Städte mit polizeilicher Videografie. Im Vergleich dazu versucht in den USA eine Vielzahl einflussreicher Bürgerrechtsgruppen durch Kontrolle und Informationspolitik auf die Ausweitung von CCTV-Systemen einzuwirken.

Die Sicherheitspolitik sowie die Entscheidungsdynamik zur Anwendung von CCTVSystemen finden in einem gesamtgesellschaftlichen Kontext statt. Um die unterschiedlichen institutionellen Entscheidungsstrukturen über die Anwendung von Überwachungskameras in öffentlichen Räumen verstehen $\mathrm{zu}$ können, erscheint es sinnvoll, über den Bereich dieser politischen Praxis hinauszugehen. Im Folgenden werden die öffentlichen Videoüberwachungsmaßnahmen in den Zusammenhang der politisch-kulturellen Rahmenbedingungen gestellt. Dies bedarf einer genaueren Untersuchung der unterschiedlichen Politikmodelle, die bestimmte hemmende bzw. treibende Eigenschaften der Politikgestaltung zur Einführung von Überwachungskameras beinhalten. Die Diskrepanzen länderspezifischer Merkmale von Akteursnetzwerken und institutionellen Regeln sind, so die Annahme dieser Arbeit, auf die jeweiligen politisch-administrativen Kulturen in diesen drei Ländern zurückzuführen.

Dieser Abschnitt der Arbeit widmet sich demnach der Frage, warum bestimmte Akteure in den drei Ländern mehr Einfluss auf die CCTV-Politik haben als andere. Es werden neben länderspezifischen Eigenschaften des politischen Systems und der Rechtsordnungen auch die prägenden historischen Ereignisse in diesen drei Nationen in Betracht gezogen. Das Ziel ist, die unterschiedlichen Akteurskonstellationen 
in der CCTV-Politik, die für die Nutzungsintensität dieser Technik ausschlaggebend sind, verständlich zu machen.

\section{Deutschland - Rechtsstaatliche Repräsentativdemo- kratie}

\subsection{Einleitung}

In einer Demokratie ist das Volk der ursprüngliche Träger der Staatsgewalt. Die Beteiligung des Volkes an der Ausübung der Staatsgewalt erfolgt in der Bundesrepublik Deutschland im Sinne des Grundgesetzes durch gewählte Repräsentanten. ${ }^{723}$ Durch die periodisch gewählte Volksvertretung ist Deutschland eine repräsentative Demokratie. $^{724}$

Ein wesentliches Kennzeichen des deutschen politischen Handlungsmusters besteht darin, den Staat auch als Garanten individueller Freiheiten zu sehen. Die staatszentrierte Tradition der deutschen Staatslehre hat sich schon nach dem Zeitalter der Glaubenskriege mit der fürstlichen Souveränität im aufgeklärten Absolutismus ab der zweiten Hälfte des 17. Jahrhunderts entwickelt. ${ }^{725}$ In der deutschen Staatslehre dominiert die Idee, dass die bürgerlichen Freiheitsrechte am besten durch die staatliche Souveränität garantiert seien, auch wenn diese eine andere Struktur aufweisen sollte als die des absolutistischen Fürstentums. Als Instrument zur Regulierung individueller Interessen und Freiheiten dienen allgemeingültige Gesetzestexte, für deren Formulierung juristischer Sachverstand erforderlich ist.

Wenn man diese zwei politisch-kulturellen Eigenschaften in Betracht zieht, kann man davon ausgehen, dass der Staat in der repräsentativ ausgerichteten Bundesrepublik für die Koordination vielfältiger Interessen die Hauptrolle spielt und durch Verhandlungen, Übereinkünfte und Ausgleich mit den beteiligten Akteuren eine kompromissreiche Politik betreibt. Mit Hilfe universell gültiger Gesetze werden unterschiedliche Interessen und individuelle Freiheiten aufeinander abgestimmt und in ihrer Entwicklung miteinander vereint. Es wird in dieser Arbeit angenommen, dass diese Strukturmerkmale des deutschen Regulierungsstils für die starke staatsinterne

\footnotetext{
${ }^{723}$ Art. 20 Abs. 2 des deutschen Grundgesetzes (GG) lautet: „Alle Staatsgewalt geht vom Volke aus. Sie wird vom Volke in Wahlen und Abstimmungen und durch besondere Organe der Gesetzgebung, der vollziehenden Gewalt und der Rechtsprechung ausgeübt."

${ }^{724}$ Mehr zu politischer Repräsentation in Deutschland vgl. Steinberger (1993), S. $137 \mathrm{ff}$.

${ }^{725}$ Hiernach wird die Sicherung der individuellen Freiheit weder in der Teilung politischer Gewalten, noch in der Teilnahme der Bürger, sondern in der Souveränität der Fürsten gesehen. Der Fürst ist verpflichtet, die freiheitlichen Rechte der Bürger zu sichern. Damit er ohne Einschränkung seiner Souveränität die Konflikte zwischen den Bürgern klären kann, besteht keine zusätzliche Kontrolle seiner Macht durch die Bürger. Münch (1986a), S. 782. Vgl. auch Rudzio (2000), S. 535 ff.
} 
(Selbst-)Kontrolle verantwortlich sind, die die Nutzungsintensität von Überwachungskameras in öffentlichen Räumen beeinflussen.

Im Folgenden wird der Versuch unternommen, die deutsche Akteurskonstellation im Entscheidungsprozess über die Videoüberwachung anhand politisch-kultureller Rahmenbedingungen verständlich zu machen.

\subsection{Staatszentrierte Tradition}

Für Georg Wilhelm Friedrich Hegel ist der Staat ein Meister, der für Zucht und Ordnung sorgt und das Gemeinwohl in einer sonst chaotischen und desorganisierten Gesellschaft garantiert. Nach Hegels Auffassung stellt der Staat nicht eine politische Einrichtung der Gesellschaft dar, sondern vielmehr eine unanfechtbare Instanz, die gesellschaftliche Verhältnisse im Gleichgewicht hält. In Anlehnung an Hegels Staatsidee argumentiert Sontheimer wie folgt: „Das deutsche politische Denken sah seit der Mitte des 19. Jahrhunderts die ungeformte Gesellschaft als Gegenspieler des geformten Staates. Dementsprechend wurden Zucht, Pflicht und Gehorsam stets höher eingeschätzt als Freiheit, Individualität und Opposition. ${ }^{4726}$ Nach von Treitschkes Verständnis wird die Freiheit des Individuums in Deutschland im Staat gesucht, während in angelsächsischer Tradition die individuelle Freiheit als Schutz vor staatlichen Eingriffen verstanden wird. ${ }^{727}$ In diesem Kontext wird im Folgenden davon ausgegangen, dass diese staatszentrierte Ausprägung des institutionellen Wesensmerkmals das gesamte politische System und somit auch den Entfaltungsprozess der Videoüberwachung in der Bundesrepublik charakterisiert.

Die staatlichen Institutionen sind dem Grundsatz des deutschen Regulierungsstils entsprechend die Protagonisten in Entscheidungen über den Einsatz von Überwachungskameras in öffentlichen Räumen. Dies konnte bereits in Teil III dieser Arbeit verdeutlicht werden. Im traditionell staatszentrierten Handlungsmuster bestimmen staatliche Akteure nicht nur in Form von Polizei und Kommunen über die Videoüberwachung öffentlicher Räume, sondern übernehmen auch zugleich als Datenschutzbehörden die Kontrollaufgabe über die Entfaltung dieser Technik. In der Regel werden unabhängig von öffentlichen Diskussionen in den Expertengremien über den Einsatz bzw. das Fortsetzen von Maßnahmen polizeilicher Videoaufzeichnung entschieden. An solchen auf Sachlichkeit beruhende Gremien sind zuständige Polizeidirektionen, Kommunen und in manchen Fällen auch die Datenschutzbehörden beteiligt. Beispielsweise wurden die rechtlichen Grundlagen der Pilotprojekte polizeili-

\footnotetext{
${ }^{726}$ Sontheimer; Bleek (1998), S. 179.

${ }^{727}$ von Treitschke (1871), S. 3 ff.
} 
cher Videoüberwachung in Leipzig und Stuttgart sowie des Videoeinsatzes auf dem Oktoberfest in München mit Vorabprüfung von Datenschutzbeauftragten abgesichert. Mit ausgeprägten repräsentativdemokratischen Elementen in ihrem politischen Handlungsmuster wollen die staatlichen Akteure unterschiedliche Interessen und möglichst viele relevante Gesichtspunkte bei ihrem Urteil über den Einsatz der Videotechnik in Betracht ziehen.

Dies hat zur Folge, dass eine Kluft zwischen den Experten mit Wissensvorsprung und der breiten Öffentlichkeit ohne Fachwissen entsteht. Ohne die Fähigkeit, Sachverstand in das Politikfeld der Kriminalprävention einzubringen, erscheint die Öffentlichkeit hochgradig emotionalisiert. Erst durch Aufklärungspolitik kann die Kluft zwischen der Sachpolitik und dem öffentlichen Diskurs verringert werden. Die öffentlichen politischen Debatten in Deutschland haben deshalb häufig eine belehrende und aufklärende Funktion, um die universelle Vernunft der Mündigen (Experten) unter den Unmündigen (Bürger) zu verbreiten. ${ }^{728}$ Während in Deutschland nach dem Beschluss in Expertenrunden die Polizei mittels Informationsblätter die Öffentlichkeit über die Videoüberwachungsmaßnahmen in Kenntnis setzt, werden dagegen in den USA meistens in Gemeindeversammlungen partikulare Interessen geäußert, Informationen ausgetauscht und Entscheidungen getroffen. ${ }^{729}$

Die staatszentrierte Tradition der Bundesrepublik mit einem repräsentativdemokratisch ausgerichteten Regierungssystem trägt demzufolge dazu bei, dass die Hauptkräfte, die der Nutzung polizeilicher Videoüberwachung treibend bzw. bremsend wirken, vom Staat zentral gesteuert werden. Mit wissenschaftlicher Expertise bringen die staatlichen Akteure disparate Interessen in die Entscheidungen über den Videoeinsatz ein, wobei die Öffentlichkeit sowie die zivilgesellschaftlichen Akteure ohne Sachverstand kaum die Chance haben, in die Beurteilungsprozesse einzugreifen.

\subsection{Rechtsstaatlichkeit}

Die Rechts- und Staatslehre von Kant hat bis heute großen Einfluss auf die Idee des deutschen Rechtsstaatsprinzips ausgeübt. Sie legt das ganze Gewicht in die Ordnung der individuellen Freiheiten durch das allgemeine Gesetz. Die primäre Funktion des Staates ist dabei, die Freiheit des Menschen zu regulieren und vielfältige Interessen in Einklang zu bringen. Dabei dient dem Staat das Recht, das auf einem unveränder-

\footnotetext{
${ }^{728}$ Münch (1986a), S. 350.

${ }^{729}$ Vgl. Teil III, Kap. 10.1.1 und Kap. 10.2.1 dieser Arbeit. 
lichen Verfassungskern basiert, als Herrschaftsinstrument. Nach Kants Staatslehre ist das Dasein des Staates nicht in seiner Zweckdienlichkeit für die Bürger, sondern vielmehr in den Grundsätzen der reinen praktischen Vernunft begründet. ${ }^{730}$ Nur durch die staatlichen Regulierungen, welche frei sind von sinnlichen Neigungen und Interessen, können allgemeingültige Rechtsprinzipien für das Wohl aller Bürger geschaffen werden. Das Grundgesetz in der Bundesrepublik genießt somit als alle Staatsgewalt bindende Rechtsnorm die höchste Priorität in der politischen Rangordnung.

Wenn die Freiheiten der Individuen in Konflikt geraten, werden im Kant'schen Sinne nicht wie in angelsächsischer Tradition die situativen Bedingungen in Betracht gezogen, sondern die allgemeingültigen Gesetze, um das Handeln der Individuen zu regulieren: „Das Recht ist also der Inbegriff der Bedingungen, unter denen die Willkür des einen mit der Willkür des anderen nach einem allgemeinen Gesetze der Freiheit zusammen vereinigt werden kann. “731

Mit der Annahme, dass jeder Mensch ein Verstandeswesen ist, das unabhängig von sinnlichen, triebhaften Bestrebungen ist, geht Kant davon aus, dass der vernünftige Bürger der Allgemeingültigkeit und Rechtmäßigkeit der Gesetze zustimmt. ${ }^{732}$ In diesem Sinne werden Freiheit und Gesetz in den staatlichen Institutionen vereinbart und aufeinander abgestimmt. Der Bürger gehorcht solchen Gesetzen, denen er in vollkommener Freiheit zugestimmt hat, d.h. nur Gesetzen, die er sich selbst in der Vereinigung mit anderen auferlegt hat. Diese allgemeinen Gesetze müssen durch die Administration bruchlos ausgeführt werden. Ihre Beachtung durch die Individuen zu kontrollieren und mittels Gewalt durchzusetzen obliegt der richterlichen Gewalt, vor der jeder Bürger gleich ist, unabhängig von Abstammung oder gesellschaftlicher Zugehörigkeit. Vor den Gesetzen ist also jeder ein Untertan, der nur zu gehorchen hat. ${ }^{733}$ In konsequenter Durchführung der Logik von Kants Argumentation wird dem Volk das Widerstandsrecht gegen die allgemeinen Gesetze und den Gesetzgeber aberkannt, da die Universalität einer idealen Gesetzgebung der Partikularität individueller Interessen vorgezogen wird. Vor diesem Hintergrund ist es einleuchtend, dass ein Bündel von schriftlich fixierten Gesetzen zur Regelung öffentlicher Videoüberwachung notwendig ist, um in Vereinbarung mit den rechtsstaatlichen Prinzipien alle staatliche Gewalt an Gesetz und Recht zu binden. In diesem Sinne wird durch

\footnotetext{
${ }^{730}$ Kant (1956a), S. 431.

${ }^{731}$ Ebenda, S. 337.

${ }^{732}$ Ebenda, S. 432 ff.

${ }^{733}$ Ebenda, S. 145 ff.
} 
die Änderungen der Polizeigesetze der Einsatz moderner Technik zu kriminalpräventiven Zwecken legitimiert, aber gleichzeitig werden auch datenschutzrechtliche Regelungen zur Überwachung und Eingrenzung des polizeilichen Handelns geschaffen. Als Konsequenz dieses Regulierungsstils in Deutschland liegen im Gegensatz zu den anderen zwei Vergleichsländern gesetzliche Regelungen zur Videoüberwachung vor.

Die Freiheit des Individuums besteht im Rahmen der Kant'schen Theorien nicht in dem Schutz vor staatlicher Gewalt; sie wird vielmehr in der Idee einer allgemeinen Gesetzgebung aufgehoben. Für Kant ist eine Beteiligung aller Bürger an der Gesetzgebung erst möglich, wenn alle Individuen als Verstandeswesen handeln. Solange dies nicht der Fall ist, sind Repräsentanten des Volkes notwendig, um die Einhaltung der allgemeinen Gesetzgebung zu sichern. ${ }^{734}$ Diese Staatslehre von Kant ist richtungweisend für die deutsche Auffassung von staatlicher Garantie bürgerlicher Freiheit und erklärt die politische Dominanz staatlicher Akteure in Entscheidungsprozessen über den Einsatz von Überwachungskameras in Deutschland. In einer repräsentativ ausgerichteten Rechtsdemokratie mit staatszentrierter Tradition sind es vor allem die staatlichen Akteure und Netzwerke, die die Dynamik der deutschen Sicherheitspolitik bestimmen. Sowohl die Interessen für mehr Sicherheit (Pro-CCTVArgumente) als auch die Nachfrage nach mehr Anonymität (Contra-CCTVArgumente) werden hauptsächlich von den Staatsorganen vertreten.

Angesichts der starken Obrigkeitstradition erscheint die Idee der Rechtsstaatlichkeit in Deutschland auf den ersten Blick widersprüchlich, da die rechtsstaatlichen Prinzipien das Abschaffen staatszentrierter Strukturen implizieren. „Der in den Verfassungskämpfen des 19. Jahrhunderts vom liberalen Bürgertum geschichtlich auf den Weg gebrachte Rechtsstaatsgedanke hat in Deutschland nie eine die Staatsmacht wirklich herausfordernde Rolle spielen können. Der obrigkeitsstaatlich gezähmte Rechtsstaat konnte vielmehr zum Symbol der obrigkeitsstaatlich ausgerichteten deutschen bürgerlichen Gesellschaft werden. ${ }^{4735}$ In Deutschland wird außerdem viel Wert auf die Ausführungsautorität der Verwaltung gelegt. Das Handeln der Verwaltung kann nur selten durch die einzelnen Bürger beeinflusst werden und die verwaltungsrechtlich bindenden Entscheidungen werden als allgemeingültig akzeptiert. Münch beschreibt die Befugnisse der Verwaltung in Deutschland wie folgt: „Die konkrete Abstimmung der Freiheiten der Individuen erfolgt (...) durch eine Verwal-

\footnotetext{
${ }^{734}$ Kant (1956b), S. 788.

${ }^{735}$ Blasius (1986), S. 135.
} 
tung, deren Entscheidungen automatisch aus dem objektiven Gehalt der allgemeinen Gesetze und ihren Ausführungsbestimmungen resultieren. Zwischen der Verwaltung und dem Bürger gibt es nichts zu verhandeln, sondern nur auszuführen und zu gehorchen. ${ }^{\text {736 }}$

Dennoch hat sich in der Bundesrepublik eine einzigartige Form der Rechtsstaatlichkeit etablieren können. Das Wort „Recht“ ist ein häufig verwendetes Wort in der deutschen Gesellschaft. „Rechtlosigkeit war die Signatur der Nazizeit gewesen, in der gleichsam die niederen Dämonen in realer, politisch und gesellschaftlich zu erklärender Gestalt Deutschland beherrscht hatten. ${ }^{4737}$ Vor dem Hintergrund des nationalsozialistischen Terrorregimes entwickelt sich in der deutschen Gesellschaft ein neues Bewusstsein bezüglich des Auf- und Ausbaus eines Rechtsstaates. Gustav Radbruch hebt die Wichtigkeit der Rechtsstaatsidee hervor, indem er kurz nach dem Zweiten Weltkrieg schreibt: „Demokratie ist ein preiswertes Gut, Rechtsstaat aber ist wie das tägliche Brot, wie Wasser zum Trinken und wie Luft zum Atmen, und das Beste an der Demokratie [ist] gerade dieses, dass nur sie geeignet ist, den Rechtsstaat zu sichern. “738

Unter dem Grundprinzip des Rechtsstaats versteht man heute in Deutschland die Rechtsbindung der staatlichen Verwaltung an das Gesetz, das jede willkürliche Sonderbehandlung oder Diskriminierung von bestimmten Personengruppen eindämmt und somit die Ablaufprozesse der Verwaltung transparent und berechenbar macht. Die bundesdeutschen Datenschutzbehörden verkörpern heute in der Praxis der Videoüberwachung diese rechtsstaatlichen Richtlinien, indem sie die rechtlichen Voraussetzungen für die Installation von Überwachungskameras überprüfen und für die verwaltungsrechtliche Transparenz der Videodaten sorgen. Durch die Tätigkeiten der Beauftragten für den Datenschutz wird manchen gesetzwidrigen Maßnahmen der Videoaufzeichnung Einhalt geboten bzw. werden Berichtigungsvorschläge für die Implementierung der Anlagen erarbeitet. Die in allgemeinen Begriffen formulierten Datenschutzgesetze gewinnen erst durch das Handeln der Datenschützer ihre reale Gültigkeit in der polizeilichen Praxis mit Überwachungskameras.

Friedrich Karl Fromme definiert die Prinzipien der Rechtsstaatlichkeit zutreffend wie folgt: „Ein Staat (...) ist Rechtsstaat in dem Maße, in dem eine Rechtsordnung die Bahnen und Grenzen der öffentlichen Gewalt normalisiert und durch unabhängige

\footnotetext{
${ }^{736}$ Münch (1986a), S. 796.

${ }^{737}$ Wassermann (1985), S. 6.

${ }^{738}$ Radbruch (1957), S. 124. Vgl. auch Wassermann (1985), S. 6.
} 
Gerichte, deren Autorität respektiert wird, kontrolliert. ${ }^{4739}$ Für die Kontrolle der Gesetzmäßigkeit des staatlichen Handelns ist also die Justiz zuständig. Bei der ausgeprägten Dominanz der Verfassung bedeutet dies in Deutschland als demokratischem Rechtsstaat, dass die Grundrechte auf jeden Fall zu berücksichtigen sind und die staatlichen Vollzugsorgane „an Gesetz und Recht gebunden“ sind (Art. 20 Abs. 1-3 GG). Diese verfassungsrechtlichen Grundnormen werden in Art. 28 Abs. 1 Satz 1 GG als „Grundsätze des republikanischen, demokratischen und sozialen Rechtsstaats im Sinne dieses Grundgesetzes" zusammengetragen. ${ }^{740}$

Zur Wahrung der Rechtsstaatlichkeit staatlicher Gewalt wird in Art. 19 GG die Verwaltungsgerichtsbarkeit zwischen Justiz und Administration schriftlich festgehalten. ${ }^{741}$ Die Verwaltungsgerichtsbarkeit wurde somit zum „organisatorischen Kennzeichen des Rechtsstaates“ erklärt. ${ }^{742}$ Auf der Grundlage von „Gesetzmäßigkeit, Kompetenzmäßigkeit, Kontrollierbarkeit und Justizförmigkeit“ staatlicher Behörden sollen die bürgerlichen Freiheiten vor staatlicher Willkür geschützt werden. ${ }^{73}$ Der Rechtsstaatsgedanke ist bis heute in den Diskussionen über die Videoüberwachung präsent geblieben. Die unklare Rechtslage polizeilicher Videografie wurde letztlich durch das Bedürfnis nach Rechtmäßigkeit des polizeilichen Handelns geklärt, indem Änderungen der Polizeigesetze vorgenommen wurden. Auch wenn hiermit der Polizei in manchen Bundesländern die Möglichkeit zur präventiven Bekämpfung abstrakter Gefahren verschafft wurde, so haben manche Polizeidienststellen das Datenschutzbewusstsein so sehr internalisiert, dass sie von sich aus „britische Verhältnisse“ der Videoüberwachung öffentlicher Räume ablehnen. Als beispielsweise in Stuttgart und Heilbronn die notwendigen Voraussetzungen zur Videoüberwachung entfallen sind, da die ursprünglichen „Kriminalitätsbrennpunkte“ nach dem Einsatz von Überwachungskameras nicht mehr als solche definiert werden konnten, entschieden sich die jeweiligen Polizeidirektionen selbstständig für das Abschalten der Anlagen.

In der nach allgemeinen Rechtsprinzipien arbeitenden staatlichen Verwaltung sieht man somit die Freiheit des Individuums gut aufgehoben. Angesichts dieses Verständnisses von Rechtsstaatlichkeit erscheint die verstärkte Verwaltungsgerichtsbarkeit in Hinblick auf die Nutzung von Überwachungskameras in der Bundesrepublik plausibel. Während in den USA und Großbritannien keine konkreten rechtlichen

\footnotetext{
${ }^{739}$ Fromme (1960), S. 186 f.

${ }^{740}$ Starck (2002), S. 300.

${ }^{741}$ Wassermann (1985), S. 6.

${ }^{742}$ Blasius (1986), S. 136; Schmitt (1970), S. $131 \mathrm{f.}$

${ }^{743}$ Ebenda.
} 
Grundlagen existieren, werden in Deutschland unter anderem spezielle Rahmenbedingungen im Bundesdatenschutzgesetz festgelegt. Dabei sind die deutschen Datenschutzbeauftragten nicht nur für die Transparenz der Daten, sondern auch für die Kontrolle der Vorgänge innerhalb von Behörden auf Landes- bzw. Bundesebene zuständig.

Selbstverständlich wird das Recht der Individuen, vor Gericht zu klagen, im Grundgesetz (Art. 19 Abs. 4 GG) garantiert, wenn seine Rechte durch die öffentliche Gewalt verletzt werden. Dabei gilt das Prinzip Kants politischer Philosophie, dass der Wortlaut der Gesetze über den individuellen Interessen und den situativen Bedingungen steht. Anders ausgedrückt bedeutet das, dass, wenn der Bürger Einspruch gegen Entscheidungen der staatlichen Verwaltung einlegt, nicht die Gerechtigkeit des Verfahrens, die individuelle Situation des Bürgers oder seine ausreichende Beteiligung am Verfahren geprüft und berücksichtigt werden, sondern die objektive Richtigkeit der Verwaltungsentscheidung nach dem Wortlaut des allgemeinen Gesetzes, das über allen individuellen Interessen steht. Aus diesem Grund ist die prägnante Auslegung der Gesetze zu Maßnahmen der öffentlichen Videoüberwachung notwendig, damit im Streitfall die Rechtmäßigkeit der Handlungen von den Akteuren auf den entsprechenden Grundlagen geprüft werden kann. Als notwendige Voraussetzung für die Videoüberwachung öffentlicher Räume gilt die besondere Kriminalitätsbelastung in der zu überwachenden Zone, die sich deutlich von anderen Örtlichkeiten abhebt. Anhand dieser rechtlichen Grundlage wurde beispielsweise der Einsatz von Überwachungskameras auf dem Schützenfest 2004 in Biberach auf Antrag eines Bürgers vom Verwaltungsgericht Sigmaringen untersagt, während die Klage gegen Videoüberwachung auf dem Rutenfest in Ravensburg vom selben Gericht abgewiesen wurde. ${ }^{744}$ Auch in Mannheim wurde die Rechtmäßigkeit des Pilotprojektes zur Videoüberwachung nach eingereichten Klagen vom Karlsruher Verwaltungsgerichtshof geprüft und aufgrund der Erfüllung der entsprechenden Rechtsgrundlage für zulässig erklärt. ${ }^{745}$

\subsection{Reaktion auf die NS-Zeit}

In einem demokratisch ausgerichteten Regierungssystem bedarf der Staat eines Spielregelkomplexes, um die vielfältigen Interessen unter den politischen Akteuren

\footnotetext{
${ }^{744}$ Der Landesbeauftragte für den Datenschutz Baden-Württemberg (2004), S. 13 ff.; Pressemitteilungen des Verwaltungsgerichts Sigmaringen vom 05.07.2004 und 27.07.2004. Vgl. Verwaltungsgericht Sigmaringen (2004b) und Verwaltungsgericht Sigmaringen (2004a).

${ }^{745}$ Das Innenministerium Baden-Württemberg (2001) und Das Innenministerium Baden-Württemberg (2003).
} 
aufeinander abstimmen zu können. Dabei dient ihm das Rechtssystem als Regulierungsinstrument. Die Akzentuierung des Rechts im deutschen Politikmodell ist jedoch ohne die Berücksichtigung der nationalsozialistischen Vergangenheit nicht zu begreifen.

Die starke Obrigkeitstradition in Deutschland ist besonders in der nationalsozialistischen Diktatur ersichtlich. Blasius hebt den Zusammenhang zwischen dieser sozialkulturell verfestigten Eigenart deutscher politischer Kultur und der NS-Erfahrung zutreffend hervor: „[Die] Tradition der in Deutschland übermächtigen Obödienzgesinnung (...) bildet eine wichtige Mentalitätskonstante des Dritten Reiches. Die gesellschaftliche Akzeptanz von Unrecht verweist auf Unterwürfigkeit als historisches Sozialisationsmuster der deutschen Gesellschaft. Die vom alten Obrigkeitsstaat gestiftete Mentalität vernebelte während des Nationalsozialismus den Blick für Rechtsmissbrauch und Rechtszerstörung. ${ }^{\text {“746 }}$

Nach der Erfahrung des Unrechtsstaates wurde in der deutschen Verfassung besonderer Wert auf die Menschen- und Bürgerrechte gelegt. Als am 8. Mai 1949 die Beratung über die Billigung des Grundgesetzes vom Parlamentarischen Rat beendet wurde, war es den Verfassungsvätern klar, dass als oberste Prinzipien des Grundgesetzes die Wertegebundenheit sowie die Achtung der Menschenwürde stehen müssen. ${ }^{747}$ Durch die im Grundgesetz festgehaltenen unverletzlichen Menschenrechte soll die Macht staatlicher Instanzen in der Bundesrepublik eingegrenzt werden. Im Bonner Grundgesetz (BGG) wurden die demokratischen Grundsätze zur Gewaltenteilung (Art. 20 Abs. 2 BGG; Art. I Abs. 3 BGG) und die gesetzmäßige Bindung des staatlichen Handelns und der Rechtsprechung an Gesetz und Recht (Art. 20 Abs. 3 BGG) ausdrücklich formuliert. ${ }^{748} \mathrm{Im}$ Grundgesetz wird die „politische Struktur des Staates mit juristischen Mitteln verbindlich festgelegt ${ }^{\prime \prime}{ }^{749}$

In der Bundesrepublik darf, so schreibt es das Grundgesetz vor, kein Gesetz, kein verwaltungsrechtliches Handeln oder kein Gerichtsurteil in Widerspruch zu der Verfassung stehen. Zur Wahrung dieses Wertesystems ist das Bundesverfassungsgericht als in der Bundesrepublik neu eingesetzte Instanz zur Sicherung der rechtsstaatlichen Prinzipien verpflichtet, in Konfliktsituation die Unverletzlichkeit der Grundgesetze zu garantieren. Infolgedessen wird die Funktion des Staates von herrschender

\footnotetext{
${ }^{746}$ Blasius (1986), S. 136.

${ }^{747}$ Wassermann (1985), S. 4 f.

${ }^{748}$ Fromme (1960), S. 186 f.

${ }^{749}$ Hesselberger (1999), S. 52.
} 
zu dienender Natur umdefiniert. ${ }^{750}$ Das vom Bundesverfassungsgericht im Volkszählungsurteil vom Jahr 1983 verabschiedete Recht auf die informationelle Selbstbestimmung dient heute auch als rechtliches Instrument zum Schutz der Bürger vor Videoüberwachung. ${ }^{751}$

In seiner ersten Regierungserklärung am 20. September 1949 betonte Bundeskanzler Konrad Adenauer die Bedeutsamkeit der Persönlichkeitsrechte nach der Erfahrung mit dem NS-Regime: „Unsere Wirtschaft ist im Aufstieg. Wir haben vor allem aber wieder den Schutz der Persönlichkeitsrechte. Niemand kann bei uns (...) durch Geheime Staatspolizei oder ähnliche Einrichtungen der Freiheit und des Lebens beraubt werden. Diese Güter: Rechtsschutz, Schutz der persönlichen Freiheit, die wir lange Jahre nicht besaßen, sind so kostbar, dass wir trotz allem, was uns noch fehlt, uns darüber freuen müssen, dass wir diese Persönlichkeitsrechte wieder besitzen. ${ }^{4752}$ Die in den institutionellen Strukturen tief verankerte Wertegebundenheit des politischen Handelns erlaubt die öffentliche Videoüberwachung in Deutschland deshalb nur unter Berücksichtigung bestimmter rechtlicher Regelungen. Die mit den Videoüberwachungsmaßnahmen einhergehenden gravierenden Eingriffe in das Persönlichkeitsrecht von überwiegend gesetzestreuen Bürgern können demnach erst hingenommen werden, wenn es sich um Kriminalitätsschwerpunkte handelt, die das gesellschaftliche Allgemeinwohl gefährden. Dieses charakteristische Strukturprinzip des deutschen politischen Systems verhindert die Standardisierung der Videoüberwachungsmaßnahmen und schränkt somit die Überwachungsinfrastruktur mittels Rechtsordnung ein.

Vor diesem politisch-historischen Hintergrund wird die Anwendung von CCTVSystemen selbst von der Polizei als Eingriff in die Persönlichkeitsrechte der Betroffenen gesehen. Das institutionell internalisierte Bewusstsein des Persönlichkeitsschutzes veranlasst sogar einige Polizeidirektionen (z.B. in Stuttgart und Heilbronn) eigenständig die Überwachungstätigkeiten einzustellen, sobald ein „Kriminalitätsbrennpunkt" durch Rückgang von Kriminalität nicht mehr als solcher bezeichnet werden kann. Einige Polizeidienststellen verzichten freiwillig auf die Vernetzung von Überwachungsanlagen, während die Mehrheit der Städte gar keinen Gebrauch von dieser Technik macht. Die räumliche Eingrenzung des Überwachungsgebiets,

\footnotetext{
${ }^{750}$ "Mit der ausschließlichen Kompetenz der Normenkontrolle gehen die Zuständigkeiten des Bundesverfassungsgerichts entscheidend über die des Staatsgerichtshofes der WRV [Weimarer Rechtsverfassung] hinaus, der im Wesentlichen auf die föderative Schlichtung beschränkt war." Vgl. Fromme (1960), S. 192 f.; Wassermann (1985), S. 5.

${ }^{751}$ Vgl. Teil III, Kap.10.1.2.1 dieser Arbeit.

${ }^{752}$ Schmidt (1992), S. 182.
} 
die Zeitfrist sowie das Definieren des konkreten Einsatzziels bei den Datenschutzbehörden belegen die Verhältnismäßigkeit des Videoeinsatzes in der Bundesrepublik. Bei rechtlichen Fragen werden in vielen Fällen die Beauftragten für den Datenschutz von der Polizei verständigt, um gemeinsam datenschutzrechtlich korrekte Problemlösungen zu erarbeiten.

Auch wenn in der Realität die Kooperationen zwischen Polizei und Datenschutzbehörden nicht immer reibungslos verlaufen, kann angesichts der spezifischen institutionellen Strukturen und Akteurkonstellation angenommen werden, dass das selbstkritische und rechtsschutzbewusste Handeln der Polizei durch die politischkulturellen Rahmenbedingungen nach der NS-Zeit geprägt wird. Dadurch wird die Ausweitung der Videoüberwachung in öffentlichen Straßen und Plätzen eingeschränkt.

\subsection{Politische Partizipation}

Die individuellen Freiheitsrechte in einem liberalen Rechtsstaat werden durch die allgemeinen gesetzlichen Bestimmungen garantiert, für deren Ausarbeitung und Umsetzung die Repräsentativorgane zuständig sind. Die Übergabe dieser Verantwortung in die Treuhand der Repräsentanten wird mit der Effektivität der Bearbeitung begründet: Je mehr die Bürger sich in die Entscheidungsverfahren der Expertengremien einbringen, desto schwieriger ist es für die Spezialisten, die Gesetze sachgerecht auszuarbeiten und anzuwenden. ${ }^{753}$

In der deutschen obrigkeitsstaatlichen Tradition sieht man also die Garantie individueller Freiheiten in der Aufhebung der partikularen Individualität durch die unbestreitbare Allgemeingültigkeit der staatlichen Gesetzgebung. Dieses Denken beeinflusst bis heute die Entstehung der Interessenverbände und anderer Bürgerinitiativen in Deutschland. Die politischen Interessen der deutschen Bevölkerung werden deshalb viel mehr indirekt durch Parteien und andere politische Institutionen vertreten als, wie in den USA, durch Selbstorganisation der Bürger. Beispielsweise kann man dies an den im Vergleich zu den USA quantitativ und qualitativ weniger ausgeprägten Aktionen gegen die staatlichen Videoüberwachungsmaßnahmen erkennen. So wie viele andere politische Angelegenheiten übernimmt auch der Staat (in Form von Datenschutzbehörden) in diesem Fall die Kontrollaufgabe über die Rechtmäßigkeit des Ablaufes zur Videoüberwachung in Deutschland, während diese in den USA von den gut organisierten Bürgerrechtsgruppen durchgeführt wird. Die politische Teilnahme auf lokaler Ebene in der Bundesrepublik ist insgesamt, im

${ }^{753}$ Münch (2000b), S. 17 f. 
Teilnahme auf lokaler Ebene in der Bundesrepublik ist insgesamt, im Gegensatz zu angelsächsischen Gesellschaften, wenig ausgeprägt. ${ }^{754}$ Zwar gibt es zahlreiche Bürgerinitiativen und -bewegungen in der Bundesrepublik, sie sind aber überwiegend von allgemeinen Ideen ökologischer Art oder lokal-politischen Anlässen geprägt, wie z.B. Friedensbewegungen, Abrüstungs- und Umweltschutzinitiativen, Bürgerinitiativen gegen Schließung von Schulen oder Errichtung von Flughäfen. Im Bereich der Bürgerrechtsbewegungen, vor allem solchen gegen die öffentliche Videoüberwachung, ist die politische Partizipation seitens der Bevölkerung vergleichsweise wenig ausgeprägt.

Richard Münch hat in seiner vergleichenden Untersuchung über die verwaltungsgerichtliche Kontrolle von Verwaltungsentscheidungen in den USA und Deutschland festgestellt, dass in Deutschland bei Genehmigungsverfahren ein kartellartiges Netzwerk zwischen Staat und Großverbänden die Entscheidungen in die Hand nimmt, wobei es für die neu formierten Vereinigungen und sozialen Bewegungen schwer ist, in den inneren Kern des geschlossenen Genehmigungskartells einzudringen. Sie haben praktisch kaum Einfluss auf die Entscheidungsprozesse. Es ist deswegen schwierig für deutsche Interessengruppen, in der öffentlichen Diskussion Fuß zu fassen. Wenn die Interessengruppen Medienaufmerksamkeit gewinnen und in die öffentliche Diskussion einbezogen werden wollen, müssen sie auf sachlicher Ebene ihre Kompetenz beweisen, da sie sonst wenig Gehör finden. ${ }^{755}$ Wer nicht über das Fachwissen verfügt und keine rationalen Argumente vorbringen kann, wird mit den unsachlichen Laien gleichgesetzt. Der Policy-Prozess in der Bundesrepublik wird also vom sachlichen Diskurs der Experten bestimmt, der sich einer emotionalisierten Öffentlichkeit gegenüber sieht. ${ }^{756}$ Wie bereits geschildert wurde, sieht man in der Bundesrepublik die Gewährleistung individueller Freiheiten in den allgemeinen Gesetzen, für deren Formulierung vor allem juristischer Sachverstand erforderlich ist. In diesem Sinne werden öffentliche Diskussionen von Sachverständigen beherrscht.

Nach der vorangegangenen Analyse kann festgestellt werden, dass die wirksamsten Gegenkräfte gegen Maßnahmen der Videoaufzeichnung in Deutschland von den staatlichen Akteuren ausgehen. Zwar haben die von Bürgerinitiativen organisierten

\footnotetext{
${ }^{754}$ Sontheimer; Bleek (1998), S. 179.

${ }^{755}$ Ebenda, S. 179.

${ }^{756}$ Jürgen Gerhards und Dieter Rucht konnten in ihrer Untersuchung über die Abtreibungsdebatten in den USA und Deutschland diese Eigenschaften der deutschen Politik bestätigen. Im Gegensatz zu den USA dominieren nicht die Bürgerrechtsgruppen, sondern die staatlichen Akteure und die Großverbände viele Debatten in der deutschen Politik. Vgl. Gerhards; Rucht (2000), S. 165 ff. Auch in der Politik der Luftreinhaltung können diese Merkmale des deutschen Politikstils festgestellt werden. Vgl. Stark; Peters (2000); 181 ff; Münch; Lahusen (2000), S. 344 ff; Lahusen (2003), S. 84 ff.; 145 ff.; 305 ff.
} 
Anti-Kamera-Demonstrationen in Leipzig zum Abbau einer Polizeikamera geführt, aber die durchgreifende Kontrolle wird über den parlamentarischen Weg, wie z.B. von Oppositionspolitikern in Weimar, oder mittels gerichtlicher Entscheidungen, z.B. in Biberach, ausgeübt. Im Vergleich mit US-amerikanischen Interessengruppen sind die deutschen Bürgerrechtsorganisationen sowohl in ihrem Umfang als auch in ihren Interventionsmöglichkeiten unterlegen. Zudem genießen sie viel weniger öffentliche Aufmerksamkeit als die Datenschutzbeauftragten, die als staatliche Kontrollinstanzen in den Entscheidungsprozessen über Kameraeinsatz eher involviert werden.

\subsection{Zusammenfassung}

Das Politikmodell in Deutschland ist gekennzeichnet durch Dominanz staatlicher Akteure und starke Akzentuierung des Rechts, wobei deren Ausformulierung und Anwendung auf dem Wissen der Fachleute basieren. Politische Entscheidungen werden deswegen vor allem in Expertengremien getroffen, zu denen zivilgesellschaftliche Akteure nur schwer Zugang finden, da sie nicht über ausreichendes Fachwissen verfügen.

Auch die Politik der Videoüberwachung öffentlicher Straßen und Plätze in der Bundesrepublik wird vor allem von staatlichen Institutionen gesteuert. Gebremst wird die Zunahme der Überwachungskameras überwiegend durch Vorbehalte mancher Polizeidienststellen oder durch die Kontrolle der Datenschutzbehörde. Als Konsequenz aus den NS-Erfahrungen wird der Verwaltungsgerichtsbarkeit sowie der Rechtsgebundenheit staatlicher Handlungen besondere Aufmerksamkeit geschenkt. Die Bemühungen zur Rückgewinnung von demokratischen, rechtsstaatlichen, gewaltteilenden Grundprinzipien in einer neuen Staatlichkeit nach dem NSTerrorregime kann man vor allem in der Wertegebundenheit der deutschen Verfassung sowie dem Aufbau eines Rechtsstaates sehen ${ }^{757}$ Die Bedeutsamkeit der Rechtsordnung ist prägend für das gesamte deutsche Politiknetzwerk, wobei die rechtlichen Normen nicht nur die partikularen Interessen unter den Bürgern, sondern auch zwischen den staatlichen Institutionen regulieren. Präzise Auslegung des Gesetzestextes ist dabei unabdingbar.

Selbst in der heutigen Praxis polizeilicher Videoüberwachung ist die Bedeutsamkeit des Rechts unverkennbar. Das internalisierte Rechtsbewusstsein ist nach der vorangegangenen Analyse für die ablehnende Haltung der deutschen Polizei gegenüber den „britischen Verhältnissen“ der flächendeckenden Videoüberwachung aus-

${ }^{757}$ Vgl. hierzu Wassermann (1985), S. 4 ff. 
schlaggebend. In Anlehnung an die staatszentrierte Tradition übernehmen Datenschützer die Rolle als "Anwalt der Bürger" und überwachen als staatsinterne Aufsichtsbehörde das polizeiliche Handeln und die Einhaltung datenschutzrechtlicher Vorschriften. Vor diesem Hintergrund ist es erforderlich, die polizeiliche Videoüberwachung in Deutschland zum Zweck der Rechtmäßigkeit mit Änderungen der jeweiligen Polizeigesetze einzuleiten. Das Bewusstsein des Rechtsschutzes, welches im deutschen Staatsapparat verankert ist, scheint also für die rechtmäßigen und vorsichtigen Entscheidungsprozesse zur öffentlichen Videoüberwachung verantwortlich zu sein. 


\section{USA - Pluralistische Wettbewerbsdemokratie}

\subsection{Einleitung}

Die Gründer der amerikanischen Verfassung befürchteten nach den Unabhängigkeitskämpfen von England nichts mehr als die Gefährdung individueller Freiheiten. Der Schutz dieser Freiheitsrechte wird als eine der wichtigsten Aufgaben des Staates gesehen, insbesondere auch der Schutz der Bürger vor staatlichen Übergriffen.

Die Schutzbestimmungen der Bill of Rights, die der Verfassung hinzugefügt wurden, und die durch die Verfassung festgelegte Gewaltenteilung in die sich gegenseitig kontrollierenden staatlichen Organe (Judikative, Legislative und Exekutive) ermöglichen den Schutz vor Übergriffen durch den Staat. Auch die Vermeidung von Machtkonzentration durch die Teilung der Zuständigkeiten zwischen Bund, Einzelstaaten und Kommunen dient demselben Zweck. ${ }^{758}$ Die hohe Wertigkeit des Schutzes vor staatlicher Willkür und des Prinzips der Volkssouveränität kann man z.B. daran erkennen, dass „das Individuum selbst für seine Sicherheit sorgen kann und dazu nicht der staatlichen Hilfe und damit auch Kontrolle bedarf. Dieses Recht ist in der Gesellschaft selbstständiger Eigentumsbesitzer verwurzelt, in der jeder Bürger die Waffe in der Hand des Staates mehr ablehnte als die Waffe in der Hand des Nachbarn. ${ }^{7759}$ Die politische Freiheit in den USA basiert auf dem Recht des Individuums, an der Gesetzgebung selbst mitzuwirken und keines der Gesetze anzuerkennen, das von einer ihm unzugänglichen Stelle erlassen wurde. Nirgendwo, so Richard Münch, hat dieses Recht auf politische Beteiligung so lange Tradition und vielfältige Praxis wie in den USA. ${ }^{760}$

Der amerikanische Policy-Prozess ist also insgesamt gekennzeichnet durch große Offenheit, Inklusivität, Gewaltenteilung und Fragmentierung. In dieser liberalen Demokratie geht es vor allem um die maximale Entfaltung eines Pluralismus von Einzelinteressen, die nicht selten zum heftigen Wettstreit unter den beteiligten Akteuren führt. Dieser Politikstil findet seine Entsprechung und Legitimation in der institutionellen Entscheidungsstruktur über die Implementierung von Videoüberwachung. In diesem Abschnitt der Arbeit werden einige relevante Strukturmerkmale dieses Politikmodells herausgearbeitet, wobei es wichtig ist anzumerken, dass die politisch-kulturellen Eigenschaften der USA aufgrund ihrer Vielfältigkeit und ihrer regionalen Heterogenität nur schwer zu bestimmen sind. Eine detaillierte Strukturie-

\footnotetext{
${ }^{758}$ Münch (2000b), S. 21.

${ }^{759}$ Ebenda, S. 410.

${ }^{760}$ Ebenda.
} 
rung dieser Unterschiede gehört nicht zum Rahmen dieser Arbeit und soll deswegen an dieser Stelle nicht weiter vertieft werden. Im Folgenden handelt es sich demnach lediglich um einen Versuch, die Nutzungsintensität von Videoüberwachungsgeräten unter Berücksichtigung einiger relevanter nationaler Besonderheiten der USamerikanischen Gesellschaft in Bezug auf die Akteurskonstellation im Umgang mit CCTV-Überwachung zu analysieren.

\subsection{Prinzip der Volkssouveränität}

Die Gemeinde in den USA ist die erste Ebene der politischen Teilnahme und das Zentrum des amerikanischen Alltags. Die wichtigen kommunalen Entscheidungen werden direkt auf den Gemeindeversammlungen, an denen jeder Bürger teilnehmen kann, getroffen. Dadurch entsteht die lange Tradition der weitgehenden Unabhängigkeit des amerikanischen Gemeindewesens von einem übergeordneten Zentralorgan und der Selbstbestimmung sowie Teilnahme des Bürgers an den kommunalen Angelegenheiten. Diese Tradition macht auf der kommunalen Ebene die politische Freiheit in den Vereinigten Staaten aus.

Die besondere Autonomie des Volkes und die politische Dezentralisierung der Gemeinde in der amerikanischen Gesellschaft sind nach Tocquevilles Untersuchung im Vergleich zu den anderen Industrienationen einzigartig: „Das Volk ist in der Gemeinde wie überall die Quelle der sozialen Befugnisse, aber nirgends übt es seine Macht unmittelbarer aus. In Amerika ist das Volk ein Herr, dem man bis zu den äuBersten Grenzen des Möglichen entgegenkommen musste. “761

Diese unmittelbare Partizipationsmöglichkeit ist auch in den institutionellen Strukturen der CCTV-Politik erkennbar. Beispielsweise wird die aktuelle Information über den Stand der Videoüberwachung in Washington D.C. über regelmäßige Versammlungen auf kommunaler Ebene vermittelt. Auch öffentliche Anhörungen und Aufrufe zur Teilnahme am Entscheidungsprozeß durch die Bürger gehören zur Einführung von Überwachungsmaßnamen via Videotechnik. ${ }^{762}$ Beispielsweise agiert in Tacoma, Washington sogar die Gemeinde als Hauptinitiator bei der Implementierung von Überwachungskameras in öffentlichen Räumen. ${ }^{763}$

Um die Begrenzung der staatlichen Gewalt gegenüber dem Individuum zu ermöglichen und somit die Freiheitsrechte des Volkes zu garantieren, sollten die kleinsten gesellschaftlichen Einheiten möglichst viele Selbstbestimmungsrechte erhalten und

\footnotetext{
${ }^{761}$ Tocqueville (1976), S. 69. Vgl. auch Münch (1986b), S. 400

${ }^{762}$ Vgl. Teil III, Kap. 10.2.1 dieser Arbeit.

${ }^{763}$ Vgl. Teil I, Kap. 3.2.2 dieser Arbeit.
} 
die größeren Einheiten nur so viel Macht wie notwendig bekommen. Was von den Individuen ohne gegenseitige Eingrenzung der Freiheitsrechte bewältigt werden kann, sollte auch den Individuen überlassen werden. Erst wenn die individuellen Freiheiten miteinander in Konflikt geraten, werden Konfliktlösungen auf einer höheren Rangstufe, also auf der Gemeindeebene, gesucht. Bei kommunalen Problemen ist der Kreis (County) zuständig, dessen Schwierigkeiten wiederum von Einzelstaaten geregelt werden. Erst bei Auseinandersetzungen auf nationaler Ebene ist der Bund verantwortlich. So wie die meisten politischen Angelegenheiten, die in Europa überwiegend vom Staat reguliert werden, werden Entscheidungen zur Einführung von Überwachungskameras in öffentlichen Räumen vor allem auf lokaler Ebene getroffen. ${ }^{764}$ In der vorangegangenen Analyse konnte deutlich gemacht werden, dass zwar eine staatliche Finanzierung für CCTV-Programme von der Zentralregierung bereitgestellt wurde, aber die meisten Entscheidungen über den Kameraeinsatz in der Lokalpolitik getroffen und von den lokalen Akteursnetzwerken finanziert werden. Das Paradebeispiel für das Prinzip der Volkssouveränität zeigt sich im Videoüberwachungsprojekt in Anchorage, Alaska, in dem die Bürger Überwachungsaufgaben via Videotechnik und die Informationsverbreitung über die Verdächtigen übernehmen, die sonst in den Zuständigkeitsbereich der Polizei gehören. ${ }^{765}$ Auch in anderen Projekten wie z.B. in Hollywood und San Diego stellen die kommunalen und privaten Akteure einen zentralen Dreh- und Angelpunkt der lokalen CCTVPolitik dar.

Die Kommunalpolitik in den USA ist also durch die Interessenvielfalt und Aktivitäten seitens der Bürger geprägt. Die Protagonisten des lokalen Wettbewerbs um den Einsatz der Kameras in öffentlichen Räumen sind nicht nur staatliche Akteure, sondern auch gleichrangige lokale Interessengruppen. In vielen Großstädten finden nicht selten harte Kämpfe zwischen den lokalen Akteuren statt, die üblicherweise in anderen Industrieländern erst auf nationaler Ebene ausgetragen werden.

\subsection{Rolle der Gerichte}

Im föderalen Aufbau des amerikanischen Regierungssystems, in dem sich die verschiedenen Behörden nach dem System der Checks and Balances gegenseitig in Schach

\footnotetext{
${ }^{764}$ Die lokale Autonomie und die bürgerliche Teilnahme am politischen Entscheidungsprozess kann man u.a. daran erkennen, dass in vielen westlichen demokratischen Nationen die behördeninternen Ämter durch Berufung und Ernennung besetzt werden, während in den Vereinigten Staaten dies durch öffentliche Wahlen geschieht. Außerdem gründen amerikanische Bürger häufiger Bürgervereinigungen, um bestimmte Interessen durchzusetzen, während in anderen Ländern die Bürger individuell als Einzelkämpfer gegenüber der Administration antreten. Vgl. Münch (1986b), S. 401 f.

${ }^{765} \mathrm{Vgl}$. Teil I, Kap. 3.2.2.6 dieser Arbeit.
} 
halten, spielen richterliche Gewalt und Rechtsprechung nicht nur für die Praxis der Videoüberwachung eine besondere Rolle. In einer liberalen Demokratie, wie der in den USA, ist es schwierig, im Voraus konkrete Konfliktlösungen auszuarbeiten. Diese entstehen erst bei Auseinandersetzungen über private Interessen. Es wird hierbei weniger Wert auf die Vollständigkeit der Gesetze im Voraus und die Richtigkeit der richterlichen Entscheidungen gelegt, als vielmehr auf die Fairness des Verfahrens beim Rechtsstreit vor Gerichten in konkreten Fällen. ${ }^{766}$ Die politische Freiheit der Individuen wird nicht durch allgemeine Gesetze, wie in der Bundesrepublik, definiert, sondern im Einzelfall unter ihrer Beteiligung miteinander abgestimmt.

Die Gerichte haben somit bei der Umsetzung der Idee einer liberalen Demokratie an besonderer Bedeutung gewonnen, die anderswo kaum in vergleichbarem Ausmaß erreicht wird. Richard Münch spricht in diesem Zusammenhang von einer Gerichtsdemokratie. ${ }^{767}$ Tocqueville stellt in seinen Beobachtungen über die Demokratie in Amerika ebenfalls die wichtige Rolle der Richter fest: „Bis heute hat, glaube ich, kein Volk auf Erden der richterlichen Gewalt eine gleiche Form gegeben wie die Amerikaner. ${ }^{4768}$ Das Recht, Gesetze als verfassungswidrig oder als verfassungskonform zu deklarieren, sichert den amerikanischen Richtern, die in vielen Bereichen regulierend eingreifen, ihre bemerkenswerte Position in der Politik. Durch die Unabhängigkeit der Gerichte bilden die richterlichen Entscheidungen das wichtigste Gegengewicht gegen die Mehrheitsherrschaft. Ihre herausragende Rolle sichert die politische Freiheit des Individuums gegen staatliche Willkür. Vor allem zu Beginn der 1950er Jahre haben die Gerichte sich gegen die öffentliche Mehrheitsmeinung durchgesetzt und außerordentlich liberale Urteile für die Sicherung bürgerlicher Freiheit und die Durchsetzung sozialer Gleichheit durch rassische Desegregation ausgesprochen. Die Bürgerrechtsbewegungen und die begleitenden Gerichtsklagen in Bezug auf die rassischen Diskriminierungen sind für die amerikanische Gesellschaft nicht nur damals, sondern auch in der Gegenwart prägend ${ }^{769}$ Dies trägt außerdem dazu bei, dass die nichtstaatlichen Akteure eine den staatlichen Institutionen gleichrangige Machtposition in den politischen Entscheidungsprozessen genießen. Diese in der politischen Kultur verankerte Akteurskonstellation kann die einflussreiche Position sowie die Vielzahl der amerikanischen Bürgerrechtsorganisationen, die im Vergleich zu Großbritannien und Deutschland eindeutig hervorsticht, begreiflich machen.

\footnotetext{
${ }^{766}$ Münch (2000b), S. 22.

${ }^{767}$ Ebenda.

768 Tocqueville (1976), S. 111.

${ }^{769}$ Ebenda, S. 310 ff.; Münch (1986b), S. 403 ff.
} 
Seit der sozialen Mobilisierung in den 1950er und 1960er Jahren sind eine sprunghafte Zunahme der gerichtlichen Bürgerrechtsfälle und eine gestiegene Zahl von Anklagen gegen die Regierung durch Privatpersonen zu registrieren. Der Gebrauch von Rechtsmitteln durch die Bürger und die Sicherung der Minderheitsrechte durch die richterliche Entscheidung sind Eckpfeiler in der Sicherung der politischen Freiheit der Minderheiten in den USA. In der Tat wird in keinem anderen Land in vergleichbarem Maße vor Gericht geklagt wie in den USA. Die Gerichte haben hierbei die Aufgabe, die Gesetze in der Praxis zu konkretisieren, indem sie in einem langen Prozess des Verhandelns möglichst viele Rechte und Interessen von Individuen zu berücksichtigen versuchen. ${ }^{70}$ Dieses Merkmal wird ebenfalls an den vielfältigen Gerichtsentscheidungen in den verschiedenen Bundesstaaten in Hinblick auf die Anwendung von Überwachungskameras in den öffentlichen Räumen ersichtlich. Es konnte bisher in dieser Arbeit gezeigt werden, dass nicht nur die Definitionen von "Right of Privacy“, sondern auch die Rechtsprechung zum Thema Videoüberwachung in den USA je nach Bundesstaat sehr unterschiedlich ausfallen können. ${ }^{771}$ Dies entspricht dem US-Politikstil, der ein möglichst breites Spektrum von Interessenentfaltung ermöglichen soll. Da es in einer Wettbewerbsdemokratie um einen unendlichen Prozess des Abstimmens von Rechten und Interessen geht, müssen die Gesetze nicht im Voraus ihre endgültige Form besitzen, sondern erst im Rechtsbildungsprozess konkretisiert werden.

Trotz der starken Machtposition des Präsidenten funktioniert das System der Checks and Balances, denn der Präsident der Vereinigten Staaten ist kein Premierminister, dessen Kabinett die Mehrheit im Kongress besitzt. Häufig fungiert eine Mehrheit der gegnerischen Partei sowohl im Senat als auch im Repräsentantenhaus als Gegenpol zur Autorität des Präsidenten. Durch diese Gewaltenteilung ist der Kongress kein Vollstreckungsorgan der Regierung. Er kann massiven Druck auf die Regierung ausüben, z.B. in Form von Kommissionen wie bei der energischen Aufklärung des Watergate-Skandals. ${ }^{772}$ Das Handeln der Regierung steht durch solche unabhängigen Komitees unter ständiger Beobachtung. In Hinblick auf den Einsatz polizeilicher Überwachungskameras in der Hauptstadt Washington D.C. fungiert beispielsweise das House Government Reform Subcommittee als kontrollierende und beratende Instanz. ${ }^{773}$ Zur Aufklärung von Konflikten bei Verwaltungsentscheidungen sind also in

\footnotetext{
${ }^{770}$ Münch (2000b), S. 23.

${ }^{771}$ Vgl. Teil II, Kap. 5.2. und Teil III, Kap. 10.2.2 dieser Arbeit.

${ }^{772}$ Münch (1986b), S. $405 \mathrm{ff}$.

${ }^{773}$ Vgl. Teil III, Kap. 10.2.2.2 dieser Arbeit. 
den USA spezifische Regulierungsbehörden zuständig. ${ }^{774}$ Solche Kommissionen bemühen sich bei gegebenen Konflikten um konkrete Informationen durch Anhörungen der Betroffenen. Somit werden die Konflikte den Umständen entsprechend sehr unterschiedlich bearbeitet und bewältigt. Auch hier gilt das Prinzip des Checks and Balances: Diese Kommissionen sowie zahlreiche Public-Interest-Groups und Journalisten mischen sich in den Prozess politischer Handlungen ein und sorgen für ein Gegengewicht zu staatlichen Verwaltungsstellen und Behörden. Auch dieser unkalkulierbare, wenig kohärente Policy-Prozess entspricht dem Prinzip der pluralistischen Wettbewerbsdemokratie, in dem möglichst viele, auch entgegengesetzte, Interessen berücksichtigt und gegebenenfalls auch befriedigt werden sollen.

\section{4 "Relative Statelessness“ und Lobbyismus}

J. P. Nettl betont in seinem Vergleich der europäischen und amerikanischen politischen Systeme die "relative Statelessness“ des amerikanischen Modells. ${ }^{775}$ Das $\mathrm{Zu}$ sammenspiel von Interessenvielfalt, Gerichtsdemokratie und Interdependenz der Medien führt dazu, dass die Rolle des Staates in den USA im Vergleich zu den europäischen Ländern nicht so gewichtig ist. ${ }^{776}$ Auch in den meisten Videoüberwachungsmaßnahmen nimmt der amerikanische Staat eine eher zurückhaltende Rolle ein: Während in Großbritannien die Regierung als Hauptgeldgeber für CCTVÜberwachung fungiert und in Deutschland die staatsinternen Datenschutzbehörden die Kontrollaufgaben über die Rechtmäßigkeit polizeilicher Videoüberwachung übernehmen, sind es vor allem die kommunalen Akteure und Bürgerrechtsorganisationen in den Vereinigten Staaten, die diese Angelegenheit politisch thematisieren. ${ }^{777}$

\footnotetext{
${ }^{774}$ Die erste Kommission "Interstate Commerce Commission“ wurde im Jahr 1887 zur Kontrolle wirtschaftlicher Machtverteilung eingerichtet. Seitdem wurde eine Fülle von solchen Behörden gegründet, z.B. Environmental Protection Agency (EPA). Vgl. Münch (1986b), S. 411; vgl. auch Münch (2000b), S. 22; Jauß (2000), S. $268 \mathrm{ff}$.

${ }_{775}$ Nettl (1968), S. 561 ff.; Lipset (1996), S. 40.

${ }^{776}$ Vgl. hierzu Münch (2000b), S. 21 ff.

${ }^{777}$ Es herrscht in den USA ein allgemeines Misstrauen gegenüber einem starken Staat und Zurückhaltung gegenüber wohlfahrtsstaatlich orientierten politischen Maßnahmen. Man kann auch an der Privatisierung der Gefängnisbauten und -verwaltung sowie der staatlichen Einflussnahme auf die Gewerkschaften das Phänomen der „relative Statelessness“ erkennen: „Fewer than half of American union members are in favor of the goverment providing a decent standard of living for the unemployed, as compared with $69 \%$ of West German, $72 \%$ of British (...). Even before Ronald Reagan entered the White House in 1981, the USA had a lower rate of taxation, a less developed welfare state, and many fewer government-owned industries than other industrialized nations." Im Vergleich zu vier europäischen Ländern (Großbritannien, Westdeutschland, Italien und Österreich) zeigt sich in den Vereinigten Staaten sowohl in wirtschaftlichen Bereichen wie Lohnfragen, Reduzierung der Arbeitszeiten für mehr Arbeitsplätze, Preiskontrolle, als auch in sozialen Bereichen wie Rauchverbot eine eher ablehnende Haltung gegenüber staatlichen Eingriffen. Im Gegensatz zu Europäern glauben die Amerikaner nicht, dass der Staat für Arbeitsbeschaffungsmaßnahmen zuständig ist oder Mindesteinkommen und Lebensstandard der Arbeitslosen garantieren soll. Vgl. Lipset (1996), S. 38 f., 76; vgl. auch Koch (1998), S. 174 ff.
} 
Die zivilgesellschaftlichen Akteure genießen in den USA einen relativ hohen Rang in der politischen Praxis im Vergleich zu Großbritannien und Deutschland. Die USA blicken dabei auf eine lange Tradition sozialer Mobilisierung zurück, die durch die spezifisch wettbewerbsdemokratisch ausgerichtete Struktur des politischen Prozesses begünstigt wird. Besonders die Bürgerrechtsbewegungen der „schwarzen Revolution" in den 1950er und 1960er Jahren haben bedeutende Spuren in der strukturellen Dynamik der Artikulation gesellschaftlicher Interessen hinterlassen. Ihre Tragweite ist bis heute erkennbar. ${ }^{778}$ Der Schwerpunkt der Proteste in dieser Periode besteht im Kampf gegen Rassentrennung durch die Integration ethnischer Minderheiten sowie deren ökonomische Absicherung. Soziale Protestaktionen und organisierte Interessenvertretungen waren zwar schon länger in den USA legitim, aber erst seit den 1960er Jahren wurden auch die Rechte der Unterprivilegierten und ethnischen Minderheiten politisch vertreten. ${ }^{779} \mathrm{Im}$ Vergleich zu anderen Ländern haben bürgerrechtliche Themen in der US-amerikanischen Öffentlichkeit wesentlich mehr Gewicht.

In der Gegenwart ist die Dynamik des amerikanischen Politikstils, wie bereits erwähnt, gekennzeichnet durch große Offenheit, Gewaltenteilung und Segmentierung, die zu heftigen Wettkämpfen zwischen gegenläufigen Interessen führen können. Die Rolle von Lobbyisten und Interessengruppen ist in einer so wettbewerbsreichen Gesellschaft von besonderer Bedeutung. Von den insgesamt auf etwa 40.000 geschätzten Lobbyisten allein in Washington D.C sind etwa 5.000 im Kongress offiziell registriert und vertreten eine Vielzahl unterschiedlichster Interessen und Rechte, die ansonsten von Parteien und Verbänden wenig berücksichtigt werden. ${ }^{780}$

Lobbyisten sind nicht nur Interessenvertreter, sondern auch wichtiges Bindeglied zwischen Bürgern und Politikern und somit auch zwischen Gesellschaft und Regierung. So wie die staatlichen Interessenvertreter, wie die Abgeordneten und Senatoren des Repräsentantenhauses, stellen die Lobbyisten eine wichtige Informationsquelle bei der Durchsetzung bestimmter politischer Maßnahmen dar. Ihr Engagement und ihre Beteiligungen am politischen Prozess sind fundamental für die amerikanische Tradition der professionellen Interessenvertretung. Die American Civil Liber-

\footnotetext{
${ }^{778}$ Mehr zu den Bürgerrechtsbewegungen in den 1950er und 1960er Jahren sowie deren Einflussnahme auf die Gesellschaft vgl. Moosbrugger (2004), S. 51 ff., 147 ff.; Gosse; Moser (2003), S. 37 ff.; Button (1989); Marsh (1990).

${ }^{779}$ Schon im 17. und 18 Jahrhundert wurden religiöse Sektenbewegungen und Revolten von Bauern gegen das landwirtschaftliche Machtmonopol der Minderheiten festgestellt. Zwischen 1870 und 1940 waren zahlreiche Proteste der Arbeiterklasse zu verzeichnen. Mehr zur Geschichte sozialer Bewegungen vgl. Kitschelt (1985), S. 248 ff.

${ }_{780}$ Münch (2000b), S. 25; Münch (2000a), S. 370 ff; Bowles (1993), S. 207.
} 
ties Union (ACLU) nimmt als größte Bürgerrechtsorganisation in den USA dabei eine Vorreiterrolle ein und wurde z.B. bei der Einführung von Videoüberwachungsmaßnahmen in Washington D.C. mit einbezogen. Zudem basieren die ersten gesetzlichen Regelungen zur Videoüberwachung öffentlicher Räume, die auf die Überwachungsmaßnahmen in Washington D.C. angewandt werden, auf die CCTV-Leitfäden des nichtstaatlichen Rechtsberufsverbunds American Bar Association (ABA). ${ }^{781}$ Dieses unmittelbare Mitwirken nichtstaatlicher Akteure an der Implementierung öffentlicher Videoüberwachung ist in den Fallbeispielen einzigartig und wird durch die Offenheit dieser Politikgestaltung ermöglicht. Dabei gehört das traditionelle Bewusstsein des starken und beständigen Bürgerengagements, das aus der Epoche der „schwarzen Revolution“ hervorging, zum festen Bestandteil des Politiknetzwerks in den Vereinigten Staaten.

\subsection{Zusammenfassung}

Die wettbewerbsdemokratisch ausgerichteten Strukturmerkmale des amerikanischen Politiknetzwerks sind durch große Offenheit, Dezentralisierung und Lobbyismus gekennzeichnet, wobei die Sicherung privater Freiheiten einzelner Individuen sowie kommunale Entscheidungsgewalt im Vordergrund stehen. Dies bedeutet, dass ein komplexer Entscheidungsprozeß zur Implementierung von Videoüberwachung stattfindet, an dem viele gleichrangige Akteure beteiligt sind und ihre eigenen Interessen und Rechte vertreten. Das Ziel dieses Wettstreits besteht in maximaler Entfaltung und Befriedigung einer Vielzahl von Interessen. Aus diesem Grund werden lokale politische Akteure und Bürger häufig in politischen Debatten über öffentliche Videoüberwachung berücksichtigt und sind dementsprechend mehr an kommunalen Entscheidungsprozessen zur Implementierung von CCTV-Systemen beteiligt. Diese Fragmentierung politischer Entscheidungsstruktur führt allerdings auch zur uneinheitlichen Rechtsprechung, die eine klare Rechtslage über den Einsatz optischer Überwachungseinrichtungen auf öffentlichen Straßen und Plätzen verhindert. Die föderalistische Struktur des politischen Systems der USA ermöglicht also die Selbstständigkeit und Heterogenität der Einzelstaaten und der Kommunalbehörden, welche sich in der Vielfalt der Anwendungsintensität von öffentlichen Überwachungskameras widerspiegelt.

Die USA blicken auf eine lange Tradition von Bürgerrechtsbewegungen zurück, die bis in die Gegenwart das Bewusstsein des Bürgerengagements der amerikanischen

\footnotetext{
${ }^{781}$ Vgl. Teil III, Kap. 10.2.3.5 dieser Arbeit.
} 
Bürger prägt. Diese Besonderheit sozialer Mobilisierung eröffnet den organisierten Interessenverbänden die Möglichkeit, an politischen Prozessen über öffentliche Videobeobachtungsmaßnahmen zu partizipieren. Mit Hilfe unternehmerischer Strategien werben die Public Interest Groups in den USA ihre Mitglieder. Dank dieser Strategien nimmt seit den 1970er Jahren die Anzahl solcher Initiativen immer mehr zu. ${ }^{782}$ Mit der finanziellen Unterstützung ihrer Mitglieder vertreten sie mittlerweile nicht nur wirtschaftliche Interessen; sie setzen sich u.a. auch für Bürgerrechte sowie Verbraucher- und Umweltschutz ein. Durch die Ermittlung von „Issues“ versuchen sie, die amerikanische Exekutive sowie die politische und rechtliche Entscheidungsfindung durch gesellschaftliche Impulse zu beeinflussen. ${ }^{783}$ Es ist deswegen einleuchtend, dass in den USA der Widerstand durch Aktionen gegen die Verbreitung von Überwachungskameras in den öffentlichen Räumen tatkräftig von zivilgesellschaftlichen Akteuren vertreten wird, die sich nicht nur in ihrer Anzahl, sondern auch in ihrer Einflussgröße von ihren deutschen und britischen Pendants unterscheiden.

Das in den USA vorherrschende Modell der pluralistischen Wettbewerbsdemokratie verleiht den Interessenvermittlern in den USA eine wichtige Rolle und macht den Menschen „exceptionally litigious“ (ungewöhnlich prozesssüchtig). ${ }^{784}$ Es wird von der Durchsetzung der Gesetze bis zu ihrer praktischen Anwendung im Alltag um die kleinsten Vorzüge vor Gericht gestritten. Da nur finanzstarke Interessen durch professionelle Lobbyisten vertreten werden, wird nicht selten das Gemeinwohl der gesamtgesellschaftlichen Mehrheit in den Auseinandersetzungen um die Rechte und Vorteile der Einzelnen in den Hintergrund gedrängt. ${ }^{785}$

\footnotetext{
${ }^{782}$ Münch (2000b), S. 24 ff.

${ }^{783}$ Auch die Medien in den USA fungieren als externe Kontrollinstanz des politischen Handelns der Regierung. Presse, Rundfunk und Fernsehen wissen das Recht der freien Rede und Schrift zu nutzen und sichern hierdurch ihre mediale Unabhängigkeit, die im internationalen Vergleich beispielhaft ist. Die amerikanische Regierung hat nur geringfügige Befugnisse, Veröffentlichungen durch die Medien zu verhindern. Das Recht der freien Meinungsäußerung ist also ein wichtiger Eckpfeiler in der Überwachung der Regierung. Die Ambitionen der amerikanischen Journalisten, die Politiker und ihre Arbeit unter die Lupe zu nehmen und die verschiedenen betroffenen Akteure in ihrer Recherchearbeit zu berücksichtigen, ist vorbildlich für ihre Kollegen in anderen Nationen.

${ }^{784}$ Lipset (1996), S. 40.

${ }^{785}$ Münch (2000b), S. 25.
} 


\section{Großbritannien - Konsultative Westminster- Demokratie}

\subsection{Einleitung}

Entsprechend der angelsächsischen Tradition des Liberalismus ist das Regierungssystem Großbritanniens durch die Idee parlamentarischer Demokratie gekennzeichnet, welche in der britischen Form auch unter der Bezeichnung „Westminster Modell" bekannt ist. Ein Kernelement des Modells ist das Prinzip der Parlamentssouveränität. ${ }^{786}$ Das Parlament, als die Hauptbühne des britischen Policy-Prozesses, repräsentiert durch die Lenkung der Staatstätigkeiten das politische Gemeinwesen, während die Monarchie in der Politik symbolische Aufgaben übernimmt. Als Repräsentantin des Volkes verkündet die Königin bis heute das Regierungsprogramm des Premierministers im Parlament. „In der Monarchie verkörpert sich die Geschichte und die Einheit des Volkes, im Parlament die augenblickliche Konstellation der Machtverhältnisse und die aktuelle Interessenlage. ${ }^{\text {“787 }}$

Ein anderer Grundsatz des Westminster Modells ist die angelsächsische „Civic Culture ${ }^{\prime \prime}{ }^{788}$ Alond \& Verba bezeichneten in ihrer Civic-Culture-Studie aus dem Jahr 1963 die britische politische Kultur als „pluralistic culture (...) based on communication and persuasion, a culture of consensus and diversity, a culture that permitted change but moderated it". ${ }^{789}$ Nach Ansicht der Autoren entsprechen diese politischkulturellen Verhältnisse in Großbritannien, mehr als die in den USA, dem Leitbild der Zivilkultur („Civic Culture“), welche das notwendige kulturelle Fundament für eine stabile Demokratie darstellen sollte.

Die englische politische Kultur ist insofern zivil, als in Konfliktfällen stets "zivile“ Lösungen statt "staatlicher" Lösungen bevorzugt werden, um den gesellschaftlichen Frieden zu garantieren. Ein unbewaffneter englischer Polizist, im Volksmund auch „Bobby“ genannt, ist bis heute Symbolfigur einer solchen Kultur. „Der gemeinte Sinn dieser Symbolfigur ist (...), dass Menschen ohne Zwischenschaltung einer autoritären Gewalt darin übereinkommen, gemeinsame Regeln zu haben, auf deren Grundlage dann die politischen Interessenkonflikte ausgetragen werden können. ${ }^{4790}$ Zivilkultur

\footnotetext{
${ }^{786}$ Paterson (2000), S. 146 ff; Kaiser (2000), S. 12 ff.

${ }^{787}$ Münch (2000a), S. 305 ff.

${ }^{788}$ Kaiser (2000), S. 12.

${ }^{789}$ Diese Pionierstudie zum Thema politischer Kultur versuchte anhand von vergleichenden Meinungsbefragungen in fünf Ländern - USA, Großbritannien, Mexiko, Italien und Bundesrepublik Deutschland - die Unterschiede der politischen Einstellungen zwischen den Nationen und den Befragten in den einzelnen Ländern aufzuzeigen. Almond; Verba (1963), S. 1 ff.

${ }^{790}$ Rohe (1984), S. 175.
} 
beschreibt somit eine politische Kultur, die im Gegensatz zu einer Staatskultur das „Gesellschaftsvertrauen“ voraussetzt. ${ }^{791}$

Vor diesem Hintergrund ist das britische Westminster Modell parlamentarischer Demokratie an informellen Konsultationen, geringer Formalisierung und wechselseitiger Rücksichtnahme der politischen Akteure orientiert. Die starke Exekutive ist durch einen sehr kooperativen und pragmatischen Politikstil gekennzeichnet.

In diesem Abschnitt werden Erklärungsversuche für die intensive Nutzung von CCTV-Systemen in Großbritannien unternommen, und zwar unter besonderer Berücksichtigung spezifischer Spielregeln sowie institutioneller Entscheidungsstrukturen in der britischen Politik. ${ }^{792}$

\subsection{Dominanz der Exekutive und Suprematie des Parlaments}

Der britische Regulierungsstil ist durch eine starke Exekutive gekennzeichnet. Für die Eingrenzung dieser Exekutivgewalt ist das Parlament, das als Repräsentativorgan gesellschaftlicher Interessen gilt, zuständig. In der institutionellen Entscheidungsstruktur des britischen Politiknetzwerks obliegt es der Zentralregierung, die Vorgaben dieses gesetzgebenden Staatsorgans auszuführen. Die Exekutive wird deshalb in der Suprematie der Legislative als „der regierende Ausschuss des Parlaments" verstanden. ${ }^{793}$ Das Parlament ist die höchste gesetzgebende Instanz und als "Hight Court of Parliament“ zugleich auch das höchste Gericht Großbritanniens. „Die Rechtfertigung dafür liegt darin, dass im Parlament das Volk in Gestalt seiner Repräsentanten über sich selbst richtet und demgemäß keine außerhalb des Volkes stehende Instanz anerkennt. “794

Wie in Deutschland und den USA hat das britische Parlament neben der klassischen Artikulations- und Repräsentations-, Rekrutierungs-, Gesetzgebungsfunktion auch die Aufgabe, die Exekutive zu kontrollieren. ${ }^{795}$ Die parlamentarische Kontrolle auf die Exekutive wird in Großbritannien vor allem vom britischen Unterhaus (House of

\footnotetext{
${ }^{791}$ Ebenda. Vgl. auch Döring (1993), S. 177.

${ }^{792}$ Großbritannien, das England, Schottland und Wales umfasst, bildet zusammen mit Nordirland, das von gewaltsamen Auseinandersetzungen zwischen Protestanten und Katholiken erschüttert wird, das Vereinigte Königreich („United Kingdom of Great Britain and Northern Ireland“). Es ist hierbei wichtig anzumerken, dass das, was in der folgenden Darstellung wahlweise als englische oder britische politische Kultur bezeichnet wird, sich tatsächlich nur auf England bezieht. Die übrigen Regionen werden ausgeklammert, weil es für eine präzisere und differenziertere Analyse der britischen politischen Kultur an entsprechenden empirischen Daten mangelt. Diese Konzentration auf die englische politische Kultur kann allenfalls mit der konstitutiven Bedeutung gerechtfertigt werden, die den englischen Verhältnissen für die Entwicklung Großbritanniens historisch und aktuell zukommt. Vgl. Rohe (1984), S. $163 \mathrm{ff}$.

${ }^{793}$ Münch (2000a), S. 307.

${ }^{794}$ Ebenda, S. 306.

${ }^{795}$ Kaiser (2004), S. 145.
} 
Commons) ausgeübt, das als Debattierkammer der Nation verstanden werden kann, wo Abgeordnete Bürgerbeschwerden vermitteln und die Minister in Fragestunden und Plenardebatten Rede und Antwort stehen müssen. Am 02. November 1999 wurde der Innenminister Charles Clarke im Unterhaus aufgefordert, Fragen zum Thema öffentlicher Videoüberwachung zu beantworten. Allerdings wurde dabei viel mehr auf die Notwendigkeit und Effektivität dieser Technik hingewiesen als auf die Erfordernis strikter gesetzlicher Regelungen dieser Maßnahmen. Lediglich der erwähnte „Code of Practice“ und die Registrierung der Anlagen beim Data Protection Commissioner (Information Commissioner) wurden als Kontrollinstanz auf die Frage zur Regulierung von CCTV-Überwachung angegeben. ${ }^{796}$

Die Kontrollfunktion des Parlaments gegenüber der Exekutive wurde nach der Ausschussreform vom Jahr 1979 verstärkt, wobei „Select Committees“ als zusätzliche Aufsichtskommissionen gegründet wurden. ${ }^{797}$ Diese Ausschüsse haben die Aufgabe, „,to examine the expenditure, administration and policy in the principal government departments (...) and associated public bodies“ ${ }^{798}$ Der zuständige Ausschuss für die Kontrolle von CCTV-Anwendung ist, wie bereits im Teil III dieser Arbeit erwähnt wurde, das House of Lord's Select Committee on Science and Technology. Anhand von Informationsberichten der Dienststelle - Parliamentary Office of Science and Technology - ist der Ausschuss berechtigt, in Anhörungen seine Kritik zur Videoüberwachung zu äußern. Allerdings findet dieser Ausschuss nach der vorangehenden Analyse wenig Gehör in der Politik über CCTV-Überwachung und seine Warnrufe bleiben ohne Konsequenzen. Somit ist die Effektivität dieser parlamentarischen Kontrolle über die intensive Anwendung von Überwachungskameras zweifelhaft. ${ }^{799}$

In der heutigen politischen Praxis wird die britische Exekutive zwar nach wie vor als der regierende Ausschuss des Parlaments gesehen und ist weiterhin von der Parlamentsmehrheit abhängig, aber angesichts der Zunahme von Regierungstätigkeiten hat sich die politische Macht der Exekutive wesentlich ausgeweitet. Mit einem einflussreichen Premierminister ist die Regierung durchaus in der Lage, auf die Entscheidungen im Parlament einzuwirken und die Dynamik der Politik zu bestimmen. ${ }^{800}$ Margaret Thatcher hat in ihrer Amtszeit angefangen, die politische Macht auf die Zentralregierung zu verlagern. Logische Konsequenz dieses Handelns ist der Machtverlust der Kommunen. Im Jahr 1986 wurden im Zuge dieses Regierungsstils

\footnotetext{
${ }^{796}$ Hansard (1999).

${ }^{797}$ Vgl hierzu Friedmann (1970), S. 176 ff.

${ }^{798}$ Kaiser (2004), S. 151; vgl. auch Döring (1993), S. 133, 153 ff.

${ }^{799} \mathrm{Vgl}$. hierzu Teil III dieser Arbeit.

${ }^{800}$ Münch (2000a), S. 307.
} 
sechs Regionalregierungen und in London gar die Stadtregierung aufgelöst. Somit ist London eine von den wenigen Großstädten weltweit, die vom Innenministerium direkt regiert wird ${ }^{801}$ Diese unmittelbare Verwaltung durch das Innenministerium begünstigt zweifelsohne den Einsatz der Überwachungsanlagen, z.B. am "Ring of Steel“ in der britischen Hauptstadt.

Auch John Mayor hat Anfang der 1990er Jahre die Strategie der dominanten Exekutive fortgeführt und die zwei Ebenen der Kommunalverwaltung in Schottland sowie in einigen Landkreisen in England auf eine Ebene reduziert. ${ }^{802}$ Vor diesem Hintergrund ist es wenig erstaunlich, dass die vom Innenministerium organisierten CCTVWettbewerbe unproblematisch durchgeführt werden konnten und das Verweigerungsrecht der Kommunalbehörden, CCTV-Systeme in ihrem Verwaltungsgebiet installieren zu lassen, abgeschafft wurde. Regionalverwaltungen und Kommunalbehörden haben in dieser parlamentarischen Demokratie mit einer starken Exekutive keine politischen Eigenrechte und handeln lediglich auf der Grundlage von parlamentarischen Einzelermächtigungen, die jeder Zeit widerrufen werden können. Diese politische Machtkonzentration wird damit begründet, dass das Parlament als Repräsentant der Bürger gesellschaftliche Interessen vermitteln soll, welche durch die Fragmentierung der Entscheidungsstruktur in Widersprüchlichkeit und lokale Machtkämpfe geraten können. ${ }^{803}$ Dieser Regierungsstil begünstigt das zentralisierte, mächtige Polizeiwesen, das sich in Großbritannien zur Kriminalitätsverhütung für den flächendeckenden Einsatz von Überwachungskameras einsetzt.

\subsection{Informelle Konsultationskultur und das "Old Boy's Network“"}

Das Policy-Netzwerk in Großbritannien ist durch Verhandlungen zwischen den politischen Akteuren mit wechselseitiger Anpassung und Achtung geprägt. Durch die Dominanz der Exekutive hat sich eine Vielzahl von Vorhöfen in abgestufter, verzweigter Form mit unterschiedlicher Einflussgröße um das politische Machtzentrum gebildet, in denen politische Informationen gesammelt, Erfahrungen ausgetauscht, Kompromissvorschläge erarbeitet und Wünsche aufeinander abgestimmt werden können. Einerseits kann dadurch eine Fülle von gesellschaftlichen Interessen in den Policy-Prozess mit einbezogen werden, andererseits können unreife Überlegungen sowie unausgewogene und extreme Lösungsstrategien von den primären Kräften der Politikgestaltung im politischen Zentrum ferngehalten werden. ${ }^{804}$ Um eine Ange-

\footnotetext{
${ }^{801}$ Wasser; Dingeldey (1996), S. 75 f.

${ }^{802}$ Ebenda, S. 76.

${ }^{803}$ Münch (2000a), S. 300.

${ }^{804}$ Ebenda, S. 298. 
legenheit in Großbritannien zum politisch relevanten Thema zu machen, muss sie also einen Art „Filter- und Abschleifungsprozess" in der politischen Peripherie durchlaufen. Die vom House of Lord's Select Committee on Science and Technology sowie dem Parliamentary Office of Science and Technology geäußerten Kritiken über den Umgang mit der Videoüberwachungstechnik und die Forderung nach mehr Rücksicht auf Bürgerrechte dürften in diesem Abschleifungsprozess an Bedeutung verloren haben. ${ }^{805}$

Sowohl die Kooperationen zwischen den staatsinternen Instanzen als auch die $\mathrm{Zu}-$ sammenarbeit mit den staatsexternen Interessengruppen, die zu diesem „Abschleifungsprozess“ gehören, basieren auf offener, vertrauensvoller Kommunikation. Diese „informelle Konsultation“ findet gewöhnlich in Kreisen politischer Akteure statt, die sich schon gut kennen. Der vertraute Umgang zwischen den Bekannten fördert die Offenheit der Artikulation eigener Positionen sowie den Respekt für andere Standpunkte, die letztlich eine Kompromisslösung im Verhandlungsprozess für alle Beteiligten begünstigt. Diesem Handlungsmuster entsprechend finden zwischen dem Information Commissioner und den CCTV-Betreibern sowie der Polizei in der Regel nur informelle Gespräche zur Ermahnung statt. Es kommt deswegen in der Praxis der Videoüberwachung in Großbritannien eine sanftere Ausformulierung ordnungsrechtlicher Verordnungen und Verbote zur Anwendung. Selten wird auf offiziellen Wegen heftige Kritik seitens des Information Commissioners geäußert.

Diese vertrauensvolle Konfliktlösungsstrategie erfolgt meistens unter Ausschluss der Öffentlichkeit, da deren Einmischung die Harmonie der informellen Konsultation und des bekannten Spielregelkomplexes stört und als Verrat an den Verhandlungspartnern betrachtet wird. Durch den Druck der Öffentlichkeit kann demnach die Flexibilität der Verhandlungen eingeschränkt werden, da ein öffentlich vertretener Standpunkt nur schwer ohne Blamage für den Betroffenen zurückgezogen werden kann. Es ist anzunehmen, dass die Mobilisierung der Öffentlichkeit sowie radikale Kritiken am Kameraeinsatz deswegen von den britischen Interessengruppen eher vermieden werden, natürlich unter der Voraussetzung, dass diese überhaupt durch den politischen Abschleifungsprozess bis zur informellen Beratungsrunde gelangen können und nicht schon im Vorfeld ignoriert werden.

Hinter den Kulissen der politischen Hauptbühne werden also Kompromisse geschlossen und Pläne für die Programmformulierung der Regierung vorbereitet. Durch die Praxis informeller Konsultation im Voraus entstehen in der Öffentlichkeit

\footnotetext{
${ }^{805}$ Vgl. hierzu Teil III dieser Arbeit.
} 
wenig überraschende Ergebnisse im Policy-Prozess und dementsprechend wenige Anlässe für einen offenen Rechtsstreit. ${ }^{806}$ Die Tradition informeller Konsultation mit Ausgrenzung der Öffentlichkeit ist mit der Rechtsgrundlage vom Office Secrets Act von 1889 zur Sicherung der Amtsgeheimnisse bis heute legitim. ${ }^{807}$

Diese Tradition der informellen Konsultationspraxis begünstigt die verworrenen Netzwerke der zuständigen Behörden für die Videoüberwachungsmaßnahmen in Großbritannien. Durch die Einmischung der privaten Akteure in der lokalen Sicherheitspolitik werden vor allem wirtschaftliche Interessen in den Vordergrund gestellt. Fyfe \& Bannister bezeichnen die unüberschaubare Gemeinschaftsarbeit zwischen den staatlichen und privaten Akteuren in der britischen CCTV-Politik als ein demokratisches Defizit (,democratic deficit“), da ",both the operational control and strategic management of the system are the responsibility of non-elected bodies“. ${ }^{408}$ Zwischen den Behörden und den privaten Akteuren aus Sicherheits- oder Wirtschaftsbereichen finden häufig informelle Treffen statt, bei denen auf lokaler Ebene die Ziele der Sicherheitspolitik und die Definition von „Kriminellen“ bestimmt werden. In der Untersuchung von Coleman \& Sim zur Videoüberwachung in Liverpool beschreibt ein Befragter die informelle Konsultationskultur in der lokalen Sicherheitspolitik wie folgt: „One of the biggest problems has been around consultation in Liverpool and the transparency of the process itself. The temptation is when you are setting something up you go and talk to somebody who you know will respond to your need. You take the easy way around. ${ }^{4809}$

Die Konstellationen politischer Protagonisten Großbritanniens sowie deren Einflussgröße auf das politische Geschehen lassen sich auf die „politische Kultur des Personalverbandes“ zurückführen. ${ }^{810}$ Nach Sidney Low bestimmt nicht der Glaube an Prinzipien oder Ideologien die britische Politik, sondern die Treue gegenüber Personen. ${ }^{811} \mathrm{Im}$ Gegensatz zum europäischen Kontinent, der nach dem römischen Recht die Idee einer durch Juristen interpretierten vereinheitlichten öffentlichen Gewalt entwickelt hat, blieb in England ein personenbezogener Politikstil erhalten. ${ }^{812}$ Die

\footnotetext{
${ }^{806}$ Münch (2000a), S. 299.

${ }^{807}$ Ebenda.

${ }^{808}$ Fyfe; Bannister (1996), S. 44; vgl. auch Coleman; Sim (1998), S. 41.

${ }^{809}$ Coleman; Sim (2000), S. 635 f.

${ }^{810}$ Rohe (1984), S. 173.

${ }^{811}$ Low (1908), S. 120 ff.; Döring (1999), S. 169.

${ }^{812}$ Nach Habermas war das mittelalterliche Verständnis repräsentativer Öffentlichkeit im demonstrativen Sinn an „Attribute der Person geknüpft: An Insignien (Abzeichen, Waffen), Habitus (Kleidung, Haartracht); Gestus (Grußform, Gebärde) und Rhetorik". Dieser Stil einer theatralischen Zurschaustellung von Herrschaft ist in Großbritannien zum großen Teil erhalten geblieben. Das Festhalten an historischen Symbolen und Formeln dient der Legitimation der gegenwärtigen politischen Ordnung mittels zeremonieller Beschwörung der Tradition. Habermas (1965), S. 17 f.; vgl. Döring (1999), S. 169.
} 
britische Regierung wird oft aufgrund dieser personalistischen Orientierung als club government (Regierung durch Amateure) bezeichnet.

Die Macht in Westminster ist durch die informelle Konsultatonskultur vorwiegend in den Händen der hochqualifizierten, „universal gebildeten Gentlemen“ konzentriert, deren Mehrheit in den als „Public Schools“ bezeichneten privaten Eliteschulen und den beiden Eliteuniversitäten Cambridge und Oxford ausgebildet wird. ${ }^{813}$ Diese elitäre Schul- und Universitätsausbildung sieht der Demokratietheoretiker Schumpeter als „wirksame Gewähr" für die Schaffung von Politikern von „hinreichend hoher Qualität“, da diese Eliten einer sozialen Schicht angehören, „die [...] sich der Politik als einer Selbstverständlichkeit zuwendet ${ }^{\prime 2}{ }^{814}$ Man erwartet, dass die Eigenschaften eines Gentlemans die Qualität eines Politikers hinsichtlich Zuverlässigkeit und Fähigkeit garantieren. Es bildet sich dadurch in der britischen politischen Landschaft eine Art "politische Familie“, die aus gemeinsamer Ausbildungsherkunft, Verwandtschaftsbeziehungen und aus den Netzwerken der verschiedenen „Clubs“ in London entstanden ist und elitäre politische Amateure hervorbringt. Dieses berühmte "old boy's network", das also auf Bekanntschaften aus der Jugendzeit beruht, erzeugt eine politische Kultur, die überwiegend von persönlichen Kontakten und Empfehlungen gelenkt wird und weniger auf der Grundlage rechtlicher Normen basiert. „Nach wie vor erfasste die alte Redensart, dass ein Minister schon wisse 'what is done and is not done by gentlemen' einige charakteristische Grundannahmen dieser personalistisch geprägten politischen Kultur. ${ }^{\text {} 815}$

Der britische Politikstil mit informeller Konsultationskultur unter den politischen Eliten war in Augen der ehemaligen Premierministerin Magaret Thatcher eine reformfeindliche Gestaltungsschwäche in der britischen Politik, die für die sog. „englische Krankheit" verantwortlich ist. Trotz ihrer Bemühungen, den Politikstil Großbritanniens von dieser Verhandlungskultur im Bekanntenkreis, die die allseits akzeptierte Grenze nicht überschreitet, zu befreien, kann man zumindest in der heutigen institutionellen Struktur der britischen CCTV-Politik dennoch diese alte Verhandlungstradition beobachten. Vor diesem Hintergrund kann ebenfalls angenommen werden, dass die positive Haltung politischer Eliten, wie z.B. John Major und Tony Blair, gegenüber CCTV die öffentliche Meinung in Großbritannien beeinflussen könnte. ${ }^{816}$ Trotz des politisch-kulturellen Wandels spielen also die alten Traditionen

\footnotetext{
${ }^{813}$ Döring (1999), S. 166.

${ }^{814}$ Dahrendorf (1965), Kap. 18.; Döring (1999), S. 166.

${ }^{815}$ Rohe (1984), S. 172 f.; Jowell; Witherspoon (1985), S. 28; Döring (1999), S. 166 f.; vgl. auch Birch (1990), S. $137 \mathrm{ff}$.

${ }^{816}$ Vgl. Teil III dieser Arbeit.
} 
weiterhin eine wesentliche Rolle in der britischen politischen Kultur, die die explosionsartige Ausweitung der Videoüberwachungstechnik begünstigt. Das gilt sowohl für den Gedanken, „,Regierung als trusteeship (als Treuhänderschaft) zu begreifen, die im Namen des Volkes und für das Volk, aber nicht durch das Volk ausgeübt wird, als auch für das liberale und individualistische Erbe“ ${ }^{1817}$ Insgesamt sind die Grundeigenschaften dieser Zivilkultur trotz der Umsetzung der Idee des Sozialstaates in ihren grundlegenden Bestandteilen nicht verändert worden. ${ }^{818}$

\subsection{Praxis der Praktikabilität}

Die politischen Verhandlungsforen in der britischen informellen Konsultationskultur basieren auf gegenseitigem Vertrauen und Anpassungsbereitschaft aller Beteiligten. Politische Akteure betrachten sich hierbei weniger als Gegner und Konkurrenten im Kampf um Durchsetzung eigener Interessen und Rechte, sondern viel mehr als Partner, die gemeinsam an einer für alle Parteien angemessenen Lösung interessiert sind. Für erfolgreiche Kompromissfindung gilt dabei das Grundprinzip der Praktikabilität. ${ }^{819} \mathrm{Um}$ die Vielzahl von Interessen und Standpunkten auf einen gemeinsamen Nenner zu bringen, sollen die Lösungsstrategien pragmatisch und am Einzelfall orientiert sein. Nicht die vorgegebenen Rechtsnormen oder ausformulierten Gesetzestexte, sondern die praktische Durchführbarkeit der Maßnahmen tragen zur Erhöhung der Erfolgschancen von Verhandlungsergebnissen bei. Das Endergebnis der Kompromissfindung soll eine konkrete, situationsabhängige, praktisch umsetzbare Lösung bieten. Diese Praxis der Praktikabilität gibt auch den britischen Behörden zur Einführung von Videoüberwachung einen großen Spielraum zur Erarbeitung institutioneller Regeln. Nicht die Ausformulierung der formalen Regelungen, sondern praxisorientierter "Code of Practice" dienen als allgemeine Richtlinien für die polizeilichen Maßnahmen der Videoaufzeichnung.

In Großbritannien existiert kein formalisiertes Rechtssystem, das auf einer geschriebenen Verfassung basiert. Das britische Common Law stützt sich dabei nicht auf Gesetzestexte, sondern auf richterliche Urteile aus der Vergangenheit und schließt eine "offensive und systematische Verrechtlichung und Prozeduralisierung" der Politik aus. ${ }^{820}$ Vor diesem Hintergrund scheinen strikte Verordnungen mit detailliert ausgearbeiteten Rechtseingrenzungen unpraktikabel. Um den situativen Gegebenheiten und vielfältigen Akteurkonstellationen gerecht zu werden, scheint ein konsultativer,

\footnotetext{
${ }^{817}$ Rohe (1984), S. 175.

${ }^{818}$ Ebenda, S. 177.

${ }^{819}$ Lahusen (2003), S. 157 f.; Münch (2000a), S. 300 ff.

${ }^{820}$ Lahusen (2003), S. 97.
} 
auf die konkrete Sachlage ausgerichteter Politikstil vorteilhaft. Hierfür genügen allgemeine Richtlinien wie der Code of Practice, der als roter Faden in den Verhandlungsverfahren dient, aber den Verhandlungsspielraum für die einzelfallorientierte Kompromissfindung nicht einschränkt. In Anbetracht dieser spezifischen politischkulturellen Rahmenbedingungen resultieren Normierungen und Standardsetzungen in der britischen Praxis der Videoüberwachung überwiegend aus den europäischen Vorgaben. Beispiele hierfür sind die britischen Datenschutzrichtlinien und der Human Rights Act.

\subsection{Politische Partizipation und Inaktivität}

Angesichts der vorherrschenden Machtverteilungen auf der britischen Politikbühne sowie der traditionellen Konsultationspraxis unter den Eliten hinter den Kulissen, bleiben nur wenige Nebenschauplätze für Interessengruppen übrig. Die Einmischung zivilgesellschaftlicher Akteure in der Vorbereitungsphase der politischen Entscheidungsfindung ist zwecks Interessenabstimmung nicht erwünscht. Dieses auf Vertrauen, Konsultation und Kompromiss ausgerichtete Politikmodell verfügt über eine "entradikalisierende Wirkung“ auf das gesamte politische Klima, das entweder zur Einbindung oder zur Ausgrenzung bestimmter Akteure führt. ${ }^{821}$ Das Politikfeld der inneren Sicherheit in Großbritannien wird überwiegend von staatlichen Akteuren dominiert, während die Bürgerrechtsgruppen mit kritischer Haltung gegenüber CCTV-Überwachung weder in der Politik noch in den Medien Beachtung finden. Angesichts der informellen Konsultationspraxis sowie der Dominanz der politischen Eliten ist der Mangel an kraftvollem Widerstand in Hinsicht auf die Ausweitung von Überwachungskameras wenig überraschend. Zwar werden durch die Tradition informeller Konsultation gesellschaftliche Interessen auch durch nichtstaatliche Organisationen und Großverbände vertreten, allerdings beschränken sie sich überwiegend auf bereichspezifische Themen in der Politik, die wenig mit Kameraeinsatz in der Öffentlichkeit im Zusammenhang stehen.

Die Bereitschaft der Bürger zur sozialen Mobilisierung bestimmt als grundlegende Voraussetzug die Machtposition der Interessengruppen in der Politik. Die Unterstützung seitens der Bürger begünstigt die Handlungsfähigkeit dieser zivilgesellschaftlichen Akteure. Um die schwache politische Position nichtstaatlicher Akteure in der britischen CCTV-Politik besser verstehen zu können, erscheint die Berücksichtigung der Partizipationsbereitschaft der britischen Bürger unerlässlich. Die zwei Schlüsselbegriffe "Deference" und "Civility" der Fünf-Nationen-Studie von Almond \& Verba

${ }^{821}$ Ebenda, S. 295. 
werden als Interpretationshilfe zum Verständnis der Inaktivität der Bürger herangezogen. ${ }^{822}$ Auch wenn diese inzwischen als überholt gelten und umstritten sind, können dennoch einige dieser Erkenntnisse den kennzeichnenden Grundzügen englischer Konstellationen politischer Akteure geeigneten Ausdruck verleihen ${ }^{823}$ Der Begriff "Deference“ wird als Respekt gegenüber Eliten und Institutionen definiert und bezeichnet ein ehrerbietiges Vertrauen der unteren sozialen Schicht gegenüber der oberen Schicht der britischen Gesellschaft. Demgegenüber beschreibt Civility politische Mäßigung und Zurückhaltung in der britischen Gesellschaft, welche die geringe Forderung nach politischer Partizipation bedingt. ${ }^{824}$ In vielen demokratischen Gesellschaften setzen sich die Bürger bei Bedrohungen der Interessen durch staatliche Gesetzesvorlagen in Form von Interessengruppen oder Bürgerinitiativen zur Wehr, um Einfluss auf die staatlichen Entscheidungsapparate auszuüben. Allerdings zeigt sich keine kontinuierliche politische Aufmerksamkeit unter den meisten britischen Bürgern, solange die Regierung ihre regulären Aufgaben erfüllt. ${ }^{825}$

Das Vertrauen, das die britische Bevölkerung ihrer Regierung entgegenbringt, sowie die niedrige Bereitschaft zur sozialen Bewegung sind in der Praxis der Videoüberwachung wieder zu erkennen. Diese Eigenschaften fördern neben dem bereits erwähnten konsultations- und kompromissorientierten Regulierungsstil die einvernehmliche und unbürokratische Lösung für die Sicherheitsprobleme der britischen Gegenwart. Mit dem gewohnten Vertrauen in die staatlichen Institutionen, dem Glauben an die Kamera als Wunderwaffe sowie der Forderung nach sozialer Homogenität und Ordnung sind die Menschen geneigt, weitere Überwachungsmaßnahmen mittels Videotechnik zu begrüßen. Damit wird der Handlungsspielraum der britischen Sicher-

\footnotetext{
${ }^{822}$ Almond; Verba (1963), S. 103 ff.

${ }^{823}$ Aufbauend auf den Untersuchungsergebnissen der Civic-Culture-Studie versuchte Rose im Jahr 1965 die britische politische Kultur unter Berücksichtigung historischer Ereignisse sowie in Wechselbeziehung mit wirtschaftlichen und politischen Institutionen erneut $\mathrm{zu}$ untersuchen und gelangte $\mathrm{zu}$ der Erkenntnis, dass es sich bei Großbritannien um eine "traditionally modern political culture" handelt. Vgl. Rose (1965), S. 83 ff. Nachdem Kavanagh im Jahr 1973 die Schattenseiten der britischen politischen Kultur herausgearbeitet hat, fasste er im Jahr 1980 die politisch-kulturellen Abweichungen zusammen, die sich seit der Civic-Culture-Studie von Almond \& Verba ergeben haben. Vgl. Kavanagh (1980), S. 124 ff. Kavanagh führt den Wandel der Civic-Culture auf veränderte Mentalitäten in der britischen Gesellschaft zurück. Einige Forscher sprechen in diesem Zusammenhang von der „britischen Krise“ bzw. „englischen Krankheit“ und versuchen so die traditionell tief verankerten Mängel und Entwicklungsprobleme der gegenwärtigen englischen Gesellschaft zu beschreiben. Vgl. hierzu Döring (1993), S. 87 ff.

${ }^{824}$ Trotz der Bemühungen einiger Forscher bleibt die Frage, ob die zwei Schlüsselbegriffe in der Fachliteratur deference und civility besondere Merkmale der britischen politischen Kultur sind, weiterhin umstritten. Kavanagh bezweifelt, dass deference sowohl im Sinne von political deference - Respekt gegenüber politischen Institutionen und Vertrauen in die überlegene Weisheit der Regierenden - als auch von social deference - politische Unterwürfigkeit gegenüber den etablierten gesellschaftlichen Eliten - ein typisch britisches Orientierungsmuster darstellt. Vgl. hierzu Rohe (1984), 169 f., 175 ff.; Döring (1993), S. 82 ff.

${ }^{825}$ Vgl. hierzu die Studie von Barnes; Kaase (1979).
} 
heitsbehörden erweitert und die Fortsetzung dieser kriminalpräventiven Sicherheitspolitik gesichert.

Unter "Civic Culture“ fassen Almond und Verba Eigenschaften eines normativen Idealtypus zusammen, der „die Partizipationsbereitschaft unter tatsächlichem Partizipationsverzicht“ bezeichnet. ${ }^{826}$ Als Anhänger der "Theorie demokratischer Elitenherrschaft" plädieren sie dafür, dass die politischen Akteure um die Stimmen einer eher passiven Wählerschaft, die nur bei Bedrohung ihrer Freiheitsrechte politisch aktiv wird, konkurrieren. ${ }^{827}$ "So sollte einer starken Regierung freie Hand unter dem Vorbehalt spontaner Organisation der Bürger bei Amtsmissbrauch gegeben werden. ${ }^{428}$ Die britische CCTV-Politik scheint diesem Idealtypus gerecht zu werden, da das britische Innenministerium die CCTV-Maßnahmen ungehemmt und ohne Einmischung der Öffentlichkeit sowohl finanziell als auch politisch großzügig unterstützen kann.

Die Political-Action-Studie über acht Nationen von Barnes und Kaase im Jahr 1979 zeigte ferner, dass die Zahl der politischen „Inaktivisten“ in einer „so traditionsreichen Demokratie wie England" erstaunlich hoch war. Damit sind diejenigen gemeint, die gelegentlich im Freundes- und Bekanntenkreis über den Wahlkampf sprechen, über politische Themen in der Zeitung lesen und sonst nur die „konventionelle Partizipation“ durch Stimmabgabe bei der Wahl ausüben. ${ }^{829}$ Es kann in Bezug auf den CCTV-Diskurs in Großbritannien behauptet werden, dass die Mehrheit der britischen Bürger sowie der Bürgerrechtsvertretungen zwar an ihre demokratischen Partizipationsrechte glauben, aber die regelmäßige Ausübung dieser Rechte nicht wahrnehmen. Zusammen mit der vorherrschenden Haltung des ehrerbietigen Respekts (,deference“) gegenüber sozialen und politischen Autoritäten begünstigt die Inaktivität der zivilgesellschaftlichen Akteure die weltweit höchste Dichte von Videoüberwachung in Großbritannien.

\subsection{Zusammenfassung}

Der britische Policy-Prozess erfolgt überwiegend nach den informellen Regeln der Konsultationen und Verhandlungsforen sowie vertrauensvoller Absprache von praktikablen Maßnahmen unter den staatlichen Akteuren. Trotz des Fehlens eines homogenen, systematischen Rechtsschutzes der Bürger und der vergleichsweise ausge-

\footnotetext{
${ }^{826}$ Almond; Verba (1963). S. 481 ff.; Döring (1993), S. 81 ff.; Kaase (1982), 173 ff.

${ }^{827}$ Ebenda.

${ }^{828}$ Ebenda.

${ }^{829}$ Barnes; Kaase (1979); Döring (1999), S. 174; vgl. auch Döring (1993), S. 82.; vgl. auch Kaase (1982), S. 181.
} 
prägten Dominanz der Exekutive sind die britischen Bürger dennoch durch parlamentarische Kontrolle der Verwaltungsinstanzen vor staatlicher Willkür geschützt. Im Parlament, das als „Reflexionsorgan der ganzen Gesellschaft ${ }^{\text {“830 }}$ gesehen wird, werden unter Augen der Öffentlichkeit gesellschaftliche Interessen artikuliert und Regierungsgeschäfte gelenkt und kontrolliert. Allerdings gewinnt die Regierung zunehmend an Einfluss, so dass die parlamentarische Kontrolle über die Anwendung von CCTV-Anlagen in den Hintergrund gedrängt wird. Das vorherrschende Common Law begünstigt zudem allgemein geltende Richtlinien wie z.B. der "Code of Practice" als Regel für den öffentlichen Kameraeinsatz. Allerdings werden solche Richtlinien in Großbritannien nicht in den Rechtsbildungsprozessen weiter konkretisiert und deren Missachtung bringt meistens keine rechtlichen Konsequenzen mit sich.

Dieser Politikstil vermeidet Radikalisierung und stellt Mäßigung, Angemessenheit und gegenseitige Anpassung in den Vordergrund, wobei die institutionellen Entscheidungsprozesse der CCTV-Politik überwiegend unter den politischen Eliten stattfinden. Kritische Stimmen zivilgesellschaftlich-politischer Vereinigungen über die flächendeckende Videoüberwachung in Großbritannien werden in den politischen Vorhöfen mehrfach abgeschliffen und gedämpft und erreichen im Allgemeinen nicht das politische Zentrum der tatsächlichen Politikgestaltung. Weitere politisch-kulturelle Merkmale wie Deference und Civility begünstigen zudem diese traditionellen Konstellationen politischer Akteure, die ohne gesetzliche Einschränkungen und einflussreiche Partizipation organisierter Interessenvertretungen ungehindert die weiträumige Observierung der Städte vorantreiben können.

${ }^{830}$ Münch (2000a), S. 308. 


\section{Gesamtbeurteilung}

Die letzten Kapitel haben deutlich gezeigt, dass länderspezifische Politikstile und politisch-administrative Besonderheiten für die unterschiedliche Rolle politischer Akteure und somit auch für die unterschiedliche Politikgestaltung des öffentlichen Kameraeinsatzes ausschlaggebend sind. Im Folgenden werden die wichtigsten Merkmale der drei Kulturen - Deutschland, den USA und Großbritannien - miteinander verglichen.

\subsection{Politikstile im Vergleich}

Die parlamentarische Westminster-Demokratie in Großbritannien sowie die Repräsentativdemokratie mit ausgeprägter Tradition der Staatszentriertheit in Deutschland sichern der Exekutive in den beiden Ländern eine bedeutendere Einflussnahme in der Politikgestaltung zu als in den USA. In der Tradition der Volkssouveränität ist eine Dezentralisierung der politischen Gewalten kennzeichnend für den Politikstil der Vereinigten Staaten. Vor diesem Hintergrund werden auch die rechtlichen Regelungen über die Videoüberwachung auf die kommunale Ebene übertragen. Amerikanische Gemeinden verfügen deshalb über mehr Entscheidungsbefugnisse, selbstständig über Videoüberwachungsmaßnahmen zu entscheiden, während in den beiden anderen Ländern, vor allem in Großbritannien, der öffentliche Kameraeinsatz tendenziell zentral gelenkt wird. Den britischen Kommunen wurde gar das Recht, lokale Installationen von Kameras zu verbieten, verweigert. Dieser strukturelle Aufbau des politischen Systems der USA verleiht den regionalen Akteuren eine besondere Machtposition in der institutionellen Entscheidungsstruktur, die in der Idee des Systems der Checks und Balances verankert ist. ${ }^{831}$

Trotz der Gemeinsamkeit eines starken Staates unterscheidet sich, vor allem in der CCTV-Politik, das deutsche Politikmodell wesentlich von dem Großbritanniens: Manche staatlichen Befürworter der Videoüberwachungsprojekte in Deutschland äußern aus Rücksicht auf die rechtsstaatlichen Grundprinzipien, welche insbesonde-

\footnotetext{
${ }^{831}$ Jürgend Gerhards und Dieter Rucht haben im Vergleich zwischen den USA und Deutschland feststellen können, dass in Bezug auf die Frage der Abtreibung in den USA die zivilgesellschaftlichen Akteure in öffentlichen Debatten überrepräsentiert sind, während in Deutschland diese hauptsächlich von staatlichen Akteuren beherrscht werden. Es wurde erkennbar, dass die Parteien in Deutschland sechsmal so häufig als Wortführer in den Medien auftreten wie ihre amerikanischen Kollegen und die deutsche Legislative eine doppelt so hohe Medienpräsenz hat wie die in den USA. Zwar konnten die Forscher keine eindeutige Erklärung für diese Ergebnisse liefern, aber es wird vermutet, dass dies auf eine staatszentrierte öffentliche Debatte in Deutschland und einen von den Bürgerrechtlern dominierten Diskurs in den USA zurückzuführen ist. Diese Hypothese liefert wertvolle Informationen zu den politisch-kulturellen Besonderheiten dieser zwei Länder, die zur Erklärung der politischen Rangordnung der Akteure beitragen können. Vgl. Gerhards; Rucht (2000), S. 169 f.
} 
re durch die NS-Erfahrungen an Bedeutsamkeit gewonnen haben, gewisse Vorbehalte gegenüber einem breiten Einsatz der Kameras. Dagegen scheint die Tradition informeller Konsultationspraxis in Großbritannien für allgemein gesehen einheitliche Zustimmung für die öffentliche Videografie zu begünstigen. In der Tat ist die klassische Idee der Kompromissbildung im britischen „Verhandlungsnetzwerk“ ausschlaggebend. Denn politische Entscheidungen müssen nicht nur unterschiedliche Interessen und Rechte berücksichtigen, sondern auch den gegebenen Umständen entsprechend praktikabel sein. Trotz ihrer gesellschaftlichen Verankerung ist die Handlungsweise der britischen Regierung insgesamt unübersichtlicher und ad-hocorientierter als die vorherrschende politisch-administrative Kultur der Bundesrepublik. Dadurch ist das politische System Englands flexibler und genießt das Gesellschaftsvertrauen sowie wechselseitige Anpassung und Respekt der politischen Akteure, welche ein rasches, unbürokratisches, einvernehmliches Genehmigungsverfahren für Videobeobachtungsmaßnahmen ermöglichen.

Die Aufgabe der deutschen Politik besteht darin, eine rechtsstaatliche Lösung für gesellschaftliche Konflikte wie die vorhandenen Kriminalitätsprobleme zu finden. CCTV-Überwachung gilt dabei als eine mögliche Option zur Gefahrenabwehr. Die Entscheidungsfindung in der deutschen Politik ist gekennzeichnet durch eine formalisierte, bürokratische Vorgehensweise, die im Gegensatz zum britischen Modell einer schnellen Umgestaltung der Sicherheitspolitik (d.h. weiträumige Videoüberwachung) im Wege steht. Entsprechend bezeichnet Katzenstein die Bundesrepublik als „semi-souveränen Staat" mit gebändigter, gemäßigter Staatsgewalt. ${ }^{832}$ Die Ausweitung von Überwachungskameras wird demnach durch die Absicherung von Rechtsgrundlagen stark eingeschränkt. Vor diesem Hintergrund ist eine intensive Nutzung von diesem Überwachungsinstrument nach dem britischen Vorbild nicht ausführbar und auch nicht erwünscht. Im Gegensatz zur Kompromissfindung der britischen administrativen Kultur geht es im deutschen Sachdiskurs um die Wahrheitsfindung. Die Politikgestaltung in den Vereinigten Staaten ist wettbewerbsreicher als in den Vergleichsländern und führt deswegen zu einem Prozess des "joint decision making“ bei Entscheidungen über die Implementierung von Videoüberwachungsanlagen. Durch die Partizipation politischer Akteure aus unterschiedlichen Gesellschaftsbereichen und -ebenen werden möglichst viele Interessen und Rechte berücksichtigt, wobei ein faires Verhandlungsverfahren die Chancengleichheit aller Beteiligten sichern

${ }^{832}$ Schmidt (1992), S. 185; vgl. auch Katzenstein (1987). 
sollte. ${ }^{833}$ Bei dem konfrontativen Politikstil der USA ist die Politikentwicklung in der Praxis öffentlicher Videografie deswegen insgesamt fragmentierter, offener und vielfältiger, aber auch unübersichtlicher und unkoordinierter.

Diese strukturellen Unterschiede der politischen Systeme führen zu verschiedenen Machtbefugnissen der Akteure im Politikfeld der Videoüberwachung und somit auch zu Unterschieden in ihrem Engagement.

\subsection{Rechtssystem im Vergleich}

Das Recht dient in Deutschland als Instrument einer sachlich-rational orientierten Politikgestaltung. Die Verrechtlichung der deutschen Politik, insbesondere die Genehmigungsverfahren zur öffentlicher Videoüberwachung, hebt sich deutlich von den beiden anglophonen Ländern ab: Während in Deutschland Konflikte zwischen den Freiheiten der Einzelnen durch allgemeine Gesetze gelöst werden und nach einem übergeordneten System genereller Normen (staatlicher Gesetzgebung) gesucht wird, dominiert in den USA und Großbritannien die einzelfallorientierte Tradition des „Common Law“. Konflikte in den angelsächsischen Ländern werden meistens individuell und situativ zwischen den Individuen von Fall zu Fall verschieden reguliert. Allerdings unterscheiden sich die Strukturmerkmale und Orientierungsmuster in diesen beiden angelsächsischen Ländern voneinander: $\mathrm{Zu}$ dem amerikanischen System des Checks and Balances gehört vor allem die gerichtliche Kontrolle, um die partikularen Abstimmungen unter den Beteiligten durch wettbewerbsreiche Auseinandersetzungen zu ermöglichen. Dagegen sind konfrontative Rechtsstreitigkeiten unter den politischen Akteuren in Großbritannien durch die informellen, genehmigungsrelevanten Vorverhandlungen in der Politikentwicklung eher selten.

Das Recht in der Bundesrepublik basiert auf der Zusammenarbeit von Juristen und Gesetzgebern und ist somit ein Resultat akademischer Theorien oder ein Ausdruck gesetzgeberischen Willens. Die deutsche Rechtskultur ist historisch gesehen also akademisch-legislativ geprägt und gekennzeichnet durch umfassende Theorien, abstrakte Regeln und strenge Befolgung obrigkeitlicher Befehle. Das deutsche Recht betont die Formulierung, Auslegung und Anwendung autoritativer Gesetzestexte sowie die sachliche, fachliche und juristische Richtigkeit der Problemlösungen. ${ }^{834}$ Vor diesem Hintergrund ist es einleuchtend, dass im Gegensatz zu Großbritannien und den USA Regelungen in der StPO und in den Datenschutzgesetzen (BDSG) sowie Spezialregelungen zur Videoüberwachung im Polizeirecht in Deutschland notwen-

\footnotetext{
${ }^{833}$ Lahusen (2003), S. 161; Münch (1986b), S. 205 ff. und Münch (2000a), S. 370 ff.

${ }^{834}$ Reimann (2003), S. 25 ff.
} 
dig sind, damit der Einsatz der Videotechnik in öffentlichen Räumen schon im Voraus reguliert werden kann. Der deutschen Rechtskultur entsprechend möchte der Gesetzgeber die Videoüberwachung schon im Gesetz möglichst umfassend regeln, indem beispielsweise das Vorliegen eines Kriminalitätsschwerpunktes als notwendige Voraussetzung für die Implementierung von Überwachungskameras in öffentlichen Räumen gilt. Die Konkretisierung von Anwendungsregelungen wird von Expertengremien als ein reines Sachproblem behandelt und möglichst nicht einem offenen Wettbewerb zwischen unterschiedlichen Interessen überlassen. Es geht in der deutschen Videoüberwachungsfrage letztlich weniger um die Berücksichtigung der relevanten Interessen als vielmehr um die inhaltliche Richtigkeit der Entscheidungen nach dem Wortlaut des Gesetzes, welche die verrechtliche, vorsichtigere und somit zögerliche Videoüberwachungspraxis begründet.

Im Gegensatz zum deutschen Rechtssystem ist das angloamerikanische Recht ein Produkt der Kooperation zwischen Anwälten und Richtern im Prozess. Es geht hierbei um die praktische Anwendung der Gesetze im Urteil und in den Begründungen. Es existiert keine einheitliche Rechtsprechung und die Richter haben eine keiner anderen Nation vergleichbare Machtposition im Rechtssystem und verstehen sich weniger als Staatsdiener, sondern vielmehr als Beschützer der bürgerlichen Freiheiten und als Gegengewicht zur politischen Macht. Das amerikanische Recht stellt also ein lose geformtes Bündel von Richtlinien, Beweisführungen und Urteilen dar, die vor allem in der Einzelfallentscheidung anschaulich werden. ${ }^{835}$ Die Regelungen über die öffentliche Videoüberwachung werden dementsprechend durch kontinuierliche Neudefinitionen des situativen Interessenspektrums bestimmt, welche die Vielfältigkeiten in Nutzung von Überwachungskameras in der Öffentlichkeit rechtfertigen.

In Großbritannien existiert kein auf einer Verfassung begründetes Rechtssystem. Im Gegensatz zu den USA, wo das offene Partizipationsrecht Chancengleichheit garantiert, und zu Deutschland, wo Rechtssicherheit durch institutionelle Zuständigkeiten gewährleistet ist, gibt es im Vereinigten Königreich ein komplexes System von informeller Konsultationskultur zwischen den staatlichen Akteuren und den wirtschaftlichen Verbänden. Trotz der formalen Vorgaben von EUDatenschutzrichtlinien existiert im britischen Rechtssystem bis heute keine Rechtsgrundlage für die öffentliche Videoüberwachung. Dies liegt darin begründet, dass es in britischen Kompromissnetzwerken weder um die maximale Einbeziehung der Interessen noch um die sachlich korrekte, ordnungsrechtlich abgestützte Lösungsfor-

${ }^{835}$ Ebenda. 
mel geht, sondern um die Einbettung des Partikularen in die Tradition der fairen, praktikablen Entscheidungsfindung. Die Vorliebe für allgemein gehaltene Prinzipien und unbestimmte Rechtsbegriffe, die einen großen Spielraum für die britische Praxis der Videoüberwachung zulassen und die Genehmigungsverfahren zur Einführung dieser Technik unbürokratisch beschleunigen, führt zu der weltweit höchsten Kameradichte in Großbritannien.

\subsection{Bürgerengagement im Vergleich}

Geprägt von den Leitideen der Wettbewerbsdemokratie geht es in der amerikanischen Politikgestaltung vor allem um den fairen und offenen Kampf von möglichst vielen gesellschaftlichen Akteuren. Im Gegensatz zu dem deutschen und dem britischen Diskurs über die Videoüberwachung im öffentlichen Raum genießen in den USA nicht nur die staatlichen, sondern auch die zivilgesellschaftlichen Akteure die gleiche Chance, ihre Interessen und Rechte öffentlich zu vertreten. Dagegen dominieren in Deutschland die sachlich orientierten Expertengremien, während in Großbritannien aufgrund des Respekts vor traditionellen Autoritäten die gesellschaftlichen Eliten und Spitzenpolitiker über die CCTV-Politik herrschen. In der klaren Verteilung in „elitäre Gesetzesmacher" und "Gesetze befolgende Normalbürger" haben die zivilgesellschaftlichen Interessenvertretungen in diesen zwei Ländern kaum die Möglichkeit in den „wirksamen Bereich“ der CCTV-Politik zu gelangen, geschweige denn gesellschaftliche Anliegen zu artikulieren oder Einflussnahme auf die Dynamik der Entscheidungsfindung auszuüben. Zwar werden in Deutschland und Großbritannien auch die politischen Staatsorgane durch nichtstaatliche Organisationen für bestimmte Anliegen sensibilisiert, allerdings sind solche politische Themen überwiegend auf Bereiche der Ökologie, Arbeitsverhältnisse und Friedensbewegungen beschränkt. In Einklang mit der Idee der freiheitlichen Wettbewerbsdemokratie werden in den USA vergleichsweise mehr bürgerrechtliche Interessen vertreten.

Je umfassender die Ressourcen einer Organisation für die Öffentlichkeitsarbeit sind und je mehr Bedeutung diese der Öffentlichkeitsarbeit beimisst, desto wahrscheinlicher kann sie höchste öffentliche Aufmerksamkeit für sich verbuchen und mehr Einflusspotential in der Politik gewinnen. Die zivilen Interessensvertretungen sind in Hinblick auf die lange Tradition der Bürgerrechtsbewegungen in der amerikanischen Gesellschaft wesentlich ausgeprägter als in der Bundesrepublik und Großbritannien. Diese Überlegenheit der amerikanischen (lokalen) Bürgerrechtsgruppen und ehrenamtlichen Vereinigungen zeigt sich ebenfalls in der Gestaltung der Politik zum Kameraeinsatz. Im Vergleich zu den Bürgerrechtsorganisationen in den zwei europäi- 
schen Ländern sind sie insgesamt aktiver und einflussreicher. ${ }^{836}$ Auch Tocqueville hat die weite Verbreitung und große Anzahl von Interessengruppen, Vereinigungen und Organisationen als eines der besonderen Merkmale der amerikanischen Kultur beobachtet, in der die Idee der politischen Selbstorganisation fundamental ist. ${ }^{837} \mathrm{In}$ der Tat bestätigt die American Civil Liberties Union (ACLU) durch ihre umfangreiche Öffentlichkeitsarbeit, Vielzahl von landesweiten Dienststellen und klar aufgeteilte Organisationsstruktur sowie mehr Professionalität und auch mehr Einflussnahme in Bürgerrechtsfragen diese amerikanische Philosophie sozialer Mobilisierung.

Um die nationalen Diskrepanzen bezüglich Bürgerengagement besser verstehen zu können, sollte man zudem die Tatsache vor Augen führen, dass in der amerikanischen Gesellschaft mehr Misstrauen und Skepsis gegenüber dem Staat herrscht als in den anderen zwei Vergleichsländern. ${ }^{838}$ Angesichts der staatlichen Verfolgung bestimmter Religionsangehöriger wird in der amerikanischen Verfassung den Prinzipien der Freiheit und der Autonomie besondere Bedeutung beigemessen. Die Selbstorganisation ihrer Bürger sowie eine skeptische Grundhaltung gegenüber einem starken Staat sichern die Grundsteine dieser Prinzipien. Angesichts dieser amerikanischen Tradition, bei der die zivilgesellschaftlichen Akteure einen dominanten Rang im politischen Diskurs haben, ist es evident, dass die aktiven und gut organisierten Bürgerrechtsgruppen genügend Gegenkräfte zu einer maßlosen Ausweitung der optischen Überwachungsanlagen in der Öffentlichkeit bieten. Sie reagieren mit öffentlicher Kritik und professioneller Beratung auf die gesetzlichen „Lücken“ in den Regelungen zur Videoüberwachung, um als nichtstaatliche Kontrollinstanzen über den Kameraeinsatz mitzuwirken.

\subsection{Fazit}

Durch die Vergleiche von Politikstil, Rechtssystem sowie Bürgerengagement in den drei Ländern konnten politisch-administrative sowie soziokulturelle Hintergründe der unterschiedlichen Nutzungsintensität von Überwachungskameras in Großbritannien, Deutschland und den USA aufgezeigt werden.

Der durch Eliten geprägte, wenig partizipierende Politikstil sowie die Tradition informeller Konsultationsforen Großbritanniens begünstigen die Genehmigungsverfahren zur Installation von CCTV-Systemen und ermöglichen somit die welthöchste Kameradichte auf den britischen Inseln. Trotz der gemeinsamen Tradition des

\footnotetext{
${ }^{836}$ Vgl. Gerhards; Rucht (2000), S. 176.

${ }^{837}$ Gerhards (2000), S. 9; Lipset (1996), 278 f.

${ }^{838}$ Reimann (2003), S. $31 \mathrm{f}$.
} 
Common Law, bei der das Gesetz erst im Prozess der Einbeziehung von Interessen mit konkretem Inhalt ausgestattet wird, kann die Vielzahl an US-amerikanischen Bürgerinitiativen und Organisationen auf lokaler Ebene im Gegensatz zu Großbritannien einen Ausgleich zur Nutzungsintensität von dieser optischen Überwachungstechnik schaffen. Somit ist der Kameraeinsatz in den USA trotz regionaler Heterogenität insgesamt zurückhaltender als in Großbritannien. Die Verbreitung von Überwachungskameras in öffentlichen Räumen der USA, die umfangreicher ist als in der Bundesrepublik, ist letztlich ein Ergebnis von Verhandlungsprozessen zwischen den Bürgerrechtsorganisationen und den Protagonisten der Sicherheitspolitik. Auch wenn der deutsche Staat, wie die britische Exekutive, eine dominierende Rolle in der Politik zur CCTV-Einführung hat, so können die deutschen staatlichen Akteure das Tempo und das Ausmaß der Videoüberwachungstätigkeiten durch Rechtsverordnungen und Verwaltungsvorschriften zügeln. Vor diesem Hintergrund ist es wenig überraschend, dass Deutschland im Vergleich zu den beiden anderen Vergleichsländern die geringste Kameradichte aufweist.

Neben dem Mangel an Gegenkräften erhalten die lokalen Verwaltungsstellen in Großbritannien zudem von der Zentralregierung starke Unterstützung beim Aufbau von CCTV-Systemen in ihren Innenstädten, während ihnen gleichzeitig das Recht entzogen wird, Anträge für Videokamerainstallationen in ihren Zuständigkeitsbereichen abzulehnen. ${ }^{839}$

Vereinfacht lässt sich die britische Situation der Videoüberwachung wie folgt zusammenfassen: Nicht nur das Fehlen an politisch-administrativ bedingten Gegenkräften, sondern auch die ad-hoc orientierte, flexible, informelle Konsultationskultur, das Streben nach praktikablen Lösungen sowie eine unbürokratische Verwaltungskultur und die Präferenz für allgemeine und unscharfe Prinzipien tragen dazu bei, dass sich in Großbritannien die CCTV-Überwachung uneingeschränkt auf öffentlichen Straßen und Plätzen ausbreiten kann. Vor diesem Hintergrund ist es wenig überraschend, dass Großbritannien mittlerweile die höchste Kameradichte der Welt aufweist.

Der Historiker A. J. P. Taylor beschreibt das viktorianische Großbritannien als ein Land der uneingeschränkten individuellen Freiheiten: „Einem vernünftigen, gesetzestreuen Bürger war es möglich, durchs Leben zu gehen und dabei, abgesehen vom Postamt und dem Schutzmann, die Existenz des Staates kaum wahrzunehmen. Er konnte leben, wo er wollte und wie er wollte. Er hatte keine offizielle Nummer und

${ }^{839}$ Vgl den erwähnten Fall in Birmingham im Teil I, Kap. 3.3.2 und Teil III, Kap. 10.3. 
keinen Ausweis. ${ }^{\prime 840} \mathrm{Ob}$ dieses Merkmal der Zivilkultur die britische Gesellschaft der Gegenwart noch zutreffend beschreibt, ist, angesichts der Tatsache, dass die britischen Bürger bereits die am stärksten videoüberwachten Staatsbürger der Welt sind, fraglich.

${ }^{840}$ Süddeutsche Zeitung (2004a). 


\section{Teil V: Zusammenfassung}

Die Anwendungsintensität von CCTV-Anlagen ist in Großbritannien enorm. Trotz der zunehmenden Verbreitung dieser Technik auf internationaler Ebene sind die „britischen Verhältnisse“ der öffentlichen Videoüberwachung weltweit einzigartig. Ziel der vorliegenden Arbeit war, den möglichen Ursachen für diesen „britischen Sonderweg" auf den Grund zu gehen.

Insgesamt ist in den vergangenen Jahren ein struktureller Wandel der Sicherheitskonzepte vom reaktiven hin zum präventiven, proaktiven Handlungsmuster in den drei Nationen zu beobachten. Diese Verlagerung des kriminalpolitischen Schwerpunktes begünstigt die Ausweitung der Überwachungskameras in öffentlichen Räumen als Instrumente zur vorbeugenden Verbrechensbekämpfung und Gefahrenabwehr. Trotz des skizzierten, allgemeinen Trends in der internationalen Sicherheitspolitik sind länderspezifische Unterschiede in Bezug auf die Nutzungsintensität von Videoüberwachung unverkennbar. Es konnte im Vergleich mit den Daten aus den USA und der Bundesrepublik Deutschland festgestellt werden, dass die weit verbreiteten Begründungen, z.B. die erhebliche Kriminalitätsrate und/oder hohe Kriminalitätsfurcht sowie die starke Unterstützung seitens der Bevölkerung in Großbritannien, keine ausreichenden Erklärungen für die übermäßige Nutzung bieten.

In dieser Arbeit wird die These aufgestellt, dass die komplexen Akteursnetzwerke in der Sicherheitspolitik für die Einführung öffentlicher Videoüberwachung ausschlaggebend sind. Anhand funktionsspezifischer Kategorisierung der beteiligten Akteure sowie der Bewertung von deren Tätigkeiten wurden die Handlungszusammenhänge in der CCTV-Politik in den drei Vergleichsländern spezifiziert. In politischen Machtkämpfen entscheiden zahlreiche staatliche und zivilgesellschaftliche Interessenvertreter über das Tempo und Ausmaß des öffentlichen Kameraeinsatzes. Diejenigen Repräsentanten, die Sicherheitsfragen und Kriminalitätsproblematik in den politischen Mittelpunkt stellen und in Überwachungskameras ein geeignetes Mittel zur Problemlösung sehen, stellen die treibenden Kräfte für die Videoüberwachungsmaßnahmen dar. Demgegenüber versuchen diejenigen Akteure, die in der CCTVÜberwachung eine Gefahr für die elementaren Grundrechte der Bürger in einer rechtsstaatlichen Demokratie sehen, die Expansion öffentlicher Videografie und aufzeichnung zum Schutz der demokratisch-freiheitlichen Prinzipien einzuschränken. Es konnte in der vorliegenden Arbeit gezeigt werden, dass letztlich die Führungsrolle der Akteure in der Sicherheitspolitik sowie ihre Einflussnahme und Tätig- 
keiten in diesem Politikfeld entscheidend sind für das gesamte Klima in der Kriminalpolitik und somit auch für den Kameraeinsatz auf öffentlichen Straßen und Plätzen als Lösungsstrategie für Kriminalitätsprobleme.

Durch die Betrachtung der Rolle und der Einflussgröße der proaktiven Akteure sowie der staatsinternen und der staatsexternen Kontrollinstanzen in den drei Vergleichsländern kann bestätigt werden, dass deutliche länderspezifische Differenzen zwischen den Machtpositionen der untersuchten Institutionen innerhalb der Sicherheitspolitik und den damit verbundenen Entscheidungsfindungen zur Einführung von CCTV-Systemen bestehen:

Obwohl Großbritannien und Deutschland den Europäischen Datenschutzrichtlinien unterworfen sind, bestehen dennoch in der Bundesrepublik im Gegensatz zum Vereinigten Königreich spezielle Regelungen zur öffentlichen Videoüberwachung im novellierten Bundesdatenschutzgesetz, die als verbindliche Rahmenbedingungen für die polizeiliche Praxis der Videoüberwachung dienen. Zudem wird die staatsinterne Kontrolle durch Vorbehalte seitens der Polizeibehörde und aktive Kontrolltätigkeiten der Datenschutzbeauftragten verstärkt. Dies erklärt den insgesamt vorsichtigen Umgang mit der Videotechnik zum Zweck der räumlichen Überwachung.

Die USA und Großbritannien gehören zum angelsächsischen Kulturkreis, in dem im Gegensatz zu Deutschland das Rechtssystem des Common Law herrscht. In einem solchen Rechtssystem werden Regelungen erst im Laufe des Rechtsbildungsprozesses konkretisiert, wobei die Rechtsprechung zum großen Teil auf früheren Gerichtsentscheidungen basiert. Dagegen werden im kontinentalen Rechtssystem der Bundesrepublik viele Regelungen im Vorfeld festgelegt. Die rechtliche Regulierung zum öffentlichen Kameraeinsatz in den USA hängt vor diesem Hintergrund stark von den Definitionen von „Privacy“ in den einzelnen Bundesstaaten ab. Der Mangel im normativen Bereich kann gemäß der vorliegenden Untersuchung durch die aktiven und gut organisierten Bürgerrechtsgruppen kompensiert werden. Sie verfügen in der (lokalen) Sicherheitspolitik über eine gleichrangige Machtposition wie die staatlichen Akteure und üben eine ähnliche Funktion aus wie die Datenschutzbeauftragten in Deutschland. Aufgrund der Aktionen solcher Initiativen, die auf die gesetzlichen Lücken zur Regelung der Videoüberwachung reagieren, wird die Verbreitung von Überwachungskameras trotz zunehmender Tendenz eingeschränkt.

Im Vergleich zu den anderen zwei untersuchten Ländern sind die proaktiven Akteure in Großbritannien, die sich für die Einführung der Videoüberwachung einsetzen, den wenigen Skeptikern eindeutig überlegen. Sie genießen mehr politische Autono- 
mie als ihre Kollegen in den USA und Deutschland. Zudem fehlen in Großbritannien - bis auf die Registrierungspflicht der CCTV-Anlagen - nicht nur jegliche rechtliche Regelungen für die Einführung von Videoüberwachung, sondern auch kraftvoller Widerstand von Seiten der staatsexternen Akteure, die die Entwicklung von Videoüberwachungsmaßnahmen zügeln können. Die Dominanz der proaktiven Akteure aufgrund fehlender legislativer Restriktion und des Mangels an Gegenkräften begünstigt die explosionsartige Ausweitung unübersichtlicher Akteursnetzwerke und videoüberwachter Räume.

Ferner wurde der Versuch unternommen, anhand länderspezifischer Institutionsgefüge und sozialkulturell verfestigter Regulierungsstile in den drei Ländern, die Machtpositionen der untersuchten Akteure begreiflich zu machen. Es kann nach der vorangegangenen Analyse festgestellt werden, dass in Deutschland die staatszentrierte Tradition sowie das durch die NS-Erfahrung geprägte Bewusstsein der Rechtsstaatsprinzipien für die verstärkte staatsinterne Kontrolle über die öffentliche Videoüberwachung verantwortlich sind. Trotz der geringfügigen Partizipationsmöglichkeiten der Bürgerrechtsorganisationen bieten die staatsinternen Institutionen genügende Selbstkontrolle, um die öffentlichen Überwachungstätigkeiten mittels Videokameras zu mäßigen.

Die Politik in den USA ist keine hoheitliche Aufgabe des Staates. Die Gestaltung der Politik sowie der Prozess der Willensbildung und Entscheidungsfindung sind durch zahlreiche Wettkämpfe unterschiedlicher Interessenvertreter gekennzeichnet. Die Offenheit der amerikanischen Politik ermöglicht somit die Integration von Bürgerrechtsgruppen in die Entscheidungsprozesse zur Videoüberwachung öffentlicher Räume. Trotz des Fehlens einheitlicher gesetzlicher Rahmenbedingungen für die Überwachungspraxis fungieren die zivilgesellschaftlichen Akteure in der Sicherheitspolitik zur Einführung von CCTV-Überwachung als ausreichende, externe Kontrolle über die Ausweitung von Überwachungskameras in den öffentlichen Räumen. Sowohl der Tradition des starken Lobbyismus als auch dem Prinzip der Volkssouveränität verhaftet, machen Nichtregierungsorganisationen die Risiken von visueller Überwachungstechnik in der amerikanischen Öffentlichkeit resonanzfähig, um dadurch die Intensität der Videoüberwachung zu beeinflussen.

In Großbritannien wird die Politikgestaltung von der Zentralregierung dominiert. Durch die britische Tradition informeller Konsultation fehlen in der Praxis der Videoüberwachung einerseits die strikten Schranken für die Anwendung von Überwachungskameras wie in der Bundesrepublik. Andererseits mangelt es an Partizipati- 
onsmöglichkeiten und -bereitschaft zivilgesellschaftlicher Akteure wie es in den Vereinigten Staaten der Fall ist. Die strukturellen Akteurs- und Beziehungsnetzwerke der CCTV-Politik werden von den politischen Eliten (Old Boy's Network) beherrscht, deren Kommunikation durch gegenseitigen Respekt, Kompromissbereitschaft und das Prinzip der Praktikabilität charakterisiert werden. Die systematisch forcierten Kooperationen und Vernetzungen zwischen den verschiedenen Interessenten von Videoüberwachung begünstigen Einsatzbedingungen und beschleunigen die Entscheidungsverfahren. Vor diesem Hintergrund können die proaktiven Akteure die Ausweitung von CCTV-Überwachung mit wenig Widerstand in Großbritannien vorantreiben. 


\section{Literaturverzeichnis}

ACLU (1999): „Scond attempt fails to install spy cams on Oakland streets". http:/ / www.aclunc.org/aclunews/news499/oakland-cams.html

Aebi, Marcelo F. (2004): "Crime Trends in Western Europe from 1990 to 2000", in: European journal on criminal policy and research Nr. 10/2-3, S. 163-183.

Aebi, Marcelo F.; Martin Killias; Cynthia Tavares (2002): "Comparing Crime Rates: The International Crime (Victim) Survey. The European Sourcebook of Crime and Criminal Justice Statistics, and Interpol Statistics", in: International Journal of Comparative Criminology, Nr. 2/1, S. 22-37.

Almond, Gabriel Abraham; Sidney Verba (1963): The civic culture political attitudes and democracy in five nations. Princeton, N.J.: Princeton Univ. Press.

Anderson, Larry (1997): "Cameras are rolling for public safety", 1.10.1997. http:// securitysolutions.com/mag/security cameras rolling public/

Armitage, Rachel (2002): "To CCTV or not to CCTV? A review of current research into the effectiveness of CCTV systems in reducing crime", NACRO. Community safety practice briefing. http:// www.nacro.org.uk/data/briefings/nacro2002062800-csps.pdf

Banisar, David (1998): "Das Arsenal des ,Großen Bruders' im Land der Freiheit", in: Bürgerrechte \& Polizei: CILIP, Nr. 61/3, S. 19 ff.

Bannister, Jon; Nicholas R. Fyfe; Ade Kearns (1998): "Closed Circuit Television and the City", in: Clive Norris; Jade Moran; Gary Armstrong (Hrsg.): Surveillance, Closed Circuit Television and Social Control. Ashgate: Norris, C. \& Armstrong, G., S. 21-40.

Barclay, Gordon; Cynthia Tavares (2003): "International comparisions of criminal justice statistics 2001", 24.10.2003.

http:// www.csdp.org/research/hosb1203.pdf

Barnes, Samuel H.; Max Kaase (1979): Political Action. Mass Partizipation in five western democracies. Beverly Hills [u.a.]: Sage Publ.

Bartsch, Verena (2004): Rechtsvergleichende Betrachtung präventiv-polizeilicher Videoüberwachungen öffentlich zugänglicher Orte in Deutschland und in den USA, Ausg. 141. Berlin: Duncker \& Humblot.

Bässmann, Jörg; Petra Posiege (1998): Kriminalitätskontrolle in Großbritannien. Aktuelle Entwicklung aus polizeilicher Sicht. Wiesbaden: Bundeskriminalamt.

Bauman, Zygmunt (1997): Flaneure, Spieler und Touristen. Essays zu postmodernen Lebensformen. Hamburg: Hamburger Edition.

Bäumler, Helmut (1999): "Probleme der Videoaufzeichnung und -überwachung aus datenschutzrechtlicher Sicht", Vortrag auf dem 8. Wiesbadener Forum Datenschutz, Unabhängiges Landeszentrum für Datenschutz Schleswig-Holstein. http://www.schleswigholstein.datenschutz.de/material/themen/video/video.htm

Bausch, Stephan (2004): Videoüberwachung als präventives Mittel der Kriminalitätsbekämpfung in Deutschland und in Frankreich. Marburg: Tectum-Verl.

Der Bayerische Landesbeauftragte für den Datenschutz (2002): "20. Tätigkeitsbericht des Landesbeauftragten für den Datenschutz 2002", Bayerische Landtag, S. 111 ff.

— (2004): "21. Tätigkeitsbericht des Landesbeauftragten für den Datenschutz 2004", Bayerischer Landtag, S. 48 ff. http:/ / www.datenschutz-bayern.de/

Bayerisches Staatsministerium des Innern (2000): "Bericht des Herrn Staatsministers Dr. Beckstein im Ausschuß für kommunale Fragen und Innere Sicherheit am 26. Januar 2000 über das beabsichtigte Pilotprojekt zur Videoüberwachung in 
Regensburg".

http:// www.innenministerium.bayern.de/reden/regensburg.pdf

— (2004): "Videoüberwachung im öffentlichen Raum".

http:/ / www.stmi.bayern.de/sicherheit/innere/sicherleben/detail/03671/

Bennett, Richard R.; James P. Lynch (1990): "Does a difference make a difference?

Comparing cross-nation crime indicaors", in: Criminology, Nr. 28/1, S. 153-182.

Der Berliner Beauftragte für Datenschutz und Akteneinsicht (1999): "Jahresbericht des Berliner Beauftragten für Datenschutz und Akteneinsicht zum 31. Dezember 1999". http: / / www.datenschutz-berlin.de

Biedermann (2002): "Das elektronische Auge ist wachsam", 13.03.2004. http://www.fr-aktuell.de

Birch, Anthony Harold (1990): The British system of government. London [u.a.]: Unwin Hyman.

Blasius, Dirk (1986): "Rechtsstaat und Menschenwürde in der jüngeren deutschen Geschichte", in: Geschichte in Wissenschaft und Unterricht, Nr. 3, S. S. 133 ff.

Boers, Klaus (1991): Kriminalitätsfurcht : Über den Entstehungszusammenhang und die Folgen eines sozialen Problems. Pfaffenweiler: Centaurus-Verl.-Ges.

— (1993): "Kriminalitätsfurcht. Ein Beitrag zum Verständnis eines sozialen Problems", in: Monatsschrift für Kriminologie und Strafrechtsreform, Nr. 76/2, S. 65-82.

— (1996): "Sozialer Umbruch und Kriminalität in Deutschland", in: Monatsschrift für Kriminologie und Strafrechtsreform, Nr. 79, S. 314-337.

- (2004): Polizeiliche Videoüberwachung in Bielefeld, Ausg. 12. Münster: LIT Verl.

Boers, Klaus; Peter Kurz (1997): "Kriminalitätseinstellung, soziale Milieus und sozialer Umbruch", in: Klaus Boers; Günter Gutsche; Klaus Sessar (Hrsg.): Sozialer Umbruch und Kriminalität in Deutschland. Opladen: Westdt. Verl., S. 187-254.

Bowles, Nigel (1993): The government and politics of the United States. Houndmills [u.a.]: Macmillan.

Brandenburg, Land (2001): "Innenminister startet Pilotprojekt in Erkner. Schönbohm: Videoüberwachung ist wirksames Mittel zur Kriminalitätsbekämpfung", 12.11.2001. http:// www.brandenburg.de/sixcms/detail.php?id=12128

Brenneisen, Hartmut; Dirk Staack (1999a): "Die Videobildübertragung nach allgemeinem Polizeirecht das Kamera-Monitor-Prinzip", in: Datenschutz und Datensicherheit, Nr. 23/8, S. 447- 450.

— (1999b): "Die Videoüberwachung allgemein zugänglicher Flächen - Erläuterung für Praxis und Lehre", in: Recht aktuell - Schleswig-Holstein, Nr. 1, S. 1 ff.

Brown, Ben (1995): "CCTV in Town Centres: Three case studies", Police Research Group. Crime Detection and Prevention Series; Paper No. 68, London.

- (1997): "CCTV in three town centers in England", in: R.V. Clarke (Hrsg.): Situational Crime Prevention: Successful Case Studies. Guilderland, S. 167-182.

Brown, Sheila (1998): "What's the Problem Girls?" in: C. Norris, Moran J. Armstrong, G. (Hrsg.): Surveillance, Closed Circuit Television and Social Control. Ashgate, S. $207 \mathrm{ff}$.

Büllesfeld, Dirk (2002): Polizeiliche Videoüberwachung öffentlicher Straßen und Plätze zur Kriminalitätsvorsorge. Stuttgart [u.a.]: Boorberg.

Bund Deutscher Kriminalbeamten (2000): "BDK fordert Video-Überwachung". http: / / www.bdk.de/index.php?option=com content\&task=view\&id=124\&It emid=275\&mscid $=12$

Bundeskriminalamt (1997): Organisierte Kriminalität. Vorträge und Diskussionen bei der Arbeitstagung des Bundeskriminalamtes vom 18. bis 22. November 1996. Wiesbaden: Bundeskriminalamt.

— (2003): "Polizeiliche Kriminalstatistik 2003". http://www.bka.de/pks/pks2003/index2.html 
Burrows, Quentin (1997): "Scowl because you're on candid camera: privacy and video surveillance", in: Valparaiso University Law Review, Nr. LEXSEE 31 Val. U. L. Rev. 1079.

Buse, U.; C. Schnibben (1999): "Der nackte Untertan", in: Der Spiegel, Nr. 27, S. 113.

Button, James W. (1989): Blacks and social change. Impact of the civil rights movement in southern communities. Princeton, NJ: Princeton Univ. Pr.

Coleman, Roy (2004): Reclaiming the streets surveillance, social control and the city Roy Coleman. Cullompton, Devon: Willan.

Coleman, Roy; Joe Sim (1998): "From the Dockyards to the Disney Store: Surveillance, risk and security in Liverpool City Centre", in: International Review of Law Computers $\mathcal{E}$ Technology, Nr. 12/1, S. 27-45.

- (2000): "You'll never walk alone: CCTV surveillance, oder and neo-liberal rule in Liverpool city centre", in: The British Journal of Sociology, Nr. 51/4, S. 623-639.

Dahrendorf, Ralf (1965): Gesellschaft und Demokratie in Deutschland. München: Piper.

Data Protection Office UK (2000): "Guidlines on the Data Protection Act 1 March 2000". http: / / www.crimereduction.gov.uk/ cctv9.htm

Davies, Simon (1996a): Big Brother. Britain's web of surveillance amd the new technological order. London.

- (1996b): "The case against: CCTV should not be introduced", in: International Journal of Risk, Security and Crime Prevention, Nr. 1/4, S. 327-331.

Davis, Mike (1990): City of quartz. Excavating the future in Los Angeles. London [u.a.]: Verso.

- (1999): Ecology of fear Los Angeles and the imagination of disaster. London: Picador.

Deutsch, Claudia (1997): "One Camera that offers many views", in: The New York Times, 03.02.1997.

Dinges, Martin; Fritz Sack (2000): "Unsichere Großstädte?" in: Martin Dinges; Fritz Sack (Hrsg.): Unsichere Großstädte? Vom Mittelalter bis zur Postmoderne, Band 3. Konstanz: UVK Universitätsverl. Konstanz, S. 9-65.

Dittmann, Jörg (2005): "Kriminalitätsfurcht sinkt in Deutschland entgegen dem EUTrend", in: Informationsdienst Soziale Indikatoren ISI, Nr. 34, S. 6-9.

Ditton, Jason (1998): "Public Support for Town Centre CCTV Schemes: Myth or Reality?" in: Clive Norris; Jade Moran; Gary Armstrong (Hrsg.): Surveillance, Closed Circuit Television and Social Control. Ashgate, S. 221-228.

- (2000): "Crime and the City. Public Attitudes towards Open-Street CCTV in Glasgow", in: The British Journal of Criminology, Nr. 40/4, S. 692-709.

Ditton, Jason; Emma Short (1998): "Evaluating Scotland's first town centre CCTV scheme", in: Clive Norris; Jade Moran; Gary Armstrong (Hrsg.): Surveillance, Closed Circuit Television and Social Control. Ashgate, S. $155 \mathrm{ff}$.

- (1999): "Yes, it works, no, it doesn't: Comparing the effects of Open-Street CCTV in two Adjacent Scottish Town Centres", in: Kate Painter; Nick Tilley (Hrsg.): Surveillance of public space: CCTV, Street lighting and crime prevention, Band 10. Monsey, New York USA: Criminal Justice Press. Crime Prevention Studies, S. 201-223.

Dönicke, Kerstin (2005): Harenberg Aktuell 2006: das Jahrbuch Nr. 1 ; Daten, Fakten, Hintergründe. Mannheim u.a.: Meyers Lexikonverl.

Döring, Herbert (1993): Großbritannien. Regierung, Gesellschaft und politische Kultur, Ausg. 8. Opladen: Leske und Budrich.

— (1999): "Bürger und Politik - die ,Civic Culture' im Wandel", in: Hans Kastendiek; Karl Rohe; Angelika Volle (Hrsg.): Großbritannien. Geschichte, Politik, Wirtschaft, Gesellschaft. Frankfurt [u.a.]: Campus-Verl., S. 163 ff.

Edenfeld, Stefan (2000): "Videoüberwachung am Arbeitsplatz. ,Big Brother' im Büro?" in: Der Personalrat : Zeitschrift für das Personalrecht im öffentlichen Dienst, Nr. 17/8, S. 323-328. 
Eickhoff, Antje (1998): "Wir können auch anders", in: StadtRat (Hrsg.): Umkämpfte Räume. Hamburg [u.a.]: Verl. Libertäre Assoziation [u.a.], S. 13-22.

Eifler, Stefanie; Daniela Brandt (2005): ",Videoüberwachung in Deurschland' Theorie und Praxis situationsbezogener Kriminalprävention", in: Monatsschrift für Kriminologie und Strafrechtsreform, Nr. 88/3, S. 157-173.

Evangelista, Benny (2001): "Terrorist attacks have inspired nationwide interest in surveillance (cites official with Security Industry Association)", in: San Francisco Chronicle, 24.09.2001.

Fay, Stephen .J. (1998): "Tough on Crime, Tough on Civil Liberties: some negative aspects of Britain's wholesale adoption of CCTV surveillance during the 1990s", in: International Review of Law, Computer and Technology, Nr. 12/2, S. 239-271.

Feeley, Malcom; Janathan Simon (1994): "Actuarial Justice: the emerging new criminal law", in: David Nelken (Hrsg.): The futures of criminology. London u.a.: Sage, S. 173-201.

Finkel, Roland (1995): "Kriminalitätsverhütung als gesamtgesellschaftliche Aufgabe. Kommunale Präventionsräte als kriminalpolitisches Konzept am Beispiel Schleswig-Holsteins", in: Rolf Gössner (Hrsg.): Mythos Sicherheit. Der hilflose Schrei nach dem starken Staat. Baden-Baden: Nomos Verl.-Ges., S. 415 ff.

Foucault, Michel (1994): Überwachen und Strafen: die Geburt des Gefängnisses. Frankfurt am Main: Suhrkamp.

Frankfurter Allgemeine Zeitung (2002): "Video-Überwachung ein Erfolg", in: FAZ, 05.11.2002.

- (2003a): "Videokameras für den Bahnhofsvorplatz", in: FAZ, 25.03.2003.

— (2003b): "Weitere Uneinigkeiten über Video-Überwachung", in: FAZ, 25.02.2003.

Frankfurter Neue Presse (2002a): "CDU fordert mehr Überwachungskameras", in: FNP, 25.04.2002.

— (2002b): "Schwarz: Videokameras sind ein Erfolg", in: FNP, 04.11.2002.

- (2003a): "Keine neuen Kameras. Für eine Ausweitung fehlt das Geld", in: FNP, 30.01.2003.

— (2003b): "Schwarz will mehr Geld für die Videoüberwachung", in: FNP, 25.02.2003.

- (2003c): "Videokameras am Kaisersack", in: FNP, 25.03.2003.

- (2003d): "Videoüberwachung und neuer Pavillon", in: FNP, 05.03.2003.

Frankfurter Rundschau (2001): "Die Kameras bleiben", in: FR, 11.12.2001.

- (2002a): "Auch Big Brother fehlt das Geld", in: FR, 28.08.2002.

— (2002b): "Mehr Sicherheit durch Videoüberwachung", in: FR, 02.11.2002.

- (2002c): "Videoüberwachung auch künftig an der Konstabler", in: FR, 04.02.2002.

- (2003): "Debatte über Videokameras. Überwachung der Konstablerwache nur eine Ausnahme", in: FR, 25.02.2003.

Frerichs, Peter (2000): "Zur Praxis der polizeilichen Videoüberwachung - gegenwärtige und künftige Anwendungsfelder", in: Klaus Peter Möller; Friedrich von Zezschwitz (Hrsg.): Videoüberwachung - Wohltat oder Plage? Baden-Baden, S. 78 ff.

Frevel, Bernhard (1998): Wer hat Angst vor'm bösen Mann?: ein Studienbuch über Sicherheit und Sicherheitsempfinden. Baden-Baden: Nomos-Verl.-Ges.

Friedmann, Karl Anton (1970): Kontrolle der Verwaltung in England: Fallstudien zur Beschwerdenbehandlung im britischen Unterhaus. Meisenheim/Glan: Hain.

Friedrich, Carl Joachim (1970): Politik als Prozess der Gemeinschaftsbildung eine empirische Theorie. Köln [u.a.]: Westdt. Verl.

Fromme, Friedrich Karl (1960): Von der Weimarer Verfassung zum Bonner Grundgesetz: die verfassungspolitischen Folgerungen des Parlamentarischen Rates aus Weimarer Republik und nationalsozialistischer Diktatur. Tübingen: Mohr.

Fyfe, Nicholas R.; Jon Bannister (1996): "City Watching: CCTV surveillance in public spaces", in: Area, Nr. 28/1, S. 37-46. 
Garfinkel, Simson (2000): Database nation: the death of privacy in the 21st century. Beijing [u.a.]: O'Reilly.

Gärtner, Birgit (2006): "Orwell lässt grüßen", Telepolis, 31.03.2006. http:/ / www.heise.de/tp/r4/artikel/22/22360/1.html

Gerhards, Jürgen (2000): "Einleitende Bemerkungen", in: Jürgen Gerhards (Hrsg.): Die Vermessung kultureller Unterschiede. Wiesbaden: Westdeutscher Verlag, S. $7 \mathrm{ff}$.

Gerhards, Jürgen; Dieter Rucht (2000): "Öffentlichkeit, Akteure und Deutungsmuster: Die Debatte über Abtreibungen in Deutschland und den USA", in: Jürgen Gerhards (Hrsg.): Die Vermessung kultureller Unterschiede USA und Deutschland im Vergleich. Wiesbaden: Westdt. Verl., S. $165 \mathrm{ff}$.

Gerhold, Diethelm; Helmut Heil (2001): "Das neue Bundesdatenschutzgesetz 2001", in: Datenschutz und Datensicherheit (DuD), Nr. 25, S. 377-382.

Glaeßner, Gert-Joachim (2002): "Sicherheit und Freiheit", in: Aus Politik und Zeitgeschichte. Das Parlament. Beilage zur Wochenzeitung, Nr. B10-11/2002, S. 3-13.

Goffman, Erving (1971): Verhalten in sozialen Situationen: Strukturen und Regeln der Interaktion im öffentlichen Raum. Gütersloh: Bertelsmann.

Goold, Benjamin (2005): "Unter dem Auge der Kamera. Closed Circuit Television und Polizeiarbeit", in: Leon Hempel; Jörg Metelmann (Hrsg.): Bild - Raum Kontrolle: Videoüberwachung als Zeichen gesellschaftlichen Wandels. Frankfurt am Main: Suhrkamp, S. $221 \mathrm{ff}$.

Gosse, Van; Richard Moser (2003): The world the sixties made. Politics and culture in recent America. Philadelphia, Pa.: Temple University Press.

Gössner, Rolf (1995): Mythos Sicherheit der hilflose Schrei nach dem starken Staat. BadenBaden: Nomos-Verl.-Ges.

— (2000a): "Big Brother" \& Co.: der moderne Überwachungsstaat in der Informationsgesellschaft. Hamburg: Konkret-Literatur-Verl.

- (2000b): "Sicherheitsvideotie. Kameraüberwachung. Warum wir das Linsendickicht vor lauter Objektiven nicht mehr sehen können", 09.06.2000. http://www.freitag.de/2000/24/00240401.htm

Gräf, Lorenz (1993): Privatheit und Datenschutz. Eine soziologische Analyse aktueller Regelungen zum Schutz privater Bereiche vor dem Hintergrund einer Soziologie der Privatheit. Köln.

Graham, S. (1998): "Towards the Fifth Utility? On the Extention and Normalisation of Public CCTV", in: Clive Norris; Jade Moran; Gary Armstrong (Hrsg.): Surveillance, Closed Circuit Television and Social Control. Ashgate, S. $89 \mathrm{ff}$.

Graham, Stephen; John Brooks; Dan Heery (1995): "Towns on the Television: Closed Circuit TV Surveillance in British towns and cities", Working Paper No. 50, University of Newcastle upon Tyne. Centre for Urban Technology. Department of town and country planning. www.ncl.ac.uk/guru/Working\%20Papers/EWP\%2017.pdf

Gras, Marianne (2003): Kriminalprävention durch Videoüberwachung: Gegenwart in Großbritannien - Zukunft in Deutschland? Baden-Baden: Nomos-Verl.-Ges.

von Grätz, Philipp Grätzel (2003): "Big Brother is tracking you", 28.07.2003. http:/ / www.heise.de/tp/r4/artikel/15/15317/1.html

Greene, Judith A. (2001): "Zero Tolerance - Auswirkungen auf Kriminalität, Gemeinwesen und Kriminaljustiz in New York", in: Jörg-Martin Jehle (Hrsg.): Raum und Kriminalität. Sicherheit der Stadt. Migrationsprobleme. Mönchengladbach, S. 43-67.

Greiner, August (2000): "Eine Variante in der Überwachung von Kriminalitätsschwerpunkten: Pilotprojekt ,SOS-Videotechnik' in Regensburg", in: Die Polizei: Zentralorgan für d. Sicherheits- und Ordnungswesen, Polizeiwissenschaft, -recht, -praxis, Nr. 4, S. 120. 
Habermas, Jürgen (1965): Strukturwandel der Öffentlichkeit: Untersuchungen zu einer Kategorie der bürgerlichen Gesellschaft, Ausg. 4. Neuwied am Rhein [u.a.]: Luchterhand.

Halbfinger, David M. (1998): "Protesters assail rising use of police cameras", in: The New York Times, 02.02.1998.

Hale, Chris (1996): "Fear of crime: a review of literature", in: International Review of Victimology, Nr. 4/2, S. 79-150.

Hansard (1999): "House of Commons Written Answers for 2 November 1999". http:/ / www.parliament.uk/hansard/hansard.cfm

Heise Online (2002): "Automatische Gesichtserkennung taugt nicht viel". http: / / www.heise.de/newsticker/meldung/23780

Hempel, Leon (2003): "Verdrängen statt Vorbeugen. Zur mobilen Videoüberwachung in Deutschland", Telepolis, 15.01.2003. http://www.heise.de/tp/r4/artikel/13/13928/1.html

Hesselberger, Dieter (1999): Das Grundgesetz. Kommentar für die politische Bildung. Neuwied: Luchterhand.

Hobbes, Thomas (1996): Leviathan, Ausg. 491. Hamburg: Meiner.

Höfling, Wolfgang (2000): "Grundrechtliche Anforderungen an Ermächtigungen zur Videoaufzeichnung und -überwachung durch Verwaltungsbehörden", in: Klaus Peter Möller; Friedrich von Zezschwitz (Hrsg.): Videoüberwachung Wohltat oder Plage? Baden-Baden, S. $29 \mathrm{ff}$.

Hölscher, Michael (2003): "Sicherheitsgefühl und Überwachung. Eine empirische Studie zu Einstellungen der Bürger zur Videoüberwachung und ihrer Erklärung", in: Kriminologisches Journal, Nr. 35/1, S. 42-56.

Honess, Terry; Elizabeth Charman (1992): "Closed Circuit Television in public places. Its acceptability and perceived effectiveness", Crime Prevention Unit series, Paper 35, Home Office. Police Research Group.

Hough, Mike (1995): "Anxiety about crime: findings from 1994 British Crime Survey", in: Home Office Research Study, Nr. 147.

Hsu, Spencer S. (2002a): "D.C. forms network of surveillance. Police video links raise rights issues", in: The Washington Post, 17.02.02.

- (2002b): "In D.C., Tuning in to the streets. Morella raises wories about police monitoring network of video cameras", in: The Washington Post, 15.02.2002.

- (2002c): "Rules urged for surveillance. On hill, officials pledge limits for cameras on Mall, in city", in: The Washington Post, 23.03.2002.

- (2002d): "Video surveillance planned on Mall. Cameras to be installed by October in and around all major monuments", in: The Washington Post, 22.03.2002.

Hüning, Dieter (1998): Freiheit und Herrschaft in der Rechtsphilosophie des Thomas Hobbes, Ausg. 185. Berlin: Duncker \& Humblot.

- (2005): Der lange Schatten des Leviathan: Hobbes' politische Philosophie nach 350 Jahren ; Vorträge des internationalen Arbeitsgesprächs am 11. und 12. Oktober 2001 an der Herzog August Bibliothek in Wolfenbüttel, Ausg. 226. Berlin: Duncker \& Humblot.

Hutter, Dominik (2004): "Vorsicht, Kamera! Videoüberwachung am Hauptbahnhof", 22.01.2004. http://www.sueddeutsche.de/muenchen/artikel/347/25322/

Independent, The (2004): "Big brother Britain, 2004 ", in: The Independent, 12.01.2004.

Das Innenministerium Baden-Württemberg (2001): "Klage gegen Videoüberwachung abgewiesen. Pressemitteilung vom 26.10.2001". http:/ / www.polizeibw.de/pressearchiv2001/pmim121.htm

- (2002): "Moderne Technik unterstützt gezielten Einsatz der Polizei. Pressemitteilung vom 28.01.2002". http:/ / www.polizeibw.de/pressearchiv2002/pmim004.htm 
— (2003): "Videoüberwachung an Kriminalitätsbrennpunkten ist rechtmäßig. Pressemitteilung vom 21.07.2003". http:// www.polizeibw.de/pressearchiv2003/PMIM051.htm

Das Innenministerium Nordrhein-Westfalen (2005a): "Innenminister Behrens: Polizei geht mit Videoüberwachung gegen Straßenkriminalität vor - mehr Sicherheit in der Düsseldorfer Altstadt. Presemitteilung vom 27.04.2005". http://www.im.nrw.de/pe/pm2001/pm2001/news 1392.htm

— (2005b): "Rede vom Innenminister Dr. Fritz Behrens zum Start der polizeilichen Videoüberwachung in der Landeshauptstadt Düsseldorf am ,Bolker Stern' am 27.04.2005 in Düsseldorf. Presemitteilung vom 27.04.2005". http:// www.im.nrw.de/pe/pm2001/pm2001/news 1393.htm

Jauß, Claudia (2000): "USA: Arenen des Wettbewerbs", in: Richard Münch; Christian Lahusen (Hrsg.): Regulative Demokratie. Politik der Luftreinhaltung in Großbritannien, Frankreich, Deutschland und den USA. Frankfurt/Main [u.a.], S. 237 ff.

Johnston, Les (1995): "Policing in Late Modern Societies", in: International Centre for Comparative Criminology (Hrsg.): Workshop on Evaluating Police Service Delivery. Montreak, S. 422-455.

Jowell, Roger; Sharon Witherspoon (1985): British social attitudes. The 1985 Report.

Kaase, Max (1982): "Partizipatorische Revolution - Ende der Parteien?" in: Joachim Raschke (Hrsg.): Bürger und Parteien. Ansichten und Analysen einer schwierigen Beziehung. Opladen: Westdeutscher Verlag, S. 173-189.

Kaiser, André (2000): "Regieren in Westminster-Demokratien: eine Problemskizze", in: André Kaiser (Hrsg.): Regieren in Westminster-Demokratien. Baden-Baden: Nomos-Verl.-Ges., S. $11 \mathrm{ff}$.

— (2004): "Das Verhältnis von Parlament und Regierung in Großbritannien", in: Marie-Luise Recker (Hrsg.): Parlamentarismus in Europa Deutschland, England und Frankreich im Vergleich, Band Schriften des Historischen Kollegs Kolloquien 60. München: Oldenbourg, S. $139 \mathrm{ff}$.

Kaiser, Günther (1997): Kriminologie: eine Einführung in die Grundlagen. Heidelberg: Müller Jur. Verl.

Kaiser, Günther; Hans-Jürgen Kerner; Fritz Sack (1993): Kleines kriminologisches Wörterbuch. Heidelberg: Müller Jur. Verl.

Kangaspunta, Kristiina (1995): "Crime and Criminal Justice in Europe and North America 1986-1990", HEUNI Publication Series No. 25, Helsinki.

Kant, Immanuel (1956a): "Die Metaphysik der Sitten", in: Wilhelm Weischedel (Hrsg.): Immanuel Kant. Werke in sechs Bänden. Bd. IV. Frankfurt a.M.

— (1956b): "Kritik der reinen Vernunft", in: Wilhelm Weischedel (Hrsg.): Immanuel Kant. Werke in sechs Bänden. Bd. II. Frankfurt a.M.

Katzenstein, Peter J. (1987): Policy and Politics in West-Germany. The Growth of Semisovereign State. Philadelphia: Temple Univ. Pr.

Kavanagh, Dennis (1980): "Political culture in Great Britain: The decline of the Civic Culture", in: Gabriel Abraham Almond; Sidney Verba (Hrsg.): The civic culture revisited. Boston, S. $124 \mathrm{ff}$.

Keller, Christoph (2000): "Video-Überwachung: Ein Mittel der Kriminalprävention. Zum Stand der rechtlichen und taktischen Diskussion", in: Kriminalistik. Unabhängige Zeitschrift für die kriminalistische Wissenschaft und Praxis, Nr. 54/3, S. 187-191.

Kennedy, Randy (1997): "Police cameras planned for more housing projects", in: The New York Times, 13.11.1997.

Kersting, Wolfgang (1996): Thomas Hobbes, Leviathan oder Stoff, Form und Gewalt eines bürgerlichen und kirchlichen Staates, Ausg. 5. Berlin: Akad.-Verl.

Killias, Martin; Gordon Barclay; Paul Smit; Marcelo F. Aebi; Cynthia Tavares; Bruno Aubusson de Cavarlay; Jörg-Martin Jehle; Hanns von Hofer; Beata Gruszcynska; Vasilika Hysi; Kauko Aromaa (2003): "European sourcebook of crime 
and criminal justice statistics 2003", Wetenschappelijk Onderzoek- en Documentatiecentrum: Onderzoek en beleid.

http://www.europeansourcebook.org

Kinbzer, Stephen (2004): "Chicago moving to ,smart' surveillance cameras", in: The New York Times, 21.09.2004.

Kitschelt, Herbert (1985): "Zur Dynamik neuer sozialer Bewegungen in den USA", in: Karl-Werner Brand (Hrsg.): Neue soziale Bewegungen in Westeuropa und den USA. Ein internationaler Vergleich. Frankfurt am Main; New York: Campus, S. $248 \mathrm{ff}$.

Klingelschmitt, Klaus-Peter (1999): "Spaziergänger werden gefilmt", in: taz Nr. 5922, 26.08.1999.

Klocke, Gabriel \& Studiengruppe (2001): "Das Hintertürchen des Nichtwissens", in: Bürgerrechte \& Polizei: CILIP, Nr. 69/2, S. 88 ff. http:// www.cilip.de/ausgabe/69/video.htm

Koch, Jutta (1998): Zur sicherheitspolitischen Kultur der Vereinigten Staaten von Amerika Eckpunkte, Möglichkeiten, Grenzen. Baden-Baden: Nomos-Verl.-Ges.

Kohl, Andreas (1997a): "Videoüberwachung im öffentlichen Raum. Teil 1 - Erfahrung aus Großbritannien", in: Wirtschaftsschutz \& Sicherheitstechnik, Nr. 11, S. 36-38.

— (1997b): "Videoüberwachung im öffentlichen Raum. Teil 2 - Pilotprojekte in Deutschland", in: Wirtschaftsschutz E Sicherheitstechnik, Nr. 12, S. 24-26.

König, Robert (2001): Videoüberwachung: Fakten, Rechtslage und Ethik; mit dem Schwerpunkt auf generalpräventiver Videoüberwachung im öffentlichen Raum. Wien: Verl. Österreich.

Konig, Susan (1996): "Surveillance cameras monitor comings and goings in Roslyn", in: The New York Times, 18.02.1996.

Kraudzun, Henning (2002): "Vom Beobachten des Beobachters", in: taz Berlin Lokal, 19.11.2002. http:/ / www.taz.de/pt/2002/11/19/a0205.1/text

Kreuter, Frauke (2002): Kriminalitätsfurcht: Messung und methodische Probleme. Opladen: Leske + Budrich.

Krischer, Markus; Kerstin Holzer (2000): "Im Land der 1000 Augen", in: Focus, Nr. 33/2000, S. $49 \mathrm{ff}$.

Krons, Michael (2000): "Videoüberwachung durch die Polizei", 29.04.2000. http://www.zdf.msnbc.de/news/51510.asp

Kuhn, Thomas S. (1991): Die Struktur wissenschaftlicher Revolutionen, Ausg. 25. Frankfurt am Main: Suhrkamp.

Kulick, Holger (2002): "Vorsicht, Stasikamera. Big Brother an der Humboldt-Uni", 13.11.2002.

http://www.spiegel.de/unispiegel/studium/0,1518,222541,00.html

Kury, Helmut; Joachim Obergfell-Fuchs (1998a): "Kriminalitätsfurcht in Deutschland", in: Kriminalistik. Unabhängige Zeitschrift für die kriminalistische Wissenschaft und Praxis, Nr. 52/1, S. 26-36.

- (1998b): "Kriminalitätsfurcht und Alter: Ergebnisse aus Ost- und Westdeutschland", in: Monatsschrift für Kriminologie und Strafrechtsreform, Nr. 81/3, S. 198217.

Lahusen, Christian (2003): Kontraktuelle Politik: politische Vergesellschaftung am Beispiel der Luftreinhaltung in Deutschland, Frankreich, Großbritannien und den USA. Weilerswist: Velbrück.

Der Landesbeauftragte für den Datenschutz Baden-Württemberg (2001): "22. Tätigkeitsbericht 2001". http:// www.badenwuerttemberg.datenschutz.de/lfd/tb/2001/default.htm

— (2003): "24. Tätigkeitsbericht 2003". http://www.badenwuerttemberg.datenschutz.de/lfd/tb/2003/default.htm 
— (2004): "25. Tätigkeitsbericht 2004". http:// www.badenwuerttemberg.datenschutz.de/lfd/tb/2004/default.htm

— (2005a): "Polizei stellt Videoüberwachung in der Sülmer City / Heilbronn ein". http: / / www.baden-wuerttemberg.datenschutz.de/aktuell/heilbronn.htm

— (2005b): "Videoüberwachung. Pressemitteilung vom 04.05.2005". http://www.baden-wuerttemberg.datenschutz.de/aktuell/ldsg/video.htm

Langer, Gary (2005): "Poll: Support seen for Patriot Act". http: / / abcnews.go.com/US/PollVault/story?id=833703\&CMP=OTCRSSFeeds0312

Lee, Denny (1999): "Residents say drug campaign just sweeps dealers from view", in: The New York Times, 17.10.1999.

Lee, Felicia R. (1998): "Keeping watch in Washington Square", in: The New York Times, 03.01.1998.

Lee, Jennifer (2005): "Police seek to increase surveillance", in: The New York Times, 31.05.2005.

Legnaro, Aldo (1997): "Konturen der Sicherheitsgesellschaft: Eine polemischfuturologische Skizze", in: Leviathan. Zeitschrift für Sozialwissenschaft, Nr. 2, S. 271-284.

Leipziger Kamera (2003a): "Besitzen und Kontrollieren. Eine neue Kampagne gegen Videoüberwachung startet in Leipzig". http://home.pages.at/leipzigerkamera/text00.htm

— (2003b): "Videoüberwachung in Leipzig: Polizei verstößt gegen Datenschutz", 05.10.2003. http:/ / leipzigerkamera.twoday.net/stories / 772020

Leipziger Volkszeitung (2000a): "Demo gegen Überwachung verlief friedlich", in: LVZ, 08.05.2000.

— (2000b): "Erneut Demo gegen Kamera am Kreuz", in: LVZ, 02.03.2000.

— (2000c): "Friedlicher Protest gegen Video-Überwachung", in: LVZ, 01.02.2000.

- (2000d): "Zwei neue Überwachungsanlagen am Roßplatz und am Lutherring eingerichtet/ Videokamera am Connewitzer", in: LVZ, 20.04.2000.

Leopold, Nils (2002): "Du bist nicht allein. Zur Videoüberwachung öffentlicher Räume", in: Till Müller-Heidelberg; Ulrich Finckh; Elke Steven; Martin Kutscha (Hrsg.): Grundrechte-Report. Zur Lage der Bürger- und Menschenrechte in Deutschland. Reinbek, S. 59-64.

— (2005): "Rechtskulturbruch. Die Ausbreitung der Videoüberwachung und die unzulängliche Reaktion des Rechts", in: Leon Hempel; Jörg Metelmann (Hrsg.): Bild-Raum-Kontrolle. Videoüberwachung als Zeichen gesellschaftlichen Wandels, S. $273 \mathrm{ff}$.

Levin, Thomas Y. (2002): CTRL Space: Rhetorics of Surveillance from Bentham to Big Brother. On the occasion of the exhibition CTRL Space - Rhetorics of Surveillance from Bentham to Big Brother, ZKM Karlsruhe, 12 October 2001 - 24 February 2002. Karlsruhe: ZKM u.a.

Liberty (2001): "Government's New £79m for CCTV: Liberty response". http://www.liberty-human-rights.org.uk/press/press-releases2001/government-s-new-79m-for-cctv-liberty-respon.shtml

Lietz, Haiko (2004): "Videoüberwachung: Sicherheit oder Scheinlösung?" 06.07.2004. http://www.heise.de/tp/r4/artikel/17/17813/1.html

Lipset, Seymour Martin (1996): American exceptionalism. A double-edged sword. New York [u.a.]: Norton.

Lischka, Konrad (2000): "Big Brother is watching in Bayern", in: taz, 31.05.2000.

Lockhart, Charles (2003): The roots of American exceptionalism: history, institutions and culture. New York, NY u.a.: Palgrave Macmillan.

Low, Sidney (1908): Die Regierung Englands. Tübingen: Mohr. 
Maguire, Mike (1998): "Restraining big brother? The regulation of surveillance in England and Wales", in: Clive Norris; Jade Moran; Gary Armstrong (Hrsg.): Surveillance, Closed Circuit Television and Social Control. Ashgate, S. $229 \mathrm{ff}$.

Markoff, John (1997): "At the New Frontier of Eavesdropping", in: The New York Times, 19.01.1997.

Marsh, Alan (1990): Political action in Europe and the USA. London: Macmillan.

Mayhew, Pat; Philip White (1997): "The 1996 International Crime Victimisation Survey", Home Office Research and Statistics Directorate. Research Findings No. 57.

McCahill, Michael (1998): "Beyond Foucault: towards a contemporary theory of surveillance", in: Clive Norris; Jade Moran; Gary Armstrong (Hrsg.): Surveillance, Closed Circuit Television and Social Control. Ashgate, S. $41 \mathrm{ff}$.

McCahill, Michael; Clive Norris (2002a): "CCTV in Britain. Urbaneye Working Paper No. 3", Centre for Technology and Society. Technical University Berlin.

- (2002b): "CCTV in London. Urbaneye Working Paper No. 6", Centre for Technology and Society. Technical University Berlin.

Möller, Klaus Peter; von Zezschwitz Möller; Wiesbadener Forum Datenschutz (2000): Videoüberwachung - Wohltat oder Plage? Baden-Baden: Nomos-Verl.-Ges.

Moosbrugger, Daniel (2004): Die amerikanische Bürgerrechtsbewegung "schwarze Revolution" in den 1950er und 60er Jahren. Stuttgart: Ibidem-Verl.

Müller, Henning Ernst (2002): "Zur Kriminologie der Videoüberwachung", in: Monatsschrift für Kriminologie und Strafrechtsreform MschrKrim, Nr. 85/1, S. 33-46.

Müller, Rolf (1997): "Pilotprojekt zur Videoüberwachung von Kriminalitätsschwerpunkten in der Leipziger Innenstadt", in: Die Polizei: Zentralorgan für d. Sicherheits- und Ordnungswesen, Polizeiwissenschaft, -recht, -praxis, Nr. 88/3, S. 7782.

— (1998): "Nochmals: Videoüberwachung von Kriminalitätsschwerpunkten in der Leipziger Innenstadt", in: Die Polizei: Zentralorgan für d. Sicherheits- und Ordnungswesen, Polizeiwissenschaft, -recht, -praxis, Nr. 89/4, S. 114-116.

- (2000): "Nochmals: Die Videoüberwachung von Kriminalitätsbrennpunkten in Leipzig. Eine Ergänzung zu den Abhandlungen in den Heften 3/97, S. 77 ff. und 4/98, S. 114 ff." in: Die Polizei: Zentralorgan für d. Sicherheits- und Ordnungswesen, Polizeiwissenschaft, -recht, -praxis, Nr. 91/10, S. 285-292.

- (2003): "Videoüberwachung öffentlicher Räume - Konzeption und Erfahrung. Die Videoüberwachung von Kriminalitätsbrennpunkten in Leipzig". http://www.dstgb.de/index inhalt/homepage/kommunalreport/inhalt/arc hiv2004/newsitem00853/853 9 3724.pdf

Münch, Richard (1986a): "Ihre Entwicklung in Frankreich und Deutschland", in: Richard Münch (Hrsg.): Die Kultur der Moderne. Bd. 2. Frankfurt am Main: Suhrkamp, S. 499-941.

- (1986b): "Ihre Grundlagen und ihre Entwicklung in England und Amerika", in: Richard Münch (Hrsg.): Die Kultur der Moderne. Bd. 1. Frankfurt am Main: Suhrkamp, S. 1-470.

- (2000a): "Kulturen der Demokratie: Historische Gestaltung und aktuelle Herausforderungen", in: Richard Münch; Christian Lahusen (Hrsg.): Regulative Demokratie. Politik der Luftreinhaltung in Großbritannien, Frankreich, Deutschland und den USA, S. $297 \mathrm{ff}$.

— (2000b): "Politische Kultur, Demokratie und politische Regulierung: Deutschland und USA im Vergleich", in: Jürgen Gerhards (Hrsg.): Die Vermessung kultureller Unterschiede USA und Deutschland im Vergleich. Wiesbaden: Westdt. Verl., S. 15 ff.

Münch, Richard; Christian Lahusen (2000): Regulative Demokratie. Politik der Luftreinhaltung in Großbritannien, Frankreich, Deutschland und den USA, Ausg. 5. Frankfurt/Main [u.a.]: Campus-Verl. 
Musharbash, Yassin (2003): "Spitzel in Weimar". http://www.spiegel.de/politik/deutschland/0,1518,270771,00.html

Nettl, John P. (1968): "The state as a conceptual variable", in: World Politics, Nr. 7, S. 559-592.

New York Civil Liberties Union (1998): New York City: A surveillance camera town. NYCLU Special Report. 13.12.1998.

New York Surveillance Camera Players (2003): "Police surveillance cameras in Washington D.C." http:/ / www.notbored.org/ dc-police.html

- (2005): "Video surveillance in Time Square, New York City", 16.05.2005. http://www.infoshop.org/inews/article.php?story=20050516161605646

Nieto, Marcus (1997): Public Video Surveillance: Is it an effective crime prevention tool?, Ausg. June 1997. Sacramento: California Research Bureau, California State Library.

Nieto, Marcus; Kimberly Johnston-Dodds; Charlene Wear Simmons (2002): Public and Private Applications of Video Surveillance and Biometric Technology, Ausg. March 2002. Sacramento: California Research Bureau, California State Library

Nieves, Evelyn (1997): "Welcoming ,Big Brother' watchfully", in: The New York Times, 06.02.1997.

Nogala, Detlef (2002): "Ordnung durch Beobachtung - Videoüberwachung als urbane Einrichtung", in: Nobert Gestring; Herbert Glasauer; Christine Hannemann; Werner Petrowsky; Jörg Pohlan (Hrsg.): Jahrbuch StadtRegion 2002 Schwerpunkt: Die sichere Stadt. Opladen: Leske+Budrich, S. 33-52.

Nordrhein-Westfalen, Innenministerium (2002): "Kabinett stimmt Videoüberwachung in Kriminalitätsbrennpunkten zu - Behrens schlägt Erweiterung des Polizeigesetzes vor - Absage an Überwachungsstaat", 17.07.2002. http:/ / www.im.nrw.de/pe/pm2001/pm2001/news 802.htm

Norris, Clive; Gary Armstrong (1998): "Introduction: power and vision", in: Clive Norris; Jade Moran; Gary Armstrong (Hrsg.): Surveillance, Closed Circuit Television. Ashgate, S. 3 ff.

- (1999a): "CCTV and the rise of mass surveillance society", in: Pat Carlen; Rod Morgan (Hrsg.): Crime unlimited questions for the 21st century. Basingstoke [u.a.]: Macmillan, S. 76-98.

- (1999b): The maximum surveillance society : the rise of CCTV. Oxford, New York: Berg.

Norris, Clive; Jade Moran; Gary Armstrong (1998): "Algorithmic Surveillance: the future of automated visual", in: Clive Norris; Jade Moran; Gary Armstrong (Hrsg.): Surveillance, closed circuit television and social control. Aldershot [u.a.]: Ashgate, S. 255-276.

Norris, Clive; Armstrong, Gary (1998): "Smile, you're on camera. Flächendeckende Videoüberwachung in Großbritannien", in: Bürgerrechte $\mathcal{E}$ Polizei: CILIP, Nr. $61 / 3$, S. $30 \mathrm{ff}$.

Nungesser, Jochen (1988): Hessisches Datenschutzgesetz. Mainz: Dt. Gemeindeverl.

Nürnberg, Thomas (2000): "Videoüberwachung in London. Auch ein Modell für die Großstädte in Deutschland?" in: Die Polizei: Zentralorgan für d. Sicherheits- und Ordnungswesen, Polizeiwissenschaft, -recht, -praxis, Nr. 91/7-8, S. 230-235.

Panagiotides, William A. (1998): Der Data protection act 1984. Zur Geschichte der Datenschutzgesetzgebung in Großbritannien, Ausg. 10. Baden-Baden: Nomos-Verl.Ges.

Parliamentary Office of Science and Technology (2002): "POSTNOTE. April 2002 Nr. 175. CCTV".

http:/ / www.parliament.uk/parliamentary offices/post/pubs2002.cfm

Paterson, William E. (2000): "Darstellungspolitik in einer parlamentarischen Demokratie - Das Westminster-Modell im Medienzeitalter", in: Karl-Rudolf Korte; Gerhard Hirscher (Hrsg.): Darstellungspolitik oder Entscheidungspolitik? Über den 
Wandel von Politikstilen in westlichen Demokratien, Band 81. München: HannsSeidel-Stiftung, S. $146 \mathrm{ff}$.

Polizei Stuttgart (2003): "Die Arbeit der Polizei in der Landeshauptstadt Stuttgart 2003". http: / / www.polizeistuttgart.de/statistik/rueckspiegel 2003/arbeit der polizei.htm

Poole, Robert; Derek Williams (1996): "Success in the surveillance society", in: Security Management, Nr. 5, S. 29-35.

Post, Christian (2004): Polizeiliche Videoüberwachung an Kriminalitätsbrennpunkten zugleich eine Untersuchung des § 15 a PolG NW, Ausg. 8. Hamburg: Kovaéc.

Radbruch, Gustav (1957): Der Mensch im Recht. Ausgewählte Vorträge und Aufsätze über Grundfragen des Rechts, Ausg. 51/52. Göttingen: Vandenhoeck \& Ruprecht.

Reeve, Alan (1998a): "Risk and the new urban space of managed town centres", in: International Journal of Risk, Security and Crime Prevention, Nr. 3/1, S. 43-54.

- (1998b): "The panopticisation of shopping: CCTV and leisure consumption", in: Clive Norris; Jade Moran; Gary Armstrong (Hrsg.): Surveillance, Closed Circuit Television and Social Control. Ashgate, S. $69 \mathrm{ff}$.

Reimann, Mathias (2003): "Die Fremdheit des amerikanischen Rechts - Versuch einer historischen Erklärung", in: Knud Krakau; Franz Streng (Hrsg.): Konflikt der Rechtskulturen? Die USA und Deutschland im Vergleich, Band 3, Publikationen der Bayerischen Amerika-Akademie. Heidelberg: Winter, S. 23 ff.

Reuband, Karl-Heinz (1992): "Objektive und subjektive Bedrohung durch Kriminalität. Ein Vergleich der Kriminalitätsfurcht in der Bundesrepublik Deutschland und den USA 1965-1990", in: Kölner Zeitschrift für Soziologie und Sozialpsychologie, Nr. 44/2, S. 341-353.

— (1999): "Von der Kriminalitätshysterie zur Normalität?" in: Neue Kriminalpolitik, Nr. 11/4, S. 16-19.

- (2001): "Videoüberwachung. Was Bürger von der Überwachung halten", in: Neue Kriminalpolitik, Nr. 13/2, S. 5-9.

Rohe, Karl (1984): "Großbritannien: Krise einer Zivilkultur?" in: Peter Reichel (Hrsg.): Politische Kultur in Westeuropa. Bürger und Staaten in der Europäischen Gemeinschaft. Frankfurt/Main [u.a.]: Campus-Verlag, S. 167-193.

Ronneberger, Klaus (2000): "Die neofeudale Erlebnisstadt", in: Michael Häupl; Kilian Franer (Hrsg.): Das Neue und die Stadt: urbane Identitäten. Wien: Promedia, S. 117-137.

Roos, Jürgen (2002): "Nichts geht mehr ohne Kamera", in: Kriminalistik. Unabhängige Zeitschrift für die kriminalistische Wissenschaft und Praxis, Nr. 56/7, S. $464 \mathrm{ff}$.

Rose, Richard (1965): "England: a traditionally modern political culture", in: Lucian W. Pye; Sidney Verba (Hrsg.): Political culture and political development. Princeton, NJ: Princeton Uni. Press, S. 83 ff.

Rossnagel, Alexander (2003): Handbuch Datenschutzrecht. Die neuen Grundlagen für Wirtschaft und Verwaltung. München: Beck.

Rudzio, Wolfgang (2000): Das politische System der Bundesrepublik Deutschland. Opladen: Leske + Budrich.

Sack, Fritz (1995): "Prävention - ein alter Gedanke in neuem Gewand. Zur Entwicklung und Kritik der Strukturen ,postmoderner' Kontrolle", in: Rolf Gössner (Hrsg.): Mythos Sicherheit. Der hilflose Schrei nach dem starken Staat. BadenBaden: Nomos Verl.-Ges., S. $429 \mathrm{ff}$.

- (2005): "Feindstrafrecht - Auf dem Weg zu einer anderen Kriminalpolitik?" Bürgerrechte \& Polizei: CILIP. http://www.cilip.de/presse/2005/sack.htm

Sack, Fritz; Detlef Nogala; Michel Lindenberg (1997): Social control technologies. Aspekte und Konsequenzen des Technikeinsatzes bei Instanzen strafrechtlicher Sozialkontrolle im nationalen und internationalen Kontext. Hamburg: Aufbau- und Kontaktstudium Kriminologie der Universität Hamburg.

Safer Leeds (2004): "CCTV". http:/ / www.leeds-csp.org.uk/view.asp?id=20 
Schierbaum, Bruno (2003): "Videoüberwachung und Datenschutz", in: Der Personalrat: Zeitschrift für das Personalrecht im öffentlichen Dienst, Nr. 11/2003, S. 439445.

Schmidt, Manfred G. (1992): Regieren in der Bundesrepublik Deutschland, Ausg. 5. Opladen: Leske + Budrich.

Schmitt, Carl (1970): Verfassungslehre. Berlin: Duncker \& Humblot.

Schneider, Dieter; Wolfgang Daub (2000): "Videoüberwachung an Kriminalitätsbrennpunkten: Verbote des totalen Überwachungsstaates oder efektives Einsatzmittel zur Bekämpfung der Straßenkriminalität?" in: Die Polizei: Zentralorgan für d. Sicherheits- und Ordnungswesen, Polizeiwissenschaft, -recht, -praxis, Nr. 91/11, S. 322-326.

Schulzki-Haddouti, Christiane (1998): "Watching you - Spähangriff auf den Bürger", in: $c^{\prime} t$, Nr. 24, S. 84-89.

Schumacher, Thomas (1999): "Kameras im Sylter Sumpf", in: taz Bremen Nr. 5925, 30.08.1999.

Sessar, Klaus; Hans-Jürgen Kerner; Kerner Sessar (1991): Developments in crime and crime control research: German studies on victims, offenders, and the public. New York; Berlin; Heidelberg; London; Paris; Tokyo; Hong Kong; Barcelona: Springer.

Simitis, Spiros (1977): "Bundesdatenschutzgesetz - Ende der Diskussion oder Neubeginn", in: Neue juristische Wochenschrift, Elektronische NJW, S. 729 ff.

- (1990): "Zwanzig Jahre Datenschutz in Hessen - eine kritische Bilanz", in: Der Hessische Datenschutzbeauftragte. 19. Tätigkeitsbericht, S. 138 ff.

- (2003): Kommentar zum Bundesdatenschutzgesetz. Baden-Baden: NomosVerlagsgesellschaft.

Skinns, David (1998): "Crime reduction, diffusion and displacement: evaluating the effectiveness of CCTV", in: Clive Norris; Jade Moran; Gary Armstrong (Hrsg.): Surveillance, Closed Circuit Television and Social Control. Ashgate, S. 175-188.

Smith, William R.; Marie Torstensson (1997): "Gender differences in risk perception and neutralizing fear of crime: Toward resolving the paradoxes", Nr. 37/4, S. 608-634.

Sontheimer, Kurt; Wilhelm Bleek (1998): Grundzüge des politischen Systems der Bundesrepublik Deutschland, Ausg. 1200. München Zürich: Piper.

Spinrath, Norbert (1999): "Effizienzsteigerung jenseits neuer Befugnisse", in: Helmut Bäumler (Hrsg.): Polizei und Datenschutz. Neuwied: Kriftel, S. 86 ff.

Ständige Konferenz der Innenminister und -senatoren der Länder (2000): "Zur Veröffentlichung freigegebene Beschlüsse der 161. Sitzung der Ständigen Konferenz der Innenminister und -senatoren der Länder". www.polizei.nrw.de/eigensicherung/website/material/imk2000 mai.pdf

Stanley, Jay; Barry Steinhardt (2002a): Bigger Monster, Weaker Chains: The growth of an American surveillance Society: American Civil Liberties Union. Technology and Liberty Program.

- (2002b): Drawing Blanks: The failure of facial recognition technology in Tampa, Florida: American Civil Liberties Union. Special Report 03.01.2002.

Starck, Christian (2002): Freiheit und Institutionen. Tübingen: Mohr Siebeck.

Stark, Carsten; Christoph Peters (2000): "Deutschland: Politik der Machtkartelle", in: Richard Münch; Christian Lahusen (Hrsg.): Regulative Demokratie. Politik der Luftreinhaltung, in Großbritannien, Frankreich, Deutschland und den USA. Frankfurt/Main [u.a.]: Campus-Verl., S. 181 ff.

Steinberger, Helmut (1993): "Politische Repräsentation in der Bundesrepublik Deutschland", in: Paul Kirchhof; Donald P. Kommers (Hrsg.): Deutschland und sein Grundgesetz. Themen einer deutsch-amerikanischen Konferenz, Band 13. Baden-Baden: Nomos-Verl.-Ges., S. 137 ff. 
Steinert, Heinz (1995): "Prävention als kommunale Aufgabe. Jenseits von Polizei und Strafrecht", in: Rolf Gössner (Hrsg.): Mythos Sicherheit. Der hilflose Schrei nach dem starken Staat. Baden-Baden: Nomos Verl.-Ges., S. $403 \mathrm{ff}$.

Stierand, Philipp (2000): "Videoüberwachte Stadt? Sichere öffentliche Räume als Aufgabe der Stadtplanung". http://www.stierand.de/diplom/videoueberwachte stadt online.pdf

Stolle, Peer; Roland Hefendehl (2002): "Gefährliche Orte oder gefährliche Kameras? Die Videoüberwachung im öffentlichen Raum", in: Kriminologisches Journal, Nr. 34/4, S. 257-272.

Straub, Bill (1996): "TV cameras taking place of policemen in Baltimore", in: Rocky Mountain News, 10.03.1996.

Süddeutsche Zeitung (2000): "Polizei will Videokameras mit Augenmaß setzen", in: $S Z, 09.02 .2000$.

- (2004a): "Der Ausweise-Antrag. Big Blunkett is watching you: Die Briten und ihre Angst vor dem ,Stasi-Staat'", in: SZ, 19.08.2004.

— (2004b): "München wird per Video überwacht", in: SZ, 19/20.05.04.

Synder, David (2005): "Speed cameras veto is decried. Ehrlich's Decision keeps area roads unsafe, some say", in: Washington Post, 02.06.2005.

Tavernise, Sabrina (2004): "Watching big brother. On this tour, hidden cameras are hidden no more", in: The New York Times, 17.01.2004. New York.

taz (2000): "Big brother auf dem Weg zum Sielwall", in: taz Bremen Nr. 6121, 17.04.2000.

The Scottish Office (1999): "The effect of Closed Circuit Television on recorded crime rates and public concern about crime in Glasgow", Crime and Criminal Justice Research Findings No. 30. http:// www.scotland.gov.uk/cru/resfinds/crf3000.htm

Thomas, Jo (1997): "Jurors see chilling images of truck before bombing", in: The New York Times, 15.05.1997.

Times, The (1994): "Security cameras zoom in on crime", in: The Times, 06.07.1994.

Tocqueville, Alexis de (1976): Über die Demokratie in Amerika. München: Dt. Taschenbuch-Verl.

Toepffer-Wenzel, Kirsten (2004): E-Watch und Controltainment: zur Kriminologie der Kontrollkultur.

Töpfer, Eric (2005): "Die polizeiliche Videoüberwachung des öffentlichen Raums. Entwicklung und Perspektiven", in: Datenschutz-Nachrichten DANA Deutsche Vereinigung für Datenschutz, Nr. 2/2005, S. 5-9.

von Treitschke, Heinrich (1871): Historische und politische Aufsätze. Band III. Freiheit und Königthum.

Ullrich, Volker (2005): Der Fischer Weltalmanach USA, Ausg. 72301. Frankfurt am Main: Fischer.

Van Dijk, Jan J. M.; Patatricia Mayhew (1992): "Criminal victimization in the industrialized world: Key findings of 1989 and 1992 International Crime Surveys", The Hague. Ministry of Justice. Department of Crime Prevention. http://www.unicri.it/wwd/analysis/icvs/publications.php

Van Kesteren, John; Pat Mayhew; Paul Nieuwbeerta (2000): "Criminal Victimisation in Seventeen Industrialised Countries: Keys Findings from the 2000 International Crime Victims Survey", 187, The Hague. Research and Documentation Centre, Ministry of Justice. WODC.

http://www.unicri.it/wwd/analysis/icvs/publications.php

Veil, Katja (2001): "Raumkontrolle - Videokontrolle und Planung für den öffentlichen Raum". http:/ / de.geocities.com/veilkatja/

Verwaltungsgericht Sigmaringen (2004a): "Rutenfest in Ravensburg: Videoüberwachung zeitweilig zulässig", 27.07.2004. http:// www.jum.badenwuerttemberg.de/servlet/PB/menu/1193902/index.html 
— (2004b): "Schützenfest in Biberach: Videoüberwachung von Verwaltungsgericht untersagt", 05.07.2004. http:// www.justiz.badenwuerttemberg.de/servlet/PB/menu/1193904/index.html

Waechter, Kay (2001): "Videoüberwachung öffentlicher Räume und systematischer Bildabgleich", in: Niedersächsische Verwaltungsblätter: Zeitschrift für öffentliches Recht und öffentliche Verwaltung, Nr. 8/4, S. 77-86.

Walker, Keith (1996): "Verbrechensbekämpfung in Großbritannien. Nachahmenswertes Beispiel oder monströse Persönlichkeitsverletzung", in: Kriminalistik. Unabhängige Zeitschrift für die kriminalistische Wissenschaft und Praxis, Nr. 59, S. 345 ff.

Walker, Samuel (1999): In defence of American Libierties. A history of the ACLU: Southern Illinois University Press.

Wasser, Hartmut; Irene Dingeldey (1996): Krisenphänomene westlicher Demokratien in den neunziger Jahren: Bundesrepublik Deutschland, Großbritannien, Frankreich, Schweiz, Italien, USA. Weingarten: Pädagog. Hochschulen.

Wassermann, Rudolf (1985): "8. Mai 1945: Die Katastrophe als Chance zum Neubeginn. Der demokratische Rechtsstaat als Reaktion auf den nationalsozialistischen Unrechtsstaat", in: Aus Politik und Zeitgeschichte. Beilage zur Wochenzeitung Das Parlament, Nr. B16/85, S. 3 ff.

Wehrheim, Jan (2002): Die überwachte Stadt: Sicherheit, Segregation und Ausgrenzung. Opladen: Leske + Budrich.

Weichert, Thilo (1988): "Praxis und rechtliche Aspekte optischer Überwachungsmethoden. Zum Einsatz moderner Videotechnik", in: DANA. DatenschutzNachrichten, Nr. $3 / 4$.

- (1998a): "Audio- und Videoüberwachung im öffentlichen Raum", in: Vorgänge: Zeitschrift für Bürgerrechte und Gesellschaftspolitik, Nr. 144/4, S. 62-71.

- (1998b): "Audio- und Videoüberwachung. Kontrolltechniken im öffentlichen Raum", in: Bürgerrechte \& Polizei CILIP, Nr. 60/2, S. 12-19. http: / / www.cilip.de/ausgabe/60/audvideo.htm

- (1999): "Öffentliche Audio- und Videoüberwachung", in: DANA. DatenschutzNachrichten, Nr. 1, S. 4-22.

Die Welt (1999): "CDU und SPD streiten über Videoüberwachung", in: Die Welt, 12.08.1999.

Westin, Alan F. (1967): Privacy and freedom. New York: Atheneum.

Wetzels, Peter; Werner Greve; Eberhard Mecklenburg; Wolfgang Bilsky; Christian Pfeiffer (1995): Kriminalität im Leben alter Menschen : eine altersvergleichende Untersuchung von Opfererfahrungen, persönlichem Sicherheitsgefühl und Kriminalitätsfurcht, Kriminologisches Forschungsinstitut Niedersachsen (Hrsg.). Stuttgart u.a.: Bundesministerium für Familie, Senioren, Frauen und Jugend.

Whitaker, Reg (1999): Das Ende der Privatheit: Überwachung, Macht und soziale Kontrolle im Informationszeitalter. München: Kunstmann.

Williams, Katherine S.; Craig Johnstone (2000): "The politics of selective gaze: Closed Circuit Television and the policing of public space", in: Crime, Law E Social Change, Nr. 34, S. 183-210.

Zentralverband der Elektrotechnik- und Elektroindustrie e.V. (ZVEI) (2001a): "Akzeptanz der Videoüberwachung von Kriminalitätsschwerpunkten. Repräsentative Meinungsumfrage von TNS EMNID im Auftrag des Fachverbandes Sicherheitssysteme im ZVEI". http:// www.zvei.org/news/Presseinformationen/2001-05/Pr037-2001.html

- (2001b): "Videoüberwachung Berlin Hardenberg-/Breitscheidplatz". http:/ / www.zvei.org/index.php?id=340\&type=1

— (2003): "Videoüberwachung im öffentlichen Raum - Argumente für Entscheider". http://www.zvei.org/index.php?id=340\&type=1 
von Zezschwitz, Friedrich (2000): "Videoüberwachung in Hessen", in: Datenschutz und Datensicherheit (DuD), Nr. 24/11, S. 670-672.

- (2002): "Videoüberwachung. Verfassungs- und verwaltungsrechtliche Fragen". http:/ / www.datenschutz.hessen.de/o-hilfen/VideoverfassFragen.pdf

Zurawski, Nils (2004): "Die Kameras stören mich nicht!" 20.01.2004. http://www.heise.de/tp/r4/artikel/16/16542/1.html 


\section{Anhang}

Crimes $^{(1)}$ recorded by the police: Violent crime ${ }^{(2)}$

\begin{tabular}{|c|c|c|c|c|c|c|c|}
\hline Country & 1997 & 1998 & 1999 & 2000 & 2001 & $\begin{array}{l}\% \text { change } \\
1997-2001 \\
\end{array}$ & $\begin{array}{r}\% \text { change } \\
2000-2001 \\
\end{array}$ \\
\hline$E U$ average $^{(16)}$ & & & & & & $22 \%$ & $5 \%$ \\
\hline England \& Wales ${ }^{(3)}$ & 352873 & 605797 & 703107 & 733387 & 813271 & $26 \%$ & $11 \%$ \\
\hline Northern Ireland ${ }^{(4)}$ & 7837 & 21452 & 24163 & 24323 & 29757 & .. & $22 \%$ \\
\hline Scotland ${ }^{(5)}$ & 23656 & 25725 & 27321 & 27047 & 27605 & $17 \%$ & $2 \%$ \\
\hline Austria & 46942 & 48200 & 49242 & .. & .. &.. & .. \\
\hline Belgium $^{(6)}$ & 60605 & 61882 & 61992 & 59791 & .. & $11 \%^{(18)}$ & $-4 \%{ }^{(19)}$ \\
\hline Bulgaria &.. &.. & .. & .. &.. &.. &.. \\
\hline Cyprus $^{(7)}$ & 184 & 168 & 178 & 165 & 176 & $-4 \%$ & $7 \%$ \\
\hline Czech Republic & 23223 & 23464 & 23228 & 21996 & 21709 & $-7 \%$ & $-1 \%$ \\
\hline Denmark & 13963 & 13754 & 14735 & 15748 & 16010 & $15 \%$ & $2 \%$ \\
\hline Estonia & 781 & 710 & 638 & 676 & 643 & $-18 \%$ & $-5 \%$ \\
\hline Finland & 31202 & 31726 & 32089 & 34291 & 33355 & $7 \%$ & $-3 \%$ \\
\hline France & 186006 & 194873 & 215698 & 243166 & 279324 & $50 \%$ & $15 \%$ \\
\hline Germany & 186447 & 186306 & 186655 & 187103 & 188413 & $1 \%$ & $1 \%$ \\
\hline Greece & 8766 & 9312 & 9097 & 9105 & 9501 & $8 \%$ & $4 \%$ \\
\hline Hungary & 26987 & 28414 & 28277 & 29144 & 30819 & $14 \%$ & $6 \%$ \\
\hline Ireland (Eire) $)^{(8)}$ & 5488 & 4515 & .. & 3312 & 6851 & .. & .. \\
\hline Italy ${ }^{(9)}$ & 64945 & 71775 & 76823 & 74136 & .. & $20 \%{ }^{(18)}$ & $-3 \%^{(19)}$ \\
\hline Latvia & .. & .. & .. & .. & .. & .. & .. \\
\hline Lithuania & 6667 & 6633 & 6411 & 7339 & 6861 & $3 \%$ & $-7 \%$ \\
\hline Luxembourg $^{(10)}$ & 4471 & 4949 & 4376 & 4280 & 3881 & .. & $-9 \%$ \\
\hline Malta &.. & .. &.. & .. &.. & .. & .. \\
\hline Netherlands & 74691 & 76666 & 86587 & 90944 & 101141 & $35 \%$ & $11 \%$ \\
\hline Norway ${ }^{(11)}$ & 18507 & 18445 & 18811 & 20582 & 20325 & $10 \%$ & $-1 \%$ \\
\hline Poland ${ }^{(12)}$ & 66927 & 70001 & 78457 & 89993 & 84863 & $27 \%$ & $-6 \%$ \\
\hline Portugal & 16733 & 15463 & 18942 & 19730 & 21554 & $29 \%$ & $9 \%$ \\
\hline Romania & .. &.. & .. & 20818 & 25787 & .. & $24 \%$ \\
\hline Russia $^{(7)}$ & 119041 & 92697 & 97153 & 93290 & 97954 & $-18 \%$ & $5 \%$ \\
\hline Slovakia & 11564 & 12427 & 13531 & 13549 & 14450 & .. & .. \\
\hline Slovenia & 900 & 1172 & 1355 & 1414 & .. & $36 \%^{(18)}$ & $4 \%^{(19)}$ \\
\hline Spain & 87775 & 91099 & 128496 & 119923 & 130545 & $49 \%$ & $9 \%$ \\
\hline Sweden ${ }^{(13)}$ & 68310 & 70488 & 75745 & 74646 & 76758 & $12 \%$ & $3 \%$ \\
\hline Switzerland & 7472 & 8015 & 8528 & 8152 & 8653 & $16 \%$ & $6 \%$ \\
\hline Turkey &.. & .. &.. & .. & .. & .. & .. \\
\hline Australia $^{(14)}$ & 162063 & 171012 & 172972 & 179773 & 197219 & $22 \%$ & $10 \%$ \\
\hline Canada $^{(15)}$ & 296890 & 296166 & 291327 & 302098 & 309101 & $4 \%$ & $2 \%$ \\
\hline Japan & 40570 & 41751 & 43822 & 64418 & 72801 & $79 \%$ & $13 \%$ \\
\hline New Zealand & 43442 & 43734 & 42712 & 44887 & 47133 & $8 \%$ & $5 \%$ \\
\hline South Africa & 645737 & 661779 & 768932 & .. & .. &.. & .. \\
\hline U.S.A. & 1636096 & 1533887 & 1426044 & 1425486 & 1436611 & $-12 \%$ & $1 \%$ \\
\hline
\end{tabular}

(1) Definitions of offences vary between countries both due to legal differences and statistical recording methods; comparisons may be affected by these differences.

(2) Violence against the person, robbery and sexual offences.

(3) By financial year (e.g. $1997=1$ April 1997 to 31 March 1998). Revised counting rules from 1 April 1998.

(4) By financial year (e.g. $1997=1$ April 1997 to 31 March 1998). Figures from 1998/99 are recorded under revised counting rules and are not comparable with previous years.

(5) Includes homicide, other violence against the person, robbery, sexual offences (excluding indecent exposure, brothel keeping and offences related to prostitution).

(6) Excludes robbery

(7) Violence against the person, aggravated assault and sexual offences only.

(8) Includes homicide, other violence against the person, intimidation, abduction and false imprisonment, sexual offences, robbery and aggravated burglary. A new recording system is being implemented which has resulted in improvements in recording. Therefore recent figures may not be comparable with those of previous years.

(9) Includes homicide, injuries, sexual assault, robbery, extortion and kidnapping

(10) Includes homicide, murder, rebellion, intimidation, other violence against the person and sexual offences. Figures from 2000 onwards are not comparable with previous years as they no longer include offences dealt with by the Judicial Police.

(11) Includes homicide, sexual offences and robbery but excludes crimes against personal liberty (for example threats, duress and limitation of liberty).

(12) Includes homicide, rape, fighting and battery, causing bodily injury and robbery.

(13) Includes attempts, preparation and conspiracy to commit an offence.

(14) Includes murder, attempted murder, manslaughter, driving causing death, sexual assault, kidnapping and abduction, robbery, blackmail and extortion, and assault.

(15) Includes homicide, attempted murder, sexual and non-sexual assault, other sexual offences, abduction and robbery.

(16) In calculating the EU average, all EU countries have been given equal weight.

(17) Comparisons between the earlier year and 2001/2002 are based on figures for the financial year 2001/2002 which have been adjusted to take account of the effect of the new counting rules.

(18) $1996-2000$.

(19) $1999-2000$.

Data not available.

Source: Statistical contacts in each country

Quelle: International comparisons of criminal justice statistics 2001. Barkley, G. \& Tavares, C.; Ausgabe 12/ 03, 24 Oktober 2003. 
Crimes $^{(1)}$ recorded by the police: Theft of a motor vehicle ${ }^{(2)}$

\begin{tabular}{|c|c|c|c|c|c|c|c|}
\hline Country & 1997 & 1998 & 1999 & 2000 & 2001 & $\begin{array}{l}\% \text { change } \\
1997-2001 \\
\end{array}$ & $\begin{array}{r}\% \text { change } \\
2000-2001 \\
\end{array}$ \\
\hline$E U$ average $e^{(11)}$ & & & & & & $-7 \%$ & $-7 \%$ \\
\hline $\begin{array}{l}\text { England \& Wales }{ }^{(3)} \\
\text { Northern Ireland }^{(4)} \\
\text { Scotland }^{(5)}\end{array}$ & $\begin{array}{r}400524 \\
8090 \\
28646\end{array}$ & $\begin{array}{r}391807 \\
9715 \\
28433\end{array}$ & $\begin{array}{r}374686 \\
10196 \\
29818\end{array}$ & $\begin{array}{r}338796 \\
10806 \\
26238\end{array}$ & $\begin{array}{r}328147 \\
11635 \\
23208\end{array}$ & $\begin{array}{l}-30 \% \\
44 \% \\
-19 \%\end{array}$ & $\begin{array}{r}-3 \% \\
8 \% \\
-12 \%\end{array}$ \\
\hline $\begin{array}{l}\text { Austria } \\
\text { Belgium } \\
\text { Bulgaria }\end{array}$ & $\begin{array}{r}5950 \\
35242 \\
2433\end{array}$ & $\begin{array}{rl}5 & 771 \\
36 & 555 \\
1 & 433\end{array}$ & $\begin{array}{r}5679 \\
35780 \\
976\end{array}$ & $\begin{array}{r}8601 \\
33395 \\
2298\end{array}$ & $\begin{array}{r}5740 \\
. . \\
2076\end{array}$ & $\begin{array}{c}-4 \% \\
-1 \% \\
-15 \%\end{array}$ & $\begin{array}{l}-33 \% \\
-7 \% \\
-10 \%\end{array}$ \\
\hline $\begin{array}{l}\text { Cyprus } \\
\text { Czech Republic } \\
\text { Denmark }\end{array}$ & $\begin{array}{r}1609 \\
31331 \\
42701\end{array}$ & $\begin{array}{r}1252 \\
29779 \\
38871\end{array}$ & $\begin{array}{r}959 \\
28946 \\
35195\end{array}$ & $\begin{array}{r}1237 \\
25539 \\
33730\end{array}$ & $\begin{array}{r}1441 \\
23539 \\
29464\end{array}$ & $\begin{array}{l}-10 \% \\
-25 \% \\
-31 \%\end{array}$ & $\begin{array}{r}16 \% \\
-8 \% \\
-13 \%\end{array}$ \\
\hline $\begin{array}{l}\text { Estonia }^{(6)} \\
\text { Finland } \\
\text { France }\end{array}$ & $\begin{array}{r}1762 \\
22015 \\
417360\end{array}$ & $\begin{array}{r}2106 \\
26404 \\
415930\end{array}$ & $\begin{array}{r}2455 \\
29611 \\
395947\end{array}$ & $\begin{array}{r}2322 \\
26391 \\
401057\end{array}$ & $\begin{array}{r}2818 \\
22583 \\
418983\end{array}$ & $\begin{array}{r}60 \% \\
3 \% \\
0 \%\end{array}$ & $\begin{array}{r}21 \% \\
-14 \% \\
4 \%\end{array}$ \\
\hline $\begin{array}{l}\text { Germany } \\
\text { Greece }^{(7)} \\
\text { Hungary }^{(7)}\end{array}$ & $\begin{array}{r}190585 \\
6568 \\
20163\end{array}$ & $\begin{array}{r}162518 \\
7610 \\
20849\end{array}$ & $\begin{array}{r}140636 \\
7239 \\
16670\end{array}$ & $\begin{array}{r}127750 \\
5702 \\
14297\end{array}$ & $\begin{array}{r}121533 \\
5459 \\
12397\end{array}$ & $\begin{array}{l}-36 \% \\
-17 \% \\
-39 \%\end{array}$ & $\begin{array}{r}-5 \% \\
-4 \% \\
-13 \%\end{array}$ \\
\hline $\begin{array}{l}\text { Ireland (Eire) })^{(8)} \\
\text { Italy } \\
\text { Latvia }\end{array}$ & $\begin{array}{r}13589 \\
301233 \\
2082\end{array}$ & $\begin{array}{r}13793 \\
309113 \\
2483\end{array}$ & $\begin{array}{r}14851 \\
294726 \\
3102\end{array}$ & $\begin{array}{r}15964 \\
243890 \\
2932\end{array}$ & $\begin{array}{r}14533 \\
. . \\
. .\end{array}$ & $\begin{array}{c}. . \\
-23 \%{ }^{(13)} \\
32 \%\end{array}$ & $\begin{array}{c}. . \\
-17 \% \\
-5 \%\end{array}$ \\
\hline $\begin{array}{l}\text { Lithuania } \\
\text { Luxembourg }^{(8)} \\
\text { Malta }\end{array}$ & $\begin{array}{r}6697 \\
675 \\
. .\end{array}$ & $\begin{array}{r}6946 \\
655 \\
1166\end{array}$ & $\begin{array}{r}6671 \\
626 \\
1076\end{array}$ & $\begin{array}{r}9006 \\
542 \\
1051\end{array}$ & $\begin{array}{r}8924 \\
496 \\
. .\end{array}$ & $\begin{array}{r}33 \% \\
. . \\
. .\end{array}$ & $\begin{array}{l}-1 \% \\
-8 \% \\
-2 \%\end{array}$ \\
\hline $\begin{array}{l}\text { Netherlands }^{(7)} \\
\text { Norway } \\
\text { Poland }^{(7)}\end{array}$ & $\begin{array}{l}37309 \\
20019 \\
56871\end{array}$ & $\begin{array}{l}37408 \\
21672 \\
65399\end{array}$ & $\begin{array}{l}37831 \\
20863 \\
74514\end{array}$ & $\begin{array}{l}38320 \\
23339 \\
68062\end{array}$ & $\begin{array}{l}35037 \\
20598 \\
59458\end{array}$ & $\begin{array}{r}-6 \% \\
3 \% \\
5 \%\end{array}$ & $\begin{array}{r}-9 \% \\
-12 \% \\
-13 \%\end{array}$ \\
\hline $\begin{array}{l}\text { Portugal } \\
\text { Romania } \\
\text { Russia }\end{array}$ & $\begin{array}{r}22792 \\
2110 \\
35778\end{array}$ & $\begin{array}{r}26965 \\
2284 \\
35448\end{array}$ & $\begin{array}{r}28163 \\
2331 \\
37152\end{array}$ & $\begin{array}{r}26428 \\
2149 \\
38439\end{array}$ & $\begin{array}{r}26162 \\
. . \\
. .\end{array}$ & $\begin{array}{l}15 \% \\
19 \% \\
-8 \%\end{array}$ & $\begin{array}{l}-1 \% \\
-8 \% \\
3 \%\end{array}$ \\
\hline $\begin{array}{l}\text { Slovakia } \\
\text { Slovenia } \\
\text { Spain }\end{array}$ & $\begin{array}{r}7438 \\
1145 \\
133330\end{array}$ & $\begin{array}{r}7682 \\
1311 \\
136084\end{array}$ & $\begin{array}{r}7123 \\
1147 \\
138961\end{array}$ & $\begin{array}{r}6073 \\
1291 \\
134583\end{array}$ & $\begin{array}{r}6073 \\
1222 \\
147441\end{array}$ & $\begin{array}{r}-18 \% \\
7 \% \\
11 \%\end{array}$ & $\begin{array}{r}0 \% \\
-5 \% \\
10 \%\end{array}$ \\
\hline $\begin{array}{l}\text { Sweden }^{(10)} \\
\text { Switzerland } \\
\text { Turkey }\end{array}$ & $\begin{array}{r}78826 \\
. . \\
19515\end{array}$ & $\begin{array}{r}76495 \\
. . \\
19109\end{array}$ & $\begin{array}{r}78216 \\
. . \\
17912\end{array}$ & $\begin{array}{r}75125 \\
. . \\
. .\end{array}$ & $\begin{array}{r}73309 \\
. . \\
. \cdot\end{array}$ & $\begin{array}{r}-7 \% \\
. \cdot \\
. .\end{array}$ & $\begin{array}{r}-2 \% \\
. \cdot \\
\cdots\end{array}$ \\
\hline $\begin{array}{l}\text { Australia } \\
\text { Canada }^{(5)} \\
\text { Japan }\end{array}$ & $\begin{array}{ll}130 & 138 \\
177 & 130 \\
269 & 138\end{array}$ & $\begin{array}{l}131587 \\
165920 \\
282248\end{array}$ & $\begin{array}{l}129552 \\
161388 \\
286069\end{array}$ & $\begin{array}{l}139094 \\
160315 \\
309638\end{array}$ & $\begin{array}{l}139943 \\
170213 \\
305792\end{array}$ & $\begin{array}{r}8 \% \\
-4 \% \\
14 \%\end{array}$ & $\begin{array}{r}1 \% \\
6 \% \\
-1 \%\end{array}$ \\
\hline $\begin{array}{l}\text { New Zealand } \\
\text { South Africa } \\
\text { U.S.A. }\end{array}$ & $\begin{array}{r}32082 \\
100637 \\
1354189 \\
\end{array}$ & $\begin{array}{r}30803 \\
107513 \\
1242781 \\
\end{array}$ & $\begin{array}{r}25680 \\
113091 \\
1152075 \\
\end{array}$ & $\begin{array}{r}21992 \\
100647 \\
1160002 \\
\end{array}$ & $\begin{array}{r}20201 \\
98942 \\
1226457 \\
\end{array}$ & $\begin{array}{r}-37 \% \\
-2 \% \\
-9 \% \\
\end{array}$ & $\begin{array}{r}-8 \% \\
-2 \% \\
6 \% \\
\end{array}$ \\
\hline
\end{tabular}

(1) Definitions of offences vary between countries both due to legal differences and statistical recording methods; comparisons may be affected by these differences.

(2) All land vehicles with an engine that run on the road which are used to carry people (including cars, motor cycles, buses, lorries, construction and agricultural vehicles, etc.).

(3) By financial year (e.g. $1997=1$ April 1997 to 31 March 1998).

(4) By financial year (e.g. $1997=1$ April 1997 to 31 March 1998). Figures from $1998 / 99$ are recorded under revised counting rules and are not comparable with previous years.

(5) Includes attempts.

(6) Taking/conversion of motor vehicles.

(7) Cars only.

(8) A new recording system is being implemented which has resulted in improvements in recording. Therefore recent figures may not be comparable with those of previous years.

(9) Figures from 2000 onwards are not comparable with previous years as they no longer include offences dealt with by the Judicial Police.

(10) Includes attempts, preparation and conspiracy to commit an offence.

(11) In calculating the EU average, all EU countries have been given equal weight.

(12) Comparisons between the earlier year and 2001/2002 are based on figures for the financial year 2001/2002 which have been adjusted to take account of the effect of the new counting rules.

(13) $1996-2000$

(14) $1999-2000$

.. Data not available.

Source: Statistical contacts in each country.

Quelle: International comparisons of criminal justice statistics 2001. Barkley, G. \& Tavares, C.; Ausgabe 12/03, 24 Oktober 2003. 
Crimes $^{(1)}$ recorded by the police: Robbery ${ }^{(2)}$

\begin{tabular}{|c|c|c|c|c|c|c|c|}
\hline Country & 1997 & 1998 & 1999 & 2000 & 2001 & $\begin{array}{l}\text { \% change } \\
1997-2001 \\
\end{array}$ & $\begin{array}{l}\% \text { change } \\
2000-2001\end{array}$ \\
\hline England \& Wales ${ }^{(3)}$ & 62652 & 66835 & 84277 & 95154 & 121370 & $92 \%^{(10)}$ & $28 \%$ \\
\hline Northern Ireland ${ }^{(4)}$ & 1573 & 1395 & 1383 & 1767 & 2222 & .. & $26 \%$ \\
\hline Scotland & 4484 & 4951 & 5075 & 4420 & 4228 & $-6 \%$ & $-4 \%$ \\
\hline Austria & 1991 & 2234 & 2283 & 2763 & 2824 & $42 \%$ & $2 \%$ \\
\hline Cyprus & 25 & 27 & 32 & 43 & 42 & $68 \%$ & $-2 \%$ \\
\hline Czech Republic & 4751 & 4306 & 4817 & 4644 & 4372 & $-8 \%$ & $-6 \%$ \\
\hline Denmark & 2523 & 2606 & 2781 & 3152 & 3192 & $27 \%$ & $1 \%$ \\
\hline Estonia & 3478 & 3978 & 4918 & 4754 & 4475 & $29 \%$ & $-6 \%$ \\
\hline Finland & 2016 & 2092 & 2277 & 2600 & 2157 & $7 \%$ & $-17 \%$ \\
\hline Ireland (Eire) ${ }^{(6)}$ & &.. &.. & 1397 & 1744 & .. & .. \\
\hline Italy & 69993 & 73289 & 72836 & 67424 & 66671 & $-5 \%$ & $-1 \%$ \\
\hline Latvia &.. &.. &.. &.. &.. & .. & .. \\
\hline Lithuania & 3971 & 3646 & 3376 & 4374 & 4185 & $5 \%$ & $-4 \%$ \\
\hline Luxembourg $^{(7)}$ & 288 & 372 & 352 & 307 & 257 &.. & $-16 \%$ \\
\hline Malta &.. & 318 & 212 & 146 &.. &.. & $-31 \%^{(12}$ \\
\hline Netherlands & 14186 & 14447 & 17462 & 18630 & 21064 & $48 \%$ & $13 \%$ \\
\hline Norway & 1073 & 1354 & 1698 & 1781 & 1491 & $39 \%$ & $-16 \%$ \\
\hline Poland & 23988 & 26647 & 36597 & 43255 & 41208 & $72 \%$ & $-5 \%$ \\
\hline Portugal & 13901 & 12442 & 16065 & 17156 & 18585 & $34 \%$ & $8 \%$ \\
\hline Turkey & 1319 & 1477 & 1385 & 1632 & 2480 & $88 \%$ & $52 \%$ \\
\hline Australia & 21305 & 23801 & 22606 & 23314 & 26565 & $25 \%$ & $14 \%$ \\
\hline Canada $^{(5)}$ & 29587 & 28963 & 28740 & 27037 & 27414 & $-7 \%$ & $1 \%$ \\
\hline Japan & 2809 & 3426 & 4237 & 5173 & 6393 & $128 \%$ & $24 \%$ \\
\hline New Zealand & 2032 & 2004 & 1585 & 1779 & 1658 & $-18 \%$ & $7 \%$ \\
\hline South Africa & 122369 & 150430 & 178080 & 197837 & 208932 & $71 \%$ & $6 \%$ \\
\hline U.S.A. & 498534 & 447186 & 409371 & 408016 & 422921 & $-15 \%$ & $4 \%$ \\
\hline
\end{tabular}

(1) Definitions of offences vary between countries both due to legal differences and statistical recording methods: comparisons may be affected by these differences.

(2) Stealing from a person with force or threat of force. Includes muggings (bag-snatching) and theft with violence; excludes pick-pocketing, extortion and blackmailing.

(3) By financial year (e.g. $1997=1$ April 1997 to 31 March 1998). Revised counting rules from 1 April 1998.

(4) By financial year (e.g. $1997=1$ April 1997 to 31 March 1998). Figures from $1998 / 99$ are recorded under revised counting rules and are not comparable with previous years.

(5) Includes attempts.

(6) A new recording system is being implemented which has resulted in improvements in recording. Therefore recent figures may not be comparable with those of previous years.

Source: Statistical contacts in each country.
(7) Figures from 2000 onwards are not comparable with previous years as they no longer include offences dealt with by the Judicial Police.

(8) Includes attempts, preparation and conspiracy to commit an offence.

(9) In calculating the EU average, all EU countries have been given equal weight.

(10) Comparisons between the earlier year and 2001/2002 are based on figures for the financial year 2001/2002 which have been adjusted to take account of the effect of the new counting rules.

(11) $1996-2000$.

(12) $1999-2000$.

Data not available.

Quelle: International comparisons of criminal justice statistics 2001. Barkley, G. \& Tavares, C.; Ausgabe 12/03, 24 Oktober 2003. 



\section{Danksagung}

Die vorliegende Dissertation wurde im Mai 2006 von der Sozialwissenschaftlichen Fakultät der Georg-August Universität Göttingen als Dissertation angenommen. Ohne die Unterstützung einer Vielzahl von Menschen, wäre diese Arbeit nicht zustande gekommen. Mein herzlicher Dank gilt aus diesem Grund allen, die mir bei der Fertigstellung dieser Arbeit geholfen haben.

An erster Stelle gilt mein besonderer Dank meinem Doktorvater Prof. Dr. WolfSighard Rosenbaum, der mich unermüdlich in jeder Phase der Arbeit mit Fragen, Kritik und Ideen ermutigt hat, meine Arbeit weiterzuentwickeln. Durch seine Bereitschaft zu stundenlangen Diskussionen und seine bemerkenswert scharfsinnigen Erörterungen der Problemfelder habe ich viel von ihm profitieren und lernen können.

Sehr zu Dank verpflichtet fühle ich mich Dr. Michael Neumann. Durch seine wertvolle fachliche Betreuung sind u.a. die ersten Ideen zu dieser Arbeit entstanden. Seine freundliche Unterstützung war ein großer Gewinn für diese Arbeit. Herzlich danken möchte ich auch Prof. Dr. Rainer-W. Hoffmann für die zügige Erstellung des zweiten Gutachtens.

Bei meinen Eltern möchte ich mich ganz besonders bedanken, die immer liebevoll hinter mir stehen und diese Arbeit vorbehaltlos unterstützt haben. Meinem Ehemann Sven Anderson danke ich für seine aufmunternden Worte, die mich in schwierigen Zeiten an meine Motivation zur Promotion erinnert haben, sowie seine Geduld und computertechnische Hilfeleistung.

Finanzielle Unterstützung erhielt ich von der Universität Göttingen in Form eines Promotionsstipendiums nach dem Gesetz zur Förderung des wissenschaftlichen und künstlerischen Nachwuchses.

Zum Schluss möchte ich den zahlreichen Korrekturlesern ein herzliches Dankeschön aussprechen, insbesondere Kevin Ivory für seine endlose Mühe und Geduld.

Und natürlich bedanke ich mich bei all meinen Freunden, die mich in dieser Zeit immer wieder aufgemuntert und für die notwendige Regeneration zwischendurch gesorgt haben. 